

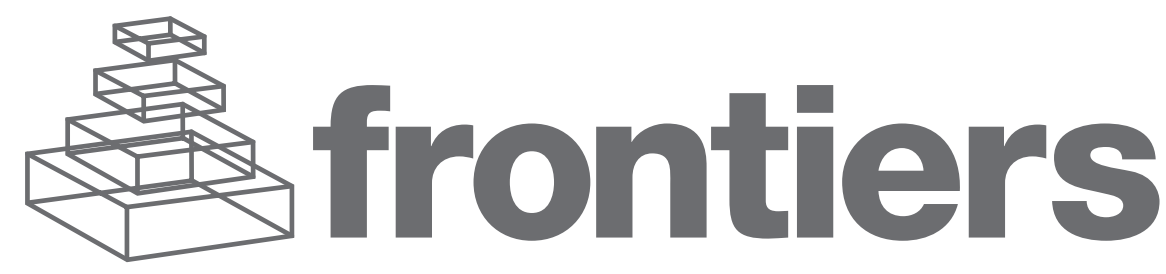

\section{FRONTIERS COPYRIGHT STATEMENT}

(C) Copyright 2007-2013

Frontiers Media SA.

All rights reserved.

All content included on this site, such as text, graphics, logos, button icons, images, video/audio clips, downloads, data compilations and software, is the property of or is licensed to Frontiers Media SA ("Frontiers") or its licensees and/or subcontractors. The copyright in the text of individual articles is the property of their respective authors, subject to a license granted to Frontiers.

The compilation of articles constituting this e-book, as well as all content on this site is the exclusive property of Frontiers. Images and graphics not forming part of user-contributed materials may not be downloaded or copied without permission.

Articles and other user-contributed materials may be downloaded and reproduced subject to any copyright or other notices. No financial payment or reward may be given for any such reproduction except to the author(s) of the article concerned.

As author or other contributor you grant permission to others to reproduce your articles, including any graphics and third-party materials supplied by you, in accordance with the Conditions for Website Use and subject to any copyright notices which you include in connection with your articles and materials.

All copyright, and all rights therein, are protected by national and international copyright laws.

The above represents a summary only. For the full conditions see the Conditions for Authors and the

Conditions for Website Use.

Cover image provided by lbbl sarl, Lausanne $\mathrm{CH}$

\section{ABOUT FRONTIERS}

Frontiers is more than just an open-access publisher of scholarly articles: it is a pioneering approach to the world of academia, radically improving the way scholarly research is managed. The grand vision of Frontiers is a world where all people have an equal opportunity to seek, share and generate knowledge. Frontiers provides immediate and permanent online open access to all its publications, but this alone is not enough to realize our grand goals.

\section{FRONTIERS JOURNAL SERIES}

The Frontiers Journal Series is a multi-tier and interdisciplinary set of open-access, online journals, promising a paradigm shift from the current review, selection and dissemination processes in academic publishing.

All Frontiers journals are driven by researchers for researchers; therefore, they constitute a service to the scholarly community. At the same time, the Frontiers Journal Series operates on a revolutionary invention, the tiered publishing system, initially addressing specific communities of scholars, and gradually climbing up to broader public understanding, thus serving the interests of the lay society, too.

\section{DEDICATIONTO QUALITY}

Each Frontiers article is a landmark of the highest quality, thanks to genuinely collaborative interactions between authors and review editors, who include some of the world's best academicians. Research must be certified by peers before entering a stream of knowledge that may eventually reach the public - and shape society; therefore, Frontiers only applies the most rigorous and unbiased reviews.

Frontiers revolutionizes research publishing by freely delivering the most outstanding research, evaluated with no bias from both the academic and social point of view.

By applying the most advanced information technologies, Frontiers is catapulting scholarly publishing into a new generation.

\section{WHAT ARE FRONTIERS RESEARCHTOPICS?}

Frontiers Research Topics are very popular trademarks of the Frontiers Journals Series: they are collections of at least ten articles, all centered on a particular subject. With their unique mix of varied contributions from Original Research to Review Articles, Frontiers Research Topics unify the most influential researchers, the latest key findings and historical advances in a hot research area!

Find out more on how to host your own Frontiers Research Topic or contribute to one as an author by contacting the Frontiers Editorial Office: researchtopics@frontiersin.org 


\section{MICROBIOLOGY OF WETLANDS}

Topic Editors:

Paul Bodelier, Netherlands Institute of Ecology (NIOO-KNAW), Netherlands

Svetlana N. Dedysh, Winogradsky Institute of Microbiology, Russian Academy of Sciences, Russia

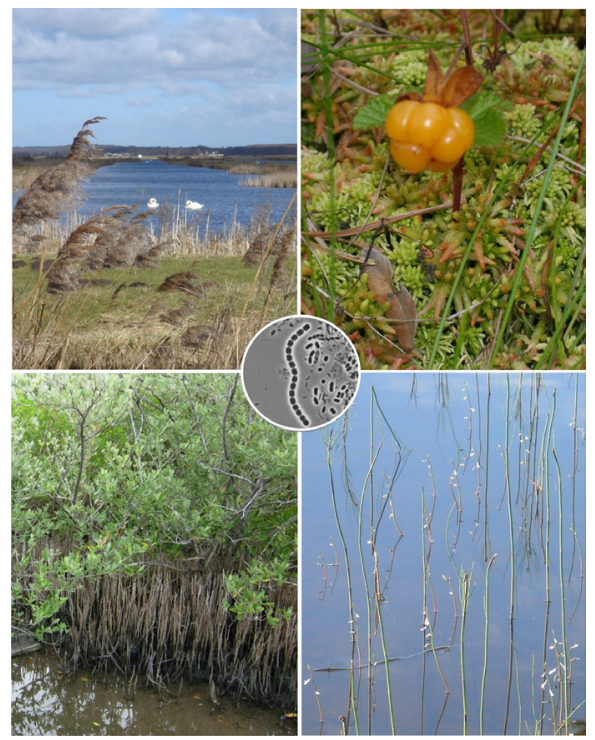

Image produced and owned by Svetlana Dedysh
Watersaturated soil and sediment ecosystems (i.e. wetlands) are ecologically as well as economically important systems due to their high productivity, their nutrient (re)cycling capacities and their prominent contribution to global greenhouse gas emissions. Being on the transition between terrestrial and - aquatic ecosystems, wetlands are buffers for terrestrial run off thereby preventing eutrophication of inland as well as coastal waters. The close proximity of oxic-anoxic conditions, often created by wetland plant roots, facilitates the simultaneous activity of aerobic as well as anaerobic microbial communities. Input of nutrients and fast recycling due to active aerobes and anaerobes makes these systems highly productive and therefore attractive for humans as well as many other organisms. Wetlands globally are under high pressure due to anthropogenic activities as well as climate change. Changes of land-use as well as altered hydrology due to climate change will lead to disturbance and loss of these habitats. However, the diversity and functioning of microbial communities in wetlands systems in highly underexplored in comparison to soils and aquatic ecosystems. Given the importance of wetlands and their immediate threats combined with the lack of knowledge on the microbiology of these systems is the basis for this special issue, focusing on the current microbiological knowledge and gaps therein to be assessed in future wetland research. Papers (research papers, reviews, perspectives, opinion papers) are welcomed that focus on all aspects that regulate the functioning and community composition of microbes 
(i.e. bacteria, archaea, protozoa, fungi) in wetland ecosystems (peat, coastal as well as freshwater marshes, flood plains, rice paddies, littoral zones of lakes etc) from all geographic regions. Welcomed topics are physiology, ecology, functioning, biodiversity, biogeography of microbes involved in nutrient cycling $(\mathrm{C}, \mathrm{N}, \mathrm{P}, \mathrm{Fe}, \mathrm{Mn})$, green house gas emissions as well as plant-microbe interactions. These studies can be multidisciplinary and cover topics from the molecular to the community level. 


\section{Table of Contents}

Paul L. E. Bodelier and Svetlana N. Dedysh

10 Microbial $\mathrm{CH}_{4}$ and $\mathrm{N}_{2} \mathrm{O}$ Consumption in Acidic Wetlands Steffen Kolb and Marcus A. Horn

18 Microbial Transformations of Nitrogen, Sulfur, and Iron Dictate Vegetation Composition in Wetlands: A Review

Leon P. M. Lamers, Josepha M. H. van Diggelen, Huub J. M. Op den Camp, Eric J. W. Visser, Esther C. H. E. T. Lucassen, Melanie A. Vile, Mike S. M. Jetten, Alfons J. P. Smolders and Jan G. M. Roelofs

30 Specificity of Salt Marsh Diazotrophs for Vegetation Zones and Plant Hosts: Results from a North American Marsh

Charles R. Lovell and Debra A. Davis

45 Sulfate-Reducing Microorganisms in Wetlands - Fameless Actors in Carbon Cycling and Climate Change

Michael Pester, Klaus-Holger Knorr, Michael W. Friedrich, Michael Wagner and Alexander Loy

64 Peatland Microbial Communities and Decomposition Processes in the James Bay Lowlands, Canada

Michael D. Preston, Kurt A. Smemo, James W. McLaughlin and Nathan Basiliko

79 Similar Diversity of Alphaproteobacteria and Nitrogenase Gene Amplicons on Two Related Sphagnum Mosses

Anastasia Bragina, Stefanie Maier, Christian Berg, Henry Müller, Vladimir Chobot, Franz Hadacek and Gabriele Berg

89 Abundance, Diversity, and Depth Distribution of Planctomycetes in Acidic Northern Wetlands

Anastasia O. Ivanova and Svetlana N. Dedysh

98 Spatial Patterns of Iron- and Methane-Oxidizing Bacterial Communities in an Irregularly Flooded, Riparian Wetland

Juanjuan Wang, Sascha Krause, Gerard Muyzer, Marion Meima-Franke, Hendrikus J. Laanbroek and Paul L. E. Bodelier

111 The Distribution of Ammonia-Oxidizing Betaproteobacteria in Stands of Black Mangroves (Avicennia Germinans)

Hendrikus J. Laanbroek, Rosalinde M. Keijzer, Jos T. A. Verhoeven and

Dennis F. Whigham 
122 Methanogenic Pathway and Archaeal Communities in Three Different Anoxic Soils Amended with Rice Straw and Maize Straw

Ralf Conrad, Melanie Klose, Yahai Lu and Amnat Chidthaisong

134 Seasonal Changes in Methanogenesis and Methanogenic Community in Three Peatlands, New York State

Christine L. Sun, Suzanna L. Brauer, Hinsby Cadillo-Quiroz, Stephen H. Zinder and Joseph B. Yavitt

142 The Effect of Nitrogen Enrichment on C1-Cycling Microorganisms and Methane Flux in Salt Marsh Sediments

Irina C. Irvine, Lucía Vivanco, Peris N. Bentley and Jennifer B. H. Martiny

152 Inhibition of Methane Oxidation by Nitrogenous Fertilizers in a Paddy Soil

M. Saiful Alam and Zhongjun Jia

165 Effects of Nitrogen Load on the Function and Diversity of Methanotrophs in the Littoral Wetland of a Boreal Lake

Henri M. P. Siljanen, Anne Saari, Levente Bodrossy and Pertti J. Martikainen

178 Water Dispersal of Methanotrophic Bacteria Maintains Functional Methane Oxidation in Sphagnum Mosses

Anuliina Putkinen, Tuula Larmola, Tero Tuomivirta, Henri M. P. Siljanen, Levente Bodrossy, Eeva-Stiina Tuittila and Hannu Fritze

188 Anoxic Iron Cycling Bacteria from an Iron Sulfide- and Nitrate-Rich Freshwater Environment

Suzanne C. M. Haaijer, Gijs Crienen, Mike S. M. Jetten and

Huub J. M. Op den Camp

196 Environmental Controls on Nitrogen and Sulfur Cycles in Surficial Aquatic Sediments

Chuanhui Gu, Anniet M. Laverman and Céline E. Pallud 


\title{
Microbiology of wetlands
}

\author{
Paul L. E. Bodelier ${ }^{1 *}$ and Svetlana N. Dedysh ${ }^{2}$ \\ ${ }^{1}$ Department of Microbial Ecology, Netherlands Institute of Ecology (NIOO-KNAW), Wageningen, Netherlands \\ ${ }^{2}$ Winogradsky Institute of Microbiology, Russian Academy of Sciences, Moscow, Russia \\ ${ }^{*}$ Correspondence: p.bodelier@nioo.knaw.nl
}

Edited by:

Lisa Y. Stein, University of Alberta, Canada

Reviewed by:

Lisa Y. Stein, University of Alberta, Canada

\section{INTRODUCTION}

Wetlands are ecologically as well as economically important systems due to their high productivity, their nutrient (re)cycling capacities, and their prominent contribution to global greenhouse gas emissions. Being on the transition between terrestrial and-aquatic ecosystems, wetlands are buffers for terrestrial run off thereby preventing eutrophication of inland as well as coastal waters. The close proximity of oxic-anoxic conditions, often created by wetland plant roots, facilitates the simultaneous activity of aerobic as well as anaerobic microbial communities. Input of nutrients and fast recycling due to active aerobes and anaerobes makes these systems highly productive and therefore attractive for humans as well as many other organisms. Wetlands globally are under high pressure due to anthropogenic activities as well as climate change. Changes of land-use as well as altered hydrology due to climate change will lead to disturbance and loss of these habitats. However, the diversity and functioning of microbial communities in wetland systems is highly underexplored in comparison to soils and aquatic ecosystems.

The special issue in Frontiers in Terrestrial Microbiology offers the collection of 4 review articles and 14 original research papers, which contribute to the current knowledge on the microbiology of wetlands and discuss the gaps therein to be assessed in future wetland research. Notably, these studies address a wide variety of wetland types including rice paddies (Alam and Jia, 2012; Conrad et al., 2012), acidic Sphagnum-dominated peatlands (Bragina et al., 2011; Ivanova and Dedysh, 2012; Kolb and Horn, 2012; Preston et al., 2012; Putkinen et al., 2012; Sun et al., 2012), riparian wetlands (Wang et al., 2012), black mangroves (Laanbroek et al., 2012), superficial aquatic sediments (Gu et al., 2012), salt marshes (Irvine et al., 2012; Lovell and Davis, 2012), and littoral boreal wetlands (Siljanen et al., 2012).

\section{KEY-DEVELOPMENTS IN WETLAND MICROBIOLOGY}

The key developments in wetland microbiology of the first decade of the twenty-first century are summarized in a series of four reviews (Kolb and Horn, 2012; Lamers et al., 2012; Lovell and Davis, 2012; Pester et al., 2012). The most general overview of the microbially-driven conversions in wetlands is given by Lamers et al. (2012), who analyze the effect of microbial activities on growth and performance of plants. As conclusively shown in this paper, many biogeochemical conversions catalyzed by microbes can ultimately control vegetation composition in wetlands. This is especially the case for conversions in nitrogen, sulfur, and iron cycling. The authors present and propose research strategies and priorities to integrate understanding of plant-microbial interactions in wetlands. Three other reviews focus on several microbial functional guilds such as sulfate reducers (Pester et al., 2012) diazotrophs (Lovell and Davis, 2012), methanotrophs and denitrifiers (Kolb and Horn, 2012). As argued by Pester et al. (2012), although forming a small population, sulfate reducers in freshwater wetlands are capable of catalyzing substantial sulfate reduction rates and interacting significantly with microbes involved in other cycles. In contrast to common association of sulfate reduction with marine habitats, freshwater wetlands harbor a highly diverse sulfate-reducing community, largely comprised of microbes not related to cultured representatives. An important role of nitrogen fixing diazotrophs in the maintenance of nutrient limited salt marshes is highlighted by Lovell and Davis (2012), who demonstrate that the highly diverse diazotrophic community displays clear biogeography within the salt marsh and even differs between plant species, pointing at niche differentiation of diazotrophs within wetlands. Finally, a mini review by Kolb and Horn (2012) focuses on methanotrophs and denitrifiers that consume atmospheric greenhouse gases $\mathrm{CH}_{4}$ and $\mathrm{N}_{2} \mathrm{O}$ in acidic wetlands. One part of this review sheds more light on the potential of the indigenous methanotrophs to consume atmospheric $\mathrm{CH}_{4}(\leq 1.75 \mathrm{ppmv})$, a fact that is currently underappreciated for acidic northern wetlands. The other part summarizes the emergent evidence for the relevance of $\mathrm{N}_{2} \mathrm{O}$ consumption in acidic wetlands and reviews the current knowledge on acid-tolerant denitrifiers.

In line with the lack of knowledge on the microbiology of wetland habitats, most research papers either focus on characterizing microbial communities in terms of composition in relation to environmental factors or link important biogeochemical reactions to the responsible microbial communities.

\section{MICROBIAL ABUNDANCE, DIVERSITY, AND SPATIAL DISTRIBUTION}

The study of Preston et al. (2012) applied multiple approaches to characterize depth-dependent microbial community structure and function in two geographically separated ombrotrophic bogs and a minerotrophic fen within the James Bay Lowlands, a large peatland complex of northern Ontario, Canada. Archaeal, bacterial, and fungal community structures in these three peatlands were characterized with terminal restriction fragment length polymorphism of ribosomal DNA and the microbial activity was measured using community level physiological profiling, extracellular enzyme activities, and the carbon mineralization rates of 
various natural and synthetic substrates. Despite differences in nutrient content, similar dominant microbial taxa were observed at all three peatlands. In contrast, basal respiration, enzyme activity, and the magnitude of substrate utilization were generally higher at a minerotrophic fen and similar between the two bogs. As concluded by the authors, microbial activity in peatlands appears to be determined by the quality of the peat substrate and the presence of potential microbial inhibitors.

A more detailed analysis of the bacterial communities colonizing two phylogenetically related Sphagnum mosses, S. fallax and S. angustifolium, is offered in a study by Bragina et al. (2011). Despite a distinct habitat preference of these two mosses with respect to the nutrient level, the hyaline cells of their leaves were dominated by members of the Alphaproteobacteria. Diversity of this numerically abundant bacterial group and the nitrogenfixing prokaryotes associated with Sphagnum species was further investigated by a barcoded pyrosequencing approach, which confirmed high similarity of the microbial assemblages on plantlets of both mosses. The extensive survey of the nifH gene diversity presented in this study is the first pyrosequencing-based insight into diversity of nitrogen-fixing prokaryotes in Sphagnum-dominated wetlands and, therefore, is of particular interest.

Apart of the nitrogen-fixing Alphaproteobacteria, planctomycetes represent another group of bacteria that are typical for acidic northern wetlands. As shown by Ivanova and Dedysh (2012), members of the Planctomycetes comprise up to $14 \%$ of total bacterial cells detected by fluorescence in situ hybridization in acidic peat. Planctomycetes inhabit both oxic and anoxic peat layers and are highly diverse, although most of these bacteria belong to as-yet-uncultivated taxa. Based on the currently available knowledge, Planctomycetes have been proposed to play a role of slow-acting decomposers of plant-derived organic matter in northern wetlands, which are crucial ecosystems in global carbon cycling.

The three abovementioned articles on acidic Sphagnumdominated wetlands (Bragina et al., 2011; Ivanova and Dedysh, 2012; Preston et al., 2012) are followed by the study of Wang et al. (2012), who focus on assessing the spatial patterns of iron- and methane-oxidizing bacterial communities in a circum-neutral, irregularly flooded, riparian wetland. This work addresses an intriguing question about the competition for limiting amounts of oxygen between iron- and methane-oxidizing aerobic bacteria. Special attention in this study is given to Gallionella-related iron oxidizers, since the authors developed a number of molecular assays to specifically detect and enumerate these bacteria. The results show that Gallionella-related iron oxidizers are highly abundant in the studied wetland and outnumber various groups of methane-oxidizers, demonstrating that iron-oxidizers are both able to compete for oxygen with methanotrophs as well as with chemical iron oxidation.

Finally, the paper of Laanbroek et al. (2012) introduces the Black mangrove wetlands as a microbial habitat to the reader. The specific focus in this study is on diversity of ammonia-oxidizing Betaproteobacteria, which reflects the changes in hydrology in three different Black mangrove habitats, i.e., locations with dwarf, sparse, and dense trees. Nitrosomonas- and Nitrosospira-related bacteria were identified as the major ammonia-oxidizers in these mangroves. Small, but significant differences in the bacterial communities between the flooded and non-flooded impoundments were also detected.

\section{BIOGEOCHEMICAL TRANSFORMATIONS DRIVEN BY MICROBES IN WETLANDS}

A long standing question in methane emission from rice paddies is to what extent rice straw affects the pathway of methane formation. Using a comprehensive combination of stable isotope fractionation and molecular detection techniques Conrad et al. (2012) demonstrated that pathways of methane formation in degradation of different types of straw (rice vs. maize) were rather similar despite the involvement of differentially composed methanogenic communities in the soils used. Hence, the temporal patterns and path of methane formation was mainly controlled by the soil type rather than by type of straw. The methane formation process was stable despite the fluctuating composition of the communities involved. In turn, the fluctuating communities may be related to the pathway of carbon degradation and the resulting substrates for methane formation.

The study of Sun (Sun et al., 2012) examined the methane production rates in relation to the diversity and dynamics of methanogens in three peatlands with contrasting characteristics: two acidic peat bogs and a minerotrophic fen. The focus in this study was on analyzing inducible shifts in methanogen populations in response to substrates (acetate and hydrogen) added to peat in short-term incubation experiments. The acetate-amendment stimulated rates of $\mathrm{CH}_{4}$ production in a fen peatland soil and increased the relative abundance of the Methanosarcinaceae. By contrast, addition of $\mathrm{H}_{2}$ stimulated $\mathrm{CH}_{4}$ production in two acidic bog soils and enhanced abundance of the E2 group of the Methanoregulaceae. As concluded by the authors, variation in the supply of metabolic substrates is a driving force of methanogen species-sorting in wetlands. Hence, methane formation and emission from wetland soils are predominantly controlled by methanogenic substrates.

Next to substrates for energy generation methanogens also need elements for building up biomass, a fact which has never been looked at in wetland systems. Irvine et al. (2012) demonstrate that methanogens in salt marshes can be N-limited, which is an alternative explanation for enhanced methane emission from wetlands upon $\mathrm{N}$-additions. This possibility was not considered as generally increased methane emissions upon addition of nitrogen were assumed to be caused by both increase in plant biomass and inhibition of methane consumption. This finding urges to rethinking of nitrogen control of methane emission from wetlands and opens up many possibilities for new research.

The consumption of methane in wetlands and upland soils has been shown to be influenced by nitrogen and nitrogenous fertilizers, however, solid mechanistic explanations substantiated by experimental data are still lacking. Alam and co-workers (Alam and Jia, 2012) executed incubation studies using rice soil and demonstrated that addition of nitrogenous fertilizers to certain levels stimulated specific methane oxidizers (i.e., type I) which confirms what has been demonstrated before for many different rice soils. However, higher doses of ammonium-based fertilizers inhibited methane oxidation which may act through 
the activity of nitrifiers given the strong negative correlation between methane oxidation and nitrate production, designating the importance of interaction between microbial groups for methane emission from rice paddies.

In contrast, applying nitrogen in situ to a natural littoral wetland in a boreal lake had neither an effect on methane oxidation potential nor on methane flux. In the study by Siljanen et al. (2012) nitrogen load activated pmoA gene transcription of type I methanotrophs, but decreased the relative abundance of $p m o A$ gene transcripts of type II methanotrophs, so that the overall methanotroph activity was not affected by the nitrogen amendment. Hence, the evaluation of the effect of nitrogen load on methane oxidation has to include laboratory as well as in situ observations and can differ significantly between different types of wetlands.

Besides nitrogen, the distribution and dispersion of methanotrophic bacteria can play a regulating role in methane cycling in wetland ecosystems as demonstrated by Putkinen et al. (2012). These authors addressed the role of water dispersal in colonization of Sphagnum mosses by methanotrophic bacteria. It is known that Sphagnum plantlets and in particular hyaline cells of these mosses are colonized by methanotrophs, which are responsible for oxidizing $\mathrm{CH}_{4}$ on its way from anoxic peat layers to the atmosphere. As shown in this study, inactive methanotrophfree Sphagnum plantlets were able to acquire methane-oxidizing activity and the respective methanotroph population after few days of transplantation next to methanotroph-containing mosses or after incubation in peat water taken from a methanotroph-active wetland site. This colonization was suggested as a resilience mechanism for peatland $\mathrm{CH}_{4}$ dynamics by allowing the re-emergence of methane oxidation activity in Sphagnum.

The last contributions to this special issue focus on interactions between elemental cycles (Fe-N, S-N cycle) in groundwater and wetland sediments. The possible presence of iron-oxidizing nitrate reducers and potentially co-occurring iron reducers was assessed in an iron-sulfide and nitrate rich groundwater in a freshwater wetland by Haaijer et al. (2012). Molecular analyses indicated a potential role of nitrate reducing iron-oxidizers. However, cultivation attempts only resulted in the isolation of Geobacterlike iron-reducers demonstrating that a polyphasic approach is

\section{REFERENCES}

Alam, M. S., and Jia, Z. (2012). Inhibition of methane oxidation by nitrogenous fertilizers in a paddy soil. Front. Microbiol. 3:246. doi: 10.3389/fmicb.2012.00246

Bragina, A., Maier, S., Berg, C., Muller, H., Chobot, V., Hadacek, F., et al. (2011). Similar diversity of alphaproteobacteria and nitrogenase gene amplicons on two related sphagnum mosses. Front. Microbiol. 2:275. doi: 10.3389/fmicb.2011.00275

Conrad, R., Klose, M., Lu, Y., and Chidthaisong, A. (2012).
Methanogenic pathway and archaeal communities in three different anoxic soils amended with rice straw and maize straw. Front. Microbiol. 3:4. doi: 10.3389/fmicb.2012.00004

Gu, C., Laverman, A. M., and Pallud, C. E. (2012). Environmental controls on nitrogen and sulfur cycles in surficial aquatic sediments. Front. Microbiol. 3:45. doi: 10.3389/fmicb.2012.00045

Haaijer, S. C. M., Crienen, G., Jetten, M. S. M., and Op Den Camp, H. J. M. (2012). Anoxic iron cycling bacteria from an iron sulfide- and required to get an unbiased picture of microbial elemental cycling and their interactions in wetlands systems. Interactions between sulfur and nitrogen cycles in a wide range of surface sediments, representing variation in major controlling factors were assessed by $\mathrm{Gu}$ et al. (2012). Using flow-through reactors nitrate- and sulfate-reducing rates were measured in the presence and absence of nitrate and sulfate. The multivariate analyses of $\mathrm{N}$ - and $\mathrm{S}$ cycling rates with the wide range of environmental conditions designated $\mathrm{pH}$ and salinity to be the most important regulating factors with little interference between nitrate and sulfate reduction. The observed coupling between nitrate reduction and sulfide oxidation may have implications for metal availability and toxicity in wetland systems.

\section{SYNTHESIS}

The research compiled in this special issue on wetland microbiology clearly demonstrates that our understanding of the microbes living in wetland ecosystems is far from complete. The eminent role of wetlands for humanity combined with the crucial role microbes play in the functioning of these threatened ecosystems necessitates the more intensive and comprehensive assessment of microbiology of wetlands in the near future research. Significant changes in the hydrology of wetlands are predicted as a result of climate change, hence deeper knowledge of wetlands as a component of terrestrial ecosystems must be achieved. However, the complexity of wetlands and the microbial ecosystems therein makes these systems unamendable for a straightforward approach. More knowledge is needed at all levels going from single-cell ecophysiology to in situ biogeochemical functioning. Hence, persistent cultivation efforts and combined stable isotope-genomic approaches in combination with appropriate environmental physico-chemical characterization are required to achieve a more profound understanding of microbes and microbial communities in wetlands.

\section{ACKNOWLEDGMENTS}

We would like to thank all authors and reviewers who have contributed to this special issue and the financing agencies involved in this research. This publication is publication number 5433 of the Netherlands Institute of Ecology (NIOO-KNAW). nitrate-rich freshwater environment. Front. Microbiol. 3:26. doi: 10.3389/fmicb.2012.00026

Irvine, I. C., Vivanco, L., Bentley, P. N., and Martiny, J. B. H. (2012). The effect of nitrogen enrichment on c(1)-cycling microorganisms and methane flux in salt marsh sediments. Front. Microbiol. 3:90. doi: 10.3389/fmicb.2012.00090

Ivanova, A. O., and Dedysh, S. N. (2012). Abundance, diversity, and depth distribution of planctomycetes in acidic northern wetlands. Front. Microbiol. 3:5. doi: 10.3389/fmicb.2012.00005
Kolb, S., and Horn, M. A. (2012). Microbial $\mathrm{CH}(4)$ and $\mathrm{N}(2) \mathrm{O}$ consumption in acidic wetlands. Front. Microbiol. 3:78. doi: 10.3389/fmicb.2012.00078

Laanbroek, H. J., Keijzer, R. M., Verhoeven, J. T. A., and Whigham, D. F. (2012). The distribution of ammonia-oxidizing betaproteobacteria in stands of Black Mangroves (Avicennia germinans). Front. Microbiol. 3:153. doi: 10.3389/fmicb.2012.00153

Lamers, L. P. M., Van Diggelen, J. M. H., Op Den Camp, H. J. M., Visser, E. J. W., Lucassen, E. C. H. 
E. T., Vile, M. A., et al. (2012). Microbial transformations of nitrogen, sulfur, and iron dictate vegetation composition in wetlands: a review. Front. Microbiol. 3:156. doi: 10.3389/fmicb.2012.00156

Lovell, C. R., and Davis, D. A. (2012). Specificity of salt marsh diazotrophs for vegetation zones and plant hosts: results from a North American marsh. Front. Microbiol. 3:84. doi: 10.3389/fmicb.2012.00084

Pester, M., Knorr, K.-H., Friedrich, M. W., Wagner, M., and Loy, A. (2012). Sulfate-reducing microorganisms in wetlands - fameless actors in carbon cycling and climate change. Front. Microbiol. 3:72. doi: 10.3389/fmicb.2012.00072
Preston, M. D., Smemo, K. A., McLaughlin, J. W., and Basiliko, N. (2012). Peatland microbial communities and decomposition processes in the james bay lowlands, Canada. Front. Microbiol. 3:70. doi: 10.3389/fmicb.2012.00070

Putkinen, A., Larmola, T., Tuomivirta, T., Siljanen, H. M. P., Bodrossy, L., Tuittila, E.-S., et al. (2012). Water dispersal of methanotrophic bacteria maintains functional methane oxidation in sphagnum mosses. Front. Microbiol. 3:15. doi: 10.3389/fmicb.2012.00015

Siljanen, H. M. P., Saari, A., Bodrossy, L., and Martikainen, P. J. (2012). Effects of nitrogen load on the function and diversity of methanotrophs in the littoral wetland of a boreal lake. Front. Microbiol. 3:39. doi: 10.3389/fmicb.2012.00039

Sun, C. L., Brauer, S. L., CadilloQuiroz, H., Zinder, S. H., and Yavitt, J. B. (2012). Seasonal changes in methanogenesis and methanogenic community in three peatlands, new york state. Front. Microbiol. 3:81. doi: 10.3389/fmicb.2012.00081

Wang, J., Krause, S., Muyzer, G., Meima-Franke, M., Laanbroek, H. J., and Bodelier, P. L. E. (2012). Spatial patterns of iron- and methane-oxidizing bacterial communities in an irregularly flooded, riparian wetland. Front. Microbiol. 3:64. doi: 10.3389/fmicb.2012. 00064
Received: 18 March 2013; accepted: 20 March 2013; published online: 05 April 2013.

Citation: Bodelier PLE and Dedysh SN (2013) Microbiology of wetlands. Front. Microbiol. 4:79. doi: 10.3389/ fmicb.2013.00079

This article was submitted to Frontiers in Terrestrial Microbiology, a specialty of Frontiers in Microbiology.

Copyright (c) 2013 Bodelier and Dedysh. This is an open-access article distributed under the terms of the Creative Commons Attribution License, which permits use, distribution and reproduction in other forums, provided the original authors and source are credited and subject to any copyright notices concerning any third-party graphics etc. 


\title{
Microbial $\mathrm{CH}_{4}$ and $\mathrm{N}_{2} \mathrm{O}$ consumption in acidic wetlands
}

\author{
Steffen Kolb* and Marcus A. Horn \\ Department of Ecological Microbiology, University of Bayreuth, Bayreuth, Germany
}

\section{Edited by:}

Svetlana N. Dedysh, Winogradsky Institute of Microbiology, Russian Academy of Sciences, Russia

\section{Reviewed by:}

Gesche Braker, Max Planck Institute for Terrestrial Microbiology, Germany Lisa Y. Stein, University of Alberta,

Canada

\section{${ }^{*}$ Correspondence:}

Steffen Kolb, Department of Ecological Microbiology, University of Bayreuth, Dr.-Hans-Frisch-Str. 1-3, 95448 Bayreuth, Germany.

e-mail: steffen.kolb@uni-bayreuth.de
Acidic wetlands are global sources of the atmospheric greenhouse gases methane $\left(\mathrm{CH}_{4}\right)$, and nitrous oxide $\left(\mathrm{N}_{2} \mathrm{O}\right)$. Consumption of both atmospheric gases has been observed in various acidic wetlands, but information on the microbial mechanisms underlying these phenomena is scarce. A substantial amount of $\mathrm{CH}_{4}$ is consumed in sub soil by aerobic methanotrophs at anoxic-oxic interfaces (e.g., tissues of Sphagnum mosses, rhizosphere of vascular plant roots). Methylocystis-related species are likely candidates that are involved in the consumption of atmospheric $\mathrm{CH}_{4}$ in acidic wetlands. Oxygen availability regulates the activity of methanotrophs of acidic wetlands. Other parameters impacting on the methanotroph-mediated $\mathrm{CH}_{4}$ consumption have not been systematically evaluated. $\mathrm{N}_{2} \mathrm{O}$ is produced and consumed by microbial denitrification, thus rendering acidic wetlands as temporary sources or sinks for $\mathrm{N}_{2} \mathrm{O}$. Denitrifier communities in such ecosystems are diverse, and largely uncultured and/or new, and environmental factors that control their consumption activity are unresolved. Analyses of the composition of $\mathrm{N}_{2} \mathrm{O}$ reductase genes in acidic wetlands suggest that acid-tolerant Proteobacteria have the potential to mediate $\mathrm{N}_{2} \mathrm{O}$ consumption in such soils. Thus, the fragmented current state of knowledge raises open questions concerning methanotrophs and denitrifiers that consume atmospheric $\mathrm{CH}_{4}$ and $\mathrm{N}_{2} \mathrm{O}$ in acidic wetlands.

Keywords: Peat, bog, fen, $\mathrm{CH}_{4}$ cycle, nitrogen cycle, greenhouse gas sink, soil microbiology

\section{INTRODUCTION}

Microbial communities of acidic wetlands are responsible for emissions of the potent greenhouse gases methane $\left(\mathrm{CH}_{4}\right)$, and nitrous oxide $\left(\mathrm{N}_{2} \mathrm{O}\right.$; Conrad, 1996; Whalen, 2005; Denman et al., 2007). The largest single global source of atmospheric $\mathrm{CH}_{4}(100-$ $237 \mathrm{Gt} \mathrm{year}^{-1}$ ) are acidic wetlands, such as peat bogs and fens that cover $3.5 \%$ of the terrestrial surface, but store about $30 \%$ of global carbon of terrestrial ecosystems (Gore, 1983; Denman et al., 2007). Largest sources of atmospheric $\mathrm{N}_{2} \mathrm{O}$ are soils under natural vegetation and agricultural use; nonetheless, certain acidic wetlands that have a high nitrogen content were recently identified as significant sources of $\mathrm{N}_{2} \mathrm{O}$ displaying $\mathrm{N}_{2} \mathrm{O}$ emissions in the range of those observed for agricultural soils (Denman et al., 2007; Repo et al., 2009; Marushchak et al., 2011). Conservative estimates suggest that $0.6 \%$ of the global annual emission of $\mathrm{N}_{2} \mathrm{O}$ might be attributed to such acidic wetlands (Repo et al., 2009).

Acidic wetlands are covered by water-adapted vascular plants, and mosses of the genus Sphagnum (Gorham, 1991). Microbes that produce $\mathrm{CH}_{4}$ are methanogenic Archaea, and those that are the main source of $\mathrm{N}_{2} \mathrm{O}$ are denitrifiers in anoxic habitats like wetlands (Conrad, 1996; Ferry, 1999; Drake et al., 2009). $\mathrm{CH}_{4}$ produced by methanogens is further oxidized by aerobic methanotrophs, which thrive as a significant part of wetland microbial communities and mitigate the net $\mathrm{CH}_{4}$ flux into the atmosphere (Hanson and Hanson, 1996; Shannon et al., 1996; Whalen, 2005; Knorr et al., 2008; Hornibrook et al., 2009). Atmospheric oxygen may penetrate soil due to water table draw downs, and gas transport through the aerenchyma of vascular plants into the rhizosphere (Moog and Bruggemann, 1998; Kettunen et al., 1999; Mainiero and Kazda,
2005; Paul et al., 2006). Acidic wetlands may temporarily turn into sinks of atmospheric $\mathrm{CH}_{4}$, or at least have the potential to consume atmospheric $\mathrm{CH}_{4}(\leq 1.75 \mathrm{ppmv}$; Table 1; Whalen and Reeburgh, 2000; Jauhiainen et al., 2005; Elberling et al., 2011), a fact that is currently underappreciated, and poorly understood on the level of microbial communities.

Association of denitrifiers with $\mathrm{N}_{2} \mathrm{O}$ production in nitrogenrich acidic wetlands is indicated by process-orientated studies of water-logged acidic soils, and denitrification is suggested as the primary $\mathrm{N}_{2} \mathrm{O}$ producing process in such systems where the water filled pore space exceeds 70\% (Davidson, 1991). Denitrifiers catalyze the sequential reduction of $\mathrm{N}$-oxides to nitrous oxide $\left(\mathrm{N}_{2} \mathrm{O}\right)$ and/or dinitrogen $\left(\mathrm{N}_{2}\right)$ via the sequential action of nitrate, nitrite, nitric oxide, and nitrous oxide reductases (Zumft, 1997). Subunits that contain the catalytic center are encoded by narG/napA, nirK/nirS, norB, and nosZ. Dissimilatory reduction of nitrate via nitrite to ammonium (DNRA) might produce $\mathrm{N}_{2} \mathrm{O}$ under oxygen limited conditions via the unspecific interaction of nitrite with nitrate reductase (Smith and Zimmermann, 1981; Smith, 1983). However, DNRA potentials are low in acidic wetland soils, and free nitrite is virtually absent from such soils, suggesting that DNRA is negligible with regards to $\mathrm{N}_{2} \mathrm{O}$ production (Anderson and Leine, 1986; Bowden, 1987). Significant products of chemodenitrification are $\mathrm{NO}$ and $\mathrm{NO}_{2}$ rather than $\mathrm{N}_{2} \mathrm{O}$ (van Cleemput, 1998; Kappelmeyer et al., 2003; Kresovic et al., 2009). $\mathrm{N}_{2} \mathrm{O}$ is also produced as a by-product during the aerobic conversion of ammonia to nitrate by nitrifiers, but nitrification is the primary source of $\mathrm{N}_{2} \mathrm{O}$ in oxic rather than water-logged soils (Davidson, 1991; Conrad, 1996). Despite the importance of denitrifiers for $\mathrm{N}_{2} \mathrm{O}$ production 


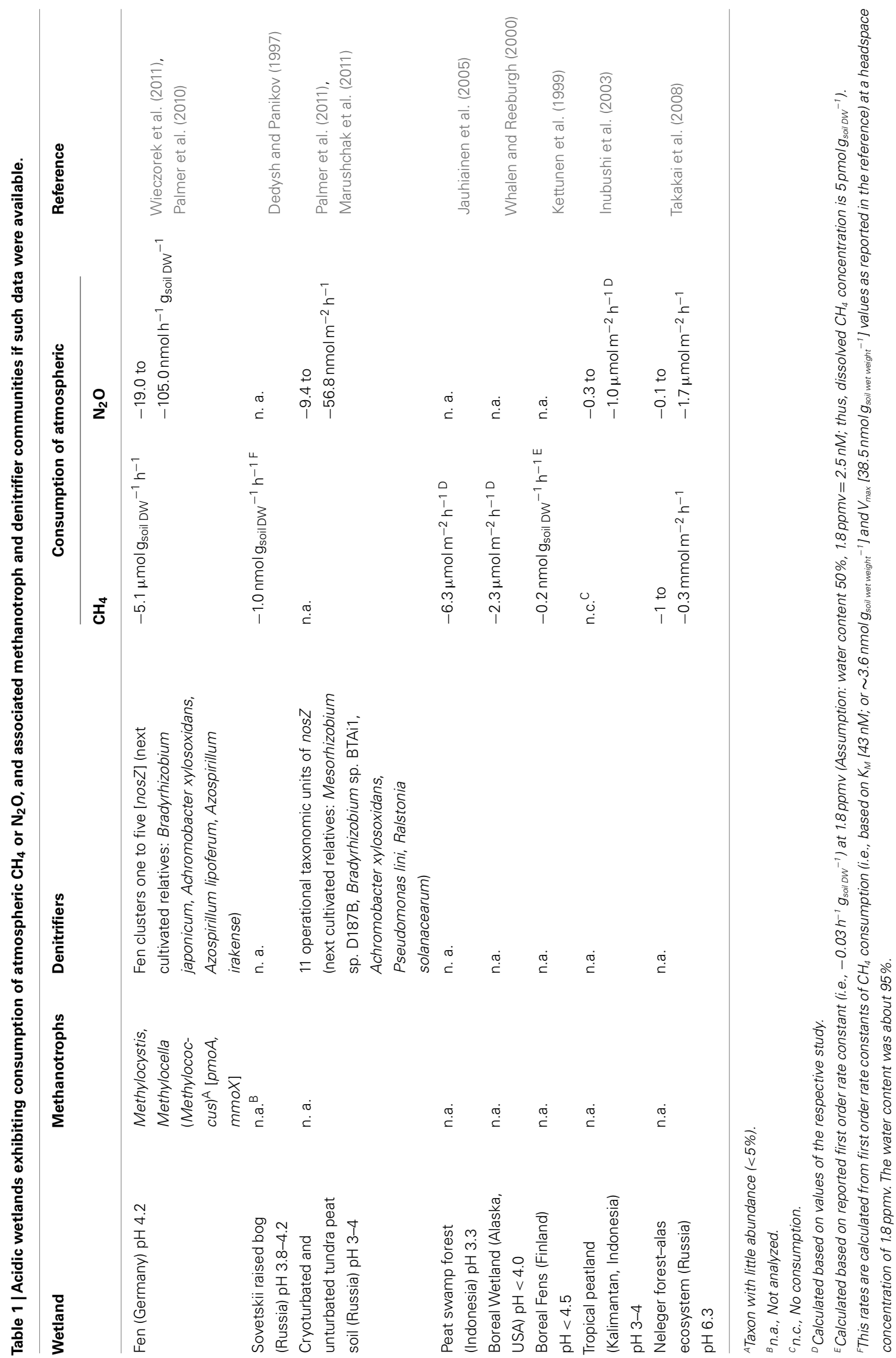


in water-logged soils and the wealth of information on denitrifiers of agricultural and pH-neutral upland soils, studies addressing acid-tolerant denitrifiers in acidic wetlands are just emerging and under-represented in current literature. Evidence is accumulating that soils including acidic wetlands can act as temporary sinks for $\mathrm{N}_{2} \mathrm{O}$ (Inubushi et al., 2003; Hadi et al., 2005; Chapuis-Lardy et al., 2007; Goldberg et al., 2010). Indeed, negative fluxes of up to $-1.7 \mu \mathrm{mol} \mathrm{N}_{2} \mathrm{O} \mathrm{m}^{-2} \mathrm{~h}^{-1}$ were observed in situ for acidic wetlands (Table 1). Thus, the review intents to delineate the current understanding of microbial communities in acidic wetlands for $\mathrm{CH}_{4}$ and $\mathrm{N}_{2} \mathrm{O}$ consumption and to highlight research needs.

\section{METHANOTROPHS OF ACIDIC WETLANDS}

$\mathrm{CH}_{4}$ fluxes of acidic wetlands are highly variable due to non-linear interactions of environmental factors that control methanogenesis, methanotrophy, and $\mathrm{CH}_{4}$ gas transport (Whalen, 2005; Spahni et al., 2011). One reason of high spatial and temporal variability of $\mathrm{CH}_{4}$ exchange with the atmosphere might be a mitigation of net flux by consumption of atmospheric $\mathrm{CH}_{4}(\mathrm{Wiec}-$ zorek et al., 2011). Hot spots of activity of methanotrophs in acidic wetlands are anoxic-oxic interfaces, where $\mathrm{CH}_{4}$ and oxygen gradients overlap (Sundh et al., 1995; Kettunen et al., 1999). Thus changes in oxygen availability alter both $\mathrm{CH}_{4}$ consumption, and production, and hence, reduce or increase net flux of $\mathrm{CH}_{4}$ from soil into the atmosphere (Kettunen et al., 1999; Whalen, 2005).

Prevalent methanotrophs of acidic wetlands belong to Alphaproteobacteria (Chen et al., 2008a; Dedysh, 2009; Wieczorek et al., 2011). Total cell numbers of methanotrophs of acidic wetlands range from $10^{6}$ to $10^{8}$ cells per gram of wet weight (Sundh et al., 1995; Dedysh et al., 2001, 2003; Dedysh, 2002, 2009; Belova et al., 2011). Methanotrophic pure cultures have primarily been isolated from Sphagnum-covered wetlands, and are acid-tolerant strains of Methylocystis (Methylocystaceae), Methylocella, and Methylocapsa (both Beijerinckiaceae; Dedysh et al., 2001, 2003; Dedysh, 2002, 2009; Kip et al., 2011). Methylocella species, and some species of Methylocystis and Methylocapsa utilize also simple multicarbon compounds, such as acetate (Dedysh et al., 2005; Theisen et al., 2005; Dunfield et al., 2010; Belova et al., 2011). Fluctuations of soil-internal methanogenesis may be caused by varying exudation of plants and redox conditions due to water table changes that can be consequences of drought periods, or heavy rainfall (Knorr et al., 2008; Knorr and Blodau, 2009, Dorodnikov et al., 2011). Acetate-utilizing methanotrophs are largely independent of such $\mathrm{CH}_{4}$ deficits in acidic wetlands.

Methylocystis strain $\mathrm{H} 2 \mathrm{~s}$ apparently represents a key methanotroph in acidic wetlands (Belova et al., 2011; Wieczorek et al., 2011). Strain H2s-related 16S rRNA genes ubiquitously occur in northern wetlands, and contribute with $18-58 \%$ (i.e., $0.4 \times 10^{7}$ to $3.4 \times 10^{7}$ cells $^{-1}$ of wet weight) to the alphaproteobacterial methanotrophs in such wetlands (Belova et al., 2011). Uncultivated species that are phylogenetically related to Methylocystis, and Methylocapsa are associated with hyaline cells of submerged mosses of Sphagnum. These Sphagnum methanotroph associations have been found in various northern wetlands (Kip et al., 2010). Methanotrophs apparently contribute up to $30 \%$ to carbon assimilation of the moss (Raghoebarsing et al., 2005; Kip et al., 2010; Larmola et al., 2010; Parmentier et al., 2011). The association is, based on current observations, not specific since different methanotroph-free Sphagnum species can be colonized by methanotrophs that were provided from the same Sphagnum individual (Larmola et al., 2010). The physiological basis of the interaction between methanotroph and moss has not been fully resolved.

Wetland methanotroph communities are usually dominated by Alphaproteobacteria, but gammaproteobacterial methanotrophs may also be present (Morris et al., 2002; Chen et al., 2008a,b; Wieczorek et al., 2011). Some of them (Methylomonas-, Methylosoma-related strains) have been isolated, which represent the first acid-tolerant members of the Methylococcaceae (Kip et al., 2011). All cultured methanotrophs of acidic wetlands are acidtolerant and have growth optima below pH6 (Dedysh, 2009; Kip et al., 2011). Most information on the identities and physiologies of methanotrophs of acidic wetlands are derived from Sphagnum-associated microbial communities, but there is a lack of information on vascular plant-associated methanotrophs in acidic wetlands.

\section{SPECIALIZED METHANOTROPHS MEDIATE $\mathrm{CH}_{4}$ SINK ACTIVITY OF ACIDIC WETLANDS}

Acidic wetlands may temporally turn into net sinks of atmospheric $\mathrm{CH}_{4}$, which has been documented in various studies, or have the capability to utilize atmospheric $\mathrm{CH}_{4}$ concentrations (Table 1; Figure 1; Dedysh and Panikov, 1997; Kettunen et al., 1999; Whalen and Reeburgh, 2000; Jauhiainen et al., 2005; Elberling et al., 2011; Wieczorek et al., 2011). Many wetland sites have annual emission rates of less than $3.8 \mathrm{~mol} \mathrm{CH}_{4} \mathrm{ha}^{-2}$ year $^{-1}$ (Dalal and Allen, 2008) indicating not necessarily only low $\mathrm{CH}_{4}$ production, but also a certain proportion of consumption of atmospheric $\mathrm{CH}_{4}$ over the year.

A very limited number of studies analyzed the composition of methanotroph communities of acidic wetlands, and measured the potential of the respective wetland to consume atmospheric $\mathrm{CH}_{4}$ (Table 1). Methylocystis species that were frequently detected in acidic wetlands are closely related to the solely known methanotroph strains that are capable of consumption of atmospheric $\mathrm{CH}_{4}$, i.e., strains LR1, SC2, and DWT (Dunfield et al., 1999, 2002; Kolb et al., 2005; Baani and Liesack, 2008; Dedysh, 2009; Wieczorek et al., 2011). Nonetheless, pmoA2 genes (that encode for the hydroxylase subunit of a high affinity $\mathrm{CH}_{4}$ mono-oxygenase) that would indicate the capability of consumption of atmospheric $\mathrm{CH}_{4}$ (Dunfield et al., 2002; Yimga et al., 2003; Ricke et al., 2004; Baani and Liesack, 2008) have only been detected at low relative abundances (<5\%; Wieczorek et al., 2011). To warrant consumption of atmospheric $\mathrm{CH}_{4}$ in wetlands a small fraction (about $10^{7}$ cells per gram dry weight in forest soils that consume atmospheric $\mathrm{CH}_{4}$; Kolb et al., 2005; Degelmann et al., 2010) of the total cell number of present methanotrophs (about $10^{8}$ cells per gram dry weight) need presumably be active to allow for consumption of atmospheric $\mathrm{CH}_{4}$ at rates that were observed in acidic wetland sites. The major proportion of detectable $p m o A$ (encodes the beta-subunit of a low affinity membrane bound $\mathrm{CH}_{4}$ mono-oxygenase) and $m m o X$ (encodes the hydroxylase subunit of a low affinity cytoplasmic bound $\mathrm{CH}_{4}$ mono-oxygenase) genes in an acidic wetland soil that exhibited the capability of consumption of atmospheric levels 
of $\mathrm{CH}_{4}$ (i.e., 82 and 64\%, respectively), affiliated with genes of Methylocystis (Wieczorek et al., 2011). Some Methylocystis species have the capability to utilize atmospheric $\mathrm{CH}_{4}$ concentrations. The abundant Methylocystis strain $\mathrm{H} 2$ s harbors as well pmoA2 indicating that this methanotroph may consume atmospheric $\mathrm{CH}_{4}$ (Dedysh, personal communication). Thus, Methylocystis species of acidic wetlands likely are capable of atmospheric $\mathrm{CH}_{4}$ consumption (Figure 1), and may have the advantage to survive more likely periods of $\mathrm{CH}_{4}$ deficiency, may be periodically the case in minerotrophic fens, and at oxygen-saturated surface-near soil layers.

Recently described thermoacidophilic methanotrophs of the Methylacidiphilaceae (Op den Camp et al., 2009) as well as anaerobic methanotrophs Candidatus "Methylomirabilis oxyfera" (Ettwig et al., 2010) have not been detected in acidic wetlands.
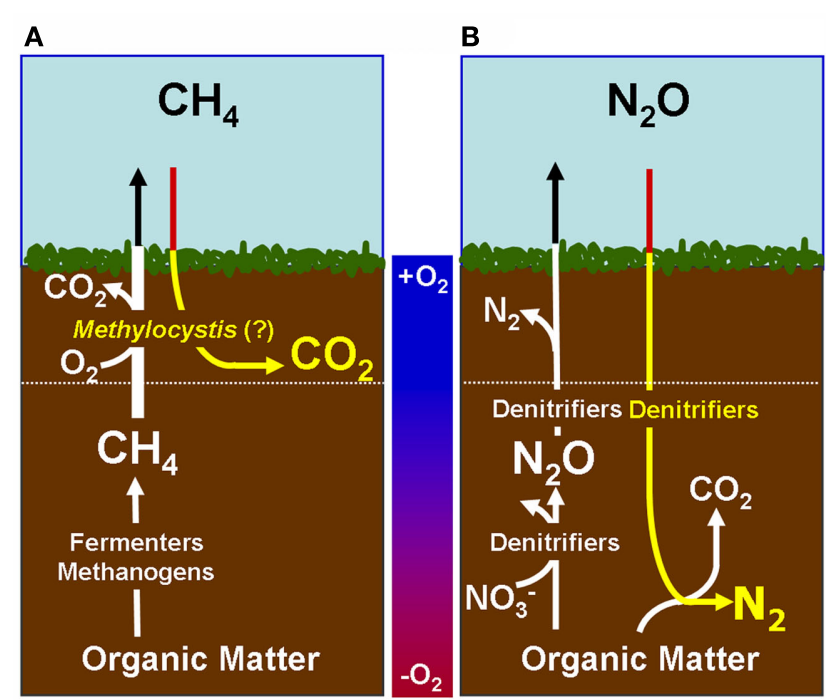

FIGURE 1 | Proposed Model of Microbes that are responsible of atmospheric sink function of $\mathrm{CH}_{4}$ and $\mathrm{N}_{2} \mathrm{O}$ in natural wetlands. The quantitative contribution to global net fluxes of $\mathrm{CH}_{4}$ and $\mathrm{N}_{2} \mathrm{O}$ into the atmosphere has not been evaluated in acidic wetlands. (A) Acidic wetland covered by Sphagnum plants with low nitrogen input and mineralization rates. White Pathway: Plant-derived organic matter is degraded by microbial fermentation, acetogenesis, and methanogenesis to $\mathrm{CH}_{4}$ that is transported to oxygen-saturated zones close to the surface. The thickness of the oxygen-saturated layer is dependent of water table level (white dotted line). Methanotrophs (such as Methylocystyceae, Beijerinkiaceae, but as well Methylococcaceae) consume up to $90 \%$ of methanogenic $\mathrm{CH}_{4}$ Products are microbial biomass and $\mathrm{CO}_{2}$. The not-consumed proportion of $\mathrm{CH}_{4}$ is released into the atmosphere. Methanotrophs convert $\mathrm{CH}_{4}$ to carbon dioxide $\left(\mathrm{CO}_{2}\right)$ which is released into the atmosphere. Yellow pathway: Methylocystis species likely consume atmospheric $\mathrm{CH}_{4}$ when $\mathrm{CH}_{4}$ supply from anoxic zones is limited. (B) Natural wetland with high nitrogen input and mineralization rates (e.g., minerotrophic fens, Palsa peats). White pathway: In nitrogen-rich acidic wetlands (e.g., Palsa peats) a part of anaerobic organic matter degradation intermediates are consumed by denitrifiers that reduce $\mathrm{NO}_{3}^{-}$to $\mathrm{N}_{2} \mathrm{O}$ and $\mathrm{N}_{2} . \mathrm{N}_{2} \mathrm{O}$ and $\mathrm{N}_{2}$ is released into the atmosphere. Ammonia-oxidizing bacteria (AOB) are known to produce small amounts of $\mathrm{N}_{2} \mathrm{O}$ during oxidation of ammonia (Schmidt et al., 2004; Braker and Conrad, 2011). Yellow pathway: Under as-yet unresolved environmental conditions atmospheric $\mathrm{N}_{2} \mathrm{O}$ may be further reduced to $\mathrm{N}_{2}$ by to date not cultured denitrifiers that use electrons from organic matter.
In summary, Methylocystis are likely involved for consumption of atmospheric $\mathrm{CH}_{4}$ in acidic wetlands. Nonetheless, an unequivocal experimental proof is missing. The role of other methanotrophs in acidic wetlands (i.e., Beijerinckiaceae, and Methylococcaceae) in consumption of atmospheric $\mathrm{CH}_{4}$ is not fully unresolved, but not very likely based on their low affinities for $\mathrm{CH}_{4}$. It is not likely that "M. oxyfera" is involved in $\mathrm{N}_{2} \mathrm{O}$ cycling since it lacks nitric oxide reductase.

\section{DO DENITRIFIERS CONSUME $\mathrm{N}_{2} \mathrm{O}$ IN ACIDIC WETLANDS?}

One of the most remarkable features of denitrifiers is their capacity to produce and consume $\mathrm{N}_{2} \mathrm{O}$ (Table 1; Figure 1; Zumft, 1997). Such organisms are widely distributed in various environments and highly diverse (e.g., Zumft, 1997; Braker and Conrad, 2011). Not all denitrifiers known to date are capable of $\mathrm{N}_{2} \mathrm{O}$ consumption (Zumft and Kroneck, 2007). However, $\mathrm{N}_{2} \mathrm{O}$ is a common intermediate during denitrification and serves as sole electron acceptor for supporting growth of many denitrifiers (Zumft, 1997; Strohm et al., 2007). DNA based stable isotope probing with ${ }^{13} \mathrm{C}$-labeled succinate as electron donor and $\mathrm{N}_{2} \mathrm{O}$ as electron acceptor and cultivation-based studies demonstrated growth of putative denitrifiers by $\mathrm{N}_{2} \mathrm{O}$ reduction in rice field soil (Ishii et al., 2011). These findings are in line with a $\Delta G_{0}^{\prime}$ of $\mathrm{N}_{2} \mathrm{O}$ reduction to $\mathrm{N}_{2}$ that approximates $-340 \mathrm{~kJ} \mathrm{~mol}^{-1}$ under standard conditions, indicating a highly exergonic process (Zumft and Kroneck, 2007). Thus, it might not be surprising that $\mathrm{N}_{2} \mathrm{O}$ consumption by soil communities is a more common phenomenon than previously thought (Table 1; reviewed in Holtan-Hartwig et al., 2000; Chapuis-Lardy et al., 2007).

$\mathrm{N}_{2} \mathrm{O}$ reductases of denitrifiers catalyze the efficient reduction of $\mathrm{N}_{2} \mathrm{O}$ to $\mathrm{N}_{2}$ and are copper-dependent metallo-enzymes that exhibit $K_{\mathrm{M}}$ values in the lower micromolar range for $\mathrm{N}_{2} \mathrm{O}$, highlighting the potential of denitrifiers to consume low concentrations of $\mathrm{N}_{2} \mathrm{O}$ (Zumft, 1997). Abiotic conversion of $\mathrm{N}_{2} \mathrm{O}$ at ambient temperatures might occur with (reduced) transitionmetal complexes (which occur in the active site of $\mathrm{N}_{2} \mathrm{O}$ converting enzymes) and metal amides (Banks et al., 1968; Zumft and Kroneck, 2007). Metallo-enzymes like carbon monoxide dehydrogenase and cobalamin-dependent methionine synthase are also capable of reducing $\mathrm{N}_{2} \mathrm{O}$ to $\mathrm{N}_{2}$, while nitrogenase converts $\mathrm{N}_{2} \mathrm{O}$ to $\mathrm{NH}_{3}$; bacterial nitrite cytochrome c reductase transforms $\mathrm{N}_{2} \mathrm{O}$ to an unknown product (Jensen and Burris, 1986; Bannerjee and Matthews, 1990; Lu and Ragsdale, 1991; Drummond and Matthews, 1994; Stach et al., 2000). Such enzymes are hosted by diverse organisms including non-denitrifiers (see references in Zumft, 1997; Zumft and Kroneck, 2007). However, the conversion of $\mathrm{N}_{2} \mathrm{O}$ by these aforementioned enzymes is regarded as a nonphysiological reaction. Low $K_{\mathrm{M}}$ values and high specific activities for $\mathrm{N}_{2} \mathrm{O}$ (as were demonstrated for $\mathrm{N}_{2} \mathrm{O}$ reductases of denitrifiers) have not been demonstrated for such enzymes, suggesting a minor role, if any, for the consumption of atmospheric $\mathrm{N}_{2} \mathrm{O}$ concentrations ( $319 \mathrm{ppb}$, equivalent to app. $8 \mathrm{nmol} \mathrm{N}_{2} \mathrm{O}$ per liter soil solution; Conrad, 1996) in soils (Zumft, 1997; Stach et al., 2000; Zumft and Kroneck, 2007). In this context, dissimilatory reducers of nitrate producing ammonia of the Enterobacteriaceae that were shown to consume $\mathrm{N}_{2} \mathrm{O}$ in the laboratory displayed a $K_{\mathrm{M}}$ value of $3 \mathrm{mM}$ for $\mathrm{N}_{2} \mathrm{O}$, likewise suggesting that the $\mathrm{N}_{2} \mathrm{O}$ reduction is 
a non-physiological reaction and probably of minor importance in situ (Kaldorf et al., 1993). Moreover, assimilatory reduction of $\mathrm{N}_{2} \mathrm{O}$ that might theoretically proceed via nitrogenase action was not detected in soils (Vieten et al., 2008). Thus, denitrifiers hosting $\mathrm{N}_{2} \mathrm{O}$ reductases deserve primary attention in the context of $\mathrm{N}_{2} \mathrm{O}$ consumption in soils.

Denitrification rates and the ratio of $\mathrm{N}_{2} \mathrm{O}$ to total nitrogen gas products are regulated by oxygen availability, $\mathrm{pH}$, temperature, carbon to nitrogen ratio, the availability of substrates, and electron acceptors, as well as by the denitrifier community composition (van Cleemput, 1998; Dörsch et al., 2011). Anoxia (as indicated by a water filled pore space of greater than 60\%), a carbon to nitrogen ratio greater than 30 , and $\mathrm{pH}$-neutral conditions favor complete denitrification to $\mathrm{N}_{2}$ in soils including acidic wetlands (Conrad, 1995, 1996; Klemedtsson et al., 2005; Cuhel et al., 2010; Braker and Conrad, 2011). A pH value below 5 is often encountered in peatlands, and is hypothesized to impair $\mathrm{N}_{2} \mathrm{O}$ reduction and to increase the product ratio of $\mathrm{N}_{2} \mathrm{O}$ to $\mathrm{N}_{2}$ (Simek and Cooper, 2002; Cuhel et al., 2010). However, acidic wetlands host acid-tolerant denitrifiers capable of $\mathrm{N}_{2} \mathrm{O}$ reduction and complete denitrification (Palmer et al., 2010, 2011). Moreover, evidence of active denitrification-associated $\mathrm{N}_{2} \mathrm{O}$ production and consumption, (including consumption of atmospheric $\mathrm{N}_{2} \mathrm{O}$ concentrations) was obtained by compound specific stable isotope analyses of $\mathrm{N}_{2} \mathrm{O}$ in one acidic wetland (Goldberg et al., 2008, 2010). In that specific wetland, $\delta^{15} \mathrm{~N}$ values indicated that $\mathrm{N}_{2} \mathrm{O}$ produced in deep soil layers was partially consumed upon its diffusion to the soil surface (Goldberg et al., 2008, 2010), suggesting that denitrifiers might contribute to the mitigation of $\mathrm{N}_{2} \mathrm{O}$ emission from acidic wetlands. Denitrifiers that exhibit the genetic potential to consume $\mathrm{N}_{2} \mathrm{O}$ were detected in acidic wetlands by the analysis of nos $Z$ genes. Detected nos $Z$ genes in acidic wetlands mostly affiliated with nos $Z$ from uncultured soil bacteria or were only distantly related to known genes, suggesting a wealth of uncultured denitrifier diversity in acidic wetlands (Palmer et al., 2010, 2011). Phylogenies of nos $Z$ and 16S rRNA genes from the same organisms are basically congruent (Jones et al., 2008; Palmer et al., 2009), allowing to speculate on the identity of organisms hosting the detected nos $Z$. Thus, putative $\mathrm{N}_{2} \mathrm{O}$ reducers in acidic wetlands include Alphaproteobacteria (Azospirillum, Brady-, and

\section{REFERENCES}

Anderson, I. C., and Leine, J. S. (1986). Relative rates of nitric oxide and nitrous oxide production by nitrifiers, denitrifiers, and nitrate respires. Appl.Environ. Microbiol.51, 938-945.

Baani, M., and Liesack, W. (2008). Two isozymes of particulate methane monooxygenase with different methane oxidation kinetics are found in Methylocystis sp. strain SC2. Proc. Natl. Acad. Sci. U.S.A. 105, 10203-10208.

Banks, R. G. S., Henderson, R. J., and Pratt, J. M. (1968). Reactions of gases in solution. Part III. Some reactions of nitrous oxide with transition-metal complexes.
J. Chem. Soc. A 2886-2889. doi: 10.1039/J19680002886

Bannerjee, R. V., and Matthews, R. G. (1990). Cobalamin-dependent methionine synthase. FASEB J. 4, 1450-1459.

Belova, S. E., Baani, M., Suzina, N. E., Bodelier, P. L. E., Liesack, W., and Dedysh, S. N. (2011). Acetate utilization as a survival strategy of peatinhabiting Methylocystis spp. Environ. Microbiol. Rep. 3, 36-46.

Bowden, W. B. (1987). The biogeochemistry of nitrogen in freshwater wetlands. Biogeochemistry 4, 313-348.

Braker, G., and Conrad, R. (2011). "Diversity, structure, and size of $\mathrm{N}_{2} \mathrm{O}$-producing microbial

Mesorhizobium), Betaproteobacteria (Achromobacter, Ralstonia), and Gammaproteobacteria (Pseudomonas). However, it remains to be determined whether the detected $\mathrm{N}_{2} \mathrm{O}$ reductase genes were expressed, i.e., the detected organisms reduce $\mathrm{N}_{2} \mathrm{O}$ in situ (Figure 1).

Analyses of other genes associated with denitrification corroborate that acidic wetlands harbor diverse and new denitrifiers (Palmer et al., 2010, 2011). However, given the low number of studies addressing $\mathrm{N}_{2} \mathrm{O}$-consuming denitrifier communities in acidic wetlands, and the selectivity of PCR-based gene marker analyses, the present studies have to be regarded as providing a minimal estimate of denitrifier diversity capable of $\mathrm{N}_{2} \mathrm{O}$ consumption (Throback et al., 2004; Green et al., 2010; Heylen et al., 2011; Jones et al., 2011). The fact that high affinity respiratory $\mathrm{N}_{2} \mathrm{O}$ reduction occurs in non-denitrifying organisms that reduce nitrate but lack nitrite reductase activity, and that nitrifiers were shown to have the capability to consume $\mathrm{N}_{2} \mathrm{O}$ and produce $\mathrm{N}_{2}$ further complicates matters (Yoshinari, 1980; McEwan et al., 1985; Zumft, 1997; Schmidt et al., 2004). Nevertheless, the relevance of $\mathrm{N}_{2} \mathrm{O}$ consumption for mitigation of $\mathrm{N}_{2} \mathrm{O}$ emissions, and eventually a temporary sink function of acidic wetlands for $\mathrm{N}_{2} \mathrm{O}$ is emerging, although the physiology and taxonomic identity of "microbial catalysts" have not been sufficiently resolved. Furthermore, the regulation of $\mathrm{N}_{2} \mathrm{O}$ reduction in situ and on cellular level, and thus the potential of the soil to reduce $\mathrm{N}_{2} \mathrm{O}$ to $\mathrm{N}_{2}$, and the diffusivity of $\mathrm{N}_{2} \mathrm{O}$ within the soil profile will impact the sink functions of wetland soils for $\mathrm{N}_{2} \mathrm{O}$ but are likewise only poorly resolved.

\section{FUTURE PERSPECTIVES}

Few studies addressed the role of methanotrophs and denitrifiers in consumption of atmospheric $\mathrm{CH}_{4}$ and $\mathrm{N}_{2} \mathrm{O}$ in acidic wetlands. Potential consumption activities have been measured in laboratory-scale experiments, and first evidence for denitrification-associated $\mathrm{N}_{2} \mathrm{O}$ consumption in situ is available. Systematic in situ flux measurements combined with measurements of environmental parameters, consumption potentials, stable isotope signatures of carbon and nitrogen in $\mathrm{CH}_{4}$ and $\mathrm{N}_{2} \mathrm{O}$ pools, and community analyses are needed to improve our understanding of environmental factors that trigger $\mathrm{CH}_{4}$ and $\mathrm{N}_{2} \mathrm{O}$ consumption in acidic wetland soils.

communities in soils - what matters for their functioning?" in Advances in Applied Microbiology, Vol. 75, eds A. I. Laskin, S. Sariaslani, and G. M. Gadd (San Diego: Elsevier Academic Press Inc.), 33-70.

Chapuis-Lardy, L., Wrage, N., Metay, A., Chotte, J. L., and Bernoux, M. (2007). Soils, a sink for $\mathrm{N}_{2} \mathrm{O}$ ? A review. Glob. Chang. Biol. 13, 1-17.

Chen, Y., Dumont, M. G., Mcnamara, N. P., Chamberlain, P. M., Bodrossy, L., Stralis-Pavese, N., and Murrell, J. C. (2008a). Diversity of the active methanotrophic community in acidic peatlands as assessed by mRNA and SIP-PLFA analyses. Environ. Microbiol. 10, 446-459.
Chen, Y., Dumont, M. G., Neufeld, J. D., Bodrossy, L., Stralis-Pavese, N., Mcnamara, N. P., Ostle, N., Briones, M. J., and Murrell, J. C. (2008b). Revealing the uncultivated majority: combining DNA stableisotope probing, multiple displacement amplification and metagenomic analyses of uncultivated Methylocystis in acidic peatlands. Environ. Microbiol. 10, 2609-2622.

Conrad, R. (1995). "Soil microbial processes involved in production and consumption of atmospheric trace gases," in Advances in Applied Microbiology, ed. J. G. Jones (New York: Plenum Press), 207-250.

Conrad, R. (1996). Soil microorganisms as controllers of atmospheric trace 
gases $\left(\mathrm{H}_{2}, \mathrm{CO}, \mathrm{CH}_{4}, \mathrm{OCS}, \mathrm{N}_{2} \mathrm{O}\right.$, and NO). Microbiol. Rev. 60, 609-642.

Cuhel, J., Simek, M., Laughlin, R. J., Bru, D., Cheneby, D., Watson, C. J., and Philippot, L. (2010). Insights into the effect of soil $\mathrm{pH}$ on $\mathrm{N}_{2} \mathrm{O}$ and $\mathrm{N}_{2}$ emissions and denitrifier community size and activity. Appl. Environ. Microbiol. 76, 1870-1878.

Dalal, R. C., and Allen, D. E. (2008). Greenhouse gas fluxes from natural ecosystems. Aust. J. Bot. 56, 369-407.

Davidson, E. A. (1991). "Fluxes of nitrous oxide and nitric oxide from terrestrial ecosystems," in Microbial Production and Consumption of Greenhouse Gases, eds J. E. Rogers and W. B. Whitman (Washington, DC: American Society for Microbiology), 219-235.

Dedysh, S. N. (2002). Methanotrophic bacteria of acidic Sphagnum peat bogs. Microbiology 71, 638-650.

Dedysh, S. N. (2009). Exploring methanotroph diversity in acidic northern wetlands: molecular and cultivation-based studies. Microbiology 78, 655-669.

Dedysh, S. N., Derakshani, M., and Liesack, W. (2001). Detection and enumeration of methanotrophs in acidic Sphagnum peat by $16 \mathrm{~S}$ rRNA fluorescence in situ hybridization, including the use of newly developed oligonucleotide probes for Methylocella palustris. Appl. Environ. Microbiol. 67, 4850-4857.

Dedysh, S. N., Dunfield, P. F., Derakshani, M., Stubner, S., Heyer, J., and Liesack, W. (2003). Differential detection of type II methanotrophic bacteria in acidic peatlands using newly developed 16S rRNAtargeted fluorescent oligonucleotide probes. FEMS Microbiol. Ecol. 43, 299-308.

Dedysh, S. N., Knief, C., and Dunfield, P. F. (2005). Methylocella species are facultatively methanotrophic. J. Bacteriol. 187, 4665-4670.

Dedysh, S. N., and Panikov, N. S. (1997). Effect of methane concentration on the rate of its oxidation by bacteria in Sphagnum peat. Microbiology 66, 470-475.

Degelmann, D. M., Borken, W., Drake, H. L., and Kolb, S. (2010). Different atmospheric methane-oxidizing communities in European Beech and Norway Spruce soils. Appl. Environ. Microbiol. 76, 3228-3235.

Denman, K. L., Brasseur, G., Chidthaisong, A., Ciais, P., Cox, P. M., Dickinson, R. E., Hauglustaine, D., Heinze, C., Holland, E., Jacob, D., Lohmann, U., Ramachan- dran, S., Da Silva Dias, P. L., Wofsy, S. C., and Zhang, X. (2007). "Couplings between changes in the climate system and biogeochemistry," in Climate Change 2007: The Physical Science Basis (Cambridge: Cambridge University Press), 499-587.

Dorodnikov, M., Knorr, K.-H. Kuzyakov, Y., and Wilmking, M. (2011). Plant-mediated $\mathrm{CH}_{4}$ transport and contribution of photosynthates to methanogenesis at a boreal mire: a $14 \mathrm{C}$ pulse study. Biogeosciences 8, 2365-2375.

Dörsch, P., Braker, G., and Bakken, L. (2011). Community specific $\mathrm{pH}$ response of denitrification: experiments with cells extracted from organic soils. FEMS Microbiol. Ecol. 79, 530-541.

Drake, H. L., Horn, M. A., and Wüst, P. K. (2009). Intermediary ecosystem metabolism as a main driver of methanogenesis in acidic wetland soil. Environ. Microbiol. Rep. 1, 307-318.

Drummond, J. T., and Matthews, R. G. (1994). Nitrous oxide degradation by cobalamin-dependent methionine synthase: characterization of the reactants and products in the inactivation reaction. Biochemistry 33, 3732-3741.

Dunfield, P. F., Belova, S. E., Vorob'Ev, A. V., Cornish, S. L., and Dedysh, S. N. (2010). Methylocapsa aurea sp. nov., a facultative methanotroph possessing a particulate methane monooxygenase, and emended description of the genus Methylocapsa. Int. J. Syst. Evol. Microbiol. 60 2659-2664.

Dunfield, P. F., Liesack, W., Henckel, T., Knowles, R., and Conrad, R. (1999). High-affinity methane oxidation by a soil enrichment culture containing a type II methanotroph. Appl. Environ. Microbiol. 65, 1009-1014.

Dunfield, P. F., Yimga, M. T., Dedysh, S. N., Berger, U., Liesack, W., and Heyer, J. (2002). Isolation of a Methylocystis strain containing a novel pmoAlike gene. FEMS Microbiol. Ecol. 41, 17-26.

Elberling, B., Askaer, L., Jorgensen, C. J., Joensen, H. P., Kuhl, M., Glud, R. N., and Lauritsen, F. R. (2011). Linking soil $\mathrm{O}_{2}, \mathrm{CO}_{2}$, and $\mathrm{CH}_{4}$ concentrations in a wetland soil: implications for $\mathrm{CO}_{2}$ and $\mathrm{CH}_{4}$ fluxes. Env. Sci. Tech. 45, 3393-3399.

Ettwig, K. F., Butler, M. K., Le Paslier, D., Pelletier, E., Mangenot, S., Kuypers, M. M. M., Schreiber, F., Dutilh, B. E., Zedelius, J., de Beer, D., Gloerich, J., Wessels, H. J. C. T., van
Alen, T., Luesken, F., Wu, M. L., van de Pas-Schoonen, K. T., Op den Camp, H. J. M., Janssen-Megens, E. M., Francoijs, K.-J., Stunnenberg, H., Weissenbach, J., Jetten, M. S. M., and Strous, M. (2010). Nitritedriven anaerobic methane oxidation by oxygenic bacteria. Nature 464, 543-548.

Ferry, J. G. (1999). Enzymology of one-carbon metabolism in methanogenic pathways. FEMS Microbiol. Rev. 23, 13-38.

Goldberg, S. D., Knorr, K.-H., Blodau, C., Lischeid, G., and Gebauer, G. (2010). Impact of altering the water table height of an acidic fen on $\mathrm{N}_{2} \mathrm{O}$ and $\mathrm{NO}$ fluxes and soil concentrations. Glob. Chang. Biol. 16, 220-233.

Goldberg, S. D., Knorr, K.-H., and Gebauer, G. (2008). $\mathrm{N}_{2} \mathrm{O}$ concentration and isotope signature along profiles provide deeper insight into the fate of $\mathrm{N}_{2} \mathrm{O}$ in soils. Isotopes Environ. Health Stud. 44, 377-391.

Gore, A. J. P. (1983). Mires: Swamp, Bog, Fen and Moor. New York: Elsevier.

Gorham, E. (1991). Northern peatlands - role in the carbon-cycle and probable responses to climatic warming. Ecol. Appl. 1, 182-195.

Green, S. J., Prakash, O., Gihring, T. M., Akob, D. M., Jasrotia, P., Jardine, P. M., Watson, D. B., Brown, S. D., Palumbo, A. V., and Kostka, J. E. (2010). Denitrifying bacteria isolated from terrestrial subsurface sediments exposed to mixed-waste contamination Appl. Environ. Microbiol. 76, 3244-3254.

Hadi, A., Inubushi, K., Furukawa, Y., Purnomo, E., Rasmadi, M., and Tsuruta, H. (2005). Greenhouse gas emissions from tropical peatlands of Kalimantan, Indonesia. Nutr. Cycl. Agroecosys. 71, 73-80.

Hanson, R. S., and Hanson, T. E. (1996). Methanotrophic bacteria. Microbiol. Rev. 60, 439.

Heylen, K., Verbaendert, I., De Vos, P. and Boon, N. (2011). Denitrification in gram-positive bacteria: an underexplored trait. Biochem. Soc. Trans. 39, 254-258.

Holtan-Hartwig, L., Dorsch, P., and Bakken, L. R. (2000). Comparison of denitrifying communities in organic soils: kinetics of $\mathrm{NO}_{3}-$ and $\mathrm{N}_{2} \mathrm{O}$ reduction. Soil Biol. Biochem. 32, 833-843.

Hornibrook, E. R. C., Bowes, H. L., Culbert, A., and Gallego-Sala, A. V. (2009). Methanotrophy potential versus methane supply by pore water diffusion in peatlands. Biogeosciences 6, 1490-1504.

Inubushi, K., Furukawa, Y., Hadi, A., Purnomo, E., and Tsuruta, $\mathrm{H}$. (2003). Seasonal changes of $\mathrm{CO}_{2}$, $\mathrm{CH}_{4}$ and $\mathrm{N}_{2} \mathrm{O}$ fluxes in relation to land-use change in tropical peatlands located in coastal area of South Kalimantan. Chemosphere 52, 603-608.

Ishii, S., Ohno, H., Tsuboi, M., Otsuka, S., and Senoo, K. (2011). Identification and isolation of active $\mathrm{N}_{2} \mathrm{O}$ reducers in rice paddy soil. ISME J. 5, 1936-1945.

Jauhiainen, J., Takahashi, H., Heikkinen, J. E. P., Martikainen, P. J., and Vasander, H. (2005). Carbon fluxes from a tropical peat swamp forest floor. Glob. Chang. Biol. 11, 1788-1797.

Jensen, B. B., and Burris, R. H. (1986). Nitrogenase. $\mathrm{N}_{2} \mathrm{O}$ as a substrate and as a competitive inhibitor of nitrogenase. Biochemistry 25, 1083-1088.

Jones, C. M., Stres, B., Rosenquist, M., and Hallin, S. (2008). Phylogenetic analysis of nitrite, nitric oxide, and nitrous oxide respiratory enzymes reveal a complex evolutionary history for denitrification. Mol. Biol. Evol. 25, 1955-1966.

Jones, C. M., Welsh, A., Throback, I. N. Dorsch, P., Bakken, L. R., and Hallin, S. (2011). Phenotypic and genotypic heterogeneity among closely related soil-borne $\mathrm{N}_{2}$ - and $\mathrm{N}_{2} \mathrm{O}$ producing Bacillus isolates harboring the nos $Z$ gene. FEMS Microbiol. Ecol. 76, 541-552.

Kaldorf, M., Linne yon Berg, K.-H., Meier, U., Servos, U., and Bothe, H. (1993). The reduction of nitrous oxide to dinitrogen by Escherichia coli. Arch. Microbiol. 160, 432-439.

Kappelmeyer, U., Kuschk, P., and Stottmeister, U. (2003). Model experiments on the influence of artificial humic compounds on chemodenitrification. Water Air Soil Pollut. 147, 317-330.

Kettunen, A., Kaitala, V., Lehtinen, A., Lohila, A., Alm, J., Silvola, J., and Martikainen, P. J. (1999). Methane production and oxidation potentials in relation to water table fluctuations in two boreal mires. Soil Biol. Biochem. 31, 1741-1749.

Kip, N., Ouyang, W. J., Van Winden, J., Raghoebarsing, A., Van Niftrik, L., Pol, A., Pan, Y., Bodrossy, L., Van Donselaar, E. G., Reichart, G. J., Jetten, M. S. M., Damste, J. S. S., and Den Camp, H. J. M. O. (2011). Detection, isolation, and characterization of acidophilic methanotrophs from Sphagnum mosses. Appl. Environ. Microbiol. 77, 5643-5654. 
Kip, N., Van Winden, J. F., Pan, Y., Bodrossy, L., Reichart, G. J., Smolders, A. J. P., Jetten, M. S. M., Damste, J. S. S., and Op Den Camp, H. J. M. (2010). Global prevalence of methane oxidation by symbiotic bacteria in peat-moss ecosystems. Nat. Geosci. 3, 617-621.

Klemedtsson, L., Von Arnold, K., Weslien, P., and Gundersen, P. (2005). Soil $\mathrm{CN}$ ratio as a scalar parameter to predict nitrous oxide emissions. Glob. Chang. Biol. 11, 1142-1147.

Knorr, K. H., and Blodau, C. (2009). Impact of experimental drought and rewetting on redox transformations and methanogenesis in mesocosms of a northern fen soil. Soil Biol. Biochem. 41, 1187-1198.

Knorr, K. H., Glaser, B., and Blodau, C. (2008). Fluxes and 13C isotopic composition of dissolved carbon and pathways of methanogenesis in a fen soil exposed to experimental drought. Biogeosciences 5, 1457-1473.

Kolb, S., Knief, C., Dunfield, P. F., and Conrad, R. (2005). Abundance and activity of uncultured methanotrophic bacteria involved in the consumption of atmospheric methane in two forest soils. Environ. Microbiol. 7, 1150-1161.

Kresovic, M., Jakovljevic, M., Blagojevic, S., and Maksimovic, S. (2009). Specific transformations of mineral forms of nitrogen in acid soils. J. Serbian Chem. Soc. 74, 93-102.

Larmola, T., Tuittila, E. S., Tiirola, M., Nykanen, H., Martikainen, P. J., Yrjala, K., Tuomivirta, T., and Fritze, H. (2010). The role of Sphagnum mosses in the methane cycling of a boreal mire. Ecology 91, 2356-2365.

Lu, W.-P., and Ragsdale, S. W. (1991). Reductive activation of the coenzyme A/Acetyl-CoA isotopic exchange reaction catalyzed by carbon monoxide dehydrogenase from Clostridium thermoaceticum and its inhibition by nitrous oxide and carbon monoxide. J. Biol. Chem. 266, 3554-3564.

Mainiero, R., and Kazda, M. (2005). Effects of Carex rostrata on soil oxygen in relation to soil moisture. Plant Soil 270, 311-320.

Marushchak, M. E., Pitkämäki, A., Koponen, H., Biasi, C., Seppälä, M., and Martikainen, P. J. (2011). Hot spots for nitrous oxide emissions found in different types of permafrost peatlands. Glob. Chang. Biol. 17, 2601-2614.
McEwan, A. G., Greenfield, A. J., Wetzstein, H. G., Jackson, J. B., and Ferguson, S. J. (1985). Nitrous oxide reduction by members of the family Rhodospirillaceae and the nitrous oxide reductase of Rhodopseudomonas capsulata. J. Bacteriol. 164, 823-830.

Moog, P. R., and Bruggemann, W. (1998). Flooding tolerance of Carex species. II. Root gas-exchange capacity. Planta 207, 199-206.

Morris, S. A., Radajewski, S., Willison, T. W., and Murrell, J. C. (2002). Identification of the functionally active methanotroph population in a peat soil microcosm by stable-isotope probing. Appl. Environ. Microbiol. 68, 1446-1453.

Op den Camp, H. J. H., Islam, T., Stott, M. B., Harhangi, H. R., Hynes, A., Schouten, S., Jetten, M. S. M., Birkeland, N.-K., Pol, A., and Dunfield, P. F. (2009). Environmental, genomic and taxonomic perspectives on methanotrophic Verrucomicrobia. Environ. Microbiol. Rep. 1, 239-306.

Palmer, K., Biasi, C., and Horn, M. A. (2011). Contrasting denitrifier communities relate to contrasting $\mathrm{N}_{2} \mathrm{O}$ emission patterns from acidic peat soils in arctic tundra. ISME J. doi: ISMEJ.2011.172

Palmer, K., Drake, H. L., and Horn, M. A. (2009). Genome-derived criteria for assigning environmental narG and nos $Z$ sequences to operational taxonomic units of nitrate reducers. Appl. Environ. Microbiol. 75, 5170-5174.

Palmer, K., Drake, H. L., and Horn, M. A. (2010). Association of novel and highly diverse acid-tolerant denitrifiers with $\mathrm{N}_{2} \mathrm{O}$ fluxes of an acidic fen. Appl. Environ. Microbiol. 76, 1125-1134.

Parmentier, F. J. W., Van Huissteden, J., Kip, N., Op Den Camp, H. J. M., Jetten, M. S. M., Maximov, T. C., and Dolman, A. J. (2011). The role of endophytic methane-oxidizing bacteria in submerged Sphagnum in determining methane emissions of Northeastern Siberian tundra. Biogeosciences 8, 1267-1278.

Paul, S., Küsel, K., and Alewell, C. (2006). Reduction processes in forest wetlands: tracking down heterogeneity of source/sink functions with a combination of methods. Soil Biol. Biochem. 38, 1028-1039.

Raghoebarsing, A. A., Smolders, A. J. P., Schmid, M. C., Rijpstra, W. I. C., Wolters-Arts, M., Derksen, J., Jetten, M. S. M., Schouten, S., Damste, J.
S. S., Lamers, L. P. M., Roelofs, J. G. M., Den Camp, H. J. M. O., and Strous, M. (2005). Methanotrophic symbionts provide carbon for photosynthesis in peat bogs. Nature 436, 1153-1156.

Repo, M. E., Susiluoto, S., Lind, S. E., Jokinen, S., Elsakov, V., Biasi, C., Virtanen, T., and Martikainen, P. J. (2009). Large $\mathrm{N}_{2} \mathrm{O}$ emissions from cryoturbated peat soil in tundra. Nat. Geosci. 2, 189-192.

Ricke, P., Erkel, C., Kube, M., Reinhardt, R., and Liesack, W. (2004) Comparative analysis of the conventional and novel pmo (particulate methane monooxygenase) operons from Methylocystis strain SC2. Appl. Environ. Microbiol. 70, 3055-3063.

Schmidt, I., vanSpanning, R. J. M. and Jetten, M. S. M. (2004) Denitrification and ammonia oxidation by Nitrosomonas europaea wild-type, and NirK and NorBdeficient mutants. Microbiology 150, 4107-4114.

Shannon, R. D., White, J. R., Lawson, J. E., and Gilmour, B. S. (1996). Methane efflux from emergent vegetation in peatlands. J. Ecol. 84, 239-246.

Simek, M., and Cooper, J. E. (2002). The influence of soil $\mathrm{pH}$ on denitrification: progress towards the understanding of this interaction over the last 50 years. Eur. J. Soil Sci. 53, 345-354.

Smith, M. S. (1983). Nitrous-oxide production by Escherichia coli is correlated with nitrate reductaseactivity. Appl. Environ. Microbiol. 45, 1545-1547.

Smith, M. S., and Zimmermann, K. (1981). Nitrous oxide production by nondenitrifying soil nitrate reducers. Soil Sci. Soc. Am. J. 45, 865-871.

Spahni, R., Wania, R., Neef, L., Van Weele, M., Pison, I., Bousquet, P., Frankenberg, C., Foster, P. N., Joos, F., Prentice, I. C., and Van Velthoven, P. (2011). Constraining global methane emissions and uptake by ecosystems. Biogeosciences 8, 1643-1665.

Stach, P., Einsle, O., Schumacher, W., Kurun, E., and Kroneck, P. M. H. (2000). Bacterial cytochrome c nitrite reductase: new structural and functional aspects. J. Inorg. Biochem. 79, 381-385.

Strohm, T. O., Griffin, B., Zumft, W. G., and Schink, B. (2007). Growth yields in bacterial denitrification and nitrate ammonification. Appl. Environ. Microbiol. 73, 1420-1424.

Sundh, I., Borga, P., Nilsson, M., and Svensson, B. H. (1995). Estimation of cell numbers of methanotrophic bacteria in boreal peatlands based on analysis of specific phospholipid fatty-acids. FEMS Microbiol. Ecol. 18, 103-112.

Takakai, F., Desyatkin, A. R., Lopez, C. M. L., Fedorov, A. N., Desyatkin, R. V., and Hatano, R. (2008), $\mathrm{CH}_{4}$ and $\mathrm{N}_{2} \mathrm{O}$ emissions from a forest-alas ecosystem in the permafrost taiga forest region, eastern Siberia, Russia. J. Geophys. Res. 113, G02002.

Theisen, A. R., Ali, M. H., Radajewski, S., Dumont, M. G., Dunfield, P. F., Mcdonald, I. R., Dedysh, S. N., Miguez, C. B., and Murrell, J. C. (2005). Regulation of methane oxidation in the facultative methanotroph Methylocella silvestris BL2. Mol. Microbiol. 58, 682-692.

Throback, I. N., Enwall, K., Jarvis, A., and Hallin, S. (2004). Reassessing PCR primers targeting nirS, nirK and nos $Z$ genes for community surveys of denitrifying bacteria with DGGE. FEMS Microbiol. Ecol. 49, 401-417.

van Cleemput, O. (1998). Subsoils: chemo- and biological denitrification, $\mathrm{N}_{2} \mathrm{O}$ and $\mathrm{N}_{2}$ emissions. Nutr. Cycl. Agroecosys. 52, 187-194.

Vieten, B., Conen, F., Seth, B., and Alewell, C. (2008). The fate of $\mathrm{N}_{2} \mathrm{O}$ consumed in soils. Biogeosciences 5, 129-132.

Whalen, S. C. (2005). Biogeochemistry of methane exchange between natural wetlands and the atmosphere. Environ. Eng. Sci. 22, 73-94.

Whalen, S. C., and Reeburgh, W. S. (2000). Methane oxidation, production, and emission at contrasting sites in a boreal bog. Geomicrobiol. J. 17, 237-251.

Wieczorek, A. S., Drake, H. L., and Kolb, S. (2011). Organic acids and ethanol inhibit the oxidation of methane by mire methanotrophs. FEMS Microbiol. Ecol. 77, 28-39.

Yimga, M. T., Dunfield, P. F., Ricke, P., Heyer, H., and Liesack, W. (2003). Wide distribution of a novel pmoA-like gene copy among type II methanotrophs, and its expression in Methylocystis strain SC2. Appl. Environ. Microbiol. 69, 5593-5602.

Yoshinari, T. (1980). $\mathrm{N}_{2} \mathrm{O}$ reduction by Vibrio succinogenes. Appl. Environ. Microbiol. 39, 81-84.

Zumft, W. G. (1997). Cell biology and molecular basis of denitrification. Microbiol. Mol. Biol. Rev. 61, 533-616.

Zumft, W. G., and Kroneck, P. M. H. (2007). "Respiratory transformation of nitrous oxide $\mathrm{N}_{2} \mathrm{O}$ to dinitrogen 
by bacteria and archaea," in Advances in Microbial Physiology, Vol. 52, ed. R. K. Poole (London: Academic Press Ltd.), 107-234.

Conflict of Interest Statement: The authors declare that the research was conducted in the absence of any commercial or financial relationships that could be construed as a potential conflict of interest.

Received: 16 December 2011; accepted: 15 February 2012; published online: 02 March 2012.
Citation: Kolb $S$ and Horn $M A$ (2012) Microbial $\mathrm{CH}_{4}$ and $\mathrm{N}_{2} \mathrm{O}$ consumption in acidic wetlands. Front. Microbio. 3:78. doi: 10.3389/fmicb.2012. 00078

This article was submitted to Frontiers in Terrestrial Microbiology, a specialty of Frontiers in Microbiology.
Copyright (c) 2012 Kolb and Horn. This is an open-access article distributed under the terms of the Creative Commons Attribution Non Commercial License, which permits non-commercial use, distribution, and reproduction in other forums, provided the original authors and source are credited. 


\title{
Microbial transformations of nitrogen, sulfur, and iron dictate vegetation composition in wetlands: a review
}

\author{
Leon P. M. Lamers ${ }^{1}{ }^{*}$, Josepha M. H. van Diggelen ${ }^{2}$, Huub J. M. Op den Camp ${ }^{3}$, Eric J. W. Visser ${ }^{4}$, \\ Esther C. H. E. T. Lucassen ${ }^{1,2}$, Melanie A. Vile ${ }^{5}$, Mike S. M. Jetten $^{3}$, Alfons J. P. Smolders ${ }^{1,2}$ and \\ Jan G. M. Roelofs ${ }^{1}$ \\ 1 Department of Aquatic Ecology and Environmental Biology, Institute for Water and Wetland Research, Radboud University Nijmegen, Nijmegen, Netherlands \\ 2 B-Ware Research Center, Nijmegen, Netherlands \\ ${ }^{3}$ Department of Microbiology, Institute for Water and Wetland Research, Radboud University Nijmegen, Nijmegen, Netherlands \\ ${ }^{4}$ Department of Experimental Plant Ecology, Institute for Water and Wetland Research, Radboud University Nijmegen, Nijmegen, Netherlands \\ ${ }^{5}$ Department of Biology, Villanova University, Villanova, PA, USA
}

\section{Edited by:}

Paul Bodelier, Netherlands Institute of Ecology, Netherlands

Reviewed by:

Brajesh Singh, University of Western Sydney, Australia

Peter Frenzel, MPI for Terrestrial

Microbiology, Germany

*Correspondence:

Leon P. M. Lamers, Department of

Aquatic Ecology and Environmental

Biology, Institute for Water and

Wetland Research, Radboud

University Nijmegen,

Heyendaalseweg 135, 6525 A

Nijmegen, Netherlands.

e-mail:I.lamers@science.ru.nl
The majority of studies on rhizospheric interactions focus on pathogens, mycorrhizal symbiosis, or carbon transformations. Although the biogeochemical transformations of N, S, and $\mathrm{Fe}$ have profound effects on vegetation, these effects have received far less attention. This review, meant for microbiologists, biogeochemists, and plant scientists includes a call for interdisciplinary research by providing a number of challenging topics for future ecosystem research. Firstly, all three elements are plant nutrients, and microbial activity significantly changes their availability. Secondly, microbial oxidation with oxygen supplied by radial oxygen loss from roots in wetlands causes acidification, while reduction using alternative electron acceptors leads to generation of alkalinity, affecting $\mathrm{pH}$ in the rhizosphere, and hence plant composition. Thirdly, reduced species of all three elements may become phytotoxic. In addition, Fe cycling is tightly linked to that of $S$ and P. As water level fluctuations are very common in wetlands, rapid changes in the availability of oxygen and alternative terminal electron acceptors will result in strong changes in the prevalent microbial redox reactions, with significant effects on plant growth. Depending on geological and hydrological settings, these interacting microbial transformations change the conditions and resource availability for plants, which are both strong drivers of vegetation development and composition by changing relative competitive strengths. Conversely, microbial composition is strongly driven by vegetation composition. Therefore, the combination of microbiological and plant ecological knowledge is essential to understand the biogeochemical and biological key factors driving heterogeneity and total (i.e., microorganisms and vegetation) community composition at different spatial and temporal scales.

Keywords: biodiversity, eutrophication, heterogeneity, nutrients, plant-microbe interactions, plants, rhizosphere, toxicity

\section{INTRODUCTION}

Plant ecologists have long been focusing mainly on above-ground processes, while a significant part of the driving mechanisms of ecosystem functioning is taking place below-ground (Waisel et al., 1996). This strongly pleads for studies including biogeochemical transformations in soils and the important interactions between their key players: microorganisms and plants. This paper will focus on the roles of microbial conversions of the elements nitrogen $(\mathrm{N})$, sulfur $(\mathrm{S})$, and iron $(\mathrm{Fe})$, with respect to their major role in the functioning and succession of plant communities in wetlands. The rationale lies in the fact that all three elements can be converted to chemical species that can serve as nutrients, as terminal electron acceptors and electron donors, and can also be toxic. We hope in this review to show the fascinating biogeochemical interactions between plant communities and microbial communities, and encourage microbiologist and plant ecologists to further integrate their disciplines in the hidden half of the ecosystem
(Figure 1). Wetland overall communities (i.e., the integration of micro- and macro-communities) provide excellent examples for this complex interaction playground, the rhizosphere. We define the rhizosphere as that part of the soil where plant roots significantly interact with soil biological and chemical processes, at the scale of $10^{-4} \mathrm{~m}$ or less to $10^{-1} \mathrm{~m}$. One should realize that the root systems of plants can be very large, up to $112 \mathrm{~km} \mathrm{~m}^{-2}$ of soil (Robinson et al., 2003) and reaching a depth between $10^{-3}$ and $10 \mathrm{~m}$ (or even deeper for trees; Canadell et al., 1996). Therefore, a major part of the upper soil of all vegetated wetlands can be defined more or less as a potential rhizosphere. This urges the use of an integrated approach of microbiologists and plant ecologists, in order to understand wetland biogeochemistry, biodiversity, and resilience with respect to ecosystem changes. The purpose of this paper is to show how microbial activity related to the biogeochemical transformation of N, S, and Fe also has profound effects on the activity and competitive strength of plants in wetlands. In 


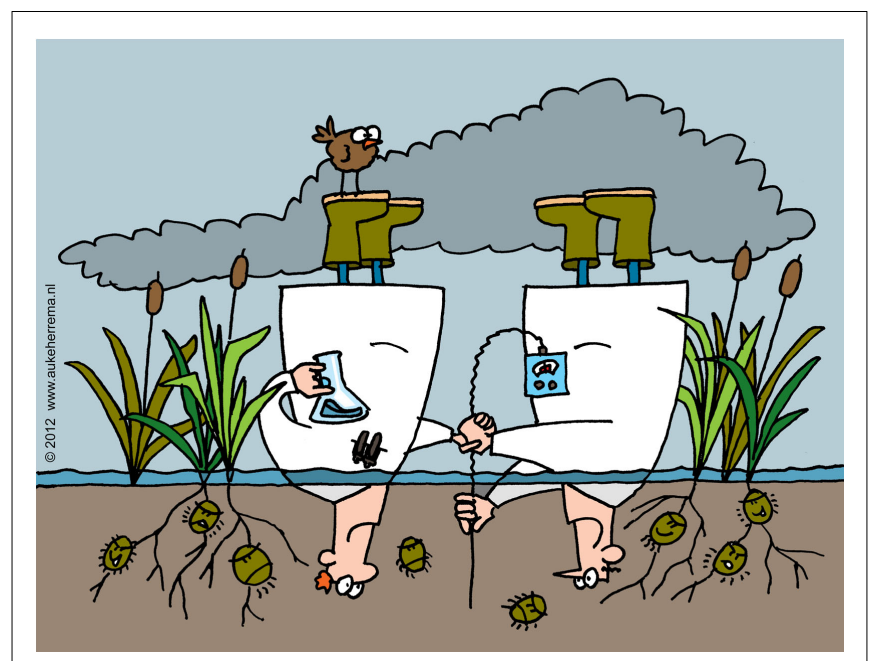

FIGURE 1 | Below-ground scientific collaboration in wetlands: microbiology meets plant ecology. Cartoon by Auke Herrema.

this way, they shape the structure, succession, and biodiversity of vegetation.

\section{HETEROGENEITY IN SOILS DRIVES BIODIVERSITY AND FUNCTIONING}

Unvegetated wetland soils, such as deeper parts of lake sediments or sediments of turbid shallow lakes (with insufficient light for underwater plant photosynthesis) are relatively homogeneous, except for the sediment-water boundary layer that generally shows a steep redox profile related to the successive depletion of terminal electron acceptors (Wetzel, 2001). One of the interesting characteristics of vegetated soils, and particularly of wetland soils, is their heterogeneity in space and time (Paul and Clark, 1989; Conrad and Frenzel, 2002; Bodelier, 2011). Microbiological batch experiments, even those containing multiple organisms, hardly resemble these soils. One of the challenges in microbial ecology is therefore to include this heterogeneity in resources (nutrients, substrates, electron acceptors) and conditions (e.g., oxygenation level, $\mathrm{pH}$ ) under experimentally controlled conditions. Even under apparently stable conditions, the outcome of competition for one or several nutrients may be chaotic (Huisman and Weissing, 1999), but heterogeneity is even more relevant, ecologically speaking, because it facilitates the formation of multiple niches and generates larger fluctuations in conditions over time. As such, heterogeneity strongly affects competition between species (or operational taxonomic units at around species level), and diversity will differ from that under homogeneous conditions. Competitive exclusion, occurring under homogeneous, stable conditions, can be prevented by spatial and temporal heterogeneity, both for microorganisms and for macroorganisms.

In soils with plants (almost all soils in the world), heterogeneity increases as a result of rhizospheric effects (Marschner, 1995) and three-dimensional gradients (changes in concentrations with distance) at the micron-millimeter scale can be very steep. Different consortia of microbial species are present inside roots, on the root surface, and occur at different distances from roots, all of which are related to root exudate concentrations, oxygen availability, nutrient availability, and pH (Brune et al., 2000; Bodelier, 2003; Bodelier et al., 2006). Plant roots even influence soil temperature, with significant effects on microbial activity (Boone et al., 1998). Rhizospheric interactions between microbes and plants have been studied to a large extent with respect to pathogens, mycorrhizal symbiosis, and carbon transformations (e.g., Callaway, 1995; Smith and Smith, 1997; Jones, 1998; Hanson et al., 2000; Whipps, 2001; Gilbert, 2002; Read and Perez-Moreno, 2003).

As a result of heterogeneity, the concentrations of terminal electron acceptors, nutrients, and toxins can differ greatly at even the micro-scale (Bodelier et al., 2006). In redox reactions, the oxidation of organic and inorganic compounds (electron donors) to generate energy has to be coupled to the reduction of electron acceptors, e.g., $\mathrm{O}_{2}, \mathrm{NO}_{3}^{-}, \mathrm{Fe}^{3+}, \mathrm{SO}_{4}^{2-}$. As a result of differences in energy generation, textbooks show a sequential "preference" for the use of electron acceptors, starting with $\mathrm{O}_{2}$. This implies that microorganisms able to use a particular electron acceptor are expected to outcompete organisms using alternative, less favorable electron acceptors. However, small-scale differences in electron acceptor availability in heterogeneous soils explain the co-existence of different microbial groups, without outcompeting one another due to thermodynamic competitive advantage. In addition, the rapid transformation of reduced products by microbial re-oxidation, loss to the atmosphere (e.g., $\mathrm{N}_{2}$ ), or chemical sequestration (e.g., $\mathrm{FeS}_{x}$ ) may lead to favorable thermodynamic conditions that are incomparable to those in closed batch systems.

Changes in plant species composition will strongly affect microbial communities in the rhizosphere. Especially in wetlands, where soils are periodically or constantly flooded or waterlogged, radial oxygen loss (ROL) from plant roots has an extreme impact on rhizospheric microbial communities, locally converting conditions in the wetland soil to those normally found in oxygenated upland soil. Using microelectrodes, Frenzel et al. (1992) showed that rice plants were well able to oxygenate the soil. Oxygen is transported through aerenchyma in the stolons and roots by diffusion or mass flow, and the extent and type of aerenchyma formation differs to a large extent among species (Jackson and Armstrong, 1999; Visser et al., 2000a,b; Voesenek et al., 2006). As a consequence, the spatial pattern of ROL, also strongly varies among wetland species, due to differences in lignin and/or suberin deposits in the exodermis of roots. These deposits act as a barrier to prevent loss of $\mathrm{O}_{2}$ in the upper soil layer and ensure $\mathrm{O}_{2}$ supply to the active root tips (Armstrong, 1978; Laan et al., 1989; Colmer, 2003), and thereby prevent root anaerobiosis (Lambers, 1976; Vartapetian and Jackson, 1997; Jackson and Armstrong, 1999). This means that steep changes in oxygen availability, and hence in microbial communities, will prevail in the rhizosphere, in contrast to anaerobic bulk soil, depending on plant species composition. For this reason, microbial communities in wetland soils may be more diverse than in upland soils. The physiological ability to oxidize rhizospheres differs among plant species, which may not only facilitate conspecifics but also heterospecifics (Callaway, 1995). Next to this spatial heterogeneity, there will also be a strong temporal heterogeneity in the rhizosphere due to changes in temperature, plant presence, plant activity, and water table. Particularly in riparian wetlands, where water tables fluctuate frequently, both resource 
availability and conditions can vary widely, providing challenges and opportunities for microbes.

\section{NUTRIENT CYCLING AND UPTAKE IN THE RHIZOSPHERE}

For both heterotrophic and autotrophic organisms including plants, sufficient nutrient acquisition is essential to transform the carbon acquired into growth and reproduction and to safeguard the fitness of their populations. The rates of transformation of dead organic material into simple organic compounds and minerals, carried out by fauna and microorganisms, strongly determine the growth rates of plants. At high nutrient availability, fastgrowing and highly competitive species will generally dominate at the expense of slow-growing species and monopolize light and space. As the quality of the dead organic matter strongly differs between plant species, decomposition (carbon mineralization) and the mineralization of the macronutrients $\mathrm{N}, \mathrm{P}$, potassium $(\mathrm{K})$, and $\mathrm{S}$, and of micronutrients including $\mathrm{Fe}$ and manganese $(\mathrm{Mn})$, will depend on the species composition. Higher nutrient concentrations in dead material may stimulate mineralization rates, in this way providing a positive feed-back (Hobbie, 1992; Aerts and Chapin, 2000). This will, however, depend on the nature of nutrient limitation of the decomposition rate, which can be limited either by $\mathrm{N}, \mathrm{P}$, or both. Although the C: $\mathrm{N}$ ratio of organic matter has traditionally been used as a quantitative indication of (potential) decomposition rates, the C:P ratio may be a better indicator for locations that show a high availability of $\mathrm{N}$, e.g., as a result of high atmospheric $\mathrm{N}$ input. However, studies on the effect of organic matter quality on decomposition and nutrient mineralization rates still show much inconsistency (Kalbitz et al., 2000). Note that rates of vegetation growth and microbial decomposition do not necessarily have to be limited by the same element. Plants are able to actively forage for nutrients, leading to selective root placement at spots enriched with nutrients (Hutchings and De Kroon, 1994; Hodge, 2004). In this way, not only nutrient availability and its heterogeneity, but also traits and plasticity of plants with respect to root foraging strategies will drive below-ground competition, vegetation diversity, and biomass production (De Kroon et al., 2012). This means that there is a complex interaction between plant species composition and microbial communities including fungi, bacteria, and archaea. For technical reasons related to root sampling, many interesting characteristics of this hidden, but very important aspect of plant communities (Waisel et al., 1996) are yet to be discovered. New techniques including soil scanning in largescale rhizotrons (Figure 2) enable an underground view on plant communities, which can be coupled to, e.g., fluorescence in situ hybridization (FISH) techniques visualizing the locations of different microbial groups or species, microarrays to rapidly check for known sequences, polymerase chain reaction (PCR) based community analyses and metagenomics (full community genomics), to gain insight into rhizospheric microbe-plant communities and interactions. Next generation DNA sequencing technologies can be expected to make rhizosphere community analyses much faster, cheaper, and easier, enabling for instance multiple comparisons between different plant species in one vegetation type, and between conspecifics under different environmental conditions.

The three elements that we focus on here, N, S, and Fe, all are essential nutrients for the metabolism and growth of both plants

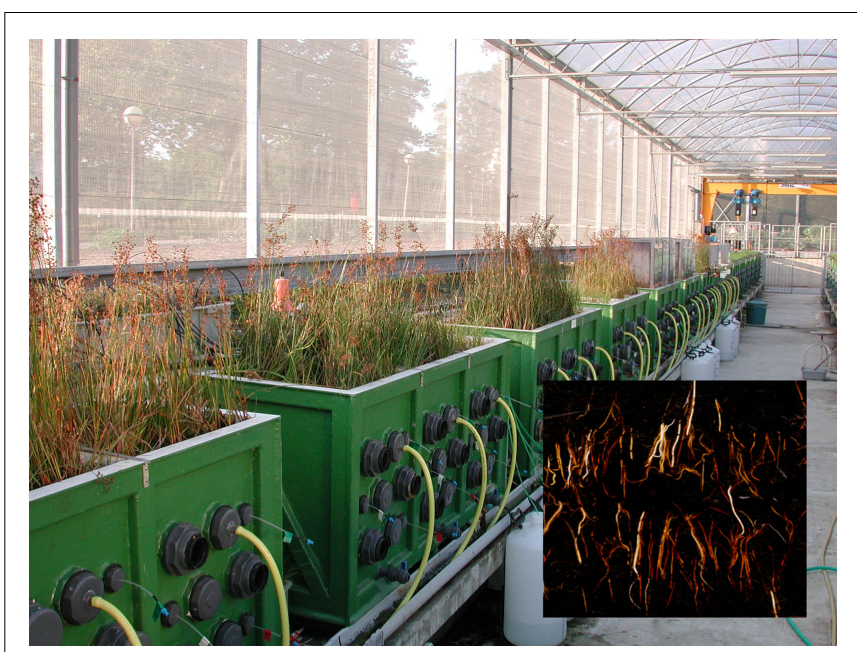

FIGURE 2 |The Nijmegen Phytotron facility, and a scan image of the root scanner in transparent tubes in the soil (inlay).

and microorganisms. These elements are predominantly taken up by plants from the soil via the roots, as only few plant species may take up high amounts of nutrients via the leaves. An exception are aquatic macrophytes that take up nutrients from the surface water, especially when soil concentrations are low or when the plants lack roots. On a quantitative base, $\mathrm{N}$ is the most important macronutrient (Marschner, 1995; Larcher, 2003), essential for the synthesis of amino acids, amines, and peptides (including proteins). As the availability and uptake of this element is a major factor limiting biomass production in many ecosystems (Vitousek and Howarth, 1991; Larcher, 2003), its availability and mobility are important drivers of species composition and biodiversity. Enhanced $\mathrm{N}$ availability changes biodiversity and heterogeneity, both above-ground and below-ground. Due to selective root placement, spots enriched in $\mathrm{N}$ contain more roots. For plants including Fabaceae (formerly called Leguminosae), the symbiotic relation with rhizobial strains of a variety of genera of Proteobacteria including Rhizobium, is of vital importance for atmospheric dinitrogen $\left(\mathrm{N}_{2}\right)$ fixation in soils that are low in N (Dakora and Phillips, 2002). The symbionts are attracted by the exudation of phenolics and aldonic acids from roots. For non-Fabaceous plants including the tree and shrub genera Alnus, Casuarina, Ceanothus, and Myrica, atmospheric $\mathrm{N}_{2}$ is supplied by Frankia Actinobacteria. The cyanobacterial symbiont Anabaena provides atmospheric $\mathrm{N}$ to waterferns (Azolla spp.). The yearly amounts of nitrogen provided by these symbionts can be as high as $100 \mathrm{~kg} \mathrm{Nha}^{-1}$ or more, which is similar to the highest anthropogenic airborne $\mathrm{N}$ fluxes reported. As a result, these plant species have a strong competitive advantage over other species under $\mathrm{N}$ limitation, especially under riparian conditions with coupled nitrification (during dry episodes) and denitrification (of generated nitrate, during wet episodes). Note that $\mathrm{N}$ limitation will also occur when $\mathrm{P}$ levels are high and $\mathrm{P}$ is no longer limiting biomass production, which explains the dominance of the AzollaAnabaena complex and free-living $\mathrm{N}$-fixing aquatic cyanobacteria under high $\mathrm{P}$ loads (Lamers et al., 2002b). In addition to the above-mentioned "usual suspects," a large phylogenetic variety of 
free-living and symbiotic microorganisms including other Proteobacteria, Archaea, and Verrucomicrobia is now known to be able to fix atmospheric dinitrogen gas (Kneip et al., 2007; Khadem et al., 2010; Reed et al., 2011).

Although less frequently, low availability of S may also hamper plant growth (Dijkshoorn and van Wijk, 1967; Marschner, 1995). Like N, S is a vital constituent for protein structuring. While N and $\mathrm{S}$ are macronutrients, $\mathrm{Fe}$ is considered a micronutrient (average $\mathrm{N}: \mathrm{S}:$ Fe in plant shoots is 500:15:1 on a molar basis; Marschner, 1995). The availability of Fe is essential for photosynthesis, as it is a cofactor for chlorophyll synthesis. During anaerobic soil conditions in wetlands, $\mathrm{Fe}$ is mainly present as $\mathrm{Fe}^{2+}$ as a result of microbial Fe reduction, and its mobility and availability are relatively high. This may even lead to Fe toxicity (see below). During aerobic conditions, $\mathrm{Fe}$ is oxidized to $\mathrm{Fe}^{3+}$ and a large part precipitates as hydroxides and oxyhydroxides, and Fe acquisition becomes hampered. To acquire Fe from Fe(III) compounds, plants have developed different mechanisms through evolution that facilitate uptake (Jones, 1998; Dakora and Phillips, 2002; Hell and Stephan, 2003). Graminaceous plants exude metal chelating amino acids called phytosiderophores, which are also important for the uptake of other micronutrient metals such as $\mathrm{Mn}$, zinc ( $\mathrm{Zn}$ ), and copper $(\mathrm{Cu})$. Non-graminaceous monocots, dicots, and bacteria release protons in the rhizosphere, or exude reducing and chelating compounds such as phenolics (Marschner, 1995; Schmidt, 1999). Soil Fe is, however, also strongly linked to phosphorus (P) availability, as both elements form a variety of chemical complexes, making $\mathrm{P}$ less available. Therefore, mechanisms to increase Fe availability may also be regarded as P mobilizing mechanisms (Bolan, 1991), next to the infection with mycorrhizal fungi.

Plants and microbes may compete for N, S, and P, depending on their relative availabilities (Hobbie, 1992), and competition models should therefore include this competition, yet few studies have. Especially at low nutrient levels, microbial uptake may significantly hamper nutrient uptake by plants, and hence reduce growth rates. As a result, they may even be able to increase the competitive advantage of slow-growing plant species and influence biodiversity. Not only competition at short-term, but also release rates from the microbial pool should be accounted for. As an example, selective root placement may be much slower than microbial colonization of a nutrient-rich patch, but subsequent release of $\mathrm{N}$ and $\mathrm{P}$ from the microbial pool can be effectively intercepted by these roots (Hodge et al., 2000).

\section{BELOW-GROUND CARBON TURNOVER}

The die-off of plant rhizomes, roots and above-ground litter, and their shredding by macro-, meio-, and microfauna strongly determines the availability of organic substrates for fermentation and the availability of organic electron donors (e.g., lactate, acetate, succinate, propionate) for a variety of microbial anaerobic and aerobic redox processes. The decomposability of dead plant material greatly varies between species, not only due to varying $\mathrm{N}$ and $\mathrm{P}$ concentrations and $\mathrm{pH}$, but also as a result of varying concentrations of recalcitrant compounds such as lignin, and of potentially toxic secondary metabolites including other phenolic compounds and alkaloids. Consequently, plant species composition of a vegetation type has a great impact on decomposition rates and nutrient cycling (Hobbie, 1992). Decomposition rates of graminoid species such as grasses (Gramineae) and sedges (Cyperaceae) are, for instance, much faster than those of peat mosses (Sphagnum), which contain high concentrations of polyphenolics and pectin-like polysaccharides (Verhoeven and Toth, 1995; Hajek et al., 2011). Even though net primary production of Sphagnum can, for instance, not compete with the highest production rates of vascular plants, low decomposition rates may still lead to fast peat accumulation. Long term accumulation rates may, however, differ from present-day rates depending on changing balances between production and decay rates (Clymo et al., 1998; Wieder et al., 2009). Next to species effects on dead organic matter (OM), microbial breakdown can also vary within one particular species. High atmospheric deposition rates of $\mathrm{N}$ may, for instance, decrease the concentration of polyphenols in Sphagnum peat and concomitantly increase decomposition rates, with consequences for net $\mathrm{C}$ sequestration (Bragazza and Freeman, 2007). The actual decomposition rates are regulated by the interaction between the nutrient $(\mathrm{N}, \mathrm{P})$ concentrations in the $\mathrm{OM}$, recalcitrant or toxic compounds, and soil conditions. Peat accumulation (i.e., sequestration of atmospheric C) depends on the precarious balance between production and decomposition, and high production rates are generally coupled to higher decomposition rates as a result of organic matter quality.

Phenolic compounds have been shown to block the decomposition in peatlands to a large extent by inhibiting the activity of various crucial microbial enzymes in carbon transformation (Freeman et al., 2001). Oxygen intrusion during low water tables activates phenol oxidase activity, lowering phenol concentrations, and thereby stimulating overall decomposition. In addition, oxygen acts as the most favorable electron acceptor, stimulating decomposition rates by a factor of two or more. ROL from roots can be expected to have the same impact. A spectacular example is the large-scale rhizosphere oxidation by the vascular peatland plant species Astelia pumila and Donatia fascicularis, that may appear miniscule in stature above-ground, but possess extensive root systems that strongly stimulate decomposition rates to a depth of more than $1 \mathrm{~m}$ (Fritz et al., 2011). As a result of low nutrient levels in the pristine Patagonian peatlands where these species occur, carbon is preferentially allocated to root production. The strong soil oxygenation also nullifies methane emission by the inhibition of methanogenic communities and/or the stimulation of methanotrophic communities. In oligotrophic lakes, small-leaved (so-called isoetid) species with relatively large root systems have a similar effect on decomposition rates (Smolders et al., 2002). The growth rates of facultatively aerobic, heterotrophic bacteria including Pseudomonas chlororaphis are significantly enhanced under flooded conditions by ROL of emergent macrophytes such as Glyceria maxima and Oryza sativa (Bodelier et al., 1997, 1998), demonstrating the strong effect root systems may have on microbial composition and processes.

\section{MICROBIAL SOIL ACIDIFICATION AFFECTS PLANTS}

The cycling of $\mathrm{N}, \mathrm{Fe}$, and $\mathrm{S}$ in the soil is not only determined to a large extent by microbial activity, but also by uptake, release, and transformations of species of these elements due to root activity. 
Plants can change the $\mathrm{pH}$ of the rhizosphere by the exudation of protons, organic acids, $\mathrm{HCO}_{3}^{-}$, and $\mathrm{OH}^{-}$(Dakora and Phillips, 2002). By the excretion of root exudates, acids, and oxygen, plants control microbial resource availability, concentrations of oxygen as a potential toxin and electron acceptor, and $\mathrm{pH}$ in the rhizosphere. As a result of ROL or temporary water table draw-down (e.g., in riparian wetlands), $\mathrm{pH}$ can be strongly lowered due to microbial and chemical oxidation of N, S, Fe, generating acid (oxygen literally means acid generator). This may even lower the availability and uptake of redox-sensitive metals (e.g., Fe, Mn) or increase the availability and uptake of $\mathrm{pH}$-sensitive metals that are not redox-sensitive (e.g., aluminum, $\mathrm{Al}$ ). The $\mathrm{pH}$ change by the oxidation of ammonium and nitrite by nitrifying proteobacteria (e.g., the genera Nitrosomonas, Nitrosospira, Nitrobacter, Nitrospira) or crenarchaea, reduced $\mathrm{S}$ including sulfides to $\mathrm{S}$ and $\mathrm{SO}_{4}^{2-}$ by $\mathrm{S}$ oxidizing proteobacteria (e.g., Beggiatoa, Thiobacillus), and ferrous iron to ferric iron (e.g., Gallionella ferruginea) not only influences microbial communities, but also plant communities. Most plant species are sensitive to low soil $\mathrm{pH}$ values $(\mathrm{pH}<5)$, not only by direct effects on membrane physiology, but also indirectly, by $\mathrm{Al}$ toxicity and by the impairment of the uptake of potassium $(\mathrm{K})$, calcium (Ca), and magnesium (Mg; Marschner, 1995). Although $\mathrm{Al}$ is one of the most common metals in soils, its toxicity is completely dependent on its mobility, which is strongly regulated by $\mathrm{pH}$. The $\mathrm{pH}$ in the rhizosphere may be much lower than that of the bulk soil. The regulation of $\mathrm{pH}$ is a combined effect of ROL activity, rhizospheric oxygen consumption, proton loss by roots (e.g., for $\mathrm{NH}_{4}^{+}$uptake), availability of electron donors like $\mathrm{N}, \mathrm{Fe}$, and $S$, and the acid neutralizing capacity (ANC) of the soil. Depending on the $\mathrm{pH}$ range (from 8 down to 3 ), $\mathrm{ANC}$ is provided by bicarbonate and carbonate, exchange of base cations such as $\mathrm{Ca}$ and $\mathrm{Mg}$ at soil cation exchange sites, and the dissolution of $\mathrm{Fe}$ and Al-oxides and hydroxides and silicates. Where bulk soil will be buffered under anaerobic conditions by the microbial reduction of $\mathrm{N}$, manganese $(\mathrm{Mn}), \mathrm{Fe}$, and $\mathrm{S}$ (all generating alkalinity, i.e., consuming $\mathrm{H}^{+}$), local oxidation by ROL will reverse this process. As such, high ROL activity can mimic the lowering of the water table in wetlands at a very local, but crucial scale. Under flooded or waterlogged conditions, most bulk soils are buffered around pH 6-6.5 by the $\mathrm{CO}_{2}-\mathrm{HCO}_{3}^{-}$buffering mechanism. As microbial decomposition (generating inorganic carbon) is generally coupled to microbial mineralization of $\mathrm{P}$ and $\mathrm{N}$, microbially derived $\mathrm{HCO}_{3}^{-}$ concentrations can even be used as a proxy for nutrient availability in freshwater and marine soils (Van der Heide et al., 2010).

\section{NITROGEN: A MOBILE NUTRIENT THAT MAY BECOME TOXIC}

Either the availability of electron donors or the availability of electron acceptors determines the nature and rates of microbial redox reactions in wetland soils. In the rhizosphere of plants showing high rates of ROL, oxidation of $\mathrm{N}, \mathrm{S}$, and Fe takes place (Bodelier, 2003). This implies that there will be a strong gradient in microbial communities at the micro-scale, from close to the roots toward the bulk soil. Ammonium $\left(\mathrm{NH}_{4}^{+}\right)$produced in the bulk soil is oxidized to nitrate/nitrite $\left(\mathrm{NO}_{3}^{-} / \mathrm{NO}_{2}^{-}\right)$by $\mathrm{N}$ oxidizing communities, including Crenarchaeota (Leininger et al., 2006; Jetten, 2008). Such local redox processes create a variety of $\mathrm{N}$ species, which have effect on plant performance. Although plants can use oxidized inorganic $\mathrm{N}\left(\mathrm{NO}_{3}^{-}\right)$, reduced inorganic $\mathrm{N}\left(\mathrm{NH}_{4}^{+}\right)$, and organic $\mathrm{N}$ (amino acids) as $\mathrm{N}$ source, plants adapted to soils with low $\mathrm{pH}$ and low redox potential prefer $\mathrm{NH}_{4}^{+}$(Marschner, 1995). For plants adapted to soils with higher $\mathrm{pH}$, it has been shown that $\mathrm{NH}_{4}^{+}$can be toxic to a variety of plant species, mainly by leading to nutrient imbalances ( $\mathrm{K}, \mathrm{Mg}$ deficiency) or internal acidification in roots. Aquatic macrophytes prefer either $\mathrm{NH}_{4}^{+}$or $\mathrm{NO}_{3}^{-}$, depending on the $\mathrm{pH}$ of the surface water where the species mainly occurs (Roelofs et al., 1984). Most rooting wetland plants are evolutionary adapted to $\mathrm{NH}_{4}^{+}$uptake, although $\mathrm{NH}_{4}^{+}$may also be taken up after rhizospheric oxidation to $\mathrm{NO}_{3}^{-}$. Plants of riparian wetlands, however, are known to face problems at a high $\mathrm{NH}_{4}^{+}: \mathrm{NO}_{3}^{-}$ratio in acidified soil during lower water tables in the growing season (Lucassen et al., 2003; Van den Berg et al., 2005). Increased anthropogenic $\mathrm{NH}_{4}^{+}$inputs, as a result of ammonia $\left(\mathrm{NH}_{3}\right)$ emissions in regions with intensive cattle breeding, have for this reason led to the decrease of sensitive species and loss of biodiversity (Stevens et al., 2011). In riparian wetlands with a low soil ANC, acidification due to high $\mathrm{N}$ and $\mathrm{S}$ inputs increases the $\mathrm{NH}_{4}^{+}: \mathrm{NO}_{3}^{-}$ratio due to a decrease of the activity of $\mathrm{N}$ oxidizers. In soils that have been acidic for longer time, nitrification rates may be higher due to the development of acid-resistant $\mathrm{N}$ reducers (De Boer and Kowalchuk, 2001). In soils with a high $\mathrm{pH}(>8.5)$, a significant proportion of $\mathrm{NH}_{4}^{+}$(ammonium) is present as ammonia $\left(\mathrm{NH}_{3} ; \mathrm{pK}=9.25\right)$, which is highly toxic to plant roots (Schenk and Wehrmann, 1979). Similarly, high $\mathrm{pH}$ values of surface water, e.g., as a result of aquatic photosynthesis $(\mathrm{pH}>10)$, can lead to $\mathrm{NH}_{3}$ toxicity to submerged vegetation and fauna in $\mathrm{N}$ loaded aquatic systems (Thurston et al., 1981). The actual toxicity of $\mathrm{N}$ depends on its accumulation in plant tissues and becomes higher under P-limited conditions due to extra accumulation. By the production of $\mathrm{N}$-rich free amino acids, plants are able to detoxify excess internal $\mathrm{N}$, but only to a certain level (Tomassen et al., 2003).

It has been shown that increased availability of $\mathrm{NO}_{3}^{-} / \mathrm{NO}_{2}^{-}$by increased nitrification rates in the rhizosphere may raise denitrification in the anaerobic bulk soil the root zone with sufficient oxygen supply (Reddy et al., 1989; Arth et al., 1998). In addition, higher rates of anaerobic ammonium oxidation (anammox) or dissimilatory nitrate reduction to ammonium (DNRA) can be expected to increase at the oxic/anoxic interface (Jetten et al., 1998; Burgin and Hamilton, 2007; Hu et al., 2011). The uptake of $\mathrm{NH}_{4}^{+}$or $\mathrm{NO}_{3}^{-}$by plant roots may, however, lower denitrification rates in freshwater and marine wetlands by reducing the $\mathrm{N}$ pool (Bodelier et al., 1996; Welsh et al., 2000). For vegetation, the rates of these $\mathrm{N}$ conversions are important, as most of the gaseous reaction products $\left(\mathrm{N}_{2}\right.$ and $\left.\mathrm{N}_{2} \mathrm{O}\right)$ leave the soil compartment and are no longer available (except through microbial $\mathrm{N}_{2}$ refixation). $\mathrm{N}_{2}$ production by $\mathrm{N}$ reduction is strongly reduced by lowering of $\mathrm{pH}$ from 7 to 4 , but the (net) $\mathrm{N}_{2} \mathrm{O}: \mathrm{N}_{2}$ production ratio shows an exponential increase in this transect as a result of the inhibition of $\mathrm{N}_{2} \mathrm{O}$ reduction at low $\mathrm{pH}$ (Van den Heuvel et al., 2011). The heterogeneity with respect to $\mathrm{N}_{2} \mathrm{O}$ emission rates seems to be explained by differences in soil structure affecting gas transport rather than by microbial composition (Van den Heuvel et al., 2009), and probably also by vegetation composition. As such, $\mathrm{N}$ biogeochemistry is far more complex and variable than that of $\mathrm{P}$, which is only released to the atmosphere in very small quantities as phosphine (Wetzel, 
2001). In riparian wetlands, the water table strongly dominates $\mathrm{N}$ cycling and availability. $\mathrm{N}$ dynamics are influenced by microbial activity at all spatial scales, from the rhizosphere (plant $\mathrm{N}$ availability) through the community level (competition between species under $\mathrm{N}$ limitation) to the ecosystem level ( $\mathrm{N}$ exchange with the surroundings, including the atmosphere). In addition, there is high variability at the temporal scale, mostly coupled to seasonal change and water table fluctuations (Neubauer et al., 2005).

High inputs of $\mathrm{NO}_{3}^{-}$in wetland soils are known to inhibit microbial Fe reduction for thermodynamical reasons (hence $\mathrm{N}$ reducers outcompete Fe reducers). This may not only lead to Fe deficiency in vegetation (Smolders and Roelofs, 1993), but also to reduced mobilization and availability of $\mathrm{P}$ in the rhizosphere (Lucassen et al., 2004). A significant part of soil P is sequestered by $\mathrm{Fe}$, and ferrous $\left(\mathrm{Fe}^{2+}\right)$ iron phosphate complexes are more soluble than ferric $\left(\mathrm{Fe}^{3+}\right)$ iron phosphate compounds (Richardson, 1985; Scheffer and Schachtschabel, 2002). For the vegetation involved, increased $\mathrm{N}$ inputs may have contrasting effects, depending on the actual nutrient limiting the rate of biomass production. For $\mathrm{N}$-limited systems, biomass production will increase and plant biodiversity will generally decrease by out-competition of slowgrowing species. For P-limited systems, productivity may become lower and biodiversity become increased as a result of lower $\mathrm{Fe}$ reduction rates, leading to lower $\mathrm{P}$ availability. The latter is the reason why P-loaded lakes have even been treated with $\mathrm{NO}_{3}^{-}$in order to change the eutrophic state, dominated by algae, to a less eutrophic state in which underwater vegetation receives more light (Ripl, 2010).

\section{TOXICITY OF S AND Fe, AND THEIR INTERACTIONS WITH P AVAILABILITY}

Fe reduction by bacteria, including sulfate reducing bacteria (e.g., Geobacter sulfurreducens), and archaea converts ferric compounds into ferrous iron (Lovley and Phillips, 1988; Coleman et al., 1993; Lovley et al., 2004; Weiss et al., 2004), which is much more mobile and is preferentially taken up by plants. The reduction of ferric iron, produced as a result of ROL, may suppress other anaerobic processes including methanogenesis (Frenzel et al., 1999). Although Fe is an essential micronutrient, high levels of Fe may become phytotoxic. This toxicity may even become visible aboveground as necrotic spots on the leaves of wetland plants (Lucassen et al., 2000). The oxidation of Fe by ROL may detoxify Fe due to the microbial or chemical precipitation of Fe hydroxides in the soil (Armstrong, 1978; Bienfait, 1989). However, excess Fe in combination with relatively low ROL can generate problems for plants due to Fe plaque formation on the root surface or by Fe deposition in the root apoplast (Taylor et al., 1984; Smolders and Roelofs, 1996; Emerson et al., 1999). These incrustations include Fe oxides (e.g., ferrihydrite), Fe oxyhydroxides (e.g., goethite), Fe carbonates (e.g., siderite), and Fe phosphates (e.g., vivianite), microbially derived organic-metal complexes, bacterial biofilms, and co-deposition of other metals such as manganese, copper, zinc, and lead (Batty et al., 2000; Hansel et al., 2001). Root physiology can be negatively affected by this plaque that acts as a physical barrier and interferes with P metabolism (Snowden and Wheeler, 1995). An interesting aspect of Fe hydroxide precipitation on microbes is the fact that they act as nanowires shuttling electrons in microbial communities
(Lovley, 2006; Rabaey et al., 2007), and also electrically connect them to plant roots.

The activity of sulfate reducing prokaryotes (SRP) is also of high relevance to vegetation development. Dissimilatory sulfate reducers include both Bacteria (e.g., Desulfovibrio, Desulfobacter) and Archaea (e.g., Archaeoglobus) producing sulfide $\left(\mathrm{H}_{2} \mathrm{~S}\right)$. Whereas oxidized states of $\mathrm{S}\left(\mathrm{SO}_{4}^{2-}, \mathrm{S}\right)$ are hardly toxic to plants, $\mathrm{H}_{2} \mathrm{~S}$ is highly toxic by inhibiting the activity of cytochrome $\mathrm{c}$ oxidase in mitochondria, leading to a subsequent blocking of energy production in roots, and by inhibiting other metal containing enzymes (Koch et al., 1990; Raven and Scrimgeour, 1997). The rhizospheric oxidation of $\mathrm{S}$ (Figure 3 ) by microbial activity of $\mathrm{S}$ oxidizers including Beggiatoa detoxifies $\mathrm{H}_{2} \mathrm{~S}$, and $\mathrm{ROL}$ activity of plants will therefore moderate the sensitivity of plants to sulfide. All three $\mathrm{pH}$-dependent species of sulfide $\left(\mathrm{H}_{2} \mathrm{~S}, \mathrm{HS}^{-}\right.$, and $\mathrm{S}^{2-}, \mathrm{pK}_{1}=7.2$; $\left.\mathrm{pK}_{2}=13.7\right)$ seem to be equally toxic to plants, but for most anaerobic soils the gaseous $\mathrm{H}_{2} \mathrm{~S}$ will be prevailing due to $\mathrm{HCO}_{3}^{-}-\mathrm{CO}_{2}$ buffering around $\mathrm{pH}$ 6-6.5. For marine wetlands receiving sufficient organic matter to keep electron donor concentrations high, $\mathrm{H}_{2} \mathrm{~S}$ production affects the growth of marine and brackish water macrophytes in the millimolar range. The phytotoxin is known to hamper the establishment and growth of the two main mangrove genera Avicennia and Rhizophora (McKee et al., 1988) and of seagrasses including Thalassia testudinum and Zostera marina (Frederiksen et al., 2006; Koch et al., 2007; Holmer et al., 2009). Fluctuations in ROL of seagrass plants lead to low $\mathrm{H}_{2} \mathrm{~S}$ concentrations during daytime and increased concentrations during nighttime. At the end of the growing season decreasing ROL, higher microbial $\mathrm{O}_{2}$ consumption and $\mathrm{H}_{2} \mathrm{~S}$ toxicity in concert induce the die-off of vegetation in brackish wetlands (Azzoni et al., 2001).

Although S concentrations are generally lower in freshwater wetlands, high input rates due to volcanic activity or other geological conditions, and as a result of $S$ pollution of the atmosphere, groundwater, and surface water have raised $\mathrm{SO}_{4}^{2-}$ concentrations at a global scale. In anaerobic freshwater wetland soils, $\mathrm{SO}_{4}^{2-}$ reduction may therefore become a dominant process next to $\mathrm{Fe}$ reduction (Lamers et al., 1998), while its rate can be determined by the availability of either electron donors or $\mathrm{SO}_{4}^{2-}$ (Lamers et al., 2002a). A recent review showed that up to $50 \%$ of the anaerobic decomposition in freshwater wetlands can be attributed to $\mathrm{SO}_{4}^{2-}$ reduction (Pester et al., 2012). Sulfide concentrations in the range of $10-100 \mu \mathrm{mol} \mathrm{L}^{-1}$ are known to be toxic to the roots of freshwater plants (Tanaka et al., 1968; Armstrong et al., 1996; Smolders and Roelofs, 1996; Lamers et al., 1998; Geurts et al., 2009). Like for marine plants, $\mathrm{H}_{2} \mathrm{~S}$ toxicity to roots can be prevented by the activity of sulfur bacteria using $\mathrm{O}_{2}$ from the roots (Joshi and Hollis, 1977). In addition, volatile $\mathrm{S}$ compounds including $\mathrm{H}_{2} \mathrm{~S}$ and, after its methylation, dimethylsulfide, and methanethiol are released to the atmosphere (Lomans et al., 2002). As the thermodynamical characteristics of Fe reduction and $S$ reduction do not differ very much, these conversions take place in the same soils, and $\mathrm{FeS}_{x}$ precipitation occurs (Lamers et al., 2002a). By this sequestration the concentration of both potential phytotoxins is reduced (Van der Welle et al., 2006), and plants may even become Fe deficient (Smolders and Roelofs, 1993).

Already in the 1950s of the former century, the prominent role of $\mathrm{S}$ in aquatic nutrient biogeochemistry was described (Ohle, 


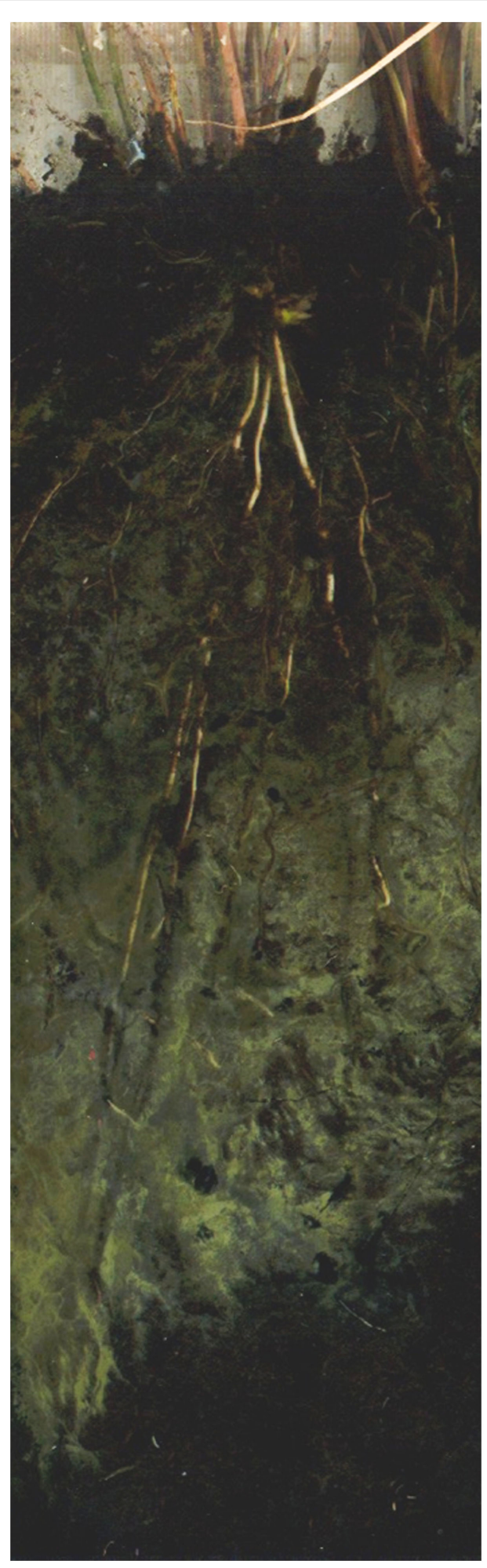

FIGURE 3 | Radial oxygen loss (ROL) of Juncus acutiflorus is shown by the oxidation of added $\mathrm{H}_{2} \mathrm{~S}$ in an anaerobic rhizotron with living plants and natural organic wetland soil. This was confirmed by the use of oxygen microelectrodes. Yellow-whitish haloes of $S^{0}$ and $S$ precipitates have been formed by microbial S oxidation (Lamers and Janssen, unpublished results).
1954). As $\mathrm{SO}_{4}^{2-}$ will serve as a terminal electron acceptor, it will speed up overall anaerobic decomposition. Increased inputs of $\mathrm{SO}_{4}^{2-}$ may additionally mobilize $\mathrm{Fe}$ bound $\mathrm{P}$ in the soil, due to its reduction to $\mathrm{H}_{2} \mathrm{~S}$ competing for Fe binding sites (Sperber, 1958; Caraco et al., 1989; Roden and Edmonds, 1997; Lamers et al., 1998; Smolders et al., 2006) or mobilization of P from polyphosphates by sulfur bacteria (Golterman, 2001). Whether or not sulfate-induced eutrophication occurs, depends on the levels of $\mathrm{P}$ in the sediment and its type of binding (Lamers et al., 2002a; Geurts et al., 2008; Loeb et al., 2008).

The large spatial and temporal heterogeneity in $\mathrm{O}_{2}$ supply (as determined by the balance between local ROL and local oxygen consumption) enables the coupling of oxidation and reduction of the same element $(\mathrm{S}, \mathrm{Fe}, \mathrm{N})$ at a small-scale in the rhizosphere. In this way, consortia of microorganisms using the same element can coexist in wetland soils, but the directions of the transformations are governed by plant physiology and soil characteristics.

In addition to the use of organic electron donors, the reduction of one of the three elements can be coupled to the oxidation of the other (chemolithotrophy). Sulfide, both dissolved and as $\mathrm{FeS}_{x}$ deposits in the soil can be used as an electron donor by proteobacteria such as Thiobacillus denitrificans coupled to the use of $\mathrm{NO}_{3}^{-}$(Haaijer et al., 2006, 2007; Burgin and Hamilton, 2008). Even in peat soils rich in organic compounds, $\mathrm{NO}_{3}^{-}$pulses are still able to stimulate to chemolithotrophic denitrification while organotrophic denitrification rates were very high (Lamers, unpublished results). For plants, this means that the detoxification of sulfide extends beyond the direct influence of ROL, and that S-rich situations may show lower $\mathrm{N}$-availability. At the landscape scale, $\mathrm{N}$ pollution of the catchment will mobilize $\mathrm{S}$ from subsoil $\mathrm{FeS}_{x}$ deposits, and the resulting $S$ pollution of groundwater will lead to $P$ pollution in wetlands where this polluted water is discharged. In this way, there is a microbial " $\mathrm{S}$ bridge" between $\mathrm{N}$ and $\mathrm{P}$ at this hydrological scale (Smolders et al., 2010). In wetland soils, partial $\mathrm{H}_{2} \mathrm{~S}$ oxidation to $\mathrm{S}^{0}$ and pyrite $\left(\mathrm{FeS}_{2}\right)$ can also be coupled to Fe reduction (Thamdrup et al., 1994), with consequences for the availability and toxicity of both elements to plants, and for the availability of $P$.

\section{GLOBAL CHANGES OF N, S, AND Fe BIOGEOCHEMISTRY}

As a result of anthropogenic forcing, the input of all three elements, $\mathrm{N}, \mathrm{S}$, and $\mathrm{P}$, into wetlands has strongly changed at a global scale (Schlesinger, 1997; Vitousek et al., 1997). As a result of urbanization, industrialization, and intensive farming, surface waters of many wetlands have become polluted by $\mathrm{N}$ and $\mathrm{P}$ (Carpenter et al., 1998). In contrast to $\mathrm{P}$, increased $\mathrm{N}$ inputs $\left(\mathrm{NO}_{x}\right.$ and $\left.\mathrm{NH}_{y}\right)$ are also the result of atmospheric deposition, which has strongly increased in industrialized regions and in regions with intensive farming (Vitousek et al., 1997; Bobbink et al., 1998). Whereas S deposition rates in Europe have been reduced by $80-90 \%$ as a result of legislation, they are strongly increasing in other parts of the world. In fast-developing regions such as Asia (particularly China), $\mathrm{SO}_{x}$ emissions may soon equal the combined emissions of North America and Europe as a result of the large-scale use of coal as a fuel (Shah et al., 2000). In addition to $\mathrm{N}$ and $\mathrm{S}$ pollution, many wetlands have been drained for land use change (Lamers et al., in press), which has not only resulted in the loss of wetlands, but also 
in significant changes in the hydrochemistry of wetlands that have not suffered from complete dehydration. Lowering of groundwater tables, also due to the extraction of drinking water and industrial process water, has decreased the influence of groundwater in wetlands to a large extent. As a result, the discharge of anaerobic, Fe-rich groundwater has decreased. This means that

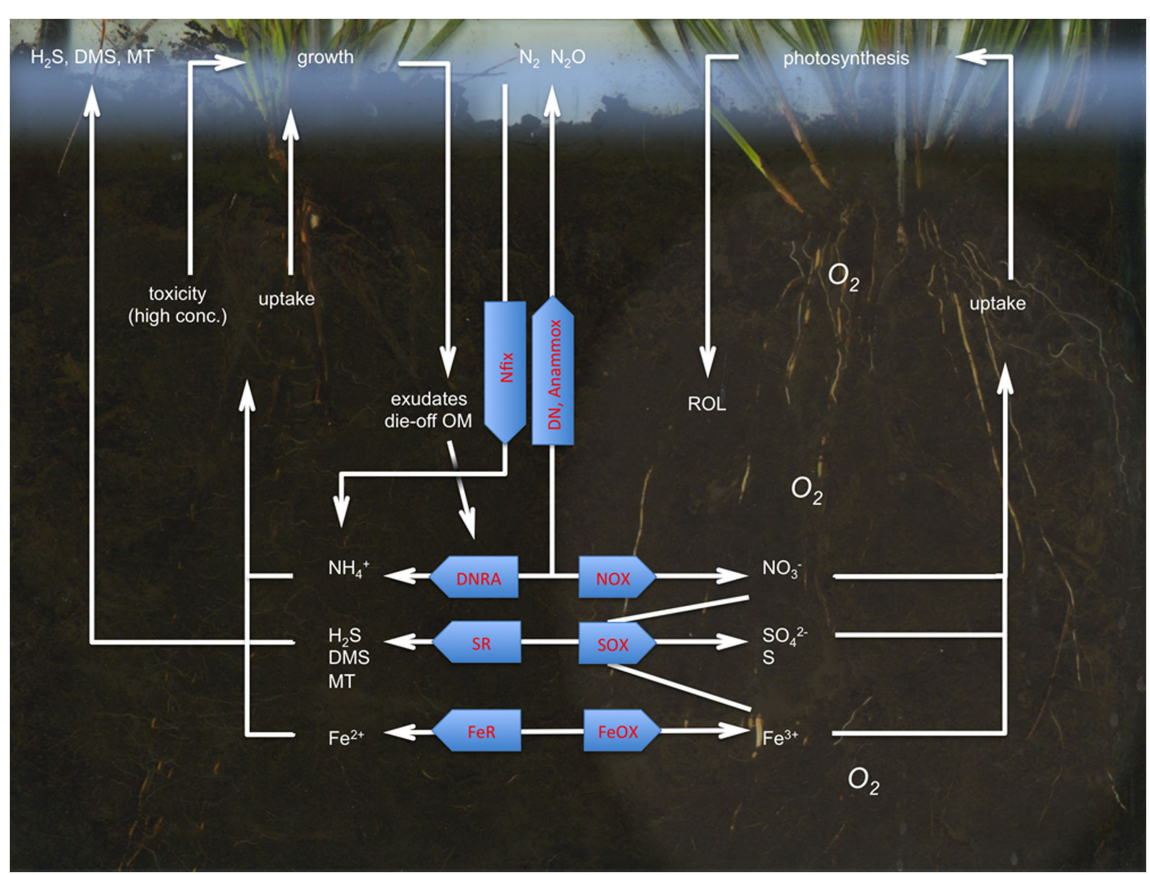

FIGURE 4 | Microbe-plant interactions in the biogeochemistry of N, S, and $\mathrm{Fe}$ in wetland soils. Losses of volatile $\mathrm{N}$ and $\mathrm{S}$ compounds to the atmosphere also occur through plant tissues, which has not been depicted here. See text for further explanation. DNRA, dissimilatory nitrate reduction to ammonium; SR, sulfate reduction; FeR, iron reduction, NOX, N oxidation to $\mathrm{NO}_{x}$, SOX, S oxidation; FeOX, Fe oxidation; DN, denitrification; Nfix, $\mathrm{N}_{2}$ fixation; Anammox, anaerobic ammonium oxidation; ROL, radial oxygen loss (by roots).

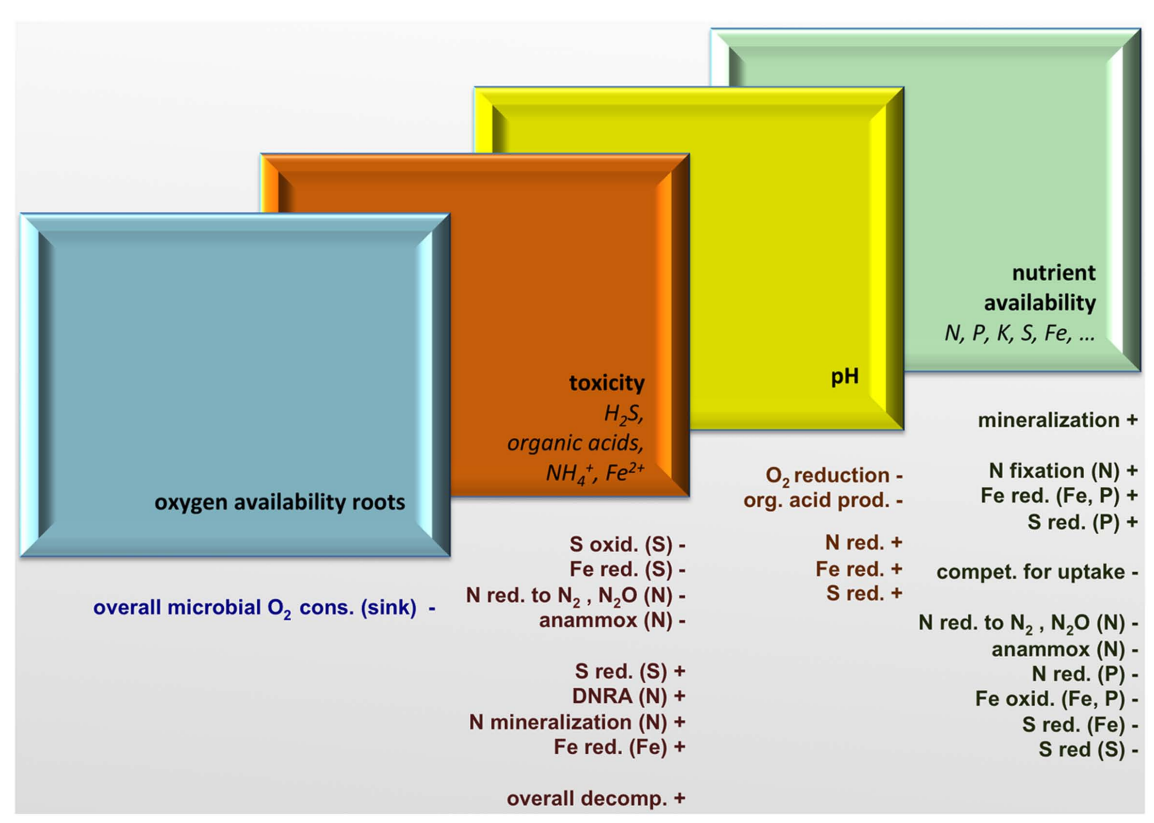

FIGURE 5 | Four filters created by microbial activities related to N, S, and Fe biogeochemistry influence the occurrence and functioning of wetland plant species, and their interspecific competition. A positive influence on the parameter mentioned on the filter frame is denoted by + , a negative by - . 
the role of $\mathrm{Fe}$ in regulating vegetation composition, $\mathrm{P}$ availability, and sulfide detoxification in wetlands has been changed (Lamers et al., in press). In combination with increased inputs of N, S, and $\mathrm{P}$, large-scale changes of wetland communities (microbial communities and their vegetation) have resulted, and ecosystem services such as $\mathrm{C}$ sequestration, flood protection, water storage, and biodiversity have been altered. The resilience of ecosystems to global change depends to a large extent on the responses microbial communities and their positive and negative feed-backs with respect to these changes. For this reason, changes in microbial composition and activity should be incorporated in ecosystem models (Treseder et al., 2011).

\section{GENERAL CONCLUSION}

The biogeochemical cycling of N, S, and Fe shows strong interactions in microbe-plant communities at various levels, from rhizosphere to landscape (Figure 4). The composition and activity of microbial communities dictate vegetation composition to a large extent by their strong effects on four important drivers (below-ground environmental filters) of the growth, composition, and biodiversity of wetland vegetation, namely root oxygen availability, phytotoxicity, $\mathrm{pH}$, and nutrient availability (Figure 5). Microbe-plant interactions provide challenging and complex new topics for highly interesting ecological research carried out by a consortium of specialists. In addition to correlative research, experimental research in the field and lab is essential to determine causal relationships. The fast development of new and much cheaper molecular techniques opens up a whole new world of rhizosphere research, in which basic and applied ecological issues on plant-microbe communities (Table 1) can be addressed that were impossible or much more difficult in the recent past. In addition, new students should be challenged and trained to address ecological topics in this multi-disciplinary way. Especially on a rapidly changing globe, it is vital that both microbiologists and plant ecologists meet in the hidden half of plant communities to better understand ecosystem changes at multiple levels.

Table 1 | Examples of fundamental and applied ecological challenges regarding plant-microbe communities in wetlands (and other ecosystem types).

\section{LANDSCAPE/ECOSYSTEM}

Interrelations among geohydrology, microbial communities, and vegetation development

Biogeochemical controls of carbon dynamics (primary production-decomposition feed-backs)

Impacts of anthropogenic hydrological changes (e.g., change from discharge of Fe-rich groundwater to recharge) on the interactions between microbial communities and vegetation

Pollution effects (e.g., $\mathrm{N}$ and $\mathrm{S}$ pollution groundwater, $\mathrm{P}$ pollution surface water, increased airborne $\mathrm{N}$ and $\mathrm{S}$ ) on plant-microbe interactions

Climate change (e.g., changes in precipitation and temperature patterns), effects on landscape biogeochemistry

Microbial ecology in conservation biology

Microbial ecology in restoration ecology

\section{ECOSYSTEM}

Role of microorganisms in vegetation succession and development

Role of vegetation in the succession and dynamics of microbial communities

Role of soil heterogeneity (e.g., nutrients, organic substrates, toxins, temperature, electron acceptors) in the functioning of plant-microbe communities, including the competition among microorganisms

Biodiversity in plant-microbe communities: niche differentiation, disturbance, fluctuation, neutral theory

Biodiversity of plant-microbe communities and ecosystem functioning and resilience

Microbial consortia in three-dimensional rhizosphere gradients

Rhizosphere community dynamics (e.g., diurnal, seasonal)

Plant host specificity of microbial communities and symbionts (e.g., comparison of species, same species under different environmental conditions)

Competition among plants based on their microbial communities (e.g., rhizosphere community as a plant trait)

Competition among microbes as a result of plant community changes

Competition for nutrients between microbes and plants, community effects

Dispersal of microbes and plants

Climate change effects (temperature, rainfall, $\mathrm{CO}_{2}$ ) on plant-microbe interactions

Optimization of water purification in constructed wetlands based on the manipulation of soil-plant-microbe interactions

\section{ECOPHYSIOLOGY}

Microbial controls on nutrient and water uptake by plants (including costs and benefits of mycorrhiza)

Gas (e.g., $\mathrm{CO}_{2}, \mathrm{CH}_{4}, \mathrm{~N}_{2}, \mathrm{~N}_{2} \mathrm{O}$ ) exchange in the plant-microbe continuum; effects of methane oxidizing symbionts on photosynthesis (e.g., Sphagnum mosses)

Selective root placement and microbial communities

Dynamics in anaerobiosis and microbe-plant interactions

Microbial manipulation of phytotoxic compounds (including agricultural crops, e.g., $\mathrm{H}_{2} \mathrm{~S}$ oxidation by symbiotic $\mathrm{S}$ oxidizers)

Generation of electricity in constructed wetlands

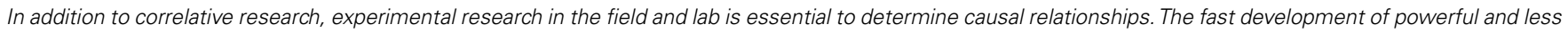
expensive molecular techniques will strongly facilitate comparative and experimental community studies. 


\section{REFERENCES}

Aerts, R., and Chapin, F. S. (2000). The mineral nutrition of wild plants revisited: a re-evaluation of processes and patterns. Adv. Ecol. Res. 30, 1-67.

Armstrong, J., Afreen-Zobayed, F., and Armstrong, W. (1996). Phragmites die-back: sulphide- and acetic acidinduced bud and root death, lignifications, and blockages within aeration and vascular systems. New Phytol. 134, 601-614.

Armstrong, W. (1978). "Root aeration in the wetland condition," in Plant Life in Anaerobic Environments, eds D. D. Hook and R. M. M. Crawford (Ann Arbor, MI: Ann Arbor Science Publishers), 269-297.

Arth, I., Frenzel, P., and Conrad, R. (1998). Denitrification coupled to nitrification in the rhizosphere of rice. Soil Biol. Biochem. 30, 509-515.

Azzoni, R., Giordani, C., Bartoli, M., Welsh, D. T., and Viaroli, P. (2001). Iron, sulphur and phosphorus cycling in the rhizosphere sediments of a eutrophic Ruppia cirrhosa meadow (Valle Smarlacca, Italy). J. Sea Res. 45, 15-26.

Batty, L. C., Baker, A. J. M., Wheeler, B. D., and Curtis, C. D. (2000). The effect of $\mathrm{pH}$ and plaque on the uptake of $\mathrm{Cu}$ and $\mathrm{Mn}$ in Phragmites australis (Cav.) Trin ex. Steudel. Ann. Bot. 86, 647-653.

Bienfait, H. F. (1989). Prevention of stress in iron-metabolism of plants. Acta Bot. 38, 105-129.

Bobbink, R., Hornung, M., and Roelofs, J. G. M. (1998). The effects of airborne nitrogen pollutants on species diversity in natural and semi-natural European vegetation. J. Ecol. 86, 717-738.

Bodelier, P. L. E. (2003). "Interactions between oxygen-releasing roots and microbial processes in flooded soils and sediments," in Root Ecology, eds H. De Kroon and E. J. W. Visser (Berlin: Springer-Verlag), 331-362.

Bodelier, P. L. E. (2011). Toward understanding, managing, and protecting microbial ecosystems. Front. Microbiol. 2:80. doi:10.3389/fmicb.2011.00080

Bodelier, P. L. E., Duyts, H., Blom, C. W. P. M., and Laanbroek, H. J. (1998). Interactions between nitrifying and denitrifying bacteria in gnotobiotic microcosms planted with the emergent macrophyte Glyceria maxima. FEMS Microbiol. Ecol. 25, 63-78.

Bodelier, P. L. E., Libochant, J. A., Blom, C. W. P. M., and Laanbroek, H. J. (1996). Dynamics of nitrification and denitrification in root-oxygenated sediments and adaptation of ammonia-oxidizing bacteria to low-oxygen or anoxic habitats. Appl. Environ. Microbiol. 62, 4100-4107.

Bodelier, P. L. E., Sorrell, B., Drake, H. L., Küsel, K., Hurek, T. P., ReinholdHurek, B., Lovell, C., Megonigal, P., and Frenzel, P. (2006). "Ecological aspects of microbes and microbial communities inhabiting the rhizosphere of wetland plants," in Wetlands as a Natural Resource, Vol. 2, eds R. Bobbink, B. Beltman, J. T. A. Verhoeven, and D. F Whigman (New York: Springer Verlag), 205-238.

Bodelier, P. L. E., Wijlhuizen, A. G., Blom, C. W. P. M., and Laanbroek, H. J. (1997). Effects of photoperiod on growth of and denitrification by Pseudomonas chlororaphis in the root zone of Glyceria maxima, studied in a gnotobiotic microcosm. Plant Soil 190, 91-103.

Bolan, N. S. (1991). A critical review on the role of mycorrhizal fungi in the uptake of phosphorus by plants. Plant Soil 134, 189-207.

Boone, R. D., Nadelhoffer, K. J., Canary, J. D., and Kayeet, J. P. (1998). Roots exert a strong influence on the temperature sensitivity of soil respiration. Nature 396, 570-572.

Bragazza, L., and Freeman, C. (2007). High nitrogen availability reduces polyphenol content in Sphagnum peat. Sci. Total Environ. 377, 439-443.

Brune, A., Frenzel, P., and Cypionka, H. (2000). Life at the oxic-anoxic interface: microbial activities and adaptations. FEMS Microbiol. Rev. 24, 691-710.

Burgin, A. J., and Hamilton, S. K. (2008). $\mathrm{NO} 3$ - driven $\mathrm{SO}_{4}{ }^{-}$production in freshwater ecosystems: implications for $\mathrm{N}$ and S cycling. Ecosystems 11, 908-922.

Burgin, A. J., and Hamilton, S. K. (2007). Have we overemphasized the role of denitrification in aquatic ecosystems? A review of nitrate removal pathways. Front. Ecol. Environ. 5, 89-96.

Callaway, R. M. (1995). Positive interactions among plants. Bot. Rev. 61, 306-349.

Canadell, J., Jackson, R. B., Ehleringer, J. R., Mooney, H. A., Sala, O. E., and Schulze, E.-D. (1996). Maximum rooting depth of vegetation types at the global scale. Oecologia 108, 583-595.

Caraco, N. F., Cole, J. J., and Likens, G. E. (1989). Evidence for sulphatecontrolled phosphorus release from sediments of aquatic systems. Nature 341, 316-318.
Carpenter, S. R., Caraco, N. F., Correll, D. L., Howarth, R. W., Sharpley, A. N., and Smith, V. H. (1998). Nonpoint pollution of surface waters with phosphorus and nitrogen. Ecol. Appl. 8, 559-568.

Clymo, R. S., Turunen, J., and Tolonen, K. (1998). Carbon accumulation in peatland. Oikos 81, 368-388.

Coleman, M. L., Hedrick, D. B., Lovley, D. R., White, D. C., and Pye, K. (1993). Reduction of Fe(III) in sediments by sulfate-reducing bacteria. Nature 361, 436-438.

Colmer, T. D. (2003). Long-distance transport of gases in plants: a perspective on internal aeration and radial oxygen loss from roots. Plant Cell Environ. 26, 17-36.

Conrad, R., and Frenzel, P. (2002). "Flooded soils," in Encyclopedia of Environmental Microbiology, ed. G. Bitton (New York: Wiley), 1316-1333.

Dakora, F. D., and Phillips, D. A (2002). Root exudates as mediators of mineral acquisition in lownutrient environments. Plant Soi 245, 35-47.

De Boer, W., and Kowalchuk, G. A. (2001). Nitrification in acid soils: micro-organisms and mechanisms. Soil Biol. Biochem. 33, 853-866.

De Kroon, H., Hendriks, M., Van Ruijven, J., Ravenek, J., Padilla, F. M., Jongejans, E., Visser, E. J. W., and Mommer, L. (2012). Root responses to nutrients and soil biota: drivers of species coexistence and ecosystem productivity. J. Ecol. 100, 6-15.

Dijkshoorn, W., and van Wijk, A. L. (1967). Sulphur requirements of plants as evidenced by sulphurnitrogen ratio in organic matter. A review of published data. Plant Soil 26, 129-157.

Emerson, D., Weiss, J. V., and Megonigal, J. P. (1999). Iron-oxidizing bacteria are associated with ferric hydroxide precipitates (Fe-plaque) on the roots of wetland plants. Appl. Environ. Microbiol. 65 2758-2761.

Frederiksen, M. S., Holmer, M., Borum, J., and Kennedy, H. (2006). Temporal and spatial variation of sulfide invasion in eelgrass (Zostera marina) as reflected by its sulfur isotopic composition. Limnol. Oceanogr. 51, 2308-2318.

Freeman, C., Ostle, N., and Kang, H. (2001). An enzymic "latch" on a global carbon store - a shortage of oxygen locks up carbon in peatlands by restraining a single enzyme. Nature 409, 149-149.

Frenzel, P., Rothfuss, F., and Conrad, R. (1992). Oxygen profiles and methane turnover in a flooded rice mesocosm. Biol. Fert. Soils 14, 84-89.

Frenzel, P., Bosse, U., and Janssen, P. H. (1999). Rice roots and methanogenesis in a paddy soil: ferric iron as an alternative electron acceptor in the rooted soil. Soil Biol. Biochem. 31, 421-430.

Fritz, C., Pancotto, V. A., Elzenga, J. T. M., Visser, E. J. W., Grootjans, A. P., Pol, A., Iturraspe, R., Roelofs, J. G. M., and Smolders, A. J. P. (2011). Zero methane emission bogs: extreme rhizosphere oxygenation by cushion plants in Patagonia. New Phytol. 190, 398-408.

Geurts, J. J. M., Sarneel, J. M., Willers, B. J. C., Roelofs, J. G. M., Verhoeven, J. T. A., and Lamers, L. P. M. (2009). Interacting effects of sulphate pollution, sulphide toxicity and eutrophication on vegetation development in fens: a mesocosm experiment. Environ. Pollut. 157, 2072-2081.

Geurts, J. J. M., Smolders, A. J. P., Verhoeven, J. T. A., Roelofs, J. G. M., and Lamers, L. P. M. (2008). Sediment $\mathrm{Fe}: \mathrm{PO}(4)$ ratio as a diagnostic and prognostic tool for the restoration of macrophyte biodiversity in fen waters. Freshw. Biol. 53, 2101-2116.

Gilbert, G. S. (2002). Evolutionary ecology of plant diseases in natural ecosystems. Annu. Rev. Phytopathol. 40, 13-43.

Golterman, H. L. (2001). Phosphate release from anoxic sediments or "What did Mortimer really write?" Hydrobiologia 450, 99-106.

Haaijer, S. C. M., Lamers, L. P. M., Smolders, A. J. P., Jetten, M. S. M., and Op den Camp, H. J. M. (2007). Iron sulfide and pyrite as potential electron donors for microbial nitrate reduction in freshwater wetlands. Geomicrobiol. J. 24, 391-401.

Haaijer, S. C. M., Van der Welle, M. E. W., Schmid, M. C., Lamers, L. P. M. Jetten, M. S. M., and Op den Camp, H. J. M. (2006). Evidence for the involvement of betaproteobacterial Thiobacilli in the nitrate-dependent oxidation of iron sulfide minerals. FEMS Microbiol. Ecol. 58, 439-448.

Hajek, T., Ballance, S., Limpens, J., Zijlstra, M., and Verhoeven, J. T. A. (2011). Cell-wall polysaccharides play an important role in decay resistance of Sphagnum and actively depressed decomposition in vitro. Biogeochemistry 103, 45-57.

Hansel, C. M., Fendorf, S., Sutton, S. and Newville, M. (2001). Characterization of Fe plaque and associated metals on the roots of mine-waste impacted aquatic plants. Environ. Sci. Technol. 35, 3863-3868. 
Hanson, P. J., Edwards, N. T., Garten, C. T., and Andrews, J. A. (2000). Separating root and soil microbial contributions to soil respiration: a review of methods and observations. Biogeochemistry 48, 115-146.

Hell, R., and Stephan, U. W. (2003). Iron uptake, trafficking and homeostasis in plants. Planta 216, 541-551.

Hobbie, S. E. (1992). Effects of plantspecies on nutrient cycling. Trends Ecol. Evol. (Amst.) 7, 336-339.

Hodge, A. (2004). The plastic plant: root responses to heterogeneous supplies of nutrients. New Phytol. 162, 9-24.

Hodge, A., Robinson, D., and Fitter, A. (2000). Are microorganisms more effective than plants at competing for nitrogen? Trends Plant Sci. 5, 304-308.

Holmer, M., Pedersen, O., KrauseJensen, D., Olesen, B., Petersen, M. H., Schopmeyer, S., Koch, M., Lomstein, B. A., and Jensen, H. S. (2009). Sulfide intrusion in the tropical seagrasses Thalassia testudinum and Syringodium filiforme. Estuar. Coast. Shelf Sci. 85, 319-326.

$\mathrm{Hu}$, B.-I., Rush, D., van der Biezen, E., Zheng, P., Van Mullekom, M., Schouten, S., Damste, J. S. S., Smolders, A. J. P., Jetten, M. S. M., and Kartal, B. (2011). New anaerobic, ammonium-oxidizing community enriched from peat soil. Appl. Environ. Microbiol. 77, 966-971.

Huisman, J., and Weissing, F. J. (1999). Biodiversity of plankton by species oscillations and chaos. Nature 402, 407-410.

Hutchings, M. J., and De Kroon, H. (1994). Foraging in plants - the role of morphological plasticity in resource acquisition. Adv. Ecol. Res. 25, 159-238.

Jackson, M. B., and Armstrong, W. (1999). Formation of aerenchyma and the processes of plant ventilation in relation to soil flooding and submergence. Plant Biol. 1, 274-287.

Jetten, M. S. M. (2008). The microbial nitrogen cycle. Environ. Microbiol. 10, 2903-2909.

Jetten, M. S. M., Strous, M., Van de Pas-Schoonen, K. T., Schalk, J., Van Dongen, U., Van de Graaf, A. A., Logemann, S., Muyzer, G., Van Loosdrecht, M. C. M., and Kuenen, J. G. (1998). The anaerobic oxidation of ammonium. FEMS Microbiol. Rev. 22, 421-437.

Jones, D. L. (1998). Organic acids in the rhizosphere - a critical review. Plant Soil 205, 25-44.

Joshi, M. M., and Hollis, J. P. (1977). Interaction of Beggiatoa and rice plant - detoxification of hydrogensulfide in rice rhizosphere. Science 195, 179-180.

Kalbitz, K., Solinger, S., Park, J. H., Michalzik, B., and Matzner, E. (2000). Controls on the dynamics of dissolved organic matter in soils: a review. Soil Sci. 165, 277-304.

Khadem, A. F., Pol, A., Jetten, M. S. M., and Opden Camp, H. J. M. (2010). Nitrogen fixation by the verrucomicrobial methanotroph "Methylacidiphilum fumariolicum" SolV. Microbiology 156, 1052-1059.

Kneip, C., Lockhart, P., Voß, C., and Maier, U.-G. (2007). Nitrogen fixation in eukaryotes - new models for symbiosis. BMC Evol. Biol. 7, 55. doi:10.1186/1471-2148-7-55

Koch, M. S., Mendelssohn, I. A., and McKee, K. L. (1990). Mechanism for the hydrogen sulfide-induced growth limitation in wetland macrophytes. Limnol. Oceanogr. 35, 399-408.

Koch, M. S., Schopmeyer, S. A., KyhnHansen, C., and Madden, C. J. (2007). Synergistic effects of high temperature and sulfide on tropical seagrasses. J. Exp. Mar. Biol. Ecol. 341, 91-101.

Laan, P., Berrevoets, M. J., Lythe, S., Armstrong, W., and Blom, C. W. P. M. (1989). Root morphology and aerenchyma formation as indicators of the flood-tolerance of Rumex species. J. Ecol. 77, 693-703.

Lambers, H. (1976). Respiration and NADH-oxidation of the roots of flood-tolerant and flood-intolerant Senecio species as affected by anaerobiosis. Physiol. Plant. 37, 117-122.

Lamers, L. P. M., Falla, S. J., Samborska, E. M., Van Dulken, L. A. R., Van Hengstum, G., and Roelofs, J. G. M. (2002a). Factors controlling the extent of eutrophication and toxicity in sulfate-polluted freshwater wetlands. Limnol. Oceanogr. 47, 585-593.

Lamers, L. P. M., Smolders, A. J. P., and Roelofs, J. G. M. (2002b). The restoration of fens in the Netherlands. Hydrobiologia 478, 107-130.

Lamers, L. P. M., Tomassen, H. B. M., and Roelofs, J. G. M. (1998). Sulfateinduced eutrophication and phytotoxicity in freshwater wetlands. Environ. Sci. Technol. 32, 199-205.

Lamers, L. P. M., Vile, M. A., Grootjans, A. P., Acreman, M. C., Van Diggelen, R., Evans, M. G., Richardson, C. J., Rochefort, L., Roelofs, J. G. M., and Smolders, A. J. P. (in press). "The restoration of fens and fen waters in agricultural areas: from trial and error to predictability," in Restoring Peatlands - Delivering Multiple
Benefits, eds A. Bonn, T. Allott, M. Evans, H. Joosten, and R. Stoneman (Cambridge University Press).

Larcher, W. (2003). Physiological Plant Ecology, 4th Edn. Berlin: Springer.

Leininger, S., Urich, T., Schloter, M., Schwark, L., Qi, J., Nicol, G. W., Prosser, J. I., Schuster, S. C., and Schleper, C. (2006). Archaea predominate among ammoniaoxidizing prokaryotes in soils. Nature 442, 806-809.

Loeb, R., Lamers, L. P. M., and Roelofs, J. G. M. (2008). Prediction of phosphorus mobilisation in inundated floodplain soils. Environ. Pollut. 156, 325-331.

Lomans, B. P., Van der Drift, C., Pol, A. and Op den Camp, H. J. M. (2002). Microbial cycling of volatile organic sulfur compounds. Cell. Mol. Life Sci. 59, 575-588.

Lovley, D. R. (2006). Bug juice: harvesting electricity with microorganisms. Nat. Rev. Microbiol. 4, 497-508.

Lovley, D. R., Holmes, D. E., and Nevin, K. P. (2004). Dissimilatory Fe(III) and $\mathrm{Mn}(\mathrm{IV})$ reduction. Adv. Microb. Physiol. 49, 219-286.

Lovley, D. R., and Phillips, E. J. P. (1988). Novel mode of microbial energy-metabolism - organiccarbon oxidation coupled to dissimilatory reduction of iron and manganese. Appl. Environ. Microbiol. 54, 1472-1480.

Lucassen, E. C. H. E. T., Bobbink, R., Smolders, A. J. P., Van der Ven, P. J. M., Lamers, L. P. M., and Roelofs, J. G. M. (2003). Interactive effects of low $\mathrm{pH}$ and high ammonium levels responsible for the decline of Cirsium dissectum (L.) Hill. Plant Ecol. 165, 45-52.

Lucassen, E. C. H. E. T., Smolders, A. J. P., and Roelofs, J. G. M. (2000). Increased groundwater levels cause iron toxicity in Glyceria fluitans (L.). Aquat. Bot. 66, 321-327.

Lucassen, E. C. H. E. T., Smolders, A. J. P., Van der Salm, A. L., and Roelofs, J. G. M. (2004). High groundwater nitrate concentrations inhibit eutrophication of sulphaterich freshwater wetlands. Biogeochemistry 67, 249-267.

Marschner, H. (1995). Mineral Nutrition of Higher Plants, 2nd Edn. London: Academic Press.

McKee, K. L., Mendelssohn, I. A., and Hester, M. W. (1988). Reexamination of pore water sulfide concentrations and redox potentials near the aerial roots of Rhizophora mangle and Avicennia germinans. Am. J. Bot. 75, 1352-1359.

Neubauer, S. C., Givler, K., Valentine, S. K., and Megonigal, J. P.
(2005). Seasonal patterns and plantmediated controls of subsurface wetland biogeochemistry. Ecology 86, 3334-3344.

Ohle, W. (1954). Sulfat als "Katalysator" des limbischen Stoffkreislaufes. Vom Wasser 21, 13-32.

Paul, E. A., and Clark, F. E. (1989). Soil Microbiology and Biochemistry. San Diego: Academic Press Inc.

Pester, M., Knorr, K.-H., Friedrich, M. W., Wagner, M., and Loy, A. (2012). Sulfate-reducing microorganisms in wetlands - fameless actors in carbon cycling and climate change. Front. Microbiol. 3:1. doi:10.3389/fmicb.2012.00072

Rabaey, K., Rodriguez, J., Blackall, L. L., Keller, J., Gross, P., Batstone, D., Verstraete, W., and Nealson, K. H. (2007). Microbial ecology meets electrochemistry: electricity-driven and driving communities. ISME J. 1 , 9-18.

Raven, J. A., and Scrimgeour, C. M. (1997). The influence of anoxia on plants of saline habitats with special reference to the sulphur cycle. Ann. Bot. 79, 79-86.

Read, D. J., and Perez-Moreno, J. (2003). Mycorrhizas and nutrient cycling in ecosystems - a journey towards relevance? New Phytol. 157, 475-492.

Reddy, K. R., Patrick, W. H., and Lindau, C. W. (1989). Nitrificationdenitrification at the plant rootsediment interface in wetlands. Limnol. Oceanogr. 34, 1004-1013.

Reed, S. C., Cleveland, C. C., and Townsend, A. R. (2011). Functional ecology of free-living nitrogen fixation: a contemporary perspective. Annu. Rev. Ecol. Evol. Syst. 42, 489-512.

Richardson, C. J. (1985). Mechanisms controlling phosphorus retention capacity in freshwater wetlands. Science 228, 1424-1427.

Ripl, W. (2010). "Restoration of eutrophic lakes by sediment treatment," in Restoration of Lakes, Streams, Floodplains, and Bogs in Europe, ed. M. Eiseltová (Amsterdam: Springer), 77-84.

Robinson, D., Hodge, A., and Fitter, A. (2003). "Constraints on the form and function of root systems," in Root Ecology, eds H. De Kroon and E. J. W. Visser (Berlin: SpringerVerlag), 1-32.

Roden, E. E., and Edmonds, J. W. (1997). Phosphate mobilization in ironrich anaerobic sediments: microbial $\mathrm{Fe}(\mathrm{III})$ oxide reduction versus ironsulfide formation. Arch. Hydrobiol. 139, 347-378.

Roelofs, J. G. M., Schuurkes, J., and Smits, A. J. M. (1984). Impact 
of acidification and eutrophication on macrophytes communities in soft waters. 2. Experimental studies. Aquat. Bot. 18, 389-411.

Scheffer, F., and Schachtschabel, P. (2002). Lehrbuch der Bodenkunde. Heidelberg: Spektrum Akademischer Verlag.

Schenk, M., and Wehrmann, J. (1979). Influence of ammonia in nutrient solution on growth and metabolism of cucumber plants. Plant Soil 52, 403-414.

Schlesinger, W. H. (1997). Biogeochemistry: An Analysis of Global Change. San Diego: Academic Press.

Schmidt, W. (1999). Mechanisms and regulation of reduction-based iron uptake in plants. New Phytol. 141, 1-26.

Shah, J., Nagpal, T., Johnson, T., Amann, M., Carmichael, G., Foell, W., Green, C., Hettelingh, L. P., Hordijk, L., Li, J., Peng, C., Pu, Y. F., Ramankutty, R., and Streets, D. (2000). Integrated analysis for acid rain in Asia: policy implications and results of RAINSASIA model. Annu. Rev. Environ. Resour. 25, 339-375.

Smith, F. A., and Smith, S. E. (1997). Tansley review no. 96 structural diversity in (vesicular)-arbuscular mycorrhizal symbioses. New Phytol. 137, 373-388.

Smolders, A. J. P., Lamers, L. P. M., Lucassen, E. C. H. E. T., Van der Velde, G., and Roelofs, J. G. M. (2006). Internal eutrophication: how it works and what to do about it - a review. Chem. Ecol. 22, 93-111.

Smolders, A. J. P., Lucassen, E. C. H. E. T., Bobbink, R., Roelofs, J. G. M., and Lamers, L. P. M. (2010). How nitrate leaching from agricultural lands provokes phosphate eutrophication in groundwater fed wetlands: the sulphur bridge. Biogeochemistry 98, 1-7.

Smolders, A. J. P., Lucassen, E. C. H. E. T., and Roelofs, J. G. M. (2002). The isoetid environment: biogeochemistry and threats. Aquat. Bot. 73, 325-350.

Smolders, A. J. P., and Roelofs, J. G. M. (1993). Sulfate-mediated iron limitation and eutrophication in aquatic systems. Aquat. Bot. 46, 247-253.

Smolders, A. J. P., and Roelofs, J. G. M. (1996). The roles of internal iron hydroxide precipitation, sulphide toxicity and oxidizing ability in the survival of Stratiotes aloides roots at different iron concentrations in sediment pore water. New Phytol. 133, 253-260.

Snowden, R. E. D., and Wheeler, B. D. (1995). Chemical changes in selected wetland plant species with increasing $\mathrm{Fe}$ supply, with specific reference to root precipitates and Fe tolerance. New Phytol. 131, 503-520.

Sperber, J. I. (1958). Release of phosphate from soil minerals by hydrogen sulphide. Nature 181, 934.

Stevens, C. J., Manning, P., Van den Berg, L. J. L., De Graaf, M. C. C., Wamelink, G. W. W., Boxman, A. W., Bleeker, A., Vergeer, P., Arroniz-Crespo, M., Limpens, J., Lamers, L. P. M., Bobbink, R., and Dorland, E. (2011). Ecosystem responses to reduced and oxidised nitrogen inputs in European terrestrial habitats. Environ. Pollut. 159, 665-676.

Tanaka, A., Ranjit, P., Mulleriyawa, R. P., and Yasu, T. (1968). Possibility of hydrogen sulfide induced iron toxicity of the rice plant. Soil Sci. Plant Nutr. 14, 1-6.

Taylor, G. J., Crowder, A. A., and Rodden, R. (1984). Formation and morphology of an iron plaque on the roots of Typha latifolia L. grown in solution culture. Am. J. Bot. 71, 666-675.

Thamdrup, B., Fossing, H., and Jorgensen, B. B. (1994). Manganese, iron, and sulfur cycling in a coastal marine sediment, Aarhus Bay, Denmark. Geochim. Cosmochim. Ac. 58, 5115-5129.

Thurston, R. V., Russo, R. C., and Vinogradov, G. A. (1981). Ammonia toxicity to fishes - effect of $\mathrm{pH}$ on the toxicity of the un-ionized ammonia species. Environ. Sci. Technol. 15, 837-840.

Tomassen, H. B. M., Smolders, A. J. P., Lamers, L. P. M., and Roelofs, J. G. M. (2003). Stimulated growth of Betula pubescens and Molinia caerulea on ombrotrophic bogs: role of high levels of atmospheric nitrogen deposition. J. Ecol. 91, 357-370.

Treseder, K. K., Balser, T. C., Bradford, M. A., Brodie, E. L., Dubinsky, E. A., Eviner, V. T., Hofmockel, K. S., Lennon, J. T., Uri, Y., Levine, U. Y., MacGregor, B. J., Pett-Ridge, J., and Waldrop, M. P. (2011). Integrating microbial ecology into ecosystem models: challenges and priorities. Biogeochemistry. doi:10.1007/s10533-011-9636-9635

Van den Berg, L. J. L., Dorland, E., Vergeer, P., Hart, M. A. C., Bobbink, R., and Roelofs, J. G. M. (2005). Decline of acid-sensitive plant species in heathland can be attributed to ammonium toxicity in combination with low $\mathrm{pH}$. New Phytol. 166, 551-564.
Van den Heuvel, R. N., Bakker, S. E., Jetten, M. S. M., and Hefting, M. M. (2011). Decreased N2O reduction by low soil $\mathrm{pH}$ causes high $\mathrm{N} 2 \mathrm{O}$ emissions in a riparian ecosystem. Geobiology 9, 294-300.

Van den Heuvel, R. N., Hefting, M. M., Tan, N. C. G., Jetten, M. S. M., and Verhoeven, J. T. A. (2009). $\mathrm{N} 2 \mathrm{O}$ emission hotspots at different spatial scales and governing factors for small scale hotspots. Sci. Total Environ. 407, 2325-2332.

Van der Heide, T., Smolders, A. J. P., Lamers, L. P. M., Van Katwijk, M. M., and Roelofs, J. G. M. (2010). Nutrient availability correlates with bicarbonate accumulation in marine and freshwater sediments empirical evidence from pore water analyses. Appl. Geochem. 25, 1825-1829.

Van der Welle, M. E. W., Cuppens, M., Lamers, L. P. M., and Roelofs, J. G. M. (2006). Detoxifying toxicants: interactions between sulfide and iron toxicity in freshwater wetlands. Environ. Toxicol. Chem. 25, 1592-1597.

Vartapetian, B. B., and Jackson, M. B. (1997). Plant adaptations to anaerobic stress. Ann. Bot. 79, 3-20.

Verhoeven, J. T. A., and Toth, E. (1995). Decomposition of Carex and Sphagnum litter in fens - effect of litter quality and inhibition by living tissue-homegenates. Soil Biol. Biochem. 27, 271-275.

Visser, E. J. W., Bögemann, G. M., Van de Steeg, H. M., Pierik, R., and Blom, C. W. P. M. (2000a). Flooding tolerance of Carex species in relation to field distribution and aerenchyma formation. New Phytol. 148, 93-103.

Visser, E. J. W., Colmer, T. D., Blom, C. W. P. M., and Voesenek, L. A. C. J. (2000b). Changes in growth, porosity, and radial oxygen loss from adventitious roots of selected mono- and dicotyledonous wetland species with contrasting types of aerenchyma. Plant Cell Environ. 23, 1237-1245.

Vitousek, P. M., Aber, J. D., Howarth, R. W., Likens, G. E., Matson, P. A., Schindler, D. W., Schlesinger, W. H., and Tilman, D. G. (1997). Human alteration of the global nitrogen cycle: sources and consequences. Ecol. Appl. 7, 737-750.

Vitousek, P. M., and Howarth, R. W. (1991). Nitrogen limitation on land and in the sea. Biogeochemistry 13, 87-115.

Voesenek, L. A. C. J., Colmer, T. D., Pierik, R., Millenaar, F. F., and Peeters, A. J. M. (2006). How plants cope with complete submergence. New Phytol. 170, 213-226.

Waisel, Y., Eshel, A., and Kafkafi, U. (1996). Plant Roots. The Hidden Half, 2nd Edn. New York: Marcel Dekker.

Weiss, J. V., Emerson, D., and Megonigal, J. P. (2004). Geochemical control of microbial $\mathrm{Fe}(\mathrm{III})$ reduction potential in wetlands: comparison of the rhizosphere to non-rhizosphere soil. FEMS Microbiol. Ecol. 48, 89-100.

Welsh, D. T., Bartoli, M., Nizzoli, D., Castaldelli, G., Riou, S. A., and Viaroli, P. (2000). Denitrification, nitrogen fixation, community primary productivity and inorganic-N and oxygen fluxes in an intertidal Zostera noltii meadow. Mar. Ecol. Prog. Ser. 208, 65-77.

Wetzel, R. G. (2001). Limnology: Rivers and Lakes. San Diego, CA: Academic Press.

Whipps, J. M. (2001). Microbial interactions and biocontrol in the rhizosphere. J. Exp. Bot. 52, 487-511.

Wieder, R. K., Scott, K. D., Kamminga, K., Vile, M. A., Vitt, D. H., Bone, T., Benscoter, B., and Bhatti, J. (2009). Carbon balance recovery in boreal bogs of Continental Western Canada. Glob. Change Biol. 15, 63-81.

Conflict of Interest Statement: The authors declare that the research was conducted in the absence of any commercial or financial relationships that could be construed as a potential conflict of interest.

Received: 10 January 2012; accepted: 04 April 2012; published online: 25 April 2012.

Citation: Lamers LPM, van Diggelen JMH, Op den Camp HJM, Visser EJW, Lucassen ECHET, Vile MA, Jetten MSM, Smolders AJP and Roelofs JGM (2012) Microbial transformations of nitrogen, sulfur, and iron dictate vegetation composition in wetlands: a review. Front. Microbio. 3:156. doi: 10.3389/fmicb.2012.00156

This article was submitted to Frontiers in Terrestrial Microbiology, a specialty of Frontiers in Microbiology.

Copyright (c) 2012 Lamers, van Diggelen, Op den Camp, Visser, Lucassen, Vile, Jetten, Smolders and Roelofs. This is an open-access article distributed under the terms of the Creative Commons Attribution Non Commercial License, which permits non-commercial use, distribution, and reproduction in other forums, provided the original authors and source are credited. 


\title{
Specificity of salt marsh diazotrophs for vegetation zones and plant hosts: results from a North American marsh
}

\author{
Charles R. Lovell * and Debra A. Davis ${ }^{\dagger}$ \\ Department of Biological Sciences, University of South Carolina, Columbia, SC, USA
}

\section{Edited by:}

Paul Bodelier, Netherlands Institute of

Ecology, Netherlands

\section{Reviewed by:}

Eric Boyd, Montana State University, USA

Gabriele Berg, Graz University of

Technology, Austria

Deniz Bombar, University of California

Santa Cruz, USA

*Correspondence:

Charles R. Lovell, Department of Biological Sciences, University of

South Carolina, 715 Sumter Street,

Columbia, SC 29208, USA.

e-mail: lovell@biol.sc.edu

${ }^{\dagger}$ Present address:

Debra A. Davis, Department of Biological Sciences, University of Alabama, P.O. Box 870344,

Tuscaloosa, AL 35487, USA.
Salt marshes located on the east coast of temperate North America are highly productive, typically nitrogen-limited, and support diverse assemblages of free-living nitrogen fixing (diazotrophic) bacteria. This article reviews and analyzes data from North Inlet estuary (SC, USA), addressing diazotroph assemblage structure and the influence of plant host and environmental conditions on the assemblage. The North Inlet estuary is a salt marsh ecosystem in which anthropogenic influences are minimal and the distributions of diazotrophs are governed by the natural biota and dynamics of the system. Denaturing gradient gel electrophoresis fingerprinting and phylogenetic analyses of recovered sequences demonstrated that the distributions of some diazotrophs reflect plant host specificity and that diazotroph assemblages distributed across marsh gradients are also heavily influenced by edaphic conditions. Broadly distributed diazotrophs that are capable of maintaining populations under all environmental conditions spanning such gradients are also present in these assemblages. Statistical analyses indicate that the structures of diazotroph assemblages in different vegetation zones are significantly $(p<0.01)$ different. New data presented here demonstrate the heterogeneity of salt marsh rhizosphere microenvironments, and corroborate previous findings from different plant hosts growing at several locations within this estuary. The data from these collected works support the hypothesis that the biogeography of microorganisms is non-random and these biogeographic patterns are predictable.

Keywords: diazotroph, salt marsh, plant host, vegetation zones, biogeography

\section{INTRODUCTION}

Numerous studies have revealed the immense diversity of microorganisms and have lent insight into their distributions within and across ecosystems (Ward et al., 1990; Øvreås, 2000; Floyd et al., 2005). A number of recent studies have demonstrated that microorganisms have distinct patterns of distribution (microbial biodiversity over space and time) reminiscent of those of macroorganisms (Hughes Martiny et al., 2006). Biogeography concepts can be used to understand why organisms are distributed as they are within and across ecosystems and why stable, mixed communities exist (Green et al., 2008). On large regional scales, biogeographic patterns of microorganisms are more heavily influenced by edaphic parameters than by the factors that typically dictate the well documented biogeography of plants and animals, such as latitude and mean annual temperature (Fierer and Jackson, 2006). However, on the local scale, microbial biogeography is influenced by both edaphic and biotic parameters such as vegetation type, carbon availability, nutrient availability, and soil moisture. These patterns have been observed in terrestrial, wetland, and aquatic ecosystems (Crump et al., 2004; Dolan, 2005; Fierer and Jackson, 2006).

Salt marsh ecosystems are excellent locations for the investigation of biogeographical patterns due to the small number of dominant macrophytes and to predictable environmental effectors such as tidal inundation and salinity. Niche differentiation patterns are well-established as gradients of these effectors and develop in response to tidal flooding and bioturbation in salt marsh ecosystems. Microbial communities express niche differentiation based on environmental gradients, often responding strongly to one or more specific environmental effectors in the ecosystem (Crump et al., 2004; Macalady et al., 2008; Dumbrell et al., 2010; Davis et al., 2011). For example, microbial diversity in estuarine tidal creeks is strongly influenced by salinity (Hollibaugh et al., 2000; Selje and Simon, 2003; Crump et al., 2004), which reflects both the direct impact of salinity on microbial communities and the influences of advective inputs of marine and freshwater microorganisms. Niche-based theories of ecology help to explain the partitioning of limiting resources between competing species and the differentiation of niche space across all species within a community (Leibold and McPeek, 2008). Particularly with reference to functional assemblages (i.e., assemblages of organisms carrying out specific ecological activities), such theories can give insight into the distribution of organisms throughout ecosystems and their ability to contribute significantly to ecosystem function in differing niche dimensions.

This review will examine recent findings from North American salt marsh ecosystems, focusing specifically on the diverse assemblage of free-living diazotrophic (nitrogen fixing) organisms found there. The salt marsh diazotroph assemblage includes organisms that are quite specific for a given marsh microenvironment as well as for specific marsh plant hosts. This assemblage is also sufficiently stable in composition (determined through field 
manipulation experiments discussed below in the Section Niche Specialization) to make analysis of geographic patterns feasible.

\section{SALT MARSH ECOSYSTEMS}

Coastal salt marshes are characteristically dominated by herbs, low shrubs and grasses bordering saline water bodies and are subjected to periodic flooding as a result of fluctuations (tidal or non-tidal) in the sea/ocean (Adam, 1990). The marshes depend on the tidal cycle to maintain water regimes, flush peat and sediment with water and dissolved nutrients, and to maintain salinity gradients (Gardner, 1973; Hemond and Fifield, 1982; Adam, 1990). Tidally dominated salt marshes are transitional between the mainly submerged sea grass communities and fully exposed terrestrial zones, and have received extensive study due to their importance as nursery grounds for commercially important fisheries species and as sources of carbon and nitrogen to nearshore waters (Long and Long, 1983; Schubauer and Hopkinson, 1984; Dame and Kenny, 1986; Dame et al., 1986; Morris and Haskin, 1990; Morris et al., 1990; King and Lester, 1995; Dai and Wiegert, 1997).

The coastal salt marshes of the south-eastern United States are typically dominated by halophyte perennial graminoids which have extensive underground rhizome systems (Odum, 1988). The number of plant species that are numerically significant in coastal salt marshes is small (Schubauer and Hopkinson, 1984) and a clear zonation of plant species that is based on edaphic environmental conditions, interspecies competition and minor differences in elevation is routinely observed (Bertness and Ellison, 1987; Adam, 1990; Pennings and Callaway, 1992). Key abiotic factors that influence plant zonation include sediment porewater salinity, soluble sulfide concentration, $\mathrm{pH}$ and redox potential (Bertness, 1991). Microbial activities have also been thought to influence the development of plant zonation, as expressed through their ability to affect the concentrations of nutrients and other solutes, particularly sulfide (King et al., 1982). The low marsh, which is regularly flooded and where salinities are higher, is dominated by halophyte grasses such as Spartina alterniflora and Spartina patens. The high marsh typically has lower salinities, undergoes irregular flooding (with frequency of flooding based on tidal heights and the elevation gradient), is closer to the terrestrial zone typically fringing the marsh, and is dominated by rushes and grasses having lower salt tolerance, such as Juncus roemerianus. Areas of disturbance in the marsh, such as those experiencing long-term waterlogged conditions or unusually high rates of evapotranspiration, are often dominated by successional species such as Salicornia virginica (Pennings and Callaway, 1992; Levine et al., 1998). These plant zones are easily recognized in the field and some are monotypic with respect to the plant present.

Crab Haul Creek Basin, North Inlet, South Carolina hosts a typical tidally dominated salt marsh with obvious plant zonation, fresh water input primarily from local rainfall, and nitrogen limitation. North Inlet is a high salinity, relatively pristine estuary (Blood and Vernberg, 1992) which serves as a benchmark system in the United States National Estuarine Research Reserve. The Crab Haul Creek Basin has a relatively minor elevation gradient, just over $1 \mathrm{~m}$ from mean high tide to the highest points within the basin, with semi-diurnal tides averaging $1.5 \mathrm{~m}$ (Kjerfve, 1986). This relatively flat landscape results in the edaphic parameter gradients that have influenced the plant zonation patterns observed in this system (Figures 1 and $\mathbf{2}$ ). Porewater salinity and sulfide concentration gradients, in particular, drive the development of macrophyte zonation along this elevation gradient. Monotypic stands of short and tall growth forms of S. alterniflora occur in the low marsh, the successional species S. virginica in the waterlogged region of the midmarsh (as well as in a mixed stand with the short growth form S. alterniflora), and J. roemerianus in the high marsh and in patches of slightly higher elevation within the low marsh zone of short growth form S. alterniflora. This pattern of plant zonation has been stable for decades (e.g., Dame and Kenny, 1986; Morris and Haskin, 1990).

Productivity in salt marshes has important impacts on coastal processes, and salt marshes are among the most productive ecosystems known (Keefe, 1972; Turner, 1976; Morris and Haskin, 1990). The average annual production ranges from 167 to $938 \mathrm{~g} \mathrm{~m}^{-2}$ year $^{-1}$, however this value varies greatly with temporal and local conditions (Kirwan et al., 2009). Despite these high levels of productivity, salt marshes are often nitrogen-limited as combined nitrogen compounds (nitrate, nitrite and ammonia) can be rapidly depleted and sources of "new" nitrogen, such as $\mathrm{N}_{2}$ fixation, must be utilized (Howarth et al., 1988). Phosphorus can also be a limiting factor for productivity of salt marshes and a seasonal switch is sometimes observed between nitrogen limitation and phosphorus limitation (Valiela and Teal, 1974; Howarth et al., 1988; van Wijnen and Bakker, 1999). Estuaries that are not subject to high levels of anthropogenic nutrient inputs are particularly susceptible to the effects of nutrient limitation. Nitrogen limitation has been demonstrated in these relatively pristine systems through nutrient addition experiments (Valiela and Teal, 1974; Marinucci et al., 1983; Hopkinson and Schubauer, 1984; Morris, 1991; Dai and Wiegert, 1997; van Wijnen and Bakker, 1999; Bagwell and Lovell, 2000a; Piceno and Lovell, 2000a,b) and through ecosystem-level mass balance considerations (Hopkinson and Schubauer, 1984; Hopkinson, 1988; Morris, 1995). Biological nitrogen fixation in salt marshes is thought to be more important than in most other ecosystems due to its significant contribution of $\mathrm{N}$ to the nitrogen budget in these systems (Capone and Carpenter, 1982).

Only organisms of the domains Bacteria and Archaea are capable of the reduction of gaseous dinitrogen to ammonia (nitrogen fixation or diazotrophy; Postgate, 1998). Ammonium levels in the sediment porewater are much higher than in salt marsh surface waters, demonstrating that the sediments are a net source of nitrogen for the system (Mendelssohn, 1979; Morris and Dacey, 1984; Sundareshwar et al., 2003). The diazotrophs in the sediments of salt marshes are thus the main source of the considerable contribution of fixed nitrogen from salt marshes to the global nitrogen cycle. This was confirmed by ${ }^{15} \mathrm{~N}_{2}$ enrichment studies using microcosms of sediment from a California estuary where nitrogen fixation was the primary method of $\mathrm{N}$ transfer to vegetation and other primary producers (Moseman-Valtierra et al., 2010). Diazotrophs associated with salt marsh grasses are present in high numbers, are most active on the roots of these plants (Patriquin, 1978; McClung et al., 1983; Whiting et al., 1986; Yoch and Whiting, 1986) and are supported by root exudates, as well as by products of plant decomposition (Whiting et al., 1986; Bagwell 


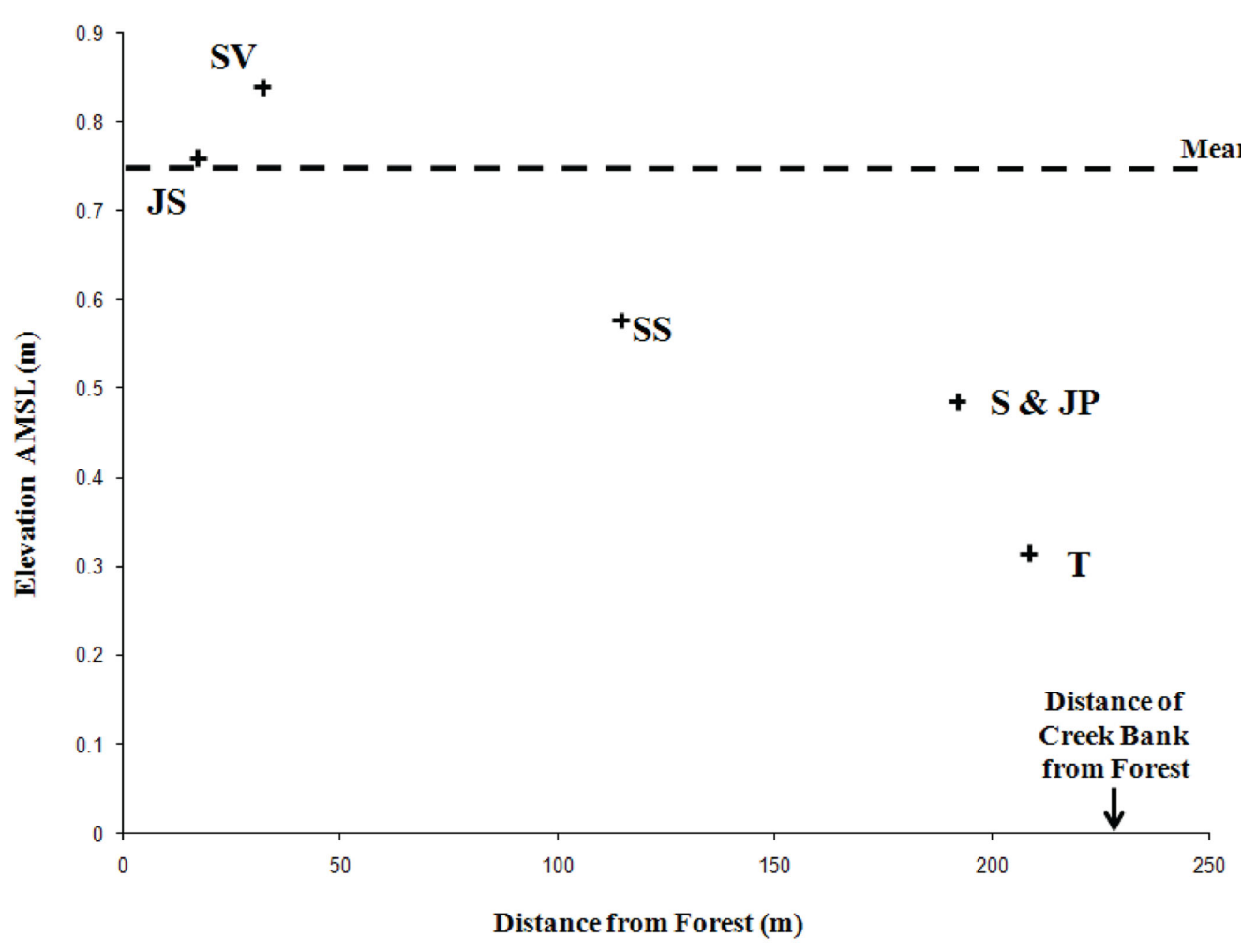

FIGURE 1 | Differences in site elevation above mean sea level (AMSL) and distance of each sampling location from the forest edge. Site designations: Juncus roemerianus stand (JS); Salicornia virginica (SV); mixed plant zone of co-occurring S. virginica and short form Spartina alterniflora (SS); short form S. alterniflora (S); patch of $J$. roemerianus in the $S$ zone (JP); and tall form $S$. alterniflora (T). Reproduced with kind permission from Davis et al. (2011), Figure 1.

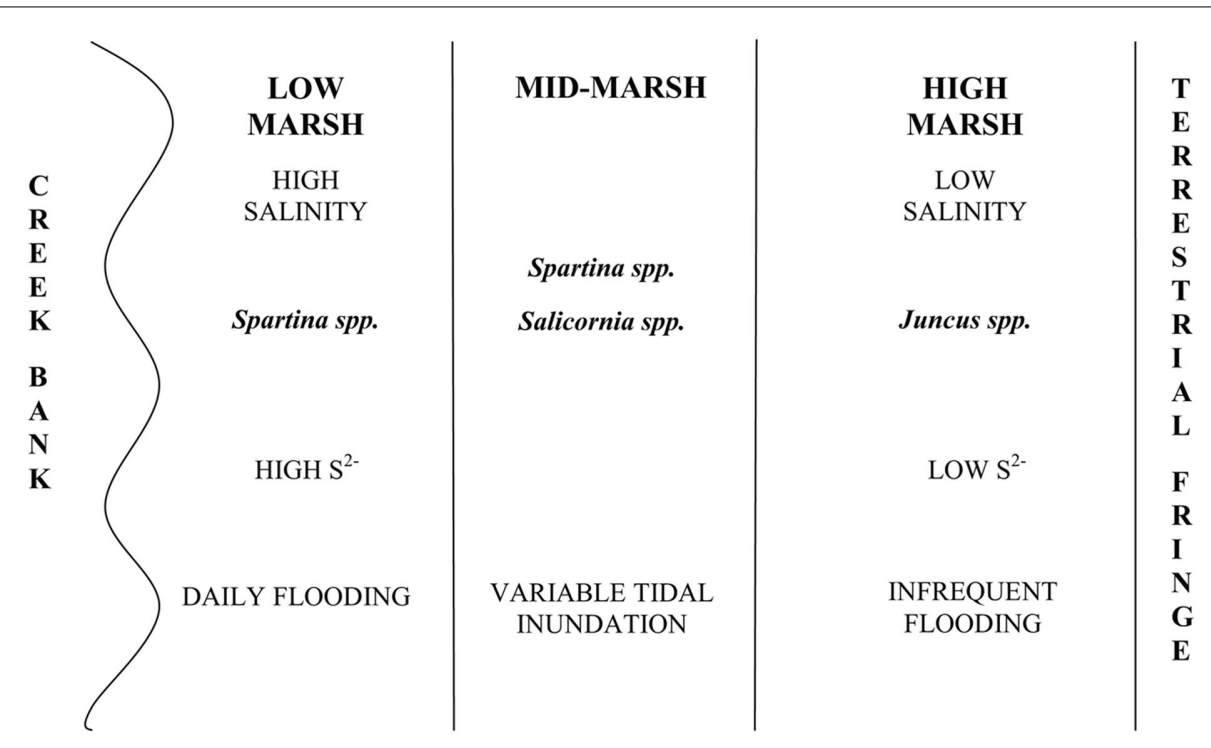

FIGURE 2 |Typical marsh zonation including vegetation zonation and gradients of influential abiotic parameters as observed in Crab Haul Creek Basin, North Inlet.

et al., 2001; Bergholz et al., 2001). Diazotrophs associated with salt have been studied extensively and the remarkable diversity of the marsh macrophytes, particularly the cordgrasses (Spartina spp.), salt marsh diazotroph assemblages documented (Bagwell et al., 
1998, 2001, 2002; Piceno et al., 1999; Bagwell and Lovell, 2000a; Lovell et al., 2000, 2001a,b; Piceno and Lovell, 2000a,b; Bergholz et al., 2001; Burke et al., 2002, 2003; Brown et al., 2003; LaRocque et al., 2004; Moisander et al., 2005; Welsh et al., 2007; MosemanValtierra et al., 2009, 2010; Gamble et al., 2010; Cramer et al., 2011; Davis et al., 2011).

\section{DIAZOTROPH ASSEMBLAGES ASSOCIATED WITH SALT MARSH GRASSES}

Bacterial diazotroph assemblages associated with salt marsh grasses are primarily composed of organisms taxonomically related to the $\alpha-, \beta-, \delta-, \varepsilon^{-}$, and $\gamma$-Proteobacteria (Bagwell et al., 1998, 2001, 2002; Piceno et al., 1999; Bagwell and Lovell, 2000a; Lovell et al., 2000, 2001a,b; Piceno and Lovell, 2000a,b; Burke et al., 2002, 2003; Brown et al., 2003; Moisander et al., 2005; Welsh et al., 2007; Gamble et al., 2010; Davis et al., 2011). Archaeal diazotrophs have not been extensively studied in most ecosystems (Zehr et al., 2003) and have yet to be examined in salt marshes. Salt marsh diazotroph assemblages consist of mainly novel, uncultivated organisms whose physiologies have not yet been determined. This is a common observation of diazotroph assemblages across natural ecosystems and the diversity of these assemblages in combination with their potentially very different physiologies has inspired many studies (Zehr et al., 2003; Bürgmann et al., 2004). Culture-dependent studies have also revealed diverse culturable assemblages, largely composed of Proteobacteria (Bagwell et al., 1998, 2001; Bagwell and Lovell, 2000a; Bergholz et al., 2001; LaRocque et al., 2004). These assemblages are capable of utilizing a host of carbon compounds found in plant root exudates as determined in studies on isolates from washed roots (Bagwell et al., 2001; Bergholz et al., 2001), and of surviving substantial ranges of environmental conditions such as $\mathrm{pH}$ and salinity (Cramer et al., 2011).

The development of nitrogenase gene specific polymerase chain reaction $(\mathrm{PCR})$ primers has allowed the investigation of salt marsh diazotroph assemblages via culture-independent methods (Zehr and McReynolds, 1989; Ueda et al., 1995; Olson et al., 1998; Piceno et al., 1999; Widmer et al., 1999; Lovell et al., 2000; Welsh et al., 2007). Briefly, the nitrogenase enzyme is composed of two multisubunit metalloproteins (reviewed in Postgate, 1998; Zehr et al., 2003). Component I contains the active site for $\mathrm{N}_{2}$ reduction and is composed of two heterodimers encoded by the nifD and nifK genes. Component II couples ATP hydrolysis to inter-protein electron transfer and is composed of two identical subunits encoded by the nifH gene. Primers specific for the nifH gene have been used extensively in culture-independent studies of diazotroph assemblages across many ecosystems resulting in a robust database of gene sequences from uncultivated microorganisms (Zehr et al., 2003). Primers specific for nifD (Ueda et al., 1995) have also been developed but have not been used as broadly or as frequently as the nifH-specific primers (Zehr et al., 2003). The diazotroph assemblages associated with salt marsh macrophytes have been investigated through PCR-amplification using nifH-specific primers and the nifH amplicons have in turn been analyzed using methods such as denaturing gradient gel electrophoresis (DGGE; Bagwell et al., 1998, 2001, 2002; Piceno et al., 1999; Bagwell and Lovell, 2000a; Lovell et al., 2000, 2001a,b; Piceno and Lovell, 2000a,b; Brown et al., 2003; Welsh et al., 2007, 2010; Gamble et al., 2010; Davis et al., 2011), restriction fragment length polymorphism (RFLP; Burke et al., 2002, 2003), and terminal restriction fragment length polymorphism (T-RFLP; Moseman-Valtierra et al., 2009, 2010). PCR-amplification of reverse-transcribed mRNA extracts has also been used to a lesser extent (Brown et al., 2003). In the North Inlet estuary, diazotrophs have been investigated via culture-dependent methods as well as DGGE (Bagwell et al., 1998, 2001, 2002; Piceno et al., 1999; Bagwell and Lovell, 2000a; Lovell et al., 2000, 2001a,b; Piceno and Lovell, 2000a,b; Brown et al., 2003; Gamble et al., 2010; Davis et al., 2011), reverse sample genome probing (Bagwell and Lovell, 2000a), clone library construction and screening (Lovell et al., 2008) and sequencing of reverse-transcribed mRNA extracts (Brown et al., 2003). The composition of the diazotroph assemblages of this ecosystem are similar to those recovered from other salt marsh ecosystems (e.g., Moisander et al., 2005) and other estuaries (e.g., Affourtit et al., 2001; Burns et al., 2002; Moisander et al., 2007). Due to the number of studies that have been done in this area, detailed phylogenetic and statistical analyses can be conducted on the nifH sequence data that have been obtained. Assemblages from the North Inlet estuary have proven to be stable, ubiquitous, functionally versatile, distributed in predictable patterns across the marsh landscape and are characterized by their content of novel and undescribed taxa (Gamble et al., 2010; Davis et al., 2011).

\section{PLANT HOST SPECIFICITY}

Culture-dependent and culture-independent analyses of diazotroph assemblages associated with the rhizospheres of salt marsh macrophytes of North Inlet have demonstrated the occurrence of plant host specific organisms. This is not uncommon, nor is it unexpected in natural ecosystems. The colonization of plant species by specific microbial populations has been repeatedly observed in terrestrial ecosystems (reviewed in Berg and Smalla, 2009). Soil quality and soil type heavily influences the root colonizing microorganisms, however it has been proven repeatedly that plant species also exerts a direct influence (Berg and Smalla, 2009). The biogeography of soil microbial communities on a large scale (i.e., continental) is controlled primarily by soil abiotic parameters, particularly soil pH (Fierer and Jackson, 2006), and it is assumed that this premise holds true for salt marsh sediment microbial communities. However, as previously mentioned, parameters such as vegetation type, carbon and nutrient availability, and soil moisture have a more direct influence on the diversity of the local microbial community (Fierer and Jackson, 2006). Plant type and the root exudates that individual plant species produce affect the relative abundance and diversity of indigenous microbial communities at the root and in the rhizosphere (Berg and Smalla, 2009) resulting in plant host specific phylotypes.

LaRocque et al. (2004) examined diazotrophs isolated from J. roemerianus rhizoplanes from two habitats differing in abiotic parameters. The two monotypic Juncus stands were in different marsh zones having different salinities (29 and 40 parts per thousand), different porewater chemistries and experiencing different extents and durations of tidal inundation (LaRocque et al., 2004). The higher salinity Juncus habitat is regularly inundated during daily tidal cycles, whereas the lower salinity stand is in the high 
marsh and not as frequently inundated. Diazotrophs from both habitats were analyzed in parallel using the same protocols (including nifH PCR-amplification). The presence of nif $H$ was confirmed in each isolate and isolates were grouped based on their carbon substrate utilization patterns. Three major substrate utilization clusters were identified and each cluster contained isolates from both monotypic stands. DGGE analysis of rhizoplane (sediment free roots) and rhizosphere (sediments influenced by the roots) nifH amplicons from both Juncus stands confirmed the presence of host specific diazotrophs - diazotrophs that were present in both assemblages despite differences in salinity, sulfide, and $\mathrm{pH}$. The use of both culture-dependent and independent methods in this study reduced the impact of biases that could have been introduced had only data from a single method been examined.

Bergholz et al. (2001) isolated diazotrophs from the rhizoplanes of $S$. patens growing in two physically different habitats of North Inlet estuary, along with diazotrophs from other macrophytes. The diazotrophs were grouped based on substrate utilization and strains from $S$. patens formed two distinct clusters each containing strains from both habitats. Of the 16 physiologically different groups, only one strain isolated from $S$. patens was similar to diazotroph strains isolated from other macrophytes in the same salt marsh ecosystem. Diazotroph strains from S. virginica were different from strains from other plants growing in other marsh zones, but were more similar to strains from host plants growing in the same marsh zone (Bagwell et al., 2001). As described above and in Figure 2, marsh zones are defined by edaphic parameters (Bertness and Ellison, 1987; Adam, 1990; Pennings and Callaway, 1992).
Diazotrophs isolated from plant hosts in the same zone are presumed to be heavily influenced by the edaphic parameters of the marsh zone.

nifH DGGE analysis of diazotroph assemblages recovered from the rhizosphere and rhizoplane of host plants in North Inlet also confirm the plant host specificity observed in the culturedependent studies (Gamble et al., 2010; Davis et al., 2011). Assemblages from S. alterniflora growing in two differing tidal drainage systems within North Inlet estuary showed seasonal variability but no significant site-influenced variability (Gamble et al., 2010). The host plants were the same in both locations (short and tall growth forms of S. alterniflora) and the subtle changes in edaphic parameters with changes in seasons shaped the seasonally responsive segments of the diazotroph assemblages in these two locations. Assemblages from the rhizospheres of plant hosts in the Crab Haul Creek Basin that exhibit zonation due to elevation differences, contained host specific diazotrophs as well as diazotrophs having broad distributions across the landscape (Davis et al., 2011). As described above, plant zones contain specific macrophytes due to the differences in marsh environments. A clear response of diazotroph assemblages to plant host zonation and seasonal changes in edaphic parameters was observed from principal component analysis (PCA) of the recovered nifH amplicons (Gamble et al., 2010; Davis et al., 2011). The results obtained by Davis et al. (2011) confirmed the seasonal responses (Figure 3) and plant host specificity (Figure 4) observed by Gamble et al. (2010), and also included diazotroph assemblages associated with multiple plant hosts.

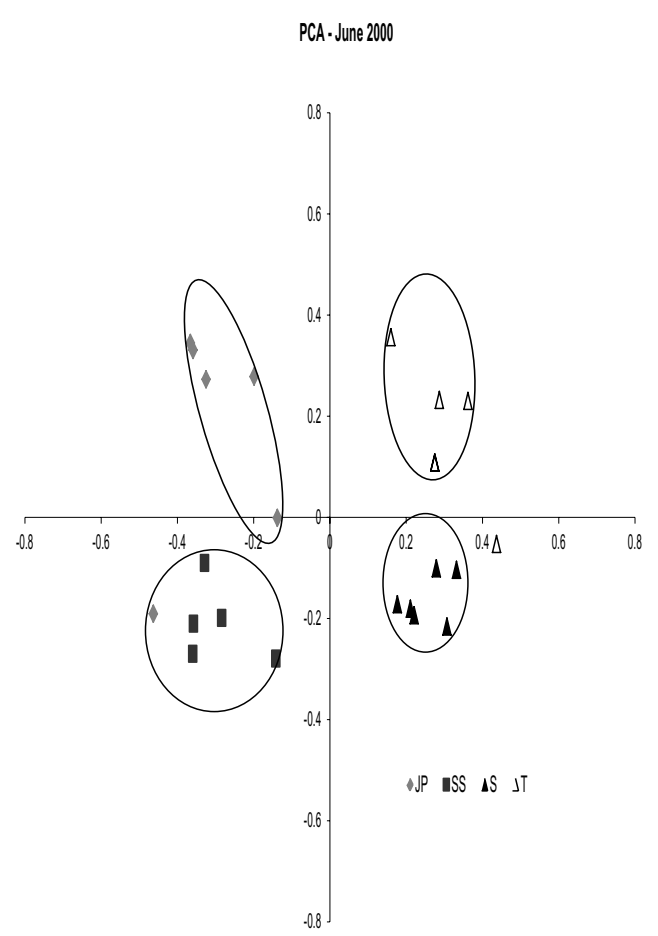

FIGURE 3 | Principal Components Analysis results for dates June (SS, JP, S, and T) and September 2000 (SV, SS, S, and T). Circles denote significance $(p<0.001)$ for clustering. For June 2000 Axis 1 represents $28.4 \%$ of the

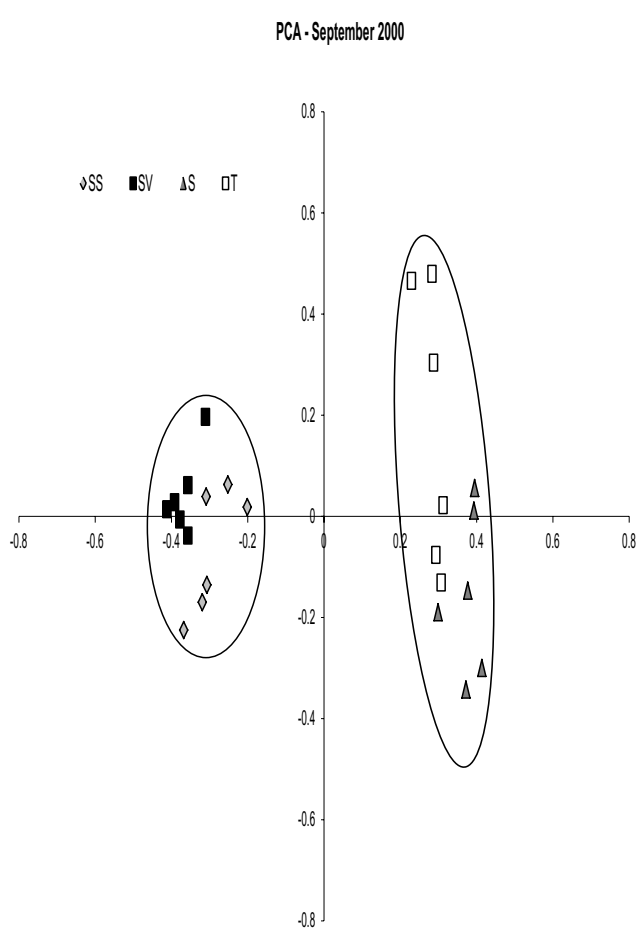

variance and Axis 2 represents $14.7 \%$ of the variance. For September 2000 Axis 1 represents $31.5 \%$ of the variance and Axis 2 represents $11.5 \%$ of the variance. Reproduced with kind permission from Davis et al. (2011), Figure 3. 


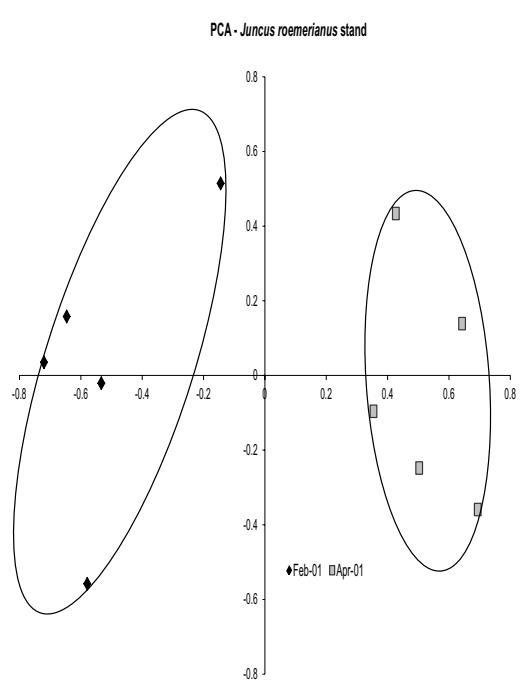

FIGURE 4 | Principal Components Analysis results for vegetation zones Juncus roemerianus stand and tall form Spartina alterniflora on all dates. Circles denote significance $(p<0.001)$ for clustering. For $J$. roemerianus stand Axis 1 represents $31.2 \%$ of the variance and Axis 2

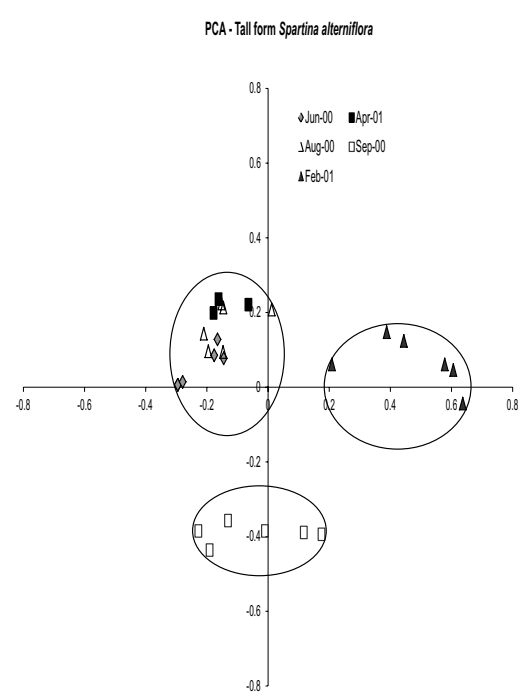

represents $20.8 \%$ of the variance. For tall form S. alterniflora Axis 1 represents $25.8 \%$ of the variance and Axis 2 represents $15.5 \%$ of the variance. Reproduced with kind permission from Davis et al. (2011), Supplementary Figure 1A.
To confirm the results from PCA analysis, mothur (Schloss et al., 2009) was used to conduct parsimony tests on neighbor-joining trees created using nifH sequences (400-420 bp). These sequences were recovered from DGGE banding patterns of rhizoplane and rhizosphere samples from all plant zones except the mixed zone of co-occurring S. virginica and short form S. alterniflora (Davis, 2010). Included in the phylogenetic analysis were plant zones (with designations): J. roemerianus stand (JS), S. virginica (SV), short form S. alterniflora (SS), patch of J. roemerianus in the SS zone (JP), and tall form S. alterniflora (TS). Using a significance threshold of $p<0.01$ it was confirmed that diazotroph assemblages in the same marsh zone (based on edaphic parameters) had similar structures (Table 1). Phylogenetic analyses of the sequences recovered from these assemblages also revealed clusters of plant host specific sequences that were considered identical (sensu Venter et al., 2004; see also Lovell et al., 2008) throughout the nifH phylogenetic trees (Figure 5; Table A2 in Appendix, 19 clusters in the high marsh; Figures 6 and 7; Table A4 in Appendix, 39 clusters in the low marsh). These results provide additional and extensive evidence of diazotroph specificity for the plant host.

Multiple analyses of datasets obtained in several different studies provide strong evidence of plant host specific diazotroph assemblages associated with the rhizospheres of salt marsh plants. These organisms have been detected through both culturedependent and culture-independent methods, in different sites throughout North Inlet estuary, and over the course of more than a decade. It is very clear that salt marsh diazotrophs have a distinct biogeography driven by both biotic (host plant) and abiotic environmental parameters (i.e., salinity, tidal inundation, elevation, etc.). The results of these studies also indicate substantial resilience of some members of the diazotroph assemblages that are capable of withstanding wide ranges of environmental conditions and are present in multiple marsh zones.
Table 1 | Results from parsimony tests (mothur) of neighbor-joining trees containing diazotroph sequences recovered from band stabs of DGGE gels of PCR-amplified nifH amplicons from rhizoplane (roots) or rhizosphere (sediments) of different plant zones.

\begin{tabular}{llc}
\hline Trees & Parsimony score & Parsimony significance*** \\
\hline RHIZOPLANE & & \\
JPR v. SSR & 16.00 & 0.08 \\
All others & $9.00-22.00$ & $<0.01$ \\
RHIZOSPHERE & & \\
JPS v. SSS & 44.00 & 0.038 \\
All others & $29.00-41.00$ & $<0.01$ \\
\end{tabular}

*** Significance threshold (using Bonferroni corrections) $=0.05 / 5=0.01$.

All pairs yielding a parsimony significance $<0.01$ have significantly different structures from each other. Key: JPX, J. roemerianus patch in short growth form S. alterniflora; SSX, short growth form S. alterniflora; XXR, rhizoplane; XXS, rhizosphere.

\section{NICHE SPECIALIZATION}

Studies of diazotroph assemblages associated with the salt marsh plants in North Inlet have demonstrated a diverse yet stable assemblage. Bagwell and Lovell (2000b) conducted a series of field fertilization experiments and through reverse sample genome probing revealed a highly resilient, niche specialized diazotroph assemblage. The assemblage responded to environmental manipulations through increases and decreases in quantities of specific taxa, but not through loss of taxa (Bagwell and Lovell, 2000b). DGGE analysis of diazotroph assemblages in long- and short-term fertilization experiments (fertilized with $16.3 \mathrm{~g} \mathrm{~N} \mathrm{~m}^{-2} \mathrm{NH}_{4} \mathrm{NO}_{3}$ and $\left.18.0 \mathrm{~g} \mathrm{P} \mathrm{m}^{-2} \mathrm{P}_{2} \mathrm{O}_{5}\right)$ confirmed the stability of these assemblages (Piceno and Lovell, 2000a,b). The results of these experiments indicate that salt marsh diazotrophs are quite competitive 


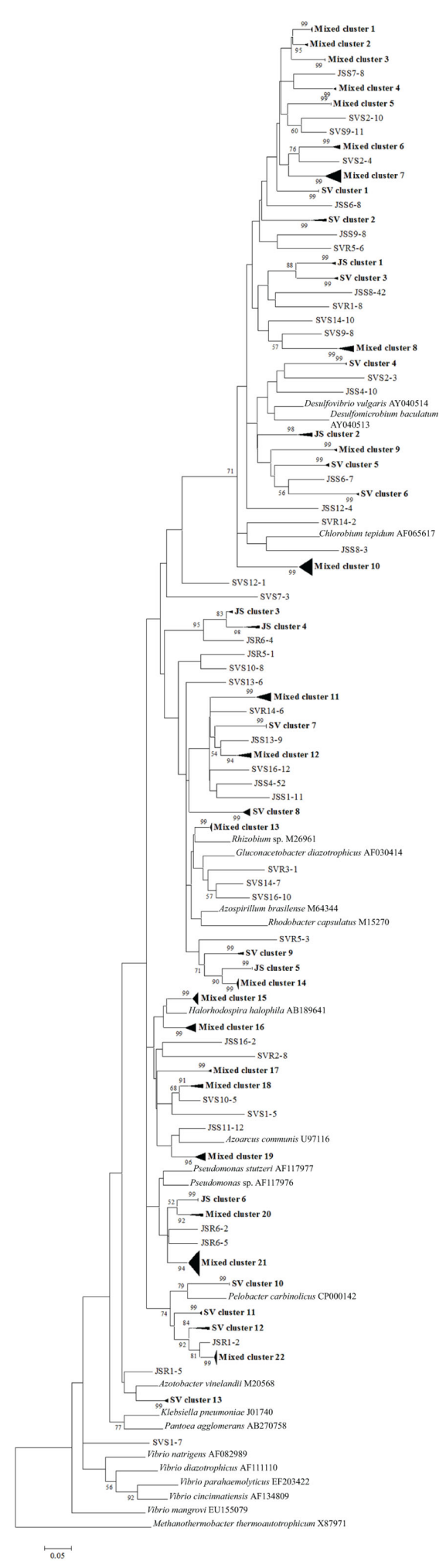

FIGURE 5 | Phylogenetic analysis of all nifH sequences from DGGE bands of rhizoplane (R) and rhizosphere (S) samples from the high marsh plant zones (nucleotide sequences, Neighbor-Joining, Jukes Cantor correction, complete deletion of gaps and missing data, 1000 bootstrap replicates). Boot strap values below $50 \%$ are not shown. Abbreviations: JS, Juncus roemerianus stand; SV, Salicornia virginica.

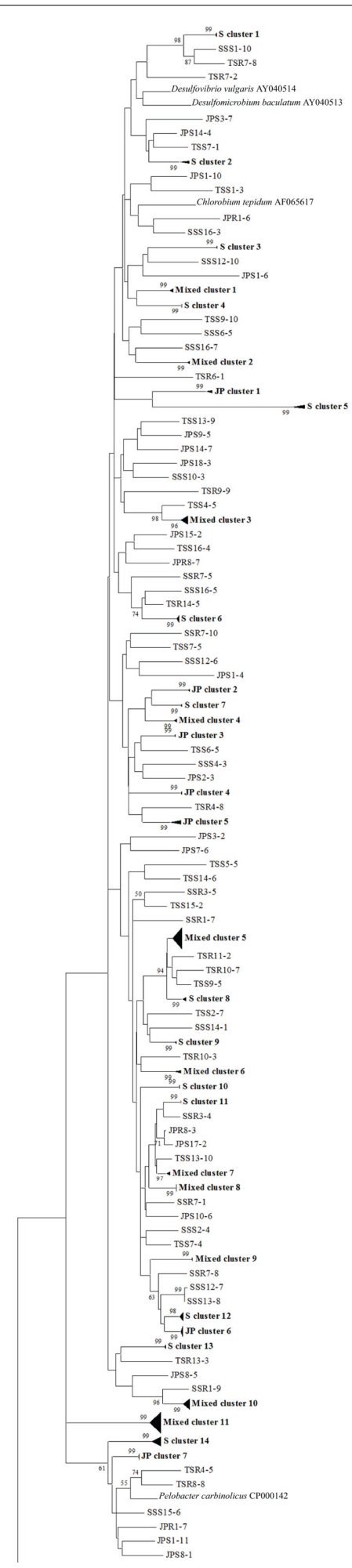

FIGURE 6 | Phylogenetic analysis of all nifH sequences from DGGE bands of rhizoplane (R) and rhizosphere (S) samples from the low marsh plant zones (nucleotide sequences, Neighbor-Joining, Jukes Cantor correction, complete deletion of gaps and missing data, 1000 bootstrap replicates). Boot strap values below $50 \%$ are not shown. Abbreviations: JP, J. roemerianus patch; SS, short form S. alterniflora; TS, tall form S. alterniflora. The phylogram is continued in Figure 7. 


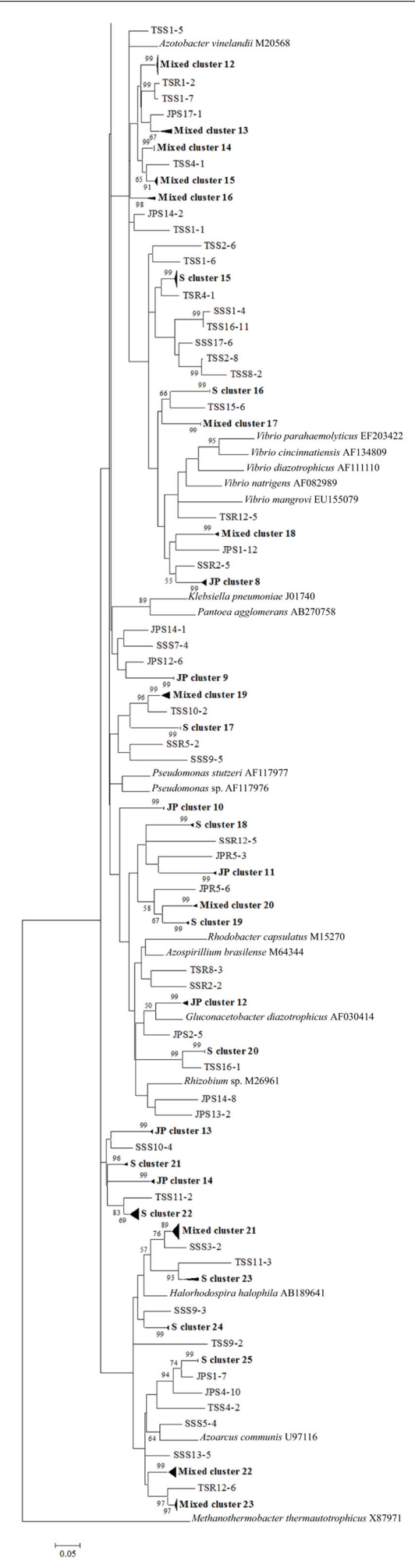

FIGURE 7 | Continuation of Figure 6 - phylogenetic analysis of all nifH sequences recovered from the low marsh plant zones (nucleotide sequences, Neighbor-Joining, Jukes Cantor correction, complete deletion of gaps and missing data, $\mathbf{1 0 0 0}$ bootstrap replicates). Abbreviations: JP, J. roemerianus patch; SS, short form S. alterniflora; TS, tall form S. alterniflora. with non-diazotrophs and are able to maintain their populations despite the energy expense of nitrogen fixation. The resilience of diazotrophs associated with salt marsh plants has also been observed during periods of extreme environmental conditions (Davis, 2010).

In stark contrast to the diversity of diazotrophs associated with the rhizospheres of salt marsh plants, nifH sequences recovered from standing dead S. alterniflora biomass from North Inlet and Sapelo Island (GA, USA) salt marshes revealed a diazotroph assemblage with markedly lower diversity (Lovell et al., 2001b). These assemblages can produce significant levels of diazotrophy (based on rates of nitrogen fixation) despite the highly mineralized and frequently dry microenvironments they occupy (Newell et al., 1985, 1992). The analysis methods (including nifH-specific PCR), which were also utilized in other studies, revealed that approximately $90 \%$ of nifH sequences from these assemblages were similar to those from $\alpha$-Proteobacteria. This demonstrates that the methods of nifH sequence recovery employed in these studies are sound, as the $\alpha$-Proteobacteria are poorly represented in most salt marsh rhizosphere diazotroph assemblages (Lovell et al., 2000, 2008; Gamble et al., 2010; Davis et al., 2011). For example, Figures 57 show the small number of nifH sequences that are similar to those from $\alpha$-Proteobacteria ${ }^{*}$-labeled clusters in Tables A1 and A4 in Appendix) in comparison to the large number of recovered sequences related to those from the $\gamma$-Proteobacteria. The majority of the $\alpha$-Proteobacteria-like salt marsh sequences have been recovered from the high marsh, particularly in the J. roemerianus plant zone. In addition, approximately half of the $\alpha$-Proteobacteria-like sequences that were recovered from the low marsh were from the patch of J. roemerianus growing in the short form S. alterniflora zone. This analysis clearly demonstrates specificity of diazotroph assemblages for specific niches.

Principal component analysis and phylogenetic analyses by Gamble et al. (2010) revealed that changes in edaphic parameters associated with plant senescence, tidal intrusion, and nutrient cycling produced different responses from the seasonally (growing season/summer vs. plant senescence/winter) responsive groups within the diazotroph assemblages (Gamble et al., 2010). A seasonally responsive $\gamma$-Proteobacteria clade was detected during the Spartina growing season while, an anaerobic clade was only detected during plant senescence. Some clades were also recovered throughout all seasons, indicating a resilient portion of the assemblage. These diazotrophs are capable of competing for resources and maintaining populations over seasonal changes in both biotic and abiotic environmental variables.

Phylogenetic analyses of the recovered sequences from differing plant zones by Davis et al. (2011) demonstrated broadly distributed (and mostly novel), frequently detected (FD) diazotroph sequences that did not respond detectably to seasonal changes (Davis et al., 2011). These sequences were not detected in studies employing the same methods to examine diazotrophic assemblages associated with standing dead Spartina (Lovell et al., 2001b) or seagrasses (Bagwell et al., 2002). This indicates that they were unlikely to derive from sample contamination. Sequences were also identified (via statistical tests in PCA) as contributing significantly to the structure of the diazotroph assemblages (LV sequences from bands producing long eigenvectors in Euclidean 
bi-plot analysis of PCA results; for full explanation see Davis et al., 2011). LV sequences drive the formation of these assemblages throughout the ecosystem. Phylogenetic analysis revealed several groups of FD and LV sequences that were virtually identical (sensu Venter et al., 2004; see also Lovell et al., 2008) to each other and to previously recovered "seasonally non-responsive" (detected throughout all seasons) sequences from Gamble et al. (2010). This work demonstrates that there are diazotrophs that have become specialized for this ecosystem. They have been recovered from multiple sites in North Inlet estuary and differ from those recovered from other ecosystems. Most importantly, these organisms have maintained ubiquity and strong influence on ecosystem function in an ecosystem characterized by distinct plant zones resulting from varying edaphic parameters. It has been determined in terrestrial ecosystems that free-living diazotrophs are functionally significant (Bürgmann et al., 2004; Hsu and Buckley, 2009). It is reasonable to assume, based on the results of these studies, that these organisms are equally important in salt marsh ecosystems. Phylogenetic analysis of sequences recovered from high marsh and low marsh zones (Figures 5-7) also confirm the presence of diazotrophs specific to marsh zones. Throughout the phylograms are clades containing virtually identical sequences recovered from host plants in the same marsh zone (plant host labeled clusters in bolded font in Figures 5-7, and sequences listed in Tables A2 and A4 in Appendix), indicating niche specificity of these diazotrophs for the edaphic parameters present in these zones.

These data have given insight into the distributions of diazotroph populations throughout the nitrogen-limited salt marsh ecosystem of North Inlet, SC, USA. These diazotrophs are specialized for the niches within this ecosystem, whether the niches are defined by the microenvironment of the plant host, or by marsh zone, or by both. They maintain populations that are readily detectable by methods employed in multiple studies (particularly nifH based PCR and DGGE fingerprinting) and influence ecosystem function as well as diazotroph assemblage structure.

\section{CONCLUDING REMARKS}

Studies of this salt marsh ecosystem have revealed that the structure of a functional microbial assemblage can be predicted, based on specific environmental parameters. Plant hosts and edaphic factors that vary in response to elevation are the key parameters that predict the biogeography of these organisms. On a continental scale, the biogeography of microbial communities in terrestrial ecosystems is predicted by abiotic parameters, particularly soil $\mathrm{pH}$, rather than by geographic distance or vegetation type (Fierer and Jackson, 2006). However, on a local scale, environmental parameters and vegetation type more heavily influence the diversity of microbial populations. These patterns have been observed in this estuarine system and can be used to predict biogeographical patterns of diazotroph assemblages associated with salt marsh grass rhizospheres. Diazotroph assemblages of salt marsh ecosystems are also capable of resisting relatively large changes in environmental parameters to maintain detectable and functionally important populations (Davis, 2010) and can be understood in the context of biogeographical concepts that have been applied to macroorganisms.

Strong evidence of plant host specificity and niche specialization in these assemblages has been compiled in this review; however the methods used to obtain the data to support these hypotheses are not perfect. Limitations of DGGE include the co-migration of DNA fragments which will result in a loss of information (Gelsomino et al., 1999; Maarit-Niemi et al., 2001; Kirk et al., 2004). Also, the detection of nifH gene sequences by PCR does not confirm the expression of this gene. Methods of quantification such as quantitative reverse transcriptase-PCR would be useful as this would identify the dominant diazotrophic phylotypes that actively fix nitrogen and could help to quantify the sizes of their populations. Continuing difficulties in the cultivation of these organisms results in a very limited understanding of their physiology, with much of that understanding inferred from known physiologies of related organisms. Finally, the evolutionary distances separating most salt marsh diazotrophs from their nearest characterized relatives limits even inference of ecologically significant characteristics of many of these organisms. A great deal remains to be done in identifying the taxa that contribute substantially to diazotrophy in salt marsh ecosystems, though a small start has been made (Brown et al., 2003). Greater knowledge of these organisms may allow us to refine our cultivation strategies and finally isolate the key organisms into pure culture for characterization. Perhaps metagenomic approaches could be employed, but the great diversity of distinct strains within even well studied lineages may limit the gains from these methods as chimeric genomic fragments may be encountered. Clearly, many challenges remain to be overcome.

Based on current climate models, coastal salt marshes are in danger of being completely submerged by the end of the century (Nicholls et al., 2007; Craft et al., 2009). This is due to the accelerating rate of sea level rise. Currently, it is expected that the ecogeomorphic feedbacks of these dynamic coastal ecosystems [i.e., rapid vegetation growth during years of low and high sea level (Morris et al., 2002); sediment trapping, organic matter accretion and limiting erosion (Fagherazzi et al., 2004)] that have allowed the survival of intertidal wetlands over time will continue to do so. However, the ever increasing number of completely submerged wetlands indicates that the current rate of sea level rise may exceed the abilities of ecogeomorphic feedbacks to preserve tidal ecosystems, particularly salt marshes (Kirwan et al., 2010). Continuous submersion of coastal salt marshes will result in losses of vegetation (Penland et al., 2001; Hartig et al., 2002; Kearnery et al., 2002; Kirwan et al., 2010) and consequently loss of microorganisms restricted to a particular plant host or microenvironment (Berg and Smalla, 2009). Loss of microorganisms critical to ecosystem function would clearly be detrimental to the ecosystem that is dependent on their activity and interactions with macrophytes (primary producers). These events will eventually interrupt food webs and littoral biogeochemical cycles affecting the quality of estuarine water due to eutrophication and increasing the export of particulates (Kearnery et al., 2002).

The ability to predict biogeographical distributions of microorganisms as critical to ecosystem function as diazotrophs are to salt marshes will be advantageous to ecosystem modelers, especially those involved in determining the effects of global climate change. These data clearly show that the distribution of diazotrophs is non-random and is driven directly or indirectly by edaphic parameters in their habitat. The assemblages contain 
microorganisms that appear to be restricted in their distributions, as well as broadly distributed microorganisms. Each group is clearly engaged in ecosystem function as evidenced by their resilience and stability within the assemblages. However, even with this apparent ability to prosper over wide ranges of environmental parameters, there are limits to their survival. The flooding of coastal wetlands as sea level continues to rise could result in large losses from these assemblages. The biogeographical patterns observed in North Inlet estuary can be applied to tidally dominated coastal wetlands when the edaphic parameters of the system in question are taken into consideration.

\section{REFERENCES}

Adam, P. (1990). Saltmarsh Ecology. Cambridge: Cambridge University Press.

Affourtit, J., Zehr, J. P., and Pearl, H. W. (2001). Distribution of nitrogenfixing microorganisms along the Neuse River Estuary, North Carolina. Microb. Ecol. 41, 114-123.

Bagwell, C. E., Dantzler, M., Bergholz, P. W., and Lovell, C. R. (2001). Host-specific ecotype diversity of rhizoplane diazotrophs of the perennial glasswort Salicornia virginica and selected salt marsh grasses. Aquat. Microb. Ecol. 23, 293-300.

Bagwell, C. E., LaRocque, J. R., Smith, G. W., Polson, S. W., Friez, M. J., Longshore, J. W., and Lovell, C. R. (2002). Molecular diversity of diazotrophs in oligotrophic tropical seagrass bed communities. FEMS Microbiol. Ecol. 39, 113-119.

Bagwell, C. E., and Lovell, C. R. (2000a). Microdiversity of culturable diazotrophs from the rhizoplanes of the salt marsh grasses Spartina alterniflora and Juncus roemerianus. Microb. Ecol. 39, 128-136.

Bagwell, C. E., and Lovell, C. R. (2000b). Persistence of selected Spartina alterniflora rhizoplane diazotrophs exposed to natural and manipulated environmental variability. Appl. Environ. Microbiol. 66, 4625-4633.

Bagwell, C. E., Piceno, Y. M., AshburneLucas, A., and Lovell, C. R. (1998). Physiological diversity of the rhizosphere diazotroph assemblages of selected salt marsh grasses. Appl. Environ. Microbiol. 64, 4276-4282.

Berg, G., and Smalla, K. (2009). Plant species and soil type cooperatively shape the structure and function of microbial communities in the rhizosphere. FEMS Microbiol. Ecol. 68, 1-13.

Bergholz, P. W., Bagwell, C. W., and Lovell, C. R. (2001). Physiological diversity of rhizoplane diazotrophs of the saltmeadow cordgrass, Spartina patens: implications for host specific ecotypes. Microb. Ecol. $42,466-476$
Bertness, M. D. (1991). Zonation of Spartina patens and Spartina alterniflora in New England salt marsh. Ecology 72, 138-148.

Bertness, M. D., and Ellison, A. M. (1987). Determinants of pattern in a New England salt marsh plant community. Ecol. Monogr. 57, 129-147.

Blood, E. R., and Vernberg, F. J. (1992). "Characterization of the physical, chemical, and biological conditions and trends in Winyah Bay and North Inlet estuaries: 1970-1985," in Characterization of the Physical, Chemical, and Biological Conditions and Trends in Three South Carolina Estuaries. Winyah Bay and North Inlet Estuaries Vol II. Charleston, SC: Sea Grant Consortium, 162.

Brown, M. M., Friez, M. J., and Lovell, C. R. (2003). Expression of nifH genes by diazotrophic bacteria in the rhizosphere of short form Spartina alterniflora. FEMS Microbiol. Ecol. $43,411-417$.

Bürgmann, H., Widmer, F., Von Sigler, W., and Zeyer, J. (2004). New molecular screening tools for analysis of free-living diazotrophs in soil. Appl. Environ. Microbiol. 70, 240-247.

Burke, D. J., Hamerlynck, E. P., and Hahn, D. (2002). Interactions among plant species and microorganisms in salt marsh sediments. Appl. Environ. Microbiol. 68, 1157-1164.

Burke, D. J., Hamerlynck, E. P., and Hahn, D. (2003). Interactions between the salt marsh grass Spartina patens, arbuscular mycorrhizal fungi and sediment bacteria during the growing season. Soil Biol. Biochem. 35, 501-511.

Burns, J. A., Zehr, J. P., and Capone, D. G. (2002). Nitrogen-fixing phylotypes of Chesapeake Bay and Neuse River Estuary sediments. Microb. Ecol. 44, 336-343.

Capone, D. G., and Carpenter, E. J. (1982). Nitrogen fixation in the environment. Science 217, $1140-1142$.

Craft, C., Clough, J., Ehman, J., Joye, S., Park, R., Pennings, S., Guo, H., and Machmuller, M. (2009). Forecasting

\section{ACKNOWLEDGMENTS}

We acknowledge the Belle W. Baruch Institute for Coastal and Marine Sciences for access to sampling sites and for logistical support. Six hundred twenty-seven sequences recovered from DGGE bands (Figures 5-7; Tables A1-A4 in Appendix) were deposited with the National Center for Biotechnology Information (NCBI) GenBank (accession numbers HM750282 - HM750907). We thank Paul Bodelier for his invitation to contribute to this special topics volume on the Microbiology of Wetlands. This is contribution 1645 of the Belle W. Baruch Institute for Coastal and Marine Sciences.

the effects of accelerated sea-level rise on tidal marsh ecosystem services. Front. Ecol. Environ. 7, 73-78.

Cramer, M. J., Haghshenas, N., Bagwell, C. E., Matsui, G. Y., and Lovell, C. R. (2011). Celerinatantimonas diazotrophica gen. nov., sp nov., a nitrogen-fixing bacterium representing a new family in the Gammaproteobacteria, Celerinatantimonadaceae fam. nov. Int. J. Syst. Evol. Microbiol. 61, 1053-1060.

Crump, B. C., Hopkinson, C. S., Sogin, M. L., and Hobbie, J. E. (2004). Microbial biogeography along an estuarine salinity gradient: combined influences of bacterial growth and residence time. Appl. Environ. Microbiol. 70, 1494-1505.

Dai, T., and Wiegert, R. G. (1997). A field study of photosynthetic capacity and its response to nitrogen fertilization in Spartina alterniflora. Estuar. Coast. Shelf Sci. 45, 273-283.

Dame, R., Chrzanowski, T., Bildstein, K., Kjerfve, B., Mckellar, H., Nelson, D., Spurrier, J., Stancyk, S., Stevenson, H., Vernberg, J., and Zingmark, R. (1986). The outwelling hypothesis and North Inlet, South Carolina. Mar. Ecol. Prog. Ser. 33, 217-229.

Dame, R. F., and Kenny, P. D. (1986). Variability of Spartina alterniflora primary production in the euhaline North Inlet estuary. Mar. Ecol. Prog. Ser. 32, 71-80.

Davis, D. A. (2010). Diazotroph Assemblages of Salt Marsh Plants Growing Along an Environmental Gradient: Assemblage Composition and Responses to Environmental Conditions. Ph.D. thesis, University of South Carolina, Columbia, SC.

Davis, D. A., Gamble, M. D., Bagwell, C. E., Bergholz, P. W., and Lovell, C. R. (2011). Responses of salt marsh plant rhizosphere diazotroph assemblages to changes in marsh elevation, edaphic conditions and plant host species. Microb. Ecol. 61, 386-398.

Dolan, J. R. (2005). An introduction to the biogeography of aquatic microbes. Aquat. Microb. Ecol. 41, 39-48.
Dumbrell, A. J., Nelson, M., Helgason, T., Dytham, C., and Fitter, A. H. (2010). Relative roles of niche and neutral processes in structuring a soil microbial community. ISME $J$. 4, 337-345.

Fagherazzi, S., Marani, M., and Blum, L. K. (ed.). (2004). The Ecogeomorphology of Tidal Marshes. Washington, DC: AGU.

Fierer, N., and Jackson, R. B. (2006). The diversity and biogeography of soil bacterial communities. Proc. Natl. Acad. Sci. U.S.A. 103, 626-631.

Floyd, M. M., Tang, J., Kane, M., and Emerson, D. (2005). Captured diversity in a culture collection: case study of the geographic and habitat distributions of environmental isolates held at the American type culture collection. Appl. Environ. Microbiol. 71, 2813-2823.

Gamble, M. D., Bagwell, C. E., LaRocque, J., Bergholz, P. W., and Lovell, C. R. (2010). Seasonal variability of diazotroph assemblages associated with the rhizosphere of the salt marsh cordgrass, Spartina alterniflora. Microb. Ecol. 59, 253-265.

Gardner, L. (1973). The effect of hydrologic factors on the pore water chemistry of intertidal marsh sediments. SouthEastern Geol. 15, 17-28.

Gelsomino, A., Keijzer-Wolters, A. C., Cacco, G., and Van Elsas, J. D. (1999). Assessment of bacterial community structure in soil by polymerase chain reaction and denaturing gradient gel electrophoresis. J. Microbiol. Methods 38, 1-15.

Green, J. L., Bohannon, B. J. M., and Whitaker, R. J. (2008). Microbial biogeography: from taxonomy to traits. Science 320, 1039-1043.

Hartig, E. K., Gornitz, V., Kolker, A., Mushacke, F., and Fallon, D. (2002). Anthropogenic and climate-change impacts on salt marshes of Jamaica Bay, New York City. Wetlands 22, 71-89.

Hemond, H. F., and Fifield, J. L. (1982). Subsurface flow in a salt marsh peat: a model and field study. Limnol. Oceanogr. 27, 126-136. 
Hollibaugh, J., Wong, P. S., and Murrell, M. C. (2000). Similarity of particleassociated and free-living bacterial communities in northern San Francisco Bay, California. Aquat. Microb. Ecol. 21, 103-114.

Hopkinson, C. S. (1988). "Patterns of organic carbon exchange between coastal ecosystems: the mass balance approach in salt marsh ecosystems," in Coastal-Offshore Ecosystem Interactions (Lecture Notes on Coastal and Estuarine Studies), ed. B.-O. Jansson (New York: Springer-Verlag), 122-154.

Hopkinson, C. S., and Schubauer, J. P. (1984). Static and dynamic aspects of nitrogen cycling in the salt marsh graminoid Spartina alterniflora. Ecology 65, 961-969.

Howarth, R. W., Marino, R., and Lane, J. (1988). Nitrogen fixation in freshwater, estuarine, and marine ecosystems. 1. Rates and importance. Limnol. Oceanogr. 33, 669-687.

Hsu, S. F., and Buckley, D. H. (2009). Evidence for the functional significance of diazotroph community structure in soil. ISME J. 3, 124-136.

Hughes Martiny, J. B., Bohannan, B. J. M., Brown, J. H., Colwell, R. K., Fuhrman, J. A., Green, J. L., HornerDevine, M. C., Kane, M., AdamsKrumins, J., Kuske, C. R., Morin, P. J., Naeem, S., Øvreås, L., Reysenbach, A.-L., Smith, V. L., and Staley, J. T. (2006). Microbial biogeography: putting microorganisms on the map. Nat. Rev. Microbiol. 4, 102-112.

Kearnery, M. S., Rogers, A. S., Townshend, J. R. G., Rizzo, E., and Stutzer, D. (2002). Landsat imagery shows decline of coastal marshes in Chesapeake and Delaware Bays. Eos (Washington DC) 83, 173-178.

Keefe, C. W. (1972). Marsh production: a summary of the literature. Contrib. Mar. Sci. 16, 163-181.

King, G. M., Klug, M. J., Wiegert, R. G., and Chalmers, A. G. (1982). Relation of soil water movement and sulfide concentration to Spartina alterniflora production in a Georgia salt marsh. Science 218, 61-63.

King, S. E., and Lester, J. N. (1995). The value of salt-marsh as a sea defense. Mar. Pollut. Bull. 30, 180-189.

Kirk, J. L., Beaudete, L. A., Hart, M., Moutoglis, P., Klironomos, J. N., Lee, H., and Trevors, J. T. (2004). Methods of studying soil microbial diversity. J. Microbiol. Methods 58, 169-188.

Kirwan, M. L., Guntenspergen, G. R., D’Alpaos, A., Morris, J. T., Mudd, S. M., and Temmerman, S. (2010).
Limits on the adaptability of coastal marshes to rising sea level. Geophys. Res. Lett. 37, L23401.

Kirwan, M. L., Guntenspergen, G. R., and Morris, J. T. (2009). Latitudinal trends in Spartina alterniflora productivity and the response of coastal marshes to global change. Glob. Chang. Biol. 15, 1982-1989.

Kjerfve, B. (1986). "Circulation and salt flux in a well mixed estuary," in Physics of Shallow Estuaries and Bays, ed. J. van De Kreeke (New York: Springer-Verlag), 22-29.

LaRocque, J. R., Bergholz, P. W., Bagwell, C. E., and Lovell, C. R. (2004). Influence of host plant-derived and abiotic environmental parameters on the composition of the diazotroph assemblage associated with roots of Juncus roemerianus. Antonie Van Leeuwenhoek 86, 249-261.

Leibold, M. A., and McPeek, M. A. (2008). Coexistence of niche and neutral prespectives in community ecology. Ecology 87, 1399-1410.

Levine, J. M., Brewer, J. S., and Bertness, M. D. (1998). Nutrients, competition and plant zonation in a New England salt marsh. J. Ecol. 86, 285-292.

Long, S. P., and Long, C. F. (1983). Saltmarsh Ecology. Glasgow: Blackie.

Lovell, C. R., Bagwell, C. E., Czako, M., Marton, L., Piceno, Y. M., and Ringelberg, D. B. (2001a). Stability of a rhizosphere microbial community exposed to natural and manipulated environmental variability. FEMS Microbiol. Ecol. 38, 69-76.

Lovell, C. R., Friez, M. J., Longshore, J. W., and Bagwell, C. E. (2001b). Recovery and phylogenetic analysis of nifH sequences from diazotrophic bacteria associated with dead aboveground biomass of Spartina alterniflora. Appl. Environ. Microbiol. 67, 5308-5314.

Lovell, C. R., Decker, P. V., Bagwell, C. E., Thompson, S., and Matsui, G. Y. (2008). Analysis of a diverse assemblage of diazotrophic bacteria from Spartina alterniflora using DGGE and clone library screening. J. Microbiol. Methods 73, 160-171.

Lovell, C. R., Piceno, Y. M., Quattro, J. M., and Bagwell, C. E. (2000). Molecular analysis of diazotroph diversity in the rhizosphere of the smooth cordgrass, Spartina alterniflora. Appl. Environ. Microbiol. 66, 3814-3822.

Maarit-Niemi, R., Heiskanen, I., Wallenius, K., and Lindstrom, K. (2001). Extraction and purification of DNA in rhizosphere soil samples for PCR-DGGE analysis of bacterial consortia. J. Microbiol. Methods 45, 155-165.

Macalady, J. L., Dattagupta, S., Schaperdoth, I., Jones, D. S., Druschel, G. K. and Eastman, D. (2008). Niche differentiation among sulfur-oxidizing bacterial populations in cave waters. ISME J. 2, 590-601.

Marinucci, A. C., Hobbie, J. E., and Helfrich, J. V. K. (1983). Effect of litter nitrogen on decomposition and microbial biomass in Spartina alterniflora. Microb. Ecol. 9, 27-40.

McClung, C. R., Van Berkum, P., Davis, R. E., and Sloger, C. (1983). Enumeration and localization of $\mathrm{N}_{2}$ fixing bacteria associated with roots of Spartina alterniflora Loisel. Appl. Environ. Microbiol. 45, 1914-1920.

Mendelssohn, I. A. (1979). Nitrogen metabolism in the height forms of Spartina alterniflora in North Carolina. Ecology 60, 574-584.

Moisander, P. H., Morrison, A. E., Ward, B. B., Jenkins, B. D., and Zehr, J. P. (2007). Spatial-temporal variability in diazotroph assemblages in Chesapeake Bay using an oligonucleotide nifH microarray. Environ. Microbiol. 9, 1823-1835.

Moisander, P. H., Piehler, M. F., and Paerl, H. W. (2005). Diversity and activity of epiphytic nitrogen-fixers on standing dead stems of the salt marsh grass Spartina alterniflora. Aquat. Microb. Ecol. 39, 271-279.

Morris, J. T. (1991). Effects of nitrogen loading on wetland ecosystems in particular reference to atmospheric deposition. Annu. Rev. Ecol. Syst. 22 257-279.

Morris, J. T. (1995). The mass balance of salt and water in intertidal sediments: results from North Inlet, South Carolina. Estuaries 18, 556-567.

Morris, J. T., and Dacey, J. W. H. (1984). Effects of $\mathrm{O}_{2}$ on ammonium uptake and root respiration by Spartina alterniflora. Am. J. Bot. 71, 979-985.

Morris, J. T., and Haskin, B. (1990). A 5 -yr record of aerial primary production and stand characteristics of Spartina alterniflora. Ecology 71 , 2209-2217.

Morris, J. T., Kjerfve, B., and Dean, J. M. (1990). Dependence of estuarine productivity on anomalies in mean sea level. Limnol. Oceanogr. 35 926-930.

Morris, J. T., Sundareshwar, P. V., Nietch, C. T., Kjerfve, B., and Cahoon, D. R. (2002). Responses of coastal wetlands to rising sea level. Ecology 83, 2869-2877.

Moseman-Valtierra, S. M., ArmaizNolla, K., and Levin, L. A. (2010). Wetland response to sedimentation and nitrogen loading: diversification and inhibition of nitrogenfixing microbes. Ecol. Appl. 20, 1556-1568.

Moseman-Valtierra, S. M., Johnson, R., Zhang, R., and Qian, P. Y. (2009). Differences in cordgrass structure between a mature and developing marsh reflect distinct $\mathrm{N}_{2}$-fixing communities. Wetlands 29,919-930.

Newell, S. Y., Fallon, R. D., Cal Rodriguez, R. M., and Groene, L. C. (1985). Influence of rain, tidal wetting and relative humidity on release of carbon dioxide by standingdead salt-marsh plants. Oecologia 68, 73-79.

Newell, S. Y., Hopkinson, C. S., and Scott, L. A. (1992). Patterns of nitrogenase activity (acetylene reduction) associated with standing, decaying shoots of Spartina alterniflora. Estuar. Coast Shelf Sci. 35, 127-140.

Nicholls, R. J., Wong, P. P., Burkett, V. R., Codignotto, J. O., Hay, J. E., Mclean, R. F., Ragoonaden, S., and Woodroffe, C. D. (2007). "Coastal systems and low-lying areas," in Climate Change 2007: Impacts, Adaptation and Vulnerability. Contribution of Working Group II to the Fourth Assessment Report of the Intergovernmental Panel on Climate Change, eds M. L. Parry, O. F. Canziani, J. P. Palutikof, P. J. Van Der Linden, and C. E. Hanson (Cambridge: Cambridge University Press), 315-356.

Odum, W. E. (1988). Comparative ecology of tidal freshwater and salt marshes. Annu. Rev. Ecol. Syst. 19, $147-176$.

Olson, J. B., Steppe, T. F., Litaker, R. W., and Paerl, H. W. (1998). $\mathrm{N}_{2}$-fixing microbial consortia associated with the ice cover of Lake Bonney, Antarctica. Microb. Ecol. 36, 231-238.

Øvreås, L. (2000). Population and community level approaches for analysing microbial diversity in natural environments. Ecol. Lett. 3, 236-251.

Patriquin, D. G. (1978). Factors affecting nitrogenase activity (acetylenereducing activity) associated with excised roots of the emergent halophyte Spartina alterniflora Loisel. Aquat. Bot. 4, 193-210.

Penland, S., Wayne, L., Britsch, L. D. Williams, S. J., Beall, A. D., and Butterworth, V. C. (2001). Geomorphic Classification of Coastal Land Loss Between 1932 and 1990 in the Mississippi River Delta Plain, Southeastern Louisiana. USGS Open-file Report 00-417, Woods Hole, MA.

Pennings, S. C., and Callaway, R. M. (1992). Salt marsh zonation: the relative importance of competition 
and physical factors. Ecology 73, 681-690.

Piceno, Y. M., and Lovell, C. R. (2000a). Stability in natural bacterial communities: I. Nutrient addition effects on rhizosphere diazotroph assemblage composition. Microb. Ecol. 39, 32-40.

Piceno, Y. M., and Lovell, C. R. (2000b). Stability in natural bacterial communities: II. Plant resource allocation effects on rhizosphere diazotroph assemblage composition. Microb. Ecol. 39, 41-48.

Piceno, Y. M., Noble, P. A., and Lovell, C. R. (1999). Spatial and temporal assessment of diazotroph assemblage composition in vegetated salt marsh sediments using denaturing gradient gel electrophoresis. Microb. Ecol. 38, 157-167.

Postgate, J. (1998). Nitrogen Fixation. Cambridge: University Press.

Schloss, P. D., Westcott, S. L., Ryabin, T., Hall, J. R., Hartmann, M., Hollister, E. B., Lesniewski, R. A., Oakley, B. B., Parks, D. H., Robinson, C. J., Sahl, J. W., Stres, B., Thallinger, G. G., Van Horn, D. J., and Weber, C. F. (2009). Introducing mothur: Open-source, platform-independent, communitysupported software for describing and comparing microbial communities. Appl. Environ. Microbiol. 75, 7537-7541.

Schubauer, J. P., and Hopkinson, C. S. (1984). Above- and belowground emergent macrophyte production and turnover in a coastal marsh ecosystem, Georgia. Limnol. Oceanogr. 29, 1052-1065.
Selje, N., and Simon, M. (2003). Composition and dynamics of particleassociated and free-living communities in the Weser estuary, Germany. Aquat. Microb. Ecol. 30, 221-237.

Sundareshwar, P. V., Morris, J. T., Koepfler, E. K., and Fornwalt, B. (2003). Phosphorus limitation of coastal ecosystem processes. Science 299, 563-565.

Turner, R. E. (1976). Geographic variations in salt marsh macrophyte production: a review. Contrib. Mar. Sci. 20, 47-68.

Ueda, T., Suga, Y., Yahiro, N., and Matsuguchi, T. (1995). Genetic diversity of N2- fixing bacteria associated with rice roots by molecular analysis of a nifD library. Can. J. Microbiol. $41,235-240$.

Valiela, I., and Teal, J. M. (1974). "Nutrient limitation in salt marsh vegetation," in Ecology of Halophytes, eds R. J. Reimold and W. H. Queen (New York: Academic Press, Inc.), 547-563.

van Wijnen, H. J., and Bakker, J. P. (1999). Nitrogen and phosphorous limitation in a coastal barrier salt marsh: the implications for vegetation succession. J. Ecol. 87, 265-272.

Venter, J. C., Remington, K., Heidelberg, J. F., Halpern, A. L., Rusch, D., Eisen, J. A., Wu, D., Paulsen, I., Nelson, K. E., Nelson, W., Fouts, D. E., Levy, S., Knap, A. H., Lomas, M. W., Nealson, K., White, O., Peterson, J., Hoffman, J., Parsons, R., Baden-Tillson, H., Pfannkoch, C., Rogers, Y.-H., and Smith, H. O. (2004). Environmental genome shotgun sequencing of the Sargasso Sea. Science 304, 66-74.

Ward, D. M., Weller, R., and Bateson, M. M. (1990). 16S ribosomalRNA sequences reveal numerous uncultured microorganisms in a natural community. Nature 345 , 63-65.

Welsh, A., Burke, D. J., and Hahn, D. (2007). Analysis of nitrogenfixing members of the $\varepsilon$-subclass of Proteobacteria in salt marsh sediments. Appl. Environ. Microbiol. 73 , 7747-7752.

Welsh, A. K., Burke, D. J., Hamerlynck, E. P., and Hahn, D. (2010). Seasonal analyses of arbuscular mycorrhizae, nitrogen-fixing bacteria and growth performance of the salt marsh grass Spartina patens. Plant Soil 330, 251-266.

Whiting, G. J., Gandy, E. L., and Yoch, D. C. (1986). Tight coupling of root-associated nitrogen fixation and plant photosynthesis in the salt marsh grass Spartina alterniflora and carbon dioxide enhancement of nitrogenase activity. Appl. Environ. Microbiol. 52, 108-113.

Widmer, F., Shaffer, B. T., Porteous, L. A., and Seidler, R. J. (1999). Analysis of nifH gene pool complexity in soil and litter at a Douglas fir forest site int eh Oregon Cascade mountain range. Appl. Environ. Microbiol. 65, 374-380.

Yoch, D. C., and Whiting, G. Y. (1986) Evidence for $\mathrm{NH}_{4}^{+}$switch-off regulation of nitrogenase activity by bacteria in salt marsh sediments and roots of the grass Spartina alterniflora. Appl. Environ. Microbiol. 51, 143-149.

Zehr, J. P., Jenkins, B. D., Short, S. M., and Steward, G. F. (2003). Nitrogenase gene diversity and microbial community structure: a crosssystem diversity. Environ. Microbiol. 5, 539-554

Zehr, J. P., and McReynolds, L. A. (1989). Use of degenerate oligonucleotides for amplification of the nifH gene from the marine cyanobacterium Trichodesmium thiebautii. Appl. Environ. Microbiol. 55, 2522-2526.

Conflict of Interest Statement: The authors declare that the research was conducted in the absence of any commercial or financial relationships that could be construed as a potential conflict of interest.

Received: 23 November 2011; accepted: 19 February 2012; published online: 16 March 2012.

Citation: Lovell CR and Davis DA (2012) Specificity of salt marsh diazotrophs for vegetation zones and plant hosts: results from a North American marsh. Front. Microbio. 3:84. doi: 10.3389/fmicb.2012.00084

This article was submitted to Frontiers in Terrestrial Microbiology, a specialty of Frontiers in Microbiology.

Copyright $\odot 2012$ Lovell and Davis. This is an open-access article distributed under the terms of the Creative Commons Attribution Non Commercial License, which permits non-commercial use, distribution, and reproduction in other forums, provided the original authors and source are credited. 


\section{APPENDIX}

Table A1 | Sequences included in the mixed clusters designated in Figure 5 ( ${ }^{*} \alpha$-Proteobacteria clusters).

\section{Grouping}

Sequences

Mixed cluster 1

Mixed cluster 2

Mixed cluster 3

Mixed cluster 4

Mixed cluster 5

Mixed cluster 6

Mixed cluster 7

Mixed cluster 8

Mixed cluster 9

JSS13-4, JSS13-8, JSS13-22, SVS10-9

JSS13-2, SVS13-4

JSS9-5, SVS7-2

JSS1-10, SVS2-5

JSS3-6, SVS3-8

JSS6-2, JSS6-4, SVS4-12

JSS4-2, JSS4-3, JSS4-4, SVS2-8, SVS4-3, SVS4-9, SVS5-1, SVS6-6, SVS8-8, SVS8-10, SVS9-6

JSS8-4, SVR14-3, SVR15-4, SVR15-6, SVR15-8

JSS7-2, SVS7-1

Mixed cluster 10

Mixed cluster 11

Mixed cluster 12

Mixed cluster $13^{*}$

Mixed cluster 14

Mixed cluster 15

Mixed cluster 16

Mixed cluster 17

Mixed cluster 18

Mixed cluster 19

Mixed cluster 20

Mixed cluster 21

JSS4-1, JSS5-2, JSS7-4, JSS7-10, JSS8-5, JSS8-9, SVS3-9, SVS3-10, SVS4-10, SVS4-11, SVS6-8, SVS6-9, SVS6-10, SVS7-6, SVS8-7

JSR3-1, JSS4-11, JSS4-102, JSS11-7, SVR1-7, SVR2-4, SVR5-4

JSS15-4, JSS16-1, SVR10-1, SVR10-3

JSS4-9, JSS8-1, JSS8-11, JSS8-102, JSS8-22, SVS3-12

JSS10-22, JSS10-32, JSS10-52, JSS11-2, JSS12-12, JSS12-3, JSS12-42, JSS12-52, SVR12-2

JSS6-9, JSS13-3, SVS9-1, SVS12-6, SVS13-2, SVS15-8, SVS16-6, SVS16-13, SVS17-4, SVS17-5

JSR2-1, JSR7-4, JSR7-5, JSR8-2, JSS2-1, SVS11-6, SVS14-1

JSS4-8, SVR7-3

JSS12-22, SVS10-1, SVS15-11

JSS1-1, JSS1-3, JSS1-7, JSS1-9, JSS1-12, JSS1-102, SVR1-3

JSS3-4, SVR2-5

JSR2-2, JSR5-4, JSR7-2, JSR8-1, JSR8-5, JSR9-1, JSR9-2, JSR9-4, JSR9-5, JSS2-2, JSS13-7, SVR9-8, SVR12-4, SVR12-8, SVR13-2, SVR13-8, SVR14-1, SVR14-7, SVS11-2, SVS11-3, SVS11-5, SVS11-13

Mixed cluster 22 
Table A2 | Sequences included in the plant host clusters designated in Figure 5.

\begin{tabular}{ll}
\hline Grouping & Sequences \\
\hline JS cluster 1 & JSS3-2, JSS3-5 \\
JS cluster 2 & JSR7-1, JSR7-3, JSS13-6 \\
JS cluster 3 & JSR6-1, JSR8-3 \\
JS cluster 4 & JSR6-3, JSR9-3 \\
JS cluster 5 & JSR2-5, JSS2-5 \\
JS cluster 6 & JSS14-1, JSS14-2 \\
SV cluster 1 & SVR13-7, SVR14-8 \\
SV cluster 2 & SVS10-3, SVS12-4 \\
SV cluster 3 & SVS4-1, SVS5-8 \\
SV cluster 4 & SVR9-2, SVS10-11 \\
SV cluster 5 & SVS6-3, SVS6-4, SVS8-9 \\
SV cluster 6 & SVS15-6, SVS16-82 \\
SV cluster 7 & SVR14-4, SVR14-5, SVR15-7 \\
SV cluster 8 & SVS13-3, SVS14-2, SVS14-3, SVS14-4, SVS14-92, SVS17-11 \\
SV cluster 9 & SVR5-2, SVR11-5 \\
SV cluster 10 & SVS5-6, SVS6-7 \\
SV cluster 11 & SVR7-4, SVR7-5, SVR7-6 \\
SV cluster 12 & SVR9-5, SVS15-7 \\
SV cluster 13 & SVS1-4, SVS1-6, SVS1-8 \\
\hline
\end{tabular}

Table A3 | Sequences included in the mixed clusters designated in Figures 6 and 7.

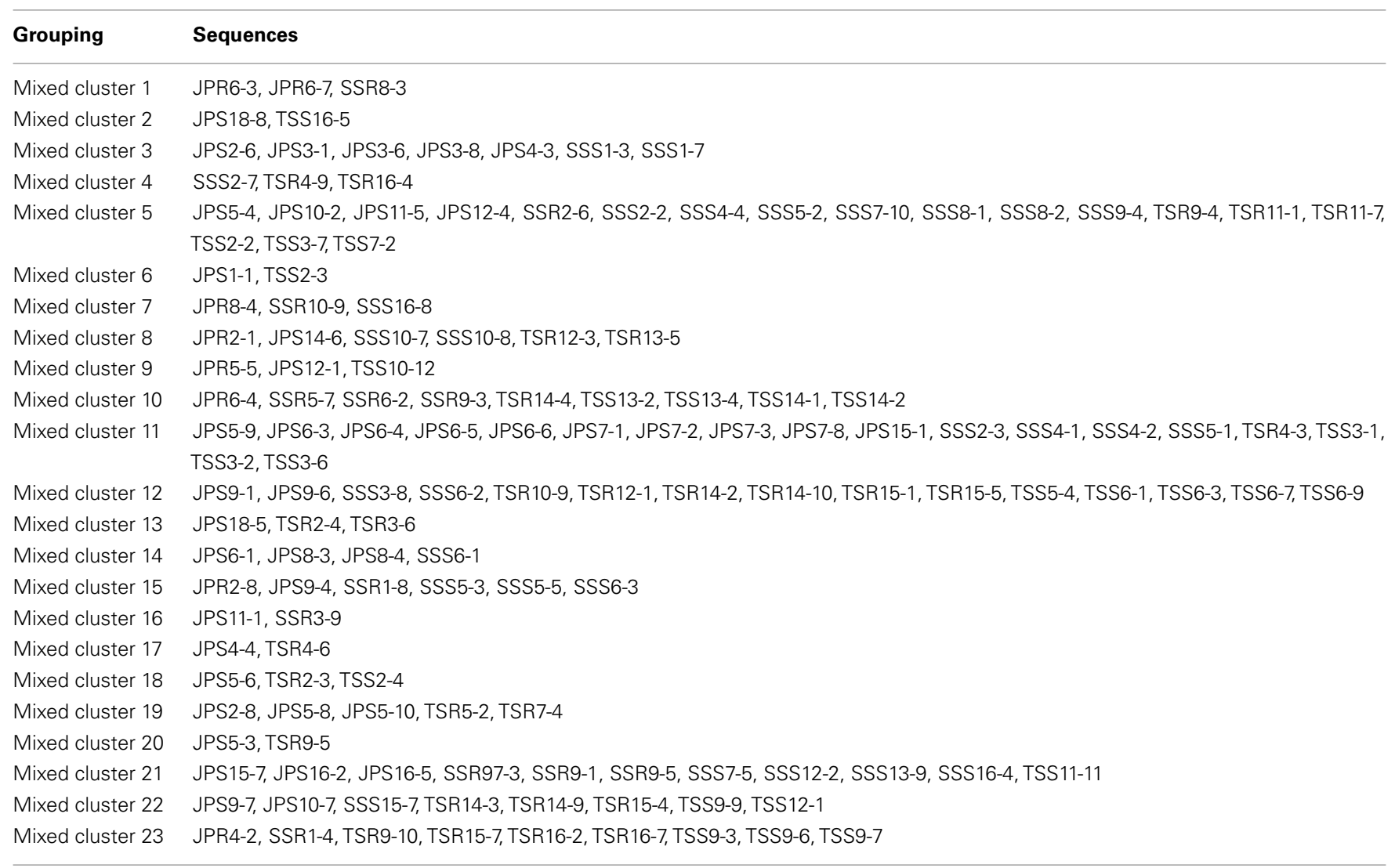


Table A4 | Sequences included in the plant host clusters designated in Figures 6 and 7 (* $\alpha$-Proteobacteria clusters).

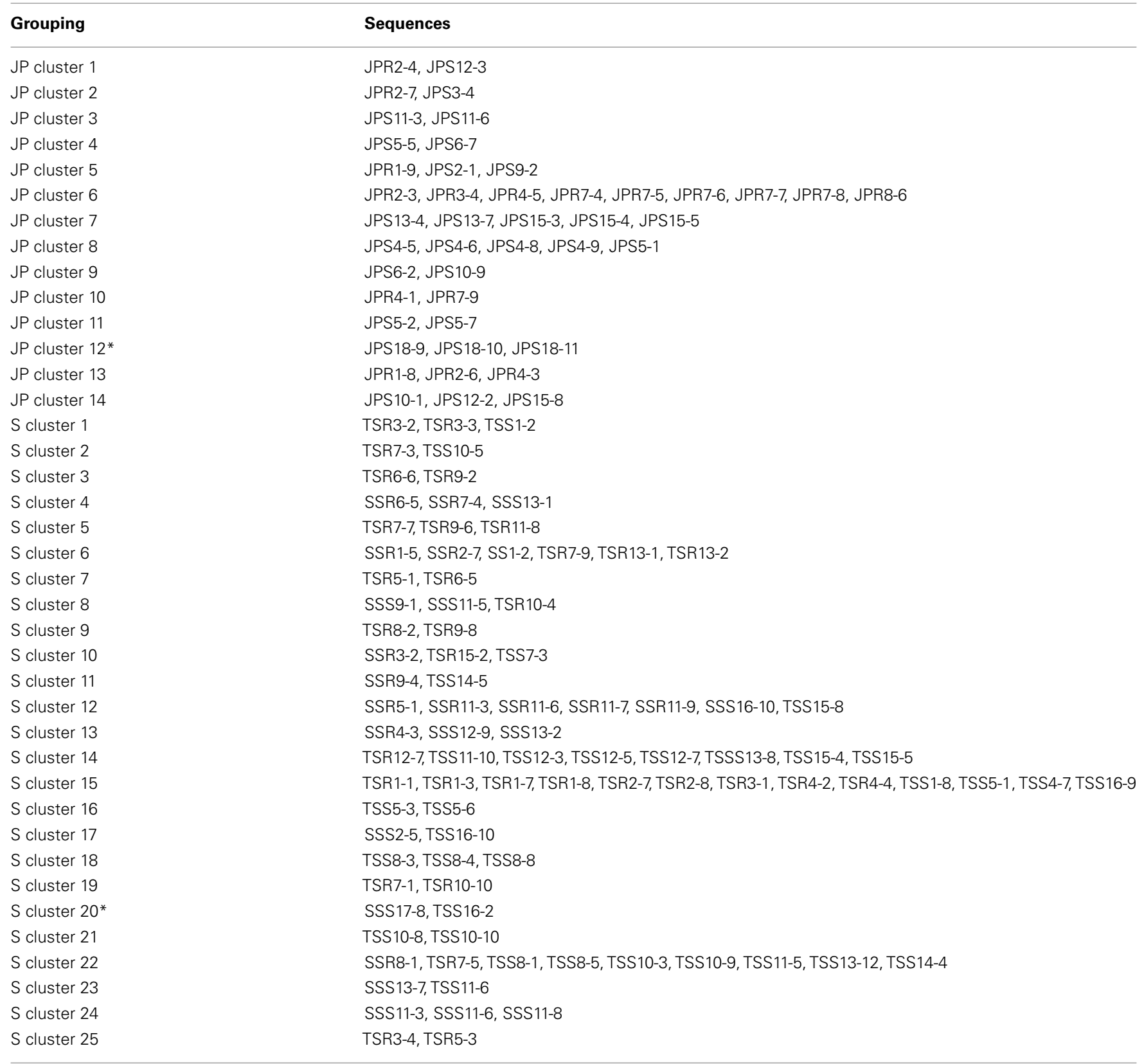




\title{
Sulfate-reducing microorganisms in wetlands - fameless actors in carbon cycling and climate change
}

\author{
Michael Pester ${ }^{1}$, Klaus-Holger Knorr ${ }^{2}$, Michael W. Friedrich ${ }^{3}$, Michael Wagner $^{1}$ and Alexander Loy ${ }^{1}{ }^{*}$ \\ 1 Department of Microbial Ecology, Vienna Ecology Center, Faculty of Life Sciences, University of Vienna, Wien, Austria \\ ${ }^{2}$ Department of Hydrology, University of Bayreuth, Bayreuth, Germany \\ ${ }^{3}$ Department of Microbial Ecophysiology, University of Bremen, Bremen, Germany
}

Edited by:

Paul Bodelier, Netherlands Institute of

Ecology, Netherlands

\section{Reviewed by:}

Timothy Ferdelman, Max Planck Institute for Marine Microbiology, Germany

Nathan Basiliko, University of Toronto, Canada

\section{${ }^{*}$ Correspondence:}

Alexander Loy, Department for Microbial Ecology, University of Vienna, Althanstrasse 14, A-1090 Vienna, Austria.

e-mail: loy@microbial-ecology.net
Freshwater wetlands are a major source of the greenhouse gas methane but at the same time can function as carbon sink. Their response to global warming and environmental pollution is one of the largest unknowns in the upcoming decades to centuries. In this review, we highlight the role of sulfate-reducing microorganisms (SRM) in the intertwined element cycles of wetlands. Although regarded primarily as methanogenic environments, biogeochemical studies have revealed a previously hidden sulfur cycle in wetlands that can sustain rapid renewal of the small standing pools of sulfate. Thus, dissimilatory sulfate reduction, which frequently occurs at rates comparable to marine surface sediments, can contribute up to $36-50 \%$ to anaerobic carbon mineralization in these ecosystems. Since sulfate reduction is thermodynamically favored relative to fermentative processes and methanogenesis, it effectively decreases gross methane production thereby mitigating the flux of methane to the atmosphere. However, very little is known about wetland SRM. Molecular analyses using $d s r A B$ [encoding subunit $A$ and $B$ of the dissimilatory (bi)sulfite reductase] as marker genes demonstrated that members of novel phylogenetic lineages, which are unrelated to recognized SRM, dominate dsrAB richness and, if tested, are also abundant among the dsr $A B$-containing wetland microbiota. These discoveries point toward the existence of so far unknown SRM that are an important part of the autochthonous wetland microbiota. In addition to these numerically dominant microorganisms, a recent stable isotope probing study of SRM in a German peatland indicated that rare biosphere members might be highly active in situ and have a considerable stake in wetland sulfate reduction. The hidden sulfur cycle in wetlands and the fact that wetland SRM are not well represented by described SRM species explains their so far neglected role as important actors in carbon cycling and climate change.

Keywords: $d s r A B$, dissimilatory (bi)sulfite reductase, rare biosphere, sulfur cycle, peatland, rice paddy, sulfatereducing microorganisms, sulfur pollution

\section{INTRODUCTION}

Freshwater wetlands (from here on referred to as wetlands) comprise diverse habitats ranging from peatlands with and without permafrost (e.g., ombrotrophic bogs and minerotrophic fens), freshwater marshes (e.g., the Everglades or the Okavango delta), freshwater swamps including riparian zones, constructed wetlands for waste water treatment, and agricultural wetlands (Mitsch et al., 2009; Kögel-Knabner et al., 2010; Vymazal, 2010). All wetlands have in common that they are periodically or permanently watersaturated soil environments with a characteristic vegetation and a water table at or close to the soil surface (Mitsch and Gosselink, 2007). As a consequence, they are characterized by steep gradients in soil redox conditions that sustain a complex pattern of biogeochemical cycling of elements (Limpens et al., 2008; KögelKnabner et al., 2010). Natural wetlands can act as a net sink of carbon depending on wetland type, age, and location as well as the prevailing climate and environmental conditions (Blodau, 2002; Bridgham et al., 2006; Kayranli et al., 2010). Over the past millennia, they accumulated up to one third of the terrestrial organic carbon just considering peatlands (Limpens et al., 2008), which represents half of the carbon that is in the atmosphere as carbon dioxide (Dise, 2009). At the same time, anthropogenic wetlands such as rice paddies are maintained for agriculture to provide food for more than $50 \%$ of the world's population (http://beta.irri.org).

Organic carbon degradation in wetlands is catalyzed by different functional guilds of aerobic and anaerobic microorganisms, whose competition for electron donors or syntrophic cooperation determines how much of the carbon loss from wetlands proceeds through the emission of carbon dioxide or the more potent greenhouse gas methane (Clymo, 1984; Yao et al., 1999; Dedysh et al., 2001; Frolking et al., 2001; Conrad, 2002; Horn et al., 2003; Loy et al., 2004; Beer et al., 2008; Hamberger et al., 2008; Küsel et al., 2008; Wüst et al., 2009). Although natural and anthropogenic wetlands together cover just 7\% of Earth's land surface (Batzer and Sharitz, 2006; Limpens et al., 2008; Kögel-Knabner et al., 2010), they are made responsible for $30-40 \%$ of the global emission of methane (Houweling et al., 1999; Wuebbles and Hayhoe, 2002). It is currently not clear how the carbon balance of wetlands will 
change in the upcoming decades to centuries due to global warming, which is connected to rising atmospheric carbon dioxide levels and changes in precipitation amount and frequency (IPCC, 2007; Dise, 2009). Such variations of environmental conditions on short- and long-term scales have important implications for the biogeochemical cycling of elements in wetlands and govern transitions between synergistic and antagonistic trophic interactions among wetland microorganisms, which ultimately also determine the extent of carbon mineralization that is channeled through methanogenesis.

Sulfur cycling in wetlands has been studied since the 1980s, revealing that sulfate reduction operates at rates that are comparable to marine surface sediments, where this process is the most important anaerobic degradation pathway for organic matter (Jørgensen, 1982 and references in Table 1). Nevertheless, the importance of sulfate reduction for wetland biogeochemistry has remained underestimated because standing pools of sulfate are typically in the lower micromolar-range and were thus generally interpreted to be too low to sustain sulfate reduction over longer periods of time. This perception was perpetuated by the fact that known taxa of sulfate-reducing microorganisms (SRM) were usually not detected at all or constituted only a very minor fraction of the wetland microbiota (Costello and Schmidt, 2006; Dedysh et al., 2006; Kraigher et al., 2006). However, a series of studies provided cumulative evidence for a hidden sulfur cycle that contributes to rapid recycling of sulfide to sulfate in low-sulfate environments and thus sustains the observed high sulfate reduction rates (SRR; Wieder and Lang, 1988; Jørgensen, 1990; Elsgaard and Jørgensen, 1992; Wind and Conrad, 1997; Mandernack et al., 2000; Heitmann and Blodau, 2006; Blodau et al., 2007; Heitmann et al., 2007; Knorr and Blodau, 2009; Knorr et al., 2009).

Because SRM couple sulfate dissimilation with heterotrophic carbon degradation or carbon dioxide fixation, sulfate reduction directly influences the carbon cycle in wetlands. SRM are known to be metabolically versatile and are able to utilize a great variety of substrates ranging from hydrogen, short-chained fatty acids, and other degradation intermediates like ethanol and lactate up to monosaccharides, amino acids, aromatic compounds, alkanes, and alkenes (Rabus et al., 2006; Muyzer and Stams, 2008). In contrast, organic polymers such as cellulose, proteins, or DNA and RNA are typically not degraded by known SRM (Muyzer and Stams, 2008). Of importance is that SRM are energetically favored in the competition for substrates with microorganisms involved in the methanogenic degradation pathways, resulting in a considerable diversion of the carbon flow from methane to carbon dioxide (Gauci et al., 2004). This mitigating effect of sulfate reduction on the methane flux from wetlands is expected to become even more pronounced in the near future (Gauci et al., 2004). Despite successful efforts to reduce aerial sulfur pollution in developed countries, global $\mathrm{SO}_{2}$ emission is predicted to increase in the next decades due to increasing untreated combustion of coal and other fossil fuels in developing countries situated mainly in Asia (Smith et al.,

Table 1 | Summary of sulfate reduction rates in environments with low-sulfate concentrations ( $\mu \mathrm{M}$-range) as determined with ${ }^{35} \mathrm{SO}_{4}^{2-}$-radiotracer methods.

\begin{tabular}{|c|c|c|c|c|c|}
\hline Habitat & Site description & $\begin{array}{l}\text { Sulfate } \\
(\mu \mathrm{M})\end{array}$ & $\begin{array}{l}\text { Sulfate reduction rate } \\
\left(\mathrm{nmol} \mathrm{cm}^{-3} \mathrm{day}^{-1}\right)\end{array}$ & $\begin{array}{l}\text { Turnover of } \\
\text { sulfate pool (day) }\end{array}$ & Reference \\
\hline \multirow[t]{8}{*}{ Peatlands } & Schlöppnerbrunnen fen II, Germany & $25-100$ & $0-340$ & $1.2-1.6$ & $\begin{array}{l}\text { Knorr and Blodau (2009), } \\
\text { Knorr et al. (2009) }\end{array}$ \\
\hline & Big Run Bog, VA, USA & 10-198 & $\sim 3-7$ & 1.1 & Wieder and Lang (1988) \\
\hline & Bleak Lake Bog, AB, Canada & 61 & 5 & $12.2^{\mathrm{a}}$ & Vile et al. (2003b) \\
\hline & Oceán Bog, Czech Republic & 417 & 170 & $2.5^{\mathrm{a}}$ & \\
\hline & McDonalds Branch watershed, NJ, USA & $10-150$ & $1-173$ & & Spratt et al. (1987) \\
\hline & Ellergower Moss, UK & $28-127$ & & $2-15$ & Nedwell and Watson (1995) \\
\hline & Big Run Bog, VA, USA & $>0-350$ & $2.5-1568$ & $1.5^{\mathrm{b}}$ & Wieder et al. (1990) \\
\hline & Buckle's Bog, VA, USA & $>0-300$ & $0.2-1883$ & $5.8^{b}$ & \\
\hline \multirow[t]{2}{*}{ Everglades } & Water Conservation Area 2A, site F1, FL, USA & $\sim 950$ & $\sim 120$ & $7.9^{a}$ & Castro et al. (2002) \\
\hline & Water Conservation Area 2A, site U3, FL, USA & $\sim 300$ & $\sim 30$ & $10.0^{\mathrm{a}}$ & \\
\hline \multirow[t]{2}{*}{ Rice paddies } & Bulk soil, Vercelli, Italy & $4-150$ & $12-97$ & $0.3-0.5^{a}$ & Wind and Conrad (1997) \\
\hline & Rice rhizosphere, Vercelli, Italy & $13-99$ & $200-500$ & $0.1-0.2^{a}$ & \\
\hline \multirow[t]{4}{*}{ Lake sediments } & Lake Constance, Germany & $10-300$ & $90-1800$ & $0.1^{\mathrm{b}}$ & Bak and Pfennig (1991a) \\
\hline & Wintergreen Lake, MI, USA & $<34$ & $18-171$ & $0.1^{b}$ & Smith and Klug (1981) \\
\hline & Little Rock Lake, WI, USA & $6-62$ & $0-70$ & $0.3-1.3$ & Urban et al. (1994) \\
\hline & Lake Mendota, WI, USA & $100-220$ & $83-554$ & $0.4-1.0$ & Ingvorsen et al. (1981) \\
\hline
\end{tabular}

${ }^{a}$ Calculated from data of the original study.

${ }^{b}$ Reported mean. 
2005; Ward, 2009). Subsequent sulfuric acid deposition on wetlands by acid rain is predicted to stimulate sulfate reduction and thus to cause a suppression of global wetland methane emission by up to $15 \%$ (Gauci et al., 2004).

Here, we provide an overview on the process of sulfate reduction in wetlands, with a focus on ombrotrophic and minerotrophic peatlands, river floodplains, and rice paddies. The first part of this review highlights the biogeochemistry of sulfate reduction in such wetlands, with insights into possible mechanisms that could sustain rapid sulfur cycling. The second part summarizes current knowledge on the identity and activity of SRM in wetlands, including a meta-analysis of all sequences of the marker genes $d s r A B$ that were recovered from wetland microorganisms.

\section{BIOGEOCHEMISTRY OF SULFATE REDUCTION IN FRESHWATER WETLANDS \\ SULFATE REDUCTION IN FRESHWATER WETLANDS AND ITS IMPACT ON CARBON CYCLING AND GREENHOUSE GAS EMISSION}

Sulfate concentrations in natural wetlands and rice paddy soils are typically in the micromolar-range and are thus often considered to be too low to sustain long-term sulfate reduction. However, $\delta^{34} \mathrm{~S}$ values and the fact that wetlands can function as sulfate sink despite their often low anion exchange capacity indicate that sulfate reduction is occurring over long time periods in these low-sulfate environments (Spratt et al., 1987; Alewell and Gehre, 1999; Groscheova et al., 2000; Alewell and Novak, 2001; Jacks and Norrström, 2004; Novak et al., 2005; Paul et al., 2006; Alewell et al., 2008). Even more striking, measured SRR can vary dramatically over time and space in freshwater wetlands, ranging from non-detectable to $>100 \mathrm{nmol} \mathrm{cm}^{-3} \mathrm{day}^{-1}$ and in extreme cases reaching even values of $>1.000 \mathrm{nmol} \mathrm{cm}^{-3} \mathrm{day}^{-1}$ (Table 1). Often these rates are in the same order of magnitude as observed SRR in marine surface sediments, which are characterized by much higher sulfate concentrations (mM-range) and where sulfate reduction was shown to be the most important anaerobic degradation process (Jørgensen, 1982; Howarth and Jørgensen, 1984; Skyring, 1987). These high SRR in freshwater wetlands initially raised concerns about the reliability of such measurements, because these numbers would indicate a very rapid turnover of the complete sulfate pools within hours to days and necessitate a rapid recycling of sulfate. In many studies, SRR in low-sulfate environments were measured by the ${ }^{35} \mathrm{~S}$-radiotracer assay, where ${ }^{35} \mathrm{~S}$-labeled sulfate is added to either intact soil or sediment cores or to slurries thereof (Jørgensen, 1978; Chapman and Davidson, 2001; King, 2001). Thereafter, the turnover of labeled sulfate to sulfide is analyzed after a given time interval (e.g., $90 \mathrm{~min}$ ). The produced sulfide either stays in solution as hydrogen sulfide or rapidly reacts to various forms of metal mono- or disulfides (mostly in combination with iron) or to elemental sulfur. Therefore, the ${ }^{35} \mathrm{~S}$-label is recovered from the sum of these inorganic reduced sulfur species and used in combination with the initial amount of ${ }^{35} \mathrm{~S}$-sulfate tracer, the overall sulfate pool, and the incubation time to calculate SRR (for details see Kallmeyer et al., 2004). Although regarded as the most reliable method to determine SRR, there are indeed a number of caveats (Jørgensen, 1978; Moeslund et al., 1994; Kallmeyer et al., 2004; Canfield et al., 2005). For example, an overestimation of sulfate concentrations, ${ }^{35} \mathrm{~S}$-isotope exchange between sulfate and more reduced sulfur species $\left(\mathrm{S}^{2-}, \mathrm{S}_{n}^{2-}, \mathrm{S}^{0}\right)$, and a stimulation of SRM by the added ${ }^{35}$ S-sulfate could lead to an overestimation of the measured SRR. However, sulfate concentrations can be reliably measured down to $0.15 \mu \mathrm{M}$ (Tarpgaard et al., 2011), ${ }^{35} \mathrm{~S}$-isotope exchange between sulfate and the more reduced sulfur species was shown not to occur within $144 \mathrm{~h}$ (Fossing and Jørgensen, 1990), which is much longer than the typical incubations times of 30-90 min (Wind and Conrad, 1997; Knorr and Blodau, 2009; Knorr et al., 2009) or the sometimes extended incubations times of up to $48 \mathrm{~h}$ (e.g., Vile et al., 2003b), and the added tracer ( $1 \mathrm{nmol}$ per injection of ca. $50 \mathrm{kBq}^{35} \mathrm{SO}_{4}^{2-}$, Kallmeyer et al., 2004) represents a negligible fraction of the total sulfate pool, even at wetland sulfate concentrations of only $1 \mu \mathrm{M}$. Also impurities in commercially supplied ${ }^{35} \mathrm{SO}_{4}^{2-}$, which can constitute up to $0.05 \%$ of the total radioactivity and co-extract with reduced sulfur compounds during turnover measurements (Kallmeyer et al., 2004), would not explain the high SRR measured in wetland samples. On the contrary, an underestimation of SRR in freshwater wetlands is often more likely, especially when prolonged incubations times are used (several hours to days), because of (i) re-oxidation of reduced sulfur compounds to sulfate under anoxic conditions (Jørgensen, 1990; Elsgaard and Jørgensen, 1992; Fossing, 1995), (ii) ${ }^{35} \mathrm{~S}$-tracer back flux from sulfide to sulfate due to the reversibility of enzyme reactions within the sulfate reduction pathway (Holler et al., 2011), and (iii) the possible incorporation of reduced sulfur species and thus of tracer into organic matter (Wieder and Lang, 1988; Wind and Conrad, 1997; Chapman and Davidson, 2001), which would not be detected by the standard ${ }^{35}$ S-radiotracer assay (Canfield et al., 1986; Fossing and Jørgensen, 1989; Kallmeyer et al., 2004).

A number of peatland studies reported excess carbon dioxide over methane production under anoxic conditions; results that could not be explained by methanogenesis as the sole terminal degradation process (Segers and Kengen, 1998; Vile et al., 2003a; Yavitt and Seidmann-Zager, 2006; Blodau et al., 2007; Keller and Bridgham, 2007; Wüst et al., 2009). It was hypothesized that the excess carbon dioxide may stem from fermentation (Vile et al., 2003a,b), but the typically lacking accumulation of fermentation products (such as hydrogen or short chain fatty acids) lead to the hypothesis that this carbon dioxide may stem from alternative anaerobic degradation processes such as sulfate reduction, iron reduction, organic matter reduction, or a combination thereof (Wieder et al., 1990; Segers and Kengen, 1998; Blodau et al., 2007; Küsel et al., 2008; Limpens et al., 2008). This was supported by the fact that high SRR prevailed even under prolonged anoxic periods (16-228 days) and under depletion of the sulfate pools below a detection limit of about $0.5 \mu \mathrm{M}$ in large peat soil mesocosms in the laboratory as well as in field plots (Figures 1A-D; Knorr and Blodau, 2009; Knorr et al., 2009). The actual contribution of sulfate reduction to anaerobic carbon mineralization in wetlands has not yet been conclusively elucidated and so far mostly relies on incubation assays rather than on in situ measurements. Nevertheless, for peatlands current estimates range from 0 to $50 \%$ using inhibition assays of SRM by the addition of molybdate, which functions as an intracellular competitor to sulfate (Blodau et al., 2007; Keller and Bridgham, 2007), and from 1 to $36 \%$ using the ${ }^{35}$ S-radiotracer assay (Vile et al., 2003b). 

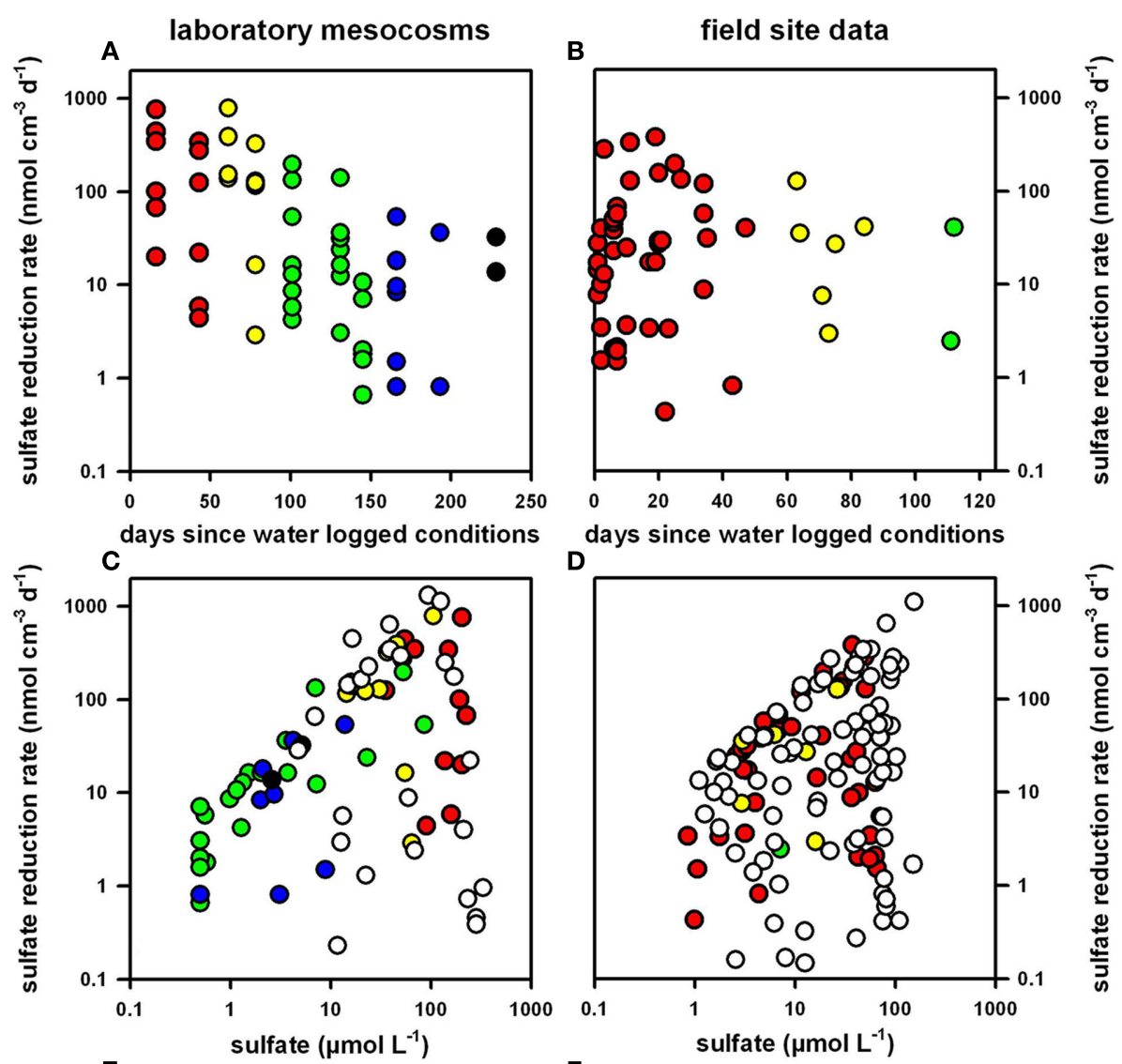

days since water logged conditions D
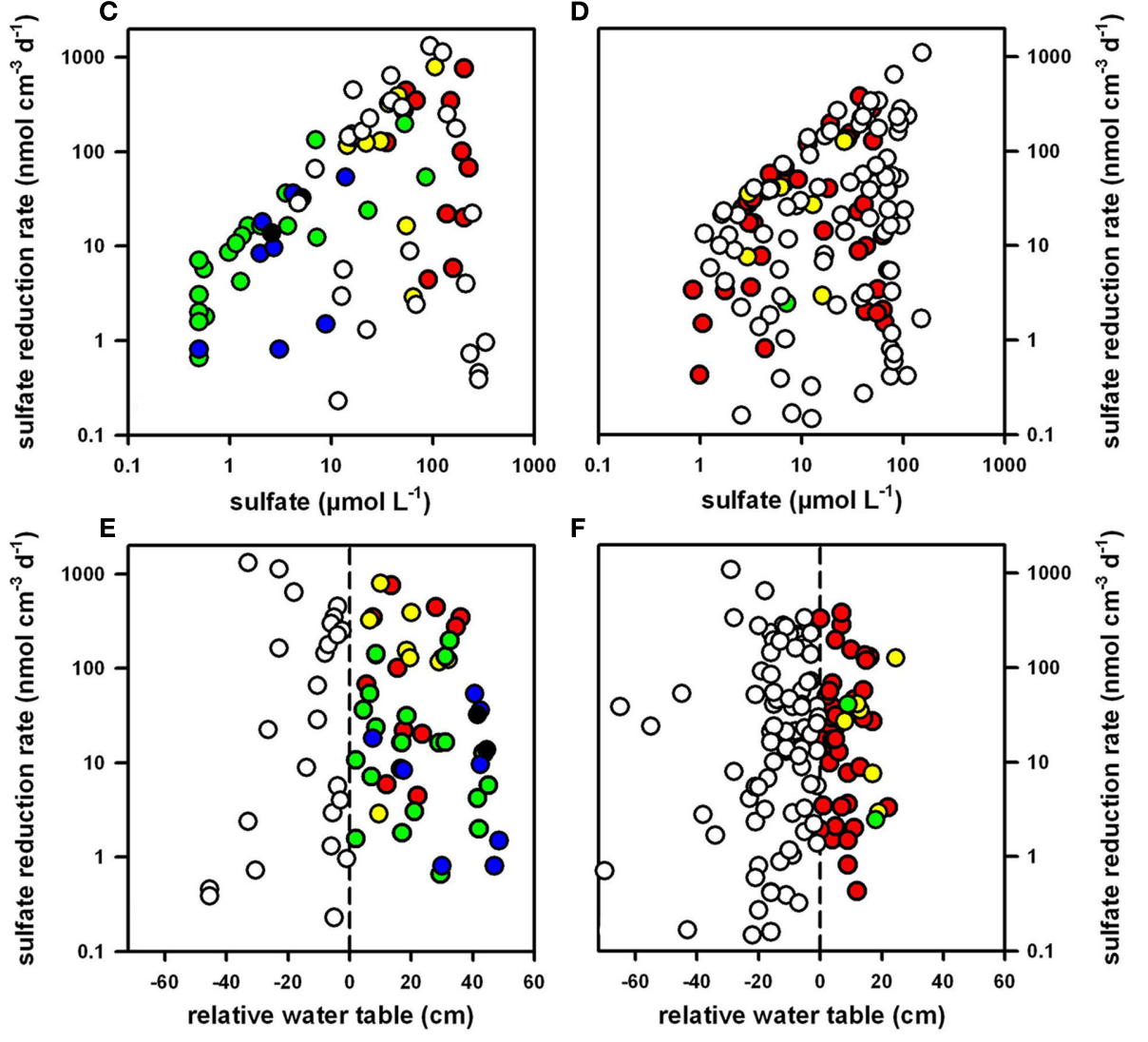

$\mathrm{F}$

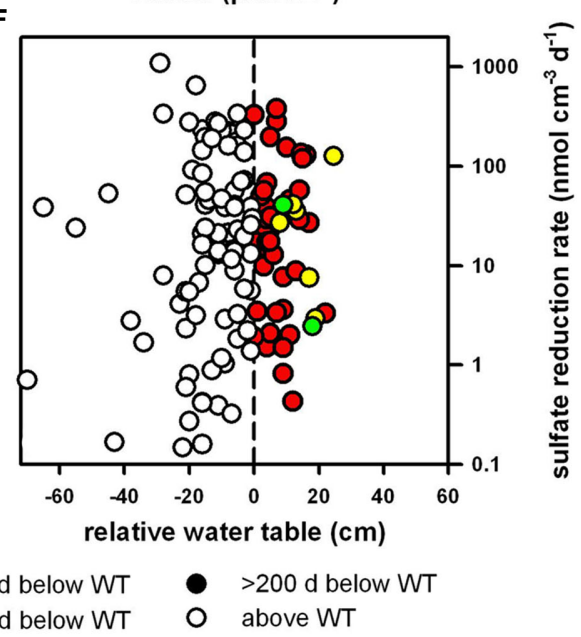

FIGURE 1 | Compilation of sulfate reduction rates from large peat soil mesocosms $[60 \mathrm{~cm}$ in diameter and $60 \mathrm{~cm}$ in depth; left column $(A, C, E)$; Knorr and Blodau, 2009] and from field samples [right column (B,D,F); Knorr et al., 2009] of the German peatland Schlöppnerbrunnen II. Both, data from mesocosm and field samples demonstrate decreasing maximum sulfate reduction rates with increasing exposure to water logging, which represents anoxic conditions (A,B). Maximum sulfate reduction rates depended on prevailing sulfate concentrations (C,D) and a similar wide span in sulfate reduction rates was observed above and below the water table with the water table representing the transition zone between oxic to anoxic conditions (E,F). Time spans in the legend represent the incubation time (days) of soils below the water table (WT). Negative and positive values on the abscissa ( $x$-axis) in subfigure $(\mathbf{E})$ and $(\mathbf{F})$ represent relative positions above and below the water table, respectively.
From a thermodynamic point of view, SRM typically outcompete microorganisms involved in the methanogenic degradation pathways such as primary and secondary fermenters, homoacetogens, and methanogens for substrates (Muyzer and Stams, 2008), thus diverting anaerobic carbon mineralization away from methanogenesis to carbon dioxide production. However, 
SRM are also known to grow in syntrophic association with hydrogen-scavenging methanogens or can themselves constitute the hydrogen-scavenging partner in syntrophic associations (Rabus et al., 2006). Especially under sulfate-limiting conditions, it has been proposed that such syntrophic associations play an important role in organic matter degradation, with hydrogenutilizing methanogens being replaced by hydrogen-utilizing SRM (Muyzer and Stams, 2008). Indeed, SRM were shown to effectively compete with methanogens for hydrogen and acetate at the naturally occurring low sulfate and substrate concentrations in different freshwater habitats ranging from peat and rice paddy soil to lake sediments (lower micromolar-range of sulfate and acetate and nanomolar-range for hydrogen; Lovley and Klug, 1983; Achtnich et al., 1995; Watson and Nedwell, 1998). At the same time, molybdate inhibition assays of different peat soils revealed that SRM and methanogens do not always compete but can also form syntrophic associations as revealed by co-inhibition of sulfate reduction and methanogenesis upon molybdate addition (Watson and Nedwell, 1998; Blodau et al., 2007), with the inhibition of methanogenesis being reversible when additional hydrogen was supplied (Watson and Nedwell, 1998). If anaerobic oxidation of methane (AOM) coupled to sulfate reduction, an important process in anoxic marine environments that is catalyzed by syntrophic consortia of archaeal methanotrophs and SRM (Knittel and Boetius, 2009), takes also place in freshwater wetlands is not completely clear. From a thermodynamic point of view, AOM coupled to sulfate reduction would yield a $\Delta G$ of -14 to $-19 \mathrm{~kJ} /$ reaction under the substrate concentrations occurring in wetlands (Smemo and Yavitt, 2011), which overlaps with energy yields of AOM observed in marine sediments $(\Delta G=-18$ to $-35 \mathrm{~kJ} /$ reaction, Thauer, 2011). There are a few studies that found hints for AOM in wetlands, however, with no clear connection to sulfate reduction (Smemo and Yavitt, 2011). Adding to these intertwined relationships between SRM and methanogens in freshwater wetlands, seasonal shifts in the dominance of sulfate reduction over methanogenesis and vice versa were observed for two peatlands in the UK (Nedwell and Watson, 1995; Watson and Nedwell, 1998). When combining the carbon flow through sulfate reduction and methanogenesis (but not taking other anaerobic degradation processes into account), the contribution of sulfate reduction ranged from 6-96\%. However, it was not clear whether the dominance of sulfate reduction was an effect of higher natural sulfate concentrations (up to $700 \mu \mathrm{M}$ ), lower temperatures during winter time, or a combination of both (Nedwell and Watson, 1995; Watson and Nedwell, 1998).

On the scale of field manipulation studies, deposition or experimental addition of sulfate has been shown to reduce net methane emissions from natural wetlands (Dise and Verry, 2001; Gauci et al., 2002, 2004) and rice paddies (Lindau et al., 1993; Yagi et al., 1997; van der Gon et al., 2001) for prolonged time periods spanning from several weeks to 2 years. In this respect, it should be noted that not only stimulated sulfate reduction might have led to a suppression of methanogenesis but also increased plant growth by a fertilization effect of added sulfur in sulfur-deficient soils such as nitrogen/phosphorous-fertilized rice paddies or ombrotrophic peatlands. For rice plants, it was suggested that this fertilization effect would lead to a redirection of photosynthate to grain production, accompanied by reduced rhizospheric carbon leakage and thus reduced root-derived substrate supply to methanogenesis (Gauci et al., 2008). Also in ombrotrophic peatlands, a large fraction of sulfur deposited by rain was repeatedly observed to be scavenged by the living plant layer (Urban et al., 1989; Steinmann and Shotyk, 1997; Blodau et al., 2007; Bottrell et al., 2010). However, if this directly influences peatland methane gross production or emission has not been investigated in detail so far.

\section{SULFUR CYCLING IN WETLANDS: SPATIOTEMPORAL DIFFERENCES OF REDOX CONDITIONS AND A HIDDEN ANOXIC SULFUR CYCLE}

Ongoing sulfate reduction in wetlands, which can be observed over long time periods despite small pool sizes, needs either an effective recycling mechanism for sulfate to prevent rapid depletion of the sulfate pool and/or a constant external input of sulfate, e.g., through atmospheric deposition, groundwater flow, and/or the overlaying water. Reported turnover times of sulfate pools were often as short as hours to days (Table 1) and only a fraction thereof could be explained by externally supplied sulfate (Wieder and Lang, 1988; Urban et al., 1994; Nedwell and Watson, 1995; Wind and Conrad, 1997). This has led to the suggestions that recycling of reduced sulfur compounds to sulfate is the main mechanisms that drives sulfate reduction in wetlands (Wieder and Lang, 1988; Jørgensen, 1990; Wieder et al., 1990; Urban et al., 1994; Nedwell and Watson, 1995; Wind and Conrad, 1997; Blodau et al., 2007).

Recycling of reduced sulfur compounds to sulfate can be complex and may occur at different spatiotemporal scales as well as under oxic and anoxic conditions. On large spatial scale, modeling studies suggest that water movement and mixing in the capillary fringe (i.e., the soil layer in which groundwater seeps up from the water table to fill soil pores by capillary action) and shallow groundwater (Reeve et al., 2006) as well as different flow paths of water through wetland soils (Fleckenstein et al., 2011) may be important for creating redox gradients and for the provision and recycling of electron acceptors. Also a temporal decoupling of sulfate reduction and re-oxidation of reduced sulfur compounds, such as during short-term (Deppe et al., 2009; Knorr and Blodau, 2009) or seasonal water table fluctuations (Alewell and Novak, 2001), which influences the transition zone from oxic to anoxic conditions, is possible. This is supported by experimental evidence, where recycling of sulfur compounds along an elevational transect through a North American peatland (Mandernack et al., 2000) and heterogeneous distribution of sulfate reduction and sulfide re-oxidation on the range of tens to hundreds of meters in a small catchment in Central Europe (Alewell et al., 2006) was observed over the course of different seasons by $\delta^{34} S$ signatures and ${ }^{35} \mathrm{~S}$-sulfate incubations.

Recycling of reduced sulfur compounds does also occur on a smaller scale of millimeters and a number of mechanisms have been identified to chemically or microbiologically re-oxidize sulfide to sulfate, thiosulfate, or elemental sulfur (Kelly et al., 1997; Wind and Conrad, 1997; Canfield et al., 2005; Friedrich et al., 2005; Gregersen et al., 2011). A common feature of sedges and graminoids in wetlands and also of rice plants is the formation of aerenchymatic tissues to provide oxygen to their rooting system (Wind and Conrad, 1997; Brune et al., 2000; Pezeshki, 2001). Therefore, root surfaces of aerenchymatic plants have been shown 
to provide highly reactive interfaces of oxic and anoxic conditions that allow for rapid recycling of electron acceptors, such as reduced iron and sulfides (Roden and Wetzel, 1996; Wind and Conrad, 1997; Segers and Leffelaar, 2001). In addition, electric currents in marine sediments, which were proposed to be mediated by bacterial pili (nanowires), were shown to span from the sulfidic zone over a $12-\mathrm{mm}$ distance to the oxic surface layers, thereby fueling sulfide re-oxidation at depth and effectively extending the zone, in which electron acceptor resupply can fuel ongoing respiratory activity (Nielsen et al., 2010). This surprising finding has so far not been described for freshwater wetlands but there is no reason why this phenomenon should be limited to marine surface sediments.

Recycling of sulfides to oxidized sulfur species may also occur in the absence of oxygen, which is often not evident at first sight. However, high SRR that proceed over long time periods (>100-200 days) under anoxic conditions as observed, e.g., in peat monoliths and in field studies of the minerotrophic peatland Schlöppnerbrunnen II in Central Europe (Knorr and Blodau, 2009; Knorr et al., 2009; Figures 1A,B,E,F), can only be explained by an anoxic sulfur cycle. Although there is no final proof yet how this anoxic recycling proceeds, there is cumulating evidence that iron minerals and redox-active organic matter might play a role in the first step of sulfide oxidation to either elemental sulfur/polysulfide or thiosulfate (Figure 2). In marine sediments, it has been demonstrated that sulfides react with iron oxides to form Fe(II) (Canfield, 1989). The sulfides in this reaction are oxidized mainly to elemental sulfur and to a smaller extend to thiosulfate as inferred from incubations mimicking environmental conditions but free of microorganisms (Pyzik and Sommer, 1981). This process is strongly dependent on the reactivity of the present iron oxides and their surface properties (Canfield et al., 1992; Peiffer and Gade, 2007) and subsequent formation of iron sulfides, Fe(II) sorption, and associated surface passivation of iron minerals could limit this process over time (Elsgaard and Jørgensen, 1992; Roden and Urrutia, 2002). In rice paddy soil and iron-rich peatlands, formation of $\mathrm{Fe}$ (II) under anoxic conditions was repeatedly observed and often attributed solely to microbial iron reduction (Yao et al., 1999; Küsel et al., 2008; Knorr et al., 2009; Hori et al., 2010). However, $\mathrm{Fe}$ (II) formation could, at least partially, also be attributed to sulfide re-oxidation on iron oxides since this is a fast process taking place in the order of minutes to days (Peiffer and Gade, 2007). Therefore, it could be implied that not only in marine sediments but also in iron-rich wetland soils there is a competition between microbial $\mathrm{Fe}$ (III) reduction and chemical reduction of $\mathrm{Fe}$ (III) mediated by sulfide oxidation. The interaction of iron and sulfur has so far not been adequately investigated in wetlands and further investigations about the complex geochemistry of iron and sulfur in organic rich soils are needed.

From diagenetic studies it is known that sulfides may react with organic matter and form organic forms of sulfur also during early stages of diagenesis (Brown, 1986; Ferdelman et al., 1991; Bottrell et al., 2010), e.g., by addition of sulfur to quinone moieties, polysulfide bonds, formation of thiol-groups (S-H), or sulfate esters (Vairavamurthy et al., 1992; Ghani et al., 1993; Kertesz, 2000; Perlinger et al., 2002). Sulfate esters of small molecular size have been demonstrated to be utilized as alternative terminal electron acceptor by some SRM (Lie et al., 1996, 1998; Visscher et al., 1999), thus also supporting SRM activity in absence of inorganic sulfate. More recently, it has been demonstrated that humic substances can also mediate re-oxidation of sulfides and thus fuel an anoxic sulfur cycle

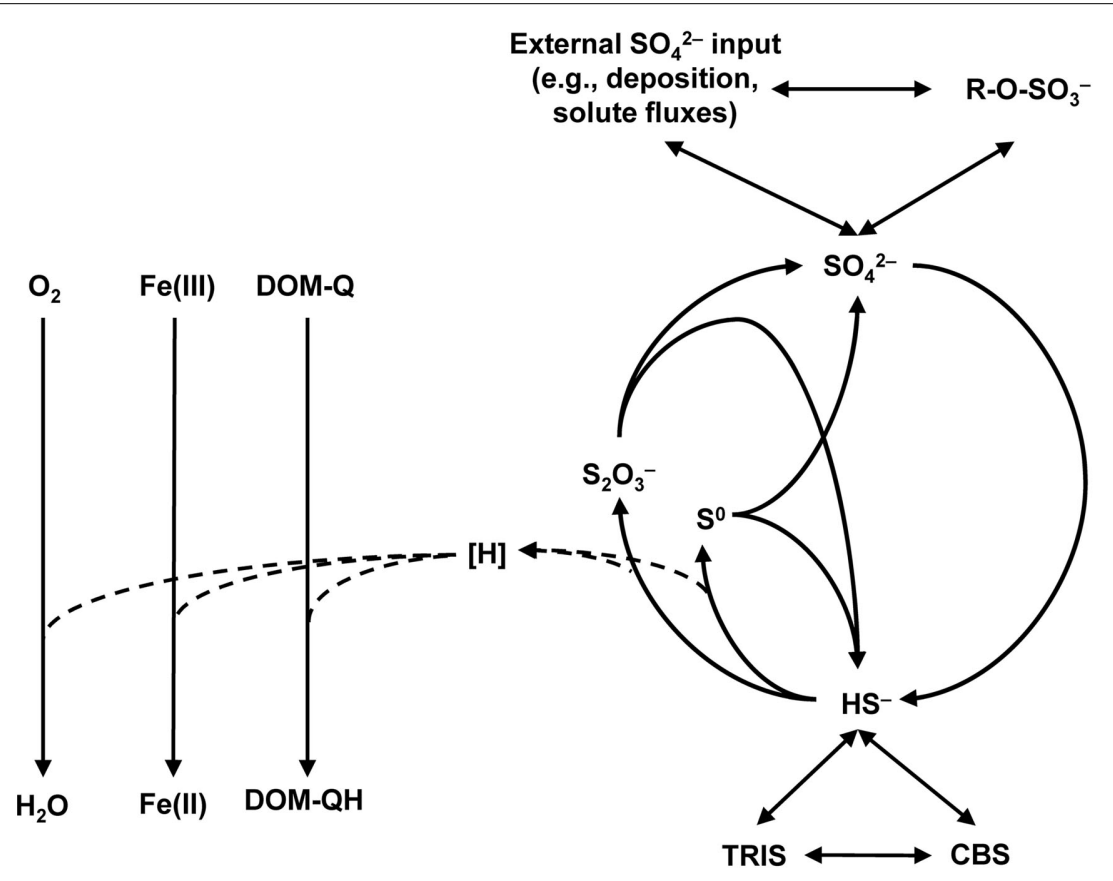

FIGURE 2 | Schematic overview of the proposed sulfur cycle in freshwater wetlands. Abbreviations: DOM-Q, quinone moieties of dissolved organic matter, $\mathrm{R}-\mathrm{O}-\mathrm{SO}_{3}^{-}$, organic sulfate esters, TRIS, total reactive inorganic sulfur, $\mathrm{CBS}$, carbon bonded sulfur. 
(Heitmann and Blodau, 2006; Heitmann et al., 2007). Although the electron transfer capacity of dissolved organic matter toward sulfides was relatively low in the study of Heitmann et al. (2007), advances in methodological approaches such as electrochemical determination of electron accepting capacities of dissolved organic matter (Aeschbacher et al., 2010) or including the solid phase material (Roden et al., 2010) may reveal a greater contribution of organic matter to total electron accepting capacities. Therefore, natural organic matter may be a key to an anoxic cycling of sulfur (Blodau et al., 2007). However, it needs to be kept in mind that the addition of sulfur to organic matter also provides a sink for sulfur and thus reduces the amount of sulfur to be recycled. One may thus hypothesize that during longer exposure to anoxic conditions, SRR tend to decrease possibly also because of a loss of sulfur into the organic fraction (e.g., Figure 1A). Indeed, a large part of sulfur in peatlands and rice paddy soils $(25$ to $>80 \%)$ is bound to the organic fraction (Wieder and Lang, 1988; Urban et al., 1989; Steinmann and Shotyk, 1997; Wind and Conrad, 1997; Mandernack et al., 2000) and investigations of stable sulfur isotopes support that a large fraction of non-humic organosulfur compounds (e.g., S-containing fulvic acids) are formed by reactions of microbiologically produced sulfides and organic matter, while humic organosulfur may preferentially originate from plant material (Bottrell et al., 2010). If non-humic organosulfur compounds are transformed to humic acid-bound sulfur during diagenesis or if this sulfur is mainly released again as inorganic sulfur available for re-oxidation, as observed in estuarine sediments (Brüchert, 1998), is yet poorly understood.

The known products of anoxic sulfide re-oxidation include elemental sulfur, thiosulfate, or polysulfides $\left(S_{n}^{2-}\right.$, Jørgensen, 1990; Canfield et al., 1992; Thamdrup et al., 1993; Heitmann and Blodau, 2006; Peiffer and Gade, 2007). Thiosulfate and elemental sulfur are known to be used for energy generation by anaerobic microorganisms including SRM. These sulfur compounds can be either reduced back to sulfide, disproportionated to sulfate and sulfide, or in the case of elemental sulfur and in the presence of $\mathrm{Mn}(\mathrm{IV})$ be oxidized completely to sulfate (Bak and Cypionka, 1987; Thamdrup et al., 1993; Lovley and Phillips, 1994; Rabus et al., 2006). For freshwater sediments at neutral $\mathrm{pH},{ }^{35} \mathrm{~S}$-radiotracer assays showed that of all the sulfur that is anoxically recycled through thiosulfate $6 \%$ gets completely oxidized to sulfate, $50 \%$ gets completely reduced to sulfide, and $44 \%$ gets disproportionated to sulfate and sulfide (Jørgensen, 1990). Due to this large shunt of thiosulfate directly back to sulfide, only $28 \%$ of the recycled sulfide ends up again in the sulfate pool, which would only partially explain how the high SRR are maintained in wetlands under anoxic conditions. Comparable flux measurements do not exist for elemental sulfur because of rapid exchange of isotopes between the pools of $\mathrm{S}^{0}, \mathrm{~S}_{n}^{2-}$, $\mathrm{H}_{2} \mathrm{~S}$, and $\mathrm{FeS}$ (Fossing and Jørgensen, 1990). However, microbially mediated disproportionation of elemental sulfur would lead to a 1:3 stoichiometry of produced sulfate to sulfide and would also not explain sufficient replenishment of the sulfate pool.

An alternative explanation that could support a major flux from sulfide to sulfate is through the intermediate elemental sulfur with its complete oxidation being mediated by unknown oxidants (e.g., redox-active organic matter). That such a reaction is in principle possible is known from the complete oxidation of elemental sulfur mediated by $\mathrm{Mn}(\mathrm{IV})$ as observed in enrichment cultures (Lovley and Phillips, 1994) or by the stimulation of sulfate production from sulfide by addition of nitrate to a bioreactor inoculated with wetland soil and operating under anoxic, freshwater conditions or to marine surface sediments (Elsgaard and Jørgensen, 1992; Haaijer et al., 2007). However, manganese and nitrate pools are generally too small in wetland types such as peatlands and rice paddies (Murase and Kimura, 1997; Yao et al., 1999; Alewell et al., 2006; Koretsky et al., 2007) to sustain massive sulfur oxidation over prolonged time periods. Minding the redox potential of the $\mathrm{MnO}_{2} / \mathrm{Mn}^{2+}$ couple $\left(E_{0}^{\prime}=+390 \mathrm{mV}\right)$, manganese could theoretically function as a redox shuttle between reduced sulfur compounds and electron acceptors with a higher redox potential than manganese (e.g., oxygen). The insolubility of $\mathrm{MnO}_{2}$ in water may nonetheless hamper the activity range of such a $\mathrm{MnO}_{2} / \mathrm{Mn}^{2+}$ redox shuttle. Also the idea of an $\mathrm{NO}_{3}^{-} / \mathrm{NH}_{4}^{+}$redox shuttle seems unlikely because this would necessitate a close coupling of oxic ammonia oxidation and anoxic nitrate ammonification under the exclusion of competing processes such as denitrification of nitrate to $\mathrm{N}_{2}$ and ammonia/nitrate uptake by plants, which both would further deplete the inorganic $\mathrm{N}$ pool in wetland soils. On the other hand, redox potentials and associated electron transfer capacities of humic acids, and probably also of other dissolved and solid organic matter, span a wide range $(>+150$ to $<-350 \mathrm{mV}$; Aeschbacher et al., 2010) and may therefore especially in carbon rich wetlands provide a significant electron accepting capacity.

Adding to the complexity of anoxic sulfate recycling, Schippers and Jørgensen (2001) could show for marine sediments that pyrite $\left(\mathrm{FeS}_{2}\right)$, a major sulfur compound in sediments that forms from the reaction of $\mathrm{H}_{2} \mathrm{~S}$ or $\mathrm{S}_{n}^{2-}$ with iron minerals such as FeS (Schippers and Jørgensen, 2001; Holmkvist et al., 2011a and references therein), is not a stable end product of sediment sulfur transformations but can also be completely re-oxidized to sulfate in the presence of $\mathrm{MnO}_{2}$ as a terminal electron acceptor with $\mathrm{Fe}(\mathrm{III}) / \mathrm{Fe}$ (II) functioning as a redox shuttle. Also the addition of nitrate to pyrite-amended groundwater (Jørgensen et al., 2009) and pure cultures of Thiobacillus denitrificans (Bosch et al., 2012) triggered oxidation of pyrite to sulfate, further highlighting the potential role of pyrite as an intermediate in sulfur cycling. Currently, it is not clear if similar processes also occur in freshwater wetlands, possibly involving organic matter as alternative electron acceptor to $\mathrm{MnO}_{2}$ and nitrate. In summary, several concepts have been put forward how the observed high SRR can be maintained over long periods of time under anoxic conditions. However, each of these concepts needs further experimental validation.

\section{DIVERSITY AND ACTIVITY OF SULFATE-REDUCING MICROORGANISMS IN WETLANDS THE IDENTITY OF SULFATE-REDUCING MICROORGANISMS IN WETLANDS IS LARGELY UNKNOWN}

Anoxic conditions, high sulfate concentrations (up to $28 \mathrm{mM}$ ), and the large extent of marine surface sediments render sulfate reduction a main driver of anaerobic carbon mineralization in the oceans. Marine surface sediments are thus considered the prime habitats for SRM. Consequently, numerous studies have determined the microbial community structures in these habitats through isolation and taxonomic description of sulfate-reducing 
strains and complementary molecular diversity surveys. We thus know today that a dominant fraction (up to 20-40\%) of the microbial community in marine sediments consists of microorganisms that are related to validly described SRM species (e.g., Ravenschlag et al., 1999; Musat et al., 2006; Uthicke and McGuire, 2007; Orcutt et al., 2011; Teske et al., 2011). This is in stark contrast to freshwater wetlands, where taxa including known SRM are rarely detected or constitute only a minor fraction $(<1 \%)$ of the microbial community, if general molecular diversity surveys based on bacterial or archaeal 16S rRNA gene clone libraries are performed (e.g., Costello and Schmidt, 2006; Dedysh et al., 2006; Kraigher et al., 2006; Lu et al., 2006; Jackson et al., 2009; Wilhelm et al., 2011). Only the application of cultivation or targeted molecular approaches revealed that members of recognized SRM taxa are actually present in freshwater wetlands. First evidence for the existence of SRM that thrive in low-sulfate environments were provided by enrichments from lake sediments (Bak and Pfennig, 1991b; Ramamoorthy et al., 2006), rice paddy fields (Dalsgaard and Bak, 1994; Wind and Conrad, 1995; Wind et al., 1999), permafrost soil (Vatsurina et al., 2008), and constructed wetlands (Lee et al., 2009) and included Desulfovibrio, Desulfobulbus, Desulfotomaculum, and Desulfosporosinus spp. In parallel, taxa including known SRM were also detected by targeted molecular analyses such as (quantitative) PCR assays with taxa-specific 16S rRNA gene-targeted primers (Scheid and Stubner, 2001; Stubner, 2002, 2004; Stahl et al., 2007) and/or with the DSR1F-DSR4R primer variants targeting the functional marker genes $d s r A B$ (Wagner et al., 2005; Steger et al., 2011; Table 2). The latter genes encode the alpha- and beta-subunits of dissimilatory (bi)sulfite reductase that is used by SRM for energy conservation. Although a few horizontal gene transfer events have slightly worsened the usefulness of $d s r A B$ as phylogenetic marker genes (Zverlov et al., 2005), the foundation of these molecular $16 \mathrm{~S}$ rRNA gene- or $d s r A B$-based diversity studies is that an unknown environmental sequence can be phylogenetically assigned with high likelihood to a described taxon, if the sequence branches unambiguously within this taxon. Using this rationale, members of the families Desulfobacteraceae and Syntrophobacteraceae and bacteria related to Desulfobacca acetoxidans were identified in more than half of the wetlands listed in Table 2. Members of other SRM families/family level lineages in the Deltaproteobacteria and the Firmicutes can also be regularly detected using these targeted approaches. Given their thermophilic lifestyle, it is not surprising that bacterial SRM of the phylum Thermodesulfobacteria and the genus Thermodesulfovibrio or archaeal SRM of the genera Archaeoglobus and Caldivirga have so far not been found in freshwater wetlands.

However, inferring ecophysiological properties of the detected SRM taxa in wetlands is notoriously difficult because even main metabolic properties of SRM, such as complete versus incomplete organic substrate mineralization, substrate utilization preferences, and alternative options for energy conservation such as fermentation or syntrophy with methanogens cannot be clearly inferred from phylogenetic analyses of 16S rRNA genes or $d s r A B$ (Stahl et al., 2007; Loy et al., 2008). For many of the wetland microorganisms that belong to known SRM taxa and were detected using cultivation-independent approaches, it even remains unknown if they are truly capable of dissimilatory sulfate reduction. This is due to exceptions of the generally close correlation of sulfate-reducing metabolism and $16 \mathrm{~S}$ rRNA and/or $d s r A B$ phylogeny. For example, the butyrate-utilizing marine syntroph Algorimarina butyrica is not capable of reducing sulfate but, based on $16 \mathrm{~S}$ rRNA phylogeny, is a member of the deltaproteobacterial family Desulfobacteraceae (Kendall et al., 2006), which has been long thought to exclusively consist of SRM. Furthermore, some syntrophs related to sulfatereducing Desulfotomaculum spp., such as members of the genera Pelotomaculum and Sporotomaculum, are not able to anaerobically grow with sulfate as electron acceptors but harbor $d s r A B$ (Zverlov et al., 2005; Imachi et al., 2006).

\section{UNCULTURED FAMILY LEVEL LINEAGES DOMINATE DIVERSITY OF DISSIMILATORY (BI)SULFITE REDUCTASE GENES IN WETLANDS}

Pure snapshot analyses of $d s r A B$ diversity in the environment have low informative value regarding the ecophysiology of the microorganisms carrying these genes, especially if contextual information such as biogeochemical process data is missing. Nevertheless, the $d s r A B$ approach has allowed important insights into the natural diversity of microorganisms carrying these genes and has revealed, for various environments, the presence of many $d s r A B$ sequences that are not closely related to $\operatorname{sr} A B$ from known SRM (Figure 3). We have performed a comprehensive phylogenetic re-analysis of all phylogenetically novel $d s r A B$ sequences retrieved from different freshwater wetland habitats (Table 3) in combination with representative sequences from other environments (see legend of Figure 3 for methodological details). The novel $d s r A B$ sequences from yet uncultivated microorganisms formed 10 monophyletic lineages (which we designated "uncultured $d s r A B$ lineage 1 to 10 "; Figure 3 ), each corresponding to a new family in the consensus tree and emphasizing the large diversity of elusive microorganisms harboring these genes. Besides uncultured $d s r A B$ lineages 5, 6, and 7 that formed independent branches close to the root, a further level of monophyletic clustering was apparent in the consensus DsrAB tree that we followed to tentatively designate three phylogenetically stable "superclusters," each having high bootstrap support and comprising at least two uncultured $\operatorname{dr} A B$ family level lineages and/or known SRM families. Two of the superclusters harbor cultured representatives and were thus named accordingly. The "Deltaproteobacteria supercluster" includes all $d s r A B$ sequences from deltaproteobacterial species (please note that the deep-branching $D$. acetoxidans lineage is tentatively considered part of this supercluster despite weak bootstrap support), laterally acquired, Deltaproteobacteria-like $d s r A B$ from Firmicutes and Thermodesulfobacteria (Zverlov et al., 2005), uncultured $d s r A B$ lineage 1 , and other environmental $d s r A B$. The Thermodesulfovibrio supercluster includes $d s r A B$ of Thermodesulfovibrio spp., uncultured $d s r A B$ lineage 10 , and other environmental $d s r A B$. The third supercluster consists exclusively of environmental $d s r A B$ sequences from yet uncultivated microorganisms, including uncultured $\operatorname{ds} A B$ lineages 8 and 9 , and was therefore named "environmental supercluster 1 ". The consensus tree provides some indication for another supercluster, including $d s r A B$ from recognized bacteria in the Firmicutes, uncultured $d s r A B$ lineages 2, 3 , and 4 , and other environmental $\operatorname{ds} A B$. However, the monophyletic origin of this supercluster is not supported by bootstrap 


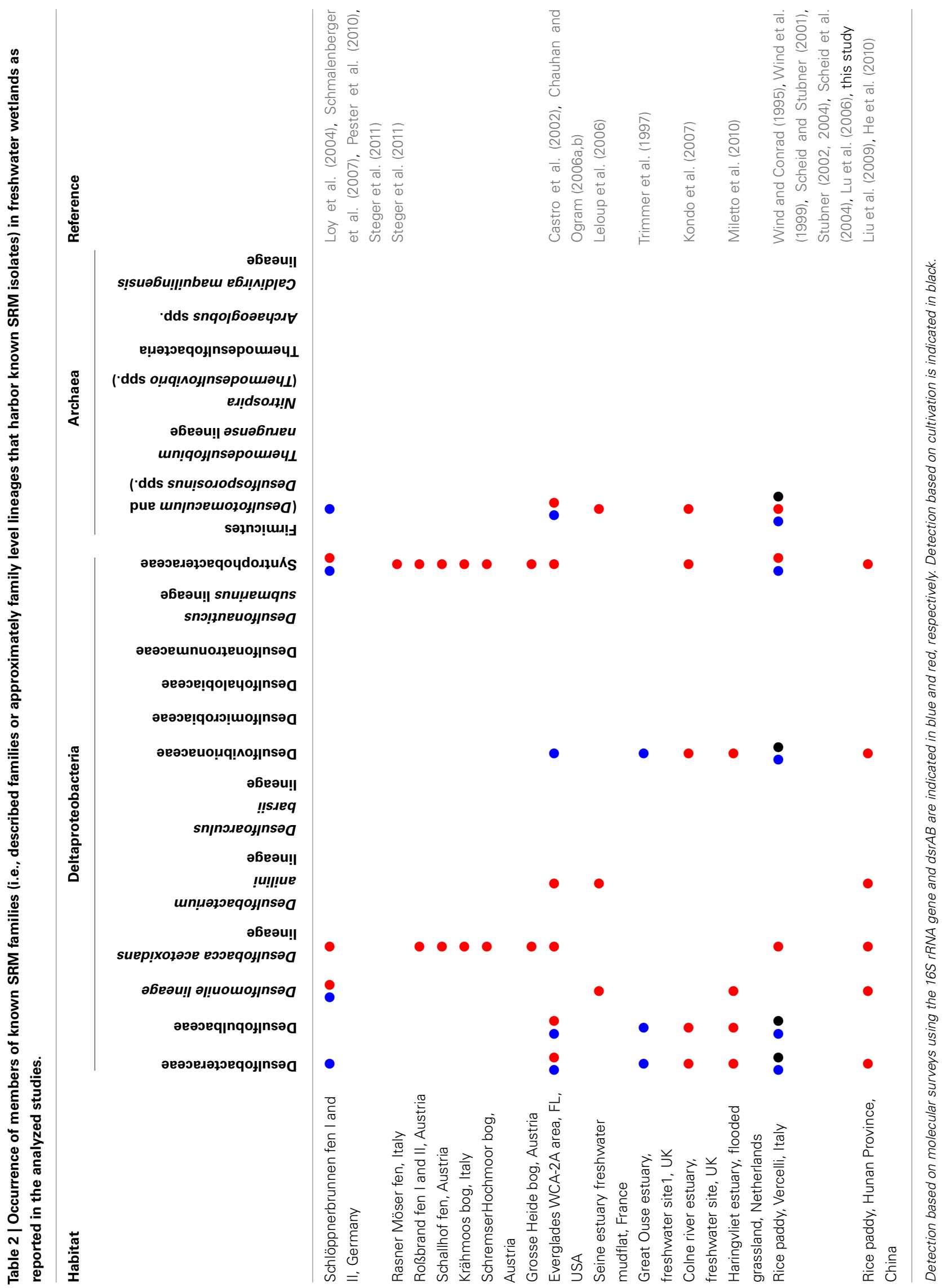




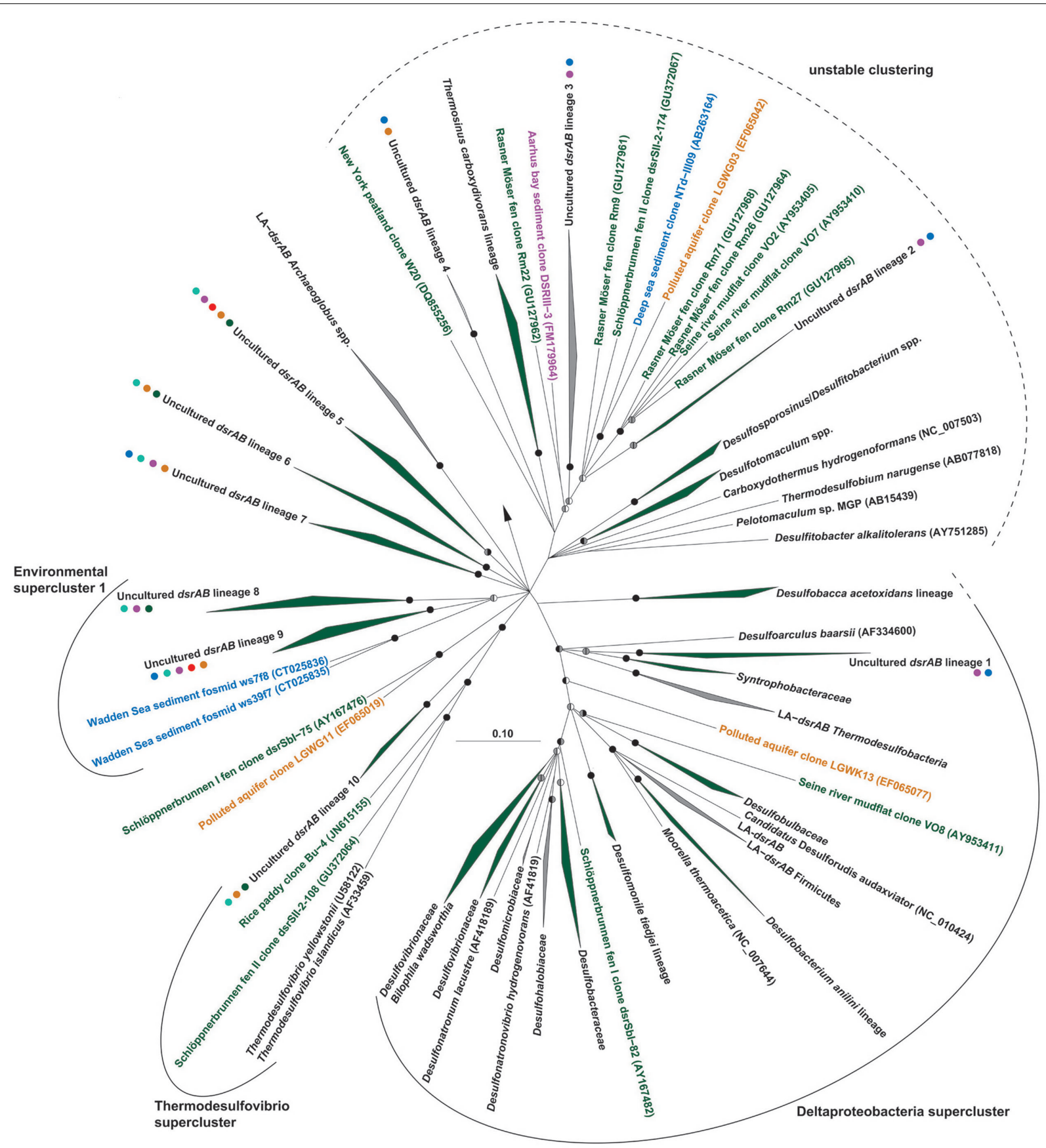

- wetland (low sulfate concentrations)

- groundwater (low and high sulfate concentrations)

- hot spring/hydrothermal vent (high sulfate concentrations)

- deep marine methanogenic sediments (low sulfate concentrations)

- brakish estuarine sediments (low and high sulfate concentrations)

- marine surface sediments (high sulfate concentrations)
Uncultured dsrAB lineage 1: AY865327, AM236154, AB263155, FM179960, FM179967 Uncultured dsrAB lineage 2: AM236177, AM236176, AM236173, AM236172, AM236171, AM236164, AM236155, AM408819, FM179976, Uncultured dsrAB lineage 3: AM236159, FM179961, FM179957, FM179955, FM179969, FM179962, FM179977, FM179971 Uncultured dsrAB lineage 4: AB263163, AB263162, AB263161, AB263160, AB263159, AB263158, AB263157, AB263156, EF 065093

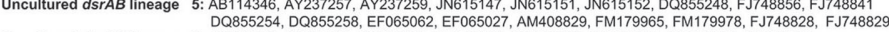
Uncultured dsrAB lineage 6: JN615150, JN615163, AY167469, GU127960, GU127967, GU127971, AY953407, AY953408,

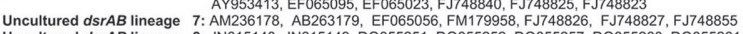

Uncultured dsrAB lineage 8: JN615148, JN615149, DO055251, DO855252, DO855257, DQ855260, DQ855261, AY167474, AY167483, AY167467, GU127963, GU127966, AY953402, GU371960, GU371961, GU371963, GU371964, GU371966, GU371967, GU371977, GU371978, GU371979, GU372063, GU372065, GU372066, GU372069, GU372072, GU372081, FM179979, FM179973, FJ748830 : AY AB263173, AB26312, ET JN615164, JN615158, JN615156, AY167472, GU127969, GU372068, EF065057, EF065049, EF065048, EF065031, FJ748852, FJ748853
FIGURE 3 | DsrAB consensus tree showing the affiliation of $d s r A B$ sequences from freshwater wetlands (sequences and lineages marked in green). Environmental DsrAB sequences not affiliated with sequences from cultured microorganisms were grouped into an "uncultured dsrAB lineage" on the approximate family level if at least two sequences with $\geq 64 \%$ amino (Continued) 


\begin{abstract}
FIGURE 3 | Continued
acid identity formed a monophyletic cluster and contained no sequence that was $\geq 64 \%$ identical to a sequence outside this lineage. The conservative $64 \%$ limit was inferred from DsrAB of cultured representatives belonging to 10 known families with a minimum intra-family amino acid sequence identity of $64-89 \%$. Bootstrap support for identified clusters is shown by split circles (right: maximum likelihood, 1000 re-samplings; left: maximum parsimony, 100 re-samplings) at the respective branches with black indicating $\geq 90 \%$ support, gray indicating $\geq 70 \%$ support, and white/absence of circles indicating $<70 \%$ support. Family level DsrAB lineages were summarized to superclusters if their monophyletic origin was supported by bootstrap values of $\geq 70 \%$. The color code of environmental DsrAB sequences or of dots behind uncultured family level DsrAB lineages indicates the habitat where the respective sequences were retrieved from (this data is not provided for recognized families). For phylogenetic inference of deduced DsrAB amino acid sequences, insertions and deletions were removed from the data set by using an alignment mask (indel filter), which resulted in 502 amino acid
\end{abstract}

positions for comparative analyses. Distance matrix (Neighbor Joining with PAM as amino acid replacement model), maximum likelihood (RAxML with PAM as amino acid replacement model), and maximum-parsimony algorithms were used as provided in the ARB software package (Ludwig et al., 2004) to determine the phylogenetic relatedness of the analyzed DsrAB sequences. Reverse DsrAB of sulfur-oxidizing bacteria were used as outgroup (Loy et al., 2009). A strict consensus tree was constructed from the individual trees obtained with the different algorithms using the Phylip (Felsenstein, 1989) and ARB (Ludwig et al., 2004) software packages. Branch lengths of the consensus tree were inferred by the Fitch algorithm using a Jukes-Cantor derived distance matrix (Phylip), the scale bar represents $10 \%$ estimated sequence divergence. Affiliation of short DsrA or DsrB sequences $(<542$ amino acids) retrieved from freshwater wetlands was inferred using the consensus tree and the quick-add-parsimony tool within ARB. Uncultured family level DsrAB lineages that comprise such short DsrA and DsrB sequences but no near full-length DsrAB sequences from freshwater wetlands are colored green but are not marked with a green dot. analysis and is also not evident in other previously published DsrAB trees (Pester et al., 2010; Steger et al., 2011). We have thus not named this putative supercluster because its members and their relative branching orders currently remain unresolved (Figure 3).

With the exception of uncultured $d s r A B$ lineages 3 and $4, d s r A B$ sequences from freshwater wetlands are present in eight of the ten uncultured family level lineages. There is additional evidence of $d s r A B$ novelty in wetlands through individual (or groups) of wetland $d s r A B$ sequences, but these did not meet our criteria to designate them as a novel "uncultured $d s r A B$ lineage" (Figure 3 ). Overall, $d s r A B$ belonging to lineage 6 (branching off close to the root), lineage 8 (environmental supercluster 1), and lineage 10 (Thermodesulfovibrio supercluster) were most often detected in freshwater wetlands (Table 3). In addition, $d s r A B$ sequences not affiliated to any of the uncultured family level lineages but belonging to the Deltaproteobacteria supercluster, the Thermodesulfovibrio supercluster, and the putative, phylogenetically unstable supercluster also contributed to the $\operatorname{ds} r A B$ diversity in most analyzed freshwater wetlands.

The $\operatorname{ds} A B$ diversity in wetlands is dominated by sequences from lineages without cultivated microorganisms (Figure 3). Key questions are (i) if each of these phylogenetically novel $d s r A B$ sequence variants is representative of an individual microorganism and (ii) if these genes potentially encode functional enzymes. Functional marker genes can be present as different copies within the same microorganism as is known, e.g., for the alpha subunit of the particulate methane monooxygenase within type II methanotrophs (Tchawa Yimga et al., 2003; Baani and Liesack, 2008) and the novel $d s r A B$ types could likewise represent phylogenetically different versions of dissimilatory (bi)sulfite reductases. However, SRM that possess multiple $d s r$ operons with significantly different sequences have not been reported so far. The only exception to this observation is the homoacetogen Moorella thermoacetica, which is not known to perform dissimilatory sulfate reduction but possesses two very distinct $d s r A B$ copies (Loy et al., 2009). In principle, the novel $d s r A B$ types found in wetlands could also be pseudogenes. However, no internal stop codons were found in these sequences and a previous analysis revealed sequence conservation of the functional site in both, subunit A and B of the enzyme, as well as a low rate of non-synonymous to synonymous substitutions (Loy et al., 2004), indicating that these genes could be expressed into functionally active proteins.

Although our $\operatorname{sr} A B$ meta-analysis included data from geographically and biogeochemically distinct wetlands (comprising minerotrophic and ombrotrophic peatlands, river floodplains, freshwater marshes within the Florida Everglades, and rice paddy fields), clear distribution patterns of major $d s r A B$ lineages or superclusters with geography or environmental parameters like $\mathrm{pH}$ were not evident at this coarse level of phylogenetic resolution. However, when the $d s r A B$ diversity of various Central European wetlands was analyzed at higher phylogenetic resolution by combined $d s r B$-fingerprinting and sequencing, signatures of biogeographical distribution became apparent and were best explained by soil pH and wetland type (Steger et al., 2011).

Thriving in freshwater wetland habitats seems to be a trait that is widely distributed in the different cultivated and uncultivated family level lineages of the DsrAB tree. Furthermore, all of the uncultured $d s r A B$ lineages that contained $d s r A B$ from freshwater wetlands also contained $d s r A B$ from many other environments (Figure 3). These environments include deep marine methanogenic sediments (Leloup et al., 2007, 2009), which are also characterized by low-sulfate concentrations and ongoing, albeit very slow, dissimilatory sulfate reduction (Holmkvist et al., $2011 \mathrm{a}, \mathrm{b})$. In addition to environments with low-sulfate concentrations, all of the uncultured family level $d s r A B$ lineages that contained $d s r A B$ from freshwater wetlands also contained $d s r A B$ from habitats influenced by both low and high sulfate concentrations such as polluted coastal aquifers (Wu et al., 2009) and estuarine sediments (Jiang et al., 2009) or habitats with permanently high sulfate concentrations comprising marine surface sediments (Leloup et al., 2007, 2009), hydrothermal vents (Dhillon et al., 2003; Mussmann et al., 2005), and hot springs (Fishbain et al., 2003). This observation emphasizes the ubiquitous distribution of members of these uncultured $d s r A B$ lineages, suggesting that adaptation to different sulfate concentrations is not a trait that leads to ecologically coherent $\operatorname{ds} A B$ sequence groups at the approximate taxonomic/phylogenetic rank of families.

Peatlands in the forested Lehstenbach catchment (Bavaria, Germany) represent attractive model ecosystems for wetland SRM studies due to the extensive characterization of their biogeochemistry and microbiota and the deposition of sulfur by acid rain 


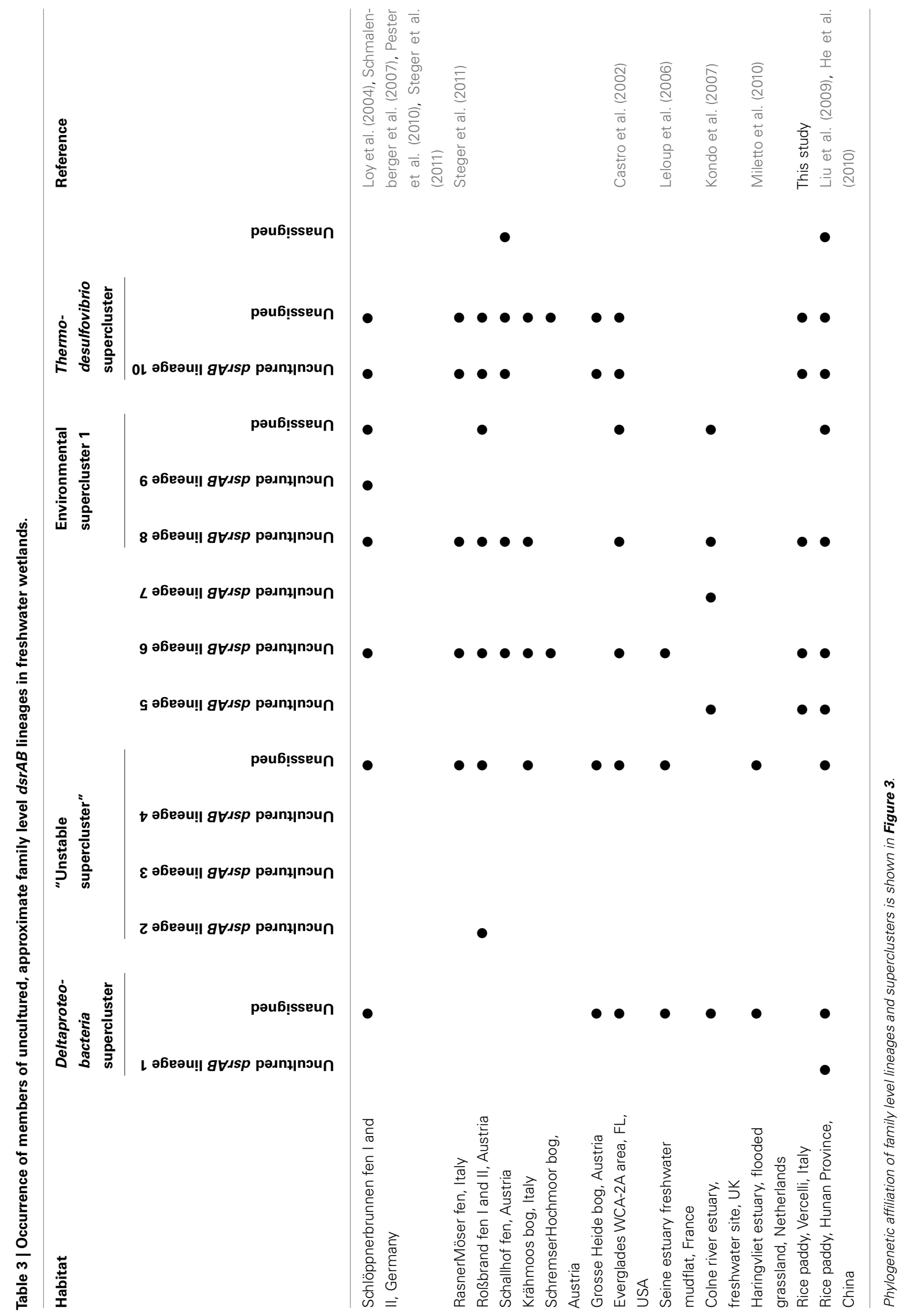




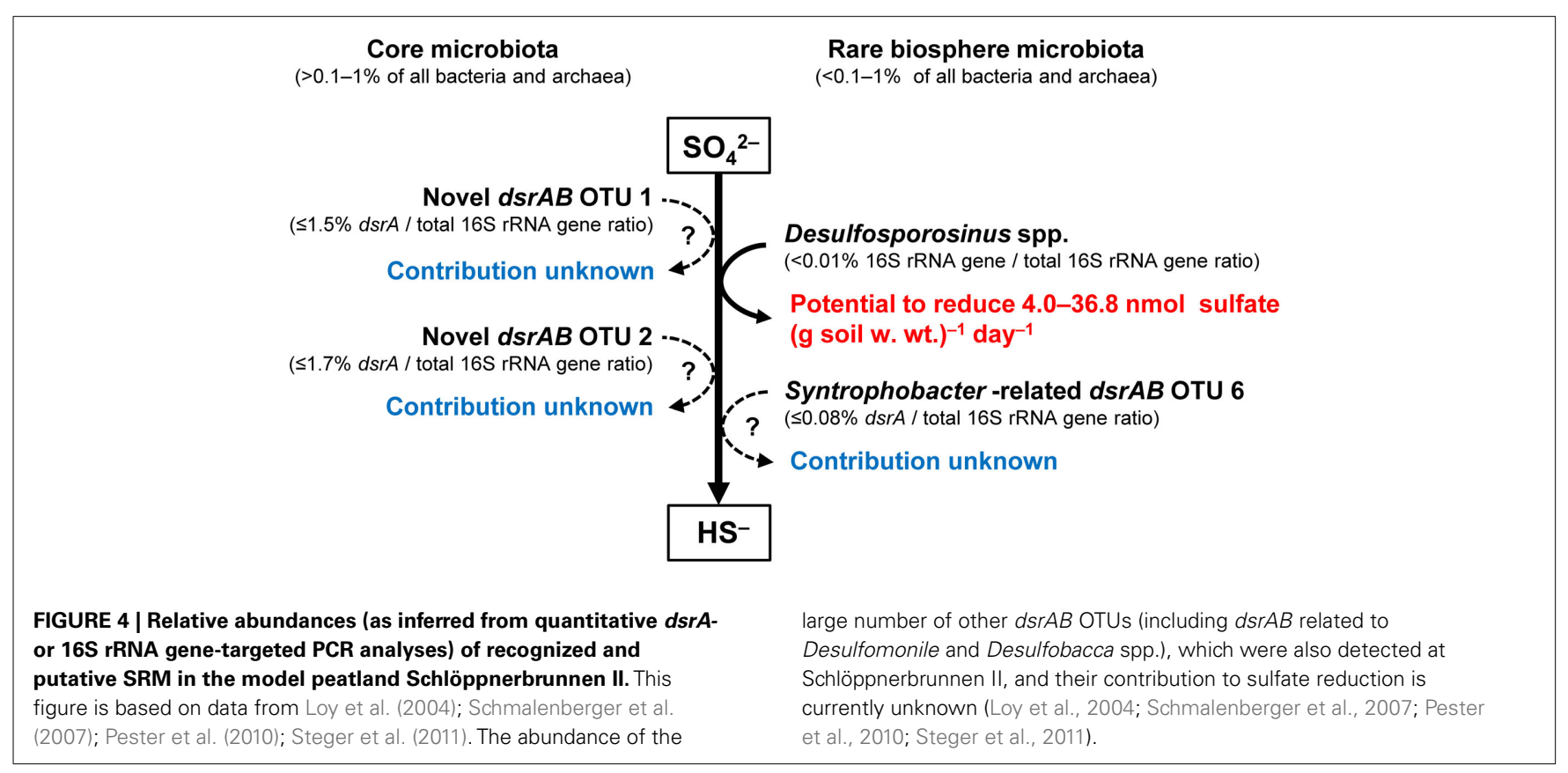

during the second half of the last century (Alewell and Novak, 2001; Matzner, 2004; Novak et al., 2005; Alewell et al., 2006; Schmalenberger et al., 2007; Küsel et al., 2008; Knorr and Blodau, 2009; Knorr et al., 2009). They are currently also the best studied wetlands with respect to the composition and environmental dynamics of $d s r A B$-containing microorganisms (Loy et al., 2004; Schmalenberger et al., 2007; Pester et al., 2010; Steger et al., 2011). In particular, the fen Schlöppnerbrunnen II comprises at least 53 different operational taxonomic units (OTUs) of $d s r A B$ at the approximate species level (Loy et al., 2004; Schmalenberger et al., 2007; Pester et al., 2010; Steger et al., 2011). More than half of these $d s r A B$ OTUs (28 out of 53 ) belong to the uncultured lineage 8 within the "environmental supercluster 1". Based on a $\operatorname{ds} A B$ microarray analysis over a 6-year period, two species level OTUs of lineage 8 (OTU 2 and 14) and two OTUs loosely affiliated to D. acetoxidans (OTU 1 and 4) were shown to dominate the $d s r A B$ diversity in the Schlöppnerbrunnen fen II. A parallel quantitative PCR analysis of OTU 1 and OTU 2 revealed that microorganisms carrying the respective $d s r A B$ each represent up to about $1-2 \%$ of the microbial community (Steger et al., 2011; Figure 4). Given this relatively high abundance for a single microbial species in soils, these microorganisms represent "core" members of the autochthonous microbial community in this wetland and certainly have an important, albeit unknown function in biogeochemical cycling (Pedrós-Alió, 2012). It would be tempting to speculate that these unknown microorganisms represent novel SRM that are actively involved in sulfate reduction in situ. However, $d s r A B$ is present not only in SRM but also in microorganisms capable of sulfite (e.g., Desulfitobacterium spp., Spring and Rosenzweig, 2006) or organosulfonate reduction (e.g., Bilophila wadsworthia, Laue et al., 2001). Furthermore, some microorganisms harboring $d s r A B$ can switch between a sulfate reducing and syntrophic lifestyle or, in the extreme case, are not capable of sulfate/sulfite reduction at all. Members of the deltaproteobacterial genus Syntrophobacter are prime examples for microorganisms that can perform dissimilatory sulfate reduction for energy generation but prefer to release generated reducing equivalents to syntrophically associated methanogens or other SRM (Wallrabenstein et al., 1994, 1995; Harmsen et al., 1998). Even more intriguing examples are Pelotomaculum spp. within the Desulfotomaculum cluster I. These syntrophic microorganisms, which typically thrive in anoxic, methanogenic environments, possibly lost the capability for sulfate reduction due to the need to adapt to low-sulfate conditions during the course of evolution. In accordance with their physiological properties, $d s r A B$ could not be detected by PCR assays in most Pelotomaculum spp. - with one exception. The type strain Pelotomaculum propionicicum MGP possesses $d s r A B$ and even transcribes these genes in the presence and, most astonishingly, also in the absence of sulfate (Imachi et al., 2006). Since $P$. propionicicum is an obligate syntroph (Imachi et al., 2007), this exemplifies that the mere presence or even transcription of $d s r A B$ does not necessarily mean that the corresponding microorganisms perform dissimilatory sulfate or sulfite reduction. Interestingly, syntrophic $d s r A B$-containing non-sulfite/sulfate reducers, syntrophic SRM, and "bona fide" sulfite/sulfate reducers can be very closely related, indicating an evolutionary association between the ability to respire sulfite/sulfate and the syntrophic lifestyle.

Linking phylogenetic information obtained from a molecular marker gene such as $16 \mathrm{~S}$ rRNA or $d s r A B$ with the physiological capability for dissimilatory sulfate reduction is not straightforward. However, great progress has been made through development of methods that combine molecular and isotope analysis to identify microorganisms metabolizing a supplemented isotopelabeled substrate under defined experimental conditions (Loy and Pester, 2010). A recent DNA stable isotope probing study of soil from Schlöppnerbrunnen fen II, using in situ concentrations of typical ${ }^{13} \mathrm{C}$-labeled carbon degradation intermediates (mixture of lactate, acetate, formate, and propionate) found no 
differential labeling of novel $d s r A B$ under sulfate-reducing versus methanogenic conditions, leaving it unexplained whether the corresponding microorganisms were active under none or both of the provided conditions (Pester et al., 2010). Therefore, it still remains unresolved whether wetland microorganisms with phylogenetically novel $d s r A B$ types are SRM, syntrophs, or capable of switching between both lifestyles.

\section{THE RARE BIOSPHERE COULD CONTRIBUTE TO PEATLAND SULFATE REDUCTION}

Microbial communities in the environment are typically composed of abundant or "core" taxa, which are considered to carry out most ecosystem functions, and a very large number of highly diverse but low abundance taxa (less than $0.1-1 \%$ of all bacteria and archaea), which are referred to as the "rare biosphere" (Pedrós-Alió, 2006; Sogin et al., 2006; Fuhrman, 2009). Other than an inventory of their $16 \mathrm{~S}$ rRNA genes very little is known about the ecological role of the "rare biosphere," which is also true for freshwater wetlands. Experimental evidence is gathering that rare microorganisms result from historical ecological change with the potential to become dominant in response to shifts in environmental conditions - the "microbial seed bank" concept (Dethlefsen et al., 2008; Brazelton et al., 2010; Lennon and Jones, 2011) or that they simply result from random dispersal (Hubert et al., 2009). In contrast to the majority of these dormant populations, it was recently found that "rare biosphere" members could also actively contribute to ecosystem functions and in this particular case to peatland sulfate reduction and carbon cycling (Figure 4). Comparative DNA stable isotope probing (Loy and Pester, 2010) of Schlöppnerbrunnen fen II soil under sulfatereducing and methanogenic conditions showed that a Desulfosporosinus spp., which constitutes only a minor proportion of the archaeal and bacterial community $(0.006 \%$ relative $16 \mathrm{~S}$ rRNA gene abundance), could be an important SRM in this particular peatland. For the identified Desulfosporosinus population, a high cell-specific SRR of up to $341 \mathrm{fmol} \mathrm{SO}_{4}^{2-}$ cell $^{-1}$ day $^{-1}$ was estimated (Pester et al., 2010), which was comparable to the highest cell-specific rates reported for SRM in pure culture (Detmers et al., 2001). Quantifying the Desulfosporosinus populations at different soil depths and relating the observed abundances to the estimated cell-specific rates revealed that they had the potential to reduce sulfate in situ at a rate of up to $4.0-36.8 \mathrm{nmol}$ (g soil $\mathrm{w}$. wt. $)^{-1}$ day $^{-1}$ (Pester et al., 2010). This could explain a considerable fraction of the radiotracer-measured SRRs of the same peatland, which ranged from 0 to ca. $340 \mathrm{nmol}$ (g soil w. wt. $)^{-1}$ day $^{-1}$ over a depth profile of $0-30 \mathrm{~cm}$ and a 300 -days period (Knorr and Blodau, 2009; Knorr et al., 2009). Modeling of sulfate diffusion to such highly active cells revealed sufficient sulfate supply even at bulk concentrations as low as $10 \mu \mathrm{M}$ (Pester et al., 2010). In addition, apparent sulfate half-saturation concentrations, $K_{\mathrm{m}}$, for sulfate reducers in pure culture (Pallud and Van Cappellen, 2006 and references therein) and in sediment slurries (Tarpgaard et al., 2011) have been reported to be as low as $2-5 \mu \mathrm{M}$ indicating no kinetic limitation from the electron acceptor side as well. These findings indicated that the identified peatland Desulfosporosinus sp. has the potential to contribute considerably to peatland sulfate reduction despite its very low abundance.
In the Schlöppnerbrunnen fen II, currently only one additional putative SRM, the Syntrophobacter-related dsrAB OTU 6, has been shown by quantitative PCR to be a autochthonous member of the "rare biosphere" (Figure 4; Steger et al., 2011). However, based on microarray analysis, a large fraction of the analyzed Schlöppnerbrunnen $d s r A B$ OTUs were of low relative abundance or below the detection limit (Steger et al., 2011) and it can be assumed that a large part of the detected $d s r A B$ diversity belongs to microorganisms that are part of the "rare biosphere" as well. However, in contrast to the rare peatland Desulfosporosinus spp., their contribution to peatland sulfate reduction is still unclear.

\section{CONCLUSION AND PERSPECTIVES}

It has long been known that dissimilatory sulfate reduction occurs in freshwater wetlands, with pioneering studies dating back to the 1980s (Table 1 and references therein). Although the measured rates were often comparable to or partly exceeded SRR in marine environments (Jørgensen, 1982; Howarth and Jørgensen, 1984; Skyring, 1987), the importance of sulfate reduction to anaerobic carbon mineralization in wetlands is still often neglected. This can be mainly attributed to the current inability to quantitatively explain how the small sulfate pools are rapidly replenished to maintain the high SRR that can be repeatedly measured in different wetland types and over prolonged periods of time. Several concepts for this apparently hidden sulfur cycle, which is not only occurring at oxic-anoxic interfaces but also in anoxic soil layers, have been put forward but need further experimental confirmation, especially in the context of the intertwined redoxcycles of sulfur and iron compounds as well as of redox-active organic matter (Figure 2). In particular, there is a need to systematically quantify the varying contribution of sulfate reduction to overall anaerobic carbon degradation and to determine fluxes of sulfur recycling through the proposed intermediates elemental sulfur and thiosulfate in the oxic-anoxic transition zone and under completely anoxic conditions.

The identification of microorganisms responsible for sulfate reduction in freshwater wetlands has just begun. Molecular surveys have revealed that many members of the autochthonous wetland microbiota harbor diverse and novel variants of the marker genes $d s r A B$. However, at the moment it is not known whether these novel $d s r A B$-containing microorganisms perform dissimilatory sulfate reduction, are capable of alternative energy generation through syntrophy with methanogens, or switch between these different lifestyles depending on the prevailing environmental conditions. Targeted cultivation and substrate-mediated isotope labeling approaches thus need to be employed more systematically to detect "true" SRM in wetlands. The identification of a peatland Desulfosporosinus spp. by stable isotope probing as an active "rare biosphere" member with potentially high cell-specific SRR (Pester et al., 2010) and the cultivation of SRM from rice paddy soil (Wind and Conrad, 1995; Wind et al., 1999) provide examples for the success of such approaches. Comparative genomics of SRM strains isolated from contrasting environments that differ in biogeochemical parameters, such as sulfate concentration, availability of nutrients and/or $\mathrm{pH}$, provide useful information on the different genomic and metabolic features that SRM have evolved to become a ubiquitously distributed microbial guild (Plugge et al., 
2011; Zhou et al., 2011). Extending genome analyses to single cells (Podar et al., 2007; Woyke et al., 2009, 2010) retrieved directly from wetland soils could lay the foundation to identify microorganisms that harbor the great diversity of novel $d s r A B$ found in wetlands and to get insights into their evolution and potential metabolic capabilities. Along with high-throughput amplicon sequencing of $d s r A / B$ - or $16 \mathrm{~S}$ rRNA genes and their transcripts in context with measurements of biogeochemical parameters and processes, these approaches will be crucial to identify SRM and understand their community dynamics and various life strategies in such heterogeneous environments such as wetlands.

\section{REFERENCES}

Achtnich, C., Bak, F., and Conrad, R. (1995). Competition for electron donors among nitrate reducers, ferric iron reducers, sulfate reducers, and methanogens in anoxic paddy soil. Biol. Fertil. Soils 19, 65-72.

Aeschbacher, M., Sander, M., and Schwarzenbach, R. P. (2010). Novel electrochemical approach to assess the redox properties of humic substances. Environ. Sci. Technol. 44, 87-93.

Alewell, C., and Gehre, M. (1999). Patterns of stable $\mathrm{S}$ isotopes in a forested catchment as indicators for biological S turnover. Biogeochemistry 47, 319-333.

Alewell, C., and Novak, M. (2001). Spotting zones of dissimilatory sulfate reduction in a forested catchment: the 34 S-35S approach. Environ. Pollut. 112, 369-377.

Alewell, C., Paul, S., Lischeid, G., and Storck, F. R. (2008). Co-regulation of redox processes in freshwater wetlands as a function of organic matter availability? Sci. Total Environ. 404, 335-342.

Alewell, C., Paul, S., Lischeld, G., Kuesel, K., and Gehre, M. (2006). Characterizing the redox status in three different forested wetlands with geochemical data. Environ. Sci. Technol. 40, 7609-7615.

Baani, M., and Liesack, W. (2008). Two isozymes of particulate methane monooxygenase with different methane oxidation kinetics are found in Methylocystis sp. strain SC2. Proc. Natl. Acad. Sci. U.S.A. 105, 10203-10208.

Bak, F., and Cypionka, H. (1987). A novel type of energy metabolism involving fermentation of inorganic sulphur compounds. Nature 326, 891-892.

Bak, F., and Pfennig, N. (1991a). Microbial sulfate reduction in littoral sediment of Lake Constance. FEMS Microbiol. Ecol. 85, 31-42.

Bak, F., and Pfennig, N. (1991b). Sulfate-reducing bacteria in littoral sediment of Lake Constance. FEMS Microbiol. Ecol. 85, 43-52.

Batzer, D. P., and Sharitz, R. R. (2006). "Ecology of freshwater and estuarine wetlands. An introduction," in Ecology of Freshwater and Estuarine Wetlands, eds D. P. Batzer and R. R. Sharitz (Berkeley: University of California Press), 1-6.

Beer, J., Lee, K., Whiticar, M., and Blodau, C. (2008). Geochemical controls on anaerobic organic matter decomposition in a northern peatland. Limnol. Oceanogr. 53, 1393-1407.

Blodau, C. (2002). Carbon cycling in peatlands - a review of processes and controls. Environ. Rev. 10, 111-134.

Blodau, C., Mayer, B., Peiffer, S., and Moore, T. R. (2007). Support for an anaerobic sulfur cycle in two Canadian peatland soils. J. Geophys. Res. 112, 1-10.

Bosch, J., Lee, K.-Y., Jordan, G., Kim, K.W., and Meckenstock, R. U. (2012). Anaerobic, nitrate-dependent oxidation of pyrite nanoparticles by Thiobacillus denitrificans. Environ. Sci. Technol. doi:10.1021/es2022329

Bottrell, S. H., Hatfield, D., Bartlett, R., Spence, M. J., Bartle, K. D., and Mortimer, R. J. G. (2010). Concentrations, sulfur isotopic compositions and origin of organosulfur compounds in pore waters of a highly polluted raised peatland. Org. Geochem. 41, 55-62.

Brazelton, W. J., Ludwig, K. A., Sogin, M. L., Andreishcheva, E. N., Kelley, D. S., Shen, C.-C., Edwards, R. L., and Baross, J. A. (2010). Archaea and bacteria with surprising microdiversity show shifts in dominance over 1,000-year time scales in hydrothermal chimneys. Proc. Natl. Acad. Sci. U.S.A. 107, 1612-1617.

Bridgham, S. D., Megonigal, J. P., Keller, J. K., Bliss, N. B., and Trettin, C. (2006). The carbon balance of North American wetlands. Wetlands 26, 889-916.

\section{ACKNOWLEDGMENTS}

We are grateful to Kirsten Küsel, Harold Drake, and Christian Blodau for introducing us to the ecology of SRM and to the biogeochemical cycles at the Schlöppnerbrunnen fens. We heartily thank Kasper U. Kjeldsen for his continuous contributions to the ${ }_{s} r A B$ database. Bianca Pommerenke and Albert Müller are acknowledged for sequencing of $d s r A B$ from rice paddy soil and for $d s r A B$ database update and maintenance, respectively. This research was funded by the Austrian Science Fund (FWF): P23117-B17 to Michael Pester; P18836-B17 and P20185-B17 to Alexander Loy.

Brown, K. A. (1986). Formation of organic sulfur in anaerobic peat. Soil Biol. Biochem. 18, 131-140.

Brüchert, V. (1998). Early diagenesis of sulfur in estuarine sediments: the role of sedimentary humic and fulvic acids. Geochim. Cosmochim. Acta 62, 1567-1586.

Brune, A., Frenzel, P., and Cypionka, H. (2000). Life at the oxic-anoxic interface: microbial activities and adaptations. FEMS Microbiol. Rev. 24, 691-710.

Canfield, D. E. (1989). Reactive iron in marine sediments. Geochim. Cosmochim. Acta 53, 619-632.

Canfield, D. E., Kristensen, E., and Thamdrup, B. (2005). "The sulfur cycle," in Aquatic Geomicrobiology, eds D. E. Canfield, E. Kristensen, and B. Thamdrup (London: Academic Press), 313-381.

Canfield, D. E., Raiswell, R., and Bottrell, S. (1992). The reactivity of sedimentary iron minerals toward sulfide. Am. J. Sci. 292, 659-683.

Canfield, D. E., Raiswell, R., Westrich, J. T., Reaves, C. M., and Berner, R. A. (1986). The use of chromium reduction in the analysis of reduced inorganic sulfur in sediments and shales. Chem. Geol. 54, 149-155.

Castro, H., Reddy, K. R., and Ogram, A. (2002). Composition and function of sulfate-reducing prokaryotes in eutrophic and pristine areas of the Florida Everglades. Appl. Environ. Microbiol. 68, 6129-6137.

Chapman, S. J., and Davidson, M. S. (2001). 35S-sulphate reduction and transformation in peat. Soil Biol. Biochem. 33, 593-602.

Chauhan, A., and Ogram, A. (2006a). Fatty acid-oxidizing consortia along a nutrient gradient in the Florida Everglades. Appl. Environ. Microbiol. 72, 2400-2406.

Chauhan, A., and Ogram, A. (2006b). Phylogeny of acetate-utilizing microorganisms in soils along a nutrient gradient in the Florida Everglades. Appl. Environ. Microbiol. $72,6837-6840$.
Clymo, R. S. (1984). The limits to peat bog growth. Philos. Trans. R. Soc Lond. B Biol. Sci. 303, 605-654.

Conrad, R. (2002). Control of microbial methane production in wetland rice fields. Nutr. Cycl. Agroecosyst. 64, 59-69.

Costello, E. K., and Schmidt, S. K. (2006). Microbial diversity in alpine tundra wet meadow soil: novel Chloroflexi from a cold, water-saturated environment. Environ. Microbiol. 8 1471-1486.

Dalsgaard, T., and Bak, F. (1994). Nitrate reduction in a sulfate-reducing bacterium, Desulfovibrio desulfuricans, isolated from rice paddy soil: sulfide inhibition, kinetics, and regulation. Appl. Environ. Microbiol. 60, 291-297.

Dedysh, S. N., Derakshani, M., and Liesack, W. (2001). Detection and enumeration of methanotrophs in acidic Sphagnum peat by 16 S rRNA fluorescence in situ hybridization, including the use of newly developed oligonucleotide probes for Methylocella palustris. Appl. Environ. Microbiol. 67, 4850-4857.

Dedysh, S. N., Pankratov, T. A., Belova, S. E., Kulichevskaya, I. S., and Liesack, W. (2006). Phylogenetic analysis and in situ identification of bacteria community composition in an acidic Sphagnum peat bog. Appl. Environ. Microbiol. 72, 2110-2117.

Deppe, M., McKnight, D. M., and Blodau, C. (2009). Effects of short-term drying and irrigation on electron flow in mesocosms of a northern bog and an alpine fen. Environ. Sci. Technol. 44, 80-86.

Dethlefsen, L., Huse, S., Sogin, M. L., and Relman, D. A. (2008). The pervasive effects of an antibiotic on the human gut microbiota, as revealed by deep $16 \mathrm{~S}$ rRNA sequencing. PLoS Biol. 6, e280. doi:210.1371/journal.pbio.0060280

Detmers, J., Bruchert, V., Habicht, K. S., and Kuever, J. (2001). Diversity of sulfur isotope fractionations by sulfate-reducing prokaryotes. Appl. Environ. Microbiol. 67, 888-894. 
Dhillon, A., Teske, A., Dillon, J., Stahl, D. A., and Sogin, M. L. (2003). Molecular characterization of sulfate reducing bacteria in the Guaymas Basin. Appl. Environ. Microbiol. 69, 2765-2772.

Dise, N., and Verry, E. (2001). Suppression of peatland methane emission by cumulative sulfate deposition in simulated acid rain. Biogeochemistry $53,143-160$

Dise, N. B. (2009). Peatland response to global change. Science 326, 810-811.

Elsgaard, L., and Jørgensen, B. B. (1992). Anoxic transformations of radiolabeled hydrogen-sulfide in marine and fresh-water sediments. Geochim. Cosmochim. Acta 56, 2425-2435.

Felsenstein, J. (1989). PHYLIPphylogeny inference package. Cladistics 5, 164-166.

Ferdelman, T. G., Church, T. M., and Luther Iii, G. W. (1991). Sulfur enrichment of humic substances in a Delaware salt marsh sediment core. Geochim. Cosmochim. Acta 55, 979-988.

Fishbain, S., Dillon, J. G., Gough, H. L., and Stahl, D. A. (2003). Linkage of high rates of sulfate reduction in Yellowstone hot springs to unique sequence types in the dissimilatory sulfate respiration pathway. Appl. Environ. Microbiol. 69, 3663-3667.

Fleckenstein, J. H., Frei, S., and Knorr, K. H. (2011). "Modelling interactions between hydrologic dynamics and biogeochemical processes in a riparian wetland of a low-order stream," in IUGG 2011, eds C. Abesser, G. Nützmann, M. C. Hill, G. Blöschl, and E. Lakshmanan (Melbourne: IAHS Red Books), 87-92.

Fossing, H. (1995). "S-35-radiolabeling to probe biogeochemical cycling of sulfur," in Geochemical Transformations of Sedimentary Sulfur, eds M. A. Vairavamurthy and M. A. A. Schoonen (Washington: American Chemical Society), 348-364.

Fossing, H., and Jørgensen, B. B. (1989). Measurement of bacterial sulfate reduction in sediments - evaluation of a single-step chromium reduction method. Biogeochemistry 8, 205-222.

Fossing, H., and Jørgensen, B. B. (1990). Isotope exchange reactions with radiolabeled sulfur compounds in anoxic seawater. Biogeochemistry 9 , 223-245.

Friedrich, C. G., Bardischewsky, F., Rother, D., Quentmeier, A., and Fischer, J. (2005). Prokaryotic sulfur oxidation. Curr. Opin. Microbiol. 8, 253-259.
Frolking, S., Roulet, N. T., Moore, T. R., Richard, P. J. H., Lavoie, M., and Muller, S. D. (2001). Modeling northern peatland decomposition and peat accumulation. Ecosystems 4, 479-498.

Fuhrman, J. A. (2009). Microbial community structure and its functional implications. Nature 459, 193-199.

Gauci, V., Dise, N., and Fowler, D. (2002). Controls on suppression of methane flux from a peat bog subjected to simulated acid rain sulfate deposition. Global Biogeochem. Cycles 16, doi:10.1029/2000gb001370

Gauci, V., Dise, N. B., Howell, G., and Jenkins, M. E. (2008). Suppression of rice methane emission by sulfate deposition in simulated acid rain. J. Geophys. Res. 113, doi:10.1029/2007JG000501.

Gauci, V., Matthews, E., Dise, N., Walter, B., Koch, D., Granberg, G., and Vile, M. (2004). Sulfur pollution suppression of the wetland methane source in the 20th and 21st centuries. Proc. Natl. Acad. Sci. U.S.A. 101, 12583-12587.

Ghani, A., McLaren, R. G., and Swift, R. S. (1993). Mobilization of recently formed soil organic sulfur. Soil Biol. Biochem. 25, 1739-1744.

Gregersen, L. H., Bryant, D. A., and Frigaard, N.-U. (2011). Mechanisms and evolution of oxidative sulfur metabolism in green sulfur bacteria. Front. Microbio. 2:116. doi:10.3389/fmicb.2011.00116

Groscheova, H., Novak, M., and Alewell, C. (2000). Changes in the delta S-34 ratio of pore-water sulfate in incubated Sphagnum peat. Wetlands 20, 62-69.

Haaijer, S. C. M., Lamers, L. P. M., Smolders, A. J. P., Jetten, M. S. M., and Den Camp, H. (2007). Iron sulfide and pyrite as potential electron donors for microbial nitrate reduction in freshwater wetlands. Geomicrobiol. J. 24, 391-401.

Hamberger, A., Horn, M. A., Dumont, M. G., Murrell, J. C., and Drake, H. L. (2008). Anaerobic consumers of monosaccharides in a moderately acidic fen. Appl. Environ. Microbiol. 74, 3112-3120.

Harmsen, H. J. M., Van Kuijk, B. L. M., Plugge, C. M., Akkermans, A. D. L., De Vos, W. M., and Stams, A. J. M. (1998). Syntrophobacter fumaroxidans sp. nov., a syntrophic propionate-degrading sulfate-reducing bacterium. Int. J. Syst. Bacteriol. 48, 1383-1387.

He, J. Z., Liu, X. Z., Zheng, Y., Shen, J. P., and Zhang, L. M. (2010). Dynamics of sulfate reduction and sulfate- reducing prokaryotes in anaerobic paddy soil amended with rice straw. Biol. Fertil. Soils 46, 283-291.

Heitmann, T., and Blodau, C. (2006). Oxidation and incorporation of hydrogen sulfide by dissolved organic matter. Chem. Geol. 235, 12-20.

Heitmann, T., Goldhammer, T., Beer, J., and Blodau, C. (2007). Electron transfer of dissolved organic matter and its potential significance for anaerobic respiration in a northern bog. Glob. Chang. Biol. 13, 1771-1785

Holler, T., Wegener, G., Niemann, H., Deusner, C., Ferdelman, T. G., Boetius, A., Brunner, B., and Widdel, F. (2011). Carbon and sulfur back flux during anaerobic microbial oxidation of methane and coupled sulfate reduction. Proc. Natl. Acad. Sci. U.S.A. 108, E1484-E1490.

Holmkvist, L., Ferdelman, T. G., and Jørgensen, B. B. (2011a). A cryptic sulfur cycle driven by iron in the methane zone of marine sediment (Aarhus Bay, Denmark). Geochim. Cosmochim. Acta 75, 3581-3599.

Holmkvist, L., Kamyshny, A. Jr., Vogt, C., Vamvakopoulos, K., Ferdelman, T. G., and Jørgensen, B. B. (2011b). Sulfate reduction below the sulfatemethane transition in Black Sea sediments. Deep Sea Res. Part I Oceanogr. Res. Pap. 58, 493-504.

Hori, T., Muller, A., Igarashi, Y. Conrad, R., and Friedrich, M. W. (2010). Identification of ironreducing microorganisms in anoxic rice paddy soil by C-13-acetate probing. ISME J. 4, 267-278.

Horn, M. A., Matthies, C., Kuesel, K., Schramm, A., and Drake, H. L. (2003). Hydrogenotrophic methanogenesis by moderately acidtolerant methanogens of a methaneemitting acidic peat. Appl. Environ. Microbiol. 69, 74-83.

Houweling, S., Kaminski, T., Dentener, F., Lelieveld, J., and Heimann, M. (1999). Inverse modeling of methane sources and sinks using the adjoint of a global transport model. J. Geophys. Res. 104, 26137-26160.

Howarth, R. W., and Jørgensen, B. B. (1984). Formation of 35S-labelled elemental sulfur and pyrite in coastal marine sediments (Limfjorden and Kysing Fjord, Denmark) during short-term 35SO42-reduction measurements. Geochim. Cosmochim. Acta 48, 1807-1818.

Hubert, C., Loy, A., Nickel, M., Arnosti, C., Baranyi, C., Bruchert, V., Ferdelman, T., Finster, K., Christensen, F. M., Rosa De Rezende, J., Vandieken,
V., and Jørgensen, B. B. (2009). A constant flux of diverse thermophilic bacteria into the cold arctic seabed. Science 325, 1541-1544.

Imachi, H., Sakai, S., Ohashi, A., Harada, H., Hanada, S., Kamagata, Y., and Sekiguchi, Y. (2007). Pelotomaculum propionicicum sp. nov., an anaerobic, mesophilic, obligately syntrophic propionate-oxidizing bacterium. Int. J. Syst. Evol. Microbiol. 57, 1487-1492.

Imachi, H., Sekiguchi, Y., Kamagata, Y., Loy, A., Qiu, Y. L., Hugenholtz, P., Kimura, N., Wagner, M., Ohashi, A., and Harada, H. (2006). Nonsulfate-reducing, syntrophic bacteria affiliated with Desulfotomaculum cluster I are widely distributed in methanogenic environments. Appl. Environ. Microbiol. 72, 2080-2091.

Ingvorsen, K., Zeikus, J. G., and Brock, T. D. (1981). Dynamics of bacterial sulfate reduction in a eutrophic lake. Appl. Environ. Microbiol. 42, 1029-1036.

IPCC. (2007). Contribution of Working Groups I, II and III to the Fourth Assessment Report of the Intergovernmental Panel on Climate Change. Cambridge: Cambridge University Press.

Jacks, G., and Norrström, A. C. (2004). Hydrochemistry and hydrology of forest riparian wetlands. For. Ecol. Manage. 196, 187-197.

Jackson, C. R., Liew, K. C., and Yule, C. M. (2009). Structural and functional changes with depth in microbial communities in a tropical Malaysian peat swamp forest. Microb. Ecol. 57, 402-412.

Jiang, L. J., Zheng, Y. P., Peng, X. T., Zhou, H. Y., Zhang, C. L., Xiao, X., and Wang, F. P. (2009). Vertical distribution and diversity of sulfatereducing prokaryotes in the Pearl River estuarine sediments, Southern China. FEMS Microbiol. Ecol. 70, 249-262.

Jørgensen, B. B. (1978). Comparison of methods for the quantification of bacterial sulfate reduction in coastal marine sediments. 1. Measurements with radiotracer techniques. Geomicrobiol. J. 1, 11-27.

Jørgensen, B. B. (1982). Mineralization of organic matter in the sea bed - the role of sulphate reduction. Nature 296, 643-645.

Jørgensen, B. B. (1990). The sulfur cycle of fresh-water sediments - role of thiosulfate. Limnol. Oceanogr. 35, 1329-1342.

Jørgensen, C. J., Jacobsen, O. S., Elberling, B., and Aamand, J. (2009). Microbial oxidation of pyrite coupled to nitrate reduction in anoxic 
groundwater sediment. Environ. Sci. Technol. 43, 4851-4857.

Kallmeyer, J., Ferdelman, T. G., Weber, A., Fossing, H., and Jørgensen, B. B. (2004). A cold chromium distillation procedure for radiolabeled sulfide applied to sulfate reduction measurements. Limnol. Oceanogr. Methods 2, 171-180.

Kayranli, B., Scholz, M., Mustafa, A., and Hedmark, A. (2010). Carbon storage and fluxes within freshwater wetlands: a critical review. Wetlands 30, 111-124.

Keller, J. K., and Bridgham, S. D. (2007). Pathways of anaerobic carbon cycling across an ombrotrophicminerotrophic peatland gradient. Limnol. Oceanogr. 52, 96-107.

Kelly, D. P., Shergill, J. K., Lu, W. P., and Wood, A. P. (1997). Oxidative metabolism of inorganic sulfur compounds by bacteria. Antonie Van Leeuwenhoek 71, 95-107.

Kendall, M. M., Liu, Y., and Boone, D. R. (2006). Butyrate- and propionatedegrading syntrophs from permanently cold marine sediments in Skan Bay, Alaska, and description of Algorimarina butyrica gen. nov., sp. nov. FEMS Microbiol. Lett. 262, 107-114.

Kertesz, M. A. (2000). Riding the sulfur cycle-metabolism of sulfonates and sulfate esters in Gram-negative bacteria. FEMS Microbiol. Rev. 24, 135-175.

King, G. M. (2001). "Radiotracer assays (S-35) of sulfate reduction rates in marine and freshwater sediments," in Methods in Microbiology, ed. J. H. Paul (San Diego: Academic Press Inc.), 489-500.

Knittel, K., and Boetius, A. (2009). Anaerobic oxidation of methane: progress with an unknown process. Annu. Rev. Microbiol. 63, 311-334.

Knorr, K.-H., and Blodau, C. (2009). Impact of experimental drought and rewetting on redox transformations and methanogenesis in mesocosms of a northern fen soil. Soil Biol. Biochem. 41, 1187-1198.

Knorr, K. H., Lischeid, G., and Blodau, C. (2009). Dynamics of redox processes in a minerotrophic fen exposed to a water table manipulation. Geoderma 153, 379-392.

Kögel-Knabner, I., Amelung, W., Cao, Z., Fiedler, S., Frenzel, P., Jahn, R., Kalbitz, K., Koelbl, A., and Schloter, M. (2010). Biogeochemistry of paddy soils. Geoderma 157, 1-14.

Kondo, R., Purdy, K. J., Silva, S. D. Q., and Nedwell, D. B. (2007). Spatial dynamics of sulphate-reducing bacterial compositions in sediment along a salinity gradient in a UK estuary. Microbes Environ. 22, 11-19.

Koretsky, C. M., Haveman, M., Beuving, L., Cuellar, A., Shattuck, T., and Wagner, M. (2007). Spatial variation of redox and trace metal geochemistry in a minerotrophic fen. Biogeochemistry 86, 33-62.

Kraigher, B., Stres, B., Hacin, J., Ausec, L., Mahne, I., Van Elsas, J. D., and Mandic-Mulec, I. (2006). Microbial activity and community structure in two drained fen soils in the Ljubljana Marsh. Soil Biol. Biochem. 38, 2762-2771.

Küsel, K., Blothe, M., Schulz, D., Reiche, M., and Drake, H. L. (2008). Microbial reduction of iron and porewater biogeochemistry in acidic peatlands. Biogeosciences 5, 1537-1549.

Laue, H., Friedrich, M., Ruff, J., and Cook, A. M. (2001). Dissimilatory sulfite reductase (desulfoviridin) of the taurine-degrading, nonsulfate-reducing bacterium Bilophila wadsworthia RZATAU contains a fused DsrB-DsrD subunit. J. Bacteriol. 183, 1727-1733.

Lee, Y.-J., Romanek, C. S., and Wiegel, J. (2009). Desulfosporosinus youngiae sp. nov., a spore-forming, sulfatereducing bacterium isolated from a constructed wetland treating acid mine drainage. Int. J. Syst. Evol. Microbiol. 59, 2743-2746.

Leloup, J., Fossing, H., Kohls, K., Holmkvist, L., Borowski, C., and Jørgensen, B. B. (2009). Sulfatereducing bacteria in marine sediment (Aarhus Bay, Denmark): abundance and diversity related to geochemical zonation. Environ. Microbiol. 11, 1278-1291.

Leloup, J., Loy, A., Knab, N. J., Borowski, C., Wagner, M., and Jørgensen, B. B. (2007). Diversity and abundance of sulfate-reducing microorganisms in the sulfate and methane zones of a marine sediment, Black Sea. Environ. Microbiol. 9, 131-142.

Leloup, J., Petit, F., Boust, D., Deloffre, J., Bally, G., Clarisse, O., and Quillet, L. (2005). Dynamics of sulfatereducing microorganisms (dsrAB genes) in two contrasting mudflats of the Seine estuary (France). Microb. Ecol. 50, 307-314.

Leloup, J., Quillet, L., Berthe, T., and Petit, F. (2006). Diversity of the $\operatorname{ds} A B$ (dissimilatory sulfite reductase) gene sequences retrieved from two contrasting mudflats of the Seine estuary, France. FEMS Microbiol. Ecol. 55, 230-238.

Lennon, J. T., and Jones, S. E. (2011). Microbial seed banks: the ecological and evolutionary implications of dormancy. Nat. Rev. Microbiol. 9, 119-130.

Lie, T. J., Leadbetter, J. R., and Leadbetter, E. R. (1998). Metabolism of sulfonic acids and other organosulfur compounds by sulfate-reducing bacteria. Geomicrobiol. J. 15, 135-149.

Lie, T. J., Pitta, T., Leadbetter, E. R., Godchaux, W., and Leadbetter, J. R. (1996). Sulfonates: novel electron acceptors in anaerobic respiration. Arch. Microbiol. 166, 204-210.

Limpens, J., Berendse, F., Blodau, C., Canadell, J. G., Freeman, C., Holden, J., Roulet, N., Rydin, H., and Schaepman-Strub, G. (2008). Peatlands and the carbon cycle: from local processes to global implications a synthesis. Biogeosciences 5, 1475-1491.

Lindau, C. W., Bollich, P. K., Delaune, R. D., Mosier, A. R., and Bronson, K. F. (1993). Methane mitigation in flooded Louisiana rice fields. Biol. Fertil. Soils 15, 174-178.

Liu, X. Z., Zhang, L. M., Prosser, J. I., and He, J. Z. (2009). Abundance and community structure of sulfate reducing prokaryotes in a paddy soil of southern China under different fertilization regimes. Soil Biol. Biochem. 41, 687-694.

Lovley, D. R., and Klug, M. J. (1983). Sulfate reducers can outcompete methanogens at freshwater sulfate concentrations. Appl. Environ. Microbiol. 45, 187-192.

Lovley, D. R., and Phillips, E. J. P. (1994). Novel processes for anaerobic sulfate production from elemental sulfur by sulfate-reducing bacteria. Appl. Environ. Microbiol. 60, 2394-2399.

Loy, A., Duller, S., Baranyi, C., Mußmann, M., Ott, J., Sharon, I., Béjà, O., Le Paslier, D., Dahl, C., and Wagner, M. (2009). Reverse dissimilatory sulfite reductase as phylogenetic marker for a subgroup of sulfur-oxidizing prokaryotes. Environ. Microbiol. 11, 289-299.

Loy, A., Duller, S., and Wagner, M. (2008). "Evolution and ecology of microbes dissimilating sulfur compounds: insights from siroheme sulfite reductases," in Microbial Sulfur Metabolism, eds C. Dahl and C. G. Friedrich (Berlin: Springer), 46-59.

Loy, A., Küsel, K., Lehner, A., Drake, H. L., and Wagner, M. (2004). Microarray and functional gene analyses of sulfate-reducing prokaryotes in lowsulfate, acidic fens reveal cooccurrence of recognized genera and novel lineages. Appl. Environ. Microbiol. 70, 6998-7009.

Loy, A., and Pester, M. (2010). "Probing identity and physiology of uncultured microorganisms with isotopic labeling techniques," in Geomicrobiology: Molecular and Environmental Perspective, eds L. Barton, M. Mandl, and A. Loy (Heidelberg: Springer), 127-146.

Lu, Y. H., Rosencrantz, D., Liesack, W., and Conrad, R. (2006). Structure and activity of bacterial community inhabiting rice roots and the rhizosphere. Environ. Microbiol. 8, 1351-1360.

Ludwig, W., Strunk, O., Westram, R., Richter, L., Meier, H., Yadhukumar, Buchner, A., Lai, T., Steppi, S., Jobb, G., Forster, W., Brettske, I., Gerber, S., Ginhart, A. W., Gross, O., Grumann, S., Hermann, S., Jost, R., Konig, A., Liss, T., Lussmann, R., May, M., Nonhoff, B., Reichel, B., Strehlow, R., Stamatakis, A., Stuckmann, N., Vilbig, A., Lenke, M., Ludwig, T., Bode, A., and Schleifer, K.H. (2004). ARB: a software environment for sequence data. Nucleic Acids Res. 32, 1363-1371.

Mandernack, K. W., Lynch, L., Krouse, H. R., and Morgan, M. D. (2000). Sulfur cycling in wetland peat of the New Jersey Pinelands and its effect on stream water chemistry. Geochim. Cosmochim. Acta 64, 3949-3964.

Matzner, E. (2004). Biogeochemistry of Forested Catchments in a Changing Environment-A German Case Study. Berlin: Springer Verlag.

Miletto, M., Loeb, R., Antheunisse, A. M., Bodelier, P. L. E., and Laanbroek, H. J. (2010). Response of the sulfate-reducing community to the re-establishment of estuarine conditions in two contrasting soils: a mesocosm approach. Microb. Ecol. 59, 109-120.

Mitsch, W. J., and Gosselink, J. G. (2007). Wetlands. New York: John Wiley \& Sons, Inc.

Mitsch, W. J., Gosselink, J. G., Anderson, C. J., and Zhang, L. (2009). Wetland Ecosystems. New York: John Wiley \& Sons, Inc.

Moeslund, L., Thamdrup, B., and Jørgensen, B. B. (1994). Sulfur and iron cycling in a coastal sediment - radiotracer studies and seasonal dynamics. Biogeochemistry 27, 129-152.

Murase, J., and Kimura, M. (1997). Anaerobic reoxidation of $\mathrm{Mn}^{+}$, $\mathrm{Fe}^{+}{ }^{+}$, S0 and S2- in submerged paddy soils. Biol. Fertil. Soils 25, 302-306.

Musat, N., Werner, U., Knittel, K., Kolb, S., Dodenhof, T., Van Beusekom, J. E. E., De Beer, D., Dubilier, N., and Amann, R. (2006). Microbial community structure of sandy intertidal sediments in the North Sea, SyltRømø Basin, Wadden Sea. Syst. Appl. Microbiol. 29, 333-348. 
Mussmann, M., Richter, M., Lombardot, T., Meyerdierks, A., Kuever, J., Kube, M., Glockner, F. O., and Amann, R. (2005). Clustered genes related to sulfate respiration in uncultured prokaryotes support the theory of their concomitant horizontal transfer. J. Bacteriol. 187, 7126-7137.

Muyzer, G., and Stams, A. J. M. (2008). The ecology and biotechnology of sulphate-reducing bacteria. Nat. Rev. Microbiol. 6, 441-454.

Nedwell, D. B., and Watson, A. (1995). $\mathrm{CH} 4$ production, oxidation and emission in a UK ombrotrophic peat bog - influence of SO42- from acid rain. Soil Biol. Biochem. 27, 893-903.

Nielsen, L. P., Risgaard-Petersen, N., Fossing, H., Christensen, P. B., and Sayama, M. (2010). Electric currents couple spatially separated biogeochemical processes in marine sediment. Nature 463, 1071-1074.

Novak, M., Vile, M. A., Bottrell, S. H., Stepanova, M., Jackova, I., Buzek, F., Prechova, E., and Newton, R. J. (2005). Isotope systematics of sulfate-oxygen and sulfate-sulfur in six European peatlands. Biogeochemistry 76, 187-213.

Orcutt, B. N., Sylvan, J. B., Knab, N. J., and Edwards, K. J. (2011). Microbial ecology of the dark ocean above, at, and below the seafloor. Microbiol. Mol. Biol. Rev. 75, 361-422.

Pallud, C., and Van Cappellen, P. (2006). Kinetics of microbial sulfate reduction in estuarine sediments. Geochim. Cosmochim. Acta 70, 1148-1162.

Paul, S., Kuesel, K., and Alewell, C. (2006). Reduction processes in forest wetlands: tracking down heterogeneity of source/sink functions with a combination of methods. Soil Biol. Biochem. 38, 1028-1039.

Pedrós-Alió, C. (2006). Marine microbial diversity: can it be determined? Trends Microbiol. 14, 257-263.

Pedrós-Alió, C. (2012). The rare bacterial biosphere. Ann. Rev. Mar. Sci. 4, 449-466.

Peiffer, S., and Gade, W. (2007). Reactivity of ferric oxides toward $\mathrm{H} 2 \mathrm{~S}$ at low pH. Environ. Sci. Technol. 41, 3159-3164.

Perlinger, J. A., Kalluri, V. M., Venkatapathy, R., and Angst, W. (2002). Addition of hydrogen sulfide to juglone. Environ. Sci. Technol. 36, 2663-2669.

Pester, M., Bittner, N., Pinsurang, D., Wagner, M., and Loy, A. (2010). A "rare biosphere" microorganism contributes to sulfate reduction in a peatland. ISME J. 4, 1591-1602.
Pezeshki, S. R. (2001). Wetland plant responses to soil flooding. Environ. Exp. Bot. 46, 299-312.

Plugge, C. M., Zhang, W., Scholten, J. C. M., and Stams, A. J. M. (2011). Metabolic flexibility of sulfate reducing bacteria. Front. Microbiol. 2:81. doi:10.3389/fmicb.2011.00081

Podar, M., Abulencia, C. B., Walcher, M., Hutchison, D., Zengler, K., Garcia, J. A., Holland, T., Cotton, D., Hauser, L., and Keller, M. (2007). Targeted access to the genomes of low-abundance organisms in complex microbial communities. Appl. Environ. Microbiol. 73, 3205-3214.

Pyzik, A. J., and Sommer, S. E. (1981). Sedimentary iron monosulfides: kinetics and mechanism of formation. Geochim. Cosmochim. Acta 45, 687-698.

Rabus, R., Hansen, T. A., and Widdel, F. (2006). "Dissimilatory sulfate- and sulfur-reducing prokaryotes," in The Prokaryotes: A Handbook on the Biology of Bacteria, 3rd Edn, eds M. Dworkin, S. Falkow, E. Rosenberg, K.-H. Schleifer, and E. Stackebrandt (Singapore: Springer), 659-768.

Ramamoorthy, S., Sass, H., Langner, H., Schumann, P., Kroppenstedt, R. M., Spring, S., Overmann, J., and Rosenzweig, R. F. (2006). Desulfosporosinus lacus sp nov., a sulfate-reducing bacterium isolated from pristine freshwater lake sediments. Int. J. Syst. Evol. Microbiol. 56, 2729-2736.

Ravenschlag, K., Sahm, K., Pernthaler, J., and Amann, R. (1999). High bacterial diversity in permanently cold marine sediments. Appl. Environ. Microbiol. 65, 3982-3989.

Reeve, A. S., Evensen, R., Glaser, P. H., Siegel, D. I., and Rosenberry, D. (2006). Flow path oscillations in transient ground-water simulations of large peatland systems. J. Hydrol. 316, 313-324.

Roden, E. E., Kappler, A., Bauer, I., Jiang, J., Paul, A., Stoesser, R., Konishi, H., and $\mathrm{Xu}, \mathrm{H}$. F. (2010). Extracellular electron transfer through microbial reduction of solid-phase humic substances. Nat. Geosci. 3, 417-421.

Roden, E. E., and Urrutia, M. M. (2002). Influence of biogenic $\mathrm{Fe}(\mathrm{II})$ on bacterial crystalline $\mathrm{Fe}$ (III) oxide reduction. Geomicrobiol. J. 19, 209-251.

Roden, E. E., and Wetzel, R. G. (1996). Organic carbon oxidation and suppression of methane production by microbial $\mathrm{Fe}(\mathrm{III})$ oxide reduction in vegetated and unvegetated freshwater wetland sediments. Limnol. Oceanogr. 41, 1733-1748.

Scheid, D., and Stubner, S. (2001). Structure and diversity of Gramnegative sulfate-reducing bacteria on rice roots. FEMS Microbiol. Ecol. $36,175-183$.

Scheid, D., Stubner, S., and Conrad, R. (2004). Identification of rice root associated nitrate, sulfate and ferric iron reducing bacteria during root decomposition. FEMS Microbiol. Ecol. 50, 101-110.

Schippers, A., and Jørgensen, B. B. (2001). Oxidation of pyrite and iron sulfide by manganese dioxide in marine sediments. Geochim. Cosmochim. Acta 65, 915-922.

Schmalenberger, A., Drake, H. L., and Küsel, K. (2007). High unique diversity of sulfate-reducing prokaryotes characterized in a depth gradient in an acidic fen. Environ. Microbiol. 9, 1317-1328.

Segers, R., and Kengen, S. W. M. (1998) Methane production as a function of anaerobic carbon mineralization: a process model. Soil Biol. Biochem. $30,1107-1117$.

Segers, R., and Leffelaar, P. A. (2001). Modeling methane fluxes in wetlands with gas-transporting plants 1. Single-root scale. J. Geophys. Res. 106, 3511-3528.

Skyring, G. W. (1987). Sulfate reduction in coastal ecosystems. Geomicrobiol. J. 5, 295-374.

Smemo, K. A., and Yavitt, J. B. (2011) Anaerobic oxidation of methane: an underappreciated aspect of methane cycling in peatland ecosystems? Biogeosciences 8, 779-793.

Smith, R. L., and Klug, M. J. (1981). Reduction of sulfur-compounds in the sediments of a eutrophic lake basin. Appl. Environ. Microbiol. 41, 1230-1237.

Smith, S. J., Pitcher, H., and Wigley, T. M. L. (2005). Future sulfur dioxide emissions. Clim. Change 73 , 267-318.

Sogin, M. L., Morrison, H. G., Huber, J. A., Mark Welch, D., Huse, S. M., Neal, P. R., Arrieta, J. M., and Herndl, G. J. (2006). Microbial diversity in the deep sea and the underexplored "rare biosphere". Proc. Natl. Acad. Sci. U.S.A. 103, 12115-12120.

Spratt, H. G., Morgan, M. D., and Good, R. E. (1987). Sulfate reduction in peat from a New Jersey pinelands cedar swamp. Appl. Environ. Microbiol. 53, 1406-1411.

Spring, S., and Rosenzweig, F. (2006). "The genera Desulfitobacterium and Desulfosporosinus: taxonomy," in The Prokaryotes: A Handbook on the Biology of Bacteria, 3rd Edn, eds M. Dworkin, S. Falkow, E. Rosenberg, K. H. Schleifer, and E. Stackebrandt (Singapore: Springer), 771-786.

Stahl, D. A., Loy, A., and Wagner, M. (2007). "Molecular strategies for studies of natural populations of sulphate-reducing microorganisms," in Sulphate-Reducing Bacteria, eds L. L. Barton and W. A. Hamilton (Cambridge: Cambridge University Press), 39-115.

Steger, D., Wentrup, C., Braunegger, C., Deevong, P., Hofer, M., Pester, M., Wagner, M., and Loy, A. (2011). Microorganisms with novel dissimilatory (bi)sulfite reductase genes are widespread and core microbiota in low-sulfate peatlands. Appl. Environ. Microbiol. 77, 1231-1242.

Steinmann, P., and Shotyk, W. (1997). Chemical composition, $\mathrm{pH}$, and redox state of sulfur and iron in complete vertical porewater profiles from two Sphagnum peat bogs, Jura Mountains, Switzerland. Geochim. Cosmochim. Acta 61, 1143-1163.

Stubner, S. (2002). Enumeration of $16 S$ rDNA of Desulfotomaculum lineage 1 in rice field soil by real-time PCR with SybrGreenTM detection. J. Microbiol. Methods 50, 155-164.

Stubner, S. (2004). Quantification of Gram-negative sulphate-reducing bacteria in rice field soil by $16 \mathrm{~S}$ rRNA gene-targeted real-time PCR. J. Microbiol. Methods 57, 219-230.

Tarpgaard, I. H., Røy, H., and Jørgensen, B. B. (2011). Concurrent low- and high-affinity sulfate reduction kinetics in marine sediment. Geochim. Cosmochim. Acta 75, 2997-3010.

Tchawa Yimga, M., Dunfield, P. F., Ricke, P., Heyer, J., and Liesack, W. (2003). Wide distribution of a novel pmoA-like gene copy among type II methanotrophs, and its expression in Methylocystis strain SC2. Appl. Environ. Microbiol. 69, 5593-5602.

Teske, A., Durbin, A., Ziervogel, K., Cox, C., and Arnosti, C. (2011). Microbial community composition and function in permanently cold seawater and sediments from an arctic fjord of Svalbard. Appl. Environ. Microbiol. 77, 2008-2018.

Thamdrup, B., Finster, K., Hansen, J. W., and Bak, F. (1993). Bacterial disproportionation of elemental sulfur coupled to chemical reduction of iron or manganese. Appl. Environ. Microbiol. 59, 101-108.

Thauer, R. K. (2011). Anaerobic oxidation of methane with sulfate: on the reversibility of the reactions that are catalyzed by enzymes also involved in methanogenesis from $\mathrm{CO} 2$. Curr. Opin. Microbiol. 14, 292-299.

Trimmer, M., Purdy, K. J., and Nedwell, D. B. (1997). Process measurement and phylogenetic analysis of the sulfate reducing bacterial communities of two contrasting benthic sites in the upper estuary of the Great Ouse, 
Norfolk, UK. FEMS Microbiol. Ecol. 24, 333-342.

Urban, N. R., Brezonik, P. L., Baker, L. A., and Sherman, L. A. (1994). Sulfate reduction and diffusion in sediments of Little-Rock Lake, Wisconsin. Limnol. Oceanogr. 39, 797-815.

Urban, N. R., Eisenreich, S. J., and Grigal, D. F. (1989). Sulfur cycling in a forested Sphagnum bog in Northern Minnesota. Biogeochemistry 7, 81-109.

Uthicke, S., and McGuire, K. (2007). Bacterial communities in Great Barrier Reef calcareous sediments: contrasting 16S rDNA libraries from nearshore and outer shelf reefs. Estuar. Coast. Shelf Sci. 72, 188-200.

Vairavamurthy, A., Mopper, K., and Taylor, B. F. (1992). Occurance of particle-bound polysulfides and significance of their reaction with organic matters in marine sediments. Geophys. Res. Lett. 19, 2043-2046.

van der Gon, D. H., Van Bodegom, P., Wassmann, R., Lantin, R., and Metra-Corton, T. (2001). Sulfatecontaining amendments to reduce methane emissions from rice fields: mechanisms, effectiveness and costs. Mitigation Adapt. Strateg. Glob. Change 6, 71-89.

Vatsurina, A., Badrutdinova, D., Schumann, P., Spring, S., and Vainshtein, M. (2008). Desulfosporosinus hippei sp. nov., a mesophilic sulfate-reducing bacterium isolated from permafrost. Int. J. Syst. Evol. Microbiol. 58, 1228-1232.

Vile, M. A., Bridgham, S. D., and Wieder, R. K. (2003a). Response of anaerobic carbon mineralization rates to sulfate amendments in a boreal peatland. Ecol. Appl. 13, 720-734.

Vile, M. A., Bridgham, S. D., Wieder, R. K., and Novak, M. (2003b). Atmospheric sulfur deposition alters pathways of gaseous carbon production in peatlands. Global Biogeochem. Cycles 17, 1058.

Visscher, P. T., Gritzer, R. F., and Leadbetter, E. R. (1999). Low- molecular-weight sulfonates, a major substrate for sulfate reducers in marine microbial mats. Appl. Environ. Microbiol. 65, 3272-3278.

Vymazal, J. (2010). Constructed wetlands for wastewater treatment: five decades of experience. Environ. Sci. Technol. 45, 61-69.

Wagner, M., Loy, A., Klein, M., Lee, N., Ramsing, N. B., Stahl, D. A., and Friedrich, M. W. (2005). Functional marker genes for identification of sulphate-reducing prokaryotes. Methods Enzymol. 397, 469-489.

Wallrabenstein, C., Hauschild, E., and Schink, B. (1994). Pure culture and cytological properties of Syntrophobacter wolinii. FEMS Microbiol. Lett. 123, 249-254.

Wallrabenstein, C., Hauschild, E., and Schink, B. (1995). Syntrophobacter pfennigii sp nov, new syntrophically propionate-oxidizing anaerobe growing in pure culture with propionate and sulfate. Arch. Microbiol. $164,346-352$.

Ward, P. L. (2009). Sulfur dioxide initiates global climate change in four ways. Thin Solid Films 517, 3188-3203.

Watson, A., and Nedwell, D. B. (1998). Methane production and emission from peat: the influence of anions (sulphate, nitrate) from acid rain. Atmos. Environ. 32, 3239-3245.

Wieder, R. K., and Lang, G. E. (1988). Cycling of inorganic and organic sulfur in peat from Big Run Bog, West Virginia. Biogeochemistry 5, 221-242.

Wieder, R. K., Yavitt, J. B., and Lang, G. E. (1990). Methane production and sulfate reduction in 2 Appalachian peatlands. Biogeochemistry 10, 81-104.

Wilhelm, R. C., Niederberger, T. D., Greer, C., and Whyte, L. G. (2011). Microbial diversity of active layer and permafrost in an acidic wetland from the Canadian High Arctic. Can. J. Microbiol. 57, 303-315.

Wind, T., and Conrad, R. (1995). Sulfur compounds, potential turnover of sulfate and thiosulfate, and numbers of sulfate-reducing bacteria in planted and unplanted paddy soil. FEMS Microbiol. Ecol. 18, 257-266.

Wind, T., and Conrad, R. (1997). Localization of sulfate reduction in planted and unplanted rice field soil. Biogeochemistry 37, 253-278.

Wind, T., Stubner, S., and Conrad, R. (1999). Sulfate-reducing bacteria in rice field soil and on rice roots. Syst. Appl. Microbiol. 22, 269-279.

Woyke, T., Tighe, D., Mavromatis, K., Clum, A., Copeland, A., Schackwitz, W., Lapidus, A., Wu, D., McCutcheon, J. P., McDonald, B. R., Moran, N. A., Bristow, J., and Cheng, J.-F. (2010). One bacterial cell, one complete genome. PLoS ONE 5, e10314. doi:10.1371/journal.pone.0010314

Woyke, T., Xie, G., Copeland, A., Gonzalez, J. M., Han, C., Kiss, H., Saw, J. H., Senin, P., Yang, C., Chatterji, S., Cheng, J.-F., Eisen, J. A., Sieracki, M. E., and Stepanauskas, R. (2009). Assembling the Marine metagenome, one cell at a time. PLoS ONE 4, e5299. doi:10.1371/journal.pone.0005299

Wu, X.-J., Pan, J.-L., Liu, X.-L., Tan, J., Li, D.-T., and Yang, H. (2009). Sulfate-reducing bacteria in leachate-polluted aquifers along the shore of the East China Sea. Can. J. Microbiol. 55, 818-828.

Wuebbles, D. J., and Hayhoe, K. (2002). Atmospheric methane and global change. Earth Sci. Rev. 57, 177-210.

Wüst, P. K., Horn, M. A., and Drake, H. L. (2009). Trophic links between fermenters and methanogens in a moderately acidic fen soil. Environ. Microbiol. 11, 1395-1409.

Yagi, K., Tsuruta, H., and Minami, K. (1997). Possible options for mitigating methane emission from rice cultivation. Nutr. Cycl. Agroecosyst. 49 213-220.

Yao, H., Conrad, R., Wassmann, R., and Neue, H. U. (1999). Effect of soil characteristics on sequential reduction and methane production in sixteen rice paddy soils from China, the Philippines, and Italy. Biogeochemistry 47, 269-295.

Yavitt, J. B., and Seidmann-Zager, M. (2006). Methanogenic conditions in northern peat soils. Geomicrobiol. J. 23, 119-127.

Zhou, J., He, Q., Hemme, C. L., Mukhopadhyay, A., Hillesland, K., Zhou, A., He, Z., Van Nostrand, J. D., Hazen, T. C., Stahl, D. A., Wall, J. D., and Arkin, A. P. (2011). How sulphate-reducing microorganisms cope with stress: lessons from systems biology. Nat. Rev. Microbiol. 9, 452-466.

Zverlov, V., Klein, M., Lucker, S., Friedrich, M. W., Kellermann, J., Stahl, D. A., Loy, A., and Wagner, M. (2005). Lateral gene transfer of dissimilatory (bi)sulfite reductase revisited. J. Bacteriol. 187, 2203-2208

Conflict of Interest Statement: The authors declare that the research was conducted in the absence of any commercial or financial relationships that could be construed as a potential conflict of interest.

Received: 25 November 2011; paper pending published: 05 January 2012; accepted: 11 February 2012; published online: 28 February 2012.

Citation: Pester M, Knorr K-H, Friedrich MW, Wagner M and Loy A (2012) Sulfate-reducing microorganisms in wetlands - fameless actors in carbon cycling and climate change. Front. Microbio. 3:72. doi: 10.3389/fmicb.2012.00072 This article was submitted to Frontiers in Terrestrial Microbiology, a specialty of Frontiers in Microbiology.

Copyright (C) 2012 Pester, Knorr, Friedrich, Wagner and Loy. This is an open-access article distributed under the terms of the Creative Commons Attribution Non Commercial License, which permits non-commercial use, distribution, and reproduction in other forums, provided the original authors and source are credited. 


\title{
Peatland microbial communities and decomposition processes in the James Bay Lowlands, Canada
}

\author{
Michael D. Preston ${ }^{1}{ }^{*}$, Kurt A. Smemo ${ }^{2,3}$, James W. McLaughlin ${ }^{4}$ and Nathan Basiliko \\ ${ }^{1}$ Department of Geography, University of Toronto Mississauga, Mississauga, ON, Canada \\ ${ }^{2}$ The Holden Arboretum, Kirtland, $\mathrm{OH}$, USA \\ ${ }^{3}$ Department of Biological Sciences, Kent State University, Kent, OH, USA \\ ${ }^{4}$ Ontario Forest Research Institute, Ontario Ministry of Natural Resources, Sault Ste Marie, ON, Canada
}

\section{Edited by:}

Svetlana N. Dedysh, Russian

Academy of Sciences, Russia

Reviewed by:

Neil Duncan Gray, University of

Newcastle, UK

Peter Frenzel, MPI for Terrestrial

Microbiology, Germany

*Correspondence:

Michael D. Preston, University of

Toronto Mississauga, 3359

Mississauga Road North,

Mississauga, ON L5L 1C6, Canada.

e-mail:michael.preston@utoronto.ca
Northern peatlands are a large repository of atmospheric carbon due to an imbalance between primary production by plants and microbial decomposition. The James Bay Lowlands (JBL) of northern Ontario are a large peatland-complex but remain relatively unstudied. Climate change models predict the region will experience warmer and drier conditions, potentially altering plant community composition, and shifting the region from a long-term carbon sink to a source. We collected a peat core from two geographically separated (ca. $200 \mathrm{~km}$ ) ombrotrophic peatlands (Victor and Kinoje Bogs) and one minerotrophic peatland (Victor Fen) located near Victor Bog within the JBL. We characterized (i) archaeal, bacterial, and fungal community structure with terminal restriction fragment length polymorphism of ribosomal DNA, (ii) estimated microbial activity using community level physiological profiling and extracellular enzymes activities, and (iii) the aeration and temperature dependence of carbon mineralization at three depths $(0-10,50-60$, and $100-110 \mathrm{~cm})$ from each site. Similar dominant microbial taxa were observed at all three peatlands despite differences in nutrient content and substrate quality. In contrast, we observed differences in basal respiration, enzyme activity, and the magnitude of substrate utilization, which were all generally higher at Victor Fen and similar between the two bogs. However, there was no preferential mineralization of carbon substrates between the bogs and fens. Microbial community composition did not correlate with measures of microbial activity but $\mathrm{pH}$ was a strong predictor of activity across all sites and depths. Increased peat temperature and aeration stimulated $\mathrm{CO}_{2}$ production but this did not correlate with a change in enzyme activities. Potential microbial activity in the JBL appears to be influenced by the quality of the peat substrate and the presence of microbial inhibitors, which suggests the existing peat substrate will have a large influence on future JBL carbon dynamics.

Keywords: peatlands, T-RFLP, microbial community, microbial activity, carbon dioxide, James Bay Lowlands, CLPP

\section{INTRODUCTION}

Peatlands are important to the global carbon cycle as they are large repositories of atmospheric carbon, with estimates ranging between 270 and $455 \mathrm{Pg}\left(10^{15}\right)$ carbon, despite only covering $3 \%$ of the Earth's surface (Gorham, 1991; Turunen et al., 2002). This is due to a relative imbalance between rates of net primary production by plants and microbial decomposition (Clymo, 1984), resulting from persistently water saturated environments and consequent anoxia (Moore and Basiliko, 2006). Such conditions also favor microbial $\mathrm{CH}_{4}$ production, thus peatlands are also significant sources of atmospheric $\mathrm{CH}_{4}$ (Moore et al., 1998; Laine et al., 2007; Roulet et al., 2007), which has a global warming potential 23 times higher than $\mathrm{CO}_{2}$ under the IPCC's 100-year timeframe (Forster et al., 2007).

The James Bay Lowlands (JBL) are a large peatland-complex that form the southeast part of the Hudson Bay Lowlands, Canada, the second largest peatland area in the world $\left(325,000 \mathrm{~km}^{2}\right)$ after the Western Siberian Lowlands (Riley, 1982; Gorham, 1991). Few studies have been conducted on carbon biogeochemistry in the JBL
(Roulet, 2000; Yu et al., 2010), which represents a massive atmospheric carbon store characterized by a mosaic of peatland types that were formed under varying environmental conditions and may differ in their sensitivity to environmental change (Martini, 2006). The JBL therefore represents both an important frontier in peatland ecology and a significant factor for the atmospheric carbon balance.

Concern has been raised over the stability of the JBL carbon store as climate models predict an increase in mean annual air temperature of $3-4^{\circ} \mathrm{C}$ by 2020 and $5-10^{\circ} \mathrm{C}$ by 2050 , with only minor increases in precipitation of $10-20 \%$ in this region by the end of the twenty-first century (Hengeveld, 2000; Gagnon and Gough, 2005). Warmer temperatures are expected to increase evapotranspiration resulting in lower water table levels (Gorham, 1991; Roulet et al., 1992). Short-term water table level fluctuations may increase decomposition as the presence of bimolecular oxygen $\left(\mathrm{O}_{2}\right)$ activates phenol oxidases responsible for the degradation of phenolic compounds (Sinsabaugh, 2010). This change can release hydrolase enzymes, responsible for labile carbon degradation, from 
inhibition and has been referred to as the "enzymic latch theory" (Freeman et al., 2001, 2004). Continued lowering of the water table height may lead to a complete shift in plant community composition (Weltzin et al., 2003; Laiho, 2006; Robroek et al., 2007), potentially altering litter decomposability (Dorrepaal et al., 2005), heterotrophic respiration (Moore and Basiliko, 2006), and increased $\mathrm{CH}_{4}$ production (Hines et al., 2008).

Many studies have demonstrated that temperature and hydrology-related redox state directly control carbon mineralization in peatlands (e.g., Moore and Dalva, 1993; Updegraff et al., 1998; Keller et al., 2004). However, microorganisms ultimately control peat decomposition and evidence indicates that the soil microbial community composition is important to ecosystem processes (Balser and Firestone, 2005; Reed and Martiny, 2007); but its effects on carbon mineralization are unresolved (Waldrop and Firestone, 2006; Bardgett et al., 2008; McGuire and Treseder, 2010). Soil pH has been identified as one of the most influential factors controlling microbial diversity and community composition across soils types (Fierer and Jackson, 2006; Allison and Treseder, 2008; Rousk et al., 2010). However, peatland microbial diversity has not been extensively categorized (Kraigher et al., 2006) but differences in microbial community structure have been identified between peatland types (i.e., bogs and fens; Jaatinen et al., 2007; Ausec et al., 2009; Peltoniemi et al., 2009) as well as among depths down the peat profile (Morales et al., 2006; Jaatinen et al., 2007), potentially due to changes in $\mathrm{pH}$.

Differences in microbial community composition among peatlands should be expected as vegetation varies from poorly decomposable mosses and shrubs in ombrotrophic bogs that only receive nutrients from dry and wet deposition (Aerts et al., 1999) to more easily decomposable sedges, herbs, and shrubs in minerotrophic fens that receive nutrients from groundwater (Bragazza et al., 2007). Although ecosystem models assume that microbial communities are functionally redundant (Reed and Martiny, 2007) differences in microbial activity have been observed among peatland habitats and depths (Fisk et al., 2003). Moreover, plant litter decomposition rates have been shown to vary depending on both the structure of the microbial community and the past resource inputs a community has experienced (Strickland et al., 2009). Given the contrasting botanical composition between bog and fen peatlands, microbial communities may preferentially utilize their "native" organic compounds to a greater extent than microbes that have been exposed to peat with a different chemical composition.

In this study we used multiple approaches to characterize depth-dependent microbial community structure and function in two bogs and a fen within the JBL. This included molecular fingerprinting techniques, two independent estimates of microbial activity and in vitro assays of microbial responses to changes in aeration and temperature. We hypothesized that (i) $\mathrm{pH}$ is the dominant control of microbial community composition and activity among sites and depths, with more diverse communities observed at higher $\mathrm{pH}$, (ii) substrate utilization patterns of carbon compounds will differ between the bogs and the fen, with the fen preferentially mineralizing labile compounds and bogs mineralizing more chemically complex compounds, (iii) measures of microbial activity and community composition correlate with carbon mineralization, and (iv) higher peat temperature and aeration results in greater rates of microbial activity, with the largest response occurring in surface peat.

\section{MATERIALS AND METHODS SAMPLE COLLECTION AND PREPARATION}

The climate of the JBL is described as being humid microthermalsubarctic (Dcf), according to the Köppen Climate Classification System (Christopherson and Byrne, 2009). Annual total precipitation ranges from 610 to $660 \mathrm{~mm}$ and mean temperatures range from -29 to $-15^{\circ} \mathrm{C}$ in January and 12 to $18^{\circ} \mathrm{C}$ in July between $50^{\circ}$ and $52^{\circ} \mathrm{N}$ (Martini, 2006). The region is essentially roadless, thus it is difficult to access and required the use of helicopters.

Three sampling locations were chosen based on their nutrient status and distance from one another. Kinoje $\left(51^{\circ} 35^{\prime} \mathrm{N} 82^{\circ} 12^{\prime} \mathrm{W}\right)$ and Victor $\left(52^{\circ} 42^{\prime} \mathrm{N} 85^{\circ} 49^{\prime} \mathrm{W}\right)$ Bogs are separated by $206 \mathrm{~km}$ and have similar characteristics. Both are ombrotrophic, characterized by Sphagnum mosses and lichen (>50\%), ericaceous shrubs (primarily members of the genera Vaccinium and Kalmia; $>50 \%$ cover), and stunted black spruce (Picea mariana; $\sim 10 \%$ cover). Victor Fen is located near Victor Bog $(\sim 1.1 \mathrm{~km})$, but is minerotrophic and dominated by Carex spp. (>50\%), with patches of Sphagnum and brown mosses (Drepanocladus, Scorpidium, Aulacomnium; $<50 \%$ cover), ericaceous shrubs $(<25 \%$ cover), and larch (Larix laricina; $\sim 10 \%$ ). Due to logistical constraints, we were able to collect one peat core (Russian pear corer) per site in the summer of 2009 to a depth of $2 \mathrm{~m}$. All cores were collected from hollows and immediately frozen at $-18^{\circ} \mathrm{C}$ at a nearby research station prior to transport back to Toronto.

Subsamples from each core were taken at $0-10 \mathrm{~cm}$ (Surface, above the water table), 50-60 cm (Middle, in a zone of fluctuating water table), and 100-110 cm (Deep, always below the water table). Surface samples from both bog cores were weakly decomposed and classified as $\mathrm{H} 3$ using the von Post system of humification (Rydin and Jeglum, 2006), while the fen surface was classed as H4. All middle and deep samples were highly decomposed and categorized as $\mathrm{H} 8$ and $\mathrm{H} 9$, respectively. To preserve the in situ microbial community from being altered by thaw-refreeze cycles, each sub-section was cut vertically in half while still frozen. The microbial community composition and activity was assessed on one of the sections while the second vertical section was subjected to a temperature and aeration manipulation experiment (below). When required for analysis the peat was thawed at $21^{\circ} \mathrm{C}$ and gently homogenized to reduce the variation within the sub-sample. Peat moisture content was determined gravimetrically by drying $1 \mathrm{~g}$ of wet peat at $105^{\circ} \mathrm{C}$ for $24 \mathrm{~h}$ and peat $\mathrm{pH}$ was measured in reverse osmosis purified water after $1 \mathrm{~h}$ (soil-to-water ratio of 1:4).

\section{PROFILING THE MICROBIAL COMMUNITY}

Archaeal, bacterial, and fungal community structure within the peat samples was profiled using terminal restriction fragment length polymorphism analysis (T-RFLP). DNA was extracted from each peat sample using the MoBio PowerSoil DNA Isolation Kit (MoBio Laboratories Inc., Carlsbad, CA, USA) according to the manufacturer's instructions. To minimize DNA extraction bias (e.g., Feinstein et al., 2009), three successive extractions were pooled per peat sample. Archaeal rDNA genes were amplified 
from total DNA using an unlabeled forward primer Ar109 (5'ACK GCT CAG TAA CAC GT-3') and the fluorescently labeled reverse primer Ar912r (5' - [6FAM]CTC CCC CGC CAA TTC CTT TA-3'; Lueders and Friedrich, 2000). Bacterial rDNA genes were amplified using a fluorescently labeled forward primer Eu27f ( $5^{\prime}$ [6FAM]AGA GTT TGA TCM TGG CTC AG-3') and an unlabeled reverse primer Eu1492r (5'-ACG GYT ACC TTG TTA CGA CTT$3^{\prime}$; Bräuer et al., 2006). Fungal rDNA genes were amplified with an unlabeled forward primer Fu-817f (5'-TTA GCA TGG AAT AAT RRA ATA GGA-3') and a fluorescently labeled reverse primer Fu-1536r (5'-[6FAM]ATT AGC AAT GCY CTA TCC CCA-3'; Edel-Hermann et al., 2004). The reaction mixture $(50 \mu \mathrm{l})$ consisted of $20 \mathrm{ng}$ soil DNA, $36.5 \mu \mathrm{l} \mathrm{H}_{2} \mathrm{O}, 5 \mu \mathrm{l} 10 \times$ buffer, $4 \mu \mathrm{l} \mathrm{MgCl}_{2}$, $1.25 \mu \mathrm{ldNTPs}, 2 \mu \mathrm{l}$ primers (forward and reverse), and $0.25 \mu \mathrm{l} \mathrm{Taq}$ (Sigma-Aldrich, USA). DNA was amplified by PCR using a Primus 96 plus thermal cycler (MWG Biotech, Germany) with the following reaction conditions: $5 \mathrm{~min} 94^{\circ} \mathrm{C}$, followed by 30 cycles of $94^{\circ} \mathrm{C}$ for $1 \mathrm{~min}$, annealing temperature $1 \mathrm{~min}, 72^{\circ} \mathrm{C}$ for $2 \mathrm{~min}$ and a final extension at $72^{\circ} \mathrm{C}$ for $10 \mathrm{~min}$. The annealing temperature for the bacterial primers was 50 and $52^{\circ} \mathrm{C}$ for archaeal and fungal primers. For each sample, the PCR product of three reactions was pooled to minimize amplification bias.

The PCR products were purified in order to remove residual primers using a GenElute PCR clean-up kit (Sigma-Aldrich, USA) according to the manufacturer's instructions and quantified using a Nanodrop spectrophotometer (Thermo Scientific, USA). Archaeal T-RFLP analysis followed the method outlined by Lueders and Friedrich (2000). Aliquots of purified archaeal amplicons (50 ng) were digested using TaqI (3 U) and $1 \mu \mathrm{l}$ of appropriate buffer supplied by the manufacturer (New England BioLabs, USA) and $1 \mu \mathrm{l}$ of bovine serum albumin were combined to a total volume of $10 \mu \mathrm{l}$ and digested at $65^{\circ} \mathrm{C}$ for $2 \mathrm{~h}$. Bacterial T-RFLP analysis followed the method outlined by Lukow et al. (2000). Aliquots of purified bacterial amplicons (50 ng) were digested with the restriction endonuclease MspI (10 U) and $1 \mu \mathrm{l}$ of appropriate buffer supplied by the manufacturer to a total volume of $10 \mu \mathrm{l}$ and digested at $37^{\circ} \mathrm{C}$ for $3 \mathrm{~h}$. Fungal T-RFLP analysis followed the method outlined by Edel-Hermann et al. (2004). Aliquots of purified fungal amplicons (50 ng) were double digested with AluI and $\mathrm{MboI}(5 \mathrm{U})$ and $1 \mu \mathrm{l}$ of the appropriate buffer supplied by the manufacturer to a total volume of $10 \mu \mathrm{l}$ and digested at $37^{\circ} \mathrm{C}$ for $3 \mathrm{~h}$. Terminal restriction fragments were measured on an ABI3730 DNA Analyzer (Applied Biosystems, Foster City, CA, USA) with GeneScan 1000-ROX ${ }^{\mathrm{TM}}$ fragment size standards (Applied Biosystems) at the University of Guelph Lab Services (ON, Canada). Terminal restriction fragment (T-RFs) lengths between 50 and $1200 \mathrm{bp}$ were determined relative to the standards. T-RFs differing by less that $2 \mathrm{bp}$ were considered to be the same fragment and their data combined and only T-RFs that represented $\geq 1 \%$ of the total sample were included for statistical analysis. The abundance (A) of each T-RF was calculated as:

$A=n_{\mathrm{i}} / N \times 10,000$

where $n_{\mathrm{i}}$ is the peak height of one T-RF, $\mathrm{N}$ is the sum of all peak heights in that sample, and multiplied by 10,000 so the data could be analyzed using traditional ecological methods. Peak heights were used in preference to peak area due to overlapping peaks (Blackwood et al., 2003) and this method is more accurate at establishing relative gene abundances (Lueders and Friedrich, 2003).

Microbial biomass carbon (MB-C) and nitrogen (MB-N) was determined using slight modifications to the chloroform $\left(\mathrm{CHCl}_{3}\right)$ fumigation extraction method by Vance et al. (1987). Three replicate $10 \mathrm{~g}$ (wet weight) samples of peat from the sub-sections were each split into two $5 \mathrm{~g}$ samples One sample was placed inside a vacuum desiccator and fumigated with ethanol-free $\mathrm{CHCl}_{3}$ in the dark for $24 \mathrm{~h}$. Due to the high moisture content of the peat soil, $0.5 \mathrm{ml}$ of $\mathrm{CHCl}_{3}$ was added directly to the surface to aid cell lysis (Ocio and Brookes, 1990) and a beaker of $1 \mathrm{~N} \mathrm{NaOH}$ was placed inside the desiccator to remove any excess $\mathrm{CO}_{2} \cdot \mathrm{CHCl}_{3}$ vapor and residue was removed through repeated evacuation. All peat samples were sealed in containers with $40 \mathrm{ml}$ of $0.5 \mathrm{M} \mathrm{K}_{2} \mathrm{SO}_{4}$, shaken for $1 \mathrm{~h}$ at $200 \mathrm{rpm}$ on an oscillating shaker, and filtered through $0.45 \mu \mathrm{m}$ glass fiber filters. The dissolved organic carbon (DOC) and $\mathrm{N}(\mathrm{DON})$ concentration of the peat soil extracts was measured with a TOC/TN analyzer (IL550, Lachat Instruments, USA). MB-C and MB-N was calculated by subtracting the nonfumigated extractable DOC/DON from the fumigated extractable DOC/DON after correcting for differences in initial peat moisture content.

\section{ESTIMATING THE ACTIVITY OF THE MICROBIAL COMMUNITY}

Microbial metabolic potential within each JBL sample was estimated by measuring the mineralization rates of four natural and six synthetic substrates of varying chemical complexity and molecular weight. Briefly, synthetic substrates were selected based on their prevalence in natural plant tissues and ranged from simple, low molecular weight compounds to large chemically complex substances. These substrates included: alkali lignin and methylcellulose, potentially representative of major, complex, high carbon concentration, structural compounds in many plants and $p$-coumaric acid (a lignin derivative from non-woody plant tissues), sodium benzoate (an aromatic organic acid and potential lignin derivative), glucose (a cellulose derivative), and a commercially available mixture of amino acids (protein derivatives, Sigma-Aldrich catalog \# R7131). The $\mathrm{pH}$ of the synthetic solutions was adjusted to that of reverse osmosis water to avoid a $\mathrm{pH}$ effect. Dissolved organic matter extracts from four plant types (two sedge and two Sphagnum) were made by autoclaving chopped plant material in reverse osmosis water and filtered through a $0.45-\mu \mathrm{m}$ glass fiber filer. Each substrate was adjusted to a standard concentration of $1 \mathrm{mg}$ carbon $\mathrm{ml}^{-1}$.

Substrate induced respiration (SIR) assays were conducted by adding $10 \mathrm{ml}$ of substrate ( $10 \mathrm{mg}$ carbon) to $5 \mathrm{~g}$ of peat (wet mass) in $30 \mathrm{ml}$ serum vials each capped with a rubber stopper and crimped. Reverse osmosis water acted as the control (basal microbial activity). Vials were vigorously shaken by hand for $30 \mathrm{~s}$ to ensure mixing and incubated under oxic conditions for $48 \mathrm{~h}$ and anoxic conditions for $72 \mathrm{~h}$. Anoxic conditions were created through repeated evacuation with a vacuum pump and backflushing with nitrogen $\left(\mathrm{N}_{2}\right)$ gas and brought to atmospheric pressure. Gas samples were taken using a 1-ml syringe following mixing of the gas in the vial and $\mathrm{CO}_{2}$ concentrations were measured using an infrared gas analyzer (Qubit Systems, Kingston, ON, Canada). 
$\mathrm{CO}_{2}$ production was monitored at five times periods $(0,4,16,24$, $48 \mathrm{~h}$ ) for the oxic assay and six time periods (additional measurement at $72 \mathrm{~h}$ ) for the anoxic assay and was calculated and expressed as total mass of $\mathrm{CO}_{2}$ produced (using the ideal gas law) per gram of dry peat. Preliminary analysis revealed that $\mathrm{CO}_{2}$ production rates increased exponentially after 16 (oxic) and 48 (anoxic) h. Thus to represent the initial responses of in situ microbial community to substrate addition, comparisons of $\mathrm{CO}_{2}$ production were made after 16 and $48 \mathrm{~h}$ for oxic and anoxic conditions, respectively. SIR data are expressed as the ratios of $\mathrm{CO}_{2}$ production divided by basal (control) respiration, allowing inter-site comparisons.

Potential extracellular enzyme activities (EEA) were determined following the method outlined by Saiya-Cork et al. (2002). Briefly, the activity of $1,4-\beta$-glucosidase, cellobiohydrolase, $1,4,-\beta-N$-acetyl-glucosaminidase, phosphatase, and sulfatase were determined fluorometrically using $200 \mu \mathrm{M}$ methylumbelliferone (MUB)-linked substrates. Peroxidase and phenol oxidase activities were determined with a colorimetric assay using $25 \mathrm{mM} \mathrm{L}-3,4,-$ dihydroxy-phenylalanine (L-DOPA) as a substrate; $10 \mu \mathrm{l}$ of $0.3 \%$ $\mathrm{H}_{2} \mathrm{O}_{2}$ was added to the peroxidase assay. A soil slurry was created by combining $0.5 \mathrm{~g}$ of peat (wet mass) to $125 \mathrm{ml}$ of acetate buffer ( $50 \mathrm{mM}, \mathrm{pH} 5)$ and homogenized for $60 \mathrm{~s}$ with a hand blender. A preliminary study showed that estimated enzyme activity was not influenced by the mass of peat used ( $\max .2 .5 \mathrm{~g}$ ). For each enzyme assay, $200 \mu \mathrm{l}$ of soil slurry and $50 \mu \mathrm{l}$ of specific substrate were loaded onto a 96-well microplate with eight analytical replicates. Each plate contained a positive and negative control. All assays were incubated at $21^{\circ} \mathrm{C}$ for $2 \mathrm{~h}$, except for phosphatase and $1,4,-\beta$ $\mathrm{N}$-acetyl-glucosaminidase assays which were incubated for $0.5 \mathrm{~h}$. To stop the reaction in the fluorometric assays $10 \mu$ l of $0.5 \mathrm{~N} \mathrm{NaOH}$ was added at the end of the incubation period. Fluorescence (excitation energy $365 \mathrm{~nm}$, emission $460 \mathrm{~nm}$ ) and absorbance (460 nm) was measured using a multi-plate spectrophotometer (Synergy HT, Biotek, USA).

\section{TEMPERATURE AND AERATION CONTROL OF MICROBIAL ACTIVITY}

To test how future environmental change might influence microbial activity, peat microcosms for each sub-sample were established by adding $5 \mathrm{~g}$ of homogenized wet peat to $20 \mathrm{ml}$ serum vials. Each vial was capped with a rubber stopper and crimped. Vials were randomly allocated to one of four treatments with two temperatures and either oxic or anoxic conditions: $4^{\circ} \mathrm{C}$ oxic, $4^{\circ} \mathrm{C}$ anoxic, $14^{\circ} \mathrm{C}$ oxic, and $14^{\circ} \mathrm{C}$ anoxic. Each treatment had three replicates. Anoxic conditions were established by repeated evacuation and back-flushing with $\mathrm{N}_{2}$ gas and brought to atmospheric pressure. Gas samples were taken at 90, 144, and $270 \mathrm{~h}$ and transferred to $10 \mathrm{ml}$ pre-evacuated glass $10 \mathrm{ml}$ crimped glass vials with butyl rubber stoppers (Geo-Microbial Technologies Inc., Ochelata, OK, USA), where they were later measured for $\mathrm{CO}_{2}$ and $\mathrm{CH}_{4}$ concentration using a SRI 8610-0040 gas chromatograph with a FID and methanizer (SRI Instruments, Torrance, CA, USA). As the enzyme assays required destructive sampling ( $0.5 \mathrm{~g}$ was removed), one replicate per treatment was analyzed for each enzyme activity per time period. The mass of the remaining peat was recorded and the treatment conditions re-established. The fractional rate of increase in microbial activity in the $14^{\circ} \mathrm{C}$ over $4^{\circ} \mathrm{C}$ temperature (the $\mathrm{Q}_{10}$ ) was calculated for each site and depth.

\section{STATISTICS}

Enzyme activity and SIR ratios were analyzed with non-metric multidimensional scaling (NMDS) ordination using Bray-Curtis distance, while T-RF proportional abundance data (square-root transformed) was analyzed with Sørensen's distance. All the NMDS ordinations were run using a random starting configuration, a maximum of 250 iterations and an instability criterion of 0.00001; two dimensions were used for all plots and Monte Carlo tests (1,000 randomized runs) was used to determine significance. The Shannon-Wiener index (Hill et al., 2003) was used to estimate T-RF diversity. Analysis of variance (ANOVA) with Tukey's post hoc test was used to determine differences in basal respiration. Classification and regression tree analysis (CART) was conducted to partition the relative effects of peat sample and the experimental variables on $\mathrm{CO}_{2}$ and $\mathrm{CH}_{4}$ production in the microcosm experiment. Relationships between $\mathrm{CO}_{2}$ and $\mathrm{CH}_{4}$ concentration were determined using Pearson's correlation analysis. Exploratory analysis of the measured variables was analyzed in two steps, as there are more variables than peat samples, following a similar method to Hudson et al. (2003). Firstly, variables that correlated with basal $\mathrm{CO}_{2}$ respiration, $\mathrm{pH}$, enzyme activity, and SIR data to a probability level of $<0.1$ were identified. Then, backward stepwise linear multiple regression was used to identify the most important variables. The residuals met the parametric assumptions of the model. All statistics were performed following tests for normality and heteroscedasticity. Data were natural log transformed when parametric assumptions were not met and $\mathrm{pH}$ data were $\log _{10}$ transformed prior to analysis. All statistical analyses were performed using R v. 2.13. (R Development Core Team, 2011) with the package vegan for NMDS ordination (Oksanen et al., 2011) and mvpart for CART analysis (De'ath, 2011).

\section{RESULTS \\ PEAT pH}

Victor Fen surface peat had the highest $\mathrm{pH}$ of 5.8 and there was no difference in $\mathrm{pH}$ between middle and deep samples ( $\mathrm{pH} 5.0$ ). Kinoje and Victor bogs were more acidic and had the same $\mathrm{pH}$ value of 3.4 at surface and similar $\mathrm{pH}$ values of 3.2 and 3.4 were observed in the middle peat samples and 3.8 and 3.5 in the deep peat, respectively.

\section{MICROBIAL COMMUNITY CHARACTERIZATION}

NMDS ordination showed that the bacterial T-RFs among the peat samples appeared to form a single cluster (Figure 1A), as many abundant T-RFs were found among the peat samples (Table A1 in Appendix). However, bacterial richness was greatest in Kinoje and Victor bogs and many of the same taxa were present in the two peatlands although more unique T-RFs were found at Victor Bog primarily at $0-10 \mathrm{~cm}$ and $50-60 \mathrm{~cm}$ (Table A1 in Appendix). NMDS ordination of the archaeal T-RFs showed clustering among the peatland types (Figure 1B), however many of the same T-RFs were identified at each site and clustering appears to be driven by a few rare T-RFs (Table A1 in Appendix). There was not enough dissimilarity among the fungal T-RFs to separate by peat sample with NMDS ordination.

Kinoje Bog MB-C at $0-10 \mathrm{~cm}$ was approximately six times greater than at both Victor Bog and Fen (Table 1). MB-C generally 

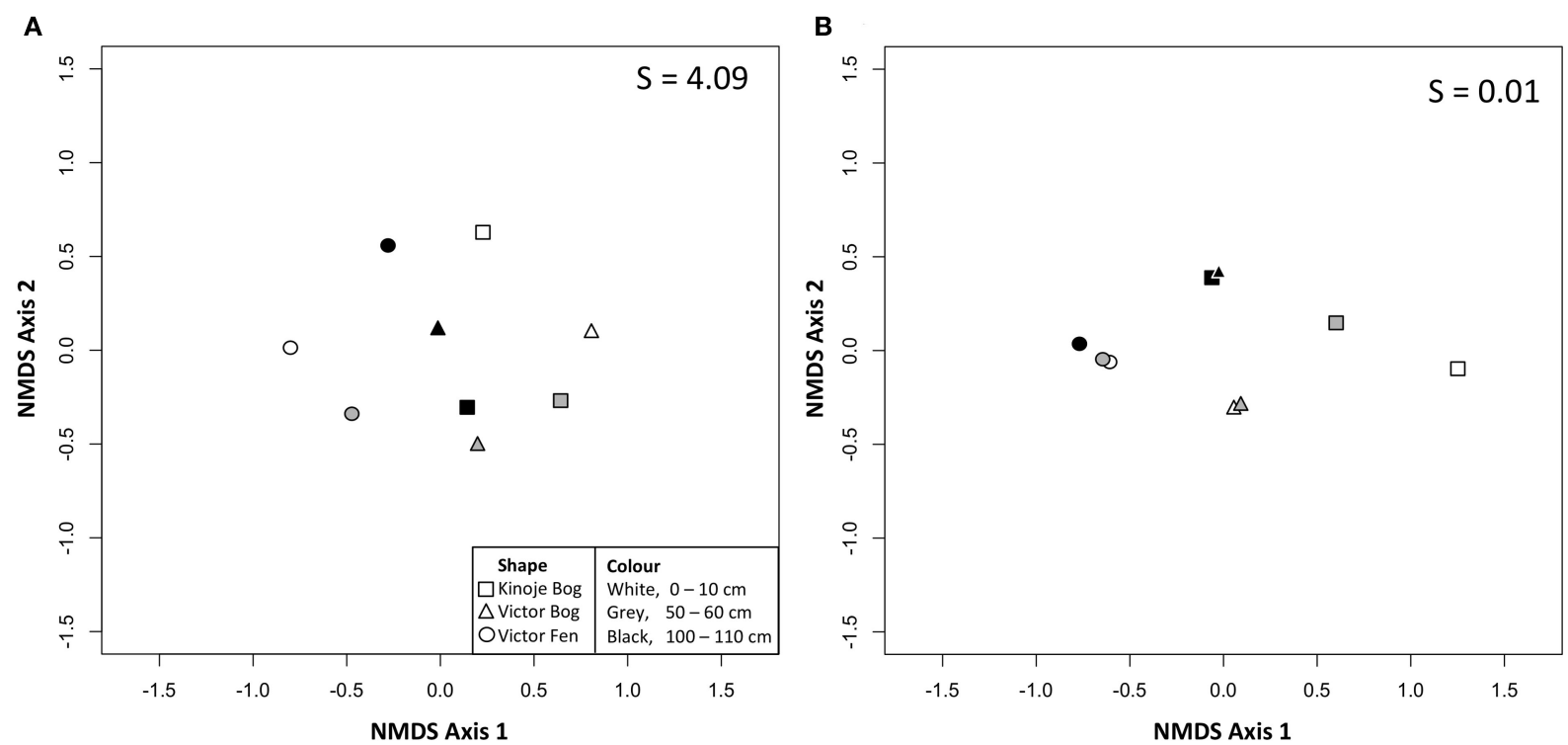

FIGURE 1 |Two dimensional non-metric multidimensional scaling (NMDS) plots of (A) bacterial terminal restriction fragments (T-RFs) and (B) archaea T-RFs identified at three depths from peat cores collected from peatlands within the James Bay Lowlands. $S$ indicates the stress value as a percentage.

Table 1 | Microbial biomass $\mathbf{C}$ and $\mathbf{N}$ within peat soil at three depths from cores collected from three James Bay peatlands $(n=1)$.

\begin{tabular}{lllll}
\hline Peatland & $\begin{array}{l}\text { Sample } \\
\text { depth }(\mathbf{c m})\end{array}$ & $\begin{array}{l}\text { MB-C } \\
\left(\boldsymbol{\mu} \mathbf{g ~ g}^{-\mathbf{1}}\right)\end{array}$ & $\begin{array}{l}\text { MB-N } \\
\left(\boldsymbol{\mu} \mathbf{g ~ g}^{-\mathbf{1}}\right)\end{array}$ & $\mathbf{C : N}$ \\
\hline Kinoje Bog & $0-10$ & 1463 & 75.5 & 19.7 \\
& $50-60$ & 211 & 14.9 & 14.7 \\
& $100-110$ & 61 & 6.5 & 10.7 \\
Victor Bog & $0-10$ & 254 & 9.9 & 26.8 \\
& $50-60$ & 431 & 22.6 & 19.5 \\
& $100-110$ & 92 & 4.6 & 22.8 \\
Victor Fen & $0-10$ & 210 & 17.7 & 11.8 \\
& $50-60$ & 9 & 5.9 & 13.5 \\
& $100-110$ & 80 & 14.8 & 5.5 \\
& & & & \\
\hline
\end{tabular}

decreased with depth except at Victor Bog 50-60 cm, which had a biomass 1.7 times greater than the surface. The carbon:nitrogen ratio typically decreased from the surface to deep samples, but the ratio was similar among all depth samples at Victor Bog.

\section{MICROBIAL ACTIVITY}

Aerobic basal $\mathrm{CO}_{2}$ respiration was significantly higher in the Victor Fen surface and middle depth peat samples compared with the deep fen peat and peat from all depths at both Kinoje and Victor Bogs $\left(F_{4,18}=84.0, p<0.001\right.$; Figure 2$)$. There was little difference in $\mathrm{CO}_{2}$ production among the bog peat samples, except for Victor Bog middle depth where $\mathrm{CO}_{2}$ production was approximately two times greater than surface and deep peat. Patterns of anaerobic basal respiration were similar to aerobic basal respiration and were strongly correlated (data not shown).

The overall magnitude of substrate utilization in the oxic SIR assay generally increased with depth as indicated by the

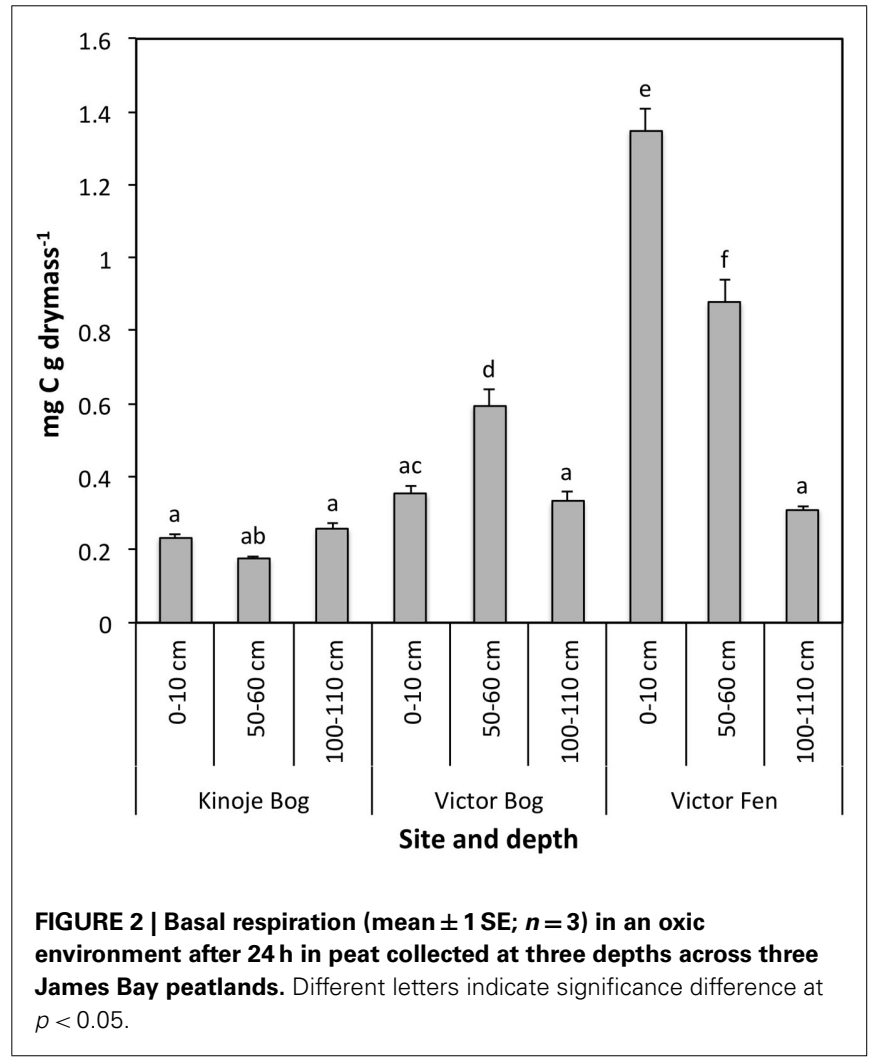

mean ratio, except for the Victor Bog middle depth sample (Table 2). Deep peat had the highest SIR ratios on average and the NMDS ordination of the oxic SIR ratios revealed that most of the deep peat samples clustered together (Figure 3A). Kinoje Bog and Victor Bog had similar responses to substrate addition 
Table 2 | Substrate induced respiration ratios (substrate/basal respiration; mean $\pm 1 \mathrm{SE}$ ) under oxic (16 $\mathrm{h}$ ) and anoxic conditions (48 $\mathrm{h}$ ) of peat soil at three depths from peat cores collected from the James Bay Lowlands.

\begin{tabular}{|c|c|c|c|c|c|c|c|}
\hline Study site & Depth (cm) & \multicolumn{6}{|c|}{ Synthetic substrates } \\
\hline \multirow[t]{3}{*}{ Kinoje Bog } & $0-10$ & $2.08(0.24)$ & $1.08(0.10)$ & $0.89(0.06)$ & $1.25(0.12)$ & $0.92(0.09)$ & $0.66(0.05)$ \\
\hline & $50-60$ & $2.03(0.08)$ & $2.06(0.13)$ & $0.99(0.08)$ & $1.27(0.09)$ & $0.94(0.04)$ & $0.86(0.06)$ \\
\hline & $100-110$ & $1.98(0.25)$ & $1.49(0.17)$ & $1.04(0.12)$ & $0.94(0.03)$ & $0.84(0.09)$ & $0.99(0.07)$ \\
\hline & $50-60$ & $1.24(0.12)$ & $1.28(0.10)$ & $0.72(0.05)$ & $0.78(0.07)$ & $0.66(0.06)$ & $0.62(0.04)$ \\
\hline & $100-110$ & $3.48(0.04)$ & $2.37(0.41)$ & $1.69(0.17)$ & $1.74(0.14)$ & $1.48(0.13)$ & $0.97(0.03)$ \\
\hline \multirow[t]{3}{*}{ Victor Fen } & $0-10$ & $1.62(0.17)$ & $2.28(0.13)$ & $3.27(0.25)$ & $0.88(0.04)$ & $1.47(0.13)$ & $2.06(0.08)$ \\
\hline & $50-60$ & $1.96(0.08)$ & $2.16(0.14)$ & $2.47(0.06)$ & $1.09(0.12)$ & $1.23(0.14)$ & $0.78(0.09)$ \\
\hline & $100-110$ & $1.85(0.06)$ & $2.71(0.15)$ & $1.49(0.12)$ & $1.02(0.08)$ & $0.96(0.05)$ & $0.81(0.06)$ \\
\hline \multicolumn{8}{|l|}{ ANOXIC } \\
\hline \multirow[t]{3}{*}{ Victor Bog } & $0-10$ & $0.91(0.24)$ & $0.93(0.05)$ & $1.26(0.27)$ & $1.08(0.04)$ & $0.52(0.04)$ & $0.47(0.05)$ \\
\hline & $50-60$ & $2.13(0.45)$ & $1.82(0.08)$ & $1.71(0.16)$ & $1.39(0.22)$ & $1.11(0.21)$ & $0.89(0.04)$ \\
\hline & $100-110$ & $1.50(0.30)$ & $1.26(0.44)$ & $1.09(0.25)$ & $1.10(0.41)$ & $0.86(0.18)$ & $0.53(0.15)$ \\
\hline \multirow[t]{3}{*}{ Victor Fen } & $0-10$ & $2.58(0.61)$ & $3.02(0.50)$ & $5.24(1.52)$ & $1.02(0.12)$ & $1.51(0.05)$ & $2.81(0.49)$ \\
\hline & $50-60$ & $1.57(0.18)$ & $2.96(0.35)$ & $2.91(1.03)$ & $0.94(0.24)$ & $0.25(0.06)$ & $0.76(0.08)$ \\
\hline & $100-110$ & $1.17(0.04)$ & $1.96(0.59)$ & $1.52(0.05)$ & $0.85(0.11)$ & $0.81(0.15)$ & $0.47(0.15)$ \\
\hline
\end{tabular}

Study site Depth (cm)

Organic substrates

\begin{tabular}{|c|c|c|c|c|c|c|}
\hline & & \\
\hline & & Rich fen sedge & Int. fen sedge & Int. fen Sphagnum & Poor fen Sphagnum & Mean ratio \\
\hline \multicolumn{7}{|l|}{ OXIC } \\
\hline \multirow[t]{3}{*}{ Kinoje Bog } & $0-10$ & $2.97(0.65)$ & $1.75(0.03)$ & $3.72(0.94)$ & $4.65(0.48)$ & 2.00 \\
\hline & $50-60$ & $3.80(0.48)$ & $2.36(0.25)$ & $4.36(0.27)$ & $4.37(0.59)$ & 2.30 \\
\hline & $100-110$ & $6.01(0.58)$ & $2.26(0.38)$ & $4.36(0.52)$ & $4.92(0.51)$ & 2.48 \\
\hline \multirow[t]{3}{*}{ Victor Bog } & $0-10$ & $3.12(0.30)$ & $2.26(0.29)$ & $5.46(0.13)$ & $6.68(0.53)$ & 2.57 \\
\hline & $50-60$ & $3.11(0.40)$ & $1.78(0.22)$ & $2.83(0.13)$ & $4.53(0.32)$ & 1.75 \\
\hline & $100-110$ & $9.53(0.55)$ & $4.85(1.33)$ & $6.55(1.23)$ & $6.60(0.64)$ & 3.93 \\
\hline \multirow[t]{3}{*}{ Victor Fen } & $0-10$ & $3.63(0.39)$ & $3.28(0.38)$ & $2.51(0.15)$ & $3.42(0.33)$ & 2.44 \\
\hline & $50-60$ & $4.88(0.30)$ & $5.72(0.54)$ & $3.09(0.29)$ & $4.48(0.42)$ & 2.79 \\
\hline & $100-110$ & 7.25 (0.88) & $4.85(0.42)$ & $4.58(0.02)$ & $6.24(0.25)$ & 3.18 \\
\hline \multicolumn{7}{|l|}{ ANOXIC } \\
\hline \multirow[t]{3}{*}{ Kinoje Bog } & $0-10$ & $2.06(0.50)$ & 1.89 (0.63) & $2.69(0.08)$ & 3.91 (1.06) & 2.18 \\
\hline & $50-60$ & $1.65(0.30)$ & $1.50(0.42)$ & $2.49(0.31)$ & $2.16(0.61)$ & 1.43 \\
\hline & $100-110$ & $2.26(0.49)$ & $3.08(0.26)$ & $2.16(0.57)$ & $2.62(0.27)$ & 1.71 \\
\hline \multirow[t]{3}{*}{ Victor Bog } & $0-10$ & $1.31(0.21)$ & $1.15(0.04)$ & $1.82(0.42)$ & $1.43(0.53)$ & 1.09 \\
\hline & $50-60$ & $2.22(0.36)$ & $1.91(0.19)$ & $3.01(0.42)$ & $2.94(0.78)$ & 1.91 \\
\hline & $100-110$ & $1.99(0.46)$ & $2.27(0.44)$ & $2.75(0.59)$ & $2.80(0.50)$ & 1.62 \\
\hline \multirow[t]{3}{*}{ Victor Fen } & $0-10$ & $4.3(0.94)$ & $5.79(1.31)$ & $3.55(0.58)$ & $4.99(0.30)$ & 3.48 \\
\hline & $50-60$ & $5.25(1.56)$ & $6.32(0.65)$ & $4.15(0.32)$ & 6.56 (1.93) & 3.17 \\
\hline & $100-110$ & $5.35(0.82)$ & $5.95(0.80)$ & $4.55(0.91)$ & $6.36(1.31)$ & 2.90 \\
\hline
\end{tabular}

Int. represents Intermediate

in both magnitude and relative ability to mineralize different substrates, while Victor Fen formed a separate cluster on the NMDS ordination, particularly as the surface and middle samples had higher average ratios than the two bogs. In contrast, substrate utilization in the anoxic SIR assay was greatest in the surface samples, except at Victor Bog where the middle peat sample was highest on average. NMDS ordination of the anoxic SIR ratios showed little clustering among the peat depth samples within 

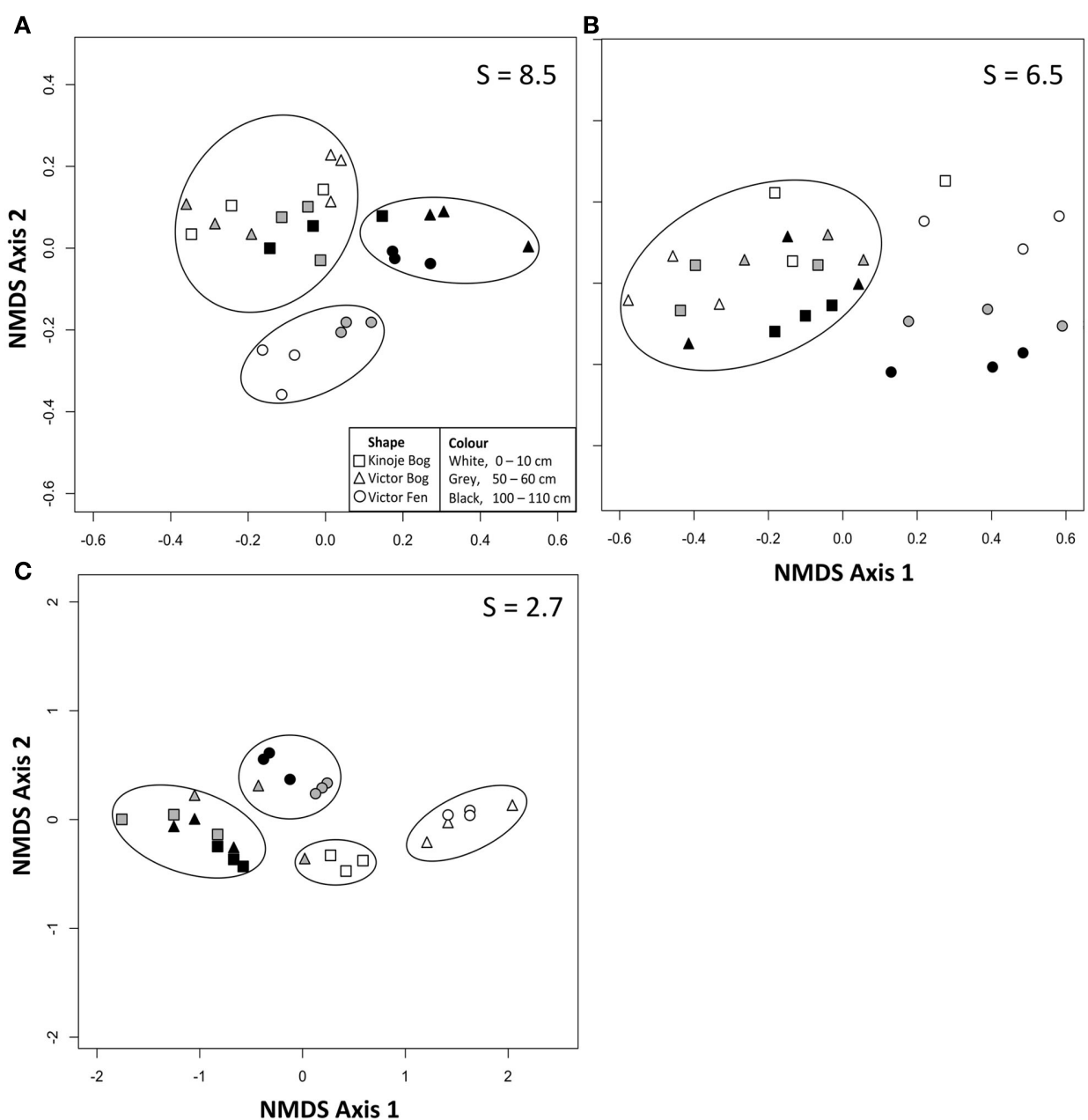

NMDS Axis 1

FIGURE 3 |Two dimensional non-metric multidimensional scaling (NMDS) plots of (A) oxic (after $16 \mathrm{~h}$ ) and (B) anoxic (after $48 \mathrm{~h}$ ) substrate induced respiration responses of peat microbial communities and (C) initial extracellular enzyme activity (EEA) from three peat cores collected from the James Bay Lowlands. S indicates the stress value as a percentage and the circles grouping data are guides only. the sites, but Kinoje and Victor Bog appear to have a similar response. There was little clustering among the Victor Fen samples (Figure 3B).

Enzyme activity generally decreased with depth, but the Kinoje Bog middle depth sample had higher $B$-xylosidase, cellobiohydrolase, sulfatase, and peroxidase activities (Table 3). NMDS ordination of the initial EEAs showed that Victor Bog and Fen surface samples had similar activities (Figure 3C). While Kinoje Bog surface peat had much lower enzyme activities (between 2.5 and 6 times; Table 3) the samples did cluster close to the Victor peatland surface samples. Similarly, Kinoje and Victor bog middle and deep samples clustered together, whereas Victor Fen middle and deep peat formed their own group as enzyme activities were much higher (range 0.5-12.7 times).

\section{INFLUENCE OF TEMPERATURE AND AERATION ON MICROBIAL ACTIVITIES}

Temperature only affected potential $\mathrm{CO}_{2}$ production rates in the surface peat samples at Victor Bog and Victor Fen (Figure 4), where rates were highest in the oxic treatment at $14^{\circ} \mathrm{C}$ and lowest in the anoxic treatment at $4^{\circ} \mathrm{C}$. Although potential $\mathrm{CO}_{2}$ production rates in an oxic environment were greatest at Victor Fen, the largest effect of temperature was observed at Victor Bog in both aeration conditions. Mean $\mathrm{Q}_{10}$ values at Victor Bog were $1.57 \pm 0.05$ and $2.34 \pm 0.07$, and $1.46 \pm 0.03$ and $1.52 \pm 0.16$ at Victor Fen in an oxic and anoxic environment, respectively. In contrast, similar potential $\mathrm{CO}_{2}$ production rates were observed in the middle and deep samples at both Victor Bog and Victor Fen. Interestingly, temperature and aeration states did not have an affect on potential $\mathrm{CO}_{2}$ production rates at Kinoje Bog, where higher rates were found in deeper peat. Overall, anoxic potential $\mathrm{CO}_{2}$ production rates followed a similar pattern to oxic production rates, and there was a strong correlation between the two $\left(t_{52}=15.5, p<0.001\right.$, $\left.r^{2}=0.82\right)$.

Similarly, temperature had no effect on potential $\mathrm{CH}_{4}$ production rates in any peat sample and there was no difference in potential $\mathrm{CH}_{4}$ production rates among the middle and deep peat samples at all three peatlands (Figure 5). Compared to middle 
Table 3 | Activity of enzymes (mean $\pm 1 \mathrm{SE} \mathrm{nmol} \mathrm{h}-1 \mathrm{~g}^{-1}$ ) within peat soil collected at three depths $(n=3)$ from peat cores collected in the James Bay Lowlands.

\begin{tabular}{|c|c|c|c|c|c|c|c|c|c|}
\hline $\begin{array}{l}\text { Sample } \\
\text { location }\end{array}$ & $\begin{array}{l}\text { Sample } \\
\text { depth }(\mathrm{cm})\end{array}$ & $\begin{array}{l}N \text {-acetyl-beta-d- } \\
\text { glucosaminide }\end{array}$ & Phosphatase & $\beta$-glucosidase & Sulfatase & $B$-xylosidase & $\begin{array}{l}\text { Cello- } \\
\text { biohydrolase }\end{array}$ & $\begin{array}{l}\text { Per- } \\
\text { oxidase }\end{array}$ & $\begin{array}{l}\text { Phenol } \\
\text { oxidase }\end{array}$ \\
\hline \multirow[t]{2}{*}{ Kinoje Bog } & $0-10$ & $360.6(67.5)$ & $8261.1(1058.4)$ & 1096.8 (101.5) & $4.8(0.9)$ & $36.6(0.6)$ & $88.1(5.8)$ & $1.9(0.7)$ & $0.3(0.1)$ \\
\hline & $100-110$ & $48.7(9.3)$ & $1845(244.3)$ & $338.5(48)$ & $0(0)$ & $45.5(14.3)$ & $21.8(1.7)$ & $2.4(1.3)$ & $0(0)$ \\
\hline \multirow[t]{2}{*}{ Victor Bog } & $0-10$ & 900.2 (333) & $45151.8(16612.7)$ & $2611.9(500.3)$ & $32.3(20.3)$ & $196.3(94.4)$ & $248.5(34.2)$ & $9.6(1.3)$ & $1.6(0.9)$ \\
\hline & $50-60$ & $139.3(76)$ & $2164.9(1264)$ & 1047.2 (313.6) & $20.6(15.7)$ & $119.1(5.1)$ & $64.6(36.7)$ & $2.1(1.1)$ & $3.4(2.4)$ \\
\hline \multirow[t]{3}{*}{ Victor Fen } & $0-10$ & 1667.6 (112.5) & 39231.2 (4371.8) & $3913.3(200.2)$ & $145.2(52.2)$ & $362.5(52.6)$ & 415.5 (16.6) & $29.4(6.5)$ & $3.5(1.9)$ \\
\hline & $50-60$ & 1777.5 (266.8) & $3227.4(60.1)$ & 2686.2 (150.8) & $85.3(15)$ & $145(5.7)$ & $344.3(24)$ & $17.3(2.6)$ & $2(0.7)$ \\
\hline & $100-110$ & 647.8 (69.9) & $1072.6(280.5)$ & 2199.1 (217.8) & $0(0)$ & $79.6(2.1)$ & $275(22.6)$ & $17.2(3.9)$ & $1.1(0.6)$ \\
\hline
\end{tabular}

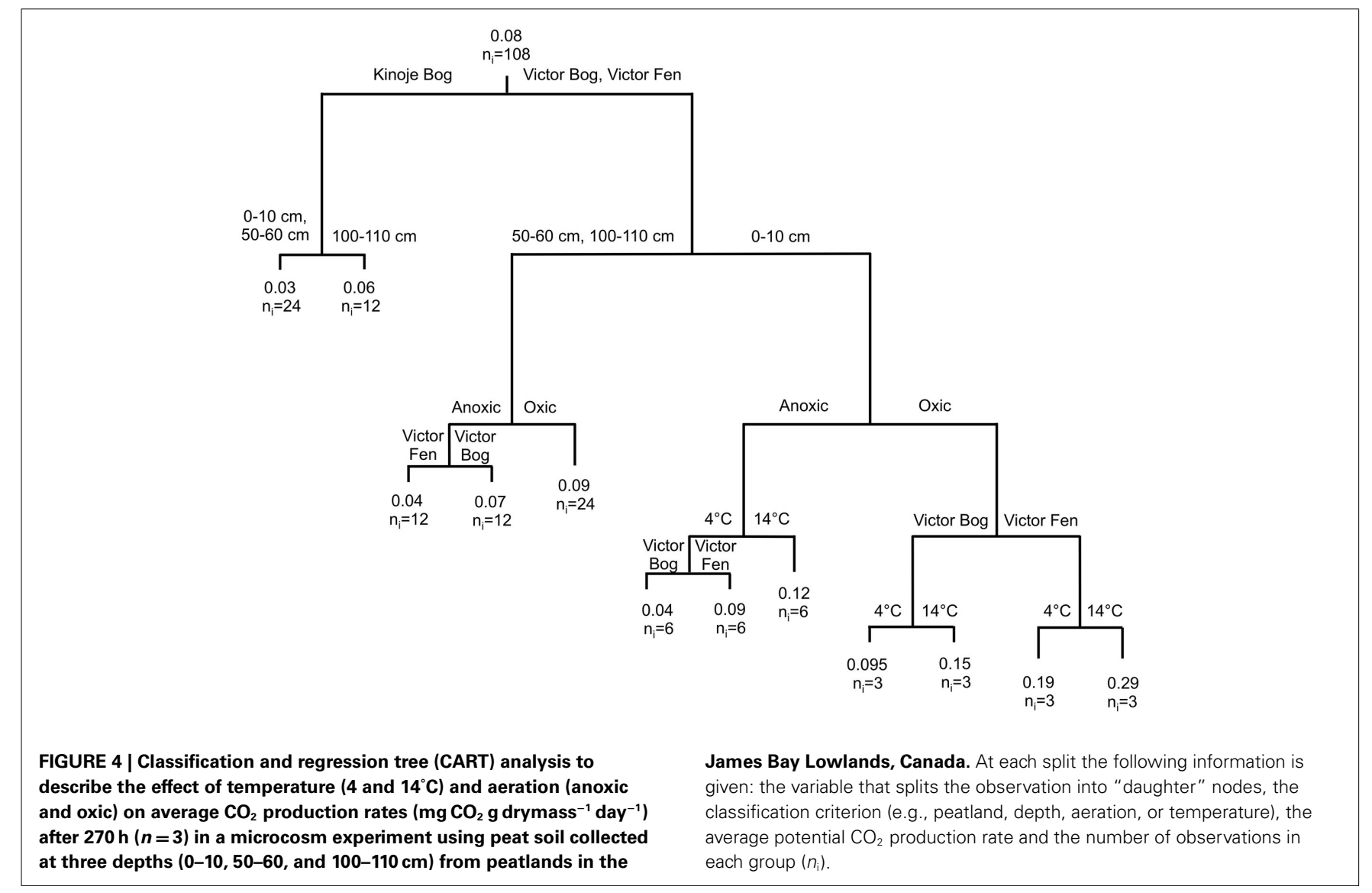

and deep peat samples the potential $\mathrm{CH}_{4}$ production rates in surface peat at Victor Fen were 2 times greater and 3.7 times greater at Victor Bog, but were approximately 50\% lower at Kinoje Bog. Moreover, anoxic $\mathrm{CH}_{4}$ production rates correlated with oxic $\left(t_{52}=5.2, p<0.001, r^{2}=0.34\right)$ and anoxic $\left(t_{52}=4.7, p<0.001\right.$, $\left.r^{2}=0.29\right) \mathrm{CO}_{2}$ production rates.

Measured EEA in the microcosm experiment at 90, 180, and $270 \mathrm{~h}$ did not correlate with $\mathrm{CO}_{2}$ production in either the oxic or anoxic environments, except for a weak correlation between oxic $\mathrm{CO}_{2}$ production and sulfatase $\left(t_{106}=4.3, p<0.001, r^{2}=0.15\right)$, but this was primarily driven by the absence of enzyme activity in deep peat.

\section{INTERACTIONS AMONG MEASURED VARIABLES}

Although basal $\mathrm{CO}_{2}$ respiration correlated well for several variables with $r$ values ranging from 0.6 to 0.85 (Table 4), only $\mathrm{pH}$ was included in the final regression model (basal $\mathrm{CO}_{2} \mathrm{mgg}^{-1}=0.07+0.48(\mathrm{pH}) ; \quad F_{1,7}=8.5, \quad p<0.05$, adjusted $\left.r^{2}=0.49\right)$. Similarly, $\mathrm{pH}$ could also explain anoxic SIR values $\left(\right.$ Anoxic NMDS SIR $=1.41-0.35(\mathrm{pH}) ; F_{1,7}=32.3, p<0.001$, adjusted $\left.r^{2}=0.77\right)$, but not oxic SIR values. Despite $\mathrm{pH}$ correlating well with several enzyme activities, it was not significant in the final regression model. Interestingly, bacterial and fungal diversity did not correlate with $\mathrm{pH}$, but good correlations were observed for measures of archaeal diversity and $\mathrm{pH}$. Overall 


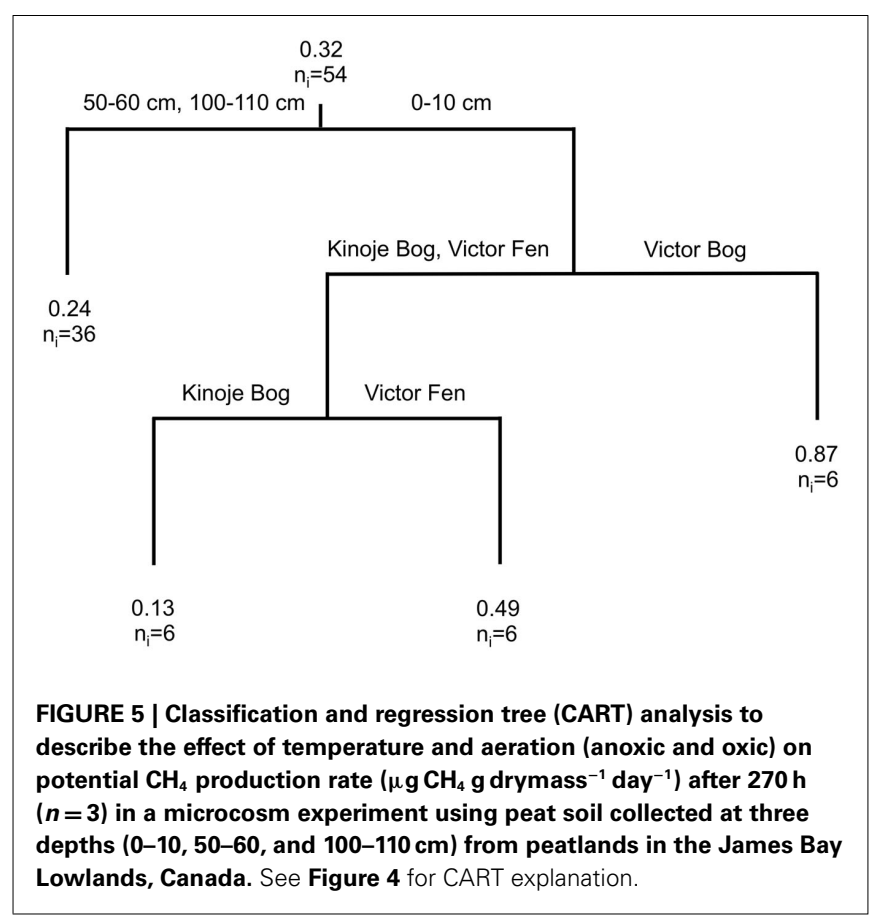

enzyme activity (NMDS values) correlated with bacterial diversity, but the regression was not significant, but there was no relationship with archaeal or fungal diversity.

\section{DISCUSSION}

\section{MICROBIAL COMMUNITY CHARACTERIZATION}

The same dominant microbial taxa identified using T-RFLP were found among all three peatlands despite differences in geographic location, nutrient status, and plant community composition. This contradicts our initial hypothesis and previous studies where differences in microbial community composition have been identified among peatlands with different vegetation characteristics (Ausec et al., 2009; Peltoniemi et al., 2009; Andersen et al., 2010). However, this finding is consistent with previous peatland studies comparing bacterial communities in two similar fens in Slovenia (Kraigher et al., 2006) and archaea and bacteria in Sphagnum dominated bogs across the northeastern USA (Basiliko et al., 2003; Morales et al., 2006). In contrast to previous studies (Båăth and Anderson, 2003; Fierer and Jackson, 2006; Rousk et al., 2010), where higher bacterial diversity is associated with more neutral $\mathrm{pH}$, a greater number of taxa were actually detected in the more acidic bogs rather than the fen. Moreover, there was no correlation between $\mathrm{pH}$ and the microbial community structure or diversity indices. However, the range of peat $\mathrm{pH}$ values in the JBL was relatively small, which may explain why diversity was not explained by $\mathrm{pH}$. Furthermore, $\mathrm{pH}$ also appeared not to influence microbial community composition in other peatland studies (Kraigher et al., 2006; Ausec et al., 2009), suggesting that the relationship between $\mathrm{pH}$ and microbial diversity in general might be less important in peatland ecosystems.

Richness was also similar among the depths with few taxa confined to a single depth profile, in contrast to Morales et al. (2006) who found a greater number of bacterial T-RFs in surface peat
$(0-15 \mathrm{~cm})$ than in deep peat $(1 \mathrm{~m})$. Although this may have been due to the relatively low detected richness level relative to Morales et al. (2006), it suggests that at least the dominant members of the microbial community are always present, despite presumed differences in oxygen content with depth.

Little is known about the role of fungi in peatlands, but diverse communities have been found beneath the Sphagnum mat and in close association with ericaceous shrubs (Thormann, 2006; Artz et al., 2007) and different fungal communities have been linked to the vegetation and nutrient status of peatlands (Artz et al., 2007; Trinder et al., 2008). Fungi are generally thought to predominate in peatland lawns and hummocks (Jaatinen et al., 2007) as they cannot utilize alternative electron acceptors in anoxic environments and successfully compete with bacteria for carbon substrates (Killham and Prosser, 2007). Thus it was interesting that most fungal taxa were identified at all three depths among the three JBL peatlands. Fungi are typically most competitive under an oxic environment, however they can carry out fermentation. So their abundance at depth may in part be due to a lack of alternative inorganic electron acceptors (e.g., sulfate) that might otherwise have facilitated anaerobic bacterial respiration in these deep anoxic peat samples. This might also imply that facultative fungi supply fermentation products that ultimately fuel methanogenesis (Conrad, 2007).

Consistent with prior studies, microbial biomass decreased with depth probably due to the presence of more labile organic matter and higher redox states typically found near the surface of peat profiles (Blodau and Moore, 2002; Blodau et al., 2004; Basiliko et al., 2007). Although microbial biomass across sites was generally quite small compared to other bogs and fens (Moore and Basiliko, 2006), it was similar to that in mined peatlands in more southern regions of Canada that have relatively low nutrient and carbon availability (Basiliko et al., 2007); which might indicate that substrate or nutrient availability for heterotrophic microbial communities is low even in the fen site. Decreasing MB-C:MB-N ratios with depth has been observed elsewhere (e.g., Basiliko et al., 2007) and is probably due to decreasing fungal:bacterial ratios with depth and the fact that bacteria typically have higher anabolic N requirements (Killham and Prosser, 2007). Bacteria often predominate in deeper more anoxic peat layers as they can utilize alternative electron acceptors (Killham and Prosser, 2007). Microbial biomass did not correlate with potential $\mathrm{CO}_{2}$ production rates in contrast to previous studies (Blodau et al., 2004; Basiliko et al., 2007). However, this may simply reflect the low microbial biomass and low amount of labile carbon in our sites.

\section{MICROBIAL ACTIVITIES}

Despite the similarity of the microbial communities among the three peatlands, there were differences in basal respiration, initial enzyme activities and substrate utilization patterns. Greater microbial activity was observed in the fen compared to the bogs, possibly due to the higher in situ nutrient concentrations and greater carbon substrate availability typically found in fens (Moore and Basiliko, 2006; Knorr and Blodau, 2009). Overall the average oxic SIR ratio response was very similar among deep peat samples in all three peatlands and greater than those in both the surface and middle peat samples. Deeper peat is older and typically has lower 
Table 4 | Pearson's product moment correlations between measures of microbial activity/pH and potential explanatory variables.

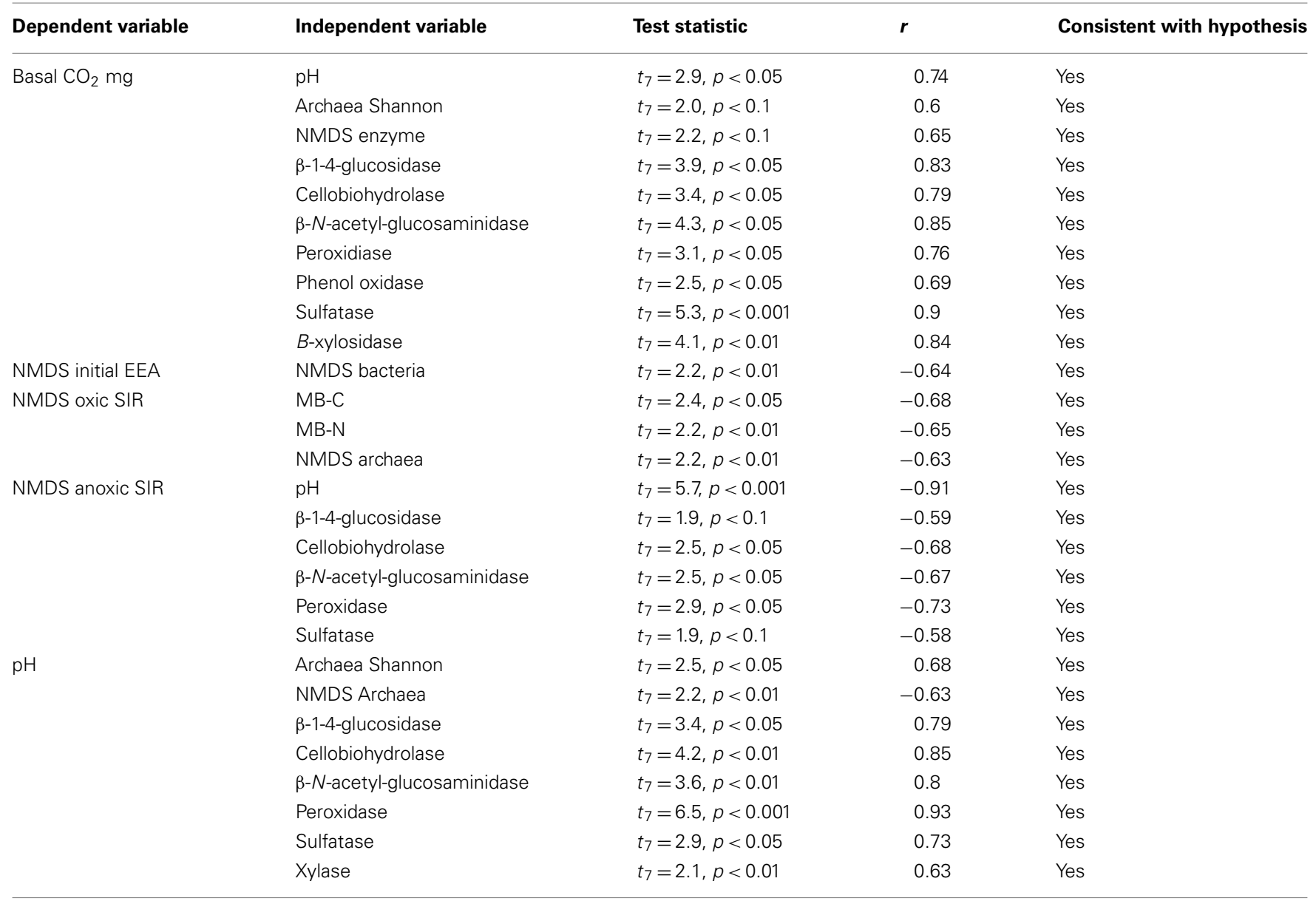

NMDS represents the first axis from the respective NMDS plot.

levels of labile carbon (Glatzel et al., 2003; Artz et al., 2006). Thus, the microbial community at these depths was probably substrate limited relative to the surface peat. However, this trend disappeared in the anoxic SIR assay, as there was little difference in the response among depths between Kinoje and Victor bogs. In contrast, Victor Fen had greater average SIR values in the surface peat sample, likely as a result of higher redox substrate concentrations (Knorr and Blodau, 2009; Webster and McLaughlin, 2010).

This apparent contradiction between microbial activity and community composition may be explained by differences in peat organic matter quality. Plant litter from bogs and fens have different nutrient concentrations (Bragazza et al., 2007) and therefore microorganisms in these contrasting habitats will have different nutrient requirements. Recently, Straková et al. (2011) identified litter type as the main factor affecting microbial EEA in bog peat soil. Similar to our study the authors reported higher enzyme activities in peat composed of vascular plants, typical in fens, rather than Sphagnum dominated peat and also failed to identify a strong relationship between microbial community composition and EEA. Moreover, the differences in SIR activities, identified by the NMDS ordination, among sites was primarily due to the magnitude of the response, but the relative substrate utilization patterns (i.e., among the 10 substrates) were actually similar among the three peatlands despite our hypothesis that the two bogs and fen would preferentially mineralize different substrates, probably because the microbial communities were similar. The subdued response to substrate addition in the bogs may be due to inhibitory effects of Sphagnum leachates on microbial activity (Verhoeven and Toth, 1995; Hättenschwiler and Vitousek, 2000; Hájek et al., 2010). Furthermore, vegetation type has been shown to influence microbial activity more than water table drawdown (Trinder et al., 2008; Straková et al., 2011) and small changes in the plant community composition can have profound affects on microbial processes, such as methanogenesis (Hines et al., 2008).

The relatively high $N$-acetyl-beta-D-glucosaminidase activity throughout the peat profile suggests a high metabolic demand for $\mathrm{N}$ released during chitin turnover (Sinsabaugh et al., 1993) and corresponds with presence and identification of fungal taxa at all peat depths. This contradicts our previous finding that carbon:nitrogen ratio decreases with depth and might represent bacterial dominance of decomposition due to higher $\mathrm{N}$ demand. However, it is not certain whether fungi or bacteria produced these enzymes or what the specific activity of the fungi is in deep peat. Interestingly, a recent meta-analysis found that shifts 
in bacterial to fungal dominance across environmental gradients often do not correlate with changes in element cycling and may be due to niche overlap between fungal and bacterial communities (Strickland and Rousk, 2010). In an antibiotic inhibition assay, Winsborough and Basiliko (2010) showed that bacteria dominated peatland microbial activity; while fungal activity did increase in acidic dry bogs it was still lower than bacterial activity. Although we do not have direct measurements of fungal biomass, these results suggest that our understanding of the relationship between fungi and ecosystem function in peat soil is incomplete.

We did not find a relationship between microbial community composition and activities in contrast to our hypothesis. Although this could be due to the issues of the taxa-level resolution using $\mathrm{T}$ RFLP small-subunit rDNA, this finding highlights the importance of carbon substrate as a proximate control of microbial community dynamics because similar communities can perform different functions given different resources and conditions.

\section{ENVIRONMENTAL CHANGE}

As predicted and consistent with previous studies (Moore and Dalva, 1993; Updegraff et al., 1998; Keller et al., 2004), an increase in aeration of the peat soil stimulated $\mathrm{CO}_{2}$ production rates, but only in Victor Bog and Fen, and temperature only affected rates in the surface peat samples. This suggests that oxygen availability is more important than temperature in increasing mineralization rates, possibly brought about by an increase in enzyme activity in response to a release from inhibition through the "enzymic latch theory" (Freeman et al., 2001, 2004). However, $\mathrm{CO}_{2}$ production did not correlate with enzyme activity probably because the enzymes measured in this study may only be a subset of those actually involved in peat decomposition (Horwath, 2007). Potential $\mathrm{CO}_{2}$ production rates among the depths were lower in anoxic conditions but there was a strong correlation between oxic and anoxic $\mathrm{CO}_{2}$ production consistent with previous investigations (Moore and Dalva, 1997; Yavitt et al., 1997; Glatzel et al., 2004). These findings suggest that similar peat properties control the activities of

\section{REFERENCES}

Aerts, A. R., Verhoeven, J. T. A., and Whigham, D. F. (1999). Plantmediated controls on nutrient cycling in temperate fens and bogs. Ecology 80, 2170-2181.

Allison, S. D., and Treseder, K. K. (2008). Warming and drying suppress microbial activity and carbon cycling in boreal forest soils. Glob. Chang. Biol. 14, 2898-2909.

Andersen, R., Grasset, L., Thormann, M., Rochefort, L., and Francez, A.-J. (2010). Changes in microbial community structure and function following Sphagnum peatland restoration. Soil Biol. Biochem. 42, 291-301.

Artz, R. R. E., Anderson, I. C., Chapman, S. J., Hagn, A., Schloter, M., Potts, J. M., and Campbell, C. D. (2007). Changes in fungal community composition in response to vegetational succession during the natural regeneration of cutover peatlands. Microb. Ecol. 54, 508-522.

Artz, R. R. E., Chapman, S., and Campbell, C. (2006). Substrate utilisation profiles of microbial communities in peat are depth dependent and correlate with whole soil FTIR profiles. Soil Biol. Biochem. 38, 2958-2962.

Ausec, L., Kraigher, B., and MandicMulec, I. (2009). Differences in the activity and bacterial community structure of drained grassland and forest peat soils. Soil Biol. Biochem. 41, 1874-1881.

Bååth, E., and Anderson, T.-H. (2003). Comparison of soil fungal/bacterial ratios in a $\mathrm{pH}$ gradient using physiological and PLFA-based techniques. Soil Biol. Biochem. 35, 955-963.

Balser, T. C., and Firestone, M. K. (2005). Linking microbial

both aerobic and anaerobic microbial metabolism (Glatzel et al., 2004; Basiliko et al., 2007). Similarly, $\mathrm{CH}_{4}$ production rates were low throughout the peat profile but still within the range of previously reported values (Moore and Dalva, 1993; Glatzel et al., 2004; Basiliko et al., 2007).

\section{CONCLUSION}

Microbial community composition was very similar among peatlands and at depths within the JBL despite differences in geographic location and nutrient status. In contrast, microbial activity appears to be determined by the quality of the peat substrate and the presence of potential microbial inhibitors. As climate change is expected to cause a shift in JBL plant community composition, this study suggests that the microbial community will respond quickly to changes in plant litter and root exudate quality but the existing peat substrate will probably have a large influence on future microbial activity. For example, a shift from Sphagnum to sedge-dominated peatlands may not necessarily result in the expected increase in carbon mineralization due to the antimicrobial properties of the Sphagnum-peat. Interestingly, we identified fungal taxa in deep peat but it is unclear what anaerobic processes are occurring and how these organisms influence carbon cycling. Thus, more in depth profiling of the JBL microbial community and identification of the potential constraints on microbial activity is required in order to better predict future peatland carbon dynamics.

\section{ACKNOWLEDGMENTS}

The authors gratefully acknowledge Benoit Hamel, Mark Crofts, and Adam Kinnunen for collection of peat samples, Varun Gupta and Charlotte Hewins for assistance with laboratory analyses and the two reviewers for comments and suggestions to improve the manuscript. Funding was provided by Ontario Ministry for Natural Resources, The National Science Foundation Enzymes in the Environment Research Coordination Network, The Corning Institute for Education and Research, and The Reinberger Foundation.

community composition and soil processes in a California annual grassland and mixed-conifer forest. Biogeochemistry 73, 395-415.

Bardgett, R. D., Freeman, C., and Ostle, N. J. (2008). Microbial contributions to climate change through carbon cycle feedbacks. ISME J. 2 , 805-814.

Basiliko, N., Blodau, C., Roehm, C., Bengtson, P., and Moore, T. R. (2007). Regulation of decomposition and methane dynamics across natural, commercially mined, and restored northern peatlands. Ecosystems 10, 1148-1165.

Basiliko, N., Yavitt, J. B., Dees, P. M., and Merkel, S. M. (2003). Methane biogeochemistry and methanogen communities in two northern peatland ecosystems, New York state. Geomicrobiol. J. 20, 563-577.
Blackwood, C. B., Marsh, T., Kim, S.H., and Paul, E. A. (2003). Terminal restriction fragment length polymorphism data analysis for quantitative comparison of microbial communities. Appl. Environ. Microbiol. 69, 926-932.

Blodau, C., Basiliko, N., and Moore, T. R. (2004). Carbon turnover in peatland mesocosms exposed to different water table levels. Biogeochemistry 67, 331-351.

Blodau, C., and Moore, T. R. (2002). Macroporosity affects water movement and pore water sampling in peat soils. Soil Sci. 167, 98-109.

Bragazza, L., Siffi, C., Iacumin, P., and Gerdol, R. (2007). Mass loss and nutrient release during litter decay in peatland: the role of microbial adaptability to litter chemistry. Soil Biol. Biochem. 39, 257-267. 
Bräuer, S. L., Cadillo-Quiroz, H., Yashiro, E., Yavitt, J. B., and Zinder, S. H. (2006). Isolation of a novel acidiphilic methanogen from an acidic peat bog. Nature 442, 192-194.

Christopherson, R., and Byrne, M.-L. (2009). Geosystems, An Introduction to Physical Geography. 2nd Canadian Edn. Toronto: Pearson Education.

Clymo, R. S. (1984). The limits to peat bog growth. Philos. Trans. R. Soc. Lond. B Biol. Sci. 303, 605-654.

Conrad, R. (2007). Microbial ecology of methanogens and methanotrophs. Adv. Agron. 96, 1-63.

De'ath, G. (2011). mvpart: Multivariate partitioning. $R$ package version 1.4-0. Available at: http://CRAN. R-project.org/package $=$ mvpart

Dorrepaal, E., Cornelissen, J. H. C., Aerts, R., Wallén, B., and Logtestijn, R. S. P. Van. (2005). Are growth forms consistent predictors of leaf litter quality and decomposability across peatlands along a latitudinal gradient? J. Ecol. 93, 817-828.

Edel-Hermann, V., Dreumont, C., Pérez-Piqueres, A., and Steinberg, C. (2004). Terminal restriction fragment length polymorphism analysis of ribosomal RNA genes to assess changes in fungal community structure in soils. FEMS Microbiol. Ecol. 47, 397-404.

Feinstein, L. M., Sul, W. J., and Blackwood, C. B. (2009). Assessment of bias associated with incomplete extraction of microbial DNA from soil. Appl. Environ. Microbiol. 75, 5428-5433.

Fierer, N., and Jackson, R. B. (2006). The diversity and biogeography of soil bacterial communities. Proc. Natl. Acad. Sci. U.S.A. 103, 626-631.

Fisk, M. C., Ruether, K. F., and Yavitt, J. B. (2003). Microbial activity and functional composition among northern peatland ecosystems. Soil Biol. Biochem. 35, 591-602.

Forster, P., Ramaswamy, V., Artaxo, P., Berntsen, T., Betts, R., Fahey, D. W., Haywood, J., Lean, J., Lowe, D. C., Myhre, G., Nganga, J., Prinn, R., Raga, G., Schulz, M., Van Dorland, R., and IPCC (2007). "Changes in atmospheric constituents and in radiative forcing," in Climate Change 2007: The Physical Science Basis. Contribution of Working Group I to the Fourth Assessment Report of the Intergovernmental Panel on Climate Change, eds S. Solomon, D. Qin, M. Manning, Z. Chen, M. Marquis, K. B. Averyt, M. Tignor, and H. L. Miller (Cambridge: Cambridge University Press), 210-215.
Freeman, C., Ostle, N., Fenner, N., and Kang, H. (2004). A regulatory role for phenol oxidase during decomposition in peatlands. Soil Biol. Biochem. 36, 1663-1667.

Freeman, C., Ostle, N., and Kang, H. (2001). An enzymic "latch" on a global carbon store. Nature 409, 149.

Gagnon, A. S., and Gough, W. A. (2005). Climate change scenarios for the Hudson Bay region: an intermodel comparison. Clim. Change 69, 269-297.

Glatzel, S., Basiliko, N., and Moore, T. R. (2004). Carbon dioxide and methane production potentials of peat from natural, harvested and restored sites, Eastern Québec, Canada. Wetlands 24, 261-267.

Glatzel, S., Kalbitz, K., Dalva, M., and Moore, T. R. (2003). Dissolved organic matter properties and their relationship to carbon dioxide efflux from restored peat bogs. Geoderma 113, 397-411.

Gorham, E. (1991). Northern peatlands: role in the carbon cycle and probable responses to climatic warming. Ecol. Appl. 1, 182.

Hájek, T., Ballance, S., Limpens, J., Zijlstra, M., and Verhoeven, J. T. A. (2010). Cell-wall polysaccharides play an important role in decay resistance of Sphagnum and actively depressed decomposition in vitro. Biogeochemistry 103, 45-57.

Hättenschwiler, S., and Vitousek, P. (2000). The role of polyphenols in terrestrial ecosystem nutrient cycling. Trends Ecol. Evol. (Amst.) 15, 238-243.

Hengeveld, H. G. (2000). Projections for Canada's Climate Future: a Discussion of Recent Simulations with the Canadian Global Climate Model. Downsview, ON: Meteorological Service Of Canada.

Hill, T. C. J., Walsh, K. A., Harris, J. A., and Moffett, B. F. (2003). Using ecological diversity measures with bacterial communities. FEMS Microbiol. Ecol. 43, 1-11.

Hines, M. E., Duddleston, K. N., Rooney-Varga, J. N., Fields, D., and Chanton, J. P. (2008). Uncoupling of acetate degradation from methane formation in Alaskan wetlands: connections to vegetation distribution. Global Biogeochem. Cycles 22, GB2017.

Horwath, W. H. (2007). “Carbon cycling and formation of soil organic matter," in Soil Microbiology, Ecology, and Biochemistry, 3rd Edn, ed. E. A. Paul (Oxford: Academic Press), 119-144.

Hudson, J. J., Dillon, P. J., and Somers, K. M. (2003). Long-term patterns in dissolved organic carbon in boreal lakes: the role of incident radiation, precipitation, air temperature, southern oscillation and acid deposition. Hydrol. Earth Syst. Sci. 7, 390-398.

Jaatinen, K., Fritze, H., Laine, J., and Laiho, R. (2007). Effects of shortand long-term water-level drawdown on the populations and activity of aerobic decomposers in a boreal peatland. Glob. Chang. Biol. 13, 491-510.

Keller, J. K., White, J. R., Bridgham, S. D., and Pastor, J. (2004). Climate change effects on carbon and nitrogen mineralization in peatlands through changes in soil quality. Glob Chang. Biol. 10, 1053-1064.

Killham, K., and Prosser, J. I. (2007). "The prokaryotes" in Soil Microbiology, Ecology, and Biochemistry, 3rd Edn, ed. E. A. Paul (Oxford: Academic Press), 119-144.

Knorr, K.-H., and Blodau, C. (2009). Impact of experimental drought and rewetting on redox transformations and methanogenesis in mesocosms of a northern fen soil. Soil Biol. Biochem. 41, 1187-1198.

Kraigher, B., Stres, B., Hacin, J., Ausec, L., Mahne, I., Vanelsas, J., and Mandicmulec, I. (2006). Microbial activity and community structure in two drained fen soils in the Ljubljana Marsh. Soil Biol. Biochem. 38, 2762-2771.

Laiho, R. (2006). Decomposition in peatlands: reconciling seemingly contrasting results on the impacts of lowered water levels. Soil Biol. Biochem. 38, 2011-2024.

Laine, A., Wilson, D., Kiely, G., and Byrne, K. A. (2007). Methane flux dynamics in an Irish lowland blanket bog. Plant Soil 299, 181-193.

Lueders, T., and Friedrich, M. (2000). Archaeal population dynamics during sequential reduction processes in rice field soil. Appl. Environ. Microbiol. 66, 2732-2742.

Lueders, T., and Friedrich, M. W. (2003). Evaluation of PCR amplification bias by terminal restriction fragment length polymorphism analysis of small-subunit rRNA and $m c r A$ genes by using defined template mixtures of methanogenic pure cultures and soil DNA extracts. Appl. Environ. Microbiol. 69, 320-326.

Lukow, T., Dunfield, P., and Liesack, W. (2000). Use of the T-RFLP technique to assess spatial and temporal changes in the bacterial community structure within an agricultural soil planted with transgenic and non-transgenic potato plants. FEMS Microbiol. Ecol. 32, 241-247.
Martini, I. P. (2006) "The cold-climate peatlands of the Hudson Bay Lowland, Canada: brief overview of recent work" in Peatlands: Evolution and Records of Environmental and Climate Changes, eds I. P. Martini, A. M. Cortizas, and W. Chesworth (Amsterdam: Elsevier), 53-84.

McGuire, K. L., and Treseder, K. K. (2010). Microbial communities and their relevance for ecosystem models: decomposition as a case study. Soil Biol. Biochem. 42, 529-535.

Moore, T. R., and Basiliko, N. (2006) "Decomposition in boreal peatlands" in Ecological Studies, Vol. 188. Boreal Peatland Ecosystems, eds R. K. Wieder and D. $\mathrm{H}$. Vitt (Berlin: Springer-Verlag), 125-143.

Moore, T. R., and Dalva, M. (1993). The influence of temperature and water table position on carbon dioxide and methane emissions from laboratory columns of peatland soils. J. Soil Sci. 44, 651-664.

Moore, T. R., and Dalva, M. (1997). Methane and carbon dioxide exchange potentials of peat soils in aerobic and anaerobic laboratory incubations. Soil Biol. Biochem. 29, 1157-1164.

Moore, T. R., Roulet, N. T., and Waddington, J. M. (1998). Uncertainty in predicting the effect of climatechange on the carbon cycling of Canadian peatlands. Clim. Change 40, 229-245.

Morales, S. E., Mouser, P. J., Ward, N., Hudman, S. P., Gotelli, N. J., Ross D. S., and Lewis, T. A. (2006). Comparison of bacterial communities in New England Sphagnum bogs using terminal restriction fragment length polymorphism (T-RFLP). Microb. Ecol. 52, 34-44.

Ocio, J., and Brookes, P. C. (1990). Soil microbial biomass measurements in sieved and unsieved soil. Soil Biol. Biochem. 22, 999-1000.

Oksanen, J., Blanchet, F. G., Kindt, R., Legendre, P., O’Hara, R. B., Simpson, G. L., Solymos, P., Stevens, M. H. H., and Wagner, H. (2011). Vegan: Community Ecology Package. R package version 1.17-9. Available at: http://CRAN.R-project.org/package =vegan

Peltoniemi, K., Fritze, H., and Laiho, R. (2009). Response of fungal and actinobacterial communities to waterlevel drawdown in boreal peatland sites. Soil Biol. Biochem. 41, 1902-1914.

R Development Core Team. (2011). R: A Language and Environment for Statistical Computing. Vienna: $R$ Foundation for 
Statistical Computing. Available at: http://www.R-project.org/

Reed, H. E., and Martiny, J. B. H. (2007). Testing the functional significance of microbial composition in natural communities. FEMS Microbiol. Ecol. $62,161-170$

Riley, J. L. (1982). Hudson Bay Lowland flouristic inventory, wetlands catalogue and conservation strategy. Nat. Can. 109, 543-555.

Robroek, B. J. M., Limpens, J., Breeuwer, A., and Schouten, M. G. C. (2007). Effects of water level and temperature on performance of four Sphagnum mosses. Plant Ecol. 190, 97-107.

Roulet, N. T. (2000). Peatlands, carbon storage, greenhouse gases, and the Kyoto protocol: prospecs and significance for Canada. Wetlands 20, 605-615.

Roulet, N. T., Lafleur, P. M., Richard, P. J. H., Moore, T. R., Humphreys, E. R., and Bubier, J. (2007). Contemporary carbon balance and late Holocene carbon accumulation in a northern peatland. Glob. Chang. Biol. 13, 397-411.

Roulet, N. T., Moore, T., Bubier, J., and Lafleur, P. M. (1992). Northern fens: methane flux and climate change. Tellus 44B, 100-105.

Rousk, J., Bååth, E., Brookes, P. C. Lauber, C. L., Lozupone, C., Caporaso, J. G., Knight, R., and Fierer, N. (2010). Soil bacterial and fungal communities across a $\mathrm{pH}$ gradient in an arable soil. ISME J 1340-1351.

Rydin, H., and Jeglum, J. K. (2006). The Biology of Peatlands. Oxford: Oxford University Press.

Saiya-Cork, K. R., Sinsabaugh, R. L. and Zak, D. R. (2002). The effects of long term nitrogen deposition on extracellular enzyme activity in an Acer saccharum forest soil. Soil Biol. Biochem. 34, 1309-1315.

Sinsabaugh, R. L. (2010). Phenol oxidase, peroxidase and organic matter dynamics of soil. Soil Biol. Biochem. 42, 391-404.

Sinsabaugh, R. L., Antibus, R. K., Linkins, A. E., McClaugherty, C. A., Rayburn, L., Repert, D., and Weiland, T. (1993). Wood decomposition: nitrogen and phosphorus dynamics in relation to extracellular enzyme activity. Ecology 74, 1586-1593.

Straková, P., Niemi, R. M., Freeman, C., Peltoniemi, K., Toberman, H., Heiskanen, I., Fritze, H., and Laiho, R. (2011). Litter type affects the activity of aerobic decomposers in a boreal peatland more than site nutrient and water table regimes. Biogeosciences 8, 2741-2755.

Strickland, M. S., Osburn, E., Lauber, C., Fierer, N., and Bradford, M. A. (2009). Litter quality is in the eye of the beholder: initial decomposition rates as a function of inoculum characteristics. Funct. Ecol. 23, 627-636.

Strickland, M. S., and Rousk, J. (2010). Considering fungal:bacterial dominance in soils - methods, controls, and ecosystem implications. Soil Biol. Biochem. 42, 1385-1395.

Thormann, M. (2006). Diversity and function of fungi in peatlands: a carbon cycling perspective. Can. J. Soil Sci. 86, 281-293.

Trinder, C. J., Johnson, D., and Artz, R. R. E. (2008). Interactions among fungal community structure, litter decomposition and depth of water table in a cutover peatland. FEMS Microbiol. Ecol. 64, 433-448.

Turunen, J., Tomppo, E., Tolonen, K., and Reinikainen, A. (2002). Estimating carbon accumulation rates of undrained mires in Finland application to boreal and subarctic regions. Holocene 12, 69-80.

Updegraff, K., Bridgham, S. D., Pastor, J., and Weishampel, P. (1998). Hysteresis in the temperature response of carbon dioxide and methane production in peat soils. Biogeochemistry 43, 253-272.

Vance, E., Brookes, P., and Jenkinson, D. (1987). An extraction method for measuring soil microbial biomass C. Soil Biol. Biochem. 19, 703-707.

Verhoeven, J. T. A., and Toth, E. (1995) Decomposition of Carex and Sphagnum litter in fens: effect of litter quality and inhibition by living tissue homogenates. Soil Biol. Biochem. 27, 271-275.

Waldrop, M. P., and Firestone, M. K. (2006). Response of microbial community composition and function to soil climate change. Microb. Ecol. 52, 716-724.

Webster, K. L., and McLaughlin, J. W. (2010). Importance of the water table in controlling dissolved carbon along a fen nutrient gradient. Soi Sci. Soc. Am. J. 74, 2254.

Weltzin, J. F., Bridham, S. C., Pastor, J., Chen, J., and Harth, C. (2003). Potential effects of warming and drying on peatland plant community composition. Glob. Chang. Biol. 9, 141-151.

Winsborough, C., and Basiliko, N. (2010). Fungal and bacterial activity in northern peatlands. Geomicrobiol. J. 27, 315-320.

Yavitt, J. B., Williams, C. J., and Wieder, R. K. (1997). Production of methane and carbon dioxide in peatland ecosystems across North America: effects of temperature, aeration, and organic chemistry of peat. Geomicrobiol. J. 14, 299-316.

Yu, Z., Loisel, J., Brosseau, D. P., Beilman, D. W., and Hunt, S. J. (2010). Global peatland dynamics since the last glacial maximum. Geophys. Res. Lett. 37, 1-5.

Conflict of Interest Statement: The authors declare that the research was conducted in the absence of any commercial or financial relationships that could be construed as a potential conflict of interest.

Received: 25 November 2011; accepted: 10 February 2012; published online: 29 February 2012.

Citation: Preston MD, Smemo KA McLaughlin JW and Basiliko N (2012) Peatland microbial communities and decomposition processes in the James Bay Lowlands, Canada. Front. Microbio. 3:70. doi: 10.3389/fmicb.2012.00070

This article was submitted to Frontiers in Terrestrial Microbiology, a specialty of Frontiers in Microbiology.

Copyright (C) 2012 Preston, Smemo, McLaughlin and Basiliko. This is an open-access article distributed under the terms of the Creative Commons Attribution Non Commercial License, which permits non-commercial use, distribution, and reproduction in other forums, provided the original authors and source are credited. 


\section{APPENDIX}

Table A1 | Operational taxonomic units (OTU) of archaea, bacteria, and fungi identified at three depths in peatlands across the James Bay Lowlands, Canada using terminal restriction fragment length polymorphism analysis (T-RFLP) of rDNA.

\begin{tabular}{|c|c|c|c|c|}
\hline \multirow[t]{2}{*}{ Site } & \multirow[t]{2}{*}{ T-RF length } & \multicolumn{3}{|c|}{ Proportion within each depth } \\
\hline & & $0-10 \mathrm{~cm}$ & $50-60 \mathrm{~cm}$ & $100-110 \mathrm{~cm}$ \\
\hline \multicolumn{5}{|l|}{ ARCHAEA } \\
\hline \multirow[t]{4}{*}{ Kinoje bog } & 51 & - & - & 0.73 \\
\hline & 178 & 1.00 & 0.25 & - \\
\hline & 384 & - & - & 0.02 \\
\hline & 483 & - & 0.75 & 0.25 \\
\hline \multirow[t]{6}{*}{ Victor bog } & 51 & 0.03 & - & - \\
\hline & 178 & 0.03 & 0.03 & - \\
\hline & 193 & 0.07 & 0.07 & - \\
\hline & 384 & 0.43 & 0.45 & 0.60 \\
\hline & 483 & 0.41 & 0.42 & 0.40 \\
\hline & 729 & 0.03 & 0.03 & - \\
\hline \multirow[t]{9}{*}{ Victor fen } & 51 & - & 0.07 & - \\
\hline & 67 & - & - & 0.04 \\
\hline & 75 & - & 0.05 & 0.11 \\
\hline & 83 & 0.11 & 0.10 & 0.42 \\
\hline & 249 & - & 0.04 & - \\
\hline & 277 & 0.27 & 0.26 & 0.11 \\
\hline & 384 & 0.28 & 0.20 & 0.14 \\
\hline & 483 & 0.34 & 0.23 & 0.13 \\
\hline & 729 & - & 0.04 & 0.05 \\
\hline \multicolumn{5}{|l|}{ BACTERIA } \\
\hline \multirow[t]{18}{*}{ Kinoje bog } & 59 & - & - & 0.02 \\
\hline & 61 & 0.07 & - & - \\
\hline & 66 & 0.88 & 0.15 & 0.04 \\
\hline & 82 & - & 0.08 & 0.02 \\
\hline & 89 & - & 0.41 & 0.01 \\
\hline & 136 & - & - & 0.02 \\
\hline & 140 & 0.02 & 0.13 & - \\
\hline & 144 & 0.03 & 0.03 & 0.02 \\
\hline & 160 & - & 0.02 & - \\
\hline & 165 & - & - & 0.12 \\
\hline & 260 & - & 0.10 & 0.04 \\
\hline & 429 & - & 0.02 & - \\
\hline & 447 & - & 0.03 & - \\
\hline & 476 & - & - & 0.17 \\
\hline & 481 & - & - & 0.26 \\
\hline & 484 & - & - & 0.24 \\
\hline & 491 & - & - & 0.03 \\
\hline & 509 & - & 0.02 & - \\
\hline \multirow[t]{8}{*}{ Victor bog } & 54 & 0.06 & - & - \\
\hline & 59 & 0.04 & - & - \\
\hline & 61 & 0.01 & 0.07 & 0.04 \\
\hline & 66 & 0.37 & 0.13 & 0.08 \\
\hline & 89 & 0.03 & 0.08 & 0.10 \\
\hline & 110 & 0.02 & - & - \\
\hline & 123 & 0.02 & - & - \\
\hline & 133 & - & 0.03 & - \\
\hline
\end{tabular}




\section{Table A1 | Continued}

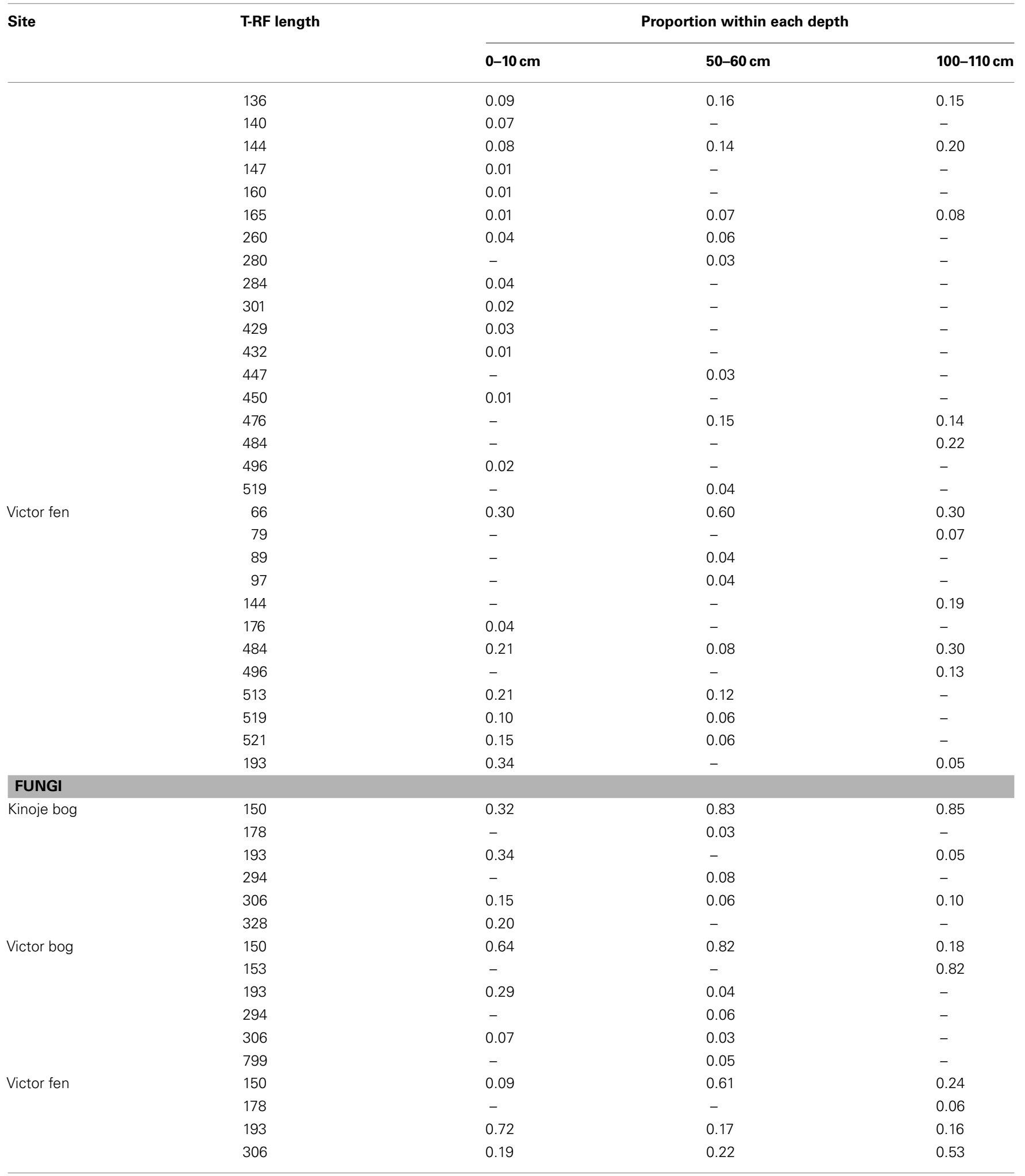

Each OTU is represented by a terminal restriction fragment (T-RF) expressed as a proportion of the total sample (e.g., Kinoje Bog 0-10 cm). 


\section{Similar diversity of Alphaproteobacteria and nitrogenase gene amplicons on two related Sphagnum mosses}

\section{Anastasia Bragina ${ }^{1 \dagger}$, Stefanie Maier ${ }^{1 \dagger}$, Christian Berg ${ }^{2}$, Henry Müller ${ }^{1}$, Vladimir Chobot $^{3}$, Franz Hadacek ${ }^{3}$ and Gabriele Berg ${ }^{1}$ *}

1 Institute of Environmental Biotechnology, Graz University of Technology, Graz, Austria

2 Institute of Plant Sciences, Karl-Franzens University of Graz, Graz, Austria

${ }^{3}$ Department of Chemical Ecology and Ecosystem Research, University of Vienna, Vienna, Austria

\section{Edited by:}

Svetlana N. Dedysh, Winogradsky Institute of Microbiology, Russian Academy of Sciences, Russia

\section{Reviewed by:}

Svetlana N. Dedysh, Winogradsky Institute of Microbiology, Russian Academy of Sciences, Russia Steffen Kolb, University of Bayreuth, Germany

*Correspondence:

Gabriele Berg, Institute of Environmental Biotechnology, Graz University of Technology, Petersgasse 12, 8010 Graz, Austria.

e-mail: gabriele.berg@tugraz.at

${ }^{\dagger}$ Anastasia Bragina and Stefanie Maier have contributed equally to this work.
Sphagnum mosses represent a main vegetation component in ombrotrophic wetlands. They harbor a specific and diverse microbial community with essential functions for the host. To understand the extend of host specificity and impact of environment, Sphagnum fallax and Sphagnum angustifolium, two phylogenetically closely related species, which show distinct habitat preference with respect to the nutrient level, were analyzed by a multifaceted approach. Microbial fingerprints obtained by PCR-single-strand conformation polymorphism of 16S rRNA and nitrogenase-encoding (nifH) genes were highly similar for both Sphagnum species. Similarity was confirmed for colonization patterns obtained by fluorescence in situ hybridization (FISH) coupled with confocal laser scanning microscopy (CLSM): Alphaproteobacteria were the main colonizers inside the hyaline cells of Sphagnum leaves. A deeper survey of Alphaproteobacteria by 16S rRNA gene amplicon sequencing reveals a high diversity with Acidocella, Acidisphaera, Rhodopila, and Phenylobacterium as major genera for both mosses. Nitrogen fixation is an important function of Sphagnumassociated bacteria, which is fulfilled by microbial communities of Sphagna in a similar way. NifH libraries of Sphagnum-associated microbial communities were characterized by high diversity and abundance of Alphaproteobacteria but contained also diverse amplicons of other taxa, e.g., Cyanobacteria and Deltaproteobacteria. Statistically significant differences between the microbial communities of both Sphagnum species could not be discovered in any of the experimental approach. Our results show that the same close relationship, which exists between the physical, morphological, and chemical characteristics of Sphagnum mosses and the ecology and function of bog ecosystems, also connects moss plantlets with their associated bacterial communities.

Keywords: Sphagnum fallax, Sphagnum angustifolium, SSCP fingerprints, FISH-CLSM, amplicon library, Alphaproteobacteria, nitrogenase

\section{INTRODUCTION}

Northern wetlands belong to the oldest vegetation forms with more or less constant conditions for thousands of years. Sphagnum-dominated peatlands represent one of the most extensive types of Northern wetlands (Dedysh, 2011). They cover with 4 million $\mathrm{km}^{2}$ approx. $3 \%$ of the Earth surface and have a high value for biodiversity-conservation, as reservoir of fresh water, for human welfare and our world climate due to its extraordinary role in carbon sequestration (Gorham, 1991; Clymo et al., 1998). Despite their age, these long-existing ecosystems are extremely sensitive to changing a-biotic factors connected with climate change (Belyea and Malmer, 2004; Dise, 2009). As the dominant vegetation component of the peatlands, Sphagnum moss has been used globally as an indicator of climate change (Gignac and Vitt, 1994; Whinam and Copson, 2006; Granath et al., 2009). The ecological significance of bogs is directly related to the physical, morphological, and chemical characteristics of Sphagnum peat mosses; which set Sphagnum apart from other mosses to practically every stage of the life cycle (Shaw et al., 2003). Moreover, Sphagnum mosses are able to change their environments: living Sphagna have extraordinarily high cation exchange capacity and therefore acidify their environment by exchanging tissue-bound protons for basic cations in surrounding water (Soudzilovskaia et al., 2010). Interestingly, Sphagnum leaves are highly specialized: they form a network of living, chlorophyll-containing chlorophytes and dead, cell contentfree hyalocytes, which are responsible for their high water holding capacity. Sphagnum species also produce species specific bioactive secondary metabolites influencing microbial colonization (Opelt et al., 2007a).

Sphagnum mosses are colonized by diverse bacterial communities. Microbial populations involved in $\mathrm{CH}_{4}$ cycling, i.e., methanotrophic bacteria (Dedysh et al., 1998; Dedysh, 2002; Raghoebarsing et al., 2005; Larmola et al., 2010; rev. in Dedysh, 2011) as well as methanogens including archaea (Horn et al., 2003; Freitag et al., 2010) have attracted research interest due to their important function for methane emission. Recently, we could show that living Sphagnum mosses are colonized in high abundances with specific microorganisms, which fulfill other important functions like 
nutrient supply and pathogen defense for moss growth and health (Opelt et al., 2007a,b). An extremely high impact of the Sphagnum species was found on the structure of the microbial diversity, and this diversity is transferred directly from the sporophyte (within the sporangium capsule) to the gametophyte and vice versa (Bragina et al., 2011). In the latter, we analyzed bacterial communities of two ubiquitous Sphagnum species, S. magellanicum, and Sphagnum fallax, in three Alpine bogs in Austria. Extremely high differences between bacterial communities of both Sphagna were found by a combination of methods independently from the site. For example, a discriminative spectrum of bacteria was identified: while Alpha- and Gamma-proteobacteria dominated $S$. magellanicum, S. fallax was mainly colonized by Verrucomicrobia, Planctomycetes, and Alphaproteobacteria. In addition, bacterial communities were strongly driven by a-biotic factors (nutrient richness and $\mathrm{pH}$ ), and correlated strongly with the composition of higher plant communities. The specific microbial diversity associated with the highly diverse Sphagnum genus (Daniels and Eddy, 1985) is largely unknown but important to understand and protect Sphagnum in bog ecosystems.

The objective of this work was to study the structure and function of Sphagnum-associated bacteria to understand extend and degree of host specificity. Therefore, two phylogenetically closely related and widely distributed species with overlapping micro-niches but varying trophic specialization were selected: Sphagnum angustifolium (Warnst.) C. E. O. Jensen and S. fallax H. Klinggr. (Daniels and Eddy, 1985; Flatberg, 1992; Sastad et al., 1999). Both Sphagnum species were first characterized by their secondary metabolite profile. A polyphasic approach was applied to study bacterial communities with a special focus on Alphaproteobacteria and nitrogen-fixing bacteria: (i) microbial fingerprints by PCR-single-strand-conformation polymorphism (SSCP) applying universal and group-specific 16S rRNA genetargeting primers and nitrogenase (nifH) gene-specific primers, (ii) fluorescent in situ hybridization with universal and groupspecific probes coupled with fluorescence in situ hybridization confocal laser scanning microscopy (FISH-CLSM) and image analysis, (iii) deep-sequencing of Alphaproteobacteria, and (iv) a functional approach to analyses the potential for nitrogen fixation by nitrogenase $(n i f H)$ genes in amplicon libraries.

\section{MATERIALS AND METHODS SAMPLING PROCEDURE}

Adult gametophytes of $S$. angustifolium (section Cuspidata) and S. fallax (section Cuspidata) were sampled from the bog "Pürgschachen Moor" (Liezen, $1.7 \mathrm{~km}$ SW Ardning, N47 $34.789^{\prime} \mathrm{E} 14^{\circ} 2017^{\prime}$ ) in Austria in July and November 2010. In this bog, S. angustifolium has broader ecological amplitude and grow in mesotrophic wet hollows with some ground water influence as well as in more ombrotrophic hummocks over ground water level. S. fallax grow only in wet mesotrophic conditions in which we collected the samples of both species in comparable ecological situations. The $\mathrm{pH}$ of the surrounding peat water was measured at all sampling points and showed mean values of 4.00 (SD, 0.15) for S. fallax and 4.04 (SD, 0.31) for S. angustifolium. Altogether eight independent replicates per Sphagnum species consisting of composite samplings of 15-20 plantlets were collected and stored separately. The approximate length of the sampled plants was $14.5 \mathrm{~cm}(\mathrm{SD}, 2.3 \mathrm{~cm})$ for $S$. fallax and $15.1 \mathrm{~cm}(\mathrm{SD}, 2.5 \mathrm{~cm})$ for S. angustifolium. The eight sampling points were situated in a distance of at least $10 \mathrm{~m}$, while both species had a distance of not more than $1 \mathrm{~m}$ at each single point. The living green parts of the plantlets were placed into sterile plastic bags and transported cooled to the laboratory.

\section{CHEMICAL ANALYSIS OF SPHAGNUM SECONDARY METABOLITES}

Spectra of secondary metabolites of Sphagnum samples were analyzed using high-performance liquid chromatography with UV photodiode array detection (HPLC-PDA) as described previously (Opelt et al., 2007a).

\section{TOTAL-COMMUNITY DNA ISOLATION}

The bacterial fraction associated with gametophytes was extracted according to the modified protocol of Opelt and Berg (2004). Briefly, $5 \mathrm{~g}$ of plant material were physically disrupted with sterile pestle and mortar and re-suspended in $10 \mathrm{ml}$ of $0.85 \% \mathrm{NaCl}$. Two milliliter of the suspension was centrifuged at $13000 \mathrm{rpm}$ for $20 \mathrm{~min}$ at $4^{\circ} \mathrm{C}$ and the pellet was used for isolation of the totalcommunity DNA. For mechanical lysis, the cells were homogenized twice in a FastPrep ${ }^{\circledR}$ FP120 Instrument (MP Biomedicals) for $30 \mathrm{~s}$ at speed 5.0. The obtained DNA was purified using the FastDNA $^{\circledast}$ SPIN Kit for Soil (MP Biomedicals) according to the manufacturer's protocol. Final aliquots of the total-community DNA were further applied in PCR-based approaches.

\section{MICROBIAL FINGERPRINTING BY PCR-SSCP}

Fingerprinting of the moss-associated bacterial communities was carried out by PCR-based SSCP described by Schwieger and Tebbe (1998). 16S rRNA genes of Bacteria were amplified with universal bacterial primers Com1/Unibac-II-927 $\mathrm{r}^{\mathrm{P}}$ (Schwieger and Tebbe, 1998; Zachow et al., 2008). A set of Alphaproteobacteria-specific primers ADF681F/1492r, followed by ADF681F/927r ${ }^{\mathrm{P}}$, was applied using a semi-nested protocol (Blackwood et al., 2005). Bacterial nitrogenase gene $(n i f H)$ fragments were amplified in a nested approach with nifH3/19F, nifH11/nifH $22^{\mathrm{P}}$ primers (Yeager et al., 2004). The amplicons were separated using the TGGE Maxi system (Biometra) at $400 \mathrm{~V}$ and $26^{\circ} \mathrm{C}$ in acrylamide gel followed by silver staining.

Strand conformation polymorphism is based on the differences in the conformation of single-stranded DNA fragments. The electrophoretic mobility of the single-stranded DNA fragments depends on their three-dimensional conformation. Each of the amplification products was identified by its electrophoretic distance on SSCP gel and the number of DNA fragments. According to the distance of the bands, the SSCP gels were virtually divided into operational taxonomic units (OTUs). The presence or absence of individual amplified product DNA bands in each group was scored. The obtained matrix was used to compare statistically (see statistics).

\section{FLUORESCENT IN SITU HYBRIDIZATION AND CONFOCAL LASER SCANNING MICROSCOPY}

Single gametophytes of $S$. angustifolium and $S$. fallax were fixed with $4 \%$ paraformaldehyde/phosphate buffered salt $(3: 1, \mathrm{v} / \mathrm{v})$. 
Separated leaves were stained by in-tube FISH (Grube et al., 2009). Fluorescently labeled rRNA-targeting probe ALF968 specific for Alphaproteobacteria (Loy et al., 2007) was applied in combination with equimolar mixture of universal bacterial probes EUB338, EUB338II, EUB338III (Amann et al., 1990; Daims et al., 1999). Sphagnum samples were consequently hybridized with ALF968 $\left(41^{\circ} \mathrm{C}, 45 \%\right.$ formamide) followed by EUB338/EUB338II/EUB338III $\left(41^{\circ} \mathrm{C}, 15 \%\right.$ formamide). Negative control was hybridized with non-target NON-EUB probe (Amann et al., 1990) at the same stringency conditions applied for the positive FISH probes.

Confocal laser scanning microscopy was performed using a confocal microscope Leica TCS SPE (Leica Microsystems). Fluorescent dyes $\mathrm{Cy} 3$ and $\mathrm{Cy} 5$ labeled to the FISH probes were sequentially excited with 532 and $635 \mathrm{~nm}$ laser beams, respectively; the emitted light was detected in the range of 556-607 and 657$709 \mathrm{~nm}$, respectively. An additional channel (excitation at $488 \mathrm{~nm}$; emission range $508-556 \mathrm{~nm}$ ) was used for acquiring the autofluorescence of the moss cells. Photomultiplier gain and offset were individually optimized for every channel and every field of view, in order to improve the signal/noise ratio. Confocal stacks were acquired with a Leica ACS APO 40X OIL CS objective (NA: 1.15) and a Leica ACS APO 63X OIL CS objective (NA: 1.30) by applying a Z-step of $0.4-0.8 \mu \mathrm{m}$. Three-dimensional reconstructions were created with the software Imaris 7.0 (Bitplane).

\section{DEEP-SEQUENCING AND BIOINFORMATIC ANALYSIS}

Diversity of Alphaproteobacteria and nitrogen-fixing bacteria associated with Sphagnum species was deeply investigated by barcoded pyrosequencing approach. The total-community DNA was amplified with the set of Alphaproteobacteria-specific primers ADF681F/Unibac-II-927r (Blackwood et al., 2005; Zachow et al., 2008) and nifH gene-specific primers nifH3/nifH4, nifH1/nifH2 in the nested approach (Zehr and Turner, 2001) using Taq$\& \mathrm{Go}^{\mathrm{TM}}$ Ready-to-use PCR Mix (MP Biomedicals). Duplicate PCR products from all templates were purified with Wizard ${ }^{\circledR}$ SV Gel and PCR Clean-Up System (Promega). Amplicons of each Sphagnum sp. were pooled together and subjected to the pyrosequencing using the Roche/454 GS FLX+ Titanium platform executed by GATC Biotech (Konstanz, Germany).

The 16S rRNA gene amplicon libraries specific for Alphaproteobacteria were analyzed as specified by Bragina et al. (2011). Shortly, raw sequencing reads were quality and length filtered ( $\geq 150 \mathrm{bp}$ ). Rarefaction analysis was performed for phylotype clusters of 97, 95, and 90\% similarity by using the tools of the RDP's Pyrosequencing Pipeline (Cole et al., 2009). Datasets were normalized to the same number of sequences. Richness estimates and diversity indices were calculated in the open source software package QIIME (Caporaso et al., 2010). Classification of the reads was performed using the BLAT pipeline within the web interface SnoWMAn version $1.11^{1}$ with $80 \%$ confidence threshold.

Amplicon libraries of the nitrogenase gene (nifH) were explored using the FunGene Pipeline of RDP server ${ }^{2}$ with parameters stated by Farnelid et al. (2011). Primer sequences were

\footnotetext{
${ }^{1}$ https://epona.genome.tugraz.at/snowman/

${ }^{2}$ http://fungene.cme.msu.edu/FunGenePipeline/
}

trimmed and reads of a low quality and shorter $200 \mathrm{bp}$ were removed. Filtered reads were translated into amino acid sequences and clipped at 60 aa. Further analyses were carried out on amino acid sequences. For the rarefaction, datasets were clustered with 100,96 , and $92 \%$ similarity cut-offs. Richness estimates and diversity indices were calculated for the subsets normalized to the same number of sequences by QIIME software. Compositional diversity was compared by Sørensen $\left(C_{\mathrm{s}}\right)$ and Shannon $\left(H^{\prime}\right)$ indices at $96 \%$ similarity level. Phylogenetic analysis was performed for the clusters of $92 \%$ similarity with $\geq 10$ sequences. Reference sequences were obtained using the NCBI algorithm TBLASTN and a phylogenetic tree was constructed as described previously (Bragina et al., 2011).

\section{STATISTICS}

Computer-assisted analysis of SSCP profiles was performed using the GelCompare II version 5.1 software package (Applied Maths). Similarity matrices were constructed based on Pearson's correlation coefficients $(r)$ and cluster analyses were done by the unweighted pair group method with average linkages (UPGMA). SSCP profiles of the microbial communities generated with universal bacterial and nifH gene-specific primers were further applied for the multivariate analysis. Single DNA bands, characterized by the relative position and abundance on the gel, were defined as OTUs and used as response variables for detrended correspondence analyses (DCA) by Canoco 4.5 for Windows (Lepš and Smilauer, 2003).

\section{RESULTS}

\section{PROFILING OF THE SPHAGNUM SECONDARY METABOLITES}

High-performance liquid chromatography-PDA profiling of plant extracts yielded notably similar chromatograms and spectra of the prevailing peaks of the secondary metabolites for both Sphagnum species. The UV spectra suggested various phenols and indol derivatives including sphagnic acid (peak 7; Figure 1). The only noteworthy difference was the more pronounced accumulation of flavonoid conjugates (naringenin and apigenin) in $S$. angustifolium. The late retention time precluded glycosides but more lipophilic molecules. The result testified common chemical basis for establishment of the similar microbial diversity of the compared moss species.

\section{MOLECULAR FINGERPRINTING OF MICROBIAL COMMUNITIES}

In the molecular fingerprinting approach we used a specific set of primers: universal primers to get an overview about the whole bacterial community associated with Sphagnum, primers for Alphaproteobacteria because this is a ubiquitous and cosmopolitan phylogenetic class associated with Sphagnum (Bragina et al., 2011), and nifH primers to detect nitrogen-fixing bacteria as important functional group (Opelt et al., 2007a). All SSCP fingerprints obtained with universal and group-specific primers revealed high similarity of the microbial communities associated with $S$. fallax and S. angustifolium (Figure 2). UPGMA analysis of the Bacteria profiles resulted in a minimum similarity level of $95.5 \%$ of bryophyte-associated communities. Alphaproteobacteria patterns formed a common cluster at $87.1 \%$ similarity. Fingerprints of the nifH gene clustered into two groups at $41.2 \%$ similarity. Within 


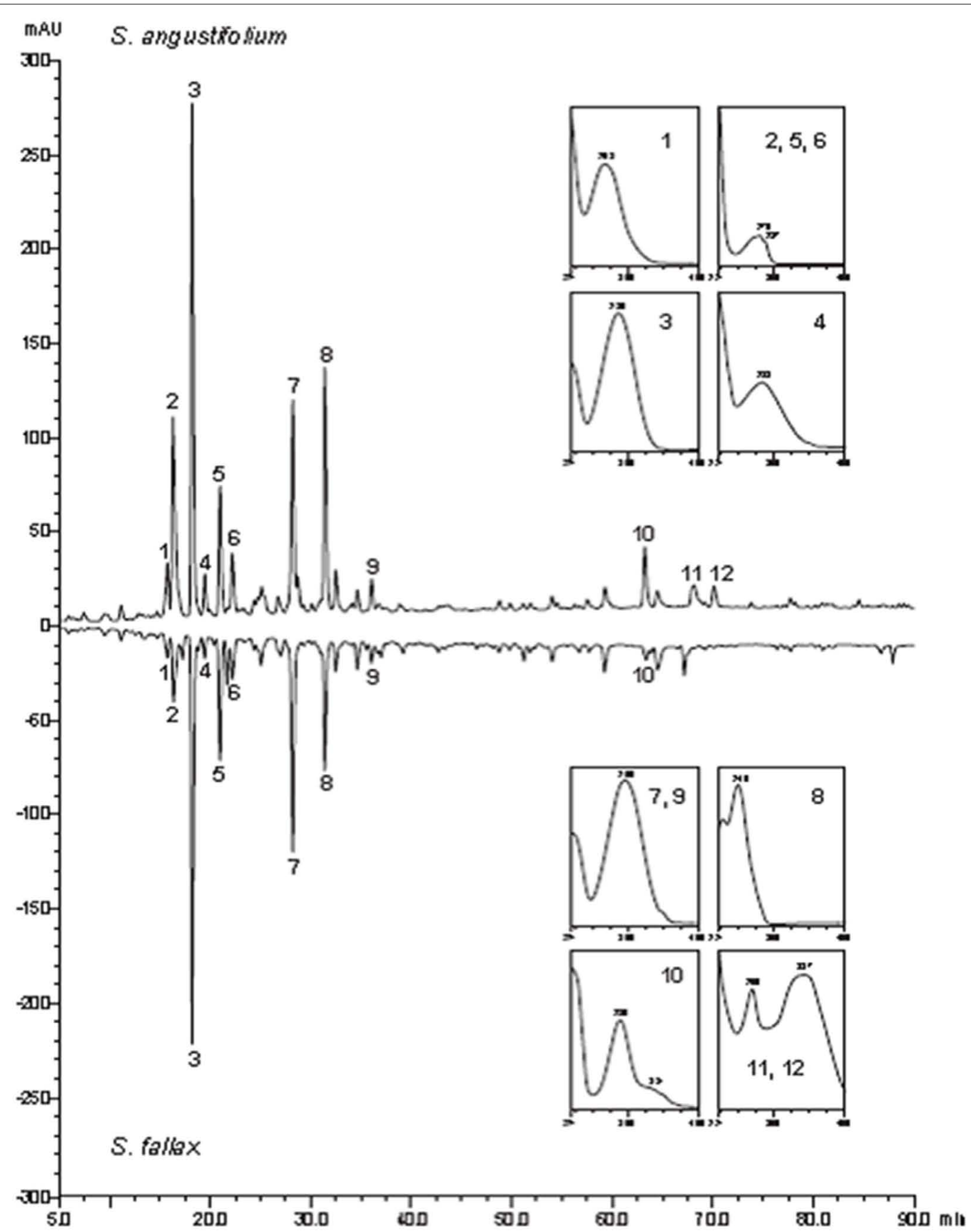

FIGURE 1 | High-performance liquid chromatography -UV secondary metabolite profiles of $\boldsymbol{S}$. angustifolium and $\mathbf{S}$. fallax at $229 \mathrm{~nm}$ (UV spectra (200-400 nm; 1, phenol; 2, 5, 6, indole derivative; 3, 4, phenols; 7, 9, sphagnic acid; 8, phenol; 10, naringenin type flavonoid; 11, 12, apigenin flavonoids.

each cluster, samples of both Sphagna grouped together. This overlap of the microbial communities was confirmed statistically by a detrended correspondence analysis (Figure 3).

\section{MICROBIAL COLONIZATION PATTERNS}

Sphagnum gametophytes characterized by the unique morphology were studied for microbial colonization patterns by FISH. Again, 
A

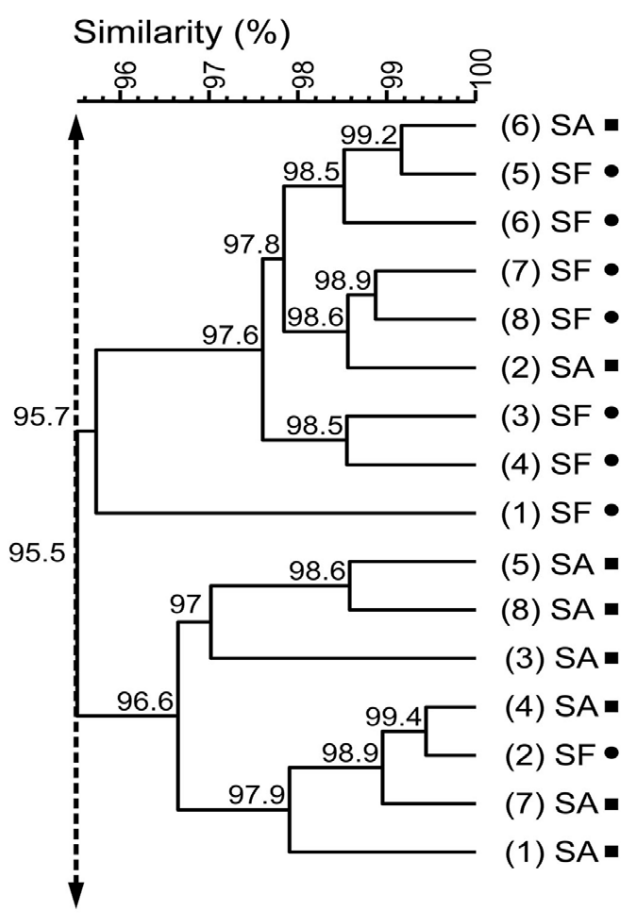

B

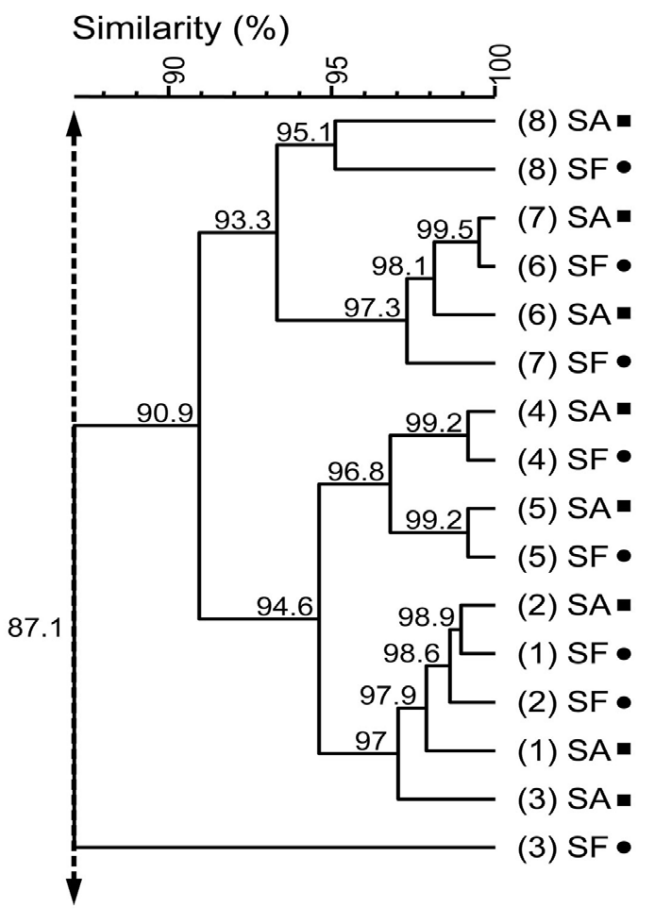

C

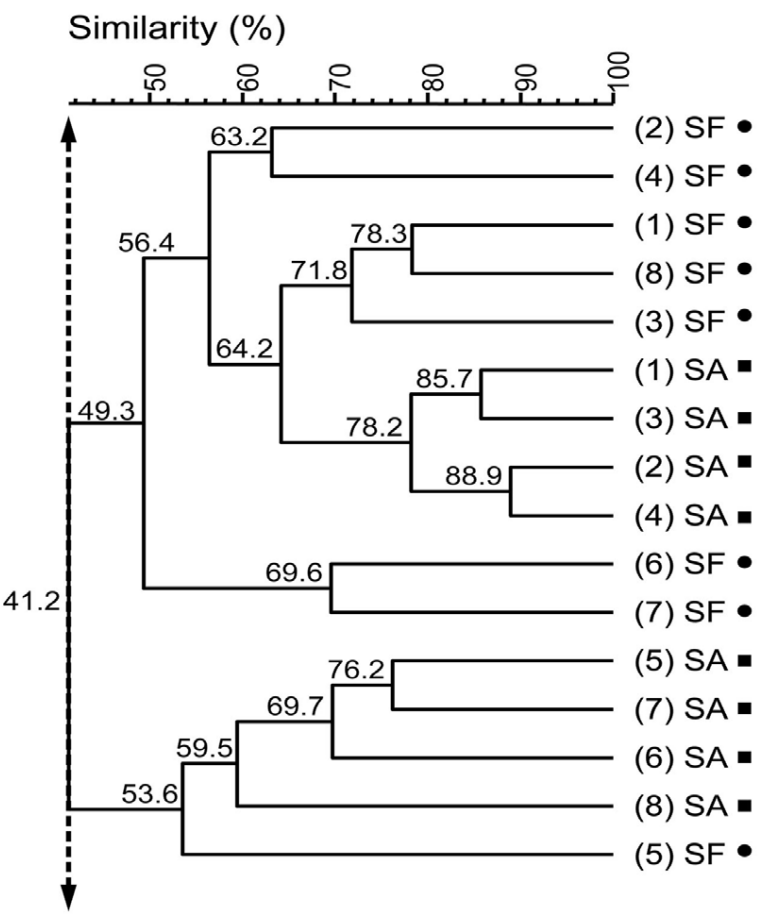

FIGURE 2 | Unweighted pair group method with average linkages dendrograms of bacterial communities associated with

$\boldsymbol{S}$. angustifolium (SA, squares) and $\boldsymbol{S}$. fallax (SF, circles). The dendrograms were generated from the PCR-SSCP profiles of Bacteria (A),
Alphaproteobacteria (B), and bacterial nifH genes (C) using unweighted pair group method with average linkages (UPGMA). Numbers in round brackets indicate replicates. Double-headed vertical arrows indicate the similarity for the groupings. we applied universal and Alphaproteobacteria-specific probes according to the above mentioned reasons. The stem and branch leaves are usually differentiated in size and shape, but equally are formed by dimorphic leaf cells in which large, empty hyaline cells perforated by pores are enclosed in a network of narrower, chlorophyllose cells (Figures 4A,D). CLSM observation of both 


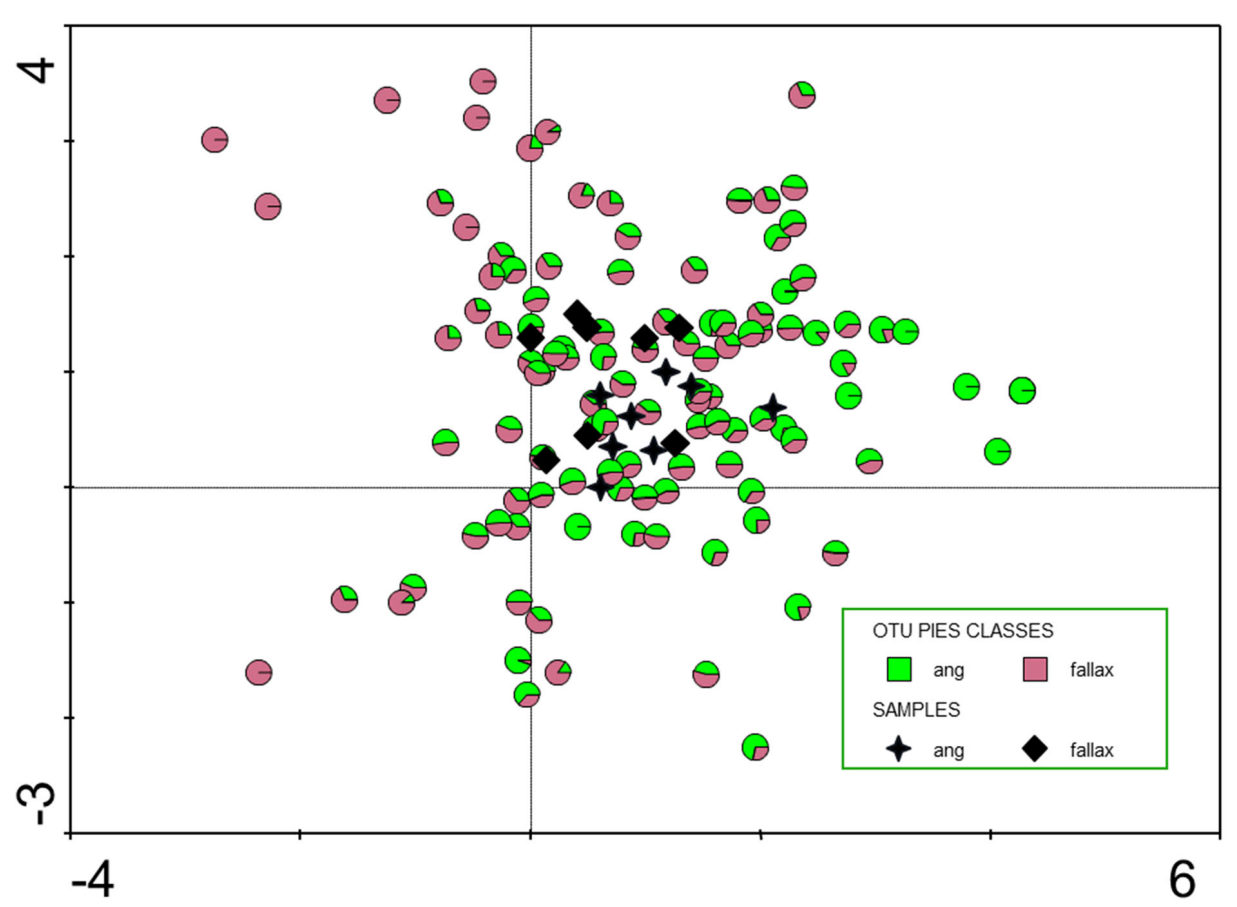

FIGURE 3 | Detrended correspondence analysis (DCA, indirect unimodal gradient analysis) of operational taxonomic units (OTUs) identified by SSCP community fingerprints. Eigenvalues of first and second axis are 0.244 and 0.141 , respectively; sum of all eigenvalues
1.715. Black stars and diamonds show the location of the 16 samples, colored circles the location of the 111 OTUs in the biplot. The colors indicate its preference to Sphagnum angustifolium (ang) or S. fallax, respectively. leave types showed dense colonization by bacterial colonies of the internal space of the gametophytes as shown for branch leaves in Figures 4B,E. Alphaproteobacterial cells presented up to 50\% of the detected bacterial colonies. Three-dimensional reconstruction of the acquired images supported that bacteria primarily occupied dead hyaline cells Figures 4C,F. In conclusion, FISHCLSM approach displayed similar colonization patterns for $S$. angustifolium and S. fallax by the bacterial communities.

\section{DEEP-SEOUENCING OF ALPHAPROTEOBACTERIA AND NIFH GENES}

Alphaproteobacteria and nitrogen-fixing bacteria were selected to get a deeper insight by a pyrosequencing approach. The 16S rRNA gene amplicon libraries specific for Alphaproteobacteria were rarefied as shown in Figure 5. Richness estimation of the normalized datasets revealed that pyrosequencing effort reached 66.0-74.2\% of estimated richness for the clusters of $90 \%$ similarity (Table 1). The clusters of 95 and $97 \%$ similarity reflected $49.3-51.2$ and $45.4-46.2 \%$ of estimated richness, respectively.

Taxonomic composition of alphaproteobacterial populations, compared at the ranks of families and genera, was substantially similar among Sphagnum spp. (Figure 6). Dominant Acetobacteraceae family was prevailed by genera Acidocella, Acidisphaera, and Rhodopila. Within families Sphingomonadaceae and Rhodospirillaceae, the most members belonged to Novosphingobium spp. and Magnetospirillum spp., correspondingly. Withal, composition and ratio of subdominant Caulobacteraceae varied between mosses. The family was more abundant in S. fallax sample and consisted of genus Phenylobacterium (detected all over) and genus Caulobacter (unique for S. fallax). Diversity of species was accessed by Shannon diversity index $\left(H^{\prime}\right)$ for clusters of $97 \%$ similarity. Comparison of the index values revealed a slightly higher diversity of Alphaproteobacteria for S. fallax (4.60) than for S. angustifolium (4.18).

According to the NCBI database, identified alphaproteobacterial genera comprise bacteria known for the nitrogen fixation. Particularly, genera Bradyrhizobium, Acetobacter, and Beijerinckia were found in both libraries, while genera Gluconacetobacter, Methylocystis, Methylosinus, and Rhizobium were solely detected in the $S$. fallax library.

Rarefaction analysis of the nitrogenase gene libraries resulted in similar saturation profiles of the Sphagnum samples (Figure 5). Normalized datasets represented $61.0-62.7 \%$ of estimated richness at $92 \%$ similarity (Table 1). The clusters of $96 \%$ similarity covered 55.2-66.6\%, while unique clusters reflected $19.8-22.1 \%$ of estimated richness, correspondingly. Compositional diversity was assessed applying $96 \%$ similarity cut-off to confine the clusters. The Sørensen similarity index indicated that samples featured $53 \%$ identity. Nitrogenase diversity estimated by Shannon was again slightly higher for S. fallax (7.59), than for S. angustifolium (7.20; Table 1).

Phylogenetic analysis of the NifH composition revealed that retrieved sequences, 60 amino acids in length, were distributed among canonical Clusters I, III, and Sub-cluster IA (Figure 7). The most abundant Cluster I, comprising sequences of Proteobacteria and Cyanobacteria, was dominated by Alphaproteobacteria. According to the BLAST analysis, the most prevalent alphaproteobacterial amplicons were $\geq 95 \%$ similar to 

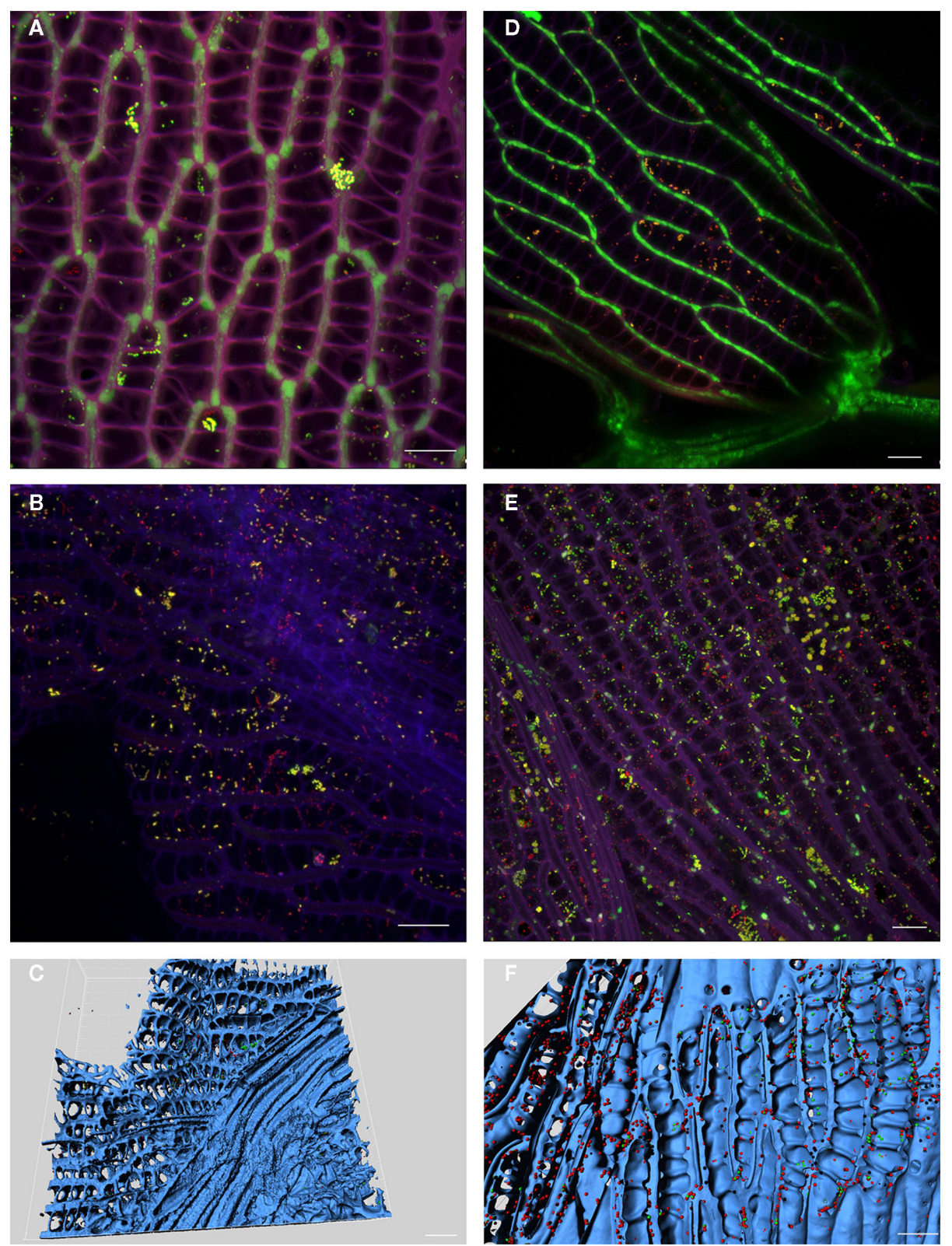

FIGURE 4 | Localization of bacteria in moss gametophytes. Fluorescent in situ hybridization of $S$. angustifolium (A-C) and S. fallax (D-F) leaves showed colonization of hyaline cells by Alphaproteobacteria. Images acquired by confocal laser scanning microscopy (CLSM) (A,B,D,E): violet - cell walls of

Sphagnum cells; green - chlorophyll-containing Sphagnum chlorocytes; yellow - Alphaproteobacteria; red - other bacteria. 3D computer reconstructions of CLSM images using Imaris7.0 (C,F): blue - moss tissue; red: Alphaproteobacteria; green: other bacteria. Scale bar $=20 \mu \mathrm{m}$.

Bradyrhizobium, Azorhizobium, Rhizobium, Methylobacterium, Rhodocista, and Acetobacter species. Considerable proportion of amplicons showed 96-100\% identity with Methylocella, Methylocapsa, and Beijerinckia reference sequences. Detected Betaproteobacteria were prevailed by Burkholderia spp. ( $\geq 95 \%$ similarity). Minor portion of Cluster I amplicons was affiliated with cyanobacterial genera Anabaena and Tolypotrix (100\% similarity). Sub-cluster IA contained sequences $96-100 \%$ similar to Geobacter sp. Within the Cluster III amplicons grouped with reference Spirochaeta and Thermincola species (82-93\% similarity).

In conclusion, nifH amplicon libraries of Sphagnum-associated microbial communities were characterized by high diversity and abundance of alphaproteobacterial amplicons.

\section{DISCUSSION}

Sphagnum mosses form an outstanding group of Bryophyta; they are unique in their morphological and developmental features at every stage of the life cycle (Shaw et al., 2003). More than for other plants, physical and chemical characteristics of Sphagnum mosses are related to the ecology and function of Northern 

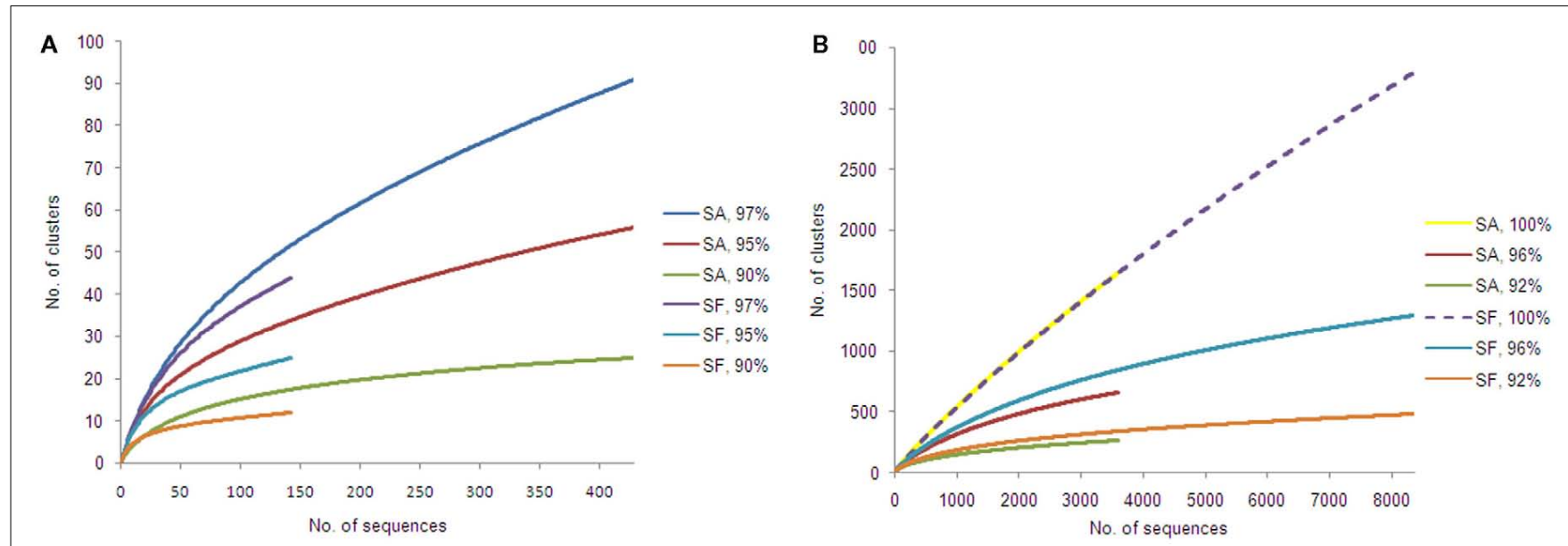

FIGURE 5 | Rarefaction curves for amplicon libraries of Sphagnum samples. Saturation curves are presented for samples of S. angustifolium (SA) and S. fallax (SF). Alphaproteobacteria (A) and nifH datasets (B) were clustered with similarity cut-offs defined.

Table 1 | Richness estimates and diversity indices for amplicon libraries of Sphagnum samples ${ }^{\mathrm{a}}$.

\section{Sphagnum species}

Indices

Index

Clusters

Chao1

Coverage (\%)

Shannon $\left(H^{\prime}\right)$

\begin{tabular}{|c|c|c|c|c|c|c|c|c|c|c|c|c|}
\hline \multicolumn{13}{|c|}{ ALPHAPROTEOBACTERIA } \\
\hline Similarity cut-offs ${ }^{b}$ & $97 \%$ & $95 \%$ & $90 \%$ & $97 \%$ & $95 \%$ & $90 \%$ & $97 \%$ & $95 \%$ & $90 \%$ & $97 \%$ & $95 \%$ & $90 \%$ \\
\hline S. angustifolium & 41 & 26 & 14 & 91 & 52 & 22 & 45.4 & 49.3 & 66.0 & 4.18 & 3.23 & 2.08 \\
\hline S. fallax & 42 & 27 & 13 & 91 & 53 & 17 & 46.2 & 51.2 & 74.2 & 4.60 & 3.72 & 2.55 \\
\hline \multicolumn{13}{|l|}{ NIFH } \\
\hline Similarity cut-offs ${ }^{\mathrm{C}}$ & $100 \%$ & $96 \%$ & $92 \%$ & $100 \%$ & $96 \%$ & $92 \%$ & $100 \%$ & $96 \%$ & $92 \%$ & $100 \%$ & $96 \%$ & $92 \%$ \\
\hline S. angustifolium & 1644 & 655 & 263 & 7447 & 983 & 420 & 22.1 & 66.6 & 62.7 & 8.76 & 7.20 & 5.72 \\
\hline
\end{tabular}

aThe number of sequences of each sample was normalized to 131 (Alphaproteobacteria) and 3601 (NifH).

${ }^{b}$ Similarity cut-offs applied for clustering of the nucleotide sequences.

' Similarity cut-offs applied for clustering of the amino acid sequences.
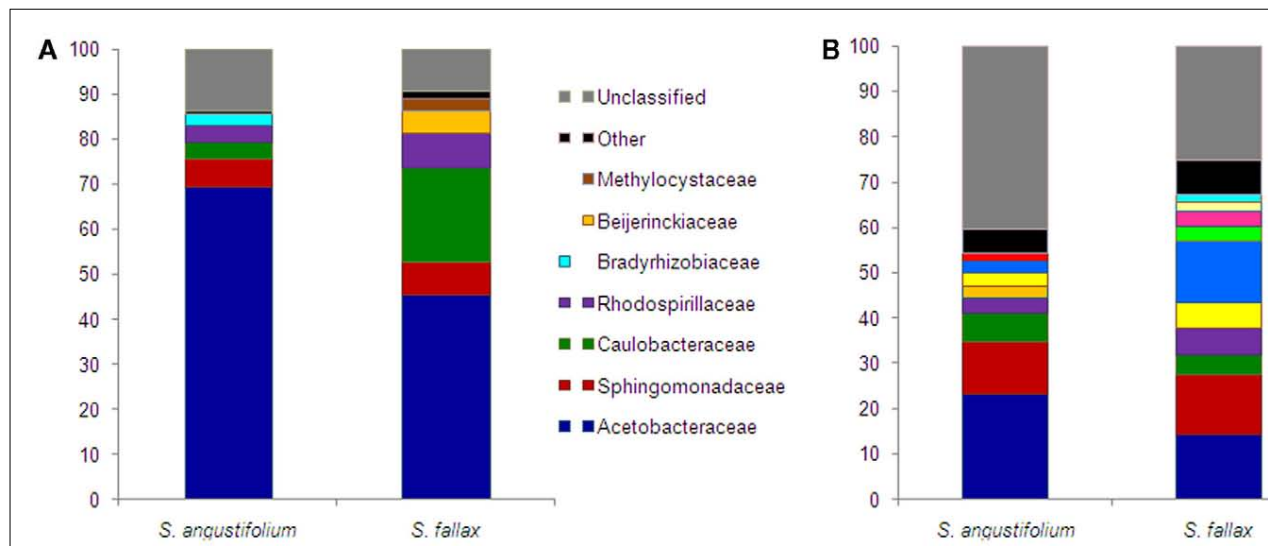

m $=$ Unclassified

- - Other

$\square$ Acetobacteraceae Roseococcus $\square$ Methylocystaceae Methylocystis nCaulobacteraceae Caulobacter

$\square$ Beijerinckiaceae Beijerinckia

- Acetobacteraceae Acetobacter

- a Caulobacteraceae Phenylobacterium

$\square \square$ Rhodospirillaceae Magnetospirillum

- Bradyhrizobiaceae Bradyrhizobium

- -Sphingomonadaceae Novosphingobium

- Acetobacteraceae Rhodopila

- Acetobacteraceae Acidisphaera

- Acetobacteraceae Acidocella

FIGURE 6 | Taxonomic classification of Alphaproteobacteria associated with $\boldsymbol{S}$. angustifolium and $\boldsymbol{S}$. fallax. Pyrosequencing reads are classified at family (A) and genus level (B) with a confidence threshold of $80 \%$. Groups below $1 \%$ of relative abundance are included in Other. Multi-colored charts at the legend are shown for each sample correspondingly. 


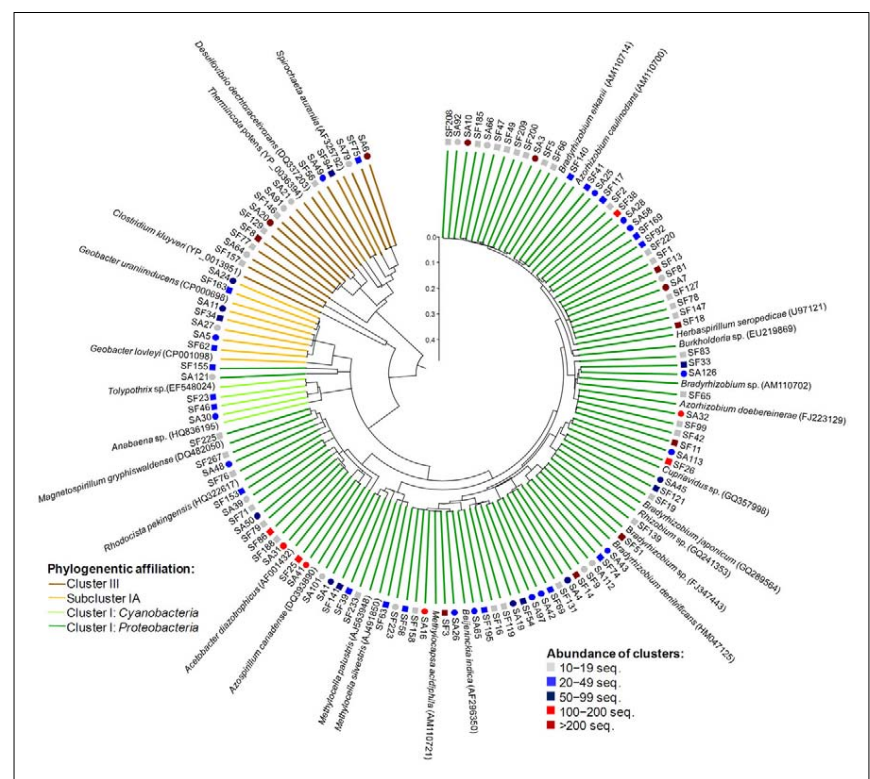

FIGURE 7 | Phylogenetic composition of the nitrogenase gene (nifH) amplicon libraries of $\boldsymbol{S}$. angustifolium (SA, circles) and $\boldsymbol{S}$. fallax (SF, squares). Neighbor-joining phylogenetic tree was constructed with both one representative sequence per $\mathrm{NifH}$ cluster ( $92 \%$ similarity) and the nearest reference sequences (accession numbers in brackets). A partial sequence of the light-independent photochlorophyllide reductase subunit $L$ (BchL) from Chlorobaculum tepidum (Acc. Nr. AAG12203) was used as out-group. Reliability of the tree topology was evaluated by 100 bootstrap resamplings (bootstrap values not shown). Abundance and phylogenetic affiliation of the clusters are indicated at the legend. Scale bar $=0.1$ substitutions per site.

peatlands. In this study we have shown the same deep relationship between moss plantlets and their associated bacterial communities. In the multifaceted approach applied to study the structure and function of bacteria, only minor but not statistically significant differences were found between S. angustifolium and S. fallax, two peat mosses which shared similar ecological conditions inside the bog ecosystem.

This high similarity is in contrast to former studies of Sphagnum-associated bacteria of different ecological amplitudes (Opelt et al., 2007c; Bragina et al., 2011). The main difference between the former studies and the present study is the close taxonomic and ecological relationship of the investigated S. angustifolium and S. fallax unlike S. magellanicum. S. magellanicum belongs to another section within the genus Sphagnum (section Sphagnum) and is typical for strong acidic, oligotrophic, and ombrotrophic habitats, whereas S. angustifolium and S. fallax (section Cuspidata) grow in weakly acid, more mesotrophic situations influenced by minerotrophic groundwater (Daniels and Eddy, 1985). Also from the morphological point of view, S. angustifolium and S. fallax are difficult to distinguish, and in former times both taxa were considered as varieties of one species S. recurvum P. Beauv (Smith, 1978). In contrast to S. magellanicum (Opelt et al., 2007a), S. angustifolium, and $S$. fallax are characterized by similar secondary metabolites. The overlap of common properties for the mosses was also found for the bacterial community. Figure 3 not only shows a high degree of similarity between the microbial communities also a differentiation in more $S$. fallax (negative along the first axis) and more S. angustifolium (positive along the first axis) preferring bacteria. So, the situation shown exemplarily in Figure 3 could be interpreted as an early state of specification of bacterial communities correspondent with an early state of host species differentiation. Interestingly, our results also explain differences between the theory of Sphagnum species specific communities established by Opelt et al. (2007c) and Bragina et al. (2011) and results obtained by Larmola et al. (2010) who identified only a-biotic drivers. For methanotrophs, they found for transplanted Sphagnum species bacterial pattern and activity typical for the a-biotic parameters of the destination site. However, this was an artificial experiment; the majority of the approx. 300 Sphagnum species has very narrow ecological amplitudes and would not grow in nature under different conditions (Daniels and Eddy, 1985). In Northern wetlands, which belong to an old vegetation type with more or less extreme but constant conditions for thousands of years, Sphagnum mosses have established a highly specific and adapted symbiosis with their associated microbes.

What are the ecological consequences of this specificity of the microbial community? Well-adapted to a-biotic parameters to the place where they live, Sphagnum mosses together with their microbiome as so called "meta-organisms" fulfill important functions for ecosystem services. These functions can only fulfilled in cooperation with the associated microbial community. The latter is responsible to fix nitrogen for the host plant, to solubilize phosphor but also to provide carbon from peatdelivered methane (Raghoebarsing et al., 2005; Opelt et al., 2007a). Studies have shown that oxidation of $\mathrm{CH}_{4}$ by methanotrophic microbes residing in the Sphagnum layer is controlled by environmental factors, i.e., water table and temperature (Larmola et al., 2010) but beside this the rate was specific for Sphagnum species (Gifford et al., 2011). Taken together, the specificity of the microbial community is essential to live under the extreme and highly varying ecological gradients within the bog ecosystem and to fulfill the ecological functions. The bog ecosystem is more complex than previously thought but this is important to know to maintain bog ecosystems in Northern wetlands. The high specificity, narrow ecological amplitude and closed relationship can be one reason that Sphagnum is highly sensitive to changing a-biotic parameters connected with climate change.

Little is known about the specific ecology of Sphagnumassociated bacteria which are to a high degree still not culturable (Dedysh, 2011). Dominant alphaproteobacterial taxa associated with Sphagna are known as acidophilic or acidotolerant bacteria able to grow chemo-organotrophically or phototrophically and to survive under oligotrophic conditions. Sphagnum-associated microbial communities should be included in biodiversityconservation agenda and used for predictive microbial ecology as requested by Bodelier (2011).

\section{ACKNOWLEDGMENTS}

This study was funded by the Austrian Science Foundation FWF by a grant to Gabriele Berg. 


\section{REFERENCES}

Amann, R. I., Binder, B. J., Olson, R. J., Chisholm, S. W., Devereux, R., and Stahl, D. A. (1990). Combination of 16S rRNA-targeted oligonucleotide probes with flow cytometry for analyzing mixed microbial populations. Appl. Environ. Microbiol. 56, 1919-1925.

Belyea, L. R., and Malmer, N. (2004). Carbon sequestration in peatland: patterns and mechanisms of response to climate change. Glob. Chang. Biol. 10, 1043-1052.

Blackwood, C. B., Adam, O., and Buyer, J. S. (2005). Phylum- and classspecific PCR primers for general microbial community analysis. Appl. Environ. Microbiol. 71, 6193-6198.

Bodelier, P. L. (2011). Toward understanding, managing, and protecting microbial ecosystems. Front. Microbiol. 2:80. doi:10.3389/fmcib.2011.00080

Bragina, A., Berg, C., Cardinale, M., Shcherbakov, A., Chebotar, W., and Berg, G. (2011). Sphagnum mosses harbor highly specific bacterial diversity during their whole life cycle. ISME J. doi:10.1038/ismej.2011.151

Caporaso, J. G., Kuczynski, J., Stombaugh, J., Bittinger, K., Bushman, F. D., Costello, E. K., Fierer, A., Pena, A. G., Goodrich, J. K., Gordon, J. I., Huttley, G. A., Kelley, S. T., Knights, D., Koenig, J. E., Ley, R. E., Lozupone, C. A., McDonald, D., Muegge, B. D., Pirrung, M., Reeder, J., Sevinsky, J. R., Tumbaugh, P. J., Walters, W. A., Widmann, J., Yatsunenko, T., Zaneveld, J., and Knight, R. (2010). QIIME allows analysis of highthroughput community sequencing data. Nat. Methods 7, 335-336.

Clymo, R. S., Turunen, J., and Tolonen, K. (1998). Carbon accumulation in peatland. Oikos 81, 368-388.

Cole, J. R., Wang, Q., Cardenas, E., Fish, J., Chai, B., Farris, R. J., KulamSyed-Mohideen, A. S., McGarrell, D. M., Marsh, T., Garrity, G. M., and Tiedje, J. M. (2009). The ribosomal database project: improved alignments and new tools for rRNA analysis. Nucleic Acids Res. 37, D141-D145.

Daims, H., Brühl, A., Amann, R., Schleifer, K. H., and Wagner, M. (1999). The domain-specific probe EUB338 is insufficient for the detection of all bacteria: development and evaluation of a more comprehensive probe set. Syst. Appl. Microbiol. 22, 434-444.

Daniels, R. E., and Eddy, A. (1985). Handbook of Europaen Sphagna. Aberystwyth: Cambrian News.
Dedysh, S. N. (2002). Methanotrophic bacteria of acid Sphagnum bogs. Mikrobiologiia 71, 741-754.

Dedysh, S. N. (2011). Cultivating uncultured bacteria from northern wetlands: knowledge gained and remaining gaps. Front. Microbiol. 2:184. doi: 10.3389/fmcib.2011. 00184

Dedysh, S. N., Panikov, N. S., and Tiedje, J. M. (1998). Acidophilic methanotrophic communities from Sphagnum peat bogs. Appl. Environ. Microbiol. 64, 922-929.

Dise, N. B. (2009). Peatland response to global change. Science 326, 810-811.

Farnelid, H., Andersson, A. F., Bertilsson, S., Al-Soud, W. A., Hansen, L. H., Sørensen, S., Steward, G. H., Hägstrom, A., and Riemann, L. (2011). Nitrogenase gene amplicons from global marine surface waters are dominated by genes of noncyanobacteria. PLoS ONE 6, e19223. doi:10.1371/journal.pone.0019223

Flatberg, K. I. (1992). The European taxa in the Sphagnum recurvum complex. 2. Amended descriptions of Sphagnum brevifolium and S. fallax. Lindbergia 17, 96-110.

Freitag, T. E., Toet, S., Ineson, P., and Prosser, J. I. (2010). Links between methane flux and transcriptional activities of methanogens and methane oxidizers in a blanket peat bog. FEMS Microbiol. Ecol. 73, 157-165.

Gifford, J., Hoopes, M., Larmola, T., Varner, R., Bubier, J., and Young, B. (2011). The Role of Sphagnum Mosses in Methane Oxidation in a Temperate Fen. Thesis, Mount Holyoke College, South Hadley, MA.

Gignac, L. D., and Vitt, D. H. (1994). Responses of Northern peatlands to climate change: effects on bryophytes. J. Hattori Bot. Lab. 75, 119-132.

Gorham, E. (1991). Nothern peatlands: role in the carbon cycle and probable responses to climatic warming. Ecol. Appl. 1, 182-195.

Granath, G., Wiedermann, M. M., and Strengbom, J. (2009). Physiological responses to nitrogen and sulphur addition and raised temperature in Sphagnum balticum. Oecologia 161, 481-490.

Grube, M., Cardinale, M., Vieira de Castro, J., Müller, H., and Berg, G. (2009). Species-specific structural and functional diversity of bacterial communities in lichen symbioses. ISME J. 3, 1105-1115.

Horn, M. A., Matthies, C., Küsel, K., Schramm, A., and Drake, H. L. (2003). Hydrogenotrophic methanogenesis by moderately acidtolerant methanogens ofa methane- emitting acidic peat. Appl. Environ. Microbiol. 69, 74-83.

Larmola, T., Tuittila, E. S., Tiirola, M., Nykänen, H., Martikainen, P. J., Yrjälä, K., Tuomivirta, T., and Fritze, H. (2010). The role of Sphagnum mosses in the methane cycling of a boreal mire. Ecology 91, 2356-2365.

Lepš, J., and Smilauer, P. (2003). Multivariate Analysis of Ecological Data Using Canoco. Cambridge: Cambridge University Press.

Loy, A., Maixner, F., Wagner, M. and Horn, M. (2007). probeBase-an online resource for rRNA-targeted oligonucleotide probes: new features 2007. Nucleic Acids Res. 35, D800D804.

Opelt, K., and Berg, G. (2004). Diversity and antagonistic potential of bacteria associated with bryophytes from nutrient-poor habitats of the Baltic Sea Coast. Appl. Environ. Microbiol. 70, 6569-6579.

Opelt, K., Chobot, V., Hadacek, F., Schönmann, S., Eberl, L., and Berg, G. (2007a). Investigations of the structure and function of bacterial communities associated with Sphagnum mosses. Environ. Microbiol. 91, 2795-2809.

Opelt, K., Berg, C., and Berg, G. (2007b). The bryophyte genus Sphagnum is a reservoir for powerful and extraordinary antagonists and potentially facultative human pathogens. FEMS Microbiol. Ecol. 61, 38-53.

Opelt, K., Berg, C., Schönmann, S., Eberl, L., and Berg, G. (2007c). High specificity but contrasting biodiversity of Sphagnum-associated bacterial and plant communities in bog ecosystems independent of the geographical region. ISME J. 1, 502-516.

Raghoebarsing, A. A., Smolders, A. J. P., Schmid, M. C., Rijpstra, W. I. C., Wolters-Arts, Derksen, J. M., Jetten, M. S. M., Schouten, S., Damsté, J. S. S., Lamers, L. P. M., Roelofs, J. G. M., Op den Camp, H. J. M., and Strous, M. (2005). Methanotrophic symbionts provide carbon for photosynthesis in peat bogs. Nature 436, 1153-1156.

Sastad, S. M., Bard, P., and Kjetil, D. (1999). Habitat-specific genetic effects on growth rate and morphology across $\mathrm{pH}$ and water level gradients within a population of the moss Sphagnum angustifolium (Sphagnaceae). Am. J. Bot. 86, 1687-1698.

Schwieger, F., and Tebbe, C. C. (1998). A new approach to utilize PCR-singe-strand-conformation polymorphism for 16S rRNA gene-based microbial community analysis. Appl. Environ. Microbiol. 64, 4870-4876.
Shaw, A. J., Cox, C. J., and Boles, S. B. (2003). Global patterns in peatmoss biodiversity. Mol. Ecol. 12, 2553-2570.

Smith, A. J. E. (1978). The Moss Flora of Britain and Ireland. Cambridge: Cambridge University Press.

Soudzilovskaia, N. A., Cornelissen, J. H. C., During, H. J., van Logtestijn, R. S. P., Lang, S. I., and Aerts, R. (2010). Similar cation exchange capacities among bryophyte species refute a presumed mechanism of peatland acidification. Ecology 91, 2716-2726.

Whinam, J., and Copson, G. (2006). Sphagnum moss: an indicator of climate change in the sub-Antarctic. Polar Rec. 42, 43-49.

Yeager, C. M., Kornosky, L., Housman, C., Grote, E. E., Belnap, J., and Kuske, C. R. (2004). Diazotrophic community structure and function in two successional stages of biological soil crusts from the Colorado Plateau and Chihuahuan Desert. Appl. Environ. Microbiol. 70, 973-983.

Zachow, C., Tilcher, R., and Berg, G. (2008). Sugar beet-associated bacterial and fungal communities show a high indigenous antagonistic potential against plant pathogens. Microb. Ecol. 55, 119-129.

Zehr, J. P., and Turner, P. J. (2001). "Nitrogen fixation: nitrogenase genes and gene expression," in Methods in Microbiology, ed. J. H. Paul (New York: Academic Press), 271-285.

Conflict of Interest Statement: The authors declare that the research was conducted in the absence of any commercial or financial relationships that could be construed as a potential conflict of interest.

Received: 11 November 2011; accepted: 22 December 2011; published online: 10 January 2012.

Citation: Bragina A, Maier S, Berg $C$, Müller $H$, Chobot $V$, Hadacek $F$ and Berg G (2012) Similar diversity of Alphaproteobacteria and nitrogenase gene amplicons on two related Sphagnum mosses. Front. Microbio. 2:275. doi: 10.3389/fmicb.2011.00275

This article was submitted to Frontiers in Terrestrial Microbiology, a specialty of Frontiers in Microbiology.

Copyright () 2012 Bragina, Maier, Berg, Müller, Chobot, Hadacek and Berg. This is an open-access article distributed under the terms of the Creative Commons Attribution Non Commercial License, which permits non-commercial use, distribution, and reproduction in other forums, provided the original authors and source are credited. 


\title{
Abundance, diversity, and depth distribution of Planctomycetes in acidic northern wetlands
}

\author{
Anastasia O. Ivanova and Svetlana N. Dedysh* \\ Winogradsky Institute of Microbiology, Russian Academy of Sciences, Moscow, Russia
}

Edited by:

Paul Bodelier, Netherlands Institute of Ecology, Netherlands

\section{Reviewed by:}

Nathan Basiliko, University of Toronto, Canada

Joseph Yavitt, Cornell University, USA

*Correspondence:

Svetlana N. Dedysh, Winogradsky Institute of Microbiology, Russian Academy of Sciences, Prospect

60-Letya Octyabrya 7/2, Moscow 117312, Russia.

e-mail: dedysh@mail.ru
Members of the bacterial phylum Planctomycetes inhabit various aquatic and terrestrial environments. In this study, fluorescence in situ hybridization (FISH) was applied to assess the abundance and depth distribution of these bacteria in nine different acidic wetlands of Northern Russia. Planctomycetes were most abundant in the oxic part of the wetland profiles. The respective cell numbers were in the range $1.1-6.7 \times 10^{7} \mathrm{cells}^{-1}$ of wet peat, comprising $2-14 \%$ of total bacterial cells, and displaying linear correlation to the peat water $\mathrm{pH}$. Most peatland sites showed a sharp decline of planctomycete abundance with depth, while in two particular sites this decline was followed by a second population maximum in an anoxic part of the bog profile. Oxic peat layers were dominated by representatives of the Isosphaera-Singulisphaera group, while anoxic peat was inhabited mostly by Zavarzinella- and Pirellula-like planctomycetes. Phylogenetically related bacteria of the candidate division OP3 were detected in both oxic and anoxic peat layers with cell densities of $0.6-4.6 \times 10^{6}$ cells $^{-1}$ of wet peat.

Keywords: Planctomycetes, candidate division OP3, FISH, depth distribution, acidic northern wetlands

\section{INTRODUCTION}

The phylum Planctomycetes is a remarkable group of budding bacteria that possess highly distinctive cell morphology, peptidoglycan-less cell-walls, and a unique cell organization (Schlesner and Stackebrandt, 1986; Fuerst, 1995; Ward et al., 2006; Fuerst and Sagulenko, 2011). Members of this phylum are ubiquitous in a wide range of aquatic and terrestrial environments with diverse conditions. Recently, it was found that planctomycetes are highly abundant in acidic Sphagnum-dominated wetlands (Dedysh et al., 2006; Kulichevskaya et al., 2006). Several moderately acidophilic, peat-inhabiting planctomycetes were isolated in pure cultures and described as representatives of the novel genera Schlesneria, Singulisphaera, and Zavarzinella (Kulichevskaya et al., 2007b, 2008, 2009, 2012). Interestingly, fluorescence in situ hybridization (FISH) with the 16S rRNA-targeted, Planctomycetespecific oligonucleotide probes revealed two distinct population maxima of these bacteria within the profile of the peat bog Bakchar, West Siberia (Dedysh et al., 2006; Ivanova and Dedysh, 2006). The first population maximum was detected in the uppermost, oxic layer of the bog profile, while the second maximum was located at a depth of $30 \mathrm{~cm}$ below the water table level. Since all currently characterized peat-inhabiting planctomycetes are chemoorganotrophs capable of growth in aerobic or microaerobic but not in anoxic conditions (Kulichevskaya et al., 2007b, 2008, 2009, 2012), the present study was initiated in order to examine depth distribution of these bacteria in different types of northern wetlands and to compare planctomycete diversity in oxic and anoxic peat layers.

\section{MATERIALS AND METHODS SAMPLING SITES}

The peat samples were collected from the depths $0-10,10-20$, $20-30,30-40$, and $40-50 \mathrm{~cm}$ over the profiles of nine different acidic wetlands of West Siberia and European North Russia (Table 1). The trophic status of these wetlands varied from oligotrophic to eutrophic and the $\mathrm{pH}$ varied from 3.7 to 6.0. Six oligotrophic wetlands (Bakchar, Obukhovskoye, Sekirnoye, Torfjanoye, Dubrovskoye, and Valdayskoye) are dominated by Sphagnum mosses. Aapa-type mesotrophic fen Muksalma is covered by Calluna vulgaris and Carex spp., while two eutrophic fens, Obskoe and Blizhnee, are dominated by Carex spp. Three subsamples collected from each depth were combined to form one composite sample per site. The samples were transported to the laboratory in boxes containing icepacks, homogenized by cutting the peat material into small fragments (about $0.5 \mathrm{~cm}$ ) with sterile scissors, and fixed for FISH or frozen at $-20^{\circ} \mathrm{C}$ for DNA extraction within 1 day after sampling.

\section{FLUORESCENCE IN SITU HYBRIDIZATION}

The fixation procedure was carried out according to Dedysh et al. (2001) and included (i) the separation of the peat water enriched with microbial cells and micro-particles of non-decomposed organic material from the rough $(\geq 2-3 \mathrm{~mm})$ Sphagnum debris by repeated stomacher treatments, (ii) recovery of the microbial cells from the peat water, and (iii) cell fixation with $4 \%(\mathrm{w} / \mathrm{v})$ freshly prepared paraformaldehyde solution. Total bacterial cell numbers were determined by means of hybridization with Cy3labeled oligonucleotide probes EUB338-mix (Daims et al., 1999). A combination of two Cy3-labeled oligonucleotide probes PLA46 and PLA886 (Neef et al., 1998) was applied for specific detection of planctomycetes. A set of eight oligonucleotide probes was used for differential detection and enumeration of specific subgroups within the Planctomycetes (Table 2). This set included the probe NLMIII 301 designed by Liu and Seviour (2001) for members of the Isosphaera-group and seven newly developed probes for specific detection of peat-inhabiting planctomycetes. 
Table 1 |The number of cells detected by FISH with the Planctomycetes-specific probes in acidic northern wetlands of different geographic location (data are presented for the uppermost $(0-10 \mathrm{~cm}$ ) peat bog layer corresponding to the maximal number of planctomycete cells detected over the bog profile).

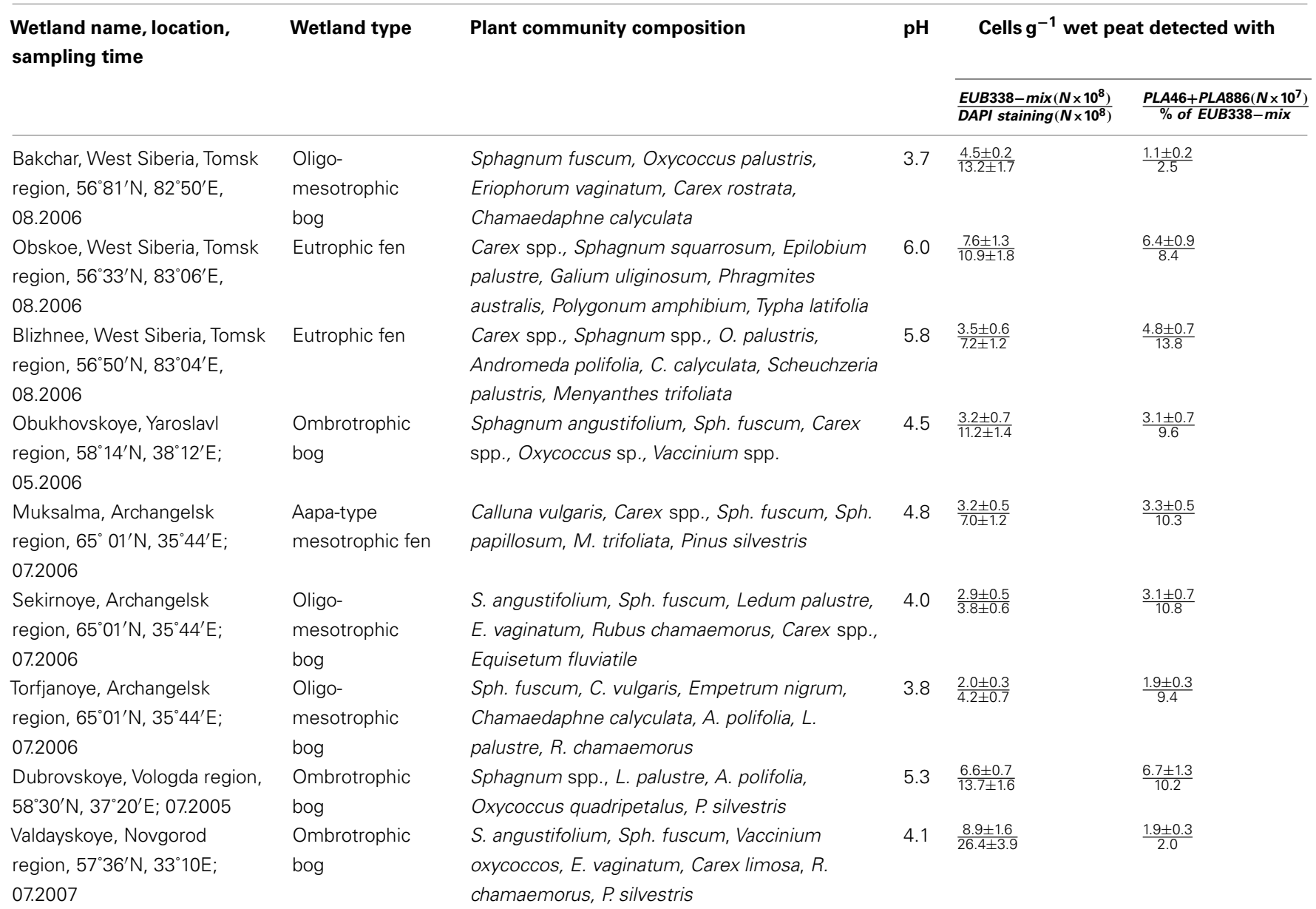

Table 2 | Planctomycete-specific FISH probes used in this study.

\begin{tabular}{|c|c|c|c|c|c|}
\hline Probe & Target & Nucleotide sequence $\left(5^{\prime}-3^{\prime}\right)$ & Range of positions ${ }^{a}$ & $\% \mathrm{FA}^{\mathrm{b}}$ & Reference \\
\hline PLA46 & Planctomycetes & GACTTGCATGCCTAATCC & $46-63$ & 30 & Neef et al. (1998) \\
\hline PLA886 & Planctomycetales & GCCTTGCGACCATACTCCC & $886-904$ & 30 & Neef et al. (1998) \\
\hline NLIMIII 301 & Isosphaera Singulisphaera & CCCAGTGTGCCGGGCCAC & $301-318$ & 20 & Liu and Seviour (2001) \\
\hline Sin-644 & Singulisphaera & ATGCCCСTCCAGACTCGT & $644-661$ & 20 & This study \\
\hline $\operatorname{Sin}-588$ & Singulisphaera & AGCGACAGACGCACGAAT & $588-605$ & 20 & This study \\
\hline Shl-129 & Schlesneria & CTCGCCCTGGGGGTACGT & $129-146$ & 20 & This study \\
\hline Shl-117 & Schlesneria & TACGTCACCTACGTGATC & $117-134$ & 20 & This study \\
\hline Zav-999 & Zavarzinella & TTCGGAGACGTACCGCTC & 999-1016 & 20 & This study \\
\hline AnPir-422d & Pirellula & GACAGCGATTTACAACCC & $422-439$ & 20 & This study \\
\hline B39-620 & OP3 & GAAGGCAGTTCTCCGATT & $620-637$ & 20 & This study \\
\hline
\end{tabular}

a Position numbers refer to the E. coli $16 S$ rRNA sequence.

${ }^{b}$ Percent formamide in the hybridization buffer.

'Used in combination with unlabeled competitor probe 5'-GCCTTGCGACCGTACTCCC-3'.

'Used in combination with unlabeled competitor probe 5'-GACAGCGGTTTACAACCC-3'.

All oligonucleotide probes applied in this study were purchased from Syntol (Moscow, Russia). Hybridization was done on gelatin-coated $(0.1 \%, \mathrm{w} / \mathrm{v})$ and dried Teflon-laminated slides (MAGV, Germany) with eight wells for independent positioning 
of the samples. The fixed samples were applied to these wells, hybridized to the corresponding fluorescent probes, and stained with the universal DNA stain 4',6-diamidino-2-phenylindole (DAPI, $1 \mu \mathrm{M}$ ) as described earlier (Dedysh et al., 2001). The cell counts were carried out with a Zeiss Axioplan 2 microscope (Zeiss, Jena, Germany) equipped with the Zeiss Filters No 20 and 02 for Cy3-labeled probes and DAPI staining, respectively. Cell counting was performed on 100 randomly chosen fields of view (FOV) for each test sample. The number of target cells per gram of wet peat was determined from the area of the sample spot, the FOV area, the volume of the fixed sample used for hybridization, and the volume of the peat water extracted from the sample.

\section{DNA EXTRACTION}

Extracts of total DNA were obtained from two peat samples collected from the uppermost, oxic $(0-10 \mathrm{~cm}$ depth) peat layers of Obukhovskoye and Bakchar peat bogs, and one peat sample collected from the anoxic $(30-40 \mathrm{~cm}$ depth) layer of the peat bog Bakchar. Two subsamples, each of $0.5 \mathrm{~g}$ wet weight, were taken from each peat sample and processed separately. The extraction was performed using a FastDNA SPIN kit for Soil (Bio101, Carlsbad, USA) according to manufacturer's instruction.

\section{PCR AMPLIFICATION, CLONING, AND SEQUENCING}

PCR-mediated amplification of the 16S rRNA gene fragments $(\sim 1350 \mathrm{bp})$ of peat-inhabiting planctomycetes was performed using the combination of the Planctomycete-specific forward primer Pla46 (5'-GGA TTA GGC ATG CAA GTC-3') targeting positions 46-63 of Escherichia coli 16S rRNA gene (Neef et al., 1998) and the universal bacterial reverse primer Univ1390R ( $5^{\prime}$ GAC GGG CGG TGT GTA CAA-3'; Zheng et al., 1996). PCR mixtures $(100 \mu \mathrm{l})$ contained $1 \mu \mathrm{l}$ of template DNA, $50 \mu \mathrm{l}$ of $2 \times$ MasterMix (Promega), and $0.3 \mu \mathrm{M}$ of each primer (Syntol). PCR amplifications were performed in a DNA thermal cycler (model 9700; PE Applied Biosystems) under the following conditions: initial denaturation $\left(4 \mathrm{~min}\right.$ at $\left.94^{\circ} \mathrm{C}\right), 33$ cycles consisting of denaturation $\left(1 \mathrm{~min}\right.$ at $\left.94^{\circ} \mathrm{C}\right)$, primer annealing $\left(1 \mathrm{~min}\right.$ at $\left.59^{\circ} \mathrm{C}\right)$, and elongation $\left(1.5 \mathrm{~min}\right.$ at $\left.72^{\circ} \mathrm{C}\right)$, with a final elongation step for $7 \mathrm{~min}$ at $72^{\circ} \mathrm{C}$. Aliquots $(5 \mu \mathrm{l})$ of the $16 \mathrm{~S}$ rRNA gene amplicons were checked on a $1.2 \%(\mathrm{w} / \mathrm{v})$ agarose gel and visualized after being stained with ethidium bromide. In order to reduce the potential bias of separate PCR reactions, the amplicons of two independent PCRs were combined before cloning. The mixed PCR product was cloned using a pGEM-T Easy Vector System II (Promega) according to the manufacturer's instructions. Clones were screened for the correct insert with T7 and SP6 primers. Plasmid DNA was purified using Wizard Plus Minipreps DNA Purification System (Promega) and the cloned inserts were sequenced using an ABI 377A sequencer (Perkin-Elmer Applied Biosystems, USA).

The 16S rRNA gene sequences were checked for chimeras using Bellerophon 3.0 with the Huber-Hugenholtz correction and a 300 bp window size (Huber et al., 2004). Sequence alignments and phylogenetic analyses were carried out using the ARB software package (Ludwig et al., 2004). Trees were constructed using the neighbor-joining method. The significance levels of interior branch points obtained in neighbor-joining analysis were determined by bootstrap analyses (1000 data resamplings) using the PHYLIP program package (Felsenstein, 1989). The 16S rRNA gene sequences retrieved from Sphagnum peat in this study have been deposited in the GenBank, EMBL, and DDBJ nucleotide sequence databases under accession numbers JN867640 to JN867719.

\section{RESULTS}

\section{ABUNDANCE OF PLANCTOMYCETES IN NORTHERN WETLANDS}

We applied a combination of two planctomycete-specific oligonucleotide probes PLA46 and PLA886 to determine the in situ abundance of these bacteria in peat sampled from nine acidic wetlands of different geographic locations within European North Russia and West Siberia (Table 1). The probes hybridized to numerous spherical or ellipsoid-shaped cells that were arranged in chains or in shapeless cell aggregates and were mostly attached to the particles of non-decomposed organic material (Figure 1). Highest abundances of cells targeted with the probes PLA46 and PLA886 were observed in the uppermost, oxic layers of the
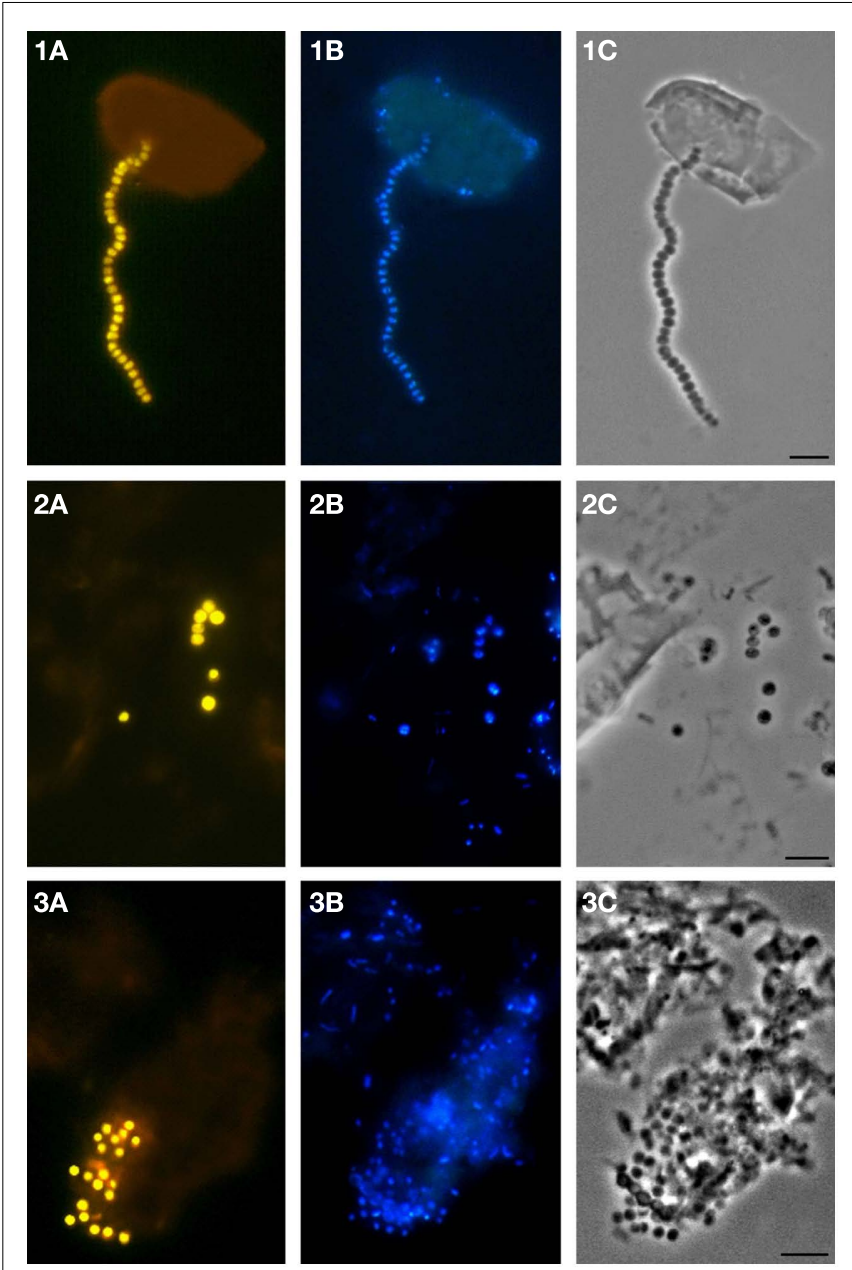

FIGURE 1 | Specific detection of planctomycete cells in Sphagnum peat by FISH. Epifluorescent micrographs of in situ hybridizations with Cy3-labeled probes PLA46 and PLA886 (A), DAPI staining (B), and the phase-contrast images (C) are shown. Bar, $10 \mu \mathrm{m}$. 


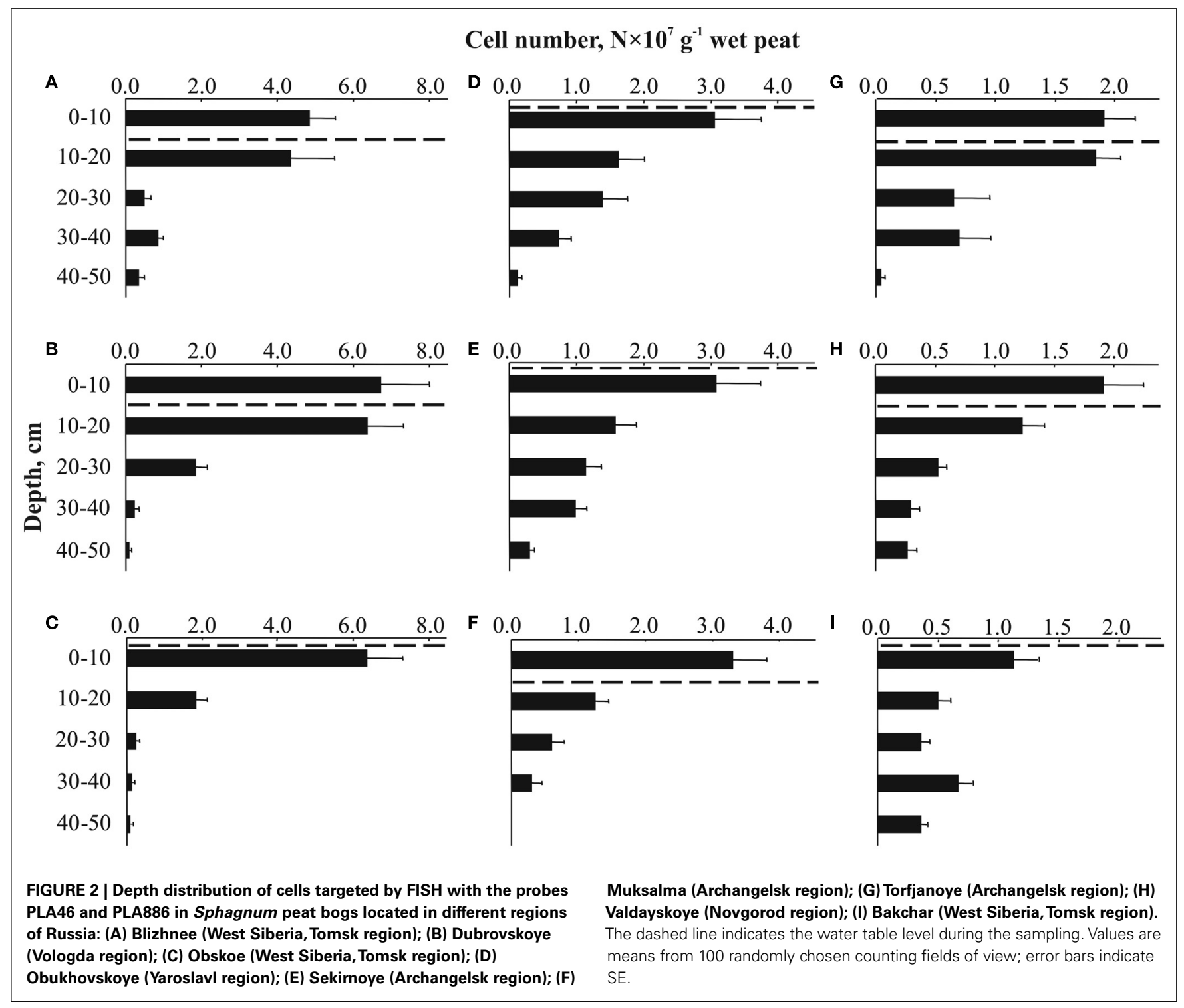

wetland profiles (Table 1; Figure 2). The cell numbers of planctomycetes in these layers were in the range 1.1-6.7 $\times 10^{7}$ cells g $^{-1}$ of wet peat, comprising $2-14 \%$ of cells detected in peat with the Bacteria-specific probe Eub338-mix. The abundance of planctomycetes in wetlands was strongly and positively correlated with $\mathrm{pH}$ value of peat water $(r=0.897$; $p$ value $<0.002$; Figure 3$)$. Highest cell numbers of these bacteria were detected in mildly acidic ( $\mathrm{pH}$ 5.3-6.0) fens, whereas low planctomycete abundance was more typical for more acidic ( $\mathrm{pH}$ 3.7-4.5) ombrotrophic bogs. By contrast, we did not observe any correspondence between the $\mathrm{pH}$ value of peat water and the cell numbers determined by hybridization with the Bacteria-specific probe Eub338-mix (Table 1).

Most peatland sites showed a sharp decline of planctomycete abundance with depth, while in two particular sites (wetlands Bakchar and Blizhnee) this decline was followed by a second population maximum in an anoxic part of the wetland profile (Tukey's HSD test, $p<0.05$; Figures 2A,I).

\section{CULTURE-INDEPENDENT IDENTIFICATION OF PEAT-INHABITING PLANCTOMYCETES}

A total of eighty $16 \mathrm{~S}$ rRNA gene clones were randomly selected for sequencing and analyzed phylogenetically. The sequences retrieved from the oxic peat layer of the peat bog Obukhovskoye were abbreviated $\mathrm{O}-\mathrm{Ox}$. The sequences obtained from the oxic and anoxic peat from the peat bog Bakchar were abbreviated B-Ox and BAn (Figure 4). Comparative sequence analysis showed that 74 of eighty 16S rRNA gene sequences affiliate with the order Planctomycetales of the phylum Planctomycetes. None of the sequences retrieved in this study belonged to Anammox-planctomycetes (Jetten et al., 2005, 2010). Finally, six clones displayed high sequence similarity (97.3-99.3\%) to the environmental clone sequence B39 (AM162486) retrieved from the West Siberian peat bog Bakchar in our previous study (Dedysh et al., 2006) and to two other environmental clone sequences, Molly56 (AY775515, 95-96\% similarity) and Molly91 (AY775535, 93-94\% similarity) retrieved from a Sphagnum peat bog in New England, USA (Morales et al., 2006). 


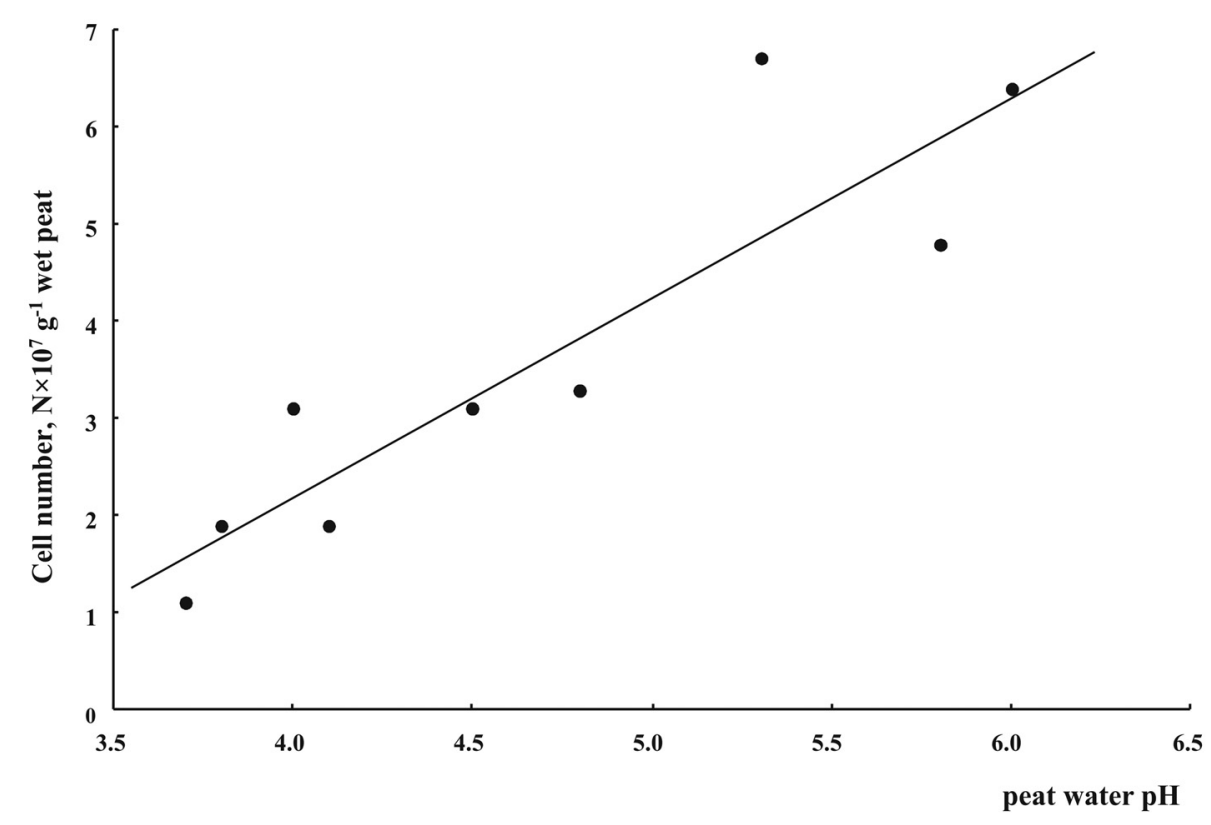

FIGURE 3 | Cell numbers of planctomycetes in oxic (0-10 cm depth) Sphagnum peat as related to peat water pH.

Taken together, these clones formed a separate phylogenetic cluster and belonged to the sub-lineage $\mathrm{V}$ within the candidate division OP3 (Glöckner et al., 2010).

The clone libraries constructed for two oxic peat samples from wetlands in West Siberia (peat bog Bakchar) and European North Russia (peat bog Obukhovskoye) had highly similar composition. More than half of all clones (53-61\%) in both clone libraries affiliated with the phylogenetic lineage defined by the genera Isosphaera and Singulisphaera. None of the peat-derived sequences, however, displayed high similarity $(\geq 97 \%)$ to those in taxonomically described members of this lineage. A group of 14 cloned 16S rRNA gene sequences showed only a distant relationship (88.8-92.8\% sequence similarity) to 16 S rRNA gene sequence from Isosphaera pallida, a neutrophilic filamentous planctomycete from a hot spring (Giovannoni et al., 1987; Figure 4). Another group of 18 clones displayed moderate similarity (93.8-95.5\%) to $16 \mathrm{~S}$ rRNA gene sequences of acidophilic peat-inhabiting planctomycete Singulisphaera acidiphila (Kulichevskaya et al., 2008) and of taxonomically uncharacterized planctomycete from activated sludge, "Nostocoida limicola III" (Liu et al., 2001). The second abundant group of sequences (25-35\% of all clones) obtained from oxic peat belonged to the phylogenetic lineage defined by the genera Gemmata and Zavarzinella. Four clones belonged to the Planctomyces-like group and displayed high sequence similarity (98.0-98.8\%) to the 16S rRNA gene sequence of another characterized peat-inhabiting planctomycete Schlesneria paludicola (Kulichevskaya et al., 2007b). Finally, only two clones affiliated with Pirellula-like planctomycetes.

By contrast, most $16 \mathrm{~S}$ rRNA gene sequences (45\% of all clones) retrieved from the anoxic peat sample clustered within the group defined by the genus Pirellula. These sequences displayed only a distant relationship $(85.7-89.7 \%$ sequence similarity) to those from taxonomically described representatives of this planctomycete group, but were highly similar $(95.2-98.7 \%)$ to the environmental clone sequences Molly75 (AY775524), Molly19 (AY775494), and B86 (AM162476) obtained from Sphagnumdominated wetlands in the USA and Russia (Dedysh et al., 2006; Morales et al., 2006). One-fourth of all sequences retrieved from anoxic peat belonged to the Gemmata-Zavarzinella-related group of planctomycetes. Four of these sequences displayed high similarity $(99.5-99.7 \%)$ to $16 \mathrm{~S}$ rRNA gene sequence of Zavarzinella formosa (Kulichevskaya et al., 2009). This planctomycete was described as an aerobic organism, which is not capable of growth in micro-oxic or anoxic conditions. Minor groups of clones in a clone library made of anoxic peat were the sequences from IsosphaeraSingulisphaera-like (15\% of all clones) and Schlesneria-like (5\%) planctomycetes.

\section{DIFFERENTIAL DETECTION OF SPECIFIC SUB-GROUPS OF PLANCTOMYCETES OVER THE BOG PROFILE}

Since the clone library composition may not adequately reflect the quantitative proportion of different bacterial groups within microbial communities, we attempted to assess the population structure of peat-inhabiting planctomycetes by means of FISH with the probes designed for differential detection of specific subgroups within the Planctomycetes (Table 2). Six of these probes were developed in this study based on 16S rRNA gene sequences of the recently described acidophilic planctomycetes, S. paludicola, $S$. acidiphila, and $Z$. formosa, and related environmental clone sequences retrieved from acidic peat. One additional probe, B39620 , was designed to specifically target the OP3-related group of bacteria from Sphagnum-dominated wetlands. The target specificity of all probes applied in this study is indicated by brackets in Figure 4. 


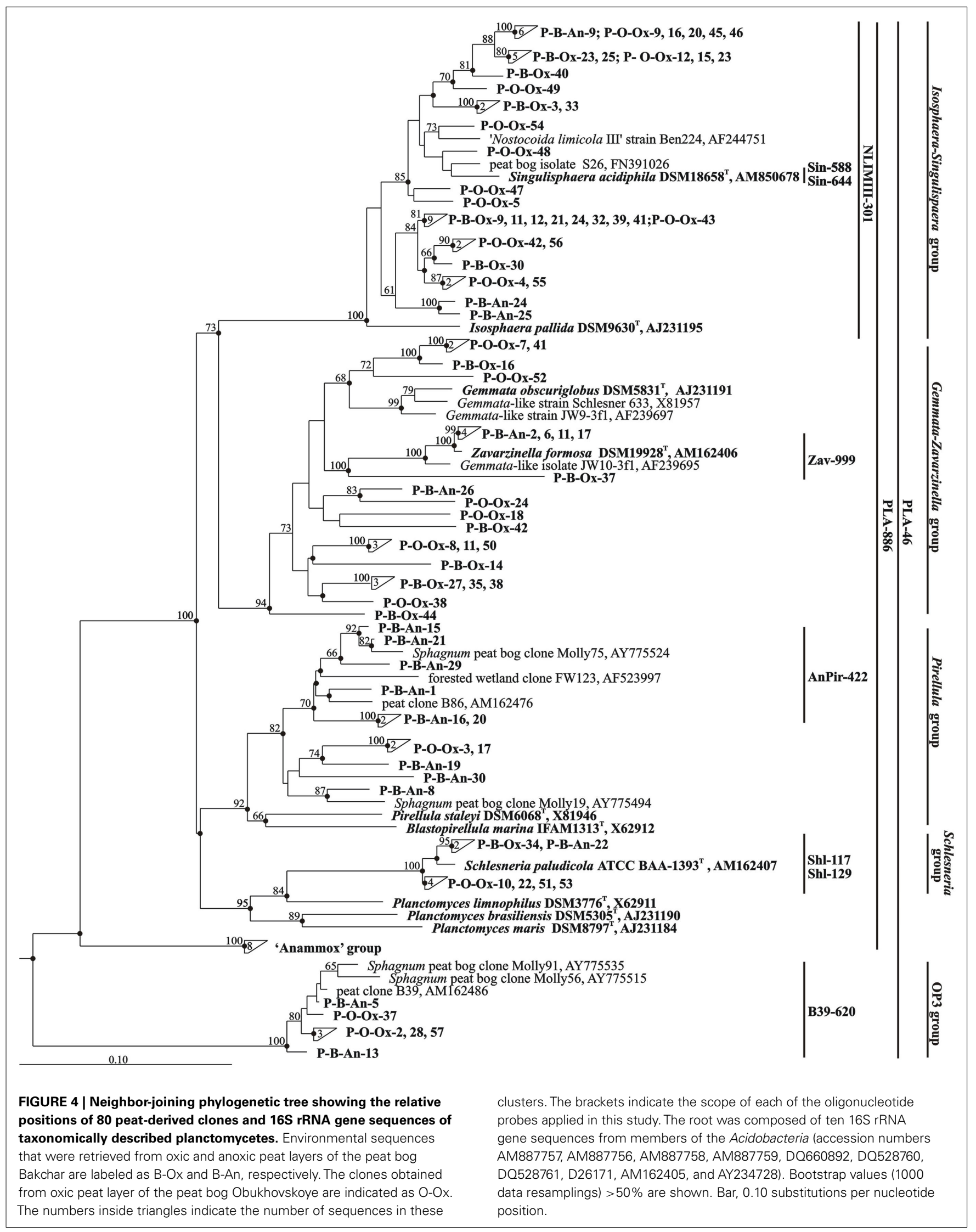


The set of probes listed in Table 2 was applied to assess the depth distribution of specific planctomycete groups in the peat bog Bakchar, West Siberia (Figure 5). The largest detectable population of indigenous planctomycetes hybridized with a probe targeting members of the Isosphaera-Singulisphaera group (Figure 5A). The population size of these planctomycetes declined from $3.7 \times 10^{7}$ cells $^{-1}$ wet peat in the uppermost, oxic peat layer to $0.1 \times 10^{7}$ cells g $^{-1}$ wet peat at a depth of $40-50 \mathrm{~cm}$. Representatives of the genus Schlesneria were significantly less abundant but showed the same distribution trend, with the population maximum in oxic peat $\left(5.0 \times 10^{6}\right.$ cells $^{-1}$ wet peat $)$ versus population minimum $\left(0.2 \times 10^{6}\right.$ cells $^{-1}$ wet peat $)$ in anoxic part of the bog profile (Figure $5 \mathrm{~B}$ ). The number of cells targeted with Pirellula-specific probe AnPir-422 was in the range of $1.0-2.1 \times 10^{6}$ cells $^{-1}$ wet peat and did not show significant variations within the bog profile. The most unexpected distribution pattern was observed for Zavarzinella-like planctomycetes, which peaked up to $4.4 \times 10^{6}$ cells $^{-1}$ wet peat at a depth of $30-40 \mathrm{~cm}$. Finally, a minor but clearly detectable population of spherical cells hybridized with a probe targeting OP3-related organisms. These bacteria were enumerated at $0.6-4.6 \times 10^{6}$ cells $^{-1}$ wet peat, which accounted for $9-20 \%$ of all cells targeted with the probes PLA46 + PLA886 (shown by white in Figure 5A). Given that OP3-related bacteria do not belong to the Planctomycetes (discussed below), we have corrected our estimations of the planctomycete abundance in peat as follows: $N_{\text {planctomycetes }}=N_{\text {PLA46 }}+$ PLA886 $-N_{\text {B39-620 }}$. The resulting range of planctomycete abundance within the profile of peat bog Bakchar was $0.6-4.6 \times 10^{7}$ cells $^{-1}$ wet peat. The estimated overall coverage of the group-specific probes used in our study was 92-98\%.

\section{DISCUSSION}

As evidenced by a number of recent studies, planctomycetes densely colonize diverse acidic ecosystems, such as acidic northern wetlands (Dedysh et al., 2006; Kulichevskaya et al., 2006; this study), tank-forming bromeliads in tropical rainforests (Goffredi et al., 2011), and acidic hot springs (Bohorquez et al., 2012). Various water-saturated habitats with primarily decay-resistant organic matter seem to be one of the preferred econiches of these bacteria. The population size of planctomycetes in peatlands $10^{7}$ cells $^{-1}$ of wet peat - is especially high in comparison to many other ecosystems. For example, the peak of planctomycete abundance, which is usually observed in marine habitats during a diatom bloom, corresponds to $10^{4}$ cells $\mathrm{ml}^{-1}$ (Morris et al., 2006; Pizzetti et al., 2011).

The highest population sizes of planctomycetes were revealed in mildly acidic peat sampled from two eutrophic fens, Obskoe ( $\mathrm{pH}$ 6.0) and Blizhnee ( $\mathrm{pH}$ 5.8), as well as in peat sampled from ombrotrophic bog Dubrovskoye ( $\mathrm{pH} 5.3$ ). Vice versa, the lowest numbers of cells targeted with the probes PLA46 + PLA886 were detected in more acidic $(\mathrm{pH} 3.7-4.1)$ peat bogs Bakchar, Torfjanoye, and Valdayskoye. These data suggest that most peatinhabiting planctomycetes are moderately acidophilic bacteria with $\mathrm{pH}$ growth optima similar to those in Schlesneria, Singulisphaera, and Zavarzinella (Kulichevskaya et al., 2007b, 2008, 2009, 2012).

The culture-independent analysis of 16S rRNA gene sequences retrieved from acidic peat using Planctomycetes-specific primer pair revealed the presence of a highly diverse community, which consisted mostly of as-yet-uncultivated and uncharacterized planctomycetes. This highlights the need for further cultivation efforts in uncovering the Planctomycetes diversity in acidic northern wetlands. Notably, none of the sequences retrieved in our study belonged to Anammox-planctomycetes. This is not surprising since only one anoxic peat sample was examined in our study, and this particular sample was taken from an oligotrophic Sphagnum peat bog where available forms of nitrogen are mostly at very low or undetectable levels.

Based on the results of differential cell counts, we were able to compare the planctomycete community structure in oxic (0-10 cm depth) and anoxic $(30-40 \mathrm{~cm}$ depth) peat layers (Figure 6). Oxic peat was dominated by members of the Isosphaera-Singulisphaera group, which accounted for up to $80 \%$ of all planctomycete cells detected by FISH. The second numerically significant planctomycete group in oxic peat was represented by members of the genus Schlesneria. By contrast, the most abundant planctomycete population in anoxic peat was Zavarzinellalike bacteria ( $45 \%$ of all planctomycete cells), while IsosphaeraSingulisphaera and Pirellula-like planctomycetes accounted for

Cell number, $\mathbf{N} \times 10^{6} \mathrm{~g}^{-1}$ wet peat
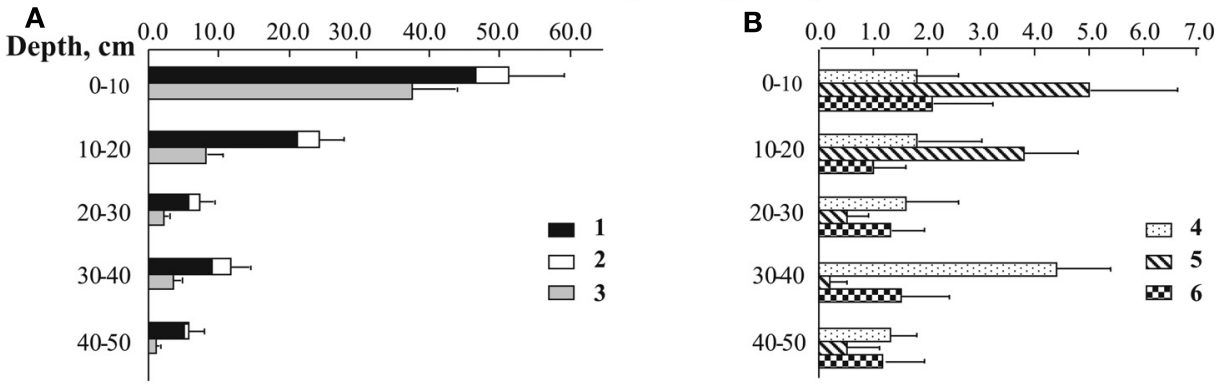

FIGURE 5 | Depth distribution of planctomycete cells detected by means of in situ hybridization with group-specific probes in Sphagnum peat bog Bakchar: (A) 1-total cell number of planctomycetes,
2 - OP3-related group, 3 - Isosphaera-Singulisphaera group, (B) 4 - Zavarzinella-like planctomycetes, 5 - Schlesneria spp., 6 - Pirellula-like planctomycetes. 

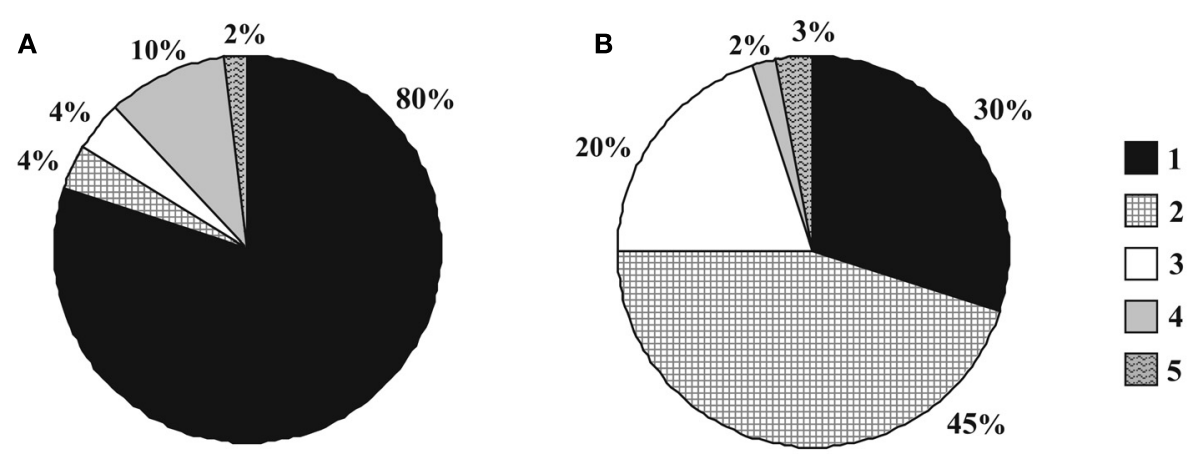

FIGURE 6 | Community structure of planctomycetes in oxic (A) versus anoxic (B) peat: 1 - Isosphaera-Singulisphaera group, 2 - Zavarzinella-like planctomycetes, 3 - Pirellula-like planctomycetes, 4 - Schlesneria spp., 5 - others.

30 and $20 \%$ of all detectable planctomycetes, respectively. High abundance of Zavarzinella-like planctomycetes in anoxic peat is difficult to explain based on the currently available information. Z. formosa was originally described as an obligately aerobic chemoheterotroph, which is not capable of growth in microaerobic or anoxic conditions (Kulichevskaya et al., 2009). Cultivation-independent retrieval of Zavarzinella-like 16S rRNA gene sequences from anoxic peat prompted us to re-analyze the ability of these planctomycetes to grow in anoxic conditions using the only currently available strain of these bacteria, $Z$. formosa $\mathrm{A} 10^{\mathrm{T}}$, but the result was negative. Possibly, other members of this genus may differ from the single taxonomically characterized representative by a number of traits. The occurrence of Pirellulalike planctomycetes in anoxic environments was well-documented before (Derakshani et al., 2001; Chouari et al., 2003; Kirkpatrick et al., 2006; Elshahed et al., 2007).

Based on our current knowledge, planctomycetes are slowacting decomposers of plant-derived organic matter. They were identified as a numerically abundant component of a bacterial community that develops in the course of Sphagnum moss decomposition (Kulichevskaya et al., 2007a). Notably, the cell numbers of planctomycetes increased at the final stage of decomposition process. Given also that all currently characterized peat-inhabiting planctomycetes are capable of degrading heteropolysaccharides but not cellulose or chitin (Kulichevskaya et al., 2007b, 2008, 2009, 2012), the role of primary degraders is unlikely to be attributed to this group of bacteria. Yet, the biogeochemical role of planctomycetes in peatlands remains to be clarified since characterized representatives make only a minor part of the whole planctomycete diversity in acidic wetlands.

Our study provided the first quantitative estimation of the OP3-related bacteria in acidic wetlands. Candidate division OP3

\section{REFERENCES}

Bohorquez, L. C., Delgado-Serrano, L., López, G., Osorio-Forero, C., Klepac-Ceraj, V., Kolter, R., Junca, H., Baena, S., and Zambrano, M. M. (2012). In-depth characterization via complementing cultureindependent approaches of the microbial community in an acidic hot spring of the Colombian Andes. Microb. Ecol. 63, 103-115.

Chouari, R., Le Paslier, D., Daegelen, P., Ginestet, P., Weissenbach, J., and Sghir, A. (2003). Molecular evidence for novel planctomycete diversity in a municipal wastewater treatment plant. Appl. Environ. Microbiol. 69, 7354-7363.

(Obsidian Pool 3) was originally described based on a single $16 \mathrm{~S}$ rRNA gene sequence retrieved from Obsidian Pool sediment (Hugenholtz et al., 1998). Later, OP3-related 16S rRNA gene sequences were obtained from a flooded paddy soil using a forward PCR primer PLA-40F that was designed for specific detection of the phyla Planctomycetes and Verrucomicrobia (Derakshani et al., 2001). Recent phylogenetic analysis of all currently available OP3-related 16S rRNA gene sequences showed that they represent at least five different subdivision level lineages, and the sequences retrieved from Sphagnum wetlands belong to the sub-lineage V (Glöckner et al., 2010). So far, OP3 bacteria were detected mostly in anoxic environments. The metagenomic analysis revealed that they share a high proportion of orthologs with members of the Deltaproteobacteria and appear to be capable of anaerobic respiration (Glöckner et al., 2010). In our study, we detected these bacteria in both oxic and anoxic parts of the bog profile, which suggests that at least members of the sub-lineage $\mathrm{V}$ may possess a facultatively anaerobic lifestyle.

In summary, we revealed the presence of a highly abundant and diverse community of Planctomycetes in acidic northern wetlands. These bacteria inhabit both oxic and anoxic peat layers and belong mostly to as-yet-undescribed taxa. Further work is needed, therefore, to characterize the unknown planctomycetes found in this habitat and to explore their physiology and functional role in wetlands.

\section{ACKNOWLEDGMENTS}

This research was supported by the Program "Molecular and Cell Biology" of Russian Academy of Sciences and the Russian Fund of Basic Research (project No 06-04-49148). The authors thank Marc Dumont for editing this manuscript.

Daims, H., Brühl, A., Amann, R., Schleifer, K.-H., and Wagner, M. (1999). The domain-specific probe EUB338 is insufficient for the detection of all bacteria: development and evaluation of a more comprehensive probe set. Syst. Appl. Microbiol. 22, 434-444.
Dedysh, S. N., Derakshani, M., and Liesack, W. (2001). Detection and enumeration of methanotrophs in acidic Sphagnum peat by $16 \mathrm{~S}$ rRNA fluorescence in situ hybridisation, including the use of newly developed oligonucleotide probes for Methylocella palustris. Appl. Environ. Microbiol. 67, 4850-4857. 
Dedysh, S. N., Pankratov, T. A., Belova, S. E., Kulichevskaya, I. S., and Liesack, W. (2006). Phylogenetic analysis and in situ identification of bacteria community composition in an acidic Sphagnum peat bog. Appl. Environ. Microbiol. 72, 2110-2117.

Derakshani, M., Lukow, T., and Liesack, W. (2001). Novel bacterial lineages at the (sub) division level as detected by signature nucleotide-targeted recovery of $16 \mathrm{~S}$ rRNA genes from bulk soil and rice roots of flooded rice microcosms. Appl. Environ. Microbiol. 67, 623-631.

Elshahed, M. S., Youssef, N. H., Luo, Q., Najar, F. Z., Roe, B. A., Sisk, T. M., Bühring, S. I., Hinrichs, K.-U., and Krumholz, L. R. (2007). Phylogenetic and metabolic diversity of Planctomycetes from anaerobic, sulfide- and sulfur-rich Zodletone Spring, Oklahoma. Appl. Environ. Microbiol. 73, 4707-4716.

Felsenstein, J. (1989). PHYLIP - phylogeny inference package (version 3.2). Cladistics 5, 164-166.

Fuerst, J. A. (1995). The Planctomycetes: emerging models for microbial ecology, evolution and cell biology. Microbiology 141, 1493-1506.

Fuerst, J. A., and Sagulenko, E. (2011). Beyond the bacterium: planctomycetes challenge our concepts of microbial structure and function. Nat. Rev. Microbiol. 9, 403-413.

Giovannoni, S. J., Schabtach, E., and Castenholz, R. W. (1987). Isosphaera pallida, gen. nov., and comb. nov., a gliding, budding eubacterium from hot springs. Arch. Microbiol. 147, 276-284.

Glöckner, J., Kube, M., Shrestha, P. M., Weber, M., Glöckner, F. O., Reinhardt, R., and Liesack, W. (2010). Phylogenetic diversity and metagenomics of candidate division OP3. Environ. Microbiol. 12, 1218-1229.

Goffredi, S. K., Kantor, A. H., and Woodside, W. T. (2011). Aquatic microbial habitats within a neotropical rainforest: bromeliads and $\mathrm{pH}-$ associated trends in bacterial diversity and composition. Microb. Ecol. 61, 529-542.

Huber, T., Faulkner, G., and Hugenholtz, P. (2004). Bellerophon; a program to detect chimeric sequences in multiple sequence alignments. Bioinformatics 20, 2317-2319.

Hugenholtz, P., Pitulle, C., Hershberger, K. L., and Pace, N. R. (1998). Novel division level bacterial diversity in a Yellowstone hot spring. J. Bacteriol.180, 366-376.

Ivanova, A. O., and Dedysh, S. N. (2006). High abundance of Planctomycetes in anoxic layers of a Sphagnum peat bog. Microbiology 75, 716-719.

Jetten, M. S. M., Cirpus, I., Kartal, B., van Niftrik, L., van de Pas-Schoonen, K. T., Sliekers, O., Haaijer, S., van der Star, W., Schmid, M., van de Vossenberg, J., Schmidt, I., Harhangi, H., van Loosdrecht, M., Kuenen, G. J., Op den Camp, H., and Strous, M. (2005). 1994-2004: 10 years of research on the anaerobic oxidation of ammonium. Biochem. Soc. Trans. 33, 119-123.

Jetten, M. S. M., Op den Camp, H., Kuenen, G. J., and Strous, M. (2010). "Order II. 'Candidatus Brocadiales' ord. nov.," in Bergey's Manual of Systematic Bacteriology, Vol. 4, eds N. R. Krieg, J. T. Staley, D. R. Brown, B. P. Hedlung, B. J. Paster, N. L. Ward, W. Ludwig, and W. B. Whitman (New York, NY: Springer), 918-925.

Kirkpatrick, J., Oakley, B., Fuchsman, C., Srinivasan, S., Staley, J. T., and Murray, J. W. (2006). Diversity and distribution of Planctomycetes and related bacteria in the suboxic zone of the Black Sea. Appl. Environ. Microbiol. 72, 3079-3083.

Kulichevskaya, I. S., Baulina, O. I., Bodelier, P. L. E., Rijpstra, W. I. C., Sinninghe Damsté, J. S., and Dedysh, S. N. (2009). Zavarzinella formosa gen. nov., sp. nov., a novel stalked, Gemmata-like planctomycete from a Siberian peat bog. Int. J. Syst. Evol. Microbiol. 59, 357-364.

Kulichevskaya, I. S., Belova, S. N., Kevbrin, V. V., Dedysh, S. N., and Zavarzin, G. A. (2007a). Analysis of the bacterial community developing in the course of Sphagnum moss decomposition. Microbiology 76, 621-629.

Kulichevskaya, I. S., Ivanova, A. O., Belova, S. E., Baulina, O. I., Bodelier, P. L. E., Rijpstra, W. I. C., Sinninghe Damsté, J. S., Zavarzin, G. A., and Dedysh, S. N. (2007b). Schlesneria paludicola gen. nov., sp. nov., the first acidophilic member of the order Planctomycetales from Sphagnum-dominated boreal wetlands. Int. J. Syst. Evol. Microbiol. 57, 2680-2687.

Kulichevskaya, I. S., Detkova, E. N., Bodelier, P. L. E., Rijpstra, W. I. C, Sinninghe Damsté, G. S., and Dedysh, S. N. (2012). Singulisphaera rosea sp. nov., a novel planctomycete from acidic Sphagnum peat. Int. J. Syst. Evol. Microbiol. 62, 118-123.

Kulichevskaya, I. S., Ivanova, A. O., Baulina, O. I., Bodelier, P. L. E., Sinninghe Damsté, J. S., and Dedysh, S. N. (2008). Singulisphaera acidiphila gen. nov., sp. nov., a nonfilamentous, Isosphaera-like planctomycete from acidic northern wetlands. Int. J. Syst. Evol. Microbiol. 58, 1186-1193.

Kulichevskaya, I. S., Pankratov, T. A., and Dedysh, S. N. (2006). Detection of representatives of the Planctomycetes in Sphagnum peat bogs by molecular and cultivation approaches. Microbiology 75, 329-335.

Liu, J.-R., McKenzie, C. A., Seviour, E. M., Webb, R. I., Blackall, L. L., Saint, C. P., and Seviour, R. J. (2001). Phylogeny of the filamentous bacterium 'Nostocoida limicola' III from activated sludge. Int. J. Syst. Evol. Microbiol. 51, 195-202.

Liu, J.-R., and Seviour, R. J. (2001). Design and application of oligonucliotide probes for fluorescent in situ identification of the filamentous bacterial morphotype Nostocoida limicola in activated sludge. Environ. Microbiol. 3, 551-560.

Ludwig, W., Strunk, O., Westram, R., Richter, L., Meier, H., Kumar, Y., Buchner, A., Lai, T., Steppi, S., Jobb, G., Förster, W., Brettske, I., Gerber, S., Ginhart, A. W., Gross, O., Grumann, S., Hermann, S., Jost, R., König, A., Liss, T., Lüssmann, R., May, M., Nonhoff, B., Reichel, B., Strehlow, R., Stamatakis, A., Stuckmann, N. Vilbig, A., Lenke, M., Ludwig, T., Bode, A., Schleifer, K. H. (2004). ARB: a software environment for sequence data. Nucleic Acids Res. 32, 1363-1371.

Morales, S. E., Mouser, P. J., Ward, N., Hudman, S. P., Gotelli, N. J., Ross, D. S., and Lewis, T. A. (2006). Comparison of bacterial communities in New England Sphagnum bogs using terminal restriction fragment length polymorphism. Microb. Ecol. $52,34-44$.

Morris, R. M., Longnecker, K., and Giovannoni, S. J. (2006). Pirellula and OM43 are among the dominant lineages identified in an Oregon coast diatom bloom. Environ. Microbiol. 8, 1361-1370.

Neef, A., Amann, R., Schlesner, H., and Schleifer, K.-H. (1998). Monitoring a widespread bacterial group: in situ detection of Planctomycetes with $16 \mathrm{~S}$
rRNA-targeted probes. Microbiology 144, 3257-3266.

Pizzetti, I., Fuchs, B. M., Gerdts, G., Wichels, A., Wiltshire, K. H., and Amann, R. (2011). Temporal variability of coastal Planctomycetes clades at Kabeltonne station, North sea. Appl. Environ. Microbiol. 77, 5009-5017.

Schlesner, H., and Stackebrandt, E. (1986). Assignment of the genera Planctomyces and Pirella to a new family Planctomycetaceae fam. nov. and description of the order Planctomycetales ord. nov. Syst. Appl. Microbiol. 8, 174-176.

Ward, N., Staley, J. T., Fuerst, J. A., Giovannoni, S., Schlesner, H., and Stackebrandt, E. (2006). “The order Planctomycetales, including the genera Planctomyces, Pirellula, Gemmata and Isosphaera and the Candidatus genera Brocadia, Kuenenia and Scalindua," in The Prokaryotes: A Handbook on the Biology of Bacteria, 3rd Edn, Vol. 7, eds M. Dworkin, S. Falkow, E. Rosenberg, K. H. Schleifer, and E. Stackebrandt (New York: Springer), 757-793.

Zheng, D., Alm, E. W., Stahl, D. A., and Raskin, L. (1996). Characterization of universal small-subunit rRNA hybridization probes for quantitative molecular microbiological ecology studies. Appl. Environ. Microbiol. 62, 4504-4513.

Conflict of Interest Statement: The authors declare that the research was conducted in the absence of any commercial or financial relationships that could be construed as a potential conflict of interest.

Received: 10 November 2011; paper pending published: 29 November 2011; accepted: 04 January 2012; published online: 18 January 2012.

Citation: Ivanova $A O$ and Dedysh SN (2012) Abundance, diversity, and depth distribution of Planctomycetes in acidic northern wetlands. Front. Microbio. 3:5. doi: 10.3389/fmicb.2012.00005

This article was submitted to Frontiers in Terrestrial Microbiology, a specialty of Frontiers in Microbiology.

Copyright $\odot 2012$ Ivanova and Dedysh. This is an open-access article distributed under the terms of the Creative Commons Attribution Non Commercial License, which permits non-commercial use, distribution, and reproduction in other forums, provided the original authors and source are credited. 


\title{
Spatial patterns of iron- and methane-oxidizing bacterial communities in an irregularly flooded, riparian wetland
}

\author{
Juanjuan Wang ${ }^{1+}$, Sascha Krause ${ }^{1}$, Gerard Muyzer ${ }^{2,3+}$, Marion Meima-Franke ${ }^{1}$, Hendrikus J. Laanbroek ${ }^{1,4}$ \\ and Paul L. E. Bodelier ${ }^{1}$ *
}

${ }^{1}$ Department of Microbial Ecology, Netherlands Institute of Ecology, Wageningen, Netherlands

${ }^{2}$ Department of Biotechnology, Delft University of Technology, Delft, Netherlands

${ }^{3}$ Institute for Biodiversity and Ecosystem Dynamics, University of Amsterdam, Amsterdam, Netherlands

${ }^{4}$ Institute of Environmental Biology, Utrecht University, Utrecht, Netherlands

\section{Edited by:}

Svetlana N. Dedysh, Winogradsky Institute of Microbiology, Russian Academy of Sciences, Russia

Reviewed by:

Marc Gregory Dumont,

Max-Planck-Institute for Terrestrial

Microbiology, Germany

Erin Field, Bigelow Laboratory for

Ocean Sciences, USA

${ }^{*}$ Correspondence:

Paul L. E. Bodelier, Department of

Microbial Ecology, Netherlands

Institute of Ecology,

Droevendaalsesteeg 10, NL-6708 PB

Wageningen, Netherlands.

e-mail:p.bodelier@nioo.knaw.nl

\section{${ }^{\dagger}$ Present address:}

Juanjuan Wang, Limnology/Aquatic Geomicrobiology, Institute of Ecology,

Friedrich Schiller University Jena, Jena, Germany;

Gerard Muyzer, Institute for

Biodiversity and Ecosystem

Dynamics, University of Amsterdam,

Amsterdam, Netherlands.
Iron- and methane-cycling are important processes in wetlands with one connected to plant growth and the other to greenhouse gas emission, respectively. In contrast to acidic habitats, there is scarce information on the ecology of microbes oxidizing ferrous iron at circumneutral $\mathrm{pH}$. The latter is mainly due to the lack of isolated representatives and molecular detection techniques. Recently, we developed PCR-DGGE and QPCR assays to detect and enumerate Gallionella-related neutrophilic iron-oxidizers (Ga-FeOB) enabling the assessment of controlling physical as well as biological factors in various ecosystems. In this study, we investigated the spatial distribution of Ga-FeOB in co-occurrence with methane-oxidizing bacteria (MOB) in a riparian wetland. Soil samples were collected at different spatial scales (ranging from meters to centimeters) representing a hydrological gradient. The diversity of Ga-FeOB was assessed using PCR-DGGE and the abundance of both $\mathrm{Ga}-\mathrm{FeOB}$ and MOB by qPCR. Geostatistical methods were applied to visualize the spatial distribution of both groups. Spatial distribution as well as abundance of $\mathrm{Ga}-\mathrm{FeOB}$ and $\mathrm{MOB}$ was clearly correlated to the hydrological gradient as expressed in moisture content of the soil. Ga-FeOB outnumbered the MOB subgroups suggesting their competitiveness or the prevalence of $\mathrm{Fe}^{2+}$ over $\mathrm{CH}_{4}$ oxidation in this floodplain.

Keywords: Gallionella, iron oxidation, methane oxidation, spatial patterns, geostatistics, riparian, wetland

\section{INTRODUCTION}

Wetland ecosystems are sites of intense biogeochemical cycling due to the interactions between the oxic surface and deeper anoxic soil layers making them highly productive ecosystems (Weiss et al., 2003; Gutknecht et al., 2006; Hartman et al., 2008; Burgin et al., 2011). Apart from being a crucial habitat for many animals, plants, and humans, wetlands are also the largest biological source of the greenhouse gas methane (Ringeval et al., 2011). Cycling of nutrients and emission of methane from wetlands is strongly intertwined due to the oxic-anoxic conditions in close proximity (Kogel-Knabner et al., 2010; Burgin et al., 2011) which is especially distinct for iron and methane (Laanbroek, 2010).

Oxic-anoxic interfaces in wetland soils are significantly extended by roots of wetland plants which are known to release oxygen from their roots, a phenomenon called "radial oxygen loss" (ROL; Armstrong, 1964; Bodelier et al., 2006; Laanbroek, 2010). Next to this, oxygen is also introduced into anoxic soils by other physical or biological processes (Doyle and Otte, 1997; Coci et al., 2005; Mermillod-Blondin and Lemoine, 2010) resulting in sharp redox gradients characteristic of wetland soils and sediments.

As one of the most important elements in biogeochemical redox reactions (Fortin and Langley, 2005), iron interacts with other elemental cycles, which in turn affect the growth and activities of plants and microorganisms. Iron oxides are widely distributed in wetland environments and will be reduced rapidly under anoxic conditions by anaerobic iron(III)-reducing bacteria, that couple the oxidation of organic carbon compounds to the reduction of iron $\left(\mathrm{Fe}^{3+}\right)$ to ferrous iron $\left(\mathrm{Fe}^{2+}\right.$; Lovley, 1997; Burgin et al., 2011). Ferrous iron can be oxidized chemically, however, in freshwater wetlands microbial activity accounts for a large part of the production of iron oxides under circumneutral $\mathrm{pH}$ conditions, despite the fact that chemical oxidation under these conditions proceeds much faster. This contradiction triggered studies detecting ironoxidizing bacteria $(\mathrm{FeOB})$ associated with iron oxides in samples from circumneutral environments (Emerson and Moyer, 1997; Weiss et al., 2003; Chan et al., 2009). Actual bacterial mediation of iron oxidation was also confirmed, further pointing to the important role of $\mathrm{FeOB}$ in the formation of iron oxides (Neubauer et al., 2002).

Despite the fact that a number of $\mathrm{FeOB}$ have been isolated and our understanding of the role of these microorganisms in iron oxidation has significantly progressed (Emerson et al., 2010) virtually nothing is known about the environmental factors affecting the diversity and distribution of $\mathrm{FeOB}$ in their natural habitats. 
Sundby et al. (2003) have proposed that seasonal changes of $\mathrm{O}_{2}$ concentration and pore water $\mathrm{Fe}^{2+}$ availability resulting from the growth and death of roots exert a major control on the precipitation of iron oxides. Neubauer et al. (2007) reported significant temporal changes in the iron-oxidizing community in microcosm studies with plants, which suggests that plant biomass and activity play a key role in rhizospheric $\mathrm{Fe}$ (II) oxidation. Changes in the Gallionella-related FeOB community composition have been observed to depend on season and hydrology in a tidal freshwater marsh (Wang et al., 2011), probably connected to the effects these parameter have on oxygen availability.

Next to chemical oxidation, there are quite a few biotic processes that consume oxygen, such as the oxidation of ammonium, methane, and sulfide, which are all products of anaerobic microbial processes. Thermodynamically, Fe(II) oxidation yields more energy than other chemolithotrophic reactions under oxygenlimiting conditions (Thauer et al., 1977), suggesting that sub-oxic conditions may be the niche occupied by FeOB in wetland soils. However, no information is available on the spatial distribution of niches suitable for FeOB as well as the competition for limiting amounts of oxygen between iron-oxidizing bacteria and other oxygen-consuming organisms.

A well characterized group of microbes also thriving at oxicanoxic boundaries are aerobic methane-oxidizing bacteria (MOB), utilizing methane for carbon as well as energy source (Semrau et al., 2010). The aerobic MOB are represented in the phylum of the Proteobacteria and recently also MOB have been identified within the Verrucomicrobia (Op den Camp et al., 2009). Many environmental factors controlling the ecology of MOB have been studied and indentified (Conrad, 2007; Semrau et al., 2010; Bodelier, 2011). The proteobacterial MOB have traditionally been divided into type I and II, based on phylogeny, physiology, and morphology. On the basis of phylogeny, type I has been subdivided in three subtypes Ia, Ib, and Ic (Lüke and Frenzel, 2011). The obligatory aerobic metabolism of most MOB suggest that their environmental distribution and demands are similar to those for FeOB. For type II and Ia MOB different ecological strategies are emerging, type II being slow responders to substrate availability but persistent in the environment, whereas type Ia harbors species that respond and grow fast upon substrate availability (Steenbergh et al., 2010; Bodelier et al., 2012). Considering this, the vast ecological knowledge available about various environmental as well as isolated subtypes of MOB may be extrapolated to possible co-occurring FeOB. Besides using microbial co-occurrence, the distribution of FeOB according to spatial gradients of controlling environmental conditions is another way of obtaining ecological information. Since the soil is a highly heterogeneous environment, soil components, and properties may exhibit high spatial variations (Franklin and Mills, 2003; Baker et al., 2009; Ferreira et al., 2010). In particular, the perceived microbial community structure may depend on the spatial scale of observation, in the range of centimeters to a few hundred meters (Ettema and Wardle, 2002; Philippot et al., 2009b). Sampling of microbial communities in a spatial design followed by geostatistical analyses has rendered important ecological information on the functioning and distribution of ammonia oxidizers (Wessen et al., 2011), denitrifiers (Philippot et al., 2009b), methane oxidizers (Siljanen et al., 2011) as well as total microbial communities (Philippot et al., 2009a) by estimating the distribution in unsampled areas of experimental plots. However so far nothing is known about the spatial distribution of iron-oxidizing bacterial communities.

The aim of this paper is to assess the spatial distribution of the Gallionella-related FeOB (Ga-FeOB) and MOB communities and their interactions in an irregularly flooded riparian wetland. Collecting samples at different spatial scales representing a hydrological gradient allowed investigating the effect of flooding intensity. Special attention is paid to the influence of sampling scale and elevation on the distribution of both Ga-FeOB and MOB. Community structure of $\mathrm{Ga}-\mathrm{FeOB}$ were measured by a previously designed nested PCR-DGGE and abundances of both Ga-FeOB and MOB by qPCR. Community was linked to environmental variables. Spatial distribution of bacterial groups was visualized by interpolated spatial maps. We hypothesized that the community structure of iron-oxidizing bacteria changes with sampling scale and elevation, having an effect on the presence of MOB or vice versa.

\section{MATERIALS AND METHODS SITE AND SAMPLING}

Soil samples were collected from the Ewijkse Waard $\left(51^{\circ} 88^{\prime} \mathrm{N}\right.$, $5^{\circ} 73^{\prime} \mathrm{E}$ ), a riparian floodplain along the River Waal (i.e., a tributary of the River Rhine) in the Netherlands, in November 2006. The soil properties have been described previously in detail (Kemnitz et al., 2004; Steenbergh et al., 2010; Bodelier et al., 2012). The sampling site is located on the embankment of a small oxbow lake which is connected to the river on one side but is separated from the river by an outflow barrier, ensuring that the oxbow lake does not become dry completely. This outflow barrier results in slow retreat of water from the sampling plot after flooding, which results in series of different flooding days within the plot; the highest part being flooded up to 2 weeks per year, while the lowest part can be flooded up to 150 days per year (Bodelier et al., 2012). To assess spatial dependence and heterogeneity a nested design was used as described by Franklin and Mills (2003). In total 73 soil cores $(1.8 \mathrm{~cm} \times 5 \mathrm{~cm})$ were collected in a $10 \mathrm{~m} \times 10 \mathrm{~m}$ plot (Figure 1A). The large-scale spatial level of sampling comprised 24 cores arranged evenly distributed along the sides and diagonals of the plot as depicted in Figure 1A. Nested around the intersection of the diagonals of the large plot, 23 samples were taken using the same distribution but now on a $1 \mathrm{~m} \times 1 \mathrm{~m}$ grid (medium scale; Figure 1B). Nested around the same diagonal again 24 samples were obtained in a $20 \mathrm{~cm} \times 20 \mathrm{~cm}$ grid (small scale; Figure 1C). The $10 \mathrm{~m} \times 10 \mathrm{~m}$ plot was situated on a slope on the embankment of the oxbow lake resulting in an elevation difference of $1.1 \mathrm{~m}$ between the lowest and highest point of the plot. The samples taken at the three spatial scales were classified according to their elevation in the following elevation level classes, low $(0-0.33 \mathrm{~m})$, intermediate $(0.34-0.66 \mathrm{~m})$, and high (0.67-1.1 m). Soil water content (based on dry weight), soil density, total soil organic matter, and water filled pore space were analyzed using standard methods.

\section{DNA EXTRACTION}

DNA was extracted using a modification of the method described Yeates and Gillings (1998), based on the FastDNA spin kit for soil (MP Biomedicals, LLC, Solon, OH, USA), as described earlier (Pan et al., 2010). Soil (0.3 g) and $780 \mu l$ lysis buffer [200 $\mathrm{mM} \mathrm{NaPO}_{4}$ 


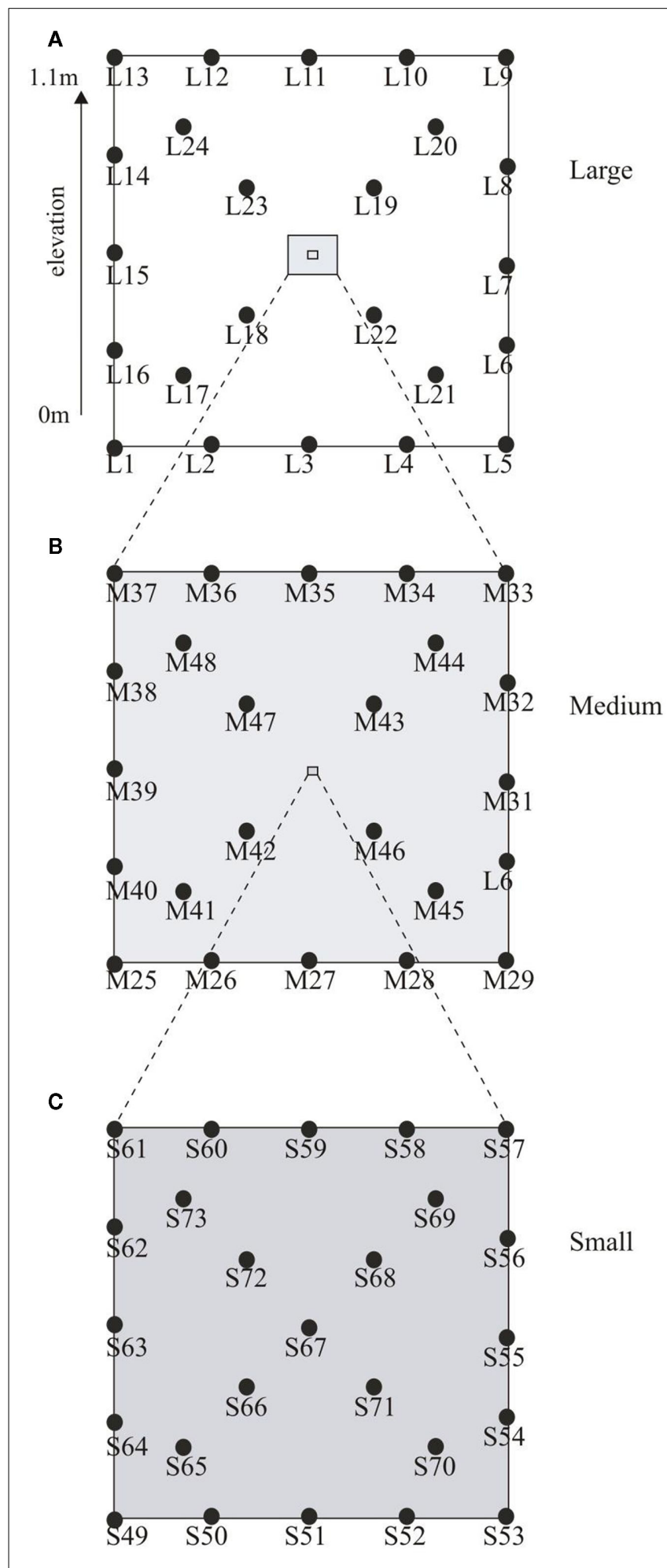

FIGURE 1 | Graphical representation of the sampling scheme. Depicted in $(\mathbf{A})$ is the large-scale plot $(10 \mathrm{~m} \times 10 \mathrm{~m})$ with an elevation from 0 to $1.1 \mathrm{~m}$. Samples were taken at $2.5 \mathrm{~m}$ intervals along the sides and $2.35 \mathrm{~m}$ intervals along the diagonals. (B) Shows the medium plot $(1 \mathrm{~m} \times 1 \mathrm{~m})$ with sampling interval of $25 \mathrm{~cm}$ along the sides and $23.5 \mathrm{~cm}$ along the diagonals while (C) depicts the small plot $(20 \mathrm{~cm} \times 20 \mathrm{~cm})$ with samples intervals of $5.0 \mathrm{~cm}$ along the sides and $4.7 \mathrm{~cm}$ along the diagonals.
pH 7.0; 1\% (w/v) CTAB; $1.5 \mathrm{M} \mathrm{NaCl} ; 2 \%$ (w/v) Polyvinylpyrrolidone $\mathrm{K} 30 ; 5 \mathrm{mg} \mathrm{ml}^{-1}$ lysozyme (added directly before use)] was added into a multimix FastPrep tube and incubated at $37^{\circ} \mathrm{C}$ for $30 \mathrm{~min}$. MT buffer $(122 \mu \mathrm{l})$, provided with the kit, was added and tubes were shaken in the FastPrep instrument (MP, Biomedicals, LLC, Solon, OH, USA) for $30 \mathrm{~s}$ at $5.5 \mathrm{~m} \mathrm{~s}^{-1}$. Subsequently, samples were centrifuged for $15 \mathrm{~min}$ at $10000 \mathrm{rpm}$ and $700 \mu \mathrm{l}$ supernatant was collected. The pellet was re-extracted by adding lysis buffer $(500 \mu \mathrm{l})$ and $50 \mu \mathrm{l}$ MT buffer to the FastPrep tubes, shaken in the FastPrep instrument for $30 \mathrm{~s}$ at $5.5 \mathrm{~m} \mathrm{~s}^{-1}$ again followed by the transfer of the second $700 \mu l$ of supernatant into separate Eppendorf tubes. At this step, $2 \mu l \times 700 \mu l$ supernatant was obtained from each sample. Five microliters of $10 \mathrm{mg} \mathrm{ml}^{-1}$ freshly made proteinase $\mathrm{K}$ was added to each tube. Tubes were incubated at $65^{\circ} \mathrm{C}$ for $30 \mathrm{~min}$. Samples were extracted with phenol-chloroformisoamyl alcohol (25:24:1), followed by a chloroform-isoamyl alcohol (24:1) extraction. One hundred twenty-five microliters of $7.5 \mathrm{M}$ potassium acetate was added, samples were incubated on ice for $5 \mathrm{~min}$, and then centrifuged at $10000 \mathrm{rpm}$ for $10 \mathrm{~min}$. Supernatants $(2 \times 700 \mu \mathrm{l}$ per soil sample) were transferred to new tubes, $700 \mu l$ Binding Matrix was added, and tubes were mixed for $5 \mathrm{~min}$ on a rotator. Binding Matrix, with bound DNA, was pelleted by 1 min centrifugation at $10000 \mathrm{rpm}$. The supernatant was discarded and pellet was resuspended in $500 \mu \mathrm{l}$ wash buffer. The resulting suspension was added into a Spin filter, and centrifuged for $1 \mathrm{~min}$ at $10000 \mathrm{rpm}$. The eluent was discarded and the pellet was washed again in $500 \mu \mathrm{l}$ wash buffer. After discarding the second eluent, the Spinfilter was centrifuged for another $10 \mathrm{~s}$ to dry the pellet. The filter was taken into a new tube and $50 \mu \mathrm{l}$ of TE $\mathrm{pH} 8.0$ was added. The filter was incubated at room temperature for $1 \mathrm{~min}$ and centrifuged for $1 \mathrm{~min}$. The filter was re-eluted in the same way with $50 \mu \mathrm{l}$ of TE $\mathrm{pH}$ 8.0. The eluent collected in the catch tube contained the purified DNA. A total of 18 out of 73 samples (i.e., L1-5, M25, M31, M 46, M 49, S50, S52, S53, S56, S60, S63, S65, S67, and S72) did not give products during PCR procedures and were excluded from further analysis.

\section{PCR-DGGE}

A nested PCR-DGGE targeting Ga-FeOB was performed using a previously developed assay (Wang et al., 2009). Briefly, $1 \mu$ of $50 \mathrm{ng}^{-1}$ purified environmental DNA was used for the first step PCR with primer set $122 \mathrm{~F}-998 \mathrm{R}$. The PCR was run in a $50-\mu \mathrm{l}$ reaction volume containing $5 \mu \mathrm{M}$ of each primer, $2.5 \mathrm{mM}$ of dNTPs, $1.5 \mathrm{mM} \mathrm{MgCl}_{2}, 2 \mathrm{mM} \mathrm{BSA}$, and 1.25 units Taq DNA polymerase. The PCR conditions included 1 cycle of $5 \mathrm{~min}$ at $94^{\circ} \mathrm{C}$, followed by 30 cycles of $1 \mathrm{~min}$ at $94^{\circ} \mathrm{C}, 1 \mathrm{~min}$ at $55^{\circ} \mathrm{C}$, and $1.5 \mathrm{~min}$ at $72^{\circ} \mathrm{C}$, the final extension cycle was $10 \mathrm{~min}$ at $72^{\circ} \mathrm{C}$. The PCR products were diluted 10 times and $2 \mu \mathrm{l}$ of the dilution was used for a second-step PCR using universal primers set GC-F357 and 907R following a touch-down PCR cycle (Schäfer et al., 2001). Clones generated in a previous study (Wang et al., 2009), representing different phylogenetic taxa, were re-amplified using general bacterial DGGE primers GC-F357 and R907 (Muyzer et al., 1993), and used as markers. DGGE was performed with the Bio-Rad Protean II system as described previously (Muyzer et al., 1993). An $8 \%$ polyacrylamide gel with a vertical gradient of $30-60 \%$ of the denaturant was used to analyze the $550 \mathrm{bp}$ PCR products. 
Equal volumes of the PCR products obtained after the second PCR reaction were loaded. The running conditions was $100 \mathrm{~V}$ at a constant temperature of $60^{\circ} \mathrm{C}$ in $23 \mathrm{~L}$ of $0.5 \times$ TAE buffer (20 mM Tris acetate, $0.5 \mathrm{mM}$ EDTA, $\mathrm{pH} 8.0$ ) for $18 \mathrm{~h}$. The DGGE gels were visualized using an UV transilluminator after ethidium bromide-staining. The representative bands were excised, purified, and sequenced. The sequences were checked and manually modified using Sequencher software (Gene Codes Corporation, City, USA) and aligned in the ARB program (Ludwig et al., 2004). A phylogenetic tree was constructed using the Neighbor Joining method. Sequences were deposited with GenBank under the following accession numbers JQ060106-JQ060114, representing DGGE bands G14-G37, respectively.

\section{REAL-TIME PCR}

A recently developed real-time PCR assay (Wang et al., 2011) was used to quantify the Ga-FeOB bacteria in the samples collected. The primer set includes a degenerate forward primer 628F (GBMAGGCTAGAGTGTAGC) and a reverse primer 998R (CTCTGGAAACTTCCTGAC). DNA from soil samples was puri-

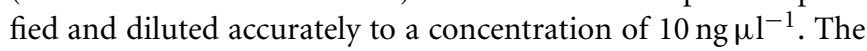
real-time PCR was performed in a $25-\mu 1$ reaction volume containing $2.5 \mu$ l purified DNA and $22.5 \mu$ SYBR $^{\circledR}$ Green PCR Master Mix

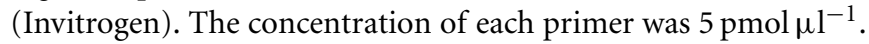
The PCR involved 45 cycles, with each cycle consisting of denaturation at $95^{\circ} \mathrm{C}$ for $20 \mathrm{~s}$, annealing at $56^{\circ} \mathrm{C}$ for $20 \mathrm{~s}$, and extension at $72^{\circ} \mathrm{C}$ for $45 \mathrm{~s}$. Data acquisition was done at $82^{\circ} \mathrm{C}$ for $10 \mathrm{~s}$, to avoid signal from primer dimer formation. The DNA copy number of $\mathrm{Ga}-\mathrm{FeOB}$ in each sample was estimated by comparing the $\mathrm{C}_{t}$ value of each sample to those of the standard regression line, which was made by using reference clones (Wang et al., 2009, 2011). Three methanotrophic subgroups were quantified by pmoA-based quantitative PCR based on the assays described by Kolb et al. (2003). The type Ia, Ib, and II assays were carried out as previously described (Pan et al., 2010) with $25 \mu \mathrm{l}$ reaction containing $12.5 \mu \mathrm{l} 2 \times$ SYBR green mix (AB gene, Epsom, UK), $2.5 \mu$ l of diluted DNA template and $0.8 \mathrm{mM}$ each of primers. The samples were diluted accurately to $1 \mathrm{ng} \mu \mathrm{l}^{-1}$. The thermal cycle started with an initial denaturation at $95^{\circ} \mathrm{C}$ for $15 \mathrm{~min}$, followed by 45 cycles of denaturation at $95^{\circ} \mathrm{C}$ for $20 \mathrm{~s}$, annealing at $64^{\circ} \mathrm{C}$ for $20 \mathrm{~s}$, and extension at $72^{\circ} \mathrm{C}$ for $45 \mathrm{~s}$. Fluorescence was recorded at $84^{\circ} \mathrm{C}$ and DNA melting curve analysis was performed at temperatures ranging from 70 to $99^{\circ} \mathrm{C}$. All assays (Ga-FeOB and $\mathrm{MOB}$ ) were performed with a RotorGene 6000 thermal cycling system (Corbett Research, Eight Mile Plains, QLD, Australia), where samples were added to aliquots of the master mixture using a CAS-1200 (Corbett Robotics Eight Mile Plains, QLD, Australia) liquid handling system. Every sample was performed in duplicate. Quantification analysis was performed by the Rotor-Gene software. A number of samples failed to reach the detection limit of the assays: Ga-FeOB (M25, M27, M31, M37, M48, S49-S59, S63, S64, S65, S67). Type Ia MOB (L2, S50, S52, S54-S59, S60, S61, S64, S65). Type Ib MOB (S52). Type II MOB (M45).

\section{DATA ANALYSIS}

DGGE gels were analyzed using Phoretix gel analysis software (Phoretix International, Newcastle upon Tyne, UK). The number of bands of each lane was defined and a matrix of band intensity was created. Lanes were created manually, with a fixed width of 5\% of the standard lane width. Each lane represents one sample. Background noise was subtracted by using the Rolling Ball algorithm with a radius of 50 pixels. Bands were detected automatically with a minimum slope of 100 and a noise reduction of 4 . Then bands were assessed and corrected by eye, matched to a reference lane (Markers), and quantified. The relative abundance of each band was defined as the intensity ratio of each band to the total intensity of individual lanes.

Similarity between DGGE community profiles was analyzed using multivariate analyses in PRIMER 5 software (Plymouth Marine Laboratory, Plymouth, UK). Relative abundance data derived from the DGGE gels were used in non-metric Multidimensional Scaling (MDS) analyses. The input of MDS analyses were Bray-Curtis similarity matrices generated using log $(x+1)$ transformed relative abundances data. The MDS analyses results in a two-dimensional plot where the distance between samples indicates the similarity of these samples relative to other samples in the plot. The accuracy of the two-dimensional representation is indicated by the "Stress" value (Kruskal's stress formula). Stress values $<0.1$ indicate a good ordination with no prospect of misleading interpretation. Stress values $<0.2$ still give a good two-dimensional representation where not too much reliance should be put on the detail. Theoretical aspects of the MDS analyses used are described by Clarke and Warwick (2001). One-way ANOSIM in PRIMER software test was used to compare samples between different scales (Clarke and Warwick, 1998). Data of the relative abundance of each band was log-transformed and analyzed using Statistica software package (Statistica version 9, StatSoft, Inc., Tulsa, USA), together with the qPCR results, and a number of defined environmental parameters. The distribution of bacterial abundance at different elevation levels and sampling scales was compared using ANOVA. Post hoc Tukey analysis was used to further compare the difference among samples. The relation between $\mathrm{Ga}-\mathrm{FeOB}$ and $\mathrm{MOB}$ was done using non-parametric pair wise correlation in Statistica.

To model the spatial structures of the total abundance of GaFeOB (logarithm of the total 16s rRNA gene copy number), MOB (logarithm of the total $p m o A$ gene copy number), and the moisture content (weight percentages) geostatistics were applied. These methods originate from mineralogy and soil science and are a common tool to identify and model spatial patterns (Legendre and Legendre, 1998). The basic principle is autocorrelation of spatial variability, i.e., close-set samples are more similar than those further apart (Ettema and Wardle, 2002). In a first step a variogram analysis was performed. In brief, semi-variances between samples were calculated and plotted against their spatial separation; the slope indicated whether a spatial structure is present or not (Ettema and Wardle, 2002). The Hawkins and Cressie's modulus estimator was calculated to create variograms and maximum likelihood (ML) estimations with Matérn covariance function was fitted to semi-variance values (Cressie, 1993). The estimated model parameters have been used for kriging. This is a geostatistical method to visualize spatial structures of properties by spatial interpolation maps (Ribeiro and Diggle, 2001). Before kriging, goodness of fit of the model parameters has been tested by cross validation. To 


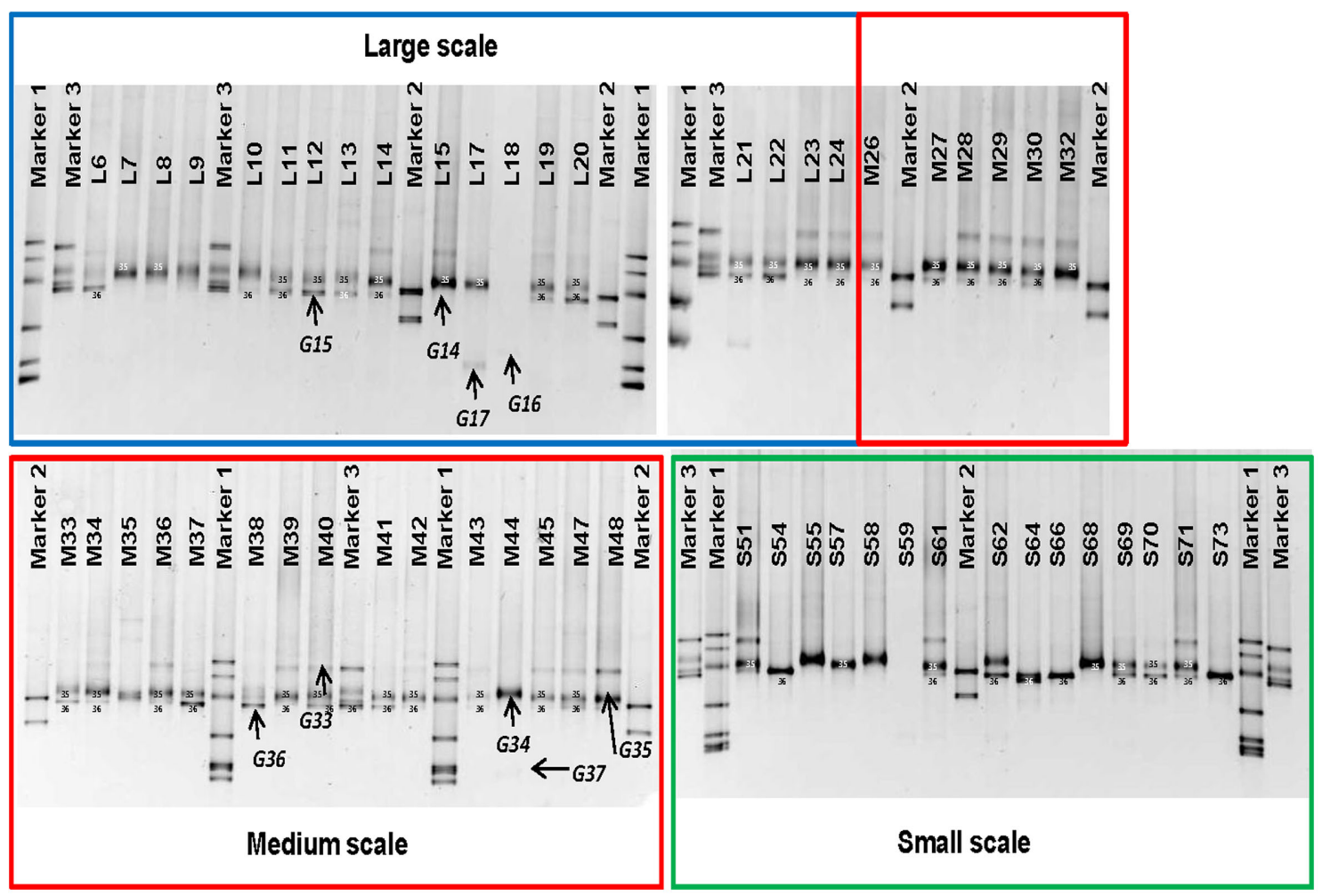

FIGURE 2 | DGGE patterns showing the distribution of iron-oxidizing bacteria at different sampling scales, which are indicated by colored boxes. Bands G14-G17 and G33-G37 were sequenced and shown in

Figure 4. Sequenced clones obtained previously were used as markers.
Marker1: MWE_C40(FJ391490), MWE_N41(FJ391496), MWE_N34(FJ391502), MWE_N13(FJ391501), MWE_N19(FJ391497), and MWE_N26(FJ391498), Marker2: Hc1(FJ391520), and Hc25(FJ391510), Marker3: Hc9(FJ391509), Hc37(FJ391515), Hc16 (FJ391516), and Hc8(FJ391513; Wang et al., 2009). create spatial interpolation maps of moisture content, Ga-FeOB, and MOB abundances we used ordinary kriging applying global neighborhood. All geostatistical analyses were performed using the geostatistical data analysis software geoR as implemented in the statistical software R (Ribeiro and Diggle, 2001; R Development Core Team, 2010).

\section{RESULTS}

\section{COMMUNITY STRUCTURE OF GALLIONELLA-RELATED FeOB}

Between one and four bands in each sample were retrieved from the DGGE gels (Figure 2). There is a trend toward fewer bands in the samples collected at the small scale. Taking the relative intensities of the bands as input matrix for multivariate analyses using multidimensional scaling showed that the Ga-FeOB community in samples taken from large and medium scales differed from the samples collected at small scale, but not from each other (Figure 3; ANOSIM analyses, $R=0.42$, large vs small, $R=0.43$ medium vs small). A total of nine bands were retrieved from the DGGE gels and sequenced. They were distantly related to known cultures, with uncultured clones as most close relatives (Figure 4). The most dominant band (G35, G14, Figure 2) from the medium-scale and large-scale samples was closely related to a recently isolated neutrophilic Ga-FeOB strain HDD (Wang, 2011). The most closely isolated relative to Band G37, G16, and G17 is Sideroxydans lithotrophicus strain LD-1 (Weiss et al., 2007), a microaerophilic iron-oxidizing bacterium. Bands G33 and G34 were most closely related to uncultured Gallionella-related clones Hc9 and Hc16, respectively (Figure 4) isolated from a freshwater wetland (Wang et al., 2009). G15 and G 36 are most closely related to Gallionella-related clones (Hc8) obtained from the same wetland (Wang et al., 2009).

\section{EFFECTS OF SPATIAL SCALE AND ELEVATION LEVEL ON THE ABUNDANCE AND DIVERSITY OF GALLIONELLA-RELATED FeOB AND MOB Spatial scale}

The abundance of Gallionella-related FeOB as determined by copy numbers of $16 \mathrm{~s}$ rRNA genes, ranged from $1 \times 10^{3}$ to $3.9 \times 10^{8}$ per gram dry soil. Five out of 23 medium-scale samples did not yield product in the qPCR analyses, indicating that their $16 \mathrm{~s}$ rRNA copy numbers were below the detection limit, and thus were excluded from the analyses. The highest copy number was observed in sample L20, taken in the high elevation part. The average copy numbers of the 16s rRNA gene from samples taken at large and medium scales, i.e., $4.6 \times 10^{7}$ and $3.7 \times 10^{7}$ copies per gram dry weight, respectively, were significantly higher than that of the small-scale samples $\left(5.4 \times 10^{6}\right.$ copies per gram dry weight; Figure 5A).

One-way ANOVA test indicated significant differences of Gallionella-related iron-oxidizing bacteria as well as methane oxidizers across spatial scales (Table 1). Post hoc Tukey test indicated that the abundance of both Ga-FeOB and MOB in samples 
taken at small scale was significantly lower than those at largeand medium-scale plots $(p<0.05)$. No difference was observed between large- and medium-scale samples.

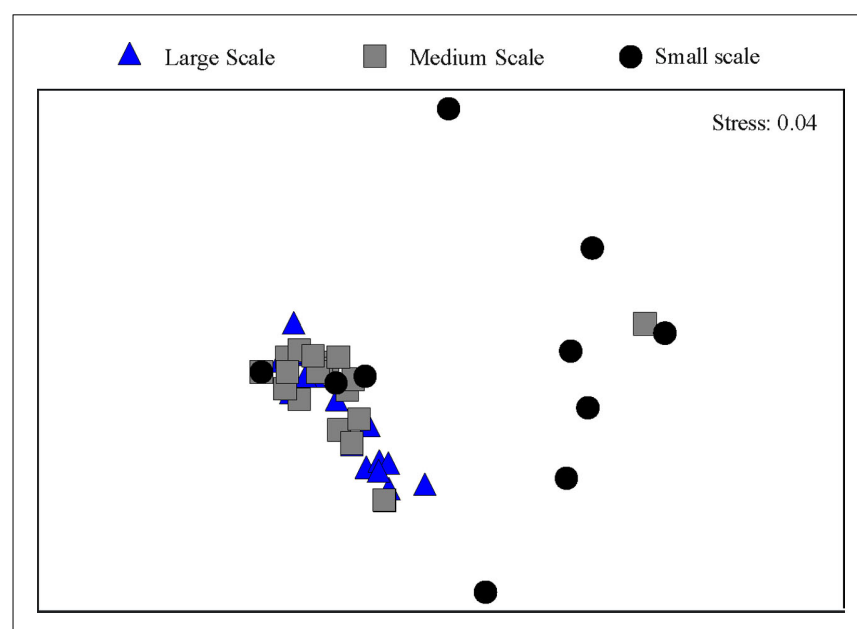

FIGURE 3 | Ordination by non-metric multidimensional scaling of log $(x+1)$ transformed relative abundance of the DGGE bands of the samples taken at different spatial scales.
At large- and medium-sampling scales, the total gene copy numbers of the different bacterial groups followed the sequence, $\mathrm{Ga}-\mathrm{FeOB}>\mathrm{MOB}$ type $\mathrm{II}>$ type $1 \mathrm{~b}>$ type Ia (Figure 5A). Significant differences were detected between all the groups except for type II and type Ib MOB. In the small-scale sampling plot, the abundance of MOB type Ia was significantly lower than in the rest of the samples (Figure 5A).

A diverse pattern of relative abundance of the bands retrieved from the DGGE gels was obtained. Among all the bands detected, band G35 and band G36 were the most abundant ones (Figure 2) off which G35 showed a similar trend to the average abundance detected using qPCR (Figure 6A). The relative abundance of band G35 dropped significantly at small-sampling scale as compared to large- and medium-scale samples whereas G36 did not. The rest of the bands did not show a clear trend given spatial level as a factor.

\section{Elevation level}

ANOVA analyses demonstrated that elevation significantly affected the numbers of FeOB and type I a MOB (Table 1). With the increase of elevation, the abundance of FeOB increased significantly (Figure 5B). Again in this case, the relative abundance of band G35 followed the same positive trend with increasing elevation which was not the case for G36 (Figure 6B). MOB showed a similar trend as the Ga-FeOB except for type Ia, which

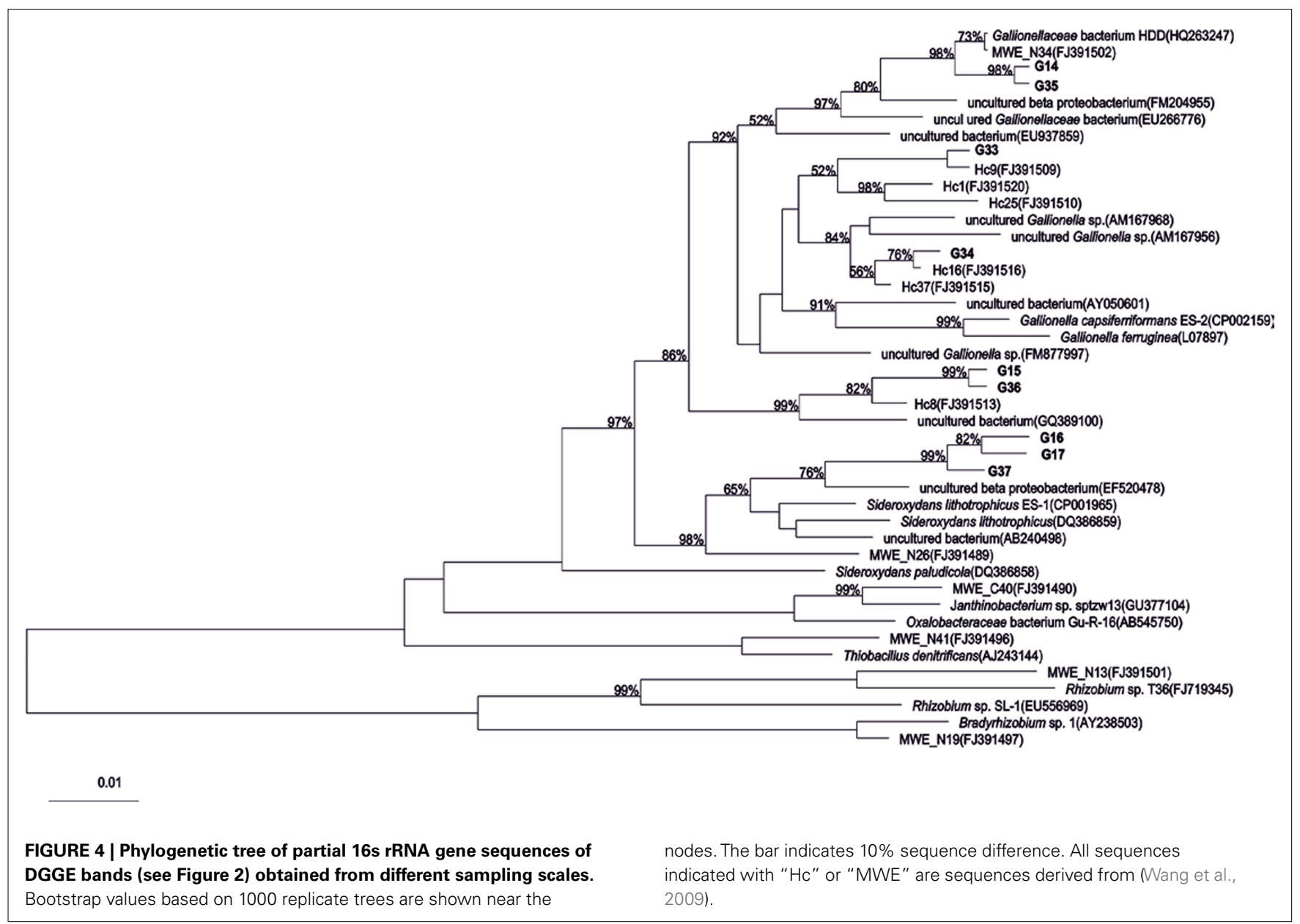




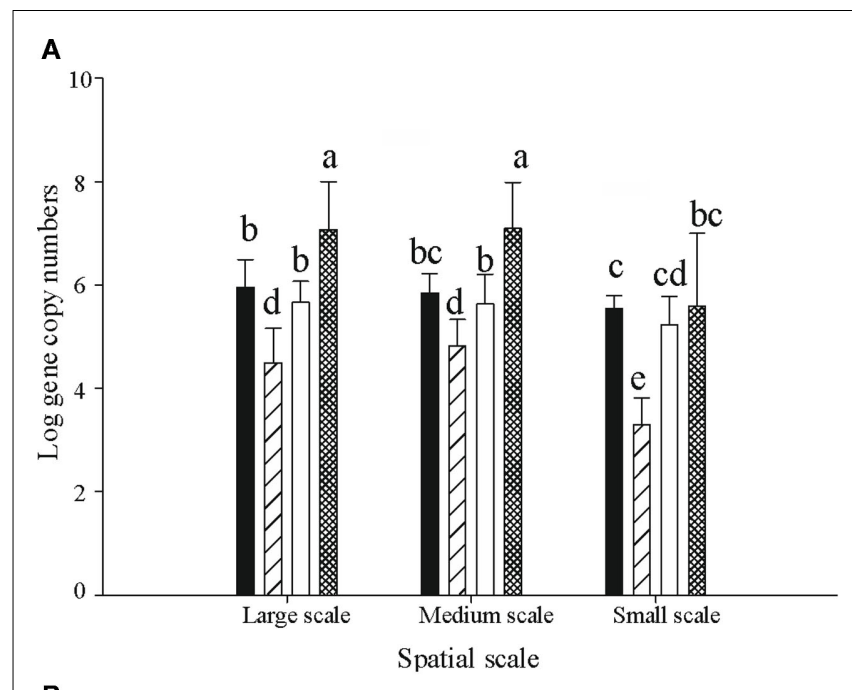

B

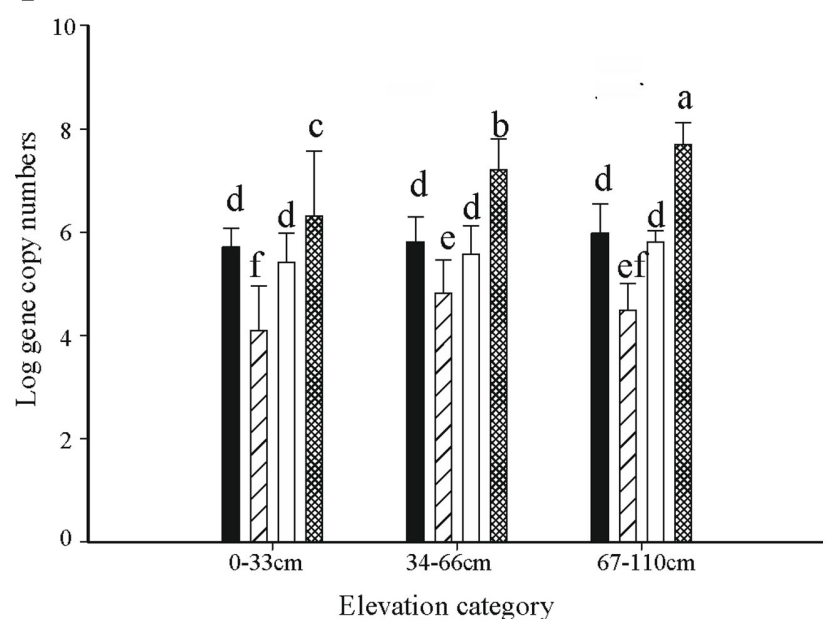

FIGURE 5 |The distribution of 16s rRNA copy numbers of Ga-FeOB and pmoA gene copy numbers of $M O B$ (both expressed per gram of dry soil) at different spatial scales (A) and elevation levels (B). Indicated are means \pm SD. Black bars depict type II, striped bars type la, and white bars type Ib MOB, while hatched bars show the Ga-FeOB. Different letters indicate significant differences $(p<0.01)$ between bars. For numbers of observations see footnote of Table 1

displayed maximum abundance in the intermediate elevation level (Figure 5B). There was a significant difference between the abundance of type Ia in samples taken from medium $(33-46 \mathrm{~cm})$ and low level $(0-33 \mathrm{~cm})$. No difference was observed among the abundance of other types of methane oxidizers along the elevation gradient.

The total 16s rRNA gene copy numbers detected for Ga-FeOB was much higher (10- to 100-fold) than the pmoA gene numbers of the different types of methane oxidizers at all elevation levels. The only reported 16s RNA copy numbers for iron-oxidizing genomes reported indicate two copies per genome (Fleming et al., 2011) while MOB generally have two to three copies of the $p m o A$ gene (Kolb et al., 2003) supporting the absolute dominance of Ga$\mathrm{FeOB}$ over MOB in terms of cell numbers. Overall, abundance of $\mathrm{Ga}-\mathrm{FeOB}$ and $\mathrm{MOB}$ of all three sub-types were positively correlated (Table 2).

\section{Spatial interpolation maps}

Interpolated maps revealed that $\mathrm{Ga}-\mathrm{FeOB}$ and $\mathrm{MOB}$ abundances display different spatial patterns (Figures 7B-E). While a gradient was observed in $\mathrm{Ga}-\mathrm{FeOB}$ and type I MOB abundances, type II MOB did not follow a gradient. A comparison between interpolated maps of soil moisture content and $\mathrm{Ga}-\mathrm{FeOB}$ abundance data indicated a negative correlation between these two factors (Figures 7A,B). This was confirmed by Spearman correlation analyses using only the measured data (Table 2). Similarly, type I MOB abundances (Figures 7A,C,D) indicated a negative correlation with moisture content which was supported by Spearman correlation (Table 2). Ga-FeOB and type Ib showed also the highest spatial dependencies (Table 3). Type Ib displayed a very similar distribution as $\mathrm{Ga}-\mathrm{FeOB}$ while type Ia abundance tends to be highest at intermediate elevations levels of the study site. Type II showed a distinctly deviating distribution (Figure 7E) which did also not correlate with moisture content (Table 2). Interestingly the lowest moisture content was observed not at the top of sampling plot, but to the side of the plot with the highest plant biomass (i.e., $0.56-1.12 \mathrm{~m}$ higher than the lowest point of the plot).

\section{DISCUSSION}

The present study gives insights into the spatial patterns of microbes involved in two important geochemical processes along a hydrological gradient. Ga-FeOB outnumber MOB but their abundance is positively correlated to various subgroups of $\mathrm{MOB}$, indicating that there are shared controlling environmental factors.

The strong increase in numbers of iron-oxidizing bacteria with elevation and the negative correlation with soil moisture content indicate that the hydrological gradient is one of the important environmental factors that control the distribution of the $\mathrm{Ga}$ $\mathrm{FeOB}$. However, the distribution of $\mathrm{Ga}-\mathrm{FeOB}$ in the present study was opposite to the distribution of $\mathrm{Ga}-\mathrm{FeOB}$ in a tidal freshwater marsh showing higher numbers in the regularly flooded, lower parts of the marsh compared to the higher parts (Wang et al., 2011). The strong relationship with $\mathrm{Fe}(\mathrm{III})$ availability and Ga$\mathrm{FeOB}$ abundance in the study of Wang et al. (2011) pointed to iron as the primary controlling factor, a fact recently also observed in drinking water distribution systems (Li et al., 2010). Although we did not measure iron availability at time of sampling in the present study, an earlier study at the same site showed that total Fe in these soils is around $5 \mathrm{ppm}$ (Conrad et al., 2008). This observation combined with the orders of magnitude higher numbers of $\mathrm{Ga}-\mathrm{FeOB}$ found as compared to the tidal freshwater marsh, indicates that iron availability was not limiting at the floodplain site. As soil moisture content decreases with elevation (Figure 7A), the availability, and penetration depth of oxygen into the soil likely increases also, which in itself should favor bacterial iron oxidation. However, when soil oxygenation increases, more ferrous iron may be consumed by chemical iron oxidation. A decrease in soil moisture content may also lead to less iron reduction, which consequently slows down the redox turnover of iron (Blothe and Roden, 2009). Together, this would lead to low ferrous iron supply, a key factor for iron-oxidizing activity. Apparently, the conditions also 
Table 1 | ANOVA analyses of effects of spatial factors and elevation on gene copy numbers of Ga-FeOB, type la, lb, and II MOB.

\begin{tabular}{|c|c|c|c|c|c|}
\hline Factor & sS & DF & MS & $F$ & $p$ \\
\hline \multicolumn{6}{|l|}{ SPATIAL } \\
\hline Ga-FeOB & 2.197 & 2 & 1.098 & 6.82 & 0.0019 \\
\hline Type la & 2.617 & 2 & 1.308 & 4.941 & 0.0099 \\
\hline Type lb & 15.045 & 2 & 7.522 & 7.550 & 0.0014 \\
\hline Type II & 0.615 & 2 & 0.307 & 1.670 & 0.1957 \\
\hline Type la & 5.9770 & 2 & 2.9885 & 5.152 & 0.0087 \\
\hline Type Ib & 1.361 & 2 & 0.680 & 2.400 & 0.0984 \\
\hline
\end{tabular}

$p$ Values in bold indicate statistically significant $(p<0.05)$ ANOVA F values and hence, significant effects of the variables on gene copy numbers. SS, sum of squares; DF, degrees of freedom; MS, mean square; F, ANOVA F statistic.

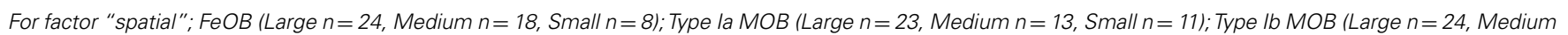

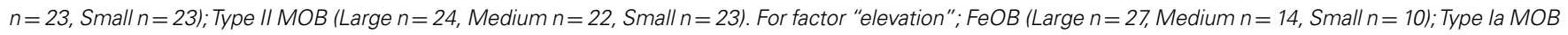
(Large $n=33$, Medium $n=17$, Small $n=10) ;$ Type Ib MOB (Large $n=40$, Medium $n=20$, Small $n=10) ;$ Type $/ /$ MOB $($ Large $n=42, M e d i u m n=20$, Small $n=10)$.

in the upper parts of the floodplain are such that oxygen and ferrous iron are both available and that $\mathrm{Ga}-\mathrm{FeOB}$ can compete with chemical oxidation.

All Ga-FeOB so far isolated are all lithotrophic obligatory aerobic bacteria which mainly are controlled by the availability of $\mathrm{Fe}_{2}^{+}$and $\mathrm{O}_{2}$ (Emerson et al., 2010). The dominant Ga-FeOB in this study (represented by band G35 and G36) display a clearly different distribution. G35 increases with elevation related to the lower water content and probably to the connected oxygen availability. The sequence is closely related to an isolate also derived from an irregular flooded riparian soil and tentatively called "Ferricurvibacter nieuwersluisensis”(Wang, 2011) which also grew in gradient tubes under microaerophilic conditions but also could tolerate exposure to higher amounts of oxygen (Wang, 2011). G36 did not display an elevation-related distribution in this irregular floodplain but is highly related to a sequence (Hc8 in Figure 2) which was the most dominant one in a tidal marsh, where it also correlated positively with iron availability (Wang, 2011). Although, we have no physiological data to support any firm conclusions regarding environmental control, it seems that within the GaFeOB there is habitat preference and niche differentiation likely related to the local regimes of $\mathrm{O}_{2}$ and or $\mathrm{Fe}_{2}^{+}$availability. Considering the limited number of isolates and lack of physiological knowledge of these isolates, it would be too speculative to discuss other environmental controls. However, considering the phylogenetic diversity in the proposed order Gallionellales (Emerson et al., 2010; Figure 4) it can be expected that behind the sequences there will be microbes with a broader metabolic repertoire and different oxygen tolerances than isolated so far, offering explanations for the environmental patterns observed in various environments.

The irregular flooded riparian floodplain studied and the tidal marsh investigated in a previous study (Wang et al., 2011) were very similar in terms of $\mathrm{Ga}-\mathrm{FeOB}$ community composition but differed markedly in Ga-FeOB abundance Although the primers are targeting Gallionella-related FeOB only, the range of different sequence types or strains potentially detected by the primers used is much higher than detected in both studies (Wang et al., 2009) rendering it unlikely that the resemblance is due to a primer bias. This leads to the conclusion that physico-chemical conditions at the irregularly flooded site are better for performance of the dominant $\mathrm{Ga}-\mathrm{FeOB}$ at that site. The alternative explanation would be that competition with other microbes and processes is more intense in the tidal freshwater marsh.

According to thermodynamics (Thauer et al., 1977; Sobolev and Roden, 2002), the oxidation processes should follow the order of ferrous iron $>$ methane $>$ sulfide $>$ ammonium oxidation under conditions of oxygen limitation. It has been suggested by Neubauer et al. (2002) that neutrophilic Fe(II)-oxidizing bacteria may compete for limiting amounts of $\mathrm{O}_{2}$ in the rhizosphere and therefore influence other wetland biogeochemical cycles. van Bodegom et al. (2001b) also reported that iron oxidation was the most important oxidative process in a rice paddy rhizosphere and accounted initially for $97 \%$ of the consumed oxygen using a detailed mechanistic model (van Bodegom et al., 2001a). However, in an accompanying study these authors did not detect iron oxidizers by means of traditional cultivation-dependent most probable number counts and concluded that this oxidation was mainly chemical and that microbial iron oxidation was negligible (van Bodegom et al., 2001b). However, in our irregularly flooded site the Ga-FeOB outnumber the various groups of MOB yielding the first experimental evidence suggesting that on microbial population level microbial iron oxidation can prevail over methane consumption and that chemical iron oxidation may not be as dominant as assumed. We have to bear in mind though that this conclusion is based on DNA-based abundance assessment and not on measured processes.

The recent isolation and genomic description of a marine neutrophilic iron oxidizer provided evidence for the microaerophilic nature and high affinity for oxygen of $\mathrm{FeOB}$, which would enable them to be active at lower oxygen concentrations than chemical oxidation and methane oxidizers can (Singer et al., 2011). However, there are no clues to the extent to which this information can be extrapolated to freshwater wetlands. The recent 

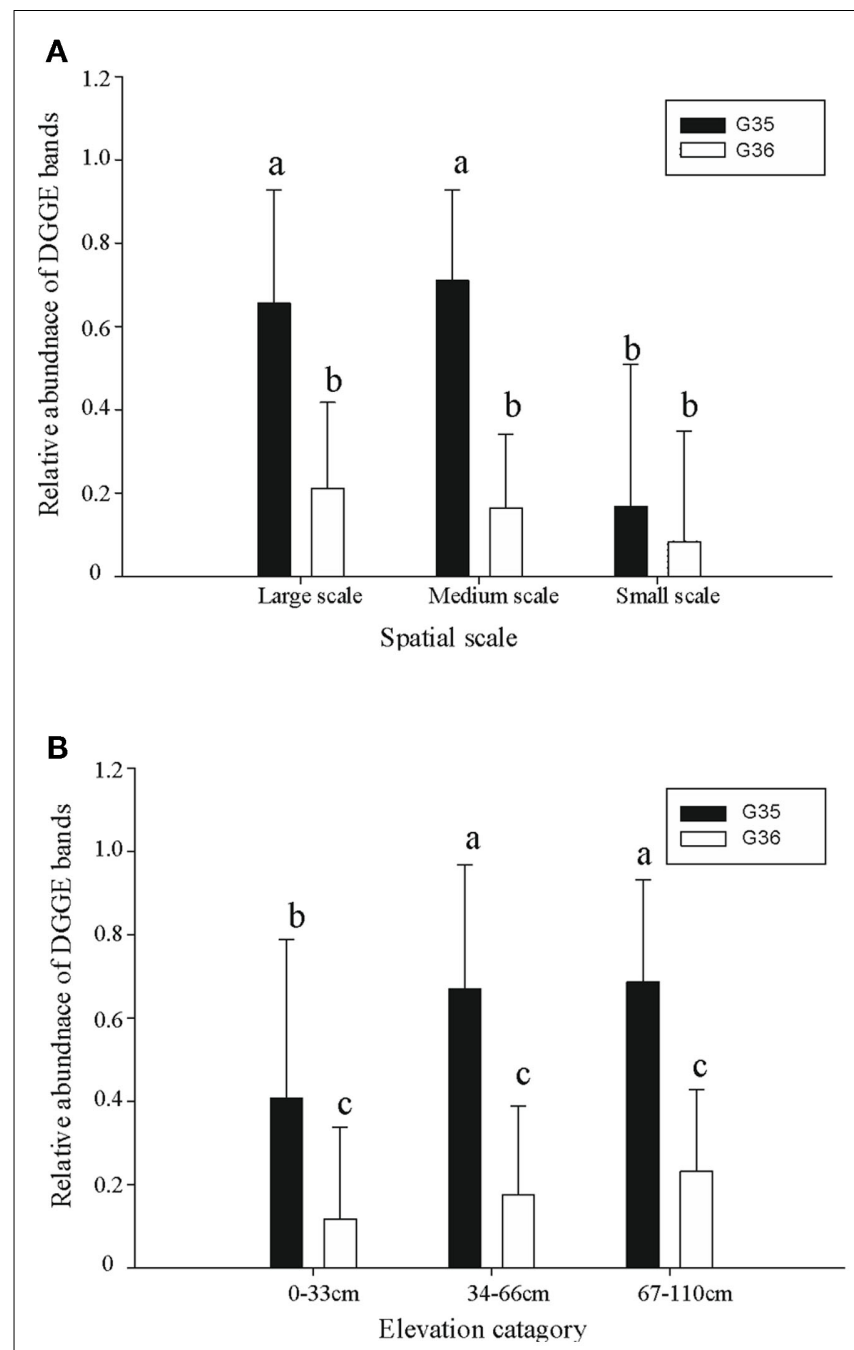

FIGURE 6 |The relative abundance of two dominant Ga-FeOB DGGE bands at different spatial scales $(A)$ and elevation levels (B). Indicated are means $\pm S D$. Different letters indicate significant differences $(p<0.01)$ between bars. For factor "spatial" number of observations is $n=18$ (Large), $n=22$ (Medium), $n=14$ (Small) while for factor "elevation" this is $n=25$ (Large), $n=19$ (Medium), $n=10$ (Small).

development of a cultivation-independent molecular detection assay allows for the reliably revealing of $\mathrm{Ga}-\mathrm{FeOB}$ in environmental settings (Wang et al., 2009; Li et al., 2010) and the ability to relate their distribution to that of other microbes and chemical oxidation processes. The strong correlation we find in this study between the abundance of Ga-FeOB and some of the MOB indicates similar controlling factors, comparable competitive abilities or both. The scarce culture information of FeOB shows that neutrophilic obligate FeOB (Weiss et al., 2007) have similar growth rates as compared to methanotrophs (Dedysh et al., 2007; Belova et al., 2011). However, growth rates under environmental conditions can be quite different from optimal conditions in cultures (Mohanty et al., 2006; Steenbergh et al., 2010) and thus the interactions and competitive abilities of $\mathrm{FeOB}$ and $\mathrm{MOB}$ have to be verified under environmental conditions.
Alternative to the ability to compete with $\mathrm{MOB}$, the dominance of FeOB over MOB may also be caused indirectly due to suppression of methanogenesis caused by substrate competition with iron reducers. Hence, sub-optimal methane supply would restrict the activities of MOB. The lag in methanogenic activity as measured in methane production assays on this site in an earlier study points into that direction (Kemnitz et al., 2004). Methane flux measurements executed on the same day as sampling was done in this study yielded values ranging from methane uptake $(24 \mathrm{mg}$ $\mathrm{CH}_{4} \mathrm{~m}^{-1}$ /day) to net emission (180 $\mathrm{mg} \mathrm{CH}_{4} \mathrm{~m}^{-1}$ /day; data not shown). This highly variable emission, with negative values and values even in the range of rice fields does not allow for conclusive statements toward methane availability for MOB. However, earlier studies on this site demonstrated immediate in vitro methane consumption displaying rates in the range of high methane habitats (Steenbergh et al., 2010; Bodelier et al., 2012) suggesting continuous methane availability for MOB. It will require more detailed studies, monitoring soil iron $\left(\mathrm{Fe}^{2+}, \mathrm{Fe}^{3+}\right)$ as well as methane availability in parallel to $\mathrm{FeOB}$ and $\mathrm{MOB}$ community assessments to obtain supporting evidence for "competitive ability" or the "substrate limitation" hypotheses.

In contrast to the distribution based on the measured points only, spatial interpolation maps of Ga-FeOB and MOB abundances reveal that $\mathrm{Ga}-\mathrm{FeOB}$ and type $\mathrm{Ib} \mathrm{MOB}$ display spatial autocorrelation which reflects the underlying hydrological gradient (i.e., combined effects of moisture content and elevation; Figure 7). Type Ia and II MOB displayed a distribution not spatially correlated to the hydrological gradient, with type Ia displaying highest abundances at intermediate moisture and type II showing a patchy distribution over the entire gradient. This differential distribution may be related to the different ecological "strategies" described for the various types of MOB (Steenbergh et al., 2010) with the fast-growing, responsive MOB (i.e., type Ia) abundant where substrates are available and type II occupying patches where survival of periods without substrate is required. A very similar spatial distribution of type II and type Ia MOB was found in a hydrological gradient in a littoral zone of a freshwater lake (Siljanen et al., 2011) supporting niche differentiation of $\mathrm{MOB}$ with respect to hydrology-associated environmental factors. In the study of Siljanen et al., type Ib also displayed a strong spatial autocorrelation with the hydrological gradient, but in contrast to the present study a positive relationship was found with moisture content. This can be explained by the fact that what is assigned as type Ib MOB contains uncultured as well as cultured representatives with quite different characteristics as might be concluded from their original habitats (Lüke et al., 2010; Semrau et al., 2010). Hence, interpreting the similarity between the distribution of type $\mathrm{Ib}$ and $\mathrm{Ga}-\mathrm{FeOB}$ in our irregularly flooded riparian site as being groups that have similar ecological characteristics, would be rather speculative. The most likely explanation for the strong cooccurrence is the common dependence on oxic-anoxic interfaces and microaerophilic conditions, which $\mathrm{Ga}-\mathrm{FeOB}$ require to compete successfully with chemical oxidation(Emerson et al., 2010) and to ensure the availability of $\mathrm{O}_{2}, \mathrm{Fe}^{2+}$, and methane. Additional support for common ecological niches comes from the fact that type Ib MOB are abundant members of the MOB community in rice field soils (Lüke et al., 2010; Ho et al., 2011), a habitat 
Table 2 | Spearman rank correlation table of measured environmental parameters and gene copy numbers of Ga-FeOB and type la, lb, and II MOB.

\begin{tabular}{|c|c|c|c|c|c|c|c|}
\hline & Elevation & Moisture (\%) & Organic matter & WFPS & Type la & Type lb & Type II \\
\hline \multicolumn{8}{|l|}{ Elevation } \\
\hline Moisture (\%) & -0.54 & & & & & & \\
\hline WFPS & -0.28 & 0.14 & 0.03 & & & & \\
\hline Type la & 0.24 & -0.38 & -0.16 & -0.33 & & & \\
\hline $\mathrm{FeOB}$ & 0.52 & -0.44 & -0.20 & 0.29 & 0.58 & 0.63 & 0.59 \\
\hline
\end{tabular}

Values in bold are statistically different $(p<0.05)$.

WFPS, water filled pore space.

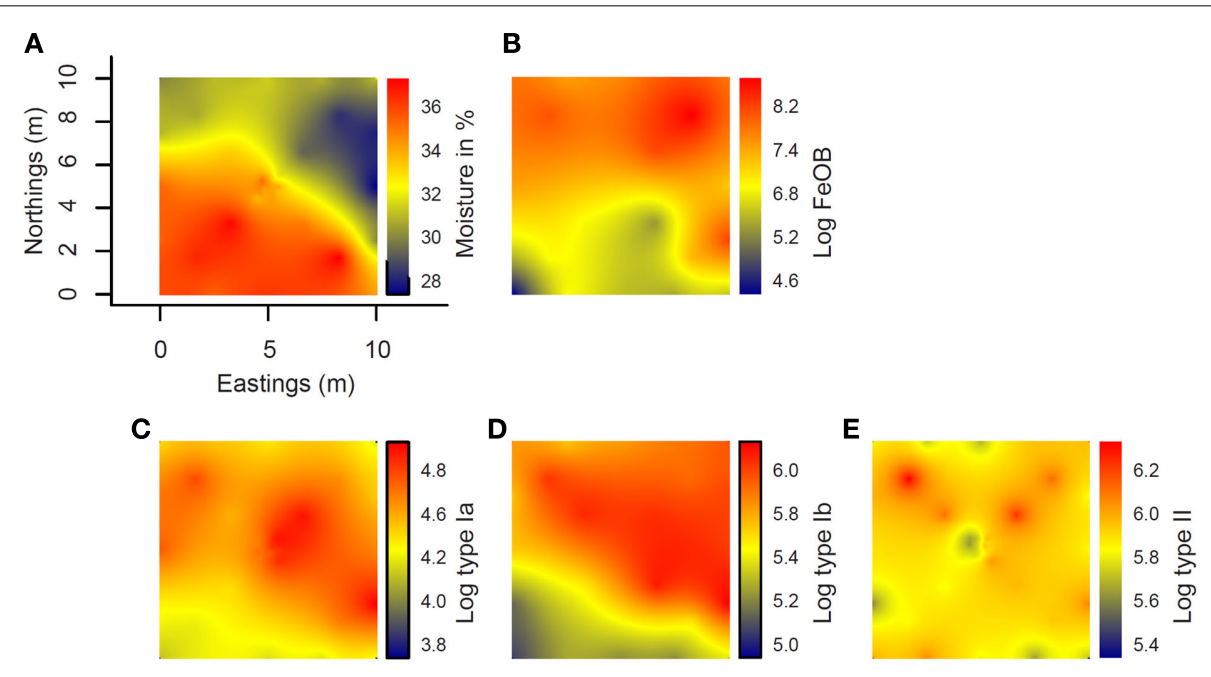

FIGURE 7 | Spatial interpolation maps (kriging maps) of the distribution at the study site of moisture content $(A)$ and log-transformed gene copy number from Ga-FeOB specific qPCR (B), type la (C), type lb (D), and type
II methanotrophs specific qPCRs (E). Color bar to the right of each map indicates extrapolated values of either moisture content or log-transformed gene copy number values.
Table 3 | Parameters for geostatistical analysis of log-transformed qPCR data of $\mathrm{FeOB}$ and MOB taxa and percentage of moisture content.

\begin{tabular}{llllc}
\hline Parameter & Nugget & Sill & $\begin{array}{l}\text { Spatial } \\
\text { dependence }\end{array}$ & $\begin{array}{l}\boldsymbol{p} \text {-Range (m) } \\
\boldsymbol{p}<\mathbf{0 . 0 5}\end{array}$ \\
\hline Moisture & 1.856 & 6.514 & 0.71 & 5.38 \\
FeOB & None & 0.922 & 1.00 & 12.57 \\
Type la & 0.261 & 0.396 & 0.34 & 6.34 \\
Type Ib & 0.047 & 0.179 & 0.74 & 14.78 \\
Type II & 0.148 & 0.218 & 0.32 & 2.07
\end{tabular}

The nugget quantifies the amount of variability at distance of zero, the sill is the value where the variogram levels off, the spatial dependence indicates the proportion of variability of the data that was modeled, the practical range (p-range) equal to the distance at which $95 \%$ of the sill has been reached.

which is very similar to the studied floodplain soil (Conrad et al., 2008).
A striking phenomenon in our study was the clear deviating Ga-FeOB and MOB abundances at the small (i.e., cm) scale. For type $\mathrm{Ia} \mathrm{MOB}$ and the $\mathrm{FeOB}$, gene copies were below detection limit in a large number of samples (Typ Ia 11 out 23, FeOB 17 out 23), but also for type Ib as well as type II the abundances were generally significantly lower. Siljanen et al. (2011) observed much less spatial structure and variance at the $\mathrm{cm}$ scale within a littoral hydrological gradient than at a larger scale. Abundance is obviously affected by small scale differences, disconnected from the large-scale environmental gradient. The only measured variables that deviated in small scale plot are moisture and organic matter contents, which are both significantly higher in the small scale samples. The combination of these factors can put constraints on the availability of oxygen by a more intense competition with heterotrophs (van Bodegom et al., 2001b). Nevertheless, the lack of direct experimental evidence for competitive interactions between heterotrophs, $\mathrm{Ga}-\mathrm{FeOB}$, and $\mathrm{MOB}$ renders every explanation speculative. Fact is though that the observed local deviations in diversity and abundance of Ga-FeOB and MOB would have 
gone unnoticed in a more coarse sampling design along with the useful ecological information associated to it. Other authors have observed clear spatial patterns in response to agricultural management on meter scales (Philippot et al., 2009a,b; Wessen et al., 2011) using geostatistical approaches. It would be exciting to see whether the generalizations derived from these latter sampling schemes would hold when small scale assessments would have been executed.

Besides the variation between sampling scales there is also large variation in gene abundance over several orders of magnitude between samples from the same sampling scale, even when $\mathrm{cm}$ apart. This holds both true for Ga-FeOB as well as MOB. Hence, the possible solutions for the observed variability should come from factors affecting both groups of microbes. Considering the conflicting aspects of $\mathrm{Fe}$ (III) and methane availability (i.e., competition of methanogens and iron reducers), oxygen would be the most likely factor affecting both the distribution of Ga-FeOB and MOB. The sampled floodplain soil consists of heavy clay which has already limited air penetration that can even be worse when the soil is compacted. The latter has been show to influence methane oxidation in soil (Dalal et al., 2008; Gebert et al., 2011.). In this floodplain this can both be caused by the floodwater itself but also by trampling of the cows which are present in this area for nature management purposes. This would lead to a highly irregular pattern of compacted parts of the soil where possibilities for growth and activity for aerobes are very limited. The higher number of samples below the detection limit in the $20 \mathrm{~cm} \times 20 \mathrm{~cm}$ plot may be simply because due to the size of cores taken, the whole surface area was samples and hence, the chance of hitting these "cold spots" is simply higher as compared to the large- and medium-scale samples.

Hence, heterogeneity of physico-chemical conditions and associated substrate availability may one part of the explanation.

\section{REFERENCES}

Armstrong, W. (1964). Oxygen diffusion from roots of some British bog plants. Nature 204, 801.

Baker, K. L., Langenheder, S., Nicol, G. W., Ricketts, D., Killham, K., Campbell, C. D., and Prosser, J. I. (2009). Environmental and spatial characterisation of bacterial community composition in soil to inform sampling strategies. Soil Biol. Biochem. 41, 2292-2298.

Belova, S. E., Baani, M., Suzina, N. E., Bodelier, P. L. E., Liesack, W., and Dedysh, S. N. (2011). Acetate utilization as a survival strategy of peatinhabiting Methylocystis spp. Environ. Microbiol. Rep. 3, 36-46.

Blothe, M., and Roden, E. E. (2009). Microbial iron redox cycling in a circumneutral-pH groundwater seep. Appl. Environ. Microbiol. 75, 468-473.

Bodelier, P. L. E. (2011). Interactions between nitrogenous fertilizers and methane cycling in wetland and upland soils.
Curr. Opin. Environ. Sustain. 3, 379-388.

Bodelier, P. L. E., Bar-Gilissen, M. J., Meima-Franke, M., and Hordijk, K. (2012). Structural and functional response of methane-consuming microbial communities to different flooding regimes in riparian soils. Ecol. Evol. 2, 106-127.

Bodelier, P. L. E., Frenzel, P., Drake, H. L., Hurek, T., Kusel, K., Lovell, C., Megonigal, P., Reinhold-Hurek, B., and Sorrell, B. (2006). "Ecological aspects of microbes and microbial communities inhabiting the rhizosphere of wetland plants," in Wetlands and Natural Resource Management, eds. J. T. A. Verheven, B. Beltman, R. Bobbink, and D. F. Whigham (Berlin: Springer), 205-238.

Burgin, A. J., Yang, W. H., Hamilton, S. K., and Silver, W. L. (2011). Beyond carbon and nitrogen: how the microbial energy economy couples elemental cycles in diverse ecosystems. Front. Ecol. Environ. 9, 44-52.

The physics of the soil may also influence biological factors like predation by protozoa (Ranjard and Richaume, 2001). The compaction may lead to a heterogenous pattern of soil space inaccessible for protozoa, leading to locally higher numbers of $\mathrm{Ga}-\mathrm{FeOB}$ and MOB. However, since we have no detailed information on soil-macro and microstructure for the respective samples the explanations offered will remain speculative.

\section{CONCLUSION}

Gallionella-related neutrophilic iron-oxidizing bacteria are abundant throughout the studied riparian floodplain, their distribution reflecting the hydrological gradient. They outnumber various groups of methane oxidizers, demonstrating that FeOB are both able to compete for oxygen with methanotrophs as well as with chemical iron oxidation. The spatial distribution of Ga-FeOB resembles the distribution of type $\mathrm{Ib} \mathrm{MOB}$, whereas it deviates from those of type Ia and type II MOB pointing to the fact only one MOB subgroup has similar ecological strategies to Ga-FeOB. Abundances of $\mathrm{Ga}-\mathrm{FeOB}$ as well as $\mathrm{MOB}$ differed significantly from larger scales when sampled on cm scale demonstrating common local limiting factors, which may indicate environmental boundaries for growth of $\mathrm{Ga}-\mathrm{FeOB}$ and MOB.

\section{ACKNOWLEDGMENTS}

The authors would like to thank Foundation "De Ark" for permitting us to take samples at "Ewijkse Waard." This study was part of the ESF-Eurodiversity program (ERAS-CT-2003-98049, 6th EU-framework program) and was financially supported by grants from the Netherlands Organization for Scientific Research (NWO; Grant no. 855.01.108) as by and by the Netherlands Darwin Center for Biogeology (grants 142.16.1031 and 142.16.1032). This publication is publication nr5218 of the Netherlands Institute of Ecology (NIOO-KNAW).

Chan, C. S., Fakra, S. C., Edwards, D. C., Emerson, D., and Banfield, J. F. (2009). Iron oxyhydroxide mineralization on microbial extracellular polysaccharides. Geochim. Cosmochim. Acta 73, 3807-3818.

Clarke, K. R., and Warwick, R. M. (1998). Quantifying structural redundancy in ecological communities. Oecologia 113, 278-289.

Clarke, K. R., and Warwick, R. M. (2001). A further biodiversity index applicable to species lists: variation in taxonomic distinctness. Mar. Ecol. Prog. Ser. 216, 265-278.

Coci, M., Riechmann, D., Bodelier, P. L. E., Stefani, S., Zwart, G., and Laanbroek, H. J. (2005). Effect of salinity on temporal and spatial dynamics of ammonia-oxidising bacteria from intertidal freshwater sediment. FEMS Microbiol. Ecol. 53, 359-368.

Conrad, R. (2007). Microbial ecology of methanogens and methanotrophs. Adv. Agron. 96, 1-63.
Conrad, R., Klose, M., Noll, M., Kemnitz, D., and Bodelier, P. L. E. (2008). Soil type links microbial colonization of rice roots to methane emission. Glob. Chang. Biol. 14, 657-669.

Cressie, N. A. C. (1993). Statistics for Spatial Data. New York: John Wiley \& Sons.

Dalal, R. C., Allen, D. E., Livesley, S. J., and Richards, G. (2008) Magnitude and biophysical regulators of methane emission and consumption in the Australian agricultural, forest, and submerged landscapes: a review. Plant Soil 309, 43-76.

Dedysh, S. N., Belova, S. E., Bodelier, P. L. E., Smirnova, K. V., Khmelenina, V. N., Chidthaisong, A., Trotsenko, Y. A., Liesack, W., and Dunfield, P. F. (2007). Methylocystis heyeri sp nov., a novel type II methanotrophic bacterium possessing "signature" fatty acids of type I methanotrophs. Int. J. Syst. Evol. Microbiol. 57, 472-479. 
Doyle, M. O., and Otte, M. L. (1997). Organism-induced accumulation of iron, zinc and arsenic in wetland soils. Environ. Pollut. 96, 1-11.

Emerson, D., Fleming, E. J., and McBeth, J. M. (2010). Iron-oxidizing bacteria: an environmental and genomic perspective. Annu. Rev. Microbiol. 64, 561-583.

Emerson, D., and Moyer, C. (1997). Isolation and characterization of novel iron-oxidizing bacteria that grow at circumneutral pH. Appl. Environ. Microbiol. 63, 4784-4792.

Ettema, C. H., and Wardle, D. A. (2002). Spatial soil ecology. Trends Ecol. Evol. (Amst.) 17, 177-183.

Ferreira, T. O., Otero, X. L., De Souza, V. S., Vidal-Torrado, P., Macias, F., and Firme, L. P. (2010). Spatial patterns of soil attributes and components in a mangrove system in Southeast Brazil (Sao Paulo). J. Soils Sediments 10, 995-1006.

Fleming, E. J., Langdon, A. E., MartinezGarcia, M., Stepanauskas, R., Poulton, N. J., Masland, E. D. P., and Emerson, D. (2011). What's new is old: resolving the Identity of Leptothrix ochracea using single cell genomics, pyrosequencing and FISH. PLOS ONE 6, el7769. doi:10.1371/journal.pone.0017769

Fortin, D., and Langley, S. (2005). Formation and occurrence of biogenic iron-rich minerals. Earth Sci. Rev. 72, 1-19.

Franklin, R. B., and Mills, A. L. (2003). Multi-scale variation in spatial heterogeneity for microbial community structure in an eastern Virginia agricultural field. FEMS Microbiol. Ecol. 44, 335-346.

Gebert, J., Groengroeft, A., and Pfeiffer, E. M. (2011). Relevance of soil physical properties for the microbial oxidation of methane in landfill covers. Soil Biol. Biochem. 43, 1759-1767.

Gutknecht, J. L. M., Goodman, R. M., and Balser, T. C. (2006). Linking soil process and microbial ecology in freshwater wetland ecosystems. Plant Soil 289, 17-34.

Hartman, W. H., Richardson, C. J., Vilgalys, R., and Bruland, G. L. (2008). Environmental and anthropogenic controls over bacterial communities in wetland soils. Proc. Natl. Acad. Sci. U.S.A. 105, 17842-17847.

Ho, A., Lüke, C., and Frenzel, P. (2011). Recovery of methanotrophs from disturbance: population dynamics, evenness and functioning. ISME J. 5, 750-758.

Kemnitz, D., Chin, K. J., Bodelier, P., and Conrad, R. (2004). Community analysis of methanogenic archaea within a riparian flooding gradient. Environ. Microbiol. 6, 449-461.

Kogel-Knabner, I., Amelung, W., Cao, Z. H., Fiedler, S., Frenzel, P., Jahn, R., Kalbitz, K., Kolbl, A., and Schloter, M. (2010). Biogeochemistry of paddy soils. Geoderma 157, $1-14$.

Kolb, S., Knief, C., Stubner, S., and Conrad, R. (2003). Quantitative detection of methanotrophs in soil by novel pmoA-targeted real-time PCR assays. Appl. Environ. Microbiol. 69, 2423-2429.

Laanbroek, H. J. (2010). Methane emission from natural wetlands: interplay between emergent macrophytes and soil microbial processes. A minireview. Ann. Bot. 105, 141-153.

Legendre, P., and Legendre, L. (1998). Numerical Ecology. Amsterdam: Elsevier.

Li, D., Li, Z., Yu, J., Cao, N., Liu, R., and Yang, M. (2010). Characterization of bacterial community structure in a drinking water distribution system during an occurrence of Red Water. Appl. Environ. Microbiol. 76, 7171-7180.

Lovley, D. R. (1997). Microbial Fe(III) reduction in subsurface environments. FEMS Microbiol. Rev. 20, 305-313.

Ludwig, W., Strunk, O., Westram, R., Richter, L., Meier, H., Yadhukumar, Buchner, A., Lai, T., Steppi, S., Jobb, G., Forster, W., Brettske, I., Gerber, S., Ginhart, A. W., Gross, O., Grumann, S., Hermann, S., Jost, R., Konig, A., Liss, T., Lussmann, R., May, M., Nonhoff, B., Reichel, B., Strehlow, R., Stamatakis, A., Stuckmann, N., Vilbig, A., Lenke, M., Ludwig, T., Bode, A., and Schleifer, K. H. (2004). ARB: a software environment for sequence data. Nucleic Acids Res. 32, 1363-1371.

Lüke, C., and Frenzel, P. (2011). Potential of pmoA amplicon pyrosequencing for methanotroph diversity studies. Appl. Environ. Microbiol. 77, 6305-6309.

Lüke, C., Krause, S., Cavigiolo, S., Greppi, D., Lupotto, E., and Frenzel, P. (2010). Biogeography of wetland rice methanotrophs. Environ. Microbiol. 12, 862-872.

Mermillod-Blondin, F., and Lemoine, D. G. (2010). Ecosystem engineering by tubificid worms stimulates macrophyte growth in poorly oxygenated wetland sediments. Funct. Ecol. 24, 444-453.

Mohanty, S. R., Bodelier, P. L. E., Floris, V., and Conrad, R. (2006). Differential effects of nitrogenous fertilizers on methane-consuming microbes in rice field and forest soils. Appl. Environ. Microbiol. 72, 1346-1354.

Muyzer, G., Dewaal, E. C., and Uitterlinden, A. G. (1993). Profiling of complex microbialpopulations by denaturing gradient gel-electrophoresis analysis of polymerase chain reaction-amplified genes-coding for $16 \mathrm{~s}$ ribosomalRNA. Appl. Environ. Microbiol. 59, 695-700.

Neubauer, S. C., Emerson, D., and Megonigal, J. P. (2002). Life at the energetic edge: kinetics of circumneutral iron oxidation by lithotrophic iron-oxidizing bacteria isolated from the wetland-plant rhizosphere. Appl. Environ. Microbiol. 68, 3988-3995.

Neubauer, S. C., Toledo-Duran, G. E., Emerson, D., and Megonigal, J. P. (2007). Returning to their roots: iron-oxidizing bacteria enhance short-term plaque formation in the wetland-plant rhizosphere. Geomicrobiol. J. 24 65-73.

Op den Camp, H. J. M., Islam, T. Stott, M. B., Harhangi, H. R., Hynes, A., Schouten, S., Jetten, M. S. M., Birkeland, N. K., Pol, A., and Dunfield, P. F. (2009). Environmental, genomic and taxonomic perspectives on methanotrophic Verrucomicrobia. Environ. Microbiol. Rep. 1, 293-306.

Pan, Y., Bodrossy, L., Frenzel, P., Hestnes, A., Krause, S. B. M., Lüke, C., MeimaFranke, M., Siljanen, H., Svenning, M. M., and Bodelier, P. L. E. (2010). Impacts of inter- and intralaboratory variations on the reproducibility of microbial community analyses. Appl. Environ. Microbiol. 76, 7451-7458.

Philippot, L., Bru, D., Saby, N. P. A., Cuhel, J., Arrouays, D., Simek, M., and Hallin, S. (2009a). Spatial patterns of bacterial taxa in nature reflect ecological traits of deep branches of the 16S rRNA bacterial tree. Environ. Microbiol. 11, 3096-3104.

Philippot, L., Cuhel, J., Saby, N. P. A., Cheneby, D., Chronakova, A., Bru, D., Arrouays, D., Martin-Laurent, F., and Simek, M. (2009b). Mapping field-scale spatial patterns of size and activity of the denitrifier community. Environ. Microbiol. 11 1518-1526.

Ranjard, L., and Richaume, A. S. (2001). Quantitative and qualitative microscale distribution of bacteria in soil. Res. Microbiol. 152, 707-716.

R Development Core Team. (2010). $R: \quad a$ Language and Environment for Statistical Computing. ver. 2.11.1. Available at: http://cran.r-project.org/

Ribeiro, J. R., and Diggle, P. J. (2001). geoR: a package for geostatistical analysis. R. J. 1, 1609-3631.

Ringeval, B., Friedlingstein, P., Koven, C., Ciais, P., De Noblet-Ducoudre, N., Decharme, B., and Cadule, P. (2011). Climate- $\mathrm{CH}_{4}$ feedback from wetlands and its interaction with the climate- $\mathrm{CO}_{2}$ feedback. Biogeosciences 8, 2137-2157.

Schäfer, H., Bernard, L., Courties, C., Lebaron, P., Servais, P., Pukall, R., Stackebrandt, E., Troussellier, M., Guindulain, T., Vives-Rego, J., and Muyzer, G. (2001). Microbial community dynamics in Mediterranean nutrient-enriched seawater mesocosms: changes in the genetic diversity of bacterial populations. FEMS Microbiol. Ecol. 34, 243-253.

Semrau, J. D., Dispirito, A. A., and Yoon, S. (2010). Methanotrophs and copper. FEMS Microbiol. Rev. 34, 496-531.

Siljanen, H. M. P., Saari, A., Krause, S., Lensu, A., Abell, G. C. J., Bodrossy, L., Bodelier, P. L. E., and Martikainen, P. J. (2011). Hydrology is reflected in the functioning and community composition of methanotrophs in the littoral wetland of a boreal lake. FEMS Microbiol. Ecol. 75, 430-445.

Singer, E., Emerson, D., Webb, E. A., Barco, R. A., Kuenen, J. G., Nelson, W. C., Chan, C. S., Comolli, L. R., Ferriera, S., Johnson, J., Heidelberg, J. F., and Edwards, K. J. (2011). Mariprofundus ferrooxydans PV-1 the first genome of a marine $\mathrm{Fe}$ (II) oxidizing Zetaproteobacterium. PLoS ONE 6, e25386. doi:10.1371/journal.pone.0025386

Sobolev, D., and Roden, E. E. (2002) Evidence for rapid microscale bacterial redox cycling of iron in circumneutral environments. Antonie Van Leeuwenhoek 81, 587-597.

Steenbergh, A. K., Meima, M. M., Kamst, M., and Bodelier, P. L. E. (2010). Biphasic kinetics of a methanotrophic community is a combination of growth and increased activity per cell. FEMS Microbiol. Ecol. 71, 12-22.

Sundby, B., Vale, C., Caetano, M., and Luther, G. W. (2003). Redox chemistry in the root zone of a salt marsh sediment in the Tagus Estuary, Portugal. Aquat. Geochem. 9, 257-271.

Thauer, R. K., Jungermann, K., and Decker, K. (1977). Energy conservation in chemotrophic anaerobic bacteria. Bacteriol. Rev. 41, 100.

van Bodegom, P., Goudriaan, J., and Leffelaar, P. (2001a). A mechanistic 
model on methane oxidation in a rice rhizosphere. Biogeochemistry 55, 145-177.

van Bodegom, P., Stams, F., Mollema, L., Boeke, S., and Leffelaar, P. (2001b). Methane oxidation and the competition for oxygen in the rice rhizosphere. Appl. Environ. Microbiol. 67, 3586-3597.

Wang, J. J. (2011). Ecology of Neutrophilic Iron-Oxidizing Bacteria in Wetland Soils. Ph.D. thesis, University of Utrecht, Utrecht.

Wang, J. J., Muyzer, G., Bodelier, P. L. E., and Laanbroek, H. J. (2009). Diversity of iron oxidizers in wetland soils revealed by novel $16 \mathrm{~S}$ rRNA primers targeting Gallionella-related bacteria. ISME J. 3, 715-725.

Wang, J. J., Vollrath, S., Behrends, T., Bodelier, P. L. E., Muyzer, G., MeimaFranke, M., Den Oudsten, F., Van
Cappellen, P., and Laanbroek, H. J. (2011). Distribution and diversity of Gallionella -like neutrophilic iron oxidizers in a tidal freshwater marsh. Appl. Environ. Microbiol. 77, 2337-2344.

Weiss, J. V., Emerson, D., Backer, S. M., and Megonigal, J. P. (2003). Enumeration of $\mathrm{Fe}(\mathrm{II})$-oxidizing and $\mathrm{Fe}$ (III)-reducing bacteria in the root zone of wetland plants: implications for a rhizosphere iron cycle. Biogeochemistry 64, 77-96.

Weiss, J. V., Rentz, J. A., Plaia, T., Neubauer, S. C., Merrill-Floyd, M., Lilburn, T., Bradburne, C., Megonigal, J. P., and Emerson, D. (2007). Characterization of neutrophilic $\mathrm{Fe}(\mathrm{II})$-oxidizing bacteria isolated from the rhizosphere of wetland plants and description of Ferritrophicum radicicola gen. nov $\mathrm{sp}$ nov., and Sideroxydans paludicola $\mathrm{sp}$ nov. Geomicrobiol. J. 24, 559-570.

Wessen, E., Soderstrom, M., Stenberg, M., Bru, D., Hellman, M., Welsh, A., Thomsen, F., Klemedtson, L., Philippot, L., and Hallin, S. (2011). Spatial distribution of ammoniaoxidizing bacteria and archaea across a 44-hectare farm related to ecosystem functioning. ISME J. 5 , 1213-1225.

Yeates, C., and Gillings, M. R. (1998). Rapid purification of DNA from soil for molecular biodiversity analysis. Lett. Appl. Microbiol. 27, 49-53.

Conflict of Interest Statement: The authors declare that the research was conducted in the absence of any commercial or financial relationships that could be construed as a potential conflict of interest.
Received: 23 November 2011; accepted: 06 February 2012; published online: 23 February 2012.

Citation: Wang J, Krause S, Muyzer G, Meima-Franke $M$, Laanbroek $H J$ and Bodelier PLE (2012) Spatial patterns of iron- and methane-oxidizing bacterial communities in an irregularly flooded, riparian wetland. Front. Microbio. 3:64. doi: 10.3389/fmicb.2012.00064

This article was submitted to Frontiers in Terrestrial Microbiology, a specialty of Frontiers in Microbiology.

Copyright (C) 2012 Wang, Krause, Muyzer, Meima-Franke, Laanbroek and Bodelier. This is an open-access article distributed under the terms of the Creative Commons Attribution Non Commercial License, which permits noncommercial use, distribution, and reproduction in other forums, provided the original authors and source are credited. 


\title{
The distribution of ammonia-oxidizing betaproteobacteria in stands of Black mangroves (Avicennia germinans)
}

\author{
Hendrikus J. Laanbroek ${ }^{1,2,3}{ }^{*}$, Rosalinde M. Keijzer ${ }^{1}$, Jos T. A. Verhoeven ${ }^{2,3}$ and Dennis F. Whigham ${ }^{3}$ \\ 1 Department of Microbial Ecology, Netherlands Institute of Ecology, Wageningen, Netherlands \\ 2 Institute of Environmental Biology, Utrecht University, Utrecht, Netherlands \\ ${ }^{3}$ Smithsonian Environmental Research Station, Edgewater, MD, USA
}

\section{Edited by:}

Svetlana N. Dedysh, Russian

Academy of Sciences, Russia

\section{Reviewed by:}

Chris Francis, Stanford University, USA

Anne Bernhard, Connecticut College, USA

\section{*Correspondence:}

Hendrikus J. Laanbroek, Department of Microbial Ecology, Netherlands Institute of Ecology (NIOO-KNAW), P.O. Box 50, 6700 AB Wageningen, Netherlands.

e-mail: r.laanbroek@nioo.knaw.nt
The distribution of species of aerobic chemolitho-autotrophic microorganisms such as ammonia-oxidizing bacteria are governed by $\mathrm{pH}$, salinity, and temperature as well as the availability of oxygen, ammonium, carbon dioxide, and other inorganic elements required for growth. Impounded mangrove forests in the Indian River Lagoon, a coastal estuary on the east coast of Florida, are dominated by mangroves, especially stands of Black mangrove (Avicennia germinans) that differ in the size and density of individual plants. In March 2009, the management of one impoundment was changed to a regime of pumping estuarine water into the impoundment at critical times of the year to eliminate breeding sites for noxious insects. We collected soil samples in three different Black mangrove habitats before and after the change in management to determine the impacts of the altered hydrologic regimes on the distribution of $16 \mathrm{~s}$ rRNA genes belonging to ammonia-oxidizing betaproteobacteria ( $\beta$-AOB). We also sampled soils in an adjacent impoundment in which there had not been any hydrologic alteration. At the level of $97 \%$ mutual similarity in the $16 \mathrm{~s}$ rRNA gene, 13 different operational taxonomic units were identified; the majority related to the lineages of Nitrosomonas marina (45\% of the total clones), Nitrosomonas sp. Nm143 (23\%), and Nitrosospira cluster 1 (19\%). Long-term summer flooding of the impoundment in 2009, after initiation of the pumping regime, reduced the percentage of $N$. marina by half between 2008 and 2010 in favor of the two other major lineages and the potential ammoniaoxidizing activity decreased by an average of $73 \%$. Higher interstitial salinities, probably due to a prolonged winter drought, had a significant effect on the composition of the $\beta$ AOB in March 2009 compared to March 2008: Nitrosomonas sp. Nm143 was replaced by Nitrosospira cluster 1 as the second most important lineage. There were small, but significant differences in the bacterial communities between the flooded and non-flooded impoundments. There were also differences in the community composition of the bacteria in the three Black mangrove habitats. N. marina was most dominant in all three habitats, but was partly replaced by Nitrosospira cluster 1 in sites dominated by sparsely distributed trees and by Nitrosomonas sp. Nm143 in sites characterized by taller, more densely distributed Black mangrove trees.

Keywords: ammonia oxidation, betaproteobacteria, mangroves, flooding

\section{INTRODUCTION}

Aerobic ammonia-oxidizing bacteria (AOB) and archaea play an important role in the global nitrogen cycle by converting ammonium to nitrite (Kowalchuk and Stephen, 2001; Schleper and Nicol, 2010). Nitrite can then be further oxidized to nitrate by nitriteoxidizing bacteria or used as an electron acceptor in a large number of microbial and chemical redox reactions. The diversity of aerobic $A O B$ is limited to a small number of genera within the classes of the beta- and gammaproteobacteria (Kowalchuk and Stephen, 2001) but, based on studies applying the phylogenetic 16s rRNA gene and the functional amoA gene, the ammonia-oxidizing betaproteobacteria $(\beta-\mathrm{AOB})$ are widely distributed and occur in many habitats. The studies that have been reported also demonstrated that their abundance is influenced by the prevailing environmental conditions. On the basis of the $16 \mathrm{~S}$ rRNA gene, for example, it was shown that sequences belonging to the Nitrosomonas oligotropha lineage dominated in the more frequently flooded and actively nitrifying habitats in tidal freshwater wetlands, whereas sequences related to the Nitrosospira lineage were more abundant in habitats that were less frequently flooded and less active in relation to ammonium oxidation (Laanbroek and Speksnijder, 2008).

Mangroves are tree-dominated intertidal wetlands along tropical and subtropical coastlines with a specialized flora adapted to waterlogged and saline conditions. Mangroves are often found in distinct zones of different species and stature (Feller et al., 2003; Lovelock and Feller, 2003) with temperature, salinity, frequency of tidal inundation, soil texture, degree of soil anoxia, 
$\mathrm{pH}$, predation, and competition being factors that account for the zonation (Alongi, 2008). Nutrient availability also varies spatially in mangroves and plays a key role in their size and distribution (Feller et al., 2003). Research on the abundance and diversity of AOB in mangroves has been limited to studies of polluted and rehabilitated mangrove sediments in Southeast Asia (Wickramasinghe et al., 2009; Cao et al., 2011b; Li et al., 2011). Hence, there is little information about the distribution and abundance of AOB in mangroves at the global scale and even less is known about the abundance and distribution of $\mathrm{AOB}$ in relation to spatial variations of mangrove species and the factors that control their distribution and growth.

Almost all mangroves in the Indian River Lagoon of Florida were impounded, primarily between 1954 and 1970, to control noxious salt-marsh mosquitoes and biting midges (Rey and Kain, 1991; Brockmeyer et al., 1997). In later years culverts were placed in the dikes around the impoundments to restore limited tidal exchange and in a few impoundments, tropical storms destroyed sections of the dikes resulting in increased tidal exchange with the estuary.

In 2008 we initiated a study to determine the effects of altered hydrologic conditions on ecological characteristics of mangroves. The study was made possible because the St. Lucie County Mosquito Control and Coastal Management Services ${ }^{1}$ had developed plans to alter the hydrology of one impoundment by pumping water into it during the season when nuisance insects were most problematic. We hypothesized that the hydrological changes would give rise to changes in ecological processes in the mangroves, including the growth rates of mangroves, the rates of nitrogen cycling, and the community composition of the AOB.

Here we report on the diversity of ammonia-oxidizing betaproteobacteria before, during, and after the changes in hydrology in three different Black mangrove habitats, i.e., locations with dwarf, sparse, and dense trees. We tested the hypotheses that changes in soil characteristics associated with habitat type and managementdirected flooding for insect control would alter the community structure of the ammonia-oxidizing betaproteobacteria and thereby the rates of potential ammonia-oxidizing activity.

\section{MATERIALS AND METHODS \\ STUDY LOCATIONS}

Soil samples were collected in March 2008, 2009, and 2010 in two mangrove-dominated impoundments $\left(27^{\circ} 33^{\prime} \mathrm{N}, 80^{\circ} 19^{\prime} \mathrm{W}\right)$ in the Indian River Lagoon, a coastal sub-estuary, located on North Hutchinson Island, St. Lucie County, FL, USA. The climatic conditions and subsoil characteristics of the study area have been previously described (Stringer, 2010; Stringer et al., 2010). Most of the mangroves in the Indian River Lagoon were impounded between 1954 and 1970 to control numbers of salt-marsh mosquitoes and biting midges. Following the establishment of the impoundments, most of the mangroves died. Subsequently, breaches in the dikes as a result of hurricanes and the installation of culverts through the dikes resulted in the restoration of tidal exchange between the impoundments and the estuary. Since the restoration of tidal

\footnotetext{
${ }^{1}$ http://www.stlucieco.gov/mosquito/index.htm
}

exchange, mangrove-dominated vegetation has re-established in the impoundments (Brockmeyer et al., 1997). Avicennia germinans L. (Black mangrove) was the dominant species in both impoundments (Feller et al., 2003; Lovelock and Feller, 2003). However, the heights of the mangroves differed. The tallest mangroves occurred in the wettest habitats and at the upland-wetland border, while the shortest trees occurred in areas where the soil salinities were very high (18). Other abundant species throughout the impoundments were Conocarpus erectus (Button bush), Batis maritima (Saltwort), Salicornia virginica (Glasswort), and Salicornia bigelovii (Dwarf glasswort).

The March 2008 sampling represented conditions in the two impoundments prior to the pumping of estuarine water into Impoundment 24. In March 2009, rotational impoundment management (i.e., seasonal flooding by pumping water into the impoundment from the lagoon) was initiated and it coincided with our soil sampling. During the period of rotational pumping of estuarine water (March-October) much of the impoundment had standing water; at other times, water levels were allowed to fluctuate naturally through the culverts. Due to the changes in management practice initiated in March 2009, groundwater levels changed substantially in Impoundment 24. Water levels also changed in Impoundment 23 (Stringer, 2010) demonstrating that the impoundments, which are immediately adjacent to each other, were hydrologically connected by groundwater that flows beneath the dike that separated them. Changes in groundwater levels were greatest in Impoundment 24, but were evident throughout Impoundment 23, with the magnitude of the changes diminishing with distance within Impoundment 23 from Impoundment 24 (M. Rains, pers. comm.).

The soil samples that were collected for the analysis of the diversity of $\beta$-AOB were obtained at sites within each impoundment that had been the focus of earlier experiments (Feller et al., 2003; Whigham et al., 2009). All sampled sites were within $500 \mathrm{~m}$ of the dike between both impoundments and they were dominated by $A$. germinans L. (Black mangrove). One of the habitats sampled was referred to as "dwarf Black mangrove" or "dwarf" (Feller et al., 2003; Lovelock and Feller, 2003) because average tree height was less than $1 \mathrm{~m}$ and tree density was low resulting in less than $30 \%$ canopy coverage. Another Black mangrove-dominated habitat was located between the areas dominated by dwarf trees and wetter habitats that had taller trees. We refer to this habitat as "sparse Black mangrove" or "sparse." Tree height in the sparse habitat averaged $1.8 \mathrm{~m}$ and tree density resulted in a canopy coverage that ranged from 30 to $80 \%$. The third Black mangrovedominated habitat, hereafter called "dense Black mangrove" or "dense," had trees that averaged $3.6 \mathrm{~m}$ in height and the tree density resulted in a canopy coverage of greater than $80 \%$. Within each impoundment, we selected five locations in each of the three habitats resulting in a total of 30 locations where soil samples were collected.

\section{SOIL COLLECTIONS}

In the March 2008, 2009, and 2010 sampling periods, three soil cores $(3.9 \mathrm{~cm}$ diameter and $10 \mathrm{~cm}$ long) were collected at each of the 30 sites. The sample locations were within 1-m of a Black mangrove that was being monitored for growth and leaf nitrogen 
content. Samples were collected with an aluminum tube that was sharpened at one end. The cores were immediately sealed at both ends with rubber stoppers and transported to the laboratory. One of the cores was used for removal of pore water that was analyzed for salinity, and $\mathrm{pH}$. The top $10-\mathrm{cm}$ of the two other cores were combined and thoroughly mixed by hand and subsequently sub-sampled for the determination of moisture content, for measurements of potential rates of nitrification, and for the analysis of the community structure of ammonia-oxidizing betaproteobacteria $(\beta$-AOB). Samples for the genetic analyses of the $\beta$-AOB were freeze-dried and stored until further analyses.

\section{DETERMINATION OF POTENTIAL AMMONIA-OXIDIZING ACTIVITIES}

To estimate the numbers of active ammonia-oxidizing cells in the soil samples, potential ammonia-oxidizing activities (PAAs) were determined in slurries of $20 \mathrm{~g}$ fresh weight soil mixed with $50 \mathrm{ml}$ of mineral medium containing ammonium at a final concentration of $1 \mathrm{mM}$, according to the protocol of Belser and Mays (1980), as modified by Verhagen and Laanbroek (1991). Salinities of the mineral media were adapted to the pore water salinity of each individual sample. The linear production of nitrite plus nitrate over time under optimal conditions of substrate, $\mathrm{pH}$, and temperature was taken as a measure of the potential rate of ammonium oxidation. Measurements were performed within $16 \mathrm{~h}$ after collection of the soil samples and the rates were followed for $6 \mathrm{~h}$ with $90 \mathrm{~min}$ sampling intervals.

\section{DNA ISOLATION}

Environmental DNA was extracted from the $0.5 \mathrm{~g}$ freeze-dried soil samples. The samples were homogenized by vortexing with $1 \mathrm{ml}$ cetyltrimethylammonium bromide (CTAB) buffer (Zhou et al., 1996) and $0.5 \mathrm{~g}$ sterilized zirconia-silica beads (diameter $0.1 \mathrm{~mm}$ ). The homogenized samples were subsequently subjected to disruption by bead-beating at a $5.0-\mathrm{m} / \mathrm{s}$ rotation for $60 \mathrm{~s}$. After the addition of $5 \mu \mathrm{l}$ proteinase $\mathrm{K}(20 \mathrm{mg} / \mathrm{ml})$, the samples were incubated for $30 \mathrm{~min}$ at $37^{\circ} \mathrm{C}$, and then vortexed after $15 \mathrm{~min}$. After the addition of $150 \mu \mathrm{l}$ of a $20 \%$ SDS solution, the samples were incubated for $1 \mathrm{~h}$ at $65^{\circ} \mathrm{C}$ in a Thermoblock apparatus and vortexed every 15-20 min. After centrifugation at $10,000 \times g$ for $10 \mathrm{~min}, 600 \mu \mathrm{l}$ of supernatant was collected in $2-\mathrm{ml}$ screw-cap tubes. The rest of the sample was re-extracted with $450 \mu \mathrm{l}$ CTAB buffer and $50 \mu \mathrm{l}$ of a $20 \%$ SDS solution, vortexed for $10 \mathrm{~s}$, incubated for $10 \mathrm{~min}$ at $65^{\circ} \mathrm{C}$, and centrifuged at $6,000 \times g$ for $10 \mathrm{~min}$. Again, $600 \mu \mathrm{l}$ was collected, added to the previously extracted supernatant, mixed with $1 \mathrm{ml}$ phenol-chloroform-isoamyl alcohol solution (25:24:1, $\mathrm{vol} / \mathrm{vol} / \mathrm{vol}$ ), and centrifuged at $6,000 \times \mathrm{g}$ for $10 \mathrm{~min}$. One milliliter of supernatant was collected and placed into a new screw-cup tube containing $700 \mu \mathrm{l}$ isopropanol, and the tube was incubated for $1 \mathrm{~h}$ at $24^{\circ} \mathrm{C}$. After $20 \mathrm{~min}$ of centrifugation at $15,000 \times \mathrm{g}$, the isopropanol was decanted and the pellet was resuspended and washed with $1 \mathrm{ml} 70 \%$ cold ethanol. This was followed by $5 \mathrm{~min}$ of centrifugation at $15,000 \times g$, decantation of the ethanol, drying of the pellet under vacuum centrifugation, and finally, resuspension in $100 \mu$ l water (Sigma). Quantification was done with 2- $\mu$ l DNA samples and a ND-1000 apparatus (Nanodrop Technology, Wilmington, DE, USA). DNA could not be obtained from four soil samples. These samples were all from Impoundment 23 in different years and mangrove habitats: one sample was from the zone with dwarf Black mangrove trees; three were from the "dense" habitat.

\section{PCR AND CONSTRUCTION OF CLONE LIBRARIES}

Extracted DNA was amplified by nested procedure using two $16 \mathrm{~s}$ rRNA gene primer sets specific for the majority of the betaproteobacterial $\mathrm{AOB}$, i.e., the $\beta \mathrm{AMO} 161 \mathrm{f}$ and $\beta \mathrm{AMO} 1301 \mathrm{r}$ primer set of McCaig et al. (1994) and the CTO189f and CTO654r primer set of Kowalchuk et al. (1997). One hundred nanograms of purified DNA was used as template for a $50-\mu l$ PCR mixture containing $1 \times \mathrm{Mg}$-free buffer (Invitrogen Corp., Carlsbad, CA, USA), $0.5 \mu \mathrm{M}$ of each primer, $200 \mu \mathrm{M}$ of each deoxynucleotide triphosphate, $1.75 \mathrm{mM} \mathrm{MgCl}_{2}, 400 \mathrm{ng} / \mu \mathrm{l}$ bovine serum albumin, $1.25 \mathrm{U}$ GoTaq Hot Start Polymerase (Promega). The thermocycling program for both steps consisted of $2 \mathrm{~min}$ of denaturation at $95^{\circ} \mathrm{C}$ followed by 35 cycles of $30 \mathrm{~s}$ of denaturation at $95^{\circ} \mathrm{C} ; 30 \mathrm{~s}$ of specific annealing at $59^{\circ} \mathrm{C}\left(\beta \mathrm{AMO}\right.$ primer set) or at $57^{\circ} \mathrm{C}$ (CTO primer set) and $45 \mathrm{~s}$ of elongation at $72^{\circ} \mathrm{C} ; 5 \mathrm{~min}$ of final elongation was performed for all reactions. Nested amplifications of 25 cycles were performed with the primer set CTO189f and CTO654r on 1:100 dilutions of PCR products from the $\beta A M O$ primer set. All reactions were verified by UV illumination of $1 \%$ agarose gels stained in a gel red or ethidium bromide solution.

Polymerase chain reaction fragments were ligated into the pGEM T-vector system (Promega Corporation, Madison, WI, USA) and transformed into JM109 competent E. coli cells (Promega) according to the manufacturers' instructions. Transformed colonies were screened for inserts of the correct size by PCR. In total 90 clone libraries were created comprising $8-32$ clones each. The number of clones was based on the number of bands detected by provisional DGGE analyses of the nested PCR products. Representative clones of the libraries were amplified with vector primers T7 and SP6 and PCR products were tested by standard preparative agarose gel electrophoresis. To ensure sequence read without ambiguities, vector products were sequenced with sufficient overlap of sequencing reads using the T7 and SP6 vector primers (Promega). Sequencing reactions were performed by Macrogen, Amsterdam, the Netherlands.

\section{SEOUENCE ANALYSES}

Sequences were aligned and checked for chimeras using Sequencher 4.1 (Gene Codes Corporation, Ann Arbor, MI, USA). The resulting contigs were visually inspected and ambiguities manually resolved. Low quality contigs were removed from the dataset. After removing sequences of insufficient length or quality, the remaining 844 sequences were further analyzed. The aligned sequences were clustered in operational taxonomic units (OTUs) with the cluster program of MOTHUR software version 1.18.1 (Schloss et al., 2009). In addition, MOTHUR was also used for establishing rarefaction curves and group (i.e., OTU) representatives. OTUs at the level of $97 \%$ mutual similarity in their 16S rRNA gene sequences $(418 \mathrm{bp}$ ) were chosen for further analyses. Sequence identification of the OTU-representatives was done by the BLASTN facility from the National Center for Biotechnology Information ${ }^{2}$. The partial 16SrRNA gene sequences

${ }^{2}$ http://www.ncbi.nlm.nih.gov/ 
were submitted to the GenBank database under accession numbers JQ725556-JQ726359.

Analysis of similarity (ANOSIM) between communities of $\beta$ AOB obtained from different impoundments, years, and mangrove habitats was done with the PRIMER software version 5.2.9 (Primer-E, Plymouth, UK). The same software was used for nonparametric multi-dimensional scaling of the $\beta$-AOB communities and for linking the community distribution to the measured environmental parameters (BIOENV).

\section{STATISTICAL ANALYSES}

The values for the PAAs obtained for the different impoundments, sampling years, and mangrove habitats were analyzed with the STATISTICA software version 10 (StatSoft, Inc., Tulsa, OK, USA). A non-parametric Spearman rank correlation analysis between the potential ammonia oxidation activities and other soil characteristics was performed with the same software package.

\section{RESULTS}

\section{SOIL MOISTURE CONTENT, PORE WATER SALINITY, AND pH}

Soil moisture content in the three habitats in 2010 was significantly higher than the moisture content measured in 2009 (Figures 1A,B; ANOVA on log-transformed data: $F=4.01, p=0.0223)$. There were no significant differences in soil moisture between 2008 and 2009 or between 2008 and 2010. There were no significant differences in soil moisture between the two impoundments but there were significant habitat differences (ANOVA on log-transformed data: $F=29.12, p=0.0000$ ); with increasing moisture in soils from the dwarf habitat compared to soils from sparse and dense habitats, respectively (Figure 1).

Pore water salinity differed significantly between years with significant higher values in 2009 (Figures 1C,D; Kruskal-Wallis non-parametric ANOVA: $H=48.7758, p=0.0000)$. Pore water salinity did not differ significantly between impoundments or the three habitats (Figures 1C,D).

Pore water $\mathrm{pH}$ differed between years with significantly lower values in 2010 after the estuarine water was pumped into Impoundment 24 (Figures 1E,F; ANOVA: $F=10.32, p=0.0001$ ). Again, there were no significant differences between impoundments, but $\mathrm{pH}$ differed across the three habitats (ANOVA on log-transformed data: $F=29.12, p=0.0000$ ) with significantly lower values in the dense mangrove habitat.

Matching the soil characteristics of the three mangrove habitat types with the community compositions of the $\mathrm{AOB}$ resulted in Spearman Rank correlations of $0.028,0.011$, and -0.034 for soil moisture content, salinity, and pore water $\mathrm{pH}$, respectively.
A
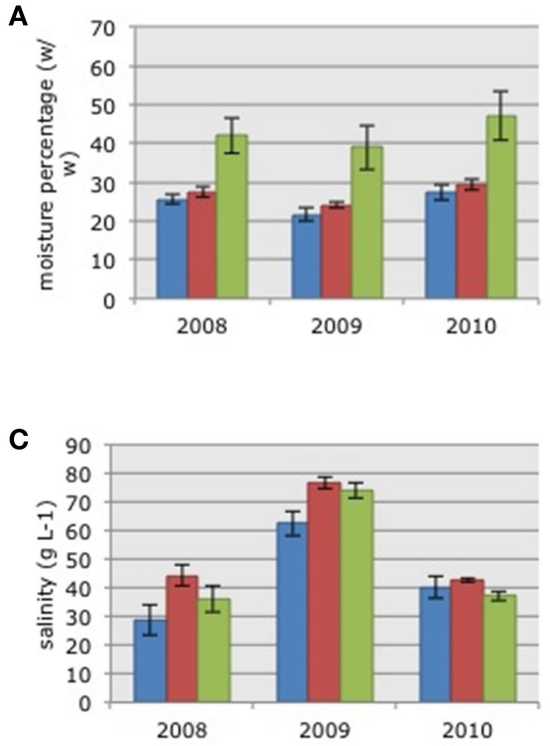

E

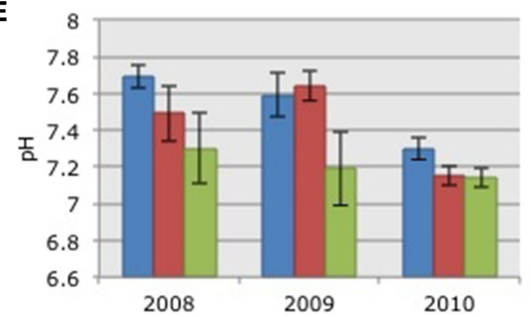

B

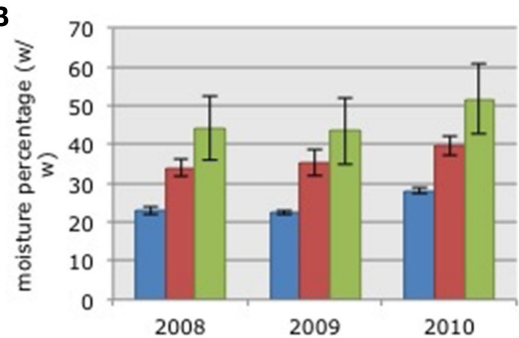

D

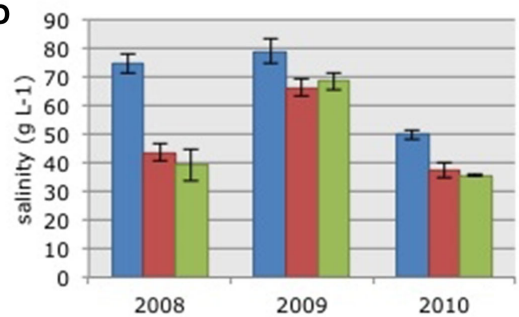

$\mathbf{F}$

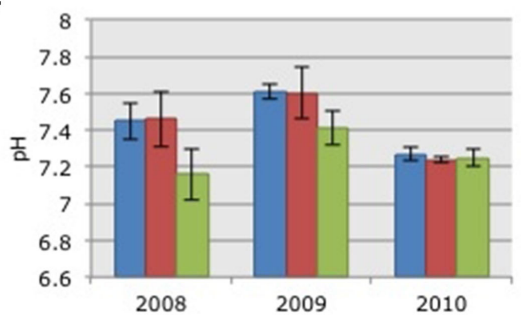

FIGURE 1 | Average soil moisture content $(A, B)$, pore water salinity $(C, D)$, and pore water $p H(E, F)$ in the samples collected in the three habitats in impoundments $23(\mathbf{A}, \mathbf{C}, \mathbf{E})$ and $24(\mathbf{B}, \mathbf{D}, \mathbf{F})$. Mangrove habitats are indicated by different colors: Blue = dwarf, red = sparse, and green = dense; SE in brackets. 


\section{POTENTIAL AMMONIA-OXIDIZING ACTIVITIES}

The activity of potential AOB declined significantly (KruskalWallis non-parametric ANOVA: $H=19.5664, p=0.0001)$ between 2008 and 2009 (Figure 2). Activity levels were lowest in 2010 but the differences between 2009 and 2010 were not significant. PAAs were not significantly different between impoundments or habitats. Testing the relationship between PAAs and the three habitats yielded a Spearman Rank correlation of 0.108 .

\section{MICROBIAL DIVERSITY}

Based on $97 \%$ mutual similarity between the 16S rRNA genes (418 bp), the 844 qualified sequences could be classified into
13 different OTUs. Due to differences in sequence quality the numbers of approved clones differed among impoundments, sampling years, and mangrove habitats (Table 1). Accounting for $45 \%$ of the total clones, OTU01 was the most numerous OTU and had the highest relative numbers in Impoundment 24, the dwarf habitat and in 2008 (Figures 3-5). With 23\% of the total, OTU04 was the second most numerous and had the highest relative abundances in Impoundment 24 and the dense habitat. Its relative abundances were similar in 2008 and 2010 and lower in 2009. The third most important OTU was OTU06 with 19\% of the total clones. The relatively abundance of OTU06 was lowest in Impoundment 23 and in 2008 and much higher in the sparse

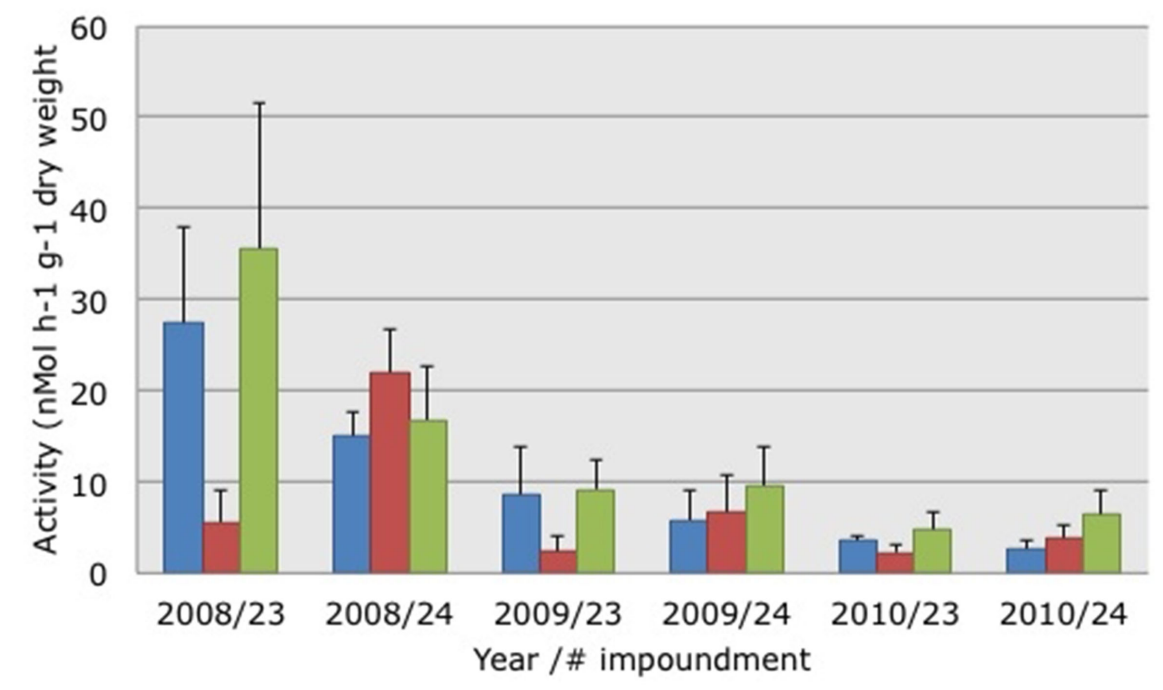

FIGURE 2 | Average potential ammonia-oxidizing activities measured in soil suspensions collected from three different habitats characterized by dwarf (blue bars), sparse (red bars), or dense (green bars) Avicennia germinans. Soils were collected in March 2008, 2009, and 2010 in impoundments 23 and 24 in the Indian River Lagoon, Florida. SE are presented in brackets.

Table 1 | Distribution of clones related to ammonia-oxidizing betaproteobacteria over the different operational taxonomic units (OTUs), impoundments, sampling years, and Black mangrove habitats.

\begin{tabular}{|c|c|c|c|c|c|c|c|c|}
\hline OTU & \multicolumn{2}{|c|}{ Impoundment } & \multicolumn{3}{|c|}{ Sampling years } & \multicolumn{3}{|c|}{ Black mangrove habitat } \\
\hline 02 & 5 & 12 & 11 & 3 & 3 & 7 & 9 & 1 \\
\hline 03 & 44 & 18 & 6 & 35 & 21 & 20 & 33 & 9 \\
\hline 04 & 72 & 121 & 76 & 41 & 76 & 25 & 59 & 109 \\
\hline 06 & 80 & 77 & 29 & 71 & 57 & 12 & 101 & 44 \\
\hline 07 & 1 & 3 & 2 & 1 & 1 & 0 & 2 & 2 \\
\hline 08 & 4 & 2 & 0 & 4 & 2 & 3 & 2 & 1 \\
\hline 09 & 8 & 1 & 0 & 9 & 0 & 8 & 0 & 1 \\
\hline 10 & 3 & 2 & 1 & 4 & 0 & 3 & 0 & 2 \\
\hline 11 & 1 & 0 & 0 & 0 & 1 & 0 & 0 & 1 \\
\hline
\end{tabular}



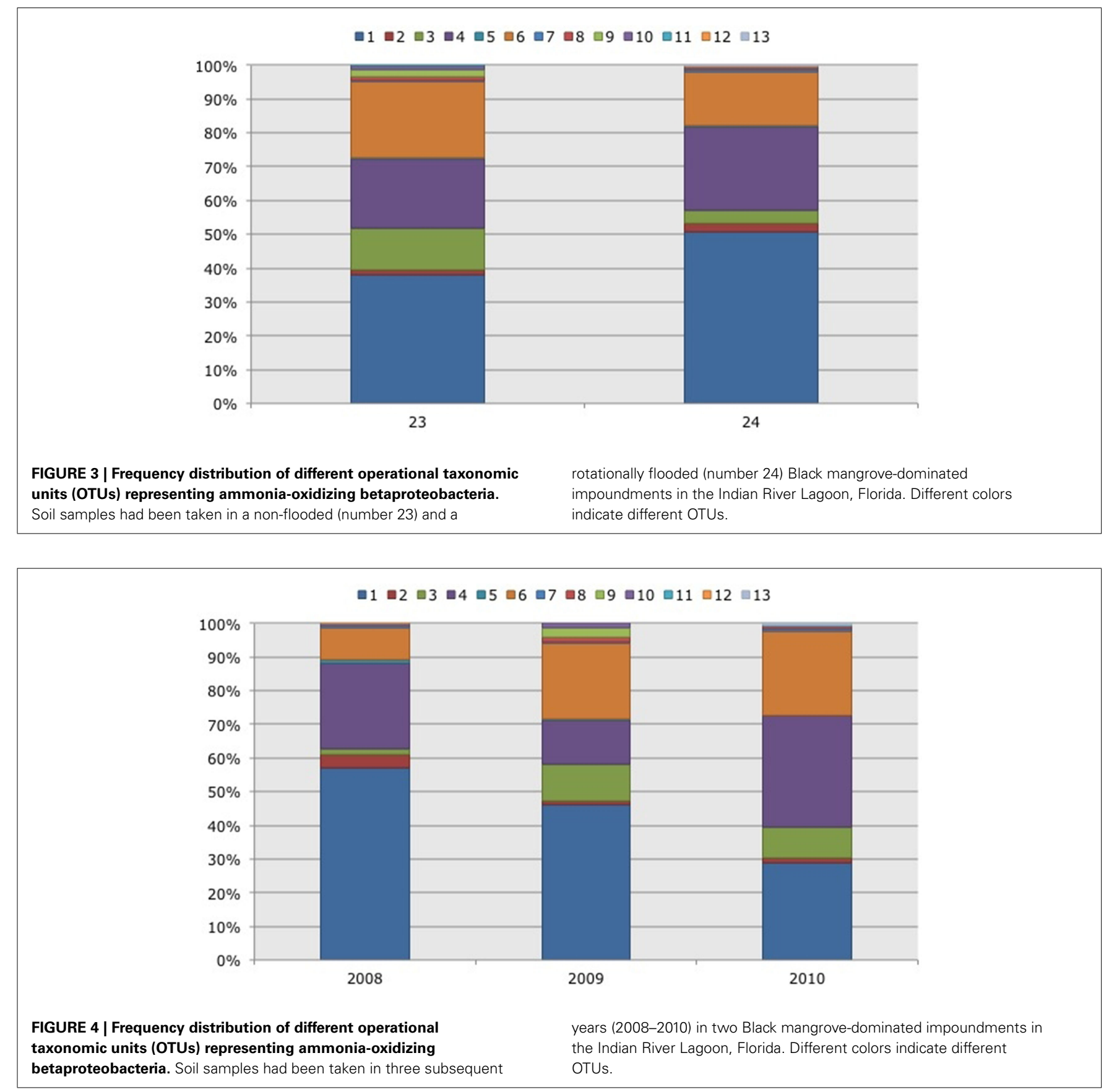

habitat. The relative abundances of the other OTUs were much lower and with the exception of OTU02 and OTU03, the minor OTUs were often absent in replicate samples of the impoundments, sampling years and habitats (Table $\mathbf{1}$ ).

With three exceptions, the OTUs were present in both impoundments (Table 1). OTU01 contributed most (i.e., 34\% of all OTUs) to the dissimilarities between both impoundments. OTU06 and OTU04 added 25 and 23\%, respectively to these dissimilarities, while the other OTUs were less important for the dissimilarity between the impoundments. The major OTUs were present in all years (Table1). Some minor OTUs were only enumerated in one of the years. Figure 4 shows the frequency distributions of the OTUs for the three years. With $35 \%$ of the total OTUs on average, OTU01 contributed most to the dissimilarities between the years. In addition, OTU04 and OTU06 accounted each for $25 \%$ on average, to the dissimilarities between the years with OTU04 being most important for dissimilarities between 2008 and 2010 and OTU06 between 2008 and 2009 and between 2009 and 2010. The dwarf and sparse habitats did not contain unique OTUs (Table 1). OTU01 was most abundant in the dwarf habitat samples whereas OTU06 and OTU04 had the highest relative abundances in the sparse and dense habitats, respectively (Figure 5). Of all 


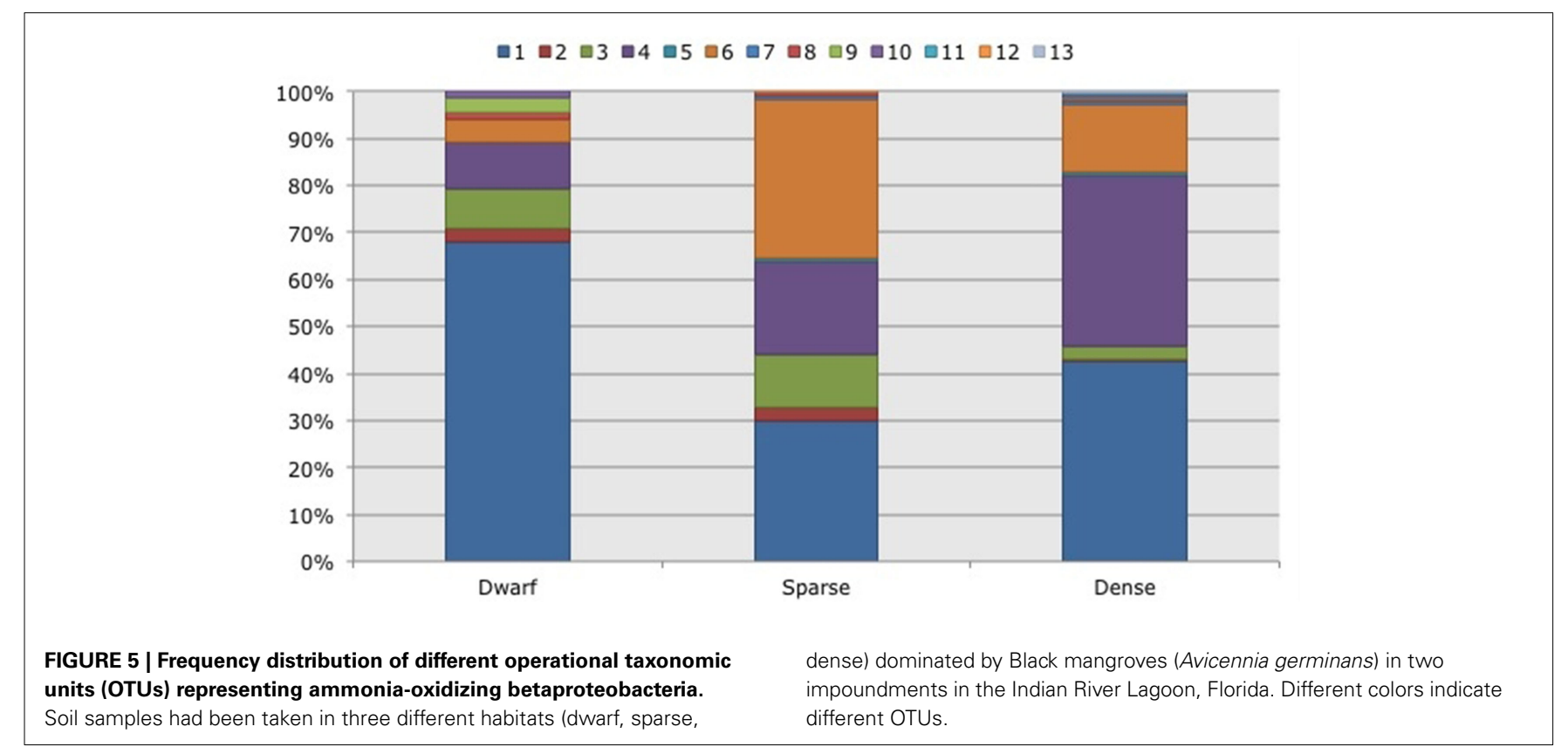

OTUs, OTU01 contributed the most to differences between the dwarf and sparse habitats and between the dwarf and dense habitats (38\% both). OTU06 was the second most abundant OTU that contributed to the differences between the dwarf and sparse habitats $(27 \%)$ and OTU04 also contributed to differences between the dwarf and dense habitats (29\%). OTU01, OTU04, and OTU06 contributed equally to the dissimilarity between the sparse and dense habitats $(29,30$, and $26 \%$, respectively).

Sequences of the clones being representative for the different OTUs according to the MOTHUR analysis showed close relationship with uncultured clones originating from mostly estuarine and marine habitats (Table 2). Exceptions were the closest relative of OTU01 that were found in a saline wetland in Chile and OTU09 and OTU10 that were encountered in nitrifying bioreactors. All OTUs were similar to uncultured clones at a level of at least $97 \%$. The number of lineages of $\beta$-AOB to which the OTUs belonged was rather limited. Only the lineages of Nitrosomonas aestuarii/Nitrosomonas marina, Nitrosomonas sp. Nm143, Nitrosomonas europaea, and Nitrosospira emerged from the search. OTUs belonging to the $N$. aestuarii/N. marina lineage, further referred as $N$. marina lineage, were by far the most numerous (Table 2), followed by OTUs identified as being related to Nitrosomonas sp. Nm143 and Nitrosospira lineages. Only 14 out of 844 sequences belonged to the two OTUs related to N. europaea and they originated from a restricted number of soil samples in 2009 (Table 1).

\section{DISTRIBUTION OF COMMUNITIES}

Operational taxonomic units of $\beta$-AOB do not appear in single populations but in communities usually composed of different OTUs. In 16 of the 90 soil samples analyzed a single OTU of $\beta$-AOB was enumerated. The number of sequences obtained from the soil samples was variable with numbers ranging from 0 to 24 , with an average of 10 . The variable number of sequences per sample or community made it difficult to compare the community structure of the $\beta$-AOB. Hence, absolute numbers of sequences were converted to percentages of OTUs in the different soil samples; samples containing less than 5 sequences were arbitrarily excluded from further analyses, as small differences in these numbers will have a large effect on the relative distribution of OTUs.

Based on a pair-wise ANOSIM, the communities present in Impoundment 23 were significantly different from those detected in Impoundment 24 (Table 3), but the difference was small $(R$ value close to zero). The comparison between years did not yield a significant time effect on the distribution of $\beta$-AOB, although the communities in 2008 were slightly different from those in 2010 (Table 3). The $\beta$-AOB community composition differed significantly between habitats with the greatest difference between the dwarf habitat and the other two (Table 3).

\section{DISCUSSION}

\section{DIFFERENCES AMONG MANGROVE HABITATS}

Overall, the communities of the $\beta$-AOB were significant different between the three mangrove habitats. Hence, the hypothesis that environmental factors that determine differences in the growth, stature, and density of Black mangroves also affect the community composition of the $\beta$-AOB was confirmed. Communities in the dwarf mangrove habitat were more different from the communities in the sparse and dense mangrove habitats and the latter two were more similar to each other. Whigham et al. (Feller et al., 2003) showed that, although all mangrove habitats were limited by nitrogen availability, this limitation was most severe in the dwarf Black mangrove habitat. The degree of nitrogen limitation was expected to also have a selective pressure on the community composition of the $\beta$-AOB (Bollmann et al., 2002).

Overall, the communities of the $\beta$-AOB were slightly different in the two impoundments (Table 3), which may have been due to differences in management (i.e., the pumping of estuarine water 
Table 2 | Operational taxonomical units (OTUs) affiliated to ammonia-oxidizing betaproteobacteria recovered from mangrove soils and their most close relatives as retrieved from BLAST search.

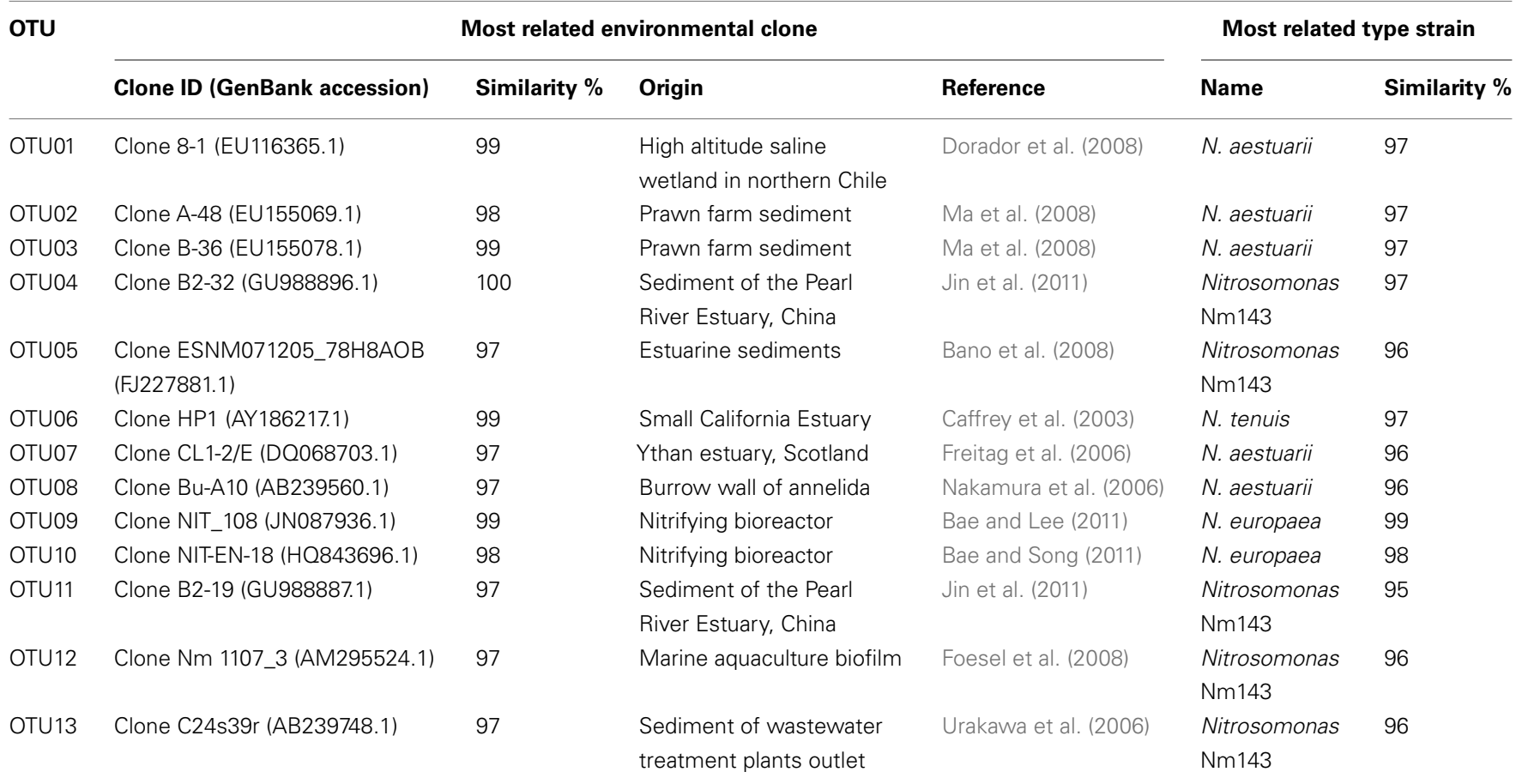

OTUs are based on 97\% mutual similarity of their 16S rRNA gene (418bp).

Table 3 | Pair-wise similarities among communities of ammoniaoxidizing betaproteobacteria as obtained from an analysis of similarity (ANOSIM) between impoundments, sampling years, and habitats of Black mangroves.

\begin{tabular}{llll}
\hline Groups & Comparison & R-value & $\boldsymbol{p}$-value \\
\hline Impoundments & \#23 versus \#24 & 0.066 & 0.012 \\
Sampling years & All years & 0.045 & 0.053 \\
& 2008 versus 2009 & 0.040 & 0.102 \\
& 2008 versus 2010 & 0.061 & 0.042 \\
& 2009 versus 2010 & 0.036 & 0.115 \\
Mangrove habitat types & All types & 0.151 & 0.001 \\
& Dwarf versus sparse & 0.261 & 0.002 \\
& Dwarf versus dense & 0.118 & 0.007 \\
& Sparse versus dense & 0.076 & 0.028 \\
\hline
\end{tabular}

An R-value of zero means no difference between groups, whereas an R-value of one means an absolute difference between groups.

into Impoundment 24) or to small differences in the characteristics of the vegetation in the two impoundments. There were only salt pans, i.e., habitats with no other plant species than Black mangroves, in Impoundment 24 before the flooding of March 2009 started. In Impoundment 23 the dwarf Black mangroves were always more intermingled with other shrub plants.

\section{EFFECTS OF FLOODING}

The hypothesis that flooding of Impoundment 24 would affect the composition of the betaproteobacterial community was not unequivocally confirmed. Although the communities changed significantly between 2008 and 2010, the change between March 2009 and March 2010, a period during which estuarine water was pumped into the impoundment for several months, was not significant. A non-significant change in the community composition did occur between 2008 and 2009, during which time east Florida experienced a prolonged winter drought leading to extremely low groundwater levels in the two impoundments (M. Rains, pers. comm.). Despite the winter drought of $2008 / 2009$, the soil moisture content at the sampling sites was not significantly different between March 2008 and March 2009. Soil moisture increased significantly between 2009 and 2010 as a result of the pumping that was initiated the exact time that we sampled the sites in 2009. At the time of our 2009 sampling, however, the impacts of the addition of water to Impoundment 24 had not yet resulted in a change in soil moisture. Independent of sampling year, we found a consistent pattern of significantly increasing soil moisture from the dwarf habitat to the dense Black mangrove habitat with intermediate soil moisture content in the sparse mangrove habitat.

One might be surprised that flooding had only a limited effect on the community composition of the $\beta$-AOB. Since flooding will limit oxygen availability in the soil, it will also repress the activity of these obligate-aerobic bacteria. Hence, changes in community composition under flooded, oxygen-restricted conditions can only be due to differences in survival between the different lineages.

In addition to the change in community composition of the $\beta$-AOB between March 2008 and 2009, the activity levels of the potential $\mathrm{AOB}$ changed over the same time period from relatively high to low and they remained low in 2010 (Figure 2). In a 
preliminary study, we had also measured relatively high PAAs in soils collected from Impoundment 24. In March 2006, the average PAAs in soils from the dwarf, sparse, and dense mangrove habitats were 15,19 , and $34 \mathrm{nMol}$ ammonia $\mathrm{h}^{-1} \mathrm{~g}^{-1}$ dry weight, respectively ( $\mathrm{P}$. Baas, unpublished results). In soils collected at the same sites in March 2007 the average PAAs were 14, 15, and $40 \mathrm{nMol}$ ammonia $\mathrm{h}^{-1} \mathrm{~g}^{-1}$ dry weight, respectively (H. J. Laanbroek, unpublished results). Hence, the values measured in 2009 and 2010 in Impoundment 24 were low compared to the three previous years; indicating that activity level and community composition of $\beta$-AOB were affected by winter drought in 2008/2009 and not by the altered management that started in March of 2009. The potential activities measured in this study were in the same range as those observed in a Rhizophora apiculata (Red mangrove) forest in Makham Bay, Thailand, by Kristensen et al. (1998).

\section{EFFECT OF SALINITY}

Although the winter drought in 2008/2009 was not reflected in a measurable change in the soil moisture content, pore water salinity had increased by an average of $72 \%$ in the three habitats (range 61-90\%) between March 2008 and 2009 (Figure 1). Following the onset of pumping of estuarine water into the impoundment in March 2009, pore water salinities decreased by an average of $43 \%$ (range 36-49\% for the three habitats) by March 2010.

The effect of salinity on the community composition of $\beta$ AOB has been observed before, but typically in estuaries where salt concentrations vary from freshwater values to marine salinities of $\sim 30 \%$. In our study, salinities measured in the soils ranged from 29 to $79 \%$ ). In marine-dominated estuarine systems, $\beta$-AOB belonging to the Nitrosospira lineage (cluster 1) dominate, but also members of the N. marina and Nitrosomonas sp. Nm143 lineages have been identified (Francis et al., 2003; Cebron et al., 2004; Bernhard et al., 2005; Freitag et al., 2006; Mosier and Francis, 2008; Sahan and Muyzer, 2008; Jin et al., 2011). Francis et al. (2003) stated that although salinity appears to play a role, no single physical or chemical parameter entirely explains the pattern of $\beta$-AOB diversity estuaries, suggesting that a combination of environmental factors may shape the overall level of $\mathrm{AOB}$ diversity in dynamic estuarine ecosystems.

In Mono Lake, a saline (68-79\%o) and alkaline ( $\mathrm{pH} 9.8)$ lake located just east of the Sierra Nevada range in northern California, Ward et al. (2000) measured a dominance of $\beta$-AOB related to N. europaea and Nitrosomonas eutropha in 1995, whereas Carini and Joye (2008) observed a dominance of Nitrosomonas halophilarelated AOB in 2002/2003. The differences in the composition of $\beta$-AOB at Mono Lake were proposed to be the result of a switch in hydrological mixing regimes resulting in reduced ammonia availabilities.

\section{DIFFERENTIAL DISTRIBUTION OF THE THREE DOMINANT LINEAGES OF $\beta$-AOB}

Based on their most close relatives, the major OTUs (i.e., OTU01, OTU04, and OTU06) identified from the impoundment soils represented the lineages $N$. marina, Nitrosomonas sp. Nm143, and Nitrosospira cluster 1, respectively (Table 2). OTU01 consisting of $N$. marine-related clones was relatively abundant in Impoundment 24, in 2008, especially in the dwarf habitat (Figures 3-5).
Prior to the pumping of water, the dwarf habitats in Impoundment 24 had the appearance of salt pans with no mangroves or scattered dwarf black mangroves in their center and high interstitial salt concentrations (Figure 1D). Subsequent to the initiation of flooding in Impoundment 24, the habitat was colonized by Salicornia spp. and interstitial salinities decreased. Also prior to the flooding of the impoundment, interstitial salinities were very high in all habitats, but especially in the salt pans, due to the regional drought that occurred in 2009 (Figure 1). The increase in interstitial salt concentrations in 2009 was coupled to an increase in relative numbers of OTU03 (Figure 4), which is also related to the $N$. marina lineage. The presence of the two related OTUs in the habitats with high interstitial salinities demonstrates that this lineage is more adapted to hypersaline concentrations.

OTU04 was comprised of Nitrosomonas sp. Nm143-related clones and it had a higher relative abundance in all habitats in 2010 and in the dense habitat in all 3 years that the soils were sampled (Figures 4 and 5). Soil moisture was highest in 2010 compared to 2008 and 2009 and it was also highest in the dense habitat in all 3 years (Figure 1). Therefore, it seems that members of this lineage are more adapted to higher moisture contents, which could be translated to limited oxygen availability, but also to changed accessibility of redox-sensitive nutrients such as iron and phosphate.

OTU06 consisting of Nitrosospira cluster one-related clones was relatively abundant in the sparse habitat. We were unable to identify a single soil factor or group of factors that were associated with OTU06. From an earlier study on the distribution of $\beta$-AOB in a tidal freshwater wetland (Laanbroek and Speksnijder, 2008), however, it was concluded that Nitrosospira lineages were better survivors under nutrient-limited conditions. Previous research at the current study sites has demonstrated the importance of nitrogen limitation on the growth form of black mangroves (Whigham et al., 2009). Nitrogen limitation is important in all three habitats but it may be the factor that is specifically associated with Nitrosospira cluster 1 in the sparse habitat.

\section{BETAPROTEOBACTERIA AND OTHER AMMONIA-OXIDIZING MICROBES}

A goal of our study was to determine if changes in impoundment management would alter the distribution of members of the $\beta$ AOB. Studies related to numbers and diversity of aerobic nitrifying microorganisms in mangroves are limited. Archaeal and bacterial amo $A$ genes were found in rehabilitated and pristine mangrove forests dominated by Gray (Avicennia marina) and White (A. alba) mangroves in the vicinity of Bangkok, Thailand (Wickramasinghe et al., 2009). Most AOB related sequences belonged to the lineages N. aestuarii/N. marina and Nitrosospira. No members of the ammonia-oxidizing gammaproteobacteria were detected. The numbers of bacterial amoA genes in a Kandelia obovatadominated mangrove forest in the New Territories of Hong Kong, outnumbered those of archaeal $a m o A$ genes by a factor of 512 (Li et al., 2011). The distance between individual mangrove trees had a significant effect on the community composition of the ammonia-oxidizing community of betaproteobacteria. The communities of $\beta$-AOB were grouped by the distance to the mangroves, whereas those of the archaeal amoA genes clustered 
into surface and deeper sediment groups. Most of the bacterial $a m o A$ clones identified from the mangrove forest soils belonged to clusters mostly related to the $N$. marina lineage. In a parallel analysis on the presence and diversity amo $A$ genes of ammoniaoxidizing archaea and bacteria in polluted mangrove sediments in the Mai Po Nature Reserve of Hong Kong, the dominance of the N. marina/N. oligotropha was confirmed (Cao et al., 2011a). No Nitrosospira-related amoA genes were detected. However, when applying the $16 \mathrm{~S}$ rRNA gene, Co and co-workers detected two clusters of Nitrosospira-related sequences. The $\beta$-AOB outnumbered the AOA with 3-6 in the polluted mangrove sediments (Cao et al., 2011a).

Meyer and colleagues (Meyer et al., 2005) reported for the first time on the presence of Planctomycetes in mangrove soils. These microorganisms are capable of oxidizing ammonia under anoxic conditions (i.e., Anammox bacteria). Wickramasinghe et al. (2009) observed different phylotypes of ammonia-oxidizing Planctomycetes in rehabilitated mangrove forests in Thailand. The Anammox bacteria were related to Candidatus Scalindua brodae and Candidatus Scalindua wagneri. Again, no members of the ammonia-oxidizing gammaproteobacteria had been detected. In a study on the presence of Anammox bacteria in a mangrove forest soil near a shrimp pond in Haiphong, Vietnam, Amano et al. (2011)) observed mixed communities of Anammox bacteria dominate by phylotypes associated with Candidatus Scalindua sorokinii and Candidatus Scalindua wagneri. In the mangrove forest soils, they observed smaller numbers of sequences belonging to Candidatus Kuenenia stuttgartiensis, the phylotypes that dominated the sediment of the shrimp pond.

\section{CONCLUSION}

In this study we observed a limited diversity among the lineages of ammonia-oxidizing betaproteobacteria in the three habitats. Although the lineages were not equally distributed among the different habitats, we were unable to identify critical soil factors

\section{REFERENCES}

Alongi, D. M. (2008). Mangrove forests: resilience, protection from tsunamis, and responses to global climate change. Estuar. Coast. Shelf Sci. 76, $1-13$.

Amano, T., Yoshinaga, I., Yamagishi, T., Chu, V. T., Pham, T. T., Ueda, S., Kato, K., Sako, Y., and Suwa, Y. (2011). Contribution of anammox bacteria to benthic nitrogen cycling in a Mangrove forest and shrimp ponds, Haiphong, Vietnam. Microbes Environ. 26, 1-6.

Bae, H., and Lee, S. (2011). Failure of SHARON Process under Organic Carbon Limitation and $\mathrm{NaOH}$ Addition. GenBank.

Bae, H., and Song, J. (2011). Microbial Community Structure in Nitrifying Bioreactor. GenBank.

Bano, N., Smith, A. D., Caffrey, J. M., and Hollibaugh, J. T. (2008). Diversity of Ammonia-oxidizing Archaea

that may have been responsible for the differences. However, as the distribution of the $\beta$-AOB lineages seems to parallel the differences in plant size and density in the three habitats, focusing future efforts on revealing the factors responsible for differences in the mangroves should also provide insight in to the factors responsible for differences in the microbial communities. Based on previous studies on nutrient limitations in mangroves, potential governing factors that should be examined are nutrient (i.e., ammonium) availability, salinity, frequency of tidal inundation, degree of soil anoxia, and $\mathrm{pH}$. Such studies could well be done in microcosms containing natural mangrove soils as we have applied in a study on the effect of marine and estuarine water on the community composition of $\beta$-AOB present in a tidal freshwater wetland (Coci et al., 2005).

One might wonder whether the dynamics in environmental parameters are immediately reflected in changes in microbial community compositions that are based on DNA analyses. Inactive cells remain present in the soil when conditions change. Analysis at the RNA level would likely have given a more actual representation of the presence of active $\beta$-AOB and hence a better correlation with changing environmental conditions.

\section{ACKNOWLEDGMENTS}

We like to thank Dr. Mark Rains of the University of South Florida for the information related to the hydrology of the impounded mangrove forest in the Avalon State Park at North Hutchinson Island, St. Lucie County, FL, USA. We also want to acknowledge the help we obtained from Dr. Valery Paul, Woody Lee, and staff of the Smithsonian Marine Station at Fort Pierce. The research was supported by a grant of the Smithsonian Marine Science Network and by resources of the Smithsonian Environmental Research Center, Utrecht University, and the Netherlands Institute of Ecology. This is publication number 5252 of the Netherlands Institute of Ecology (NIOO-KNAW) and publication number 879 of the Smithsonian Marine Station.

and Earnest, L. (1997). Rehabilitation of impounded estuarine wetlands by hydrologic reconnection to the Indian River Lagoon, Florida (USA). Wetlands Ecol. Manage. 4, 93-109.

Caffrey, J. M., Harrington, N., Solem, I., and Ward, B. B. (2003). Biogeochemical processes in a small California estuary. 2. Nitrification activity, community structure and role in nitrogen budgets. Mar. Ecol. Prog. Ser. 248, 27-40.

Cao, H. L., Li, M., Dang, H. Y., and Gu, J. D. (2011a). Responses of aerobic and anaerobic ammonia/ammoniumoxidizing microorganisms to anthropogenic pollution in coastal marine environments. Methods Enzymol. 46(Pt B), 35-62.

Cao, H. L., Li, M., Hong, Y. G., and Gu, J. D. (2011b). Diversity and abundance of ammonia-oxidizing archaea and bacteria in polluted mangrove sediment. Syst. Appl. Microbiol. 34, 513-523.

Carini, S. A., and Joye, S. B. (2008). Nitrification in Mono Lake, California: activity and community composition during contrasting hydrological regimes. Limnol. Oceanogr. 53, 2546-2557.

Cebron, A., Coci, M., Garnier, J., and Laanbroek, H. J. (2004). Denaturing gradient gel electrophoretic analysis of ammonia-oxidizing bacterial community structure in the lower Seine River: impact of Paris wastewater effluents. Appl. Environ. Microbiol. 70, 6726-6737.

at low ammonium concentration and starvation response as potential factors involved in niche differentiation among ammonia-oxidizing bacteria. Appl. Environ. Microbiol. 68, 4751-4757.

Brockmeyer, R. E., Rey, J. R., Virnstein, R. W., Gilmore, R. G.,
Coci, M., Riechmann, D., Bodelier, P. L. E., Stefani, S., Zwart, G., and Laanbroek, H. J. (2005). Effect of salinity on temporal and spatial dynamics of ammonia-oxidising bacteria from intertidal freshwater sediment. FEMS Microbiol. Ecol. 53, 359-368. 
Dorador, C., Busekow, A., Vila, I., Imhoff, J. F., and Witzel, K. P. (2008). Molecular analysis of enrichment cultures of ammonia oxidizers from the Salar de Huasco, a high altitude saline wetland in northern Chile. Extremophiles 12, 405-414.

Feller, I. C., Whigham, D. F., Mckee, K. L., and Lovelock, C. E. (2003). Nitrogen limitation of growth and nutrient dynamics in a disturbed mangrove forest, Indian River Lagoon, Florida. Oecologia 134, 405-414.

Foesel, B. U., Gieseke, A., Schwermer, C., Stief, P., Koch, L., Cytryn, E., De La Torre, J. R., Van Rijn, J., Minz, D., Drake, H. L., and Schramm, A. (2008). Nitrosomonas Nm143-like ammonia oxidizers and Nitrospira marina-like nitrite oxidizers dominate the nitrifier community in a marine aquaculture biofilm. FEMS Microbiol. Ecol. 63, 192-204.

Francis, C. A., O’Mullan, G. D., and Ward, B. B. (2003). Diversity of ammonia monooxygenase (amoA) genes across environmental gradients in Chesapeake Bay sediments. Geobiology 1, 129-140.

Freitag, T. E., Chang, L., and Prosser, J. I. (2006). Changes in the community structure and activity of betaproteobacterial ammoniaoxidizing sediment bacteria along a freshwater-marine gradient. Environ. Microbiol. 8, 684-696.

Jin, T., Zhang, T., Ye, L., Lee, O. O., Wong, Y. H., and Qian, P. Y. (2011). Diversity and quantity of ammoniaoxidizing Archaea and Bacteria in sediment of the Pearl River Estuary, China. Appl. Microbiol. Biotechnol. 90, 1137-1145.

Kowalchuk, G. A., and Stephen, J. R. (2001). Ammonia-oxidizing bacteria: a model for molecular microbial ecology. Annu. Rev. Microbiol. 55, 485-529.

Kowalchuk, G. A., Stephen, J. R., De Boer, W., Prosser, J. I., Embley, T. M., and Woldendorp, J. W. (1997). Analysis of ammonia-oxidizing bacteria of the beta subdivision of the class proteobacteria in coastal sand dunes by denaturing gradient gel electrophoresis and sequencing of PCR-amplified 16s ribosomal DNA fragments. Appl. Environ. Microbiol. 63, 1489-1497.

Kristensen, E., Jensen, M. H., Banta, G. T., Hansen, K., Holmer, M., and King, G. M. (1998). Transformation and transport of inorganic nitrogen in sediments of a southeast asian mangrove forest. Aquat. Microb. Ecol. 15, 165-175.

Laanbroek, H. J., and Speksnijder, A. G. C. L. (2008). Niche separation of ammonia-oxidizing bacteria across a tidal freshwater marsh. Environ. Microbiol. 10, 3017-3025.

Li, M., Cao, H. L., Hong, Y. G., and Gu, J. D. (2011). Spatial distribution and abundances of ammonia-oxidizing archaea (AOA) and ammoniaoxidizing bacteria (AOB) in mangrove sediments. Appl. Microbiol. Biotechnol. 89, 1243-1254.

Lovelock, C. E., and Feller, I. C. (2003). Photosynthetic performance and resource utilization of two mangrove species coexisting in a hypersaline scrub forest. Oecologia 134, 455-462.

Ma, Y., Wang, L., and Qian, L. M. (2008). Community structure of beta-proteobacterial ammoniaoxidizing bacteria in prawn farm sediment. Prog. Nat. Sci. 18, 679-684.

McCaig, A. E., Embley, T. M., and Prosser, J. I. (1994). Molecular analysis of enrichment cultures of marine ammonia oxidisers. FEMS Microbiol. Lett. 120, 363-367.

Meyer, R. L., Risgaard-Petersen, N., and Allen, D. E. (2005). Correlation between anammox activity and microscale distribution of nitrite in a subtropical mangrove sediment. Appl. Environ. Microbiol. 71, 6142-6149.

Mosier, A. C., and Francis, C. A. (2008). Relative abundance and diversity of ammonia-oxidizing archaea and bacteria in the San Francisco Bay estuary. Environ. Microbiol. 10, 3002-3016.

Nakamura, Y., Satoh, H., Kindaichi, T., and Okabe, S. (2006). Community structure, abundance, and in situ activity of nitrifying bacteria in river sediments as determined by the combined use of molecular techniques and microelectrodes.
Environ. Sci. Technol. 40, 1532-1539.

Rey, J., and Kain, T. (1991). A Guide to the Salt Marsh Impoundments of Florida. Vero Beach, FL: University of Florida, Florida Medical Entomology Laboratory.

Sahan, E., and Muyzer, G. (2008). Diversity and spatio-temporal distribution of ammonia-oxidizing archaea and bacteria in sediments of the Westerschelde estuary. FEMS Microbiol. Ecol. 64, 175-186.

Schleper, C., and Nicol, G. W. (2010). "Ammonia-oxidising archaea physiology, ecology and evolution," in Advances in Microbial Physiology, Vol. 57, ed. Robert K. Poole (Oxford: Academic Press), 1-41.

Schloss, P. D., Westcott, S. L., Ryabin, T., Hall, J. R., Hartmann, M., Hollister, E. B., Lesniewski, R. A., Oakley, B. B. Parks, D. H., Robinson, C. J., Sahl, J. W., Stres, B., Thallinger, G. G., Van Horn, D. J., and Weber, C. F. (2009). Introducing mothur: open-source, platform-independent, communitysupported software for describing and comparing microbial communities. Appl. Environ. Microbiol. 75, 7537-7541.

Stringer, C. E. (2010). Hydrologic Controls on Salinity in Mangroves and Lagoons. Doctor of Philosophy, University of South Florida, Tampa.

Stringer, C. E., Rains, M. C., Kruse, S., and Whigham, D. (2010). Controls on water levels and salinity in a Barrier Island Mangrove, Indian River Lagoon, Florida. Wetlands 30, 725-734.

Urakawa, H., Maki, H., Kawabata, S. Fujiwara, T., Ando, H., Kawai, T. Hiwatari, T., Kohata, K., and Watanabe, M. (2006). Abundance and population structure of ammoniaoxidizing bacteria that inhabit canal sediments receiving effluents from municipal wastewater treatment plants. Appl. Environ. Microbiol. 72, 6845-6850.

Verhagen, F. J. M., and Laanbroek, H. J. (1991). Competition for ammonium between nitrifying and heterotrophic bacteria in dual energy-limited chemostats. Appl. Environ. Microbiol. 57, 3255-3263.
Ward, B. B., Martino, D. P., Diaz, M. C., and Joye, S. B. (2000). Analysis of ammonia-oxidizing bacteria from hypersaline Mono Lake, California, on the basis of 16S rRNA sequences. Appl. Environ. Microbiol. 66, 2873-2881.

Whigham, D. F., Verhoeven, J. T. A., Samarkin, V., and Megonigal, P. J. (2009). Responses of Avicennia germinans (Black Mangrove) and the soil microbial community to nitrogen addition in a hypersaline wetland. Estuaries Coast 32, 926-936.

Wickramasinghe, S., Borin, M., Kotagama, S. W., Cochard, R., Anceno, A. J., and Shipin, O. V. (2009). Multi-functional pollution mitigation in a rehabilitated mangrove conservation area. Ecol. Eng. 35, 898-907.

Zhou, J. Z., Bruns, M. A., and Tiedje, J. M. (1996). DNA recovery from soils of diverse composition. Appl. Environ. Microbiol. 62, 316-322.

Conflict of Interest Statement: The authors declare that the research was conducted in the absence of any commercial or financial relationships that could be construed as a potential conflict of interest.

Received: 21 November 2011; accepted: 02 April 2012; published online: 23 April 2012.

Citation: Laanbroek HJ, Keijzer RM, Verhoeven JTA and Whigham DF (2012) The distribution of ammoniaoxidizing betaproteobacteria in stands of Black mangroves (Avicennia germinans). Front. Microbio. 3:153. doi: 10.3389/fmicb.2012.00153

This article was submitted to Frontiers in Terrestrial Microbiology, a specialty of Frontiers in Microbiology.

Copyright (c) 2012 Laanbroek, Keijzer, Verhoeven and Whigham. This is an open-access article distributed under the terms of the Creative Commons Attribution Non Commercial License, which permits non-commercial use, distribution, and reproduction in other forums, provided the original authors and source are credited. 


\title{
Methanogenic pathway and archaeal communities in three different anoxic soils amended with rice straw and maize straw
}

\author{
Ralf Conrad $^{1 *}$, Melanie Klose ${ }^{1}$, Yahai Lu ${ }^{2}$ and Amnat Chidthaisong ${ }^{3,4}$ \\ ${ }^{1}$ Max-Planck-Institute for Terrestrial Microbiology, Marburg, Germany \\ ${ }^{2}$ College of Resources and Environmental Sciences, China Agricultural University, Beijing, China \\ ${ }^{3}$ Joint Graduate School of Energy and Environment, King Mongkut's University of Technology Thonburi, Bangkok, Thailand \\ ${ }^{4}$ Center for Energy Technology and Environment, Ministry of Education, Bangkok, Thailand
}

\section{Edited by:}

Paul Bodelier, Netherlands Institute of Ecology, Netherlands

\section{Reviewed by:}

Tillmann Lueders, Helmholtz Zentrum Muenchen, Germany

Kim Yrjälä, University of Helsinki,

Finland

Sascha M. B. Krause, Netherlands Institute of Ecology Royal Dutch

Academy of Science, Netherlands

\section{${ }^{*}$ Correspondence:}

Ralf Conrad, Max-Planck-Institute for

Terrestrial Microbiology,

Karl-von-Frisch-Str. 10, 35043

Marburg, Germany.

e-mail: conrad@mpi-marburg.mpg.de
Addition of straw is common practice in rice agriculture, but its effect on the path of microbial $\mathrm{CH}_{4}$ production and the microbial community involved is not well known. Since straw from rice (C3 plant) and maize plants (C4 plant) exhibit different $\delta^{13} \mathrm{C}$ values, we compared the effect of these straw types using anoxic rice field soils from Italy and China, and also a soil from Thailand that had previously not been flooded. The temporal patterns of production of $\mathrm{CH}_{4}$ and its major substrates $\mathrm{H}_{2}$ and acetate, were slightly different between rice straw and maize straw. Addition of methyl fluoride, an inhibitor of acetoclastic methanogenesis, resulted in partial inhibition of acetate consumption and $\mathrm{CH}_{4}$ production. The $\delta^{13} \mathrm{C}$ of the accumulated $\mathrm{CH}_{4}$ and acetate reflected the different $\delta^{13} \mathrm{C}$ values of rice straw versus maize straw. However, the relative contribution of hydrogenotrophic methanogenesis to total $\mathrm{CH}_{4}$ production exhibited a similar temporal change when scaled to $\mathrm{CH}_{4}$ production irrespectively of whether rice straw or maize straw was applied. The composition of the methanogenic archaeal communities was characterized by terminal restriction fragment length polymorphism (T-RFLP) analysis and was quantified by quantitative PCR targeting archaeal 16S rRNA genes or methanogenic mcrA genes. The size of the methanogenic communities generally increased during incubation with straw, but the straw type had little effect. Instead, differences were found between the soils, with Methanosarcinaceae and Methanobacteriales dominating straw decomposition in Italian soil, Methanosarcinaceae, Methanocellales, and Methanobacteriale in China soil, and Methanosarcinaceae and Methanocellales in Thailand soil. The experiments showed that methanogenic degradation in different soils involved different methanogenic population dynamics. However, the path of $\mathrm{CH}_{4}$ production was hardly different between degradation of rice straw versus maize straw and was also similar for the different soil types.

Keywords: methanogenesis, rice field soil, straw, archaea, pathway

\section{INTRODUCTION}

Methane production in rice fields is driven by the anaerobic degradation of organic matter. The organic matter that is converted into $\mathrm{CH}_{4}$ is basically derived from three different sources, i.e., straw, soil organic matter (SOM), and plant photosynthesis (Watanabe et al., 1999). Addition of straw, which is common practice in rice agriculture to improve soil fertility, enhances $\mathrm{CH}_{4}$ production in flooded rice fields and results in increased $\mathrm{CH}_{4}$ emission (Schütz et al., 1989; Denier van der Gon and Neue, 1995; Watanabe et al., 1995; Yan et al., 2005). Under such conditions, $\mathrm{CH}_{4}$ production derived from SOM can be negligible in comparison to that derived from straw (Chidthaisong and Watanabe, 1997; Watanabe et al., 1998). The methanogenic degradation of straw is achieved by fermentation producing acetate and $\mathrm{H}_{2} / \mathrm{CO}_{2}$ as major intermediates from which $\mathrm{CH}_{4}$ is formed (Glissmann and Conrad, 2002). Besides rice straw also the addition of straw from other plants, e.g., vetch, rape seed, wheat, was studied (Cai et al., 2001; Ma et al., 2008). However, maize straw has not received much attention, despite the fact that crop rotation between maize and rice has recently increased and is now already covering about 3.5 million hectare in Asia (Timsina et al., 2010).

Both rice and maize straw consist mainly of cellulose (30-40\%), hemicellulose (25-35\%), and lignin (4-8\%; Tian et al., 1992; Singh et al., 2011). However, maize is a C4 plant while rice is a C3 plant resulting in distinct $\delta^{13} \mathrm{C}$ values of the plants and their degradation products. While plants with a C3 photosynthesis have $\delta^{13} \mathrm{C}$ values on the average of about $-27 \%$, plants with a $\mathrm{C} 4$ photosynthesis have much higher $\delta^{13} \mathrm{C}$ values, about $-13 \%$ (Farquhar et al., 1989). This difference in natural ${ }^{13} \mathrm{C}$ abundance has been exploited to study carbon turnover in soil (Amelung et al., 2008), for example, to determine the partitioning between $\mathrm{CO}_{2}$ derived from root organic matter versus SOM (Balesdent and Balabane, 1992; Hanson et al., 2000; Kuzyakov, 2006). Such determination of partitioning is possible by measuring the $\delta^{13} \mathrm{C}$ of $\mathrm{CO}_{2}$ produced 
in a field that undergoes vegetation change from $\mathrm{C} 3$ to $\mathrm{C} 4$ plant or vice versa (e.g., Rochette et al., 1999; Flessa et al., 2000; Kuzyakov and Cheng, 2001).

The partitioning of the $\mathrm{CH}_{4}$ emission should in principle also be possible and would be of great interest in order to allow better management of this important greenhouse gas. However, partitioning studies have so far only been conducted by pulse labeling experiments with ${ }^{13} \mathrm{CO}_{2}$. These studies indicate that about $50 \%$ of the $\mathrm{CH}_{4}$ emitted may originate from the rice plants, either by root exudation or root decay (Minoda and Kimura, 1994; Watanabe et al., 1999). However, pulse labeling experiments are cumbersome and invasive. Experiments using the natural abundance of $\delta^{13} \mathrm{C}$ have so far not been conducted for partitioning the $\mathrm{CH}_{4}$ production. One problem is the potentially large isotopic fractionation factors that are involved in the conversion of organic matter to $\mathrm{CH}_{4}$ (Conrad, 2005). These fractionation factors are on the order of $10-70 \%$ and thus, more than an order of magnitude larger than the fractionation factors involved in conversion of organic matter to $\mathrm{CO}_{2}$, which are only about 1-3\%o (Werth and Kuzyakov, 2010). The fractionation factors involved in $\mathrm{CH}_{4}$ production strongly depend on the path of $\mathrm{CH}_{4}$ formation. Thus, it is much larger for $\mathrm{CH}_{4}$ formation from $\mathrm{H}_{2} / \mathrm{CO}_{2}$ (typically $50-70 \%$ ) than for $\mathrm{CH}_{4}$ formation from acetate (typically $10-20 \%$; Conrad, 2005). The extent to which $\mathrm{H}_{2} / \mathrm{CO}_{2}$ and acetate contribute to $\mathrm{CH}_{4}$ formation thus crucially affects the stable carbon isotope fractionation during $\mathrm{CH}_{4}$ production from organic matter. Since the path of $\mathrm{CH}_{4}$ production may be dependent on type of organic matter degraded, we were interested whether methanogenic degradation of maize straw would be different from that of maize straw.

Methanogenic degradation of organic matter in flooded soils is achieved by a complex microbial community consisting of hydrolytic, fermenting, and methanogenic microorganisms (Conrad, 2007). The $\mathrm{CH}_{4}$ is usually produced by acetoclastic and hydrogenotrophic methanogenic archaea. Rice field soils frequently exhibit a rather large diversity of such methanogenic archaea, including acetoclastic Methanosarcinaceae and Methanosaetaceae as well as hydrogenotrophic Methanocellales, Methanomicrobiales, and Methanobacteriales. The abundance of methanogens in rice field soils is usually rather high $\left(>10^{6}\right.$ cells g $^{-1}$ dry soil) throughout the season, even when the soil is drained (Krüger et al., 2005; Ma et al., 2012). Upland soils, on the other hand, contain only very low numbers $\left(<10^{3}\right)$ of methanogens. However, these numbers may dramatically increase upon flooding of the soil (Peters and Conrad, 1996; Angel et al., 2011, 2012).

We comparatively studied carbon isotopic fractionation during $\mathrm{CH}_{4}$ production in three different soils (two rice field soils and one upland soil) amended with either rice straw or maize straw, determined the paths of $\mathrm{CH}_{4}$ formation and the methanogenic archaea involved in order to address the following research questions: (1) Is the relative contribution of hydrogenotrophic and acetoclastic methanogenesis to $\mathrm{CH}_{4}$ production different during degradation of maize straw versus rice straw; (2) is there a difference when different soils, including rice field soil and upland soil, are amended; (3) how does straw affect the composition and abundance of the methanogenic archaeal community; and (4) can amendment with maize straw serve as a labeling technique to determine partitioning of C-flux to $\mathrm{CH}_{4}$ ?

\section{MATERIALS AND METHODS SOIL INCUBATION}

Soils were collected from Italy (Vercelli), China (Fuyang), and Thailand (Suwan). The Italian soil (Vercelli), a silt loam, was originally from a rice field $\left(45.9^{\circ} \mathrm{N}, 171.6^{\circ} \mathrm{E}\right)$ at the Italian Rice Research Institute in Vercelli, Italy (Holzapfel-Pschorn et al., 1986), and has subsequently been used for cultivation of rice in our glasshouse. The China soil (Fuyang), a clay loam, was collected in 2007 from a rice field $\left(30.1^{\circ} \mathrm{N}, 119.9^{\circ} \mathrm{E}\right)$ at the China National Rice Research Institute in Fuyang, Hangzhou (Peng et al., 2008). The Thailand soil (Suwan), a clay soil, was collected in 2010 from an upland field site $\left(14.6^{\circ} \mathrm{N}, 101.3^{\circ} \mathrm{E}\right)$ at the National Corn and Sorghum Research Center of Kasetsart University (Suwanwajokkasikit Field Corps Research Station), Nakornratchasima province, Thailand (Thongsaga et al., 2010). The field had been cropped with maize for several years. The content of C (\%) of the soils from Vercelli, Fuyang, and Suwan was $1.3 \pm 0.01,2.4 \pm 0.1$, and $2.0 \pm 0.1$, respectively. The $\mathrm{N}$ content (\%) was $0.13 \pm 0.01,0.25 \pm 0.01$, and $0.19 \pm 0.03$, respectively. The soils were air-dried and stored in dry state at room temperature. This treatment ensures that methanogenic activity rapidly recovers after flooding (Mayer and Conrad, 1990). Rice straw originated from rice plants and maize straw from maize plants, both grown in our glasshouse using Italian rice field soil or commercial standard soil, respectively. The straw was air-dried and ground using a blender. The $\mathrm{C}$ and $\mathrm{N}$ contents of maize straw were $40.2 \% \mathrm{C}$ and $2.4 \% \mathrm{~N}$, of rice straw $41.7 \%$ $\mathrm{C}$ and $0.7 \% \mathrm{~N}$. The $\delta^{13} \mathrm{C}$ of the maize straw was $-12.97 \pm 0.05 \%$, that of rice straw was $-30.96 \pm 0.10 \%$.

Soil slurries were prepared by mixing $600 \mathrm{~g}$ dry soil with $600 \mathrm{~mL}$ of deionized, sterile, anoxic water, and incubating the mixture in $2 \mathrm{~L}$ bottles under a headspace of $\mathrm{N}_{2}$ at $25^{\circ} \mathrm{C}$ for 4 weeks. The soil slurry was then amended with either rice straw or maize straw at a ratio of $10 \mathrm{mg}$ dry ground straw per gram dry soil, and aliquots ( $10 \mathrm{~g}$ slurry) dispensed into $26 \mathrm{~mL}$ pressure tubes. The tubes were closed with black rubber stoppers, flushed with $\mathrm{N}_{2}$, pressurized to 0.5 bar overpressure, and incubated at $25^{\circ} \mathrm{C}$. The tubes with soil slurry were prepared in numerous parallels, of which triplicates were sacrificed for chemical analyses. The gas phase of some incubations was amended with $\mathrm{CH}_{3} \mathrm{~F}$, an inhibitor of acetoclastic methanogenesis (Janssen and Frenzel, 1997; Conrad and Klose, 1999b), at a ratio of 1 or $2 \%$. The initial $\mathrm{pH}$ values of the soil slurries were between pH 6.1 (Vercelli) and 7.3 (Suwan), but upon anoxic incubation narrowed to $\mathrm{pH}$ values between $\mathrm{pH} 6.7$ and 7.0.

\section{CHEMICAL MEASUREMENTS}

Methane was quantified in a gas chromatograph (GC) equipped with methanizer and flame ionization detector, $\mathrm{H}_{2}$ in a GC with a reduced gas detector (Conrad and Klose, 1999a). The partial pressures of $\mathrm{CH}_{4}$ measured in the headspace of the incubations were converted into molar quantities using the molar volumes of an ideal gas at the different temperatures. The isotopic composition $\left(\delta^{13} \mathrm{C}\right)$ of $\mathrm{CH}_{4}$ and $\mathrm{CO}_{2}$ were determined in a Finnigan gas chromatograph combustion isotope ratio mass spectrometer (GC-C-IRMS) system (Thermoquest, Bremen, Germany; Fey et al., 2004). Concentrations of acetate in the liquid phase of the soil incubations were analyzed by high pressure liquid chromatography (HPLC; Krumböck and Conrad, 1991), the $\delta^{13} \mathrm{C}$ 
of acetate by a HPLC-C-IRMS as described before (Conrad et al., 2007). The $\delta^{13} \mathrm{C}$ of the methyl group of acetate was determined by off-line pyrolysis followed by GC-C-IRMS analysis (Conrad et al., 2007). The $\mathrm{C}$ and $\mathrm{N}$ content of soil and straw were analyzed on a CHNS-elemental analyzer by the Analytical Chemical Laboratory of the University of Marburg. The $\delta^{13} \mathrm{C}_{\text {org }}$ of straw and the straw-amended soils were analyzed at the Centre for Stable Isotope Research and Analysis (KOSI) at the University of Göttingen using an elemental analyzer coupled to an IRMS. The $\delta^{13} \mathrm{C}_{\text {org }}$ were for Italian, China, and Thailand soil, respectively, $-27.1,-27.6$, and $-22.3 \%$ for rice straw-amended and $-24.6,-25.9$, and $-18.6 \%$ o for maize straw-amended soil.

\section{MOLECULAR ANALYSES}

DNA was extracted from the soil using the Fast DNA Spin Kit for soil (MP, Heidelberg, Germany) following the manufacturer's instructions as described in detail by Kolb et al. (2005). DNA extraction was optimized to obtain maximum copy numbers of archaeal 16S rRNA in quantitative PCR (qPCR; see below), which was by combining the DNA from 1,2, and 3 extractions for soil from Vercelli, Suwan, and Fuyang, respectively. The analysis of terminal restriction fragment length polymorphism (T-RFLP) of archaeal 16S rRNA genes was done as described (Chin et al., 1999) using the primer combination Ar109f/Ar915r (Grosskopf et al., 1998), with the reverse primer labeled with FAM (6caboxyfluorescein). The 16S rRNA gene amplicons were digested with TaqI (Fermentas, St. Leon Rot, Germany), and the products were size-separated in an ABI 3130 DNA sequencer (Applera, Darmstadt, Germany). The abundance of total archaeal 16S rRNA gene copies was determined by qPCR (Angel et al., 2011, 2012). The abundance of individual groups of archaea was calculated from the relative abundances of their T-RFs multiplied with the copy numbers of total archaeal 16S rRNA genes determined by qPCR (Conrad and Klose, 2006). The abundance of total copies of the mcrA gene, coding for a subunit of the methyl coenzyme $M$ reductase of methanogens was also determined (only in Suwan soil) by qPCR (Angel et al., 2011). The abundance of individual groups of methanogens (only in Suwan soil) was determined by TaqMan qPCR targeting specific 16S rRNA gene sequences (Yu et al., 2005) as described by Angel et al. (2012).

\section{CALCULATIONS}

Values of $\delta^{13} \mathrm{C}$ are defined by

$\delta^{13} \mathrm{C}=10^{3}\left(R_{\mathrm{sa}} / R_{\mathrm{st}}-1\right)$

with $R={ }^{13} \mathrm{C} /{ }^{12} \mathrm{C}$ of sample (sa) and standard (st) respectively, using VPDB carbonate as standard. Fractionation factors for a reaction $\mathrm{A} \rightarrow \mathrm{B}$ are defined after (Hayes, 1993; Angel et al., 2012):

$\alpha_{A, B}=\frac{\left(\delta^{13} C_{A}+1000\right)}{\left(\delta^{13} C_{B}+1000\right)}$

sometimes expressed as isotopic enrichment factor $\varepsilon \equiv 1-\alpha$ (in units of per mile). The fractionation factor for conversion of $\mathrm{CO}_{2}$ to $\mathrm{CH}_{4}$ is given by

$\alpha_{\mathrm{CO}_{2}, \mathrm{CH}_{4}}=\frac{\left(\delta^{13} \mathrm{C}_{\mathrm{CO}_{2}}+1000\right)}{\left(\delta^{13} \mathrm{C}_{\mathrm{CH}_{4}-\mathrm{mc}}+1000\right)}$ where $\delta^{13} \mathrm{C}_{\mathrm{CH}_{4}-\mathrm{mc}}$ is the $\delta^{13} \mathrm{C}$ of the $\mathrm{CH}_{4}$ derived from $\mathrm{H}_{2}+\mathrm{CO}_{2}$, i.e., the $\mathrm{CH}_{4}$ produced in the presence of $\mathrm{CH}_{3} \mathrm{~F}$, assuming that acetoclastic methanogenesis was then completely inhibited.

Relative contribution of $\mathrm{H}_{2}+\mathrm{CO}_{2}$-derived $\mathrm{CH}_{4}$ to total $\mathrm{CH}_{4}$ was determined using the following mass balance equation (Conrad, 2005):

$f_{\mathrm{CO}_{2}, \mathrm{CH}_{4}}=\frac{\left(\delta^{13} \mathrm{C}_{\mathrm{CH}_{4}}-\delta^{13} \mathrm{C}_{\mathrm{CH}_{4}-\mathrm{ma}}\right)}{\left(\delta^{13} \mathrm{C}_{\mathrm{CH}_{4}-\mathrm{mc}}-\delta^{13} \mathrm{C}_{\mathrm{CH}_{4}-\mathrm{ma}}\right)}$

where $f_{\mathrm{CO}_{2}}, \mathrm{CH}_{4}$ is the fraction of $\mathrm{CH}_{4}$ formed from $\mathrm{H}_{2}+\mathrm{CO}_{2}$, $\delta^{13} \mathrm{C}_{\mathrm{CH}_{4}}$ the $\delta^{13} \mathrm{C}$ of total produced methane, $\delta^{13} \mathrm{C}_{\mathrm{CH}_{4}-\mathrm{mc}}$ the $\delta^{13} \mathrm{C}$ of $\mathrm{CH}_{4}$ derived from $\mathrm{H}_{2}+\mathrm{CO}_{2}$, and $\delta^{13} \mathrm{C}_{\mathrm{CH}_{4}-\mathrm{ma}}$ the $\delta^{13} \mathrm{C}$ of $\mathrm{CH}_{4}$ derived from acetate determined by:

$\delta^{13} \mathrm{C}_{\mathrm{CH}_{4}-\mathrm{ma}}=\delta^{13} \mathrm{C}_{\mathrm{ac}-\text { methyl }}+\varepsilon_{\mathrm{ac}, \mathrm{CH}_{4}}$

where $\delta^{13} \mathrm{C}_{\mathrm{ac}-\text { methyl }}$ is the $\delta^{13} \mathrm{C}$ of the methyl group of acetate accumulated and $\varepsilon_{\mathrm{ac}-\text { methyl, } \mathrm{CH}_{4}}$ is the isotopic enrichment factor

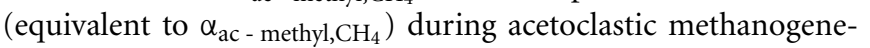
sis. It is assumed, that the methyl group of acetate was converted

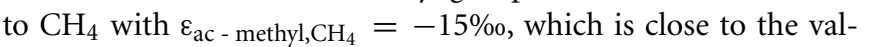
ues determined previously for straw-amended or acetate-amended rice field soil dominated by Methanosarcina species as acetoclastic methanogens (Penning and Conrad, 2007; Goevert and Conrad, 2009).

\section{RESULTS}

\section{METHANE PRODUCTION}

Methane was produced from each soil amended with either rice straw or maize straw (Figure 1). Vigorous $\mathrm{CH}_{4}$ production started after about 2 days in soil from Vercelli and Fuyang, and after about 7 days in soil from Suwan. The soil from Suwan was not an authentic rice field soil and had so far not been flooded. Note that the soil from Suwan was preincubated under anoxic conditions without straw amendment for 38 days before the experiment shown in Figure 1C was started. Furthermore, in contrast to soils from Vercelli and Fuyang, production of $\mathrm{CH}_{4}$ from Suwan soil was only observed when straw was added (data not shown). However, the maximum rates of $\mathrm{CH}_{4}$ production were in a similar range (140$200 \mathrm{nmol} \mathrm{h}^{-1} \mathrm{~g}^{-1}$ dry soil) in all three soils, irrespectively which type of straw was added. Addition of methyl fluoride (1-2\%) partially inhibited $\mathrm{CH}_{4}$ production in all incubations (Figure 1). The $\mathrm{pH}$ values during methanogenesis were between $\mathrm{pH} 6.8$ and 7.1 .

Acetate transiently accumulated in all incubations indicating that it was produced during degradation of organic matter (straw) and consumed by methanogenesis (Figure 2). The maximum amount of acetate accumulated accounted for about $30-50 \%$ of $\mathrm{CH}_{4}$ produced until the end of the incubation (a concentration of $1 \mathrm{mM}$ acetate corresponds to an amount of $1 \mu \mathrm{molg}^{-1}$ dry soil). Addition of $\mathrm{CH}_{3} \mathrm{~F}$ resulted in inhibition of acetate consumption so that acetate concentrations stayed high until the end of incubation (Figure 2). Only in Vercelli soil, acetate steadily decreased after $300 \mathrm{~h}$ of incubation, probably since Vercelli soil was only treated with $1 \% \mathrm{CH}_{3} \mathrm{~F}$, whereas the other soils were treated 

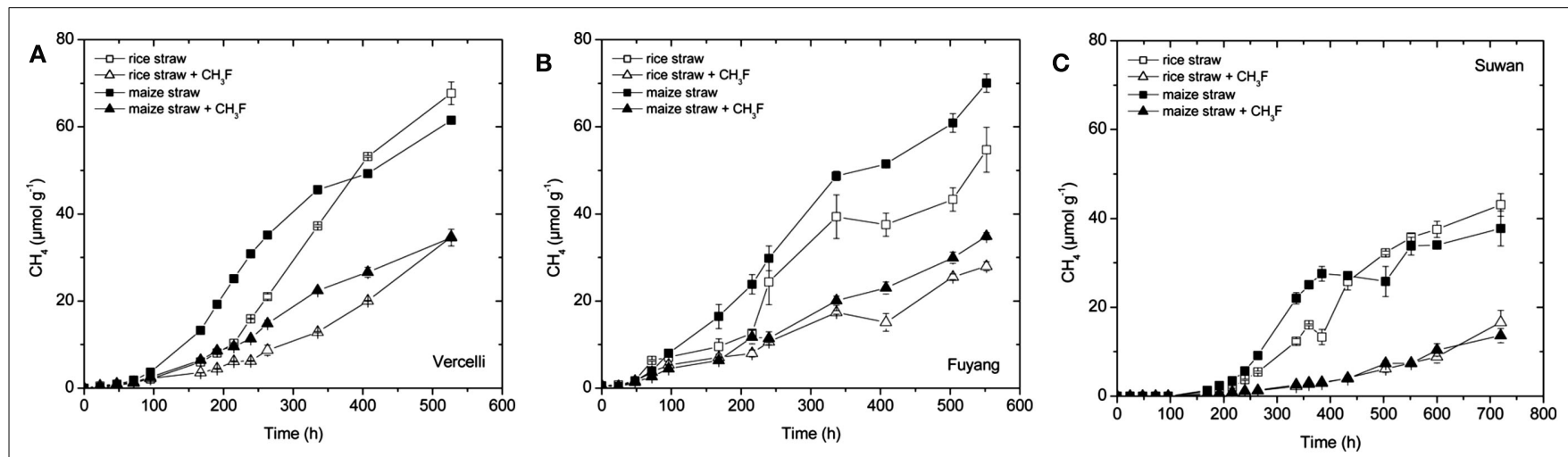

FIGURE 1 | Accumulation of $\mathrm{CH}_{4}$ in soil from (A) Vercelli, (B) Fuyang, and (C) Suwan, amended with either rice straw or maize straw and incubated

under anoxic conditions in the absence or presence of $\mathrm{CH}_{3} \mathrm{~F}(1,2$, and $2 \%$ in Vercelli, Fuyang, and Suwan soil, respectively); mean $\pm S E, n=3$.
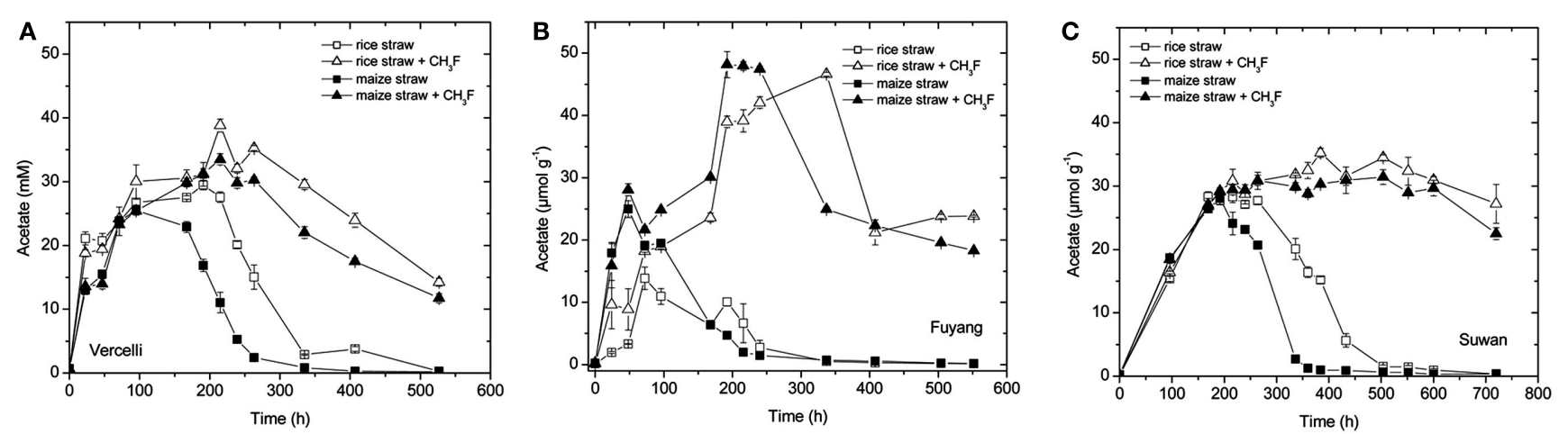

FIGURE 2 | Transient accumulation of acetate in soil from (A) Vercelli, (B) Fuyang, and (C) Suwan, amended with either rice straw or maize straw and incubated under anoxic conditions in the absence or presence of $\mathrm{CH}_{3} \mathrm{~F}(1,2$, and $2 \%$ in Vercelli, Fuyang, and Suwan soil, respectively); mean $\pm \mathrm{SE}, \boldsymbol{n}=3$.

with $2 \% \mathrm{CH}_{3} \mathrm{~F}$. Since $\mathrm{CH}_{3} \mathrm{~F}$ concentrations usually decrease slowly during incubation (Conrad and Klose, 1999b; Penning and Conrad, 2006), the $\mathrm{CH}_{3} \mathrm{~F}$ concentrations in Vercelli soil probably fell below the critical inhibitory threshold of $1 \%$ so that acetate could again be consumed by methanogens (Penning et al., 2006b). Increase of acetate (Fuyang) and/or decrease of acetate (Vercelli, Suwan) was generally faster with maize straw than with rice straw (Figure 2), being probably a reason for why $\mathrm{CH}_{4}$ production was also somewhat faster with maize straw than with rice straw (Figure 1).

Hydrogen, which is next to acetate another important substrate for methanogenesis, also accumulated transiently (Figure 3). As previously reported (Conrad, 2002) the highest $\mathrm{H}_{2}$ concentrations were reached during the initial lag phase of $\mathrm{CH}_{4}$ production. During the main phase of $\mathrm{CH}_{4}$ production $\mathrm{H}_{2}$ partial pressures were generally lower than $50 \mathrm{~Pa}$. In Vercelli and Fuyang soil, but not in Suwan soil, $\mathrm{H}_{2}$ partial pressures seemed to be generally about $2 \mathrm{~Pa}$ higher with rice straw than with maize straw (Figure 3).

The $\delta^{13} \mathrm{C}$ of the produced $\mathrm{CH}_{4}$ was generally higher for the soils amended with maize straw than with rice straw and was generally lower in the treatments with $\mathrm{CH}_{3} \mathrm{~F}$ than in the untreated controls
(Figure 4). The $\delta^{13} \mathrm{C}$ of the produced acetate was also generally higher for the soils amended with maize straw than with rice straw, and increased faster with time in the absence than in the presence of $\mathrm{CH}_{3} \mathrm{~F}$ (Figure 5). This behavior is reasonable, since $\delta^{13} \mathrm{C}$ of the residual acetate should increase because of carbon isotope fractionation during acetate consumption (cf. Penning and Conrad, 2007).

Note that $\delta^{13} \mathrm{C}$ of acetate-methyl is given in Figure 5. The data were directly measured in the incubations of Vercelli and Fuyang soil. The $\delta^{13} \mathrm{C}$ of acetate-methyl was about $10 \%$ lower than that of total acetate (Figure 6). For Suwan soil, we only analyzed the $\delta^{13} \mathrm{C}$ of total acetate. The corresponding values of acetate-methyl shown in Figure 5 were calculated by subtracting 10\% from the $\delta^{13} \mathrm{C}$ of total acetate.

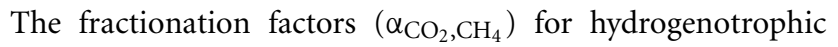
methanogenesis (calculated by Eq. 3) were in a range of 1.045$1.060,1.050-1.060$, and 1.040-1.055 for soils from Vercelli, Fuyang, and Suwan, respectively. In general, values were by about $0.005-$ 0.010 units higher in soil amended with rice straw than with maize straw (data not shown).

The percentage contribution of hydrogenotrophic methanogenesis to total $\mathrm{CH}_{4}$ production was calculated (using Eq. 4) 

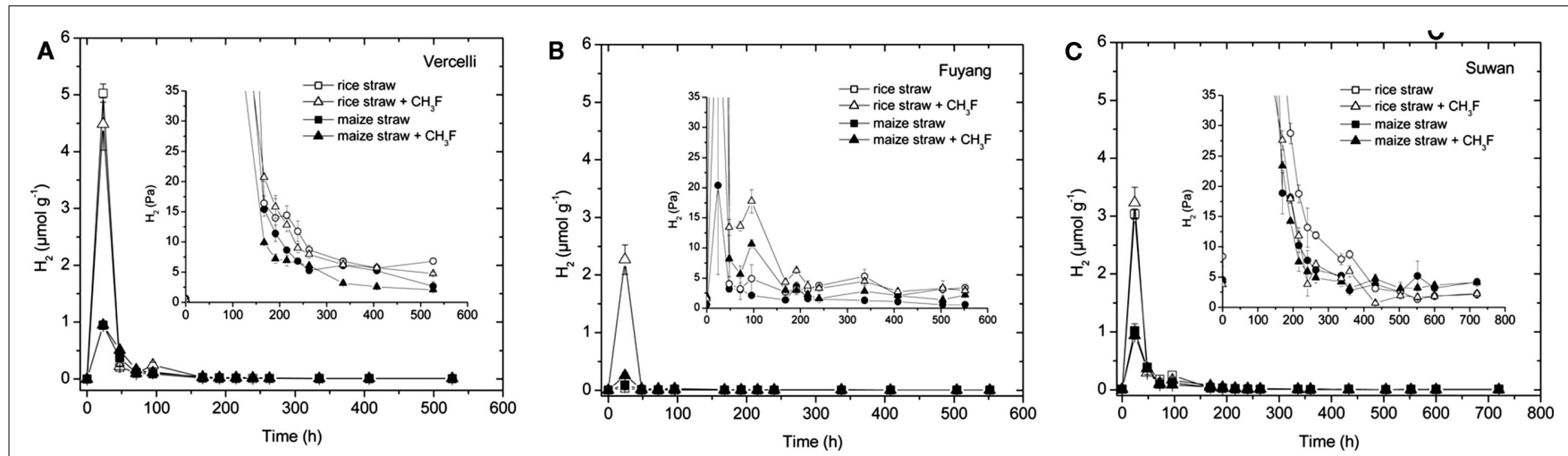

FIGURE 3 | Transient accumulation of $\mathrm{H}_{2}$ in soil from (A) Vercelli, (B) Fuyang, and (C) Suwan, amended with either rice straw or maize straw and incubated under anoxic conditions in the absence or presence of

$\mathrm{CH}_{3} \mathrm{~F}(1,2$, and $2 \%$ in Vercelli, Fuyang, and Suwan soil, respectively); mean $\pm \mathbf{S E}, \boldsymbol{n}=\mathbf{3}$. The insert shows the $\mathrm{H}_{2}$ accumulated in units of partial pressure $(\mathrm{Pa})$.
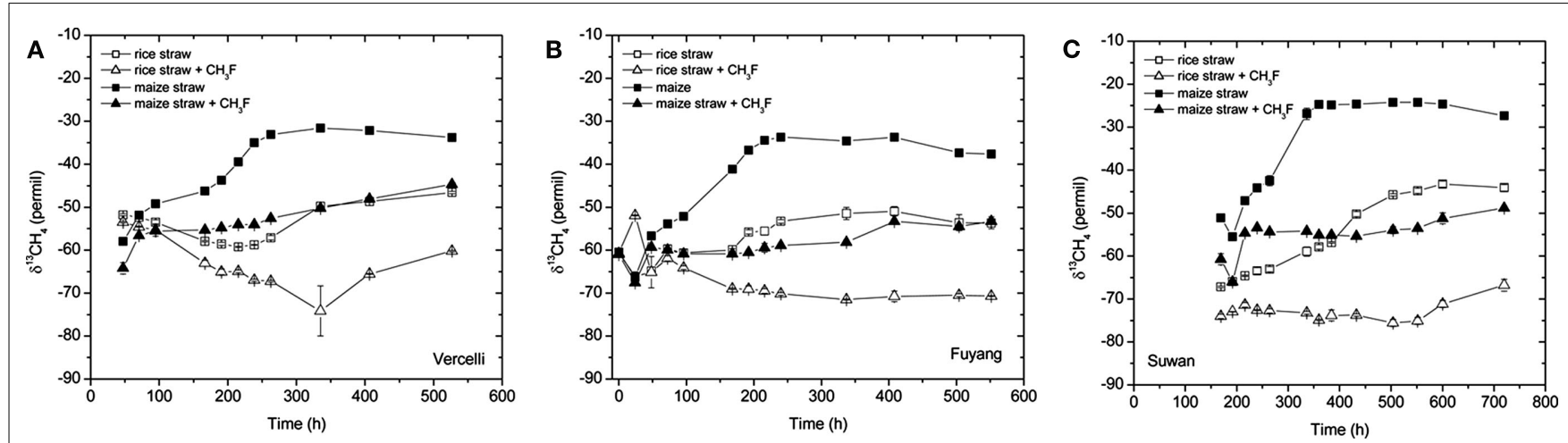

FIGURE 4 | Values of $\delta^{13} \mathrm{C}$ of the $\mathrm{CH}_{4}$ accumulated in soil from (A) Vercelli, (B) Fuyang, and (C) Suwan, amended with either rice straw or maize straw and incubated under anoxic conditions in the absence or presence of $\mathrm{CH}_{3} \mathrm{~F}(1,2$, and $2 \%$ in Vercelli, Fuyang, and Suwan soil, respectively); mean $\pm S E, n=3$
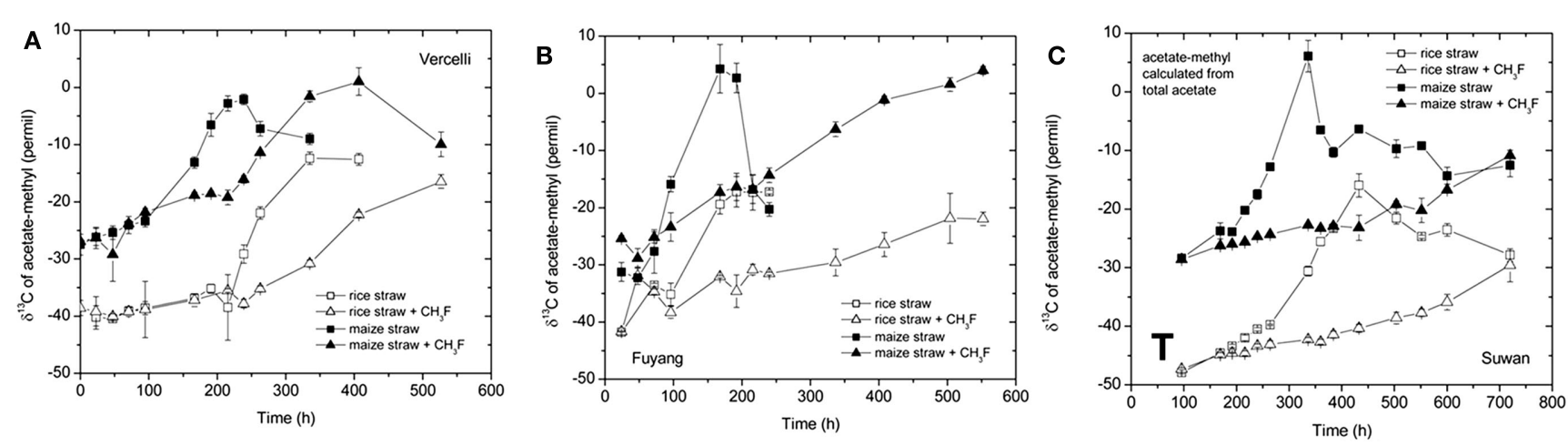

FIGURE 5 | Values of $\delta^{13} \mathrm{C}$ of the methyl group of acetate accumulated in soil from (A) Vercelli, (B) Fuyang, and (C) Suwan, amended with either rice straw or maize straw and incubated under anoxic conditions in the absence or presence of $\mathrm{CH}_{3} \mathrm{~F}(1,2$, and $2 \%$ in Vercelli, Fuyang, and Suwan soil, respectively); mean $\pm \mathrm{SE}, \boldsymbol{n}=\mathbf{3}$. The data in Vercelli and Fuyang soil were directly measured; those in Suwan soil were calculated from measured $\delta^{13} \mathrm{C}$ of total acetate using $\delta^{13} \mathrm{C}_{\mathrm{ac}-\text { methyl }}=\delta^{13} \mathrm{C}_{\mathrm{ac}}-10 \%$ 。 by mass balance of $\delta^{13} \mathrm{C}$ values of $\mathrm{CH}_{4}$ (Figure 4) and acetatemethyl (Figure 5) and scaled against the amount of $\mathrm{CH}_{4}$ produced
(Figure 1). The results show that this contribution was initially high, decreased during the time when the transiently accumulated 

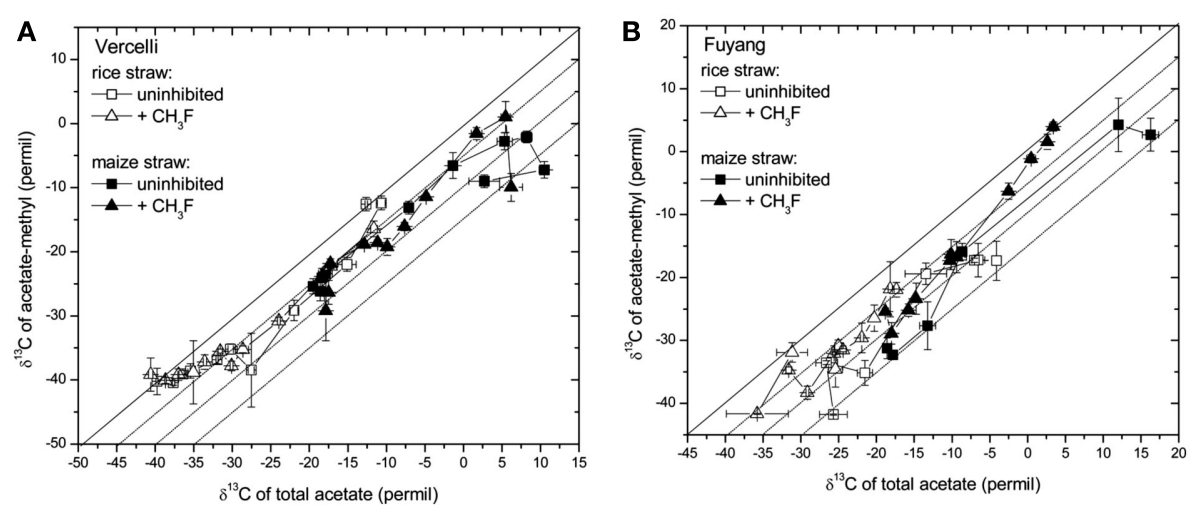

FIGURE 6 | Relation between the $\delta^{13} \mathrm{C}$ of acetate-methyl and the $\delta^{13} \mathrm{C}$ of total acetate measured in soil from (A) Vercelli, and (B) Fuyang, amended with either rice straw or maize straw and incubated under anoxic conditions in the absence or presence of $\mathrm{CH}_{3} \mathrm{~F}(1$ and $2 \%$ in Vercelli and Fuyang soil, respectively); mean $\pm \mathrm{SE}, n=3$.
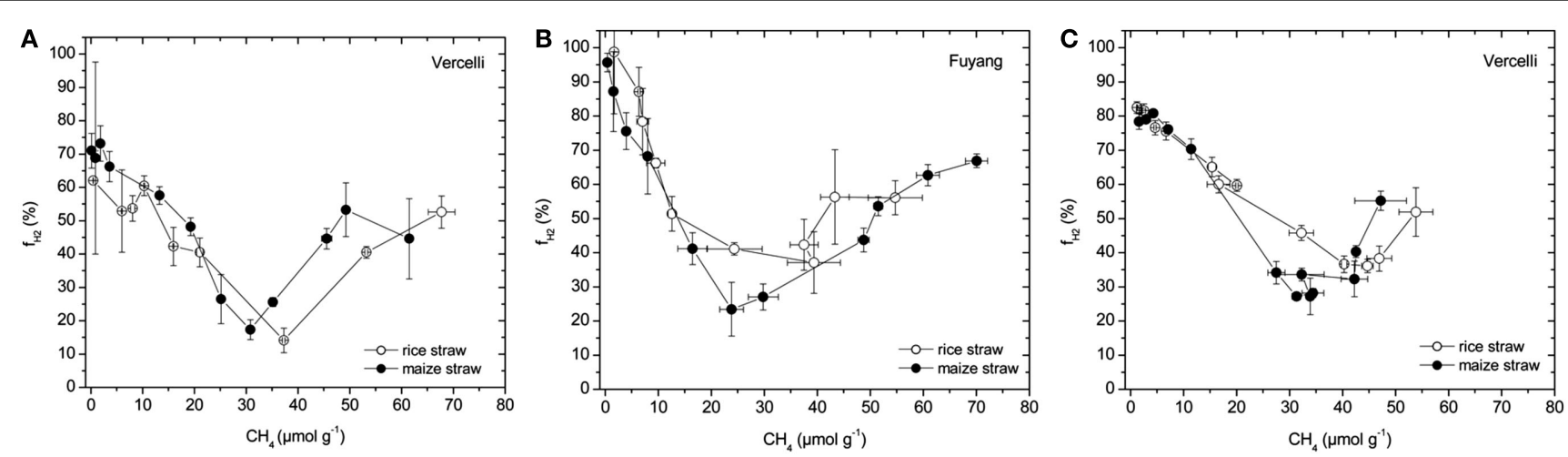

FIGURE 7 | Percentage of $\mathrm{CH}_{4}$ produced from $\mathrm{H}_{2} / \mathrm{CO}_{2}\left(f_{\mathrm{H}_{2}}\right)$ in soil from (A) Vercelli, (B) Fuyang, and (C) Suwan, amended with either rice straw or maize straw, as calculated using Equation 4, and the data shown in Figures 4 and 5.

acetate was consumed, and then increased again (Figure 7). Interestingly, the pattern was very similar for treatments with maize straw versus rice straw.

\section{METHANOGENIC ARCHAEA}

The abundance of methanogenic archaea in the authentic rice field soils from Vercelli and Fuyang was quantified before and after incubation with straw using qPCR and T-RFLP targeting archaeal 16S rRNA genes. The T-RFs detected could be affiliated to different methanogenic groups based on previous studies using T-RFLP and cloning/sequencing of archaeal genes (Chin et al., 1999; Lueders and Friedrich, 2000; Peng et al., 2008; Wu et al., 2009). The following T-RFs (in brackets) could be affiliated: Methanomicrobiales ( $84 \mathrm{bp}$ ), Methanobacteriales (92 bp), Methanosarcinaceae (186 bp), Methanosaetaceae (284 bp), and Methanocellales (393 bp). The T-RFs of 74, 381, >738 bp were only detected in low relative abundance $(<2 \%)$, and thus were not further considered. In Vercelli and Fuyang soil the T$\mathrm{RF}=186 \mathrm{bp}$ represents mainly Methanosarcinaceae. Although this T-RF can also represent non-methanogenic crenarchaeotes (Rice cluster VI or group I.1b), they generally constitute only a minor fraction of $\mathrm{T}-\mathrm{RF}=186 \mathrm{bp}$ in rice field soil and can be neglected.

Terminal restriction fragment length polymorphism patterns of archaeal 16S rRNA genes slightly changed during incubation with rice and maize straw in both Vercelli and Fuyang soil with the relative abundance of the $186 \mathrm{bp}$ peak increasing during the phase of active acetate consumption (data not shown). Similar patterns have been observed before and were interpreted as growth of acetoclastic Methanosarcina spp. (Conrad and Klose, 2006; Peng et al., 2008). In both Vercelli (Figure 8) and Fuyang (Figure 9) soil the numbers of total archaea significantly increased after incubation with straw, more in Vercelli than in Fuyang, and more with maize straw than with rice straw. The proliferating archaeal community in Vercelli soil consisted mainly of Methanosarcinaceae and Methanobacteriales, while Methanocellales were much less abundant (Figure 8). In Fuyang soil, on the other hand, Methanosarcinaceae and Methanocellales were the most abundant methanogens, but Methanobacteriales were also of relatively large importance (Figure 9). Addition of $\mathrm{CH}_{3} \mathrm{~F}$ inhibited the proliferation of the methanogenic populations in Vercelli and Fuyang soil (Figures 8 and 9). 
Vercelli, 16S rRNA gene copies per gram dry soil
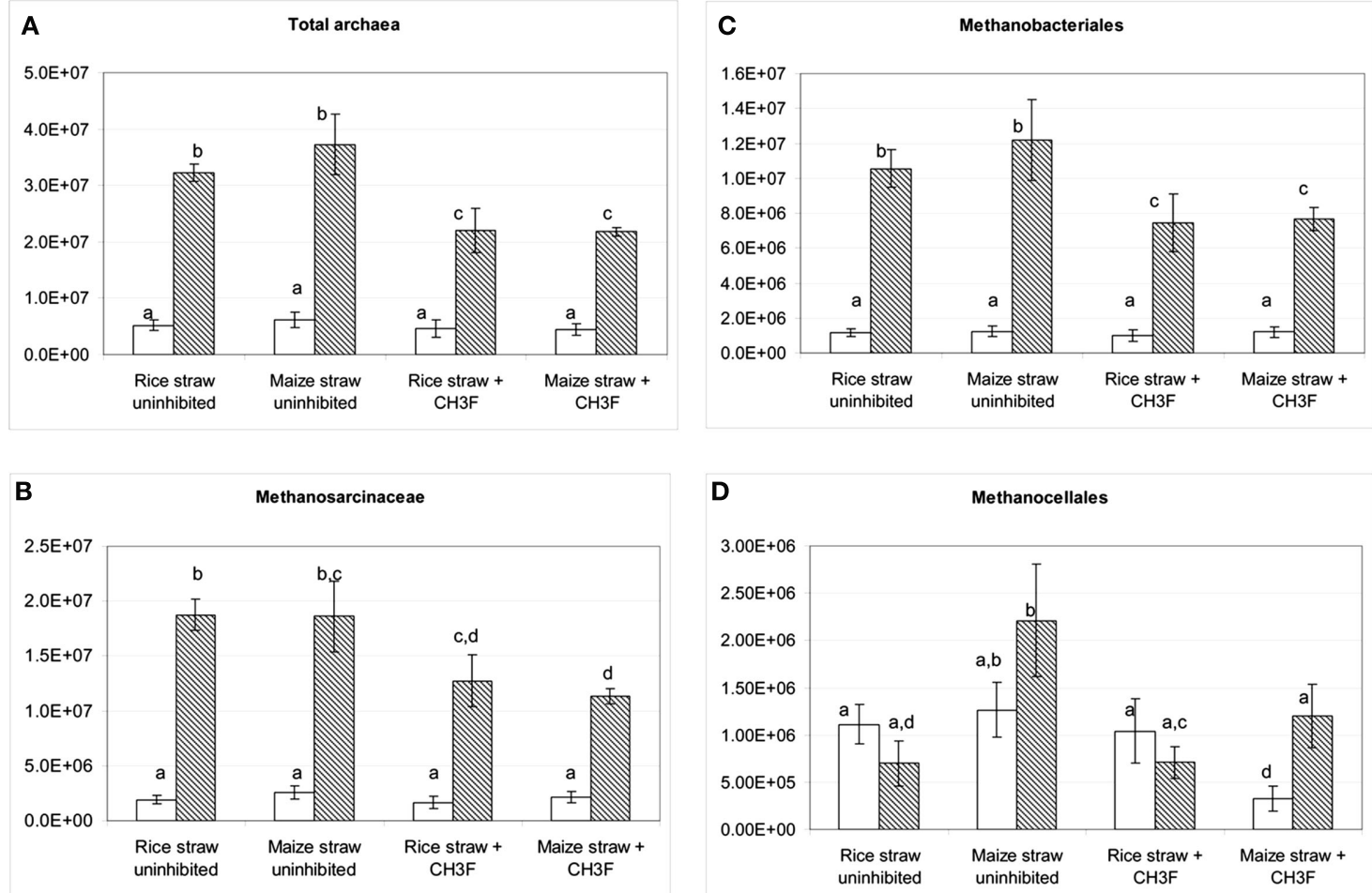

FIGURE 8 | Copy numbers in Vercelli soil of (A) total archaeal 16S rRNA genes, and of those archaeal 16S rRNA genes belonging to (B) Methanosarcinceae, (C) Methanobacteriales, and (D) Methanocellales at the beginning (left column) and the end (right column) of incubation of
Vercelli soil with either rice straw or maize straw in the presence and absence of $\mathrm{CH}_{3} \mathrm{~F} ;$ mean $\pm \mathbf{S E}, \boldsymbol{n}=3$. Different letters indicate significant $(p<0.05)$ differences between columns. Beginning and end of incubation are as in Figure 1.
The soil from Suwan had previously not been used for cultivating rice. Although archaea were abundant, the T-RFLP pattern was almost exclusively dominated by the $186 \mathrm{bp}$ T-RF. In contrast to Vercelli and Fuyang soil, the abundance of total archaea did not increase upon incubation with straw (Figure 10). Sequencing of six clones of archaeal 16S rRNA genes generally resulted in assignment to crenarchaeotes (accession numbers: JQ286402JQ286407). We therefore assumed that the archaeal 16S rRNA in this soil was mainly represented by crenarchaeotes, whose abundance was not enhanced by addition of straw. We therefore decided to quantify methanogens directly by applying QPCR assays targeting the $m c r A$ gene that is unique to methanogens. Using this assay, a significant proliferation of methanogens by two orders of magnitude was detected after incubation with straw reaching almost the abundance of total archaeal 16S rRNA gene copies (Figure 10). The methanogenic community consisted almost equally of Methanosarcinaceae and Methanocellales, with Methanomicrobiales as only minor additional component (Figure 10). Proliferation of Methanosarcinaceae and total methanogens was slightly inhibited by the presence of $\mathrm{CH}_{3} \mathrm{~F}$ (Figure 10).

\section{DISCUSSION}

Our study showed differences in the temporal patterns and rates of $\mathrm{CH}_{4}$ production, and of the transient production of the methanogenic precursors acetate and $\mathrm{H}_{2}$ especially across the different soils but also between the treatments with maize straw versus rice straw. Similarly, the composition and dynamics of the methanogenic populations were quite different in the different soils. Finally, substantial differences were found in the isotopic signatures of $\mathrm{CH}_{4}$ and acetate-methyl between maize straw and rice straw treatments, basically since the organic matter serving as substrate for methanogenic degradation had different isotopic signatures (C4 versus $\mathrm{C} 3$ plant). However, despite all these differences, $\mathrm{CH}_{4}$ production from both maize straw versus rice straw followed similar pathways, which were also quite similar for the different soils.

\section{METHANOGENIC PATHWAY}

Hence, the differences were all in details of the methanogenic degradation process and the active methanogenic populations, while the overall methanogenic path was very similar. This demonstrates an amazing constancy in system functioning despite all the differences in substrate quality (mainly based on straw type) and archaeal community composition and abundance (mainly based on soil type). We had previously observed a similar constancy in methanogenic paths in soils vegetated with cultivated rice versus wild rice, although differences in turnover rates existed (Conrad et al., 2009). However, these soils had a similar archaeal community 
Fuyang, 16S rRNA gene copies per gram dry soil
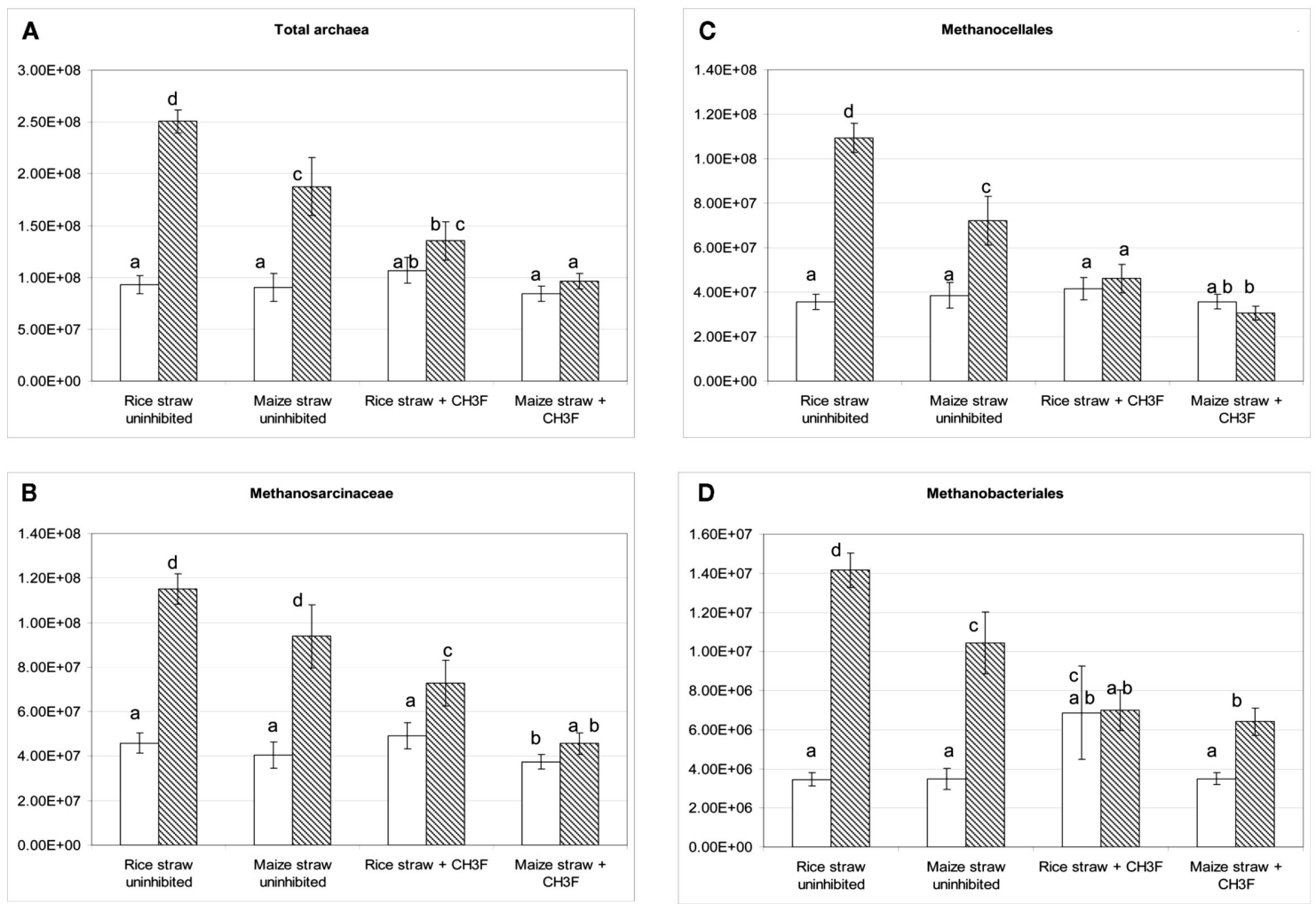

FIGURE 9 | Copy numbers in Fuyang soil of (A) total archaeal 16S rRNA genes, and of those archaeal 16S rRNA genes belonging to (B)

Methanosarcinceae, (C) Methanocellales, and (D) Methanobacteriales at the beginning (left column) and the end (right column) of incubation of

composition. On the other hand, we have observed dramatic differences in $\mathrm{CH}_{4}$ production and emission when rice was grown on different soils, and roots were colonized with crossly different methanogenic populations (Conrad et al., 2008). Therefore, we do not generally exclude that the archaeal methanogenic community composition and abundance might have a substantial effect on methanogenic functioning. In the present study, however, the methanogenic functioning was generally similar.

In general, $\mathrm{CH}_{4}$ production was at first dominated by hydrogenotrophic methanogenesis which subsequently decreased as acetoclastic methanogenesis became progressively more important, and finally increased again. This temporal pattern was paralleled by the initial peak in $\mathrm{H}_{2}$ accumulation, followed by the slower transient accumulation of acetate, which was eventually depleted to rather low concentrations characteristic for steady state between fermentative production and methanogenic consumption of acetate. Similar temporal patterns of the relative contribution of hydrogenotrophic versus acetoclastic methanogenesis have been observed before (Conrad et al., 2002; Fey et al., 2004; Penning and Conrad, 2007). Such temporal pattern has been explained by a conceptual model based on the sequential degradation of organic matter by hydrolytic fermentative, and methanogenic microbes, by the competition of sulfate-reducing and iron-reducing bacteria for $\mathrm{H}_{2}$ and by the relatively late activation of acetoclastic methanogens (Conrad, 2002; Glissmann and Conrad, 2002).

\section{METHANOGENIC ARCHAEA}

Incubation of maize straw or rice straw under methanogenic conditions generally resulted in increase of total methanogenic archaea irrespectively of the soil used. In the Vercelli and Fuyang soils, the archaeal $16 \mathrm{~S}$ rRNA genes almost exclusively belonged to methanogens and copy numbers were relatively abundant $\left(10^{6}-\right.$ $10^{8} \mathrm{~g}^{-1}$ dry soil) right from the beginning of incubation, as expected for authentic rice field soils (Krüger et al., 2005; Ma et al., 2010). In the Suwan soil by contrast, copy numbers were in the beginning rather low $\left(10^{3} \mathrm{~g}^{-1}\right.$ dry soil), which is normal for upland soil (Angel et al., 2012). In all of the soils, however, numbers of methanogens eventually increased during methanogenic degradation of straw. The most abundant methanogens always belonged to the family of Methanosarcinaceae, presumably since acetoclastic Methanosarcina species proliferated by consuming the transiently accumulated acetate. Such proliferation during degradation of straw has been observed before and the final abundance was found to be consistent with theoretical calculations based on the energetic conditions in the soil for acetate conversion to $\mathrm{CH}_{4}$ 


\section{Suwan, 16S rRNA and $m c r A$ gene copies per gram dry soil}
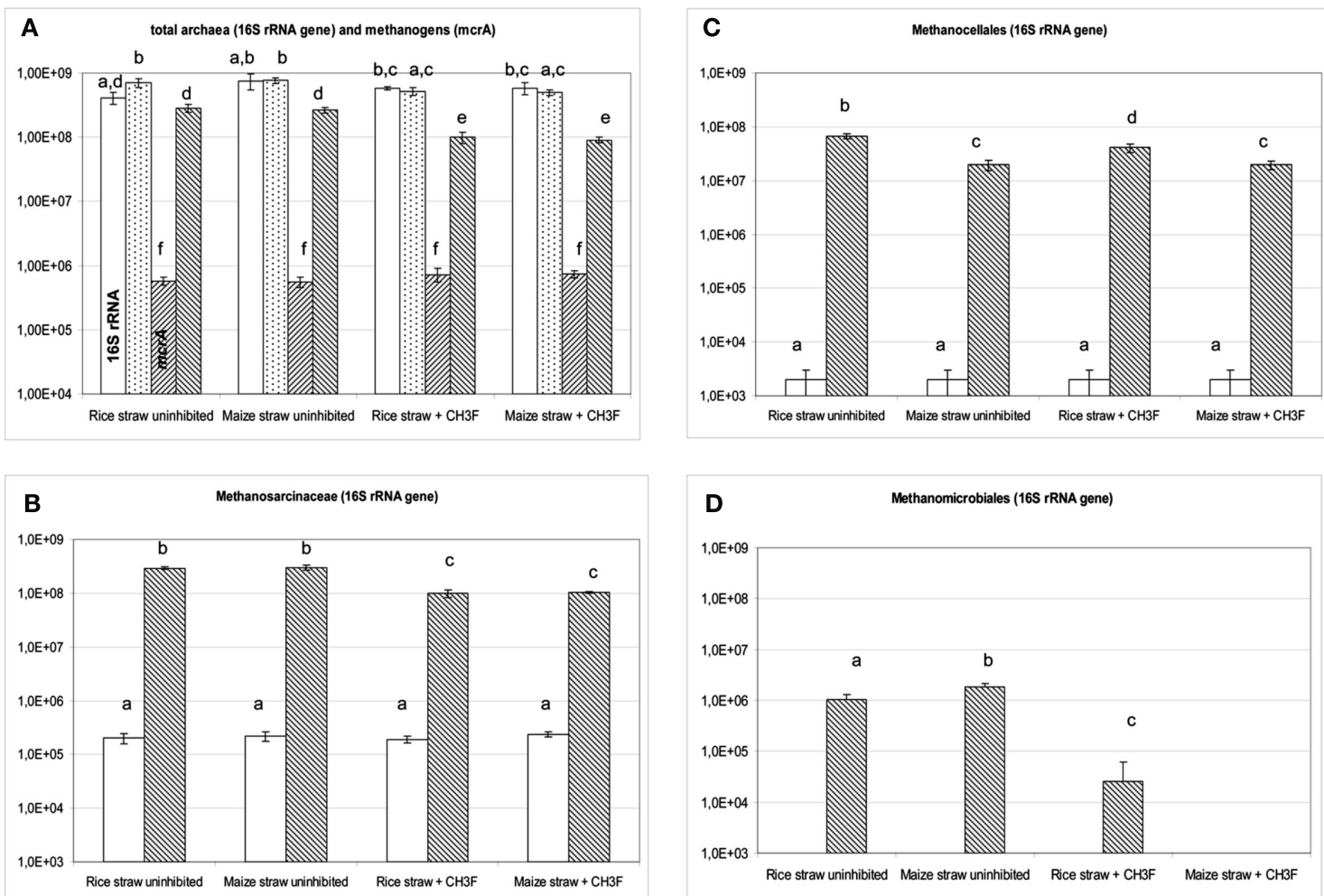

FIGURE 10 | Copy numbers in Suwan soil of (A) total archaeal 16S rRNA genes (the two left columns in each group) and total mcrA genes (the two right columns in each group), and of 16S rRNA genes belonging to (B) Methanosarcinceae, (C) Methanocellales, and (D) Methanomicrobiales at the beginning (left column) and the

end (right column) of incubation of Suwan soil with either rice straw or maize straw in the presence and absence of $\mathrm{CH}_{3} \mathrm{~F}$; mean $\pm \mathbf{S E}, \boldsymbol{n}=\mathbf{3}$. Different letters indicate significant $(p<0.05)$ differences between columns. Beginning and end of incubation are as in Figure 1.

(Conrad and Klose, 2006; Angel et al., 2012). The most abundant hydrogenotrophic methanogens were Methanobacteriales in Vercelli soil, and Methanocellales in the other two soils. The results on Vercelli (Weber et al., 2001; Conrad and Klose, 2006) and Fuyang (Peng et al., 2008) soil is consistent with previous observations. Suwan soil had not been flooded before and thus initially contained only a low abundance of methanogens. In the end, however, Methanosarcinaceae and Methanocellales dominated. In other upland soils these two methanogenic groups were also found to be the most prevalent ones, both before first flooding and after an extensive phase of methanogenesis (Angel et al., 2012). These two methanogenic groups are in particular known for potentially being able to deal with toxic $\mathrm{O}_{2}$ species and surviving oxic soil conditions (Erkel et al., 2006; Angel et al., 2011).

Addition of $\mathrm{CH}_{3} \mathrm{~F}$ generally resulted in substantial inhibition of $\mathrm{CH}_{4}$ production, irrespectively of the type of soil or straw. As $\mathrm{CH}_{3} \mathrm{~F}$ is known as specific inhibitor of acetoclastic methanogens (Janssen and Frenzel, 1997), one would expect that acetate consumption by this group of methanogens is inhibited. Thus, members of the Methanosarcinaceae should be impeded in growth unless they use an alternative energy source such as $\mathrm{CH}_{4}$ production from $\mathrm{H}_{2} / \mathrm{CO}_{2}$. A previous study using methanogenic rice roots has indeed shown that growth of acetoclastic Methanosarcinaceae was inhibited by $\mathrm{CH}_{3} \mathrm{~F}$ (Penning and Conrad, 2006). In the present study using Vercelli soil addition of $\mathrm{CH}_{3} \mathrm{~F}$ also significantly inhibited the growth of the potentially acetoclastic Methanosarcinaceae, but it also inhibited growth of non-acetoclastic Methanobacteriales. The same was observed in Fuyang soil amended with maize straw, while the methanogenic population in the rice straw treatments were not significantly inhibited at all. In Suwan soil, on the other hand, again only the growth of Methansarcinaceae but not of Methanocellales was inhibited by $\mathrm{CH}_{3} \mathrm{~F}$. Although we have no final explanation for the different behavior, we assume that it is due to the fact that Methanosarcina species are not restricted to acetoclastic methanogenic metabolism, and may have used for example $\mathrm{H}_{2} / \mathrm{CO}_{2}$ for growth in the presence of $\mathrm{CH}_{3} \mathrm{~F}$, and that growth of hydrogenotrophic methanogens was unspecifically inhibited (Conrad and Klose, 1999b).

\section{STABLE CARBON ISOTOPE FRACTIONATION}

Due to inhibition of acetoclastic methanogenesis addition of $\mathrm{CH}_{3} \mathrm{~F}$ inhibited or delayed the consumption of the accumulated acetate and resulted in lower $\delta^{13} \mathrm{C}$ of the produced $\mathrm{CH}_{4}$. The $\delta^{13} \mathrm{C}$ of the $\mathrm{CH}_{4}$ produced in the presence of $\mathrm{CH}_{3} \mathrm{~F}$ should represent the $\delta^{13} \mathrm{C}$ of hydrogenotrophically produced $\mathrm{CH}_{4}$ $\left(\delta^{13} \mathrm{C}_{\mathrm{CH}_{4}-\mathrm{mc}}\right)$. Since the fractionation factor for hydrogenotrophic 
methanogenesis is larger than for acetoclastic methanogenesis (Conrad, 2005), $\delta^{13} \mathrm{C}_{\mathrm{CH}_{4}-\mathrm{mc}}$ is expected of being lower than the $\delta^{13} \mathrm{C}$ of total $\mathrm{CH}_{4}$ or of acetoclastically produced $\mathrm{CH}_{4}$ $\left(\delta^{13} \mathrm{C}_{\mathrm{CH}_{4}-\mathrm{ma}}\right)$, which was actually observed. The fractionation factors of hydrogenotrophic methanogenesis that were calculated from the values of $\delta^{13} \mathrm{C}_{\mathrm{CH}_{4}-\mathrm{mc}}$ (Eq. 3) were in a range of $\alpha_{\mathrm{CO}_{2}, \mathrm{CH}_{4}}=1.04-1.06$, which have quite commonly been observed in rice field soils (Sugimoto and Wada, 1993; Chidthaisong et al., 2002; Penning and Conrad, 2007; Conrad et al., 2009). The same range of $\alpha_{\mathrm{CO}_{2}, \mathrm{CH}_{4}}$ has been used for calculation of $\left(f_{\mathrm{H}_{2}}\right)$ of total $\mathrm{CH}_{4}$ produced from $\mathrm{CO}_{2}$ reduction (Eq. 4) during studies on rice fields in TX, USA (Bilek et al., 1999) and Italy (Krüger et al., 2002). If acetoclastic methanogenesis is not completely inhibited (which might have been the case in Vercelli and Fuyang soil, but not in Suwan soil), ${ }^{13} \mathrm{C}_{\mathrm{CH}_{4}-\mathrm{mc}}$ would be less negative than expected and values of $f_{\mathrm{H}_{2}}$ would be overestimated (sensitivity analysis see Conrad et al., 2002). However, the range of $f_{\mathrm{H}_{2}}$ values was similar in soil from Suwan $(25-80 \%)$ as in soils from Vercelli (15-75\%) and Fuyang (25-100\%). Nevertheless, it should be noted that the $f_{\mathrm{H}_{2}}$ values that were finally reached were relatively high (50-70\%) compared to a value of $33 \%$ that is expected when carbohydrates are methanogenically decomposed under steady state conditions (Conrad, 1999).

Computation of $f_{\mathrm{H}_{2}}$ is also affected by the value of $\delta^{13} \mathrm{C}_{\mathrm{CH}_{4}-\mathrm{ma}}$, which was based on measured values of $\delta^{13} \mathrm{C}$ of acetate-methyl and the assumption of a fractionation factor for acetoclastic methano-

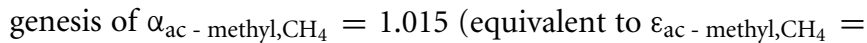
$-15 \%$ ). Such value is reasonable because acetoclastic methanogenesis was apparently dominated by Methanosarcina. In soil, Methanosarcina species exhibit $\varepsilon_{\mathrm{ac}}$ - methyl, $\mathrm{CH}_{4}$ values that are about $5-10 \%$ less negative than in pure culture which is probably due to limitation by acetate (Penning and Conrad, 2007; Goevert and Conrad, 2009). In systems dominated by Methanosaeta species, values of $\varepsilon_{\mathrm{ac}}$ - methyl, $\mathrm{CH}_{4}$ are even less negative, i.e., on the order of $>-10 \%$ (Valentine et al., 2004; Penning et al., 2006a), and fractionation may become actually zero in systems where acetate supply is so low that it is quantitatively utilized as it is produced.

\section{REFERENCES}

Amelung, W., Brodowski, S., SandhageHofmann, A., and Bol, R. (2008). Combining biomarker with stable isotope analyses for assessing the transformation and turnover of soil organic matter. Adv. Agron. 100, $155-250$.

Angel, R., Claus, P., and Conrad, R. (2012). Methanogenic archaea are globally ubiquitous in aerated soils and become active under wet anoxic conditions. ISME J. (in press). doi:10.1038/ismej.2011.141

Angel, R., Matthies, D., and Conrad, R. (2011). Activation of methanogenesis in arid biological soil crusts despite the presence of oxygen. PLoS ONE 6, e20453. doi:10.1371/journal.pone. 0020453

Balesdent, J., and Balabane, M. (1992). Maize root-derived soil organic carbon estimated by natural C- 13

Calculation of $f_{\mathrm{H}_{2}}$ results in increasing values with $\alpha_{\mathrm{ac}}$ - methyl, $\mathrm{CH}_{4}$

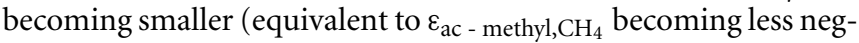
ative). However, we may assume that this was not the case in our experiments, which generally showed acetate concentrations well above $100 \mu \mathrm{M}$.

Taking all these uncertainties into account it is striking that amendment with either maize straw or rice straw had a similar effect on the overall value of $f_{\mathrm{H}_{2}}$ and its temporal change. Hence, amendment of soil with maize straw may be used for experiments in which the partitioning of $\mathrm{CH}_{4}$ production derived from root versus straw decomposition is determined. Such determinations are even feasible under field conditions by measuring the $\delta^{13} \mathrm{C}$ in the total $\mathrm{CH}_{4}$ produced by comparing fields amended with either rice straw or maize straw. We are presently about doing such studies.

\section{CONCLUSION}

The present study showed that despite the involvement of different methanogenic populations in the different soils, pathways and temporal patterns of $\mathrm{CH}_{4}$ production were nearly identical between straw treatments. Hence, the temporal patterns and paths of $\mathrm{CH}_{4}$ production were mostly dependent on the soil and not on the straw. Our study also demonstrates a surprising constancy of system functioning, despite the qualitative and quantitative differences in soil methanogenic populations, including those from a previous upland soil, and differences in straw quality. The observed constancy indicates flexible adaptation of the different microbial communities in order to achieve similar methanogenic degradation of straw.

\section{ACKNOWLEDGMENTS}

We thank Peter Claus for help during analysis of $\delta^{13} \mathrm{C}$, Roey Angel for advice concerning $\mathrm{qPCR}$, and Yanli Yuan and Pancheewan Pomphangnag for sampling of the Fuyang and Suwan soil, respectively. This study is part of the ICON project financed by the German Research Foundation. We thank Tillmann Lüders, Kim Yrjälä and Sascha Krause for helpful comments.

Geochim. Cosmochim. Acta 66, 983-995.

Chidthaisong, A., and Watanabe, I. (1997). Methane formation and emission from flooded rice soil incorporated with ${ }^{13} \mathrm{C}$-labeled rice straw. Soil Biol. Biochem. 29, 1173-1181.

Chin, K. J., Lukow, T., and Conrad, R. (1999). Effect of temperature on structure and function of the methanogenic archaeal community in an anoxic rice field soil. Appl. Environ. Microbiol. 65, 2341-2349.

Conrad, R. (1999). Contribution of hydrogen to methane production and control of hydrogen concentrations in methanogenic soils and sediments [review]. FEMS Microbiol. Ecol. 28, 193-202.

Conrad, R. (2002). Control of microbial methane production in wetland rice fields [review]. Nutr. Cycl. Agroecosyst. 64, 59-69.

Conrad, R. (2005). Quantification of methanogenic pathways using stable carbon isotopic signatures: a review and a proposal. Org. Geochem. 36, 739-752.

Conrad, R. (2007). Microbial ecology of methanogens and methanotrophs. Adv. Agron. 96, 1-63.

Conrad, R., Chan, O. C., Claus, P., and Casper, P. (2007). Characterization of methanogenic archaea and stable isotope fractionation during methane production in the profundal sediment of an oligotrophic lake (Lake Stechlin, Germany). Limnol. Oceanogr. 52, 1393-1406.

Conrad, R., and Klose, M. (1999a). Anaerobic conversion of carbon dioxide to methane, acetate and propionate on washed rice roots. FEMS Microbiol. Ecol. 30, 147-155. 
Conrad, R., and Klose, M. (1999b). How specific is the inhibition by methyl fluoride of acetoclastic methanogenesis in anoxic rice field soil? FEMS Microbiol. Ecol. 30, 47-56.

Conrad, R., and Klose, M. (2006). Dynamics of the methanogenic archaeal community in anoxic rice soil upon addition of straw. Eur. J. Soil Sci. 57, 476-484.

Conrad, R., Klose, M., and Claus, P. (2002). Pathway of $\mathrm{CH}_{4}$ formation in anoxic rice field soil and rice roots determined by ${ }^{13} \mathrm{C}$-stable isotope fractionation. Chemosphere 47 , 797-806.

Conrad, R., Klose, M., Claus, P., and Dan, J. G. (2009). Activity and composition of the methanogenic archaeal community in soil vegetated with wild versus cultivated rice. Soil Biol. Biochem. 41, 1390-1395.

Conrad, R., Klose, M., Noll, M., Kemnitz, D., and Bodelier, P. L. E. (2008). Soil type links microbial colonization of rice roots to methane emission. Glob. Chang. Biol. 14, 657-669.

Denier van der Gon, H. A. C., and Neue, H. U. (1995). Influence of organic matter incorporation on the methane emission from a wetland rice field. Global Biogeochem. Cycles 9, 11-22.

Erkel, C., Kube, M., Reinhardt, R., and Liesack, W. (2006). Genome of Rice Cluster I archaea - the key methane producers in the rice rhizosphere. Science 313, 370-372.

Farquhar, G. D., Ehleringer, J. R., and Hubick, K. T. (1989). Carbon isotope discrimination and photosynthesis. Annu. Rev. Plant Physiol. Plant Mol. Biol. 40, 503-537.

Fey, A., Claus, P., and Conrad, R. (2004). Temporal change of ${ }^{13} \mathrm{C}$-isotope signatures and methanogenic pathways in rice field soil incubated anoxically at different temperatures. Geochim. Cosmochim. Acta 68, 293-306.

Flessa, H., Ludwig, B., Heil, B., and Merbach, W. (2000). The origin of soil organic $\mathrm{C}$, dissolved organic $\mathrm{C}$ and respiration in a long-term maize experiment in Halle, Germany, determined by ${ }^{13} \mathrm{C}$ natural abundance. J. Plant Nutr. Soil Sci. $163,157-163$.

Glissmann, K., and Conrad, R. (2002). Saccharolytic activity and its role as a limiting step in methane formation during the anaerobic degradation of rice straw in rice paddy soil. Biol. Fertil. Soils 35, 62-67.

Goevert, D., and Conrad, R. (2009). Effect of substrate concentration on carbon isotope fractionation during acetoclastic methanogenesis by Methanosarcina barkeri and $M$. acetivorans and in rice field soil. Appl. Environ. Microbiol. 75, 2605-2612.

Grosskopf, R., Janssen, P. H., and Liesack, W. (1998). Diversity and structure of the methanogenic community in anoxic rice paddy soil microcosms as examined by cultivation and direct 16S rRNA gene sequence retrieval. Appl. Environ. Microbiol. 64, 960-969.

Hanson, P. J., Edwards, N. T., Garten, C. T., and Andrews, J. A. (2000). Separating root and soil microbial contributions to soil respiration: a review of methods and observations [review]. Biogeochemistry 48, 115-146.

Hayes, J. M. (1993). Factors controlling ${ }^{13} \mathrm{C}$ contents of sedimentary organic compounds: principles and evidence. Mar. Geol. 113, 111-125.

Holzapfel-Pschorn, A., Conrad, R., and Seiler, W. (1986). Effects of vegetation on the emission of methane from submerged paddy soil. Plant Soil 92, 223-233.

Janssen, P. H., and Frenzel, P. (1997). Inhibition of methanogenesis by methyl fluoride - studies of pure and defined mixed cultures of anaerobic bacteria and archaea. Appl. Environ. Microbiol. 63, 4552-4557.

Kolb, S., Knief, C., Dunfield, P. F., and Conrad, R. (2005). Abundance and activity of uncultured methanotrophic bacteria involved in the consumption of atmospheric methane in two forest soils. Environ. Microbiol. 7, 1150-1161.

Krüger, M., Eller, G., Conrad, R., and Frenzel, P. (2002). Seasonal variation in pathways of $\mathrm{CH}_{4}$ production and in $\mathrm{CH}_{4}$ oxidation in rice fields determined by stable carbon isotopes and specific inhibitors. Glob. Chang. Biol. 8, 265-280.

Krüger, M., Frenzel, P., Kemnitz, D., and Conrad, R. (2005). Activity, structure and dynamics of the methanogenic archaeal community in a flooded Italian rice field. FEMS Microbiol. Ecol. 51, 323-331.

Krumböck, M., and Conrad, R. (1991). Metabolism of position-labelled glucose in anoxic methanogenic paddy soil and lake sediment. FEMS Microbiol. Ecol. 85, 247-256.

Kuzyakov, Y. (2006). Sources of $\mathrm{CO}_{2}$ efflux from soil and review of partitioning methods [review]. Soil Biol. Biochem. 38, 425-448.

Kuzyakov, Y., and Cheng, W. (2001). Photosynthesis controls of rhizosphere respiration and organic matter decomposition. Soil Biol. Biochem. 33, 1915-1925.
Lueders, T., and Friedrich, M. (2000). Archaeal population dynamics during sequential reduction processes in rice field soil. Appl. Environ. Microbiol. 66, 2732-2742.

Ma, J., Xu, H., Yagi, K., and Cai, Z. C. (2008). Methane emission from paddy soils as affected by wheat straw returning mode. Plant Soil 313, 167-174.

Ma, K., Conrad, R., and Lu, Y. (2012). Responses of methanogen mcrA genes and their transcripts to alternate dry wet cycle of paddy field soil. Appl. Environ. Microbiol. 78, 445-454.

Ma, K., Qiu, Q. F., and Lu, Y. H. (2010). Microbial mechanism for rice variety control on methane emission from rice field soil. Glob. Chang. Biol. 16, 3085-3095.

Mayer, H. P., and Conrad, R. (1990). Factors influencing the population of methanogenic bacteria and the initiation of methane production upon flooding of paddy soil. FEMS Microbiol. Ecol. 73, 103-112.

Minoda, T., and Kimura, M. (1994). Contribution of photosynthesized carbon to the methane emitted from paddy fields. Geophys. Res. Lett. 21, 2007-2010.

Peng, J. J., Lü, Z., Rui, J., and Lu, Y. H. (2008). Dynamics of the methanogenic archaeal community during plant residue decomposition in an anoxic rice field soil. Appl. Environ. Microbiol. 74, 2894-2901.

Penning, H., Claus, P., Casper, P., and Conrad, R. (2006a). Carbon isotope fractionation during acetoclastic methanogenesis by Methanosaeto concilii in culture and a lake sediment. Appl. Environ. Microbiol. 72, 5648-5652.

Penning, H., Tyler, S. C., and Conrad, R. (2006b). Determination of isotope fractionation factors and quantification of carbon flow by stable isotope signatures in a methanogenic rice root model system. Geobiology 4, 109-121.

Penning, H., and Conrad, R. (2006). Effect of inhibition of acetoclastic methanogenesis on growth of archaeal populations in an anoxic model environment. Appl. Environ. Microbiol. 72, 178-184.

Penning, H., and Conrad, R. (2007). Quantification of carbon flow from stable isotope fractionation in rice field soils with different organic matter content. Org. Geochem. 38, 2058-2069.

Peters, V., and Conrad, R. (1996). Sequential reduction processes and initiation of $\mathrm{CH}_{4}$ production upon flooding of oxic upland soils. Soil Biol. Biochem. 28, 371-382.

Rochette, P., Flanagan, L. B., and Gregorich, E. G. (1999). Separating soil respiration into plant and soil components using analyses of the natural abundance of carbon-13. Soil Sci. Soc. Am. J. 63, 1207-1213.

Schütz, H., Holzapfel-Pschorn, A., Conrad, R., Rennenberg, H., and Seiler, W. (1989). A 3-year continuous record on the influence of daytime, season, and fertilizer treatment on methane emission rates from an Italian rice paddy. J. Geophys. Res. 94, 16405-16416.

Singh, S., Kushwaha, B., Nag, S., Mishra, A., Bhattacharya, S., Gupta, P., and Singh, A. (2011). In vitro methane emission from Indian dry roughages in relation to chemical composition. Curr. Sci. 101, 57-65.

Sugimoto, A., and Wada, E. (1993). Carbon isotopic composition of bacterial methane in a soil incubation experiment: contributions of acetate and $\mathrm{CO}_{2} / \mathrm{H}_{2}$. Geochim. Cosmochim. Acta 57, 4015-4027.

Thongsaga, K., Ranamukhaarachchi, S. L., Jampatong, S., Samarakoon, L. Noomhorm, A., Clemente, R. S., and Hannaway, D. B. (2010). Comparison of crop simulation and field performance of maize under 20day dry period imposed during selected critical growth periods in Nakhon Ratchasima province, Thailand. Recent Res. Sci. Technol. 2, 17-31.

Tian, G., Kang, B. T., and Brussaard, L. (1992). Biological effects of plant residues with contrasting chemicalcompositions under humid tropical conditions - decomposition and nutrient release. Soil Biol. Biochem. 24, 1051-1060.

Timsina, J., Jat, M. L., and Majumdar, K. (2010). Rice-maize systems of South Asia: current status, future prospects and research priorities for nutrient management [review]. Plant Soil 335, 65-82.

Valentine, D. L., Chidthaisong, A., Rice, A., Reeburgh, W. S., and Tyler, S. C. (2004). Carbon and hydrogen isotope fractionation by moderately thermophilic methanogens. Geochim. Cosmochim. Acta 68, 1571-1590.

Watanabe, A., Satoh, Y., and Kimura, M. (1995). Estimation of the increase in $\mathrm{CH}_{4}$ emission from paddy soils by rice straw application. Plant Soil 173, 225-231.

Watanabe, A., Takeda, T., and Kimura, M. (1999). Evaluation of origins of $\mathrm{CH}_{4}$ carbon emitted from 
rice paddies. J. Geophys. Res. 104, 23623-23629.

Watanabe, A., Yoshida, M., and Kimura, M. (1998). Contribution of rice straw carbon to $\mathrm{CH}_{4}$ emission from rice paddies using ${ }^{13} \mathrm{C}$-enriched rice straw. J. Geophys. Res. 103, 8237-8242.

Weber, S., Lueders, T., Friedrich, M. W., and Conrad, R. (2001). Methanogenic populations involved in the degradation of rice straw in anoxic paddy soil. FEMS Microbiol. Ecol. 38, 11-20.

Werth, M., and Kuzyakov, Y. (2010). ${ }^{13} \mathrm{C}$ fractionation at the rootmicroorganisms-soil interface: a review and outlook for partitioning studies. Soil Biol. Biochem. 42, 1372-1384.

Wu, L. Q., Ma, K., Li, Q., Ke, X. B., and $\mathrm{Lu}, \mathrm{Y}$. H. (2009). Composition of archaeal community in a paddy field as affected by rice cultivar and $\mathrm{N}$ fertilizer. Microb. Ecol. 58, 819-826.

Yan, X. Y., Yagi, K., Akiyama, H., and Akimoto, H. (2005). Statistical analysis of the major variables controlling methane emission from rice fields. Glob. Chang. Biol. 11, 1131-1141.

Yu, Y., Lee, C., Kim, J., and Hwang, S. (2005). Group-specific primer and probe sets to detect methanogenic communities using quantitative real-time polymerase chain reaction. Biotechnol. Bioeng. 89, 670-679.

Conflict of Interest Statement: The authors declare that the research was conducted in the absence of any commercial or financial relationships that could be construed as a potential conflict of interest.

Received: 18 October 2011; paper pending published: 17 November 2011; accepted: 04 January 2012; published online: 20 January 2012.
Citation: Conrad R, Klose M, Lu Y and Chidthaisong A (2012) Methanogenic pathway and archaeal communities in three different anoxic soils amended with rice straw and maize straw. Front. Microbio. 3:4. doi: 10.3389/fmicb.2012.00004

This article was submitted to Frontiers in Terrestrial Microbiology, a specialty of Frontiers in Microbiology.

Copyright (c) 2012 Conrad, Klose, Lu and Chidthaisong. This is an open-access article distributed under the terms of the Creative Commons Attribution Non Commercial License, which permits noncommercial use, distribution, and reproduction in other forums, provided the original authors and source are credited. 


\title{
Seasonal changes in methanogenesis and methanogenic community in three peatlands, New York State
}

\author{
Christine L. Sun ${ }^{1}$, Suzanna L. Brauer ${ }^{1}$, Hinsby Cadillo-Quiroz ${ }^{1}$, Stephen H. Zinder ${ }^{1}$ and Joseph B. Yavitt ${ }^{2 *}$ \\ ${ }^{1}$ Department of Microbiology, Cornell University, Ithaca, NY, USA \\ ${ }^{2}$ Department of Natural Resources, Cornell University, Ithaca, NY, USA
}

\section{Edited by:}

Svetlana N. Dedysh, Russian

Academy of Sciences, Russia

Reviewed by:

Kuk-Jeong (Kuki) Chin, Georgia State University, USA

Hannu Fritze, Finnish Forest Research Institute, Finland

${ }^{*}$ Correspondence:

Joseph B. Yavitt, Department of

Natural Resources, Bruckner

Laboratory, Cornell University, Ithaca,

NY 14853-3001, USA.

e-mail: jby1@cornell.edu

Fluctuating environmental conditions can promote diversity and control dominance in community composition. In addition to seasonal temperature and moisture changes, seasonal supply of metabolic substrates selects populations temporally. Here we demonstrate cascading effects in the supply of metabolic substrates on methanogenesis and community composition of anaerobic methanogenic archaea in three contrasting peatlands in upstate New York. Fresh samples of peat soils, collected about every 3 months for 20 months and incubated at $22 \pm 2^{\circ} \mathrm{C}$ regardless of the in situ temperature, exhibited potential rates of methane $\left(\mathrm{CH}_{4}\right)$ production of $0.02-0.2 \mathrm{mmol} \mathrm{L}^{-1}$ day $^{-1}$ [380-3800 $\mathrm{nmol} \mathrm{g}^{-1}$ (dry) day ${ }^{-1}$ ). The addition of acetate stimulated rates of $\mathrm{CH}_{4}$ production in a fen peatland soil, whereas addition of hydrogen $\left(\mathrm{H}_{2}\right)$, and simultaneous inhibition of $\mathrm{H}_{2}$-consuming acetogenic bacteria with rifampicin, stimulated $\mathrm{CH}_{4}$ production in two acidic bog soils, especially, in autumn and winter. The methanogenic community structure was characterized using T-RFLP analyses of SSU rRNA genes. The E2 group of methanogens (Methanoregulaceae) dominated in the two acidic bog peatlands with relatively greater abundance in winter. In the fen peatland, the E1 group (Methanoregulaceae) and members of the Methanosaetaceae were co-dominant, with E1 having a high relative abundance in spring. Change in relative abundance profiles among methanogenic groups in response to added metabolic substrates was as predicted. The acetate-amendment increased abundance of Methanosarcinaceae, and $\mathrm{H}_{2}$-amendment enhanced abundance of $\mathrm{E} 2$ group in all peat soils studied, respectively. Additionally, addition of acetate increased abundance of Methanosaetaceae only in the bog soils. Variation in the supply of metabolic substrates helps explain the moderate diversity of methanogens in peatlands.

Keywords: metabolic substrate, methane production, methanogenic archaea, peatland, SSU rRNA gene, temporal niche

\section{INTRODUCTION}

The ecological literature has many examples in which fluctuating environmental conditions promote diversity in community composition (Chesson and Huntly, 1997). When temperature, moisture, and resources fluctuate, optimal conditions for a given population will vary throughout the year, and thus community dominance varies accordingly. For microorganisms, there are two mechanisms. One is dispersal from a larger source that facilitates immigration and rise in dominance when optimal environmental conditions occur. This is called the mass-effect (Mouquet and Loreau, 2002) in the ecological literature. The other mechanism is called species-sorting (Leibold, 1998) in which all members of the local community are present throughout the year, but their temporal niche varies in response to optimal conditions. Understanding mechanisms that control regional and local composition of microbial communities is imperative in light of on-going environmental changes.

In boreal and cool temperate peatlands, for example, microorganisms are subjected to long, cold winters and short summers with more permissive growing conditions. Microbial activity in summer in response to warm temperatures is not surprising.
However, activity after the growing season benefits from input of senescent plant tissue that provides energy and nutrients, and microbial activity in soils in wintertime is well established (cf., McMahon et al., 2011). Therefore, the question is whether a seasonal supply of metabolic substrates is strong enough to control diversity in a microbial community (cf., Hiltunen et al., 2008).

Here we are particularly interested in saturated organic soils that provide habitat for anaerobic microorganisms. For example, $\mathrm{CH}_{4}$-producing methanogens are obligate anaerobes in the Euryarchaeota that produce $\mathrm{CH}_{4}$ from a limited number of substrates: acetate (aceticlastic methanogenesis), $\mathrm{CO}_{2}+\mathrm{H}_{2}$ (hydrogenotrophic methanogenesis), formate, methanol, and a few methylamines (Zinder, 1993). Therefore, methanogens rely on other microorganisms that decompose organic matter to supply methanogenic substrates (Drake et al., 2009). In general decomposers in peatlands feed on two sources of organic matter. One source is associated with plant roots; either root litter, or soluble organic molecules exuded from roots to soil (Williams and Yavitt, 2010). Root-associated microbial activity should peak during the growing season in response to root activity. Leaf litter is the other source of soil organic matter. In this case, input of leaf litter to 
soil occurs at the end of the growing season, and thus we expect maximum activity after the peak in soil temperature.

Fresh organic matter from high plant production is thought to fuel aceticlastic methanogenesis rather than the hydrogenotrophic pathway (Kotsyurbenko, 2010). In contrast, hydrogenotrophic pathway dominates in less productive peatlands and in those dominated by Sphagnum mosses and heath shrubs (Galand et al., 2005; Keller and Bridgham, 2007). Therefore, the aceticlastic pathway should be more prevalent in the summer and autumn with input of the freshest plant material. In this regard, Yavitt et al. (1988) found maximal rates of $\mathrm{CH}_{4}$ production in peat samples from early spring and late autumn when measurements were made at a standard temperature of $20^{\circ} \mathrm{C}$ regardless of in situ peat temperature. Juottonen et al. (2008) found that $\mathrm{CH}_{4}$ production peaked in February when the supply of metabolic substrates peaked, whereas the diversity of methanogens varied only slightly throughout the year.

Here we examine rates of $\mathrm{CH}_{4}$ production in relation to the diversity and dynamics of methanogens in three peatlands with contrasting characteristics: McLean Bog, Chicago Bog, and Michigan Hollow (local names). McLean and Chicago are both acidic peat bogs ( $\mathrm{pH} 3-4)$, whereas Michigan Hollow is a minerotrophic fen ( $\mathrm{pH} 6-7$ ). We added substrates to peat in short-term incubations of peat soil to examine substrate limitation of methanogenesis and also examine inducible shifts in populations in response to substrates. The three peatlands are isolated from each other and surrounded by a matrix of forest and agricultural land. Although dispersal of anaerobes occurs across inhospitable habitats (Yavitt et al., 2011), we found evidence for species-sorting and high diversity of the local community. Therefore, if climate changes in the future, the impact on peat $\mathrm{CH}_{4}$ production and methanogens is more complicated than simple temperature control.

\section{MATERIALS AND METHODS STUDY SITES}

The three sites were located within $40 \mathrm{~km}$ of Ithaca, NY, USA $\left(42^{\circ} 26^{\prime} \mathrm{N}, 76^{\circ} 30^{\prime} \mathrm{W}\right)$. The region is characterized by kettle-kame topography formed during Wisconsin Age glaciation (McNamara et al., 1992). This part of the Appalachian upland consists of relatively un-deformed sedimentary rocks of Ordovician, Silurian, and Devonian age that dip southward less than $1^{\circ}$. The uppermost bedrock is upper Devonian shale and thin-bedded sandstone. Above this is glacial-fluvial stratified sand and gravel with a strongly calcareous matrix. Parts of the landscape are covered by $5-12 \mathrm{~m}$ thick glacial till. Mean annual precipitation is $932 \mathrm{~mm}$, and mean annual temperature is $7.8^{\circ} \mathrm{C}$. Precipitation was above average, $125 \%$ of normal, during the first 6 months of the study period (June to December 2004), whereas as it was closer to the average, $109 \%$ of normal, after that (January 2005 to February 2006).

Chicago Bog $\left(42^{\circ} 34^{\prime} \mathrm{N}, 76^{\circ} 14^{\prime} \mathrm{W}\right)$ is a $0.05-\mathrm{km}^{2}$ kettle hole. Sedge-derived peat accumulated initially until it was above the local water table, at which point Sphagnum-derived bog peat accumulated. Total peat depth is about $6.5 \mathrm{~m}$. The bog has a ground cover of Sphagnum fuscum on elevated hummocks and S. magellenicum on recessed hollows. The drier hummocks also support the ericaceous shrub Chamaedaphne calyculata (leatherleaf). Peat soil $\mathrm{pH}$ is 4.1 at $15 \mathrm{~cm}$ depth. Water table level does not fluctuate in this site. Further site description is given in Dettling et al. (2007).

McLean Bog $\left(42^{\circ} 55^{\prime} \mathrm{N}, 76^{\circ} 26^{\prime} \mathrm{W}\right)$ is a $0.004-\mathrm{km}^{2}$ kettle hole. Total peat depth is $8 \mathrm{~m}$. Sphagnum species include $S$. angustifolium and S. amgellanicum. Shrubs include C. calyculata and Vaccinium corymbosum (highbush blueberry). The sedge Eriophorum vaginatum (cotton sedge) also is common. Peat soil $\mathrm{pH}$ is $3.4-4.3$ at $15 \mathrm{~cm}$ depth. Water table level is above the peat surface following snowmelt in spring, and it declines to about $25 \mathrm{~cm}$ below the peat surface by mid-summer. Further site description is given in Osvald (1970).

Michigan Hollow $\left(42^{\circ} 19^{\prime} \mathrm{N}, 76^{\circ} 29^{\prime} \mathrm{W}\right)$ is a $0.24-\mathrm{km}^{2}$ fen dominated by a single species of sedge, Carex lacustris (lake sedge) with patches of Typha latifolia (Common cattail) and Lythrum salicaria (Purple loosestrife). The maximum peat depth is about $1.2 \mathrm{~m}$, consisting mostly of Carex sedge-derived peat. Peat soil $\mathrm{pH}$ is 6.7 at $15 \mathrm{~cm}$ depth. Water table level fluctuates about $10 \mathrm{~cm}$ between spring snowmelt and summer in this site. Further site description is given in Bernard and Macdonald (1974).

\section{PEAT SOIL COLLECTION}

We obtained fresh soil samples on each sampling date by cutting through surface vegetation and peat soil to a depth roughly below the lowest water table level seasonally: about $10 \mathrm{~cm}$ deep in Chicago bog, $20 \mathrm{~cm}$ deep in Mclean bog, and $20 \mathrm{~cm}$ deep in Michigan Hollow. We assume this depth has the largest rate of methanogenesis because it is saturated throughout the study period. This assumption has been confirmed in previous studies at McLean Bog and Chicago Bog using samples collected in 2004 (Brauer, 2006).

For each collection, three separate portions of peat soil from $5 \mathrm{~cm}$ below the water table were collected directly into glass canning jars. Jars were sealed with an airtight lid while immersed in the peat to prevent $\mathrm{O}_{2}$ exposure to the sampled peat soil. The jars were taken within $2 \mathrm{~h}$ of sapling to the laboratory and placed in an anaerobic glove box (Coy Laboratory Products). Fresh samples were collected at 2-4 month intervals for a 12-month period between June 2004 and July 2005. We also collected small samples in November 2005 and in February 2006 when the peatland surface was partially frozen: these samples were used for analysis of community composition but not in vitro incubation for methanogenesis. Overall, the study lasted 20 months.

\section{SOIL INCUBATIONS}

We followed methods described in Bräuer et al. (2004). Briefly, inside the anaerobic glove box one gram of peat (wet mass) and $9 \mathrm{~mL}$ of anaerobic de-ionized water was placed in $18 \times 150 \mathrm{~mm}$ crimp-top tube (Bellco Glass Co., Vineland, NJ, USA). After crimping the tops, the tubes were flushed for $5 \mathrm{~min}$ with sterile $\mathrm{O}_{2}$ scrubbed $\mathrm{N}_{2} / \mathrm{CO}_{2}$ (70/30\%). Four treatments were established in triplicate for soil from each site and for each sampling period. Final concentrations for each treatment was: (1) no additions, (2) sodium acetate $(1 \mathrm{mM}),(3)$ rifampicin $\left(10 \mathrm{mg} \mathrm{L}^{-1}\right)$, and sterile $\mathrm{O}_{2}$-scrubbed $\mathrm{H}_{2} / \mathrm{CO}_{2}(80 / 20 \%)$ plus rifampicin $\left(10 \mathrm{mg} \mathrm{L}^{-1}\right)$. The purpose of rifampicin was to inhibit acetogenic bacteria, carrying out the reaction $4 \mathrm{H}_{2}+2 \mathrm{CO}_{2} \rightarrow \mathrm{CH}_{3} \mathrm{COOH}+2 \mathrm{H}_{2} \mathrm{O}$, which compete with $\mathrm{H}_{2}$-utilizing methanogens. Accumulation of acetic acid can acidify peat, which interferes with our ability to examine 
the effect of various environmental parameters on the presence of $\mathrm{H}_{2} / \mathrm{CO}_{2}$-utilizing methanogens in the peat. Rifampicin treatment is explained fully in Bräuer et al. (2004).

Tubes were incubated in the dark at $22 \pm 2^{\circ} \mathrm{C}$. Tubes with no additions and sodium acetate were incubated without shaking, whereas tubes with $\mathrm{H}_{2} / \mathrm{CO}_{2}$ were shaken to help mix gases between peat soil and headspace. Methane concentrations in each tube were determined at 2-3 day intervals by gas chromatography as in Bräuer et al. (2004). All of the samples exhibited a delay before the onset of increasing $\mathrm{CH}_{4}$ concentration. We report the length of the delay period before onset of $\mathrm{CH}_{4}$ production (in days) in order to distinguish from a true lag phase in microbial growth. Rates of potential $\mathrm{CH}_{4}$ production were determined from the linear increase in $\mathrm{CH}_{4}$ concentration for about 14 days following the onset of $\mathrm{CH}_{4}$ production. Rates of potential $\mathrm{CH}_{4}$ production are expressed as millimoles of $\mathrm{CH}_{4}$ produced per liter of wet peat soil per day. We recognize that rates are often expressed per gram of dry soil, which is standard in soil science since the wet mass of soil varies depending on soil moisture content. However, peat below the water table is essentially saturated, and thus volume is the correct unit. Moreover, volume is the convention in literature for aqueous systems and by microbiologists studying cultures. For comparison among units, the peat bulk density values are: $0.076 \pm 0.024(\mathrm{SD}) \mathrm{Mg} \mathrm{m}^{-3}$ for McLean; $0.084 \pm 0.022 \mathrm{Mg} \mathrm{m}^{-3}$ for Chicago; and, $0.105 \pm 0.018 \mathrm{Mg} \mathrm{m}^{-3}$ for Michigan Hollow. We also determined $\mathrm{pH}$ values per sample.

\section{SSU rRNA GENE ANALYSIS}

DNA was extracted from duplicate 0.5 -g portions of fresh peat from each of the triplicate samples incubated per sites per sampling date. Briefly, DNA was extracted with the Power Soil ${ }^{\mathrm{TM}} \mathrm{DNA}$ kit (MoBio) using manufacturer's protocol, with some changes. After adding the $\mathrm{C} 1$ solution, $50 \mu \mathrm{L}$ of a sterile $200 \mathrm{mM} \mathrm{AlNH}_{4}\left(\mathrm{SO}_{4}\right)_{2}$ solution was added to decrease the amount of humic acid contamination. The solution was put in a bead beater (MiniBeadbeater) for 80 s set on "homogenize." Quality of DNA was checked with agarose gel electrophoresis and spectrophotometer readings.

The primers used for PCR were 1AF ( $5^{\prime}$-TCY GKT TGA TCC YGS CRG AG-3') and 1100R (5'-TGG GTC TCG CTC GTT G-3'; Hales et al., 1996). These primers target methanogens, although other archaeal groups may also be amplified. The 1100 reverse primer was labeled on its $5^{\prime}$ end with Carboxyfluorescein $\left(5^{\prime}-/ 6\right.$ FAM). The PCR mixture ( $35 \mu \mathrm{L}$ for each reaction) contained the following components per $\mu \mathrm{L}$ : $1 \times$ Taq buffer with $1.5 \mathrm{mM} \mathrm{MgCl}_{2}$ (Eppendorf, USA), $0.2 \mathrm{mM}$ dNTPs, $0.25 \mu \mathrm{M}$ forward and reverse primers, 1.2 U of Taq Polymerase (Eppendorf), $0.2 \mu \mathrm{g}$ BSA and $0.1-0.3 \mathrm{ng}$ of extracted DNA. The PCR thermal cycler conditions are described by Hales et al. (1996), with 25 cycles. PCR products were examined by gel electrophoresis on $1 \%$ agarose for size verification (1100 bp).

The PCR was performed three times, and $30 \mu \mathrm{L}$ from each run was pooled to achieve enough PCR product from the same sample using a low number of cycles and to prevent the probability of random PCR artifacts due to location on a thermocycler surface, pipetting, etc. (Although we did not rerun every sample systematically, random samples were redone and nearly identical relative composition of community composition from the same sample supports our confidence in T-RFLP reproducibility.) The final product was purified with Quick Step ${ }^{\mathrm{TM}} 2$ PCR Purification Kit (Edge Biosystems). Then 70 ng of purified PCR products were digested with a mix of Hha (15 U) and Sau96I (10 U) enzymes (New England Biolabs for $3 \mathrm{~h}$ at $37^{\circ} \mathrm{C}$. Digested DNA was purified with the Performa ${ }^{\circledR}$ DTRV3 96-Well Short Plate Kit (Edge Biosystems) and concentrated in a vacuum centrifuge. The dehydrated products were then re-suspended with a mix of $\mathrm{Hi} \mathrm{Di-}$ Formamide (volume $\mu \mathrm{L} / \mathrm{mL}$; Applied Biosystems) and Gene Scan 500-Liz marker ( $12 \mu \mathrm{L} / \mathrm{mL}$; Applied Biosystems) to a final volume of $15 \mu \mathrm{L}$. Fragments were resolved with an Applied BioSystems 3730xl DNA Analyzer (BRC, Cornell University).

T-RF sequence length, peak height, and area were analyzed using the GeneScan Analysis Software (Applied Biosystems, 2000). The raw data used to image these T-RFLP results on an electropherogram was exported in order to standardize the profile for each sample. With a Java program (Culman et al., 2009), the relative fluorescent units (RFU) of peaks with sizes between 50 and 500 bp were combined by height and normalized to 100 total RFU units. The standardization allowed the comparison of relative abundances from sample to sample.

We used T-RFLP analysis to obtain a description of the dominant groups in the archaeal community accessible through our primer set. The 1Af-1100R primers have been thoroughly tested previously in T-RFLP analysis with minimal ambiguous identification. The T-RFLP protocol, using two restriction enzymes (HhaI and Sau96I), was designed by performing multiple in silico sequence analyses of published sequences and clone libraries, and confirming the predicted fragment size by amplifying and T-RFLP analysis clones. Cadillo-Quiroz et al. (2006) presents the identity match and predicted terminal restriction fragment (T-RF) size from the in silico digestion.

The T-RFLP analysis was repeated on peat soils following in vitro incubation for $\mathrm{CH}_{4}$ production potential. The analysis was performed 35 days after incubation for soils treated with rifampicin and rifampicin plus $\mathrm{H}_{2}$, and 70 days after incubation for the un-amended soils and for those treated with acetate.

\section{STATISTICAL ANALYSES}

Values presented below are mean $(N=3)$. We analyzed seasonal differences in methanogenesis and community composition using analysis of variance (ANOVA). The T-RFLP values were square root-transformed before analysis, whereas rates of potential $\mathrm{CH} 4$ production were log-transformed.

\section{RESULTS}

\section{RATES OF POTENTIAL CH $\mathrm{CH}_{4}$ PRODUCTION}

All of the peat soil samples exhibited a delay between the time we initiated incubation and the onset of $\mathrm{CH}_{4}$ production (Table 1). There was no consistent seasonal pattern in delay time $(P>0.05$ for sampling date); however, the average delay time was shorter for peat soil from Michigan Hollow ( 9 days) than from Chicago (11 days) and McLean (14 days). For each of the three sites, rates of potential $\mathrm{CH}_{4}$ production (measured at a consistent incubation temperature of $21^{\circ} \mathrm{C}$ ) varied 3- to 5-fold among sampling dates. In general, the slowest rates occurred for soil collected in October from Chicago and Michigan Hollow versus April for soil from 
Table 1 | Delay (days) before onset of $\mathrm{CH}_{4}$ production and rates of potential $\mathrm{CH}_{4}$ production in peat soils with no added substrates.

\begin{tabular}{|c|c|c|c|c|c|c|}
\hline \multirow[t]{2}{*}{ Month } & \multicolumn{2}{|c|}{ Chicago } & \multicolumn{2}{|c|}{ McLean } & \multicolumn{2}{|c|}{ Michigan } \\
\hline & Delay & Rate & Delay & Rate & Delay & Rate \\
\hline Jun & 11 & $0.072(0.010)$ & 11 & $0.068(0.022)$ & 11 & $0.067(0.007)$ \\
\hline Aug & 10 & $0.053(0.009)$ & 14 & $0.052(0.011)$ & 8 & $0.052(0.010)$ \\
\hline Sep/Oct & 18 & $0.037(0.003)$ & 10 & $0.042(0.001)$ & 7 & $0.037(0.006)$ \\
\hline Jan & 10 & $0.061(0.001)$ & 17 & $0.031(0.007)$ & ND & ND \\
\hline Apr & 6 & $0.045(0.001)$ & 14 & $0.020(0.003)$ & 8 & $0.129(0.031)$ \\
\hline May & 11 & $0.058(0.012)$ & 19 & $0.031(0.003)$ & 10 & $0.050(0.017)$ \\
\hline Jul & 11 & $0.081(0.007)$ & 11 & $0.099(0.011)$ & 11 & $0.181(0.025)$ \\
\hline
\end{tabular}

ND, no data. Mean rate, $\mathrm{mmol}^{-1}$ day ${ }^{-1}$, and 1 SE in parentheses.

Table 2 | Analysis of variance for rates of $\mathrm{CH}_{4}$ production.

\begin{tabular}{llrl}
\hline & df & $\boldsymbol{F}$ & $\boldsymbol{P}$ \\
\hline Site & 2 & 0.37 & 0.6908 \\
Date & 6 & 51.03 & 0.0001 \\
Site $\times$ date & 10 & 2.07 & 0.0320 \\
Treatment & 3 & 5.72 & 0.0011 \\
Treatment $\times$ site & 6 & 3.12 & 0.0070 \\
Treatment $\times$ date & 16 & 3.91 & 0.0001 \\
Site $\times$ date $\times$ treatment & 24 & 2.51 & 0.0006
\end{tabular}

Df, degrees of freedom; $F$, F ratio; $P$, probability of significant difference.

Treatment $=$ Control, + Acetate,, rifampicin, and $+\mathrm{H}_{2}+$ rifampicin .

McLean. The fastest rates occurred for samples collect in July for all three sites (Table 2).

Rates of potential $\mathrm{CH}_{4}$ production in peat soils from the three sites exhibited some degree of substrate limitation among sampling dates (Table 3). The addition of acetate to peat soils from Chicago and McLean increased rates by $30 \%$ to nearly 4 -fold, with slightly greater response for McLean than for Chicago, in particular, for soil collected in October. Added acetate had the largest effect on peat soil from Michigan Hollow. Notably, the addition of rifampicin often decreased rates of potential $\mathrm{CH}_{4}$ production by as much as $60 \%$. However, the addition of rifampicin $+\mathrm{H}_{2}$ stimulated potential $\mathrm{CH}_{4}$ production, especially, in January for peat from Chicago and October for McLean.

\section{METHANOGEN COMMUNITY STRUCTURE}

The labeling of the $1 \mathrm{Af}-1100 \mathrm{R}$ primer set combined with a double digestion with the HhaI/Sau96I restriction enzymes resolved most of the euryarchaeal groups in which each T-RF could be associated with a single group. This was confirmed by digestion of multiple clones and pure cultures as given in Cadillo-Quiroz et al. (2006), including Methanosarcinaceae (MS), Methanosaetaceae (MT), and Methanobacteriaceae (MB), as well as recently cultured groups, such as group E2' (E2) and group E1' (E1) in the order Methanomicrobiales, and rice cluster-I (RC-I) in the novel order Methanocellales. We also identified fragments associated with as yet uncultured euryarchaeal and crenarchaeal groups, including RC-II, group $1.3 \mathrm{~b}$ and $1.1 \mathrm{c}$.
We rely on PCR and T-RFLP analysis because our primary goal was presence or absence of different methanogen groups at different times of the year. We realize that qPCR is necessary for accurate assessment of abundance. Notwithstanding, the dominant group in peat soil from McLean was E2 (Figure 1). The relative abundance of E2 changed significantly $(P<0.01$ for sampling date) during the study period, with relatively greater abundance in the coldest months versus less abundance in June and July. Similarly, the MS group had greater abundance $(P<0.01$ for sampling date) in colder than in warmer months, with E1 having slightly higher relative abundance in those months. The E2 group also was the dominant group in peat soil from Chicago with proportionally greater abundance in coldest months. However in contrast to McLean, the MS group had greater abundance in warmer than in colder months in Chicago $(P<0.01$ for sampling date).

In peat soil from Michigan Hollow, MT and E1 were the dominant groups. The relative abundance of E1 is greatest in May, whereas MT were the dominant group in other sampling times $(P<0.01$ for sampling date). The group E2 was in Michigan Hollow only once in August. Overall, there were significant differences in the abundance of phylogenetic groups among the three sites. Relative abundance of MT ( $P<0.001$ for site), E2 $(P<0.001$ for site), MS $(P<0.01$ for site $)$, and E1 $(P<0.01$ for site) are all highly significantly different in all sites, with a corrected $P$ level of 0.0028 .

The addition of substrates changed the relative abundance of methanogenic groups in predictable ways (Figure 2). In peat from Mclean and Chicago, for instance, the addition of acetate led to increase relative abundance of MS and MT at the expense of E1 and E2. With added rifampicin, E1, MS, and E2 were dominant, whereas added rifampicin plus $\mathrm{H}_{2}$ led to almost $100 \% \mathrm{E} 2$. In contrast, in peat soil from Michigan Hollow, E1 and MT had substantial presence in all treatments, with MS increasing with added acetate versus $\mathrm{E} 2$ increasing with added rifampicin and $\mathrm{H}_{2}$.

\section{DISCUSSION}

\section{RATES OF POTENTIAL $\mathrm{CH}_{4}$ PRODUCTION}

In this study we incubated samples of peat soil at one temperature regardless of the in situ temperature on the date of soil collection. Our rationale for one temperature follows the well-known phenomenon that low temperatures, $<12^{\circ} \mathrm{C}$, constrain rates of $\mathrm{CH}_{4}$ production in peat soils (Yavitt et al., 1988; Juottonen et al., 2008). Therefore, measuring very low production rates in 
Table 3 | Ratio for the rate of $\mathrm{CH}_{4}$ production with added substrate versus un-amended control.

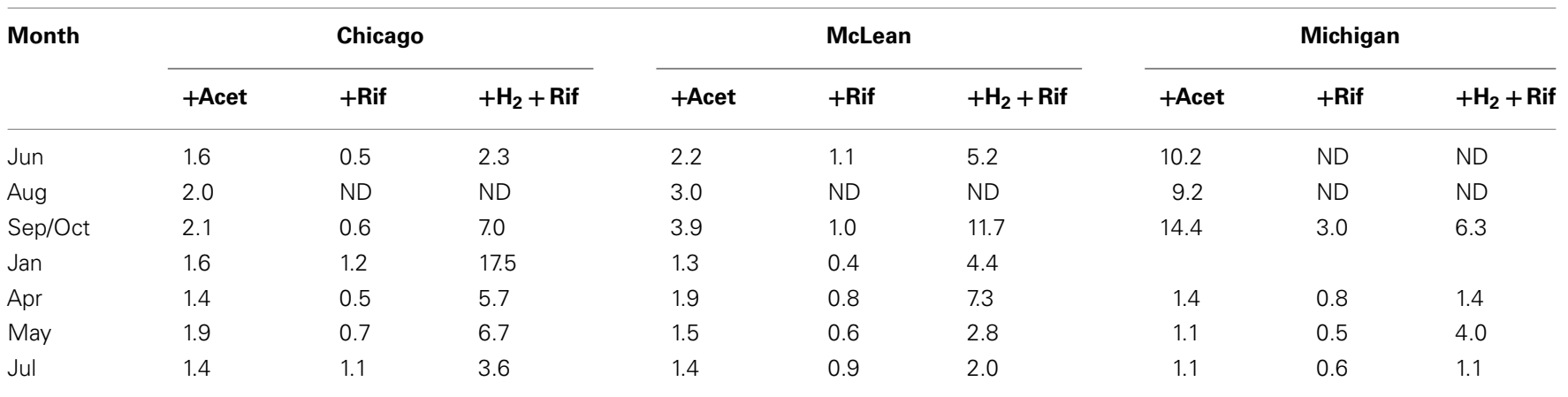

$N D$, no data. Substrates were either acetate (Acet), rifampicin (Rif), or $\mathrm{H}_{2}$ plus rifampicin $\left(+\mathrm{H}_{2}+\right.$ Rif).
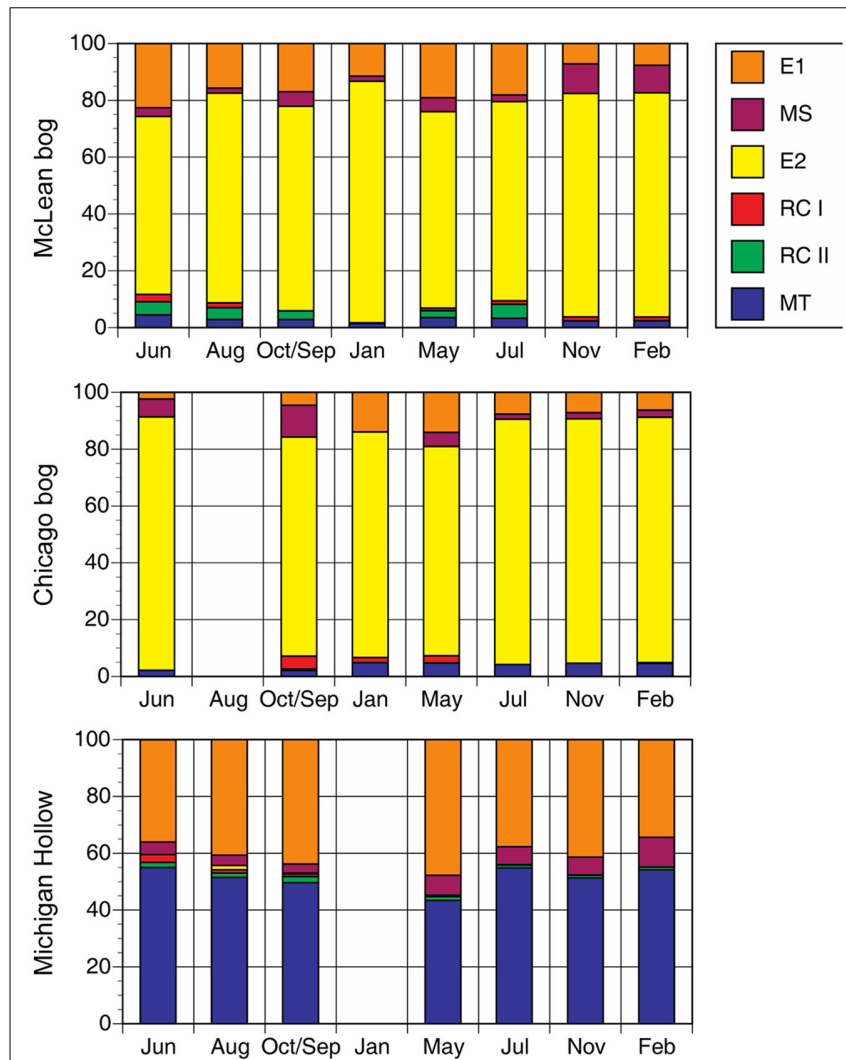

FIGURE 1 | Proportion of major methanogen groups determined by T-RFLP of SSU rRNA gene sequences for soil samples from three peatlands (no addition treatment). Legend indicates groups: E2' (E2) and $E 1^{\prime}(E 1)$ in the order Methanomicrobiales; rice cluster-I (RC-I) in the novel order Methanocellales; uncultivated RC-II; and, Methanosarcinaceae (MS) and Methanosaetaceae (MT) in the Methanosarcinales.

winter does not provide much insight into the seasonal nature of the methanogenic community. By incubating peat soils at the same temperature year-round we could gain insight into seasonal dynamics of methanogenic community without temperature constraint.

The larger mean rate of potential $\mathrm{CH}_{4}$ production in peat soil from Michigan Hollow $\left(0.086 \mathrm{mmol} \mathrm{L}^{-1}\right.$ day $\left.^{-1}\right)$ correlates with the near neutral $\mathrm{pH}$ and sedge vegetation, whereas lower

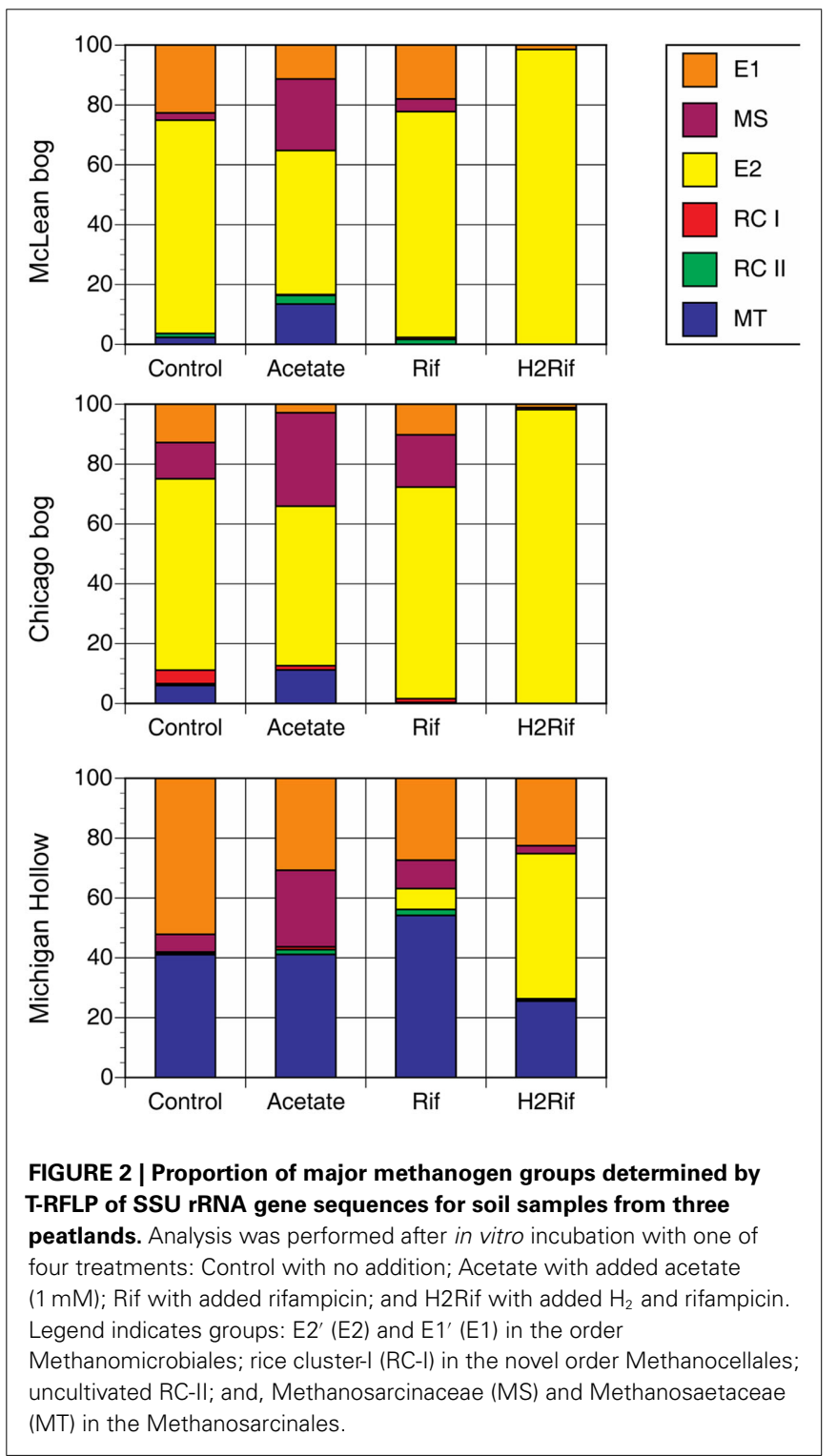

$\mathrm{CH}_{4}$ production potential occurred in acidic peat soil derived from relatively un-decomposable moss and shrub vegetation at 
the other two sites. The larger $\mathrm{CH}_{4}$ production potential in soil from Chicago $\left(0.059 \mathrm{mmol} \mathrm{L}^{-1} \mathrm{day}^{-1}\right)$ versus that at McLean $\left(0.031 \mu \mathrm{mol} \mathrm{L}^{-1} \mathrm{day}^{-1}\right)$ is notable. Chicago is a relatively dry peatland with water table $20 \mathrm{~cm}$ below the surface, whereas McLean is a relatively wet peatland in which the water table is closer to the surface. In addition, Chicago has a fen-to-bog transition about 0.6-m below the peatland surface, whereas fen peat is buried much deeper in McLean. We deduce that fen peat provides nutrients for microbial growth (Dettling et al., 2007) and reduces the delay time before the onset of methanogenesis, despite the drier condition in Chicago than in McLean.

Methanogenesis in soil cannot be measured directly in the field very easily, but rather we must rely on measurements made in vitro. Therefore, rates of potential $\mathrm{CH}_{4}$ production depend upon soil collection and storage as well as procedures used in the laboratory. For example, although methanogens are obligate anaerobes, some strains can tolerate short-term exposure to $\mathrm{O}_{2}$ (Jarrell, 1985), whereas others cannot. Consumption of methanogenic substrates can occur during storage and delay onset of $\mathrm{CH}_{4}$ production. Here we collect peat soil just below the water table level, which should have the greatest rate of $\mathrm{CH}_{4}$ production within the depth profile (Sundh et al., 1994). Also, we had minimal storage of soil samples between collection and incubation ( $<2$ days), and we prepared all of the incubations in an anaerobic glove box to prevent exposure to $\mathrm{O}_{2}$. Nevertheless, every soil sample exhibited a delay phase before the onset of $\mathrm{CH}_{4}$ production.

A delay implies either a small population size of methanogens, methanogenesis inhibited by another anaerobic process, or by the lack of methanogenic substrates. Although these peat soils contain a relatively large viable population of methanogens (CadilloQuiroz et al., 2006), we suspect that a delay results from the high in vitro dilution that reduced effective population size. We cannot rule out that the delay also was a period of low activity per cell, as methanogens are known to vary activity per cell during incubation (Krüger et al., 2005). Regardless, there was no significant seasonal pattern in the length of the delay period, suggesting the local condition just prior to sampling can influence delay time.

The fastest rates of potential $\mathrm{CH}_{4}$ production in all three sites occurred in July. This coincides with maximum plant growth, which suggests that plant root activity, and organic compounds released from plant roots fuels the greatest $\mathrm{CH}_{4}$ production potential. This might be true at Mclean, which showed a low rate outside the growing season, presumably supplemented by root-derived compounds in the growing season. Moreover, some of the plants may harbor distinct subsets of methanogens, i.e., different from those in the bulk peat, as was found in McLean Bog (CadilloQuiroz et al., 2010). However, at Chicago, a moderate high $\mathrm{CH}_{4}$ production potential in January may possibly indicate that root activity is less influential, or perhaps indicates that significant root activity is present in January, due to the abundance of evergreen shrubs. In contrast, although grasses dominate the vegetation at Michigan Hollow, and grass roots are known to release organic compounds, methanogenic activity utilizes dead plant material throughout the year in Michigan Hollow (Williams and Yavitt, 2010).

Few studies have addressed year-round patterns in $\mathrm{CH}_{4}$ production in soils, independent of in situ temperature regime (although see Yavitt et al., 1988). One such study is by Juottonen et al. (2008) that reported maximum $\mathrm{CH}_{4}$ production potential in samples of peat soils collected in winter from a boreal fen. The explanation was that low temperatures in late autumn and winter constrained $\mathrm{CH}_{4}$ production to a greater degree than hydrolysis and fermentation, thereby allowing methanogenic substrates to accumulate. When the cold temperature limitation was relaxed in the laboratory, rates of methanogenic activity responded. However, our sites occur in a temperate climate, and cold wintertime temperatures occur for no more than 4 months. For example, during our study soil temperature was $20-25^{\circ} \mathrm{C}$ in October, $4^{\circ} \mathrm{C}$ in December, and it had rebounded to $10^{\circ} \mathrm{C}$ by March. Therefore, low rates of potential $\mathrm{CH}_{4}$ production that we observed in September/October are notable because in situ temperature was permissible, which suggests a substrate limitation or competition with other anaerobic bacteria.

Some studies have suggested that substrate availability does not limit anaerobic activity because substrates exuded from plant roots fuel activity during the growing season, whereas anaerobes decompose dead plant material in the fall and wintertime (Lipson et al., 2002). Although plant roots do release organic compounds to soil, anaerobic metabolism in plants produces only ethanol and/or lactate (Good and Muench, 1993), neither of which are methanogenic substrates. However, the oxidation of these compounds produces acetate, so aceticlastic methanogenesis could be linked indirectly to plant root activity. However, added acetate had the greatest impact on $\mathrm{CH}_{4}$ production in August through October, which is after maximum root growth. The larger impact in Michigan Hollow than in the other two sites is consistent with grass derived organic matter, which decomposes more readily than moss or shrub litter and supports aceticlastic methanogens. This is supported by an increase in abundance of fragment lengths affiliated with Methanosaeta spp., known acetate-utilizing methanogens. It is logical that stimulation with acetate would produce higher rates of $\mathrm{CH}_{4}$ production. In contrast, the greater response to added $\mathrm{H}_{2}+$ rifampicin in Chicago and McLean is consistent with the methanogenic community dominated by E2, which is an $\mathrm{H}_{2}$-utilizing methanogen.

The stimulation of $\mathrm{CH}_{4}$ production by added methanogenic substrates suggests a competition for substrates with other anaerobic pathways. For example both acetate and $\mathrm{H}_{2}$ are utilized by anaerobes that carry our respiration with electron acceptors other than $\mathrm{O}_{2}$. However, in other studies we have shown that the addition of electron acceptors, such as ferric iron $\left(\mathrm{Fe}^{3+}\right)$ and sulfate did not inhibit methanogenesis completely (Dettling et al., 2006). Indeed, in some cases, the addition of $\mathrm{Fe}^{3+}$ stimulated $\mathrm{CH}_{4}$ production, suggesting that iron is an essential nutrient of methanogens, and it is short supply, which is not surprising in these relatively nutrient poor soils. Thus what processes compete with methanogens for available acetate and $\mathrm{H}_{2}$ is still not clear.

\section{METHANOGENIC COMMUNITY}

Previous work with methanogens in peat soils, in particular those studies based on SSU rRNA gene sequences, has suggested that community composition can be quite diverse (cf., Basiliko et al., 2003; Juottonen et al., 2008; Kotsyurbenko, 2010; Yavitt et al., 2011). It is well-known, however, that SSU rRNA genes target 
total community composition, including active and inactive cells (Logue and Lindström, 2010), and thus the approach has been criticized for having a biased estimate of community diversity. Notwithstanding, inactive cells at the time of soil sampling can become active during other times of the year in response to optimal environmental conditions (Lennon and Jones, 2011), resulting in a temporal niche (Loreau, 1989). Indeed, the second part of our study (see below) with in vitro incubations of portions of peat soil provides a unique opportunity to examine the temporal niche via species-sorting for methanogens in isolated peatlands.

The prevalence of E2 in McLean and Chicago is consistent with the evidence that $\mathrm{H}_{2}$-utilizing methanogens, especially members of Methanomicrobiales dominate in acidic peat soils (Galand et al., 2005; Yavitt et al., 2011). The small fraction of RC-I agrees with the notion that RC-I prefers substrate-rich habitats, such as root surfaces (Cadillo-Quiroz et al., 2010). In contrast, the E2 group appears to be adapted to low-nutrient environments, such as the bulk peat and pore water of acidic bogs. In fact, the first strain of this group, "Candidatus Methanoregula boonei," was isolated using a low-nutrient low-ionic-strength medium (Bräuer et al., 2006). Therefore, the relative dominance of E2 in both bog sites is not surprising.

The peak in relatively dominance of E2 in January in McLean versus in June in Chicago might imply no consistent seasonal pattern in relative dominance of E2 in acidic bogs. However, peak dominance in both sites correlated with a relatively small impact of added $\mathrm{H}_{2}$ (+rifampicin) on potential $\mathrm{CH}_{4}$ production (Table 3). The small impact suggests an adequate supply of substrates for methanogenesis, and thus E2 might assume a greater role when metabolic substrates are plentiful. When the relative proportion of E2 did decrease in both sites, the difference was due mostly to an increase in the proportion of E1. The E1 group also relies on $\mathrm{H}_{2} / \mathrm{CO}_{2}$ for $\mathrm{CH}_{4}$ production (Cadillo-Quiroz et al., 2008). However, more experimental studies are needed to verify whether E1 favors substrate-limited conditions, whereas E2 favors substrate-rich conditions.

The prevalence of MT in Michigan Hollow is consistent with the evidence that acetate-utilizing methanogens dominate in neutral, sedge-dominated fens (Galand et al., 2005). All known members of MT make $\mathrm{CH}_{4}$ by splitting acetate (Liu and Whitman, 2008). Moreover, they do so at concentrations of acetate as low as $5-70 \mu \mathrm{M}$ (Jetten et al., 1992), suggesting that low concentrations of acetate occur in peat pore water in Michigan Hollow. Moreover, MT is able to outcompete MS at low acetate

\section{REFERENCES}

Basiliko, N., Yavitt, J. B., Dees, P. M., and Merkel, S. M. (2003). Methane biogeochemistry and methanogen communities in two northern peatland ecosystems, New York State. Geomicrobiol. J. 20, 563-577.

Bernard, J. M., and Macdonald, J. G. Jr. (1974). Primary production and life history of Carex lacustris. Can. J. Bot. $52,117-123$.

Brauer, S. L. (2006). Methanogenesis and Methanogens in Peat-Forming Wetlands in Central New York State.
Ph.D. dissertation, Cornell University.

Bräuer, S. L., Yashiro, E., Cadillo Quiroz, H., Yavitt, J. B., and Zinder, S. H. (2006). Isolation of a novel acidiphilic methanogen from an acidic peat bog. Nature 442, 192-194.

Bräuer, S. L., Yavitt, J. B., and Zinder, S. H. (2004). Methanogenesis in McLean Bog, an acidic peat bog in upstate New York: stimulation by $\mathrm{H} 2 / \mathrm{CO} 2$ in the presence of rifampicin, or by low concentrations of

concentrations (Galand et al., 2005). Thus, finding MS and RC$\mathrm{I}$ in all three sites is interesting because they have been shown to rely on relatively large substrate concentrations for $\mathrm{CH}_{4}$ production: MS at acetate concentrations between 0.2 and $1.2 \mathrm{mM}$ (Jetten et al., 1992); and, RC-I at high $\mathrm{H}_{2}$ concentrations (Conrad et al., 2006). Indeed, our studies in other peatlands have shown the co-occurrence of MS and RC-I, associated with high substrate conditions (Yavitt et al., 2007). Although MS can make $\mathrm{CH}_{4}$ from $\mathrm{H}_{2} / \mathrm{CO}_{2}$, we did find that in vitro incubations of peat soil with added acetate led to a large increase in MS dominance, which suggests that, at least, some of the in situ members find high acetate concentrations in order to make $\mathrm{CH}_{4}$. Interestingly, the E1 group increased relative dominance in the springtime in Michigan Hollow, whereas MT decreased in abundance at the same time. Thus, the springtime appears to be a time of increased acetate supply, favoring MS over MT, with low $\mathrm{H}_{2}$ or formate for E2 growth.

Species-sorting is suggested by change in relative dominance of methanogen groups following addition of metabolic substrates to portions of peat soil maintained in the laboratory. This was demonstrated most impressively by the increase in E2 in peat soil from Michigan Hollow, going from $<1 \%$ relative dominance in situ to $45 \%$ relative dominance following in vitro incubation with added $\mathrm{H}_{2}+$ rifampicin. Likewise added acetate led to large increase in relative dominance of MS and MT in peat from the two acidic bogs. Hence experiments in the laboratory can provide insight into hidden microbial diversity in situ (cf., Meier et al., 2008). Our data collectively shows that these peatlands harbor diverse populations of methanogens even though not all populations are active continuously. Rather we suggest that the availability of substrates is an important cue for population growth. This extends the species-sorting concept to isolated peatlands, as demonstrated for bacterial communities in isolated lakes (cf., Jones and McMahon, 2008). This does not rule out the masseffect and dispersal for peatland methanogens (cf., Yavitt et al., 2011), but species-sorting might be an important mechanism for maintaining diversity on a seasonal basis.

Now, we need to know how substrate supply varies temporally in peatlands. Control on variation in substrate supply adds another dimension to global environmental change (Trumbore, 1997). For example, we need to know whether temperature and moisture regimes alone are the controlling mechanism, or whether more complex controls exist, such as via plant community composition (Hiltunen et al., 2008; Williams and Yavitt, 2010).

acetate. Geomicrobiol. J. 21, 433-443.

Cadillo-Quiroz, H., Brauer, S., Yashiro, E., Sun, C., Yavitt, J., and Zinder, S. (2006). Vertical profiles of methanogenesis and methanogens in two contrasting acidic peatlands in central New York State, USA. Environ. Microbiol. 8, 1428-1440.

Cadillo-Quiroz, H., Yashiro, E., Yavitt, J. B., and Zinder, S. H. (2008). Characterization of the archaeal community in a minerotrophic fen and terminal restriction fragment length polymorphism-directed isolation of a novel hydrogenotrophic methanogen. Appl. Environ. Microbiol. 74, 2059-2068.

Cadillo-Quiroz, H., Yavitt, J., Zinder, S., and Thies, J. (2010). Diversity and community structure of archaea inhabiting the rhizoplane of two contrasting plants from an acidic bog. Microb. Ecol. 59, 757-767.

Chesson, P., and Huntly, N. (1997). The roles of harsh and fluctuating conditions in the dynamics of ecological communities. Am. Nat. 150, 519-553. 
Conrad, R., Erkel, C., and Liesack, W. (2006). Rice cluster I methanogens, an important group of archaea producing greenhouse gas in soil. Curr. Opin. Biotechnol. 17, 262-267.

Culman, S. W., Bukowski, R., Gauch, H. G., Cadillo-Quiroz, H., and Buckley, D. H. (2009). T-REX: software for the processing and analysis of $\mathrm{T}$ RFLP data. BMC Bioinformatics 10, 171. doi:10.1186/1471-2105-10-171

Dettling, M. D., Yavitt, J. B., CadilloQuiroz, H., Sun, C., and Zinder, S. H. (2007). Soil-methanogen interactions in two peatlands (bog, fen) in central New York State. Geomicrobiol. J. 24, 247-259.

Dettling, M. D., Yavitt, J. B., and Zinder, S. H. (2006). Control of organic carbon mineralization by alternative electron acceptors in four peatlands, Central New York State, USA. Wetlands 26, 917-927.

Drake, H. L., Horn, M. A., and Wüst, P. K. (2009). Intermediary ecosystem metabolism as a main driver of methanogenesis in acidic wetland soil. Environ. Microbiol. Rep. 1, 307-318.

Galand, P. E., Fritze, H., Conrad, R., and Yrjälä, K. (2005). Pathways for methanogenesis and diversity of methanogenic archaea in three boreal peatland ecosystems. Appl. Environ. Microbiol. 71, 2195-2198.

Good, A. G., and Muench, D. G. (1993). Long-term anaerobic metabolism in root tissue: metabolic products of pyruvate metabolism. Plant Physiol. 101, 1163-1168.

Hales, B. A., Edwards, C., Ritchie, D. A., Hall, G., Pickup, R. W., and Saunders, J. R. (1996). Isolation and identification of methanogenspecific DNA from blanket bog peat by PCR amplification and sequence analysis. Appl. Environ. Microbiol. 62, 668-675.

Hiltunen, T., Laakso, J., Kaitala, V., Suomalainen, L.-R., and Pekkonen, M. (2008). Temporal variability in detritus resource maintains diversity of bacterial communities. Acta Oecologia 33, 291-299.

Jarrell, K. F. (1985). Extreme oxygen sensitivity in methanogenic archaebacteria. Bioscience 35, 298-302.

Jetten, M. S. M., Stams, A. J. M., and Zehnder, A. J. B. (1992). Methanogenesis from acetate - a comparison of the acetate metabolism in Methanothrix soehngenii and Methanosarcina spp. FEMS Microbiol. Rev. 88, 181-197.

Jones, S. E., and McMahon, K. D. (2008). Species-sorting may explain an apparent minimal effect of immigration on freshwater bacterial community dynamics. Environ. Microbiol. 11, 905-913.

Juottonen, H., Tuittila, E. S., Juutinen, S., Fritze, H., and Yrjala, K. (2008). Seasonality of rDNA- and rRNAderived archaeal communities and methanogenic potential in a boreal mire. ISME J. 2, 1157-1168.

Keller, J. K., and Bridgham, S. D. (2007). Pathways of anaerobic carbon cycling across an ombrotrophic-minerotrophic peatland gradient. Limnol. Oceanogr. 52, 96-107.

Kotsyurbenko, O. R. (2010). "Soil, wetlands, peat," in The Handbook of Hydrocarbon and Lipid Microbiology, ed. K. N. Timmis (Berlin: SpringerVerlag), 626-634.

Krüger, M., Frenzel, P., Kemnitz, D., and Conrad, R. (2005). Activity, structure and dynamics of the methanogenic archaeal community in a flooded Italian rice field. FEMS Microbiol. Ecol. 51, 323-331.

Leibold, M. A. (1998). Similarity and local co-existence of species in regional biotas. Evol. Ecol. 12, 95-110.

Lennon, J. T., and Jones, S. E. (2011). Microbial seed banks: the ecological and evolutionary implications of dormancy. Nat. Rev. Microbiol. 9, 119-130.

Lipson, D. A., Schadt, C. W., and Schmidt, S. K. (2002). Changes in microbial community structure and function in an alpine dry meadow following spring snow melt. Microb. Ecol. 43, 307-314.

Liu, Y., and Whitman, W. B. (2008). Metabolic, phylogenetic, and ecological diversity of the methanogenic archaea. Ann. N. Y. Acad. Sci. 1125, 171-189.

Logue, J. B., and Lindström, E. S. (2010). Species sorting affects bacterioplankton community composition as determined by $16 \mathrm{~S}$ rDNA and $16 \mathrm{~S}$ rRNA fingerprints. ISME J. 4, 729-738.

Loreau, M. (1989). On testing temporal niche differentiation in carabid beetles. Oecologia 81, 89-96.

McMahon, S. K., Wallenstein, M. D., and Schimel, J. P. (2011). A cross-seasonal comparison of active and total bacterial community composition in Arctic tundra soil using bromodeoxyuridine labeling. Soil Biol. Biochem. 43, 287-295.

McNamara, J. P., Siegel, D. I., Glaser, P. H., and Beck, R. M. (1992). Hydrogeologic controls on peatland development in the Malloryville Wetland, New York (USA). J. Hydrol. 140, 279-296.

Meier, C., Wehrli, B., and van der Meer, J. R. (2008). Seasonal fluctuations of bacterial community diversity in agricultural soil and experimental validation by laboratory disturbance experiments. Microb. Ecol. $56,210-222$.

Mouquet, N., and Loreau, M. (2002). Coexistence in metacommunities: the regional similarity hypothesis. Am. Nat. 159, 420-426.

Osvald, H. (1970). Vegetation and Stratigraphy of Peatlands in North America. Uppsala: Vetenskapssocieteten, 96.

Sundh, I., Nilsson, M., Granberg, G., and Svensson, B. H. (1994). Depth distribution of microbial production and oxidation of methane in northern boreal peatlands. Microb. Ecol. 27, 253-265.

Trumbore, S. E. (1997). Potential responses of soil organic carbon to global environmental change. Proc. Natl. Acad. Sci. U.S.A. 94 8284-8291.

Williams, C. J., and Yavitt, J. B. (2010). Temperate wetland methanogenesis: the importance of vegetation type and root ethanol production. Soil Sci. Soc. Am. J. 74, 317-325.
Yavitt, J. B., Basiliko, N., Turetsky, M. R., and Hay, A. G. (2007). Methanogenesis and methanogen diversity in three peatland types of the discontinuous permafrost zone, boreal western continental Canada. Geomicrobiol. J. 23, 641-651.

Yavitt, J. B., Lang, G. E., and Downey, D. M. (1988). Potential methane production and methane oxidation rates in peatland ecosystems of the Appalachian Mountains, United States. Global Biogeochem. Cycles 2, 253-268.

Yavitt, J. B., Yashiro, E., CadilloQuiroz, H., and Zinder, S. H. (2011). Methanogen diversity and community composition in peatlands of the central to northern Appalachian Mountain region, North America. Biogeochemistry doi:10.1007/s10533-011-9644-9645

Zinder, S. H. (1993). "Physiological ecology of methanogens," in Methanogenesis, ed. J. G. Ferry (New York: Chapman Hall), 128-206.

Conflict of Interest Statement: The authors declare that the research was conducted in the absence of any commercial or financial relationships that could be construed as a potential conflict of interest.

Received: 25 November 2011; accepted: 17 February 2012; published online: 06 March 2012.

Citation: Sun CL, Brauer SL, CadilloQuiroz H, Zinder SH and Yavitt $J B$ (2012) Seasonal changes in methanogenesis and methanogenic community in three peatlands, New York State. Front. Microbio. 3:81. doi: 10.3389/fmicb.2012.00081

This article was submitted to Frontiers in Terrestrial Microbiology, a specialty of Frontiers in Microbiology.

Copyright (C) 2012 Sun, Brauer, CadilloQuiroz, Zinder and Yavitt. This is an open-access article distributed under the terms of the Creative Commons Attribution Non Commercial License, which permits non-commercial use, distribution, and reproduction in other forums, provided the original authors and source are credited. 


\title{
The effect of nitrogen enrichment on $\mathrm{C}_{1}$-cycling microorganisms and methane flux in salt marsh sediments
}

\author{
Irina C. Irvine ${ }^{1,2}{ }^{*}$, Lucía Vivanco ${ }^{1,3}$, Peris N. Bentley ${ }^{1}$ and Jennifer B. H. Martiny ${ }^{1}$ \\ 'Department of Ecology and Evolutionary Biology, University of California Irvine, Irvine, CA, USA \\ ${ }^{2}$ Division of Planning, Science and Resource Management, Santa Monica Mountain National Recreation Area, U.S. National Park Service, Thousand Oaks, CA, USA \\ 3 IFEVA, Facultad de Agronomía, CONICET - Universidad de Buenos Aires, Buenos Aires, Argentina
}

\section{Edited by:}

Paul Bodelier, Netherlands Institute of Ecology, Netherlands

\section{Reviewed by:}

Marina Kalyuzhnaya, University of Washington, USA

Hinsby Cadillo-Quiroz, Arizona State University, USA

Zhongjun Jia, Chinese Academy of Sciences, China

*Correspondence:

Irina C. Irvine, Division of Planning, Science and Resource Management, Santa Monica Mountains National Recreation Area, U.S. National Park Service, 401 West Hillcrest Drive, Thousand Oaks, CA 91360, USA. e-mail: irina_irvine@nps.gov
Methane $\left(\mathrm{CH}_{4}\right)$ flux from ecosystems is driven by $\mathrm{C}_{1}$-cycling microorganisms - the methanogens and the methylotrophs. Little is understood about what regulates these communities, complicating predictions about how global change drivers such as nitrogen enrichment will affect methane cycling. Using a nitrogen addition gradient experiment in three Southern California salt marshes, we show that sediment $\mathrm{CH}_{4}$ flux increased linearly with increasing nitrogen addition $\left(1.23 \mu \mathrm{g} \mathrm{CH}_{4} \mathrm{~m}^{-2}\right.$ day $^{-1}$ for each $\mathrm{g} \mathrm{N} \mathrm{m}^{-2}$ year $^{-1}$ applied) after 7 months of fertilization. To test the reason behind this increased $\mathrm{CH}_{4}$ flux, we conducted a microcosm experiment altering both nitrogen and carbon availability under aerobic and anaerobic conditions. Methanogenesis appeared to be both nitrogen and carbon (acetate) limited. $\mathrm{N}$ and $\mathrm{C}$ each increased methanogenesis by $18 \%$, and together by $44 \%$. In contrast, methanotrophy was stimulated by carbon (methane) addition (830\%), but was unchanged by nitrogen addition. Sequence analysis of the sediment methylotroph community with the methanol dehydrogenase gene $(m x a F)$ revealed three distinct clades that fall outside of known lineages. However, in agreement with the microcosm results, methylotroph abundance (assayed by qPCR) and composition (assayed by terminal restriction fragment length polymorphism analysis) did not vary across the experimental nitrogen gradient in the field. Together, these results suggest that nitrogen enrichment to salt marsh sediments increases methane flux by stimulating the methanogen community.

Keywords: methylotrophy, methanogenesis, methanotrophy, methane flux, nitrogen gradient, nutrient limitation, mxaF, acetate

\section{INTRODUCTION}

Methane $\left(\mathrm{CH}_{4}\right)$ is an important greenhouse gas that is over 20 times more effective at trapping heat than carbon dioxide. The primary biological source of methane is microbial (methanogens in the domain Archaea), as is the primary biological sink (methanotrophs among the Bacteria and Archaea). Therefore, understanding the controls on these microorganisms is important for predicting methane flux from ecosystems, especially in the face of global change drivers such as nitrogen enrichment.

Recently, atmospheric methane has been rising non-linearly, increasing steadily by $\sim 1 \%$ per year (Lelieveld et al., 1993), leveling off between 1999 and 2007 (Rigby et al., 2008) and now rising again (Heimann, 2011). One hypothesis for these dynamics is changes in agricultural practices (including chemical fertilizers) that impact microbial sources of methane (Kai et al., 2011). Thus, understanding the controls of $\mathrm{C}_{1}$-cycling microorganisms may be central to predicting future atmospheric methane dynamics.

A variety of microbial taxa are involved in methane flux, and $\mathrm{C}_{1}$-cycling in general. Methanogens are strictly anaerobic organisms that can use a narrow range of $\mathrm{C}_{1}$ compounds and acetate (e.g., organic acids, methanol, methylamines, and $\mathrm{H}_{2}$ with $\mathrm{CO}_{2}$ ) for energy and assimilation, with methane as the final byproduct of this metabolism. In terrestrial systems, the $\mathrm{C}$ compounds that methanogens use derive from plants (root exudates or detritus) and the metabolic byproducts of heterotrophic microorganisms. Methanotrophs, which utilize methane for energy and assimilation, are a subset of the broader group of all $\mathrm{C}_{1}$-consumers known as methylotrophs. The biological oxidation of methane by methanotrophs (methanotrophy) occurs both aerobically and anaerobically. Non-methanotrophic methylotrophs, utilizing $\mathrm{C}_{1}$ compounds other than methane, are also intimately involved in the methane cycle. There is a close physical association between aerobic methanotrophs and non-methanotrophic methylotrophs in the environment (Moussard et al., 2009; Qiu et al., 2009), where methylotrophs likely consume the key intermediate of methane metabolism (methanol) that would otherwise inhibit methanotrophy (Wilkinson et al., 1974; Neufeld et al., 2008).

Anthropogenic nitrogen $(\mathrm{N})$ enrichment through atmospheric deposition and terrestrial runoff (Galloway et al., 2004; Dentener et al., 2006) impacts the biodiversity and functioning of a wide variety of ecosystems (Vitousek et al., 2002). In particular, runoff from storm water, agriculture, and industrial sources increases $\mathrm{N}$ inputs in coastal ecosystems such as salt marshes (Conley et al., 2009). This increased nutrient availability clearly alters salt marsh functioning by altering plant growth and plant community composition (Fitch et al., 2009; Graham and Mendelssohn, 2010; Cardoni et al., 2011). However, much less is known about how $\mathrm{N}$ enrichment will alter microbially mediated biogeochemical 
cycles such as $\mathrm{C}_{1}$-cycling. Nitrogen inputs may alter $\mathrm{C}_{1}$-cycling directly by affecting the abundance, composition or efficiency of $\mathrm{C}_{1}$-cycling taxa (Bodelier and Laanbroek, 2004; Aronson and Helliker, 2010). Alterations may also occur indirectly, through changes in the plant community and $\mathrm{C}$ availability to sediment microorganisms. Salt marsh plants are usually N limited (Caffrey et al., 2007; Crain, 2007), therefore $\mathrm{N}$ typically stimulates aboveground plant biomass and possibly, the amount and quality of carbon exudates leaked into the sediments (Dakora and Phillips, 2002).

It is unclear whether methanogens might be $\mathrm{N}$ limited in natural ecosystems. However, most evidence suggests that nitrate strongly suppresses methane production, whereas ammoniumbased fertilizers may sometimes have a minor suppressive effect (Conrad, 2007). In salt marshes, $\mathrm{N}$ addition might also indirectly increase methanogen abundance or metabolic efficiency through increased root exudates by reducing competition for $\mathrm{C}$ from sulfate-reducers. Indeed, methanogens in anaerobic marine sediments are thought to be out-competed for labile carbon substrates by sulfate-reducing bacteria (Oremland and Polcin, 1982) and are therefore subject to chronic $\mathrm{C}$ limitation.

Methylotrophs (including methanotrophs) are probably not $\mathrm{N}$ limited in salt marshes, as many can assimilate ammonium and some can fix nitrogen (Hanson and Hanson, 1996; Auman et al., 2001; Bodelier and Laanbroek, 2004). However, high N levels can permanently or reversibly inhibit methanotrophy (Shimel and Gulledge, 1998). N addition might also shift the methanotroph community toward better competitors in N-replete conditions (Type I methanotrophs) over those that prevail in N-limited conditions (Type II methanotrophs; Graham et al., 1993). Methylotrophs, many of which are facultative and can use non- $\mathrm{C}_{1}$ compounds, might also respond to increased $\mathrm{C}$ through plant root exudates, perhaps altering cross-feeding interactions between methanotrophs and other methylotrophs.

Apart from the unclear effects of $\mathrm{N}$ addition on methanotrophy and methanogenesis, we lack quantitative predictions about the relationship between $\mathrm{N}$ availability and net $\mathrm{CH}_{4}$ flux. Experimental gradients with multiple treatment levels allow the estimation of "response curves" to a range of $\mathrm{N}$ enrichment conditions. In this way, one might also identify critical thresholds, beyond which an ecosystem dramatically changes its functioning (Cottingham et al., 2005). Such quantitative results can then be incorporated into ecosystem models. However, the vast majority of field experiments investigating the effect of $\mathrm{N}$ addition on ecosystem functioning have used single $\mathrm{N}$ doses, making it difficult to extrapolate these results to the wide range of $\mathrm{N}$ enrichment scenarios projected in the future. Indeed, of 48 studies reviewed about the effect of $\mathrm{N}$ addition on gas fluxes (Liu and Greaver, 2009), only one had three experimental levels of $\mathrm{N}$ addition. Another meta-analysis focused specifically on methane flux showed that methane flux increases linearly with the amount of $\mathrm{N}$ added in upland soils (Aronson and Helliker, 2010); however, it remains unclear whether this crossecosystem pattern holds within any one ecosystem, let alone salt marshes.

To investigate the effect of nitrogen addition on $\mathrm{C}_{1}$-cycling microorganisms and methane flux in coastal salt marsh sediments, we conducted a nitrogen addition gradient experiment in three Southern California salt marshes. This experiment allowed us to ask quantitatively how methane flux changes in response to increased $\mathrm{N}$ addition in the field. Using laboratory microcosms, we then tested whether this response was likely due to changes in methanotrophy and/or methanogenesis via increased nitrogen or carbon availability. Finally, we tested whether $\mathrm{N}$ addition changed the abundance and composition of the methylotrophs, a broad but major player in $\mathrm{C}_{1}$-cycling.

\section{MATERIALS AND METHODS STUDY SITE DESCRIPTION}

We selected three southern California salt marshes for this study, Morro Bay National Estuary (MBE), Carpinteria Salt Marsh (CSM) Reserve, and Tijuana River Reserve Estuary (TRE). All include intertidal estuarine wetlands with deep channel sub-tidal habitat (natural and artificial channels) and receive intermittent and chronic nitrogen inputs from urban and agricultural runoff. We chose these marshes for their similarities of vegetation types, Mediterranean-type coastal climate, protected status, and having areas within the marsh with similar tidal flooding regimes (i.e., plots flood during $\mathrm{a} \geq+1.6 \mathrm{~m}$ tide). We determined sediment salinity (using a refractometer), $\mathrm{pH}$ (in a 1:1 mixture with distilled water), and total carbon and nitrogen content (by dry combustion with a Flash EA1112 Series NC Analyzer) from sediment cores taken to a depth of $10 \mathrm{~cm}$ in the three sites (Table 1 ).

Morro Bay National Estuary $\left(35^{\circ} 20^{\prime} 00^{\prime \prime} \mathrm{N}, 120^{\circ} 49^{\prime} 51^{\prime \prime} \mathrm{W}\right)$ is the northernmost marsh in our study located in Morro Bay, California (San Luis Obispo County). The 930 ha estuary is protected as a U.S. National Estuary. MBE is at the terminus of a 19,424 ha watershed that drains the Los Padres National Forest, agricultural fields, ranches and parks. MBE is fed directly by the Los Osos and Chorro Creeks. Much of the area directly surrounding the marsh is protected parkland (California State Parks) with the cities of Morro Bay and Los Osos adjacent.

Carpinteria Salt Marsh $\left(34^{\circ} 24^{\prime} 03^{\prime \prime} \mathrm{N}, 119^{\circ} 32^{\prime} 09^{\prime \prime} \mathrm{W}\right)$ is located in Carpinteria, California (Santa Barbara County) and is part of the University of California Natural Reserve System. At 93 ha, CSM is the smallest of our three study sites. CSM receives yearround nutrient inputs and other pollutants directly from culverts draining a large upstream nursery complex and the Carpinteria Creek watershed (3884 ha) that drains open field agriculture, orchards, and receives runoff from densely populated urban areas.

Tijuana River Reserve Estuary $\left(32^{\circ} 32^{\prime} 59^{\prime \prime} \mathrm{N}, 117^{\circ} 07^{\prime} 22^{\prime \prime} \mathrm{W}\right)$ is the largest and southernmost study site located just north of the

Table 1 | Sediment properties by marsh in the control (no $\mathrm{N}$ added) plots.

\begin{tabular}{llrr}
\hline & CSM & MBE & \multicolumn{1}{l}{ TRE } \\
\hline $\mathrm{pH}$ & $6.82 \pm 0.04^{\mathrm{a}}$ & $7.10 \pm 0.04^{\mathrm{b}}$ & $7.08 \pm 0.04^{\mathrm{b}}$ \\
Total N (\% in dry sediment) & $0.32 \pm 0.04^{\mathrm{a}}$ & $0.34 \pm 0.02^{\mathrm{a}}$ & $0.21 \pm 0.02^{\mathrm{b}}$ \\
Total C (\% in dry sediment) & $4.21 \pm 0.40^{\mathrm{a}}$ & $4.73 \pm 0.26^{\mathrm{a}}$ & $3.19 \pm 0.30^{\mathrm{b}}$ \\
Salinity (\% pore water) & $31.5 \pm 2.46^{\mathrm{a}, \mathrm{b}}$ & $25.0 \pm 5.02^{\mathrm{b}}$ & $40.75 \pm 0.25^{\mathrm{a}}$
\end{tabular}

Values are the means and SEM for each site $(n=5)$, except for salinity $(n=4)$. Superscript letters indicate significant differences among the marshes based on a Tukey post hoc test $(P<0.05)$. 
Mexico-United States border in Imperial Beach, California (San Diego County). The Tijuana River Reserve is part of the National Estuarine Research Reserve System. The 1024 ha estuary is at the terminus of a 453,248 ha watershed that drains the Tijuana River Valley, three quarters of which is located in Mexico. The Tijuana River has been used as a wastewater conduit for several decades. Though progress has been made to reduce the sewage that flows into the estuary with upstream treatment facilities, moderate rain events will cause raw sewage to overflow into the estuary.

\section{EXPERIMENTAL DESIGN}

In the three study sites, we established seven levels of $\mathrm{N}$ addition: $0,10,20,40,80,160$ and $320 \mathrm{~g} \mathrm{~N} \mathrm{~m}^{-2}$ year $^{-1}$. We randomly assigned treatments to $1 \mathrm{~m}^{2}$ plots spaced $2 \mathrm{~m}$ apart from each other $(\mathrm{N}=105$ plots; 3 marshes $\times 7$ treatment levels $\times 5$ replicates/treatment). Each fertilization treatment was replicated five times. This gradient included the most common fertilization rates used in $\mathrm{N}$ addition studies in wetlands (100-300 $\mathrm{g} \mathrm{N} \mathrm{m}^{-2}$ year ${ }^{-1}$; Boyer and Zedler, 1998; Boyer et al., 2001; Crain, 2007) as well as fertilization rates used in studies to evaluate the effect of $\mathrm{N}$ deposition (10-100 $\mathrm{g} \mathrm{N} \mathrm{m}^{-2}$ year $^{-1}$ ) on ecosystem functioning (Bradford et al., 2008). In each marsh, we located the plots in areas with vegetation dominated by Salicornia virginica (pickleweed) and in similar positions in the marsh (i.e., distance to main channel, distance to the ocean, similar tidal flooding regime).

We added nitrogen as slow-release granular urea to provide a sustained enrichment over time ( $\sim 10$ weeks) rather than in a single pulse. Granular urea converts rapidly to ammonium upon contact with water. We buried nine perforated $50-\mathrm{ml}$ centrifuge tubes ( 8 cuts, $4 \mathrm{~cm}$ long $\times 4 \mathrm{~mm}$ wide) per plot, leaving only the caps exposed above the sediment. Tubes were placed evenly $(33 \mathrm{~cm}$ apart) for homogeneous fertilizer delivery within the plot. The tubes remained in place during the experiment, and we replaced nylon mesh fertilizer bags in these tubes every 10 weeks during the course of the experiment. Urea-free tubes in unfertilized plots were used as disturbance controls. We applied the first fertilizer treatment in July 2008. Here we report results from February 2009, after 7 months of fertilization. We sampled each site over the course of 2 days and all sites within 1 week.

\section{FIELD GAS SAMPLING}

We measured methane flux using static gas chambers $(16 \mathrm{~cm}$ high with a surface area of $104 \mathrm{~cm}^{2}$ ) that were gently secured $2.5 \mathrm{~cm}$ deep into the sediment of each plot at the time of sampling. We clipped the plant biomass just above the sediment surface of this space at the beginning of the experiment to limit our measurements to microbial and root emissions and let the system stabilize for 7 months before sampling. We sampled gases $(5 \mathrm{ml})$ from the capped headspace by syringe. Before withdrawing the sample, we mixed the headspace gases first by pumping the syringe several times and injected it into an evacuated gas-tight vial. Each plot was sampled at four time points after securing the chamber $(0,30$, 60 , and $90 \mathrm{~min}$ ). We also intermittently collected positive control (1000 ppm $\mathrm{CO}_{2}$ ) and atmospheric samples to test for leakages, but none were detected. We analyzed $\mathrm{CH}_{4}$ concentrations with a gas chromatograph (Shimadzu GC2014, equipped with a Thermal Conductivity Detector for measuring $\mathrm{CO}_{2}$ connected in series to a
Flame Ionization Detector to measure $\mathrm{CH}_{4}$, and fitted with a 2-ml sample loop, Shimadzu Corporation, Kyoto, Japan). We calculated $\mathrm{CH}_{4}$ flux rates for each plot as the slope of the linear regression of gas concentration over time. The detection limit was $0.7 \mathrm{ppm} \mathrm{CH}_{4}$. In a few cases, we eliminated outliers and estimated the production rate without that time point.

\section{NUTRIENT ADDITION MICROCOSM EXPERIMENTS}

To assess potential $\mathrm{N}$ and $\mathrm{C}$ limitation for salt marsh methanotrophs and methanogens, we conducted two companion microcosm experiments in the laboratory. Using a fully factorial replicated design we added $\mathrm{N}, \mathrm{C}$, and both $\mathrm{N}$ and $\mathrm{C}$ to sediment cores (5 $\mathrm{cm}$ deep, $1.5 \mathrm{~cm}$ diameter) collected aseptically from an area adjacent to the established plots at Tijuana River Estuary in July 2009. To establish an aerobic environment for the methanotroph experiment and inhibit the methanogens present, each core was removed from the corer in the laboratory and homogenized thoroughly in the presence of air for $5 \mathrm{~min}$ ( 6 cores/treatment, $\mathrm{N}=24$ microcosms). We then placed the homogenized core in the microcosm tube, added the treatments described above and sealed the tube. To establish an anaerobic environment for the methanogen experiment and inhibit the methanotrophs present, other cores were kept intact in the sterile plastic corers to reduce their exposure to oxygen $(\mathrm{N}=24$ microcosms $)$.

To test for $\mathrm{N}$ limitation, we added an amount of ammonium chloride solution equivalent to 7 days of fertilization in the $160 \mathrm{~g} \mathrm{~N} \mathrm{~m}^{-2}$ year $^{-1}$ field treatment in one dose at the beginning of the experiment $(41.4 \mathrm{mg}$ ammonium chloride in a $2-\mathrm{ml}$ injection, or $383.2 \mathrm{mM}$ ). Ammonium chloride was used because it dissolves rapidly in water, delivering the $\mathrm{N}$ (as ammonium) immediately instead of the slow-release urea that was used in the field experiment. To test for $\mathrm{C}$ limitation, we added the $\mathrm{C}$ substrate in two forms depending on the experiment. To the methanotroph

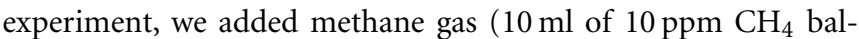
anced in air for an average starting concentration of $5.87 \mathrm{ppm}$ $\left.\mathrm{CH}_{4} \pm 0.45 \mathrm{ppm}\right)$. In comparison, the control treatment had an ambient $\mathrm{CH}_{4}$ concentration (1.7 ppm $\mathrm{CH}_{4}$; lab air verified by gas chromatography). To the methanogen experiment, we added sodium acetate as the carbon substrate $(2 \mathrm{mg}$ sodium acetate in a 2-ml injection, or $12.2 \mathrm{mM}$ ). Sodium acetate was chosen because it is labile but does not encourage fermentation reactions. We added it at approximately double the weight of microbial biomass (Allison and Vitousek, 2005), which was estimated at $0.8 \mathrm{mg} / \mathrm{g}$ dry sediment based on total $\mathrm{C}$ analysis of the sediments. The control microcosms received a sterile sodium chloride solution to account for the extra ions and water added by the treatments. After adding the nutrients by syringe throughout the cores, we sealed the tubes, and for the methanogen experiment, flushed them with pure nitrogen gas. Finally, we incubated the sealed microcosms from both experiments at $20^{\circ} \mathrm{C}$.

We collected gas samples $(5 \mathrm{ml})$ from the headspace of the microcosms at 18,48 , and $72 \mathrm{~h}$ incubation. We analyzed the first 3 day's samples; however, we report only the results from the first time point $(0-18 \mathrm{~h})$ due to the high accumulation of $\mathrm{CO}_{2}$ in the microcosms, which could alter microbial functioning. We determined $\mathrm{CH}_{4}$ concentrations with gas chromatography and $\mathrm{CH}_{4}$ flux as described above. 


\section{METHYLOTROPH DIVERSITY}

To examine the background methylotroph diversity in each salt marsh, we prepared clone libraries targeting the methanol dehydrogenase gene $(m x a \mathrm{~F})$. This gene occurs in all gram-negative methylotrophs and is diagnostic for methylotrophy (McDonald et al., 2008). Therefore mxaF should target aerobic obligate and facultative methanotrophs as well as other methylotrophs. We collected one sediment core ( $10 \mathrm{~cm}$ deep, $3 \mathrm{~cm}$ diameter core) just outside the experiment plots at each marsh in September 2008. We extracted total genomic DNA using the FastD$\mathrm{NA}^{\circledR}$ Spin Kit for Soil (MP Biomedicals, Santa Ana, CA, USA). PCR conditions for the $m x a \mathrm{~F}$ gene were: $(25-\mu \mathrm{l}$ reaction vol.) initial denaturing $95^{\circ} \mathrm{C}(5 \mathrm{~min})$, anneal at $55.6^{\circ} \mathrm{C}(30 \mathrm{~s})$, extension at $72^{\circ} \mathrm{C}(40 \mathrm{~s}), 30$ cycles total with a final extension step of $72^{\circ} \mathrm{C}$ (5 min) (PTC-100 Thermocycler, Bio-Rad, Hercules, CA, USA). [Final concentration: forward and reverse primers $250 \mathrm{nM}$ ( $m x a \mathrm{~F}$ forward $5^{\prime}$-TGGAACGAGACCATGCGTC, reverse 5'-CATGCAGATGTGGTTGATGC (Moosvi et al., 2005), 1 unit Taq polymerase, MasterAmp ${ }^{\mathrm{TM}} 1 \mathrm{x}$ Premix F (Epicentre Biotechnologies, Madison, WI, USA).] We visualized the $\sim 455$ bp product on a $0.8 \%$ agarose gel, and this fragment was then excised, purified (QIAquick Gel extraction kit, Qiagen, Valencia, CA, USA), and cloned (Invitrogen PCR4Topo kit, Carlsbad, CA, USA) following the manufacturer's protocols. Finally, 48 clones per marsh were sequenced (Beckman-Coulter Genomics, Danvers, MA, USA). We compared the sequences to the GenBank database using the nr blastx algorithm. The sequences have been submitted to GenBank under the accession numbers JQ254993-JQ255023.

\section{PHYLOGENETIC ANALYSIS}

We screened the sequences recovered from the $m x a \mathrm{~F}$ clone library for three criteria: quality ( $\geq 80 \% \mathrm{HQ}$ reads), length ( $\geq 300 \mathrm{bp}$ ), and identity (most similar to a methylotrophic bacteria using blastx). We aligned the remaining sequences $(\mathrm{N}=99)$ in protein space using Geneious Pro 5.03 (Biomatters, Auckland, New Zealand) and created a nucleotide sequence similarity matrix using Dnadist in the Phylip package (version 3.68; Felsenstein, 2005). We defined operational taxonomic units (OTUs) as sequences sharing 99\% sequence similarity (using the nearest neighbor algorithm) and classified them using the MOTHUR software (version v1.16.0; Schloss et al., 2009). We constructed a neighbor-joining tree (Geneious 5.0, Tamura-Nei distance model) using representative sequences (oturep function in MOTHUR) from this study and cultured strains from other studies, including Methylophilus methylotrophus as an outgroup.

\section{QUANTITATIVE PCR}

To quantify the abundance of methylotrophs in the experimental plots, we used the same primer pair described above. We isolated DNA from sediment cores $(10 \mathrm{~cm}$ deep, $3 \mathrm{~cm}$ diameter) collected from each plot $(\mathrm{N}=105)$ in February 2009. We extracted total genomic DNA in the same manner described above. We prepared a standard by cloning the PCR product of a Methylobacterium extorquens isolate into a vector (see above) and linearizing the DNA (SphI, New England BioLabs, Ipswich, MA, USA). To reduce the effect of PCR inhibition, we determined the appropriate environmental template concentration by performing $\mathrm{qPCR}$ on a dilution series (1:100, 1:250, 1:500, and 1:750) of three random samples from each marsh in triplicate. For the remaining samples, qPCR was performed on a 1:750 dilution, the dilution at which the copy number stabilized for all three marshes. Quantitative PCR was carried out in $25 \mu \mathrm{l}$ total volume: $5 \mu l$ template (1:750), $12.5 \mu \mathrm{l}$ iQ SybrGreen mix (Bio-Rad), forward primer $0.4 \mu \mathrm{M}$, reverse primer $0.4 \mu \mathrm{M}$. The reactions were run on an iCycler (Bio-Rad) with the following conditions: initial denature at $95^{\circ} \mathrm{C}$ for $15 \mathrm{~min}$, denature at $95^{\circ} \mathrm{C}$ for $45 \mathrm{~s}$, anneal at $59^{\circ} \mathrm{C}$ for $20 \mathrm{~s}$, extension at $72^{\circ} \mathrm{C}$ for $30 \mathrm{~s}$ - repeated 45 cycles; with a final extension at $72^{\circ} \mathrm{C}$ for $10 \mathrm{~min}$. Real time data was collected at the annealing step. The amplification was followed by a melting curve to check for unspecific priming or primer dimers starting with $50^{\circ} \mathrm{C}$ for 150 cycles, increasing $0.3^{\circ} \mathrm{C}$ per cycle.

\section{TERMINAL RESTRICTION FRAGMENT LENGTH POLYMORPHISM ANALYSIS}

We performed terminal restriction fragment length polymorphism analysis (T-RFLP) analysis on the same DNA isolated above in the qPCR assays. We targeted the $m x a \mathrm{~F}$ gene with $5^{\prime}$ 6-FAMlabeled primers (Moosvi et al., 2005) using the same endpoint PCR conditions as above. We gel purified the PCR products as before and standardized the DNA concentration (20 ng DNA/ $\mu \mathrm{l})$ for restriction enzyme digestion ( TaqI Fast Digest ${ }^{\circledR}$, Fermentas, Glen Burnie, MD, USA). Enzyme deactivation and product purification was carried out following the manufacturers' protocols (Qiaquick Nucleotide Removal Kit ${ }^{\circledR}$, Qiagen, Valencia, CA, USA). We stored the products at $-20^{\circ} \mathrm{C}$ until fragment analysis (Laragen, Los Angeles, CA, USA).

Terminal restriction fragment length polymorphism analysis peaks were identified using GeneMarker ${ }^{\circledR} 1.7$ with AFLP settings. To identify "true" peaks from background noise, we followed Abdo et al. (2006) using data points with values larger than four SD. If more than 25 peaks were detected in a sample, we manually inspected peaks within two base pairs of each other to decide if these were true peaks, then re-standardized the peak heights in these corrected samples by total fluorescence.

\section{STATISTICAL ANALYSIS}

For the field experiment, we used a generalized linear model (GLM) to test the effects of $\mathrm{N}$ addition, marsh site, and their interaction (marsh $\times \mathrm{N}$ ) on $\mathrm{CH}_{4}$ flux rates, the initial $\mathrm{CH}_{4}$ concentration $(T=0 \mathrm{~min})$, and $m x a \mathrm{~F}$ gene copy number with marsh as a categorical factor (MBE, CSM, and TRE) and $\mathrm{N}$ addition treatment as a continuous factor $\left(0,10,20,40,80,160,320 \mathrm{~g} \mathrm{~N} \mathrm{~m}^{-1}\right.$ year $\left.^{-1}\right)$. (The $m x a \mathrm{~F}$ gene copy number was log-transformed to improve normality and we report untransformed values in Figure 3C.) To provide a model for $\mathrm{N}$ addition effects on $\mathrm{CH}_{4}$ flux rates, we averaged observations for each marsh $(n=21,3$ marshes $\times 7$ treatments) because neither marsh identity ( marsh), nor an interaction between marsh and $\mathrm{N}$ treatment (marsh $\times N)$, had a significant effect on $\mathrm{CH}_{4}$ flux in the GLM analyses. We then used a linear regression to test whether the $\mathrm{CH}_{4}$ flux differed at each plot depending upon the $\mathrm{CH}_{4}$ concentration in the chamber headspace at the initial time point $(T=0 \mathrm{~min})$. These statistics were performed in JMP 8 (SAS Corporation). 
To investigate $m x a \mathrm{~F}$ gene composition among the plots, we first square root transformed the T-RFLP peak data (to downweight very abundant peaks) and calculated the Bray-Curtis similarity (Magurran, 1988) between the samples. We then used PERMANOVA (Primer 6; Anderson et al., 2008) to test whether N treatment and/or marsh location affected mxaF composition, with marsh as a random, categorical factor and $\mathrm{N}$ treatment as a continuous covariate. (Log-transforming the $\mathrm{N}$ treatment variable did not change the results, so we report only the untransformed test.) To visualize the PERMANOVA results, we performed principle coordinates analysis (PCO) on the Bray-Curtis similarity matrix in Primer 6.

For the microcosm experiments, we used two-way ANOVA to test for the differences of the rates of $\mathrm{CH}_{4}$ production or oxidation between our treatments (factors: $C$ addition, $N$ addition and $C \times N$ addition) with JMP 8 .

\section{RESULTS}

\section{METHANE EMISSIONS IN THE FIELD}

Across all the marshes, methane flux increased linearly with $\mathrm{N}$ addition (linear regression, $R^{2}=0.23, P=0.025$, Figure 1A). The linear increase of methane flux was $1.23 \mu \mathrm{g} \mathrm{CH}_{4} \mathrm{~m}^{-2} \mathrm{day}^{-1} \pm 0.42$ for each $\mathrm{g} \mathrm{N} \mathrm{m}^{-2}$ year $^{-1}$ applied, and all marshes showed similar rates $\left(\mathrm{GLM}, F_{2,103}=1.9886, P=0.1424\right)$. At the two lowest fertilization rates (control and $10 \mathrm{~g} \mathrm{~N} \mathrm{~m}^{-2}$ year $^{-1}$ ), net methane oxidation was dominant, whereas over $9.89 \mathrm{~g} \mathrm{~N} \mathrm{~m}^{-2}$ year $^{-1}$ we observed net methanogenesis.

We also observed that methane flux depended on the initial $\mathrm{CH}_{4}$ concentration measured above the sediment surface (linear regression, $R^{2}=0.397, P<0.0001$, Figure 1B). If the initial $(T=0 \mathrm{~min})$ headspace concentration was below $1.56 \mathrm{ppmv}$ (i.e., $1.10 \mathrm{mg} \mathrm{m}^{-3}$ ), then on average we observed a positive net flux. In contrast, if the initial $\mathrm{CH}_{4}$ concentrations were above that value, we generally observed a negative net flux. This cutoff is similar to the current atmospheric $\mathrm{CH}_{4}$ concentration of 1.77 ppmv (i.e., $1.25 \mathrm{mg} \mathrm{m}^{-3}$, source: http://www.ncdc.noaa.gov/ oa/climate/gases.html). Although the reason for this relationship is unclear, it does not account for the observed effect of $\mathrm{N}$ addition on $\mathrm{CH}_{4}$ flux. Initial $\mathrm{CH}_{4}$ concentration varied significantly by $\operatorname{marsh}\left(\mathrm{GLM}, F_{2,103}=21.459, P<0.0001\right)$, but not by $\mathrm{N}$ treatment (GLM, $\left.F_{2,103}=0.738, P=0.392\right)$. Further, $\mathrm{N}$ treatment still had a significant effect on the residuals of the initial $\mathrm{CH}_{4}$ concentration versus $\mathrm{CH}_{4}$ flux regression (GLM, $\left.F_{5,97}=3.133, P=0.0115\right)$.

\section{NUTRIENT ADDITION MICROCOSMS}

The microcosm experiments aimed to test whether the positive relationship between $\mathrm{CH}_{4}$ flux and $\mathrm{N}$ addition in the field was, on balance, due to stimulating methanogens or inhibiting methanotrophs. We found no evidence for $\mathrm{N}$ limitation or inhibition of methanotrophy with the single dose of $\mathrm{N}$ that the microcosms received (two-way ANOVA, $F_{3,18}=1.3194, P=0.2657$ ). However, the methanotrophs appeared to be significantly C-limited $\left(F_{3,18}=231.7242, P<0.0001\right.$, Figure 2A). With $\mathrm{C}$ (methane) addition, the average methane oxidation rate increased by $830 \%$ over controls and $\mathrm{N}$ addition treatments but there were no interactive effects of $C \times N$ addition $\left(F_{3,18}=3.1134, P=0.0946\right)$.

In contrast, the methanogens appeared to be both $N$ (two-way ANOVA, $F_{3,18}=7.6547, P=0.0127$ ) and $C$ limited $\left(F_{3,18}=6.3870, P=0.0211\right)$ with no significant $C \times N$ interaction $\left(F_{3,18}=0.1487, P=0.7043\right.$, Figure 2B). Adding either $\mathrm{C}$ or $\mathrm{N}$ increased methane production rates by $18 \%$ over controls. Adding $\mathrm{C}$ and $\mathrm{N}$ together increased methane production by $44 \%$, indicating that salt marsh methanogens may be co-limited.

\section{METHYLOTROPH COMMUNITY COMPOSITION}

The clone libraries created from sediments outside the experiment plots revealed $m x a F$ sequence diversity that falls outside of known lineages (Figure 3A). Phylogenetic analysis placed about a third of the sequences most closely related ( $92 \%$ similar) to a novel marine Methylococcus capable of growth on methane, ethane, or propane (Redmond et al., 2010). The only other known culture that was similar to these sequences is an $m x a \mathrm{~F}$ mutant created from

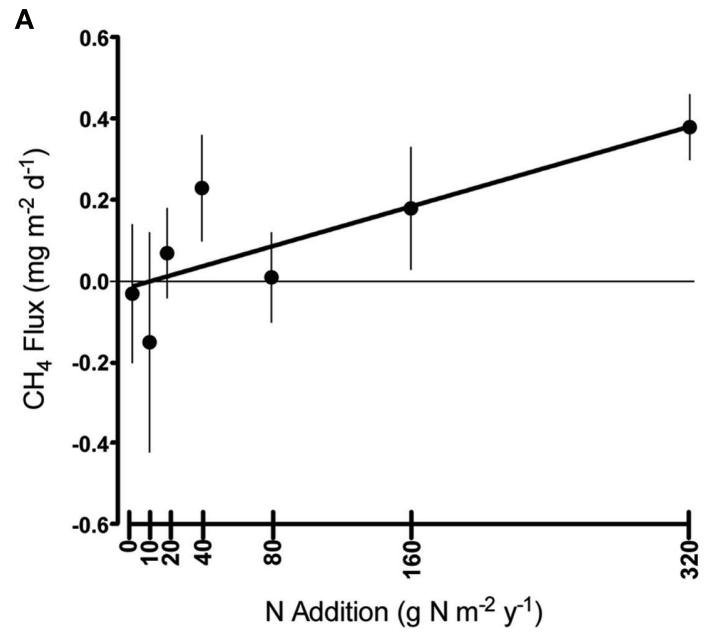

FIGURE 1 | Salt marsh field methane flux after 7 months of fertilization: (A) $\mathbf{C H}_{4}$ flux along the $\mathbf{N}$ gradient. Regression: Flux $\left(\mathrm{mg} \mathrm{CH}_{4} \mathrm{~m}^{-2}\right.$ day $\left.^{-1}\right)=0.00123 * N$ addition $\left(\mathrm{mg} \mathrm{CH}_{4} \mathrm{~m}^{-2}\right.$ day $\left.^{-1}\right)-0.0122, R^{2}=0.23$,

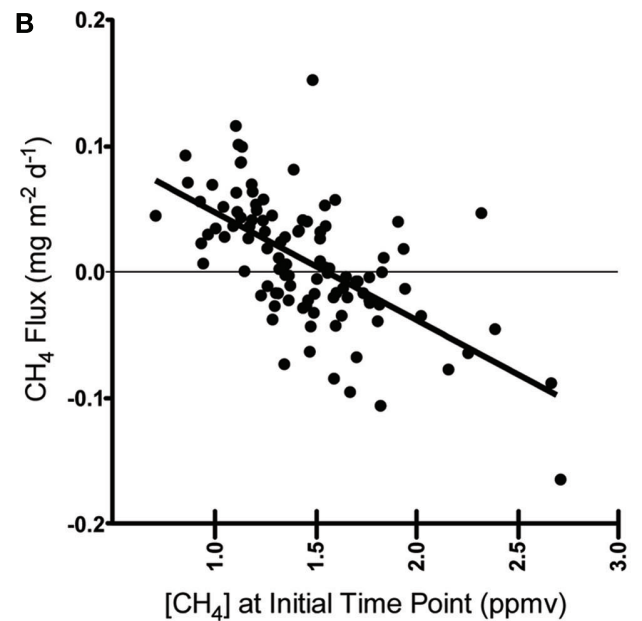

$P=0.023, \mathrm{~N}=21$, (B) $\mathrm{CH}_{4}$ flux given the initial $\mathrm{CH}_{4}$ concentration. Regression: Flux ( $\mathrm{mg} \mathrm{CH}_{4} \mathrm{~m}^{-2}$ day $\left.^{-1}\right)=-0.08551 *$ Initial (ppmv) $+0.01374, R^{2}=0.39$, $P<0.0001, N=103$. Error bars in (A) were constructed with 1 SEM. 


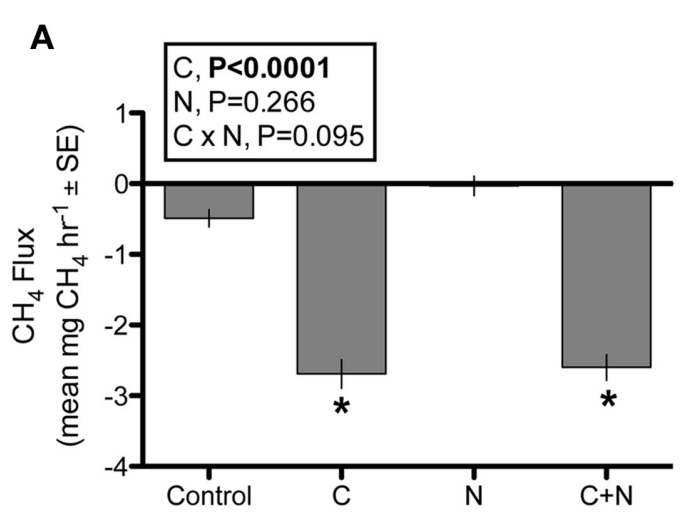

FIGURE 2 | Methane flux in the nutrient addition microcosms after $18 \mathrm{~h}$ of incubation. (A) Methanotroph response to nutrient addition; (B) Methanogen response to nutrient addition. Six

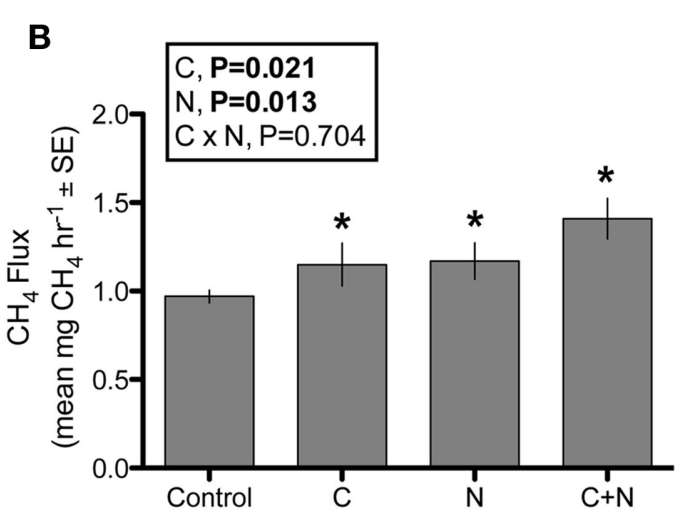

replicates per treatment/group, $\mathrm{N}=48$. Error bars were constructed using 1 SEM. Results of the two-way ANOVA are reported in the figure insert. a Hyphomicrobium strain (Fesefeldt et al., 1997). The remaining clones clustered into two distinct clades that appear to fall outside of known methylotroph lineages. None of our clones clustered with known obligate methanotroph clades.

Nitrogen addition did not affect methylotroph composition as assayed with T-RFLP either directly (PERMANOVA $\left.F_{1,100}=0.635, P=0.867\right)$ or indirectly through a marsh-by-N interaction $\left(F_{2,100}=0.698, P=0.868\right)$. Methylotroph composition varied significantly among the three marshes $\left(F_{2,100}=2.203\right.$, $P=0.002)$, although marsh location was estimated to explain relatively little $(\sim 10 \%)$ of the variation in composition. The PCO plots supported this result; marsh differences were apparent primarily along PCO3, which explained only $6.7 \%$ of total variation in community composition (Figure 3B).

Methylotroph abundance also did not respond to $\mathrm{N}$ addition (GLM, $N$ addition: $F_{2,103}=1.594, P=0.209$; $\operatorname{marsh} \times N$ addition: $\left.F_{2,103}=1.875, P=0.159\right)$. Only in the MBE marsh, was there was a trend of a linear increase in mxaF copies with increasing $\mathrm{N}$ addition (Figure 3C). However, the marshes differed significantly in average methylotroph abundance (GLM, marsh: $\left.F_{2,103}=10.962, P<0.0001\right)$. CSM had nearly twice as many $m x a \mathrm{~F}$ gene copies as both MBE and TRE, which had similar abundances (CSM: 341,401 $\pm 34,771$ SEM; MBE: 195,489 $\pm 16,942$; TRE: $171,884 \pm 15,378)$.

\section{DISCUSSION}

Temperate salt marshes generally emit low levels of methane, but these values are also highly spatially and seasonally variable (King and Wiebe, 1978; Bartlett et al., 1985; Magenheimer et al., 1996; Cheng et al., 2010). Thus, the range and variability of methane flux values observed in this study $(-0.045$ to $0.377 \mathrm{mg}$ $\mathrm{CH}_{4} \mathrm{~m}^{-2}$ day $^{-1}$ ) are similar to those reported previously for other salt marshes. Despite the high variability observed, however, our field experiment suggests that increased $\mathrm{N}$ availability increases methane emissions in southern California salt marshes, as in other ecosystems (Liu and Greaver, 2009).

Further, the effect of $\mathrm{N}$ addition in these salt marshes appears to be quantitatively predictable. Methane flux increased linearly with $\mathrm{N}$ addition in all three marshes despite differences in their macrosystem features (e.g., size, tidal flow constriction, and the nature of their watersheds). With each added $\mathrm{g} \mathrm{N} \mathrm{m}^{-2}$ year ${ }^{-1}$, we predict an additional $1.23 \mu \mathrm{g} \mathrm{CH}_{4} \mathrm{~m}^{-2}$ day $^{-1}$ will be emitted from the temperate low salt marsh zone during this time of the winter season (February). Further, the sediments switched from negative net $\mathrm{CH}_{4}$ fluxes to net positive $\mathrm{CH}_{4}$ fluxes at around $10 \mathrm{~g} \mathrm{~N} \mathrm{~m}^{-2}$ year $^{-1}$. While these results should be confirmed in other seasons and other salt marshes, they agree with a recent meta-analysis of upland soils; methane flux was also positively and linearly related to the amount of $\mathrm{N}$ added, although the vast majority of these soils were still net consumers of methane (Aronson and Helliker, 2010).

What accounts for this increase in methane flux with $\mathrm{N}$ addition? Our results are consistent with the hypothesis that $\mathrm{N}$ addition stimulates methanogenesis rather than inhibiting methanotrophy. In particular, the microcosm experiment provides evidence that $\mathrm{N}$ addition directly stimulates short-term increases in methane production under constrained conditions for aerobic methanotrophy (low oxygen conditions). In contrast, nitrogen addition did not affect methanotroph activity, either by changes in methane consumption rate in the microcosms or by changes in methylotrophic community composition or abundance in the field. Numerous studies across a variety of ecosystems suggests that $\mathrm{N}$ addition stimulates methanotrophy until a threshold, beyond which higher amounts inhibit it (Bodelier et al., 2000; Bodelier and Laanbroek, 2004; Aronson and Helliker, 2010). Thus, one interpretation is that methanotrophs in salt marshes are not $\mathrm{N}$ limited and further, the level of $\mathrm{N}$ addition in the microcosms were not inhibitory. Alternatively, we cannot exclude the possibility that some methanogenesis was occurring in the aerobic chambers, which if stimulated by $\mathrm{N}$ addition, might have masked equivalent increases in methane consumption.

Addition of a carbon substrate (sodium acetate) in the microcosms also greatly increased methanogenesis. Most likely this was due to direct stimulation of acetoclastic methanogens, which use organic acids. Hydrogenotrophic methanogens, which use $\mathrm{H}_{2}+\mathrm{CO}_{2}$, might also have been indirectly stimulated through the byproducts of heterotrophic taxa that can use acetate. 


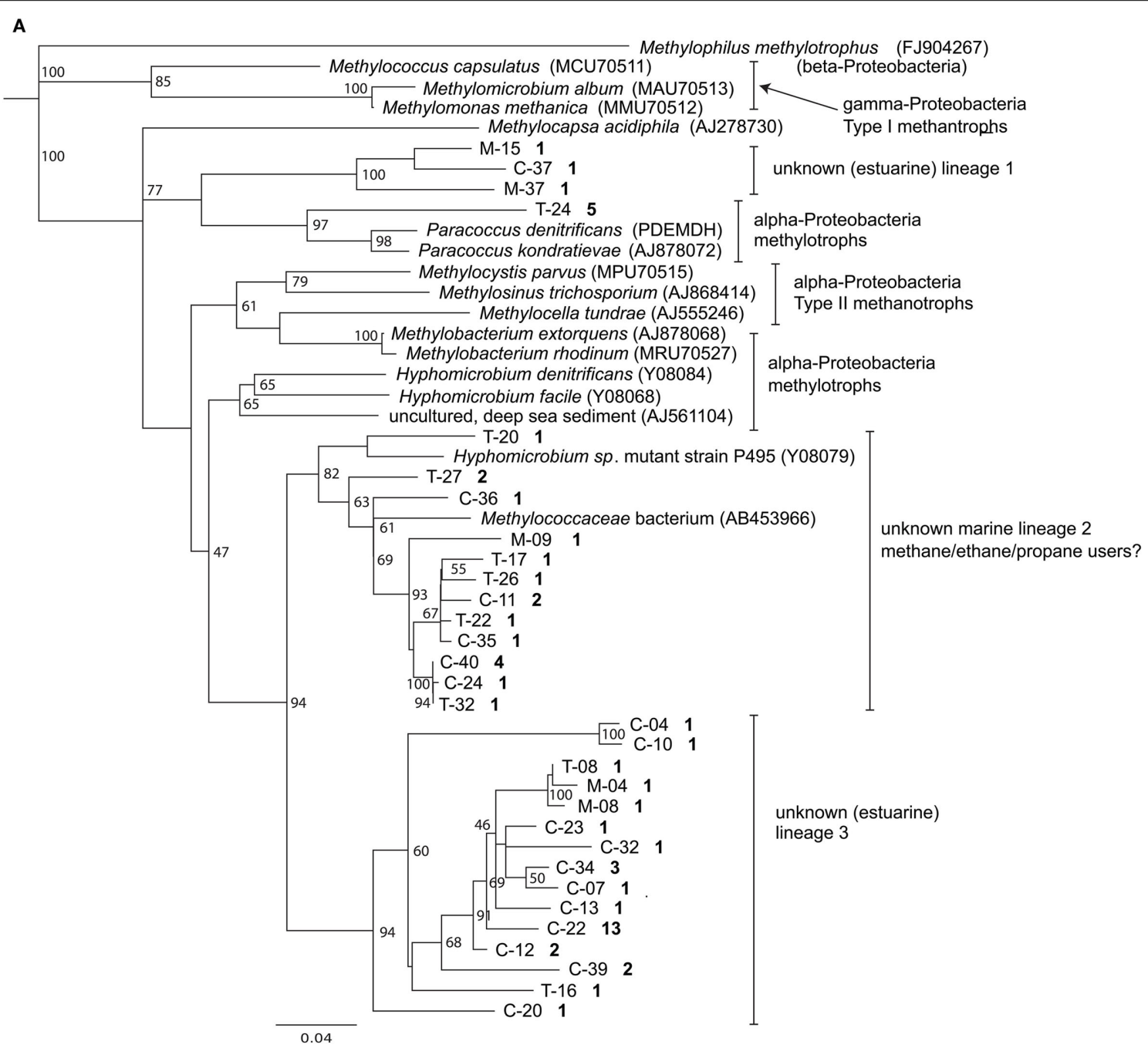

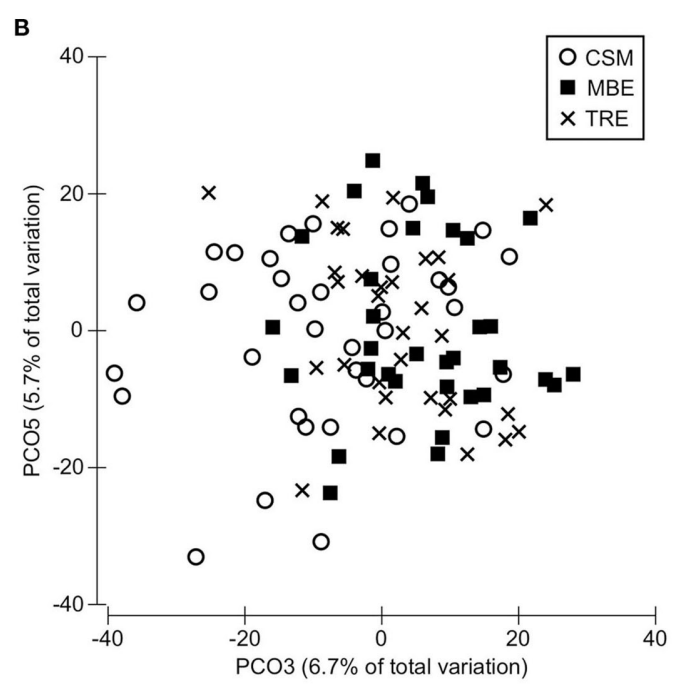

FIGURE 3 | The salt marsh sediment methylotroph community as assayed by the methanol dehydrogenase functional gene ( $m x a F$ ). (A) Neighbor-joining tree of representative OTUs ( $\geq 99 \%$ similar) based on nucleotide $m x a F$ sequences. The OTUs are designated by marsh and sequence number, where $\mathrm{C}=$ Carpinteria Salt Marsh, $\mathrm{M}=$ Morro Bay
C

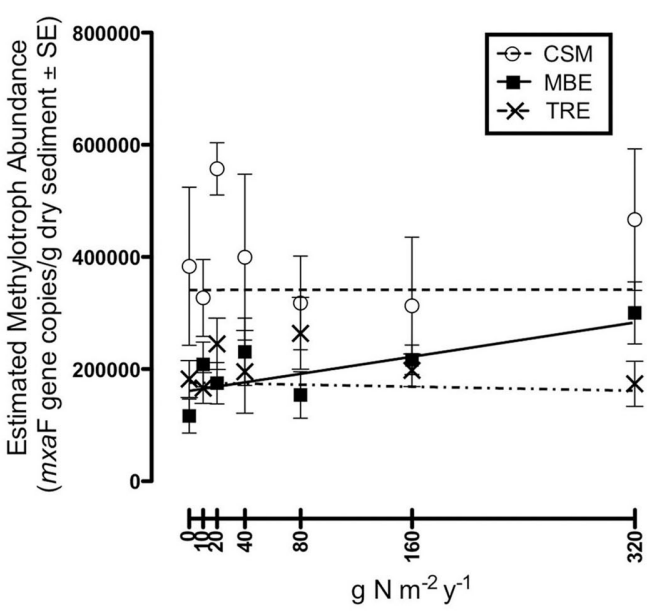

Estuary, $T=$ Tijuana River Estuary. The bold number is the number of sequences that fall within the OTU; only bootstrap values $\geq 50$ are shown; (B) Two PCO axes of the T-RFLP profiles that illustrate differences by marsh location ( $N=103)$; (C) Mean $m x a F$ gene copy number per gram dry sediment $(\mathrm{N}=105)$. 
Thus, in the field experiment, methanogenesis may have been stimulated by $\mathrm{N}$ directly and/or indirectly through an increase in plant biomass and therefore, $\mathrm{C}$ availability to sediment microorganisms. Indeed, our field experiment showed significant (linear) increases in aboveground plant biomass with increasing $\mathrm{N}$ addition (Vivanco et al., unpublished) similar to many past salt marsh studies (Boyer and Zedler, 1998; Bertness et al., 2002; Crain, 2007). Zhang and colleagues also found greater $\mathrm{CH}_{4}$ emissions in a brackish Chinese marsh, where exogenous $\mathrm{N}$ deposition increased biomass of an invasive plant (Spartina alterniflora) (Zhang et al., 2010).

Both the microcosm and field observations are in accordance with the hypothesis that salt marsh methanotrophy is limited by methane (carbon) availability. In the field in particular, we measured more negative methane fluxes for higher levels of initial methane concentration (Figure 1B), where sediments switched from positive net $\mathrm{CH}_{4}$ fluxes to negative net $\mathrm{CH}_{4}$ fluxes at around 1.56 ppmv $\mathrm{CH}_{4}$. Similarly, a study of eastern U.S. salt marshes showed an inverse relationship between methane availability and net negative methane fluxes (Bartlett et al., 1985). This dynamic association leads us to the following speculative hypothesis: that increases in $\mathrm{CH}_{4}$ due to $\mathrm{N}$ stimulation of methanogenesis might eventually be compensated for, if methanotrophy is not otherwise limited.

Even our small sampling of methylotroph sequences revealed a high degree of undescribed diversity. Similar genetic work in estuaries using 16S rDNA, methane monooxygenase (MMO) and $m x a \mathrm{~F}$ probes has also found a wide variety of taxa that share $\leq 90 \%$ similarity with isolated methylotrophs (McDonald et al., 2005b; Moosvi et al., 2005; Nercessian et al., 2005). From the phylogenetic analysis, it is difficult to know whether these new clades are gamma- or alpha-Proteobacteria, let alone what carbon substrates they may be using and specifically, whether any are methanotrophs. From work in other marine systems, we might have expected to find Type II methanotrophs (alpha-Proteobacteria; e.g., Valentine, 2011).

Further complicating the matter, new discoveries of microorganisms with novel methyl metabolism are increasingly blurring the lines between which methylotrophs can use methane and whether this function is obligate or facultative (Dedysh et al., 2005; Redmond et al., 2010). A number of methylotrophic species lack the mxaF gene (Chistoserdova et al., 2009). Thus, in the future it would be useful to combine several complementary approaches such as targeting both the particulate and soluble MMO as well as $m x a \mathrm{~F}$ (or $m d h 2$ and $x o x \mathrm{~F}$ for taxa lacking $m x a \mathrm{~F}$; Kalyuzhnaya

\section{REFERENCES}

Abdo, Z., Schüette, U. M. E., Bent, S. J., Williams, C. J., Forney, L. J., and Joyce, P. (2006). Statistical methods for characterizing diversity of microbial communities by analysis of terminal restriction fragment length polymorphisms of 16S rRNA genes. Environ. Microbiol. 8, 929-938.

Allison, S. D., and Vitousek, P. M. (2005). Responses of extracellular enzymes to simple and complex nutrient inputs. Soil Biol. Biochem. 37, 937-944.

Anderson, M. J., Gorley, R. N., and Clarke, K. R. (2008). PERMANOVA+ for PRIMER: Guide to Software and Statistical Methods. Plymouth: PRIMER-E.

Aronson, E. L., and Helliker, B. R. (2010). Methane flux in nonwetland soils in response to nitrogen addition: a meta-analysis. Ecology 91, 3242-3251. et al., 2008) with stable isotope probes (McDonald et al., 2005a) to disentangle the complex web of processes performed by the methylotrophic community (Jensen et al., 2008).

Despite these uncertainties, the clone library sequences suggest that our abundance (qPCR) and compositional (T-RFLP) assays most likely targeted non-methanotrophic bacteria. Although the composition of this group varied among marsh locations, it did not appear to respond (in abundance or composition) to $\mathrm{N}$ addition, at least as could be detected with the methods applied. These findings indicate that non-methanotrophic methylotrophs are not $\mathrm{N}$ limited in salt marshes and suggest that particular T-RFLP taxa do not specialize on different $\mathrm{N}$ availabilities nor respond indirectly to the increase in plant biomass (at least after fertilization for 7 months).

Although salt marshes are likely a minor source of global methane emissions (Hanson and Hanson, 1996), this study demonstrates again the central role of microbial communities in regulating global methane emissions. However, the intricate relationships between $\mathrm{C}_{1}$-cycling microorganisms pose a challenge for predicting how methane cycling will respond to environmental changes. Despite these interactions, however, we observed a consistent, linear response to $\mathrm{N}$ addition at all three sites, indicating that the overall methane flux response to $\mathrm{N}$ addition is predictable within an ecosystem. More work is needed to confirm these results in other seasons and more salt marshes to investigate whether this stimulation is due to changes in abundance and/or composition of the methanogen community or their metabolic efficiency.

\section{ACKNOWLEDGMENTS}

We are grateful to our reviewers for their thoughtful comments on a prior draft. We thank Todd Bank, Stephanie Chen, Pedro Flombaum, Barbara Huang, Michael Marchesano, Tim Roth, and Claudia Weihe for invaluable lab and field assistance. We also thank Roark Galloway for his technical assistance with the gas chromatograph, and Emma Aronson for invaluable discussions of these ideas. Thanks also to Jeff Crooks (National Estuarine Research Reserve, Tijuana River Estuary Reserve), Brian Collins (US Fish and Wildlife Service, San Diego Wildlife Refuges), Andrew Brooks (University of California Reserve System, Carpinteria Salt Marsh Reserve), and Vince Cicero (California State Parks, Morro Bay National Estuary) for their expertise and help regarding the study sites. Financial support was provided in part by the Gordon and Betty Moore Foundation, the National Science Foundation, the University of California at Irvine, and Mildred E. Mathias Graduate Student Research Grants.
Auman, A. J., Speake, C. C., and Lidstrom, M. (2001). nifH sequences and nitrogen fixation in Type I and Type II methanotrophs. Appl. Environ. Microbiol. 67, 4009-4016.

Bartlett, K. B., Harriss, R. C., and Sebacher, D. I. (1985). Methane flux from coastal salt marshes. J. Geophys. Res. 90, 5710-5720.

Bertness, M. D., Ewanchuck, P. J., and Silliman, B. (2002). Anthropogenic modification of New England salt marshes. Proc. Natl. Acad. Sci. U.S.A. 99, 1395-1398.

Bodelier, P. L. E., and Laanbroek, H. J. (2004). Nitrogen as a regulatory factor of methane oxidation in soils and sediments. FEMS Microbiol. Ecol. 47, 265-277.

Bodelier, P. L. E., Roslev, P., Henckel, T., and Frenzel, P. (2000). Stimulation by ammonium-based fertilizers of methane oxidation in soil around rice roots. Nature 403, 421-424. 
Boyer, E. W., and Zedler, J. (1998). Effects of nitrogen additions on the vertical structure of a constructed cordgrass marsh. Ecol. Appl. 8, 692-705.

Boyer, K. E., Fong, P., Vance, R. R., and Ambrose, R. F. (2001). Salicornia virginica in a Southern California salt marsh: seasonal patterns and a nutrient-enrichment experiment. Wetlands (Wilmington) 21, 315-326.

Bradford, M. A., Fierer, N., Jackson, R. B., Maddox, T. R., and Reynolds, J. F. (2008). Nonlinear root-derived carbon sequestration across a gradient of nitrogen and phosphorous deposition in experimental mesocosms. Glob. Chang Biol. 14, 1113-1124.

Caffrey, R. M., Murrell, J. C., Wigand, C., and McKinney, R. A. (2007). Effect of nutrient loading on biogeochemical and microbial processes in a New England salt marsh. Biogeochemistry $82,251-264$.

Cardoni, D. A., Isacch, J. P., Fanjul, M. E., Escapa, M., and Iribarne, O. O. (2011). Relationship between anthropogenic sewage discharge, marsh structure and bird assemblages in an SW Atlantic saltmarsh. Mar. Environ. Res. 71, 122-130.

Cheng, X., Luo, Y., Xu, Q., Lin, G., Zhang, Q., Chen, J., and Li, B. (2010). Seasonal variation in $\mathrm{CH}(4)$ emission and its (13)C-isotopic signature from Spartina alterniflora and Scirpus mariqueter soils in an estuarine wetland. Plant Soil 327, 85-94.

Chistoserdova, L., Kalyuzhnaya, M. G., and Lidstrom, M. E. (2009). The expanding world of methylotrophic metabolism. Аnпu. Rev. Microbiol. 63, 477-499.

Conley, D. J., Paerl, H. W., Howarth, R. W., Boesch, D. F., Seitzinger, S. P., Havens, K. E., Lancelot, C., and Likens, G. E. (2009). Controlling eutrophication: nitrogen and phosphorus. Science 323, 1014-1015.

Conrad, R. (2007). Microbial ecology of methanogens and methanotrophs. Adv. Agron. 96, 1-63.

Cottingham, K. L., Lennon, J. T., and Brown, B. L. (2005). Knowing when to draw the line: designing more informative ecological experiments. Front. Ecol. Environ. 3, 145-152.

Crain, C. (2007). Shifting nutrient limitation and eutrophication effects in marsh vegetation across estuarine salinity gradients. Estuaries Coast 30 , 26-34.

Dakora, F. D., and Phillips, D. A. (2002). Root exudates as mediators of mineral acquisition in low- nutrient environments. Plant Soil 245, 35-47.

Dedysh, S. N., Knief, C., and Dunfield, P. F. (2005). Methylocella species are facultatively methanotrophic. J. Bacteriol. 187, 4665-4670.

Dentener, F., Drevet, J., and Lamarque, J. F. (2006). Nitrogen and sulfur deposition on regional and global scales: a multimodel evaluation. Global Biogeochem. Cycles 20, GB4003.

Felsenstein, J. (2005). Theoretical Evolutionary Genetics. Available at: http:// evolution.genetics.washington.edu/ pgbook/pgbook.html

Fesefeldt, A., Poetsch, M., and Gliesche, C. G. (1997). Development of a species-specific gene probe for Hyphomicrobium facilis with inverse PCR. Appl. Environ. Microbiol. 63, 335-337.

Fitch, R., Theodose, T., and Dionne, M. (2009). Relationships among upland development, nitrogen, and plant community composition in a Maine salt marsh. Wetlands (Wilmington) 29, 1179-1188.

Galloway, J. N., Dentener, F. J., Capone, D. G., Boyer, E. W., Howarth, R. W., Seitzinger, S. P., Asner, E. P., Cleveland, C. C., Green, P. A., Holland, E. A., Karl, D. M., Michaels, A. F., Porter, J. H., Townsend, A. R., and Vorosmarty, C. J. (2004). Nitrogen cycles: past, present, and future. Biogeochemistry 70, 153-226.

Graham, D. W., Chaudhary, J. A., Hanson, R. S., and Arnold, R. G. (1993). Factors affecting competition between type I and type II methanotrophs in two-organism, continuous-flow reactors. Microb. Ecol. 25, 1-17.

Graham, S. A., and Mendelssohn, I. A. (2010). Multiple levels of nitrogen applied to an oligohaline marsh identify a plant community response sequence to eutrophication. Mar. Ecol. Prog. Ser. 417, 73-82.

Hanson, R. S., and Hanson, T. E. (1996). Methanotrophic bacteria. Microbiol. Rev. 60, 439-471.

Heimann, M. (2011). Atmospheric science: enigma of the recent methane budget. Nature 476, 157-158.

Jensen, S., Neufeld, J. D., Birkeland, N. K., Hovland, M., and Murrell, J. C. (2008). Methane assimilation and trophic interactions with marine Methylomicrobium in deepwater coral reef sediment off the coast of Norway. FEMS Microbiol. Ecol. 66, 320-330.

Kai, F. M., Tyler, S. C., Randerson, J. T., and Blake, D. R. (2011). Reduced methane growth rate explained by decreased North- ern Hemisphere microbial sources. Nature 476, 194-197.

Kalyuzhnaya, M. G., Hristova, K. R., Lidstrom, M. E., and Chistoserdova, L. (2008). Characterization of a novel methanol dehydrogenase in representatives of Burkholderiales: implications for environmental detection of methylotrophy and evidence for convergent evolution. $J$. Bacteriol. 190, 3817-3823.

King, G. M., and Wiebe, W. J. (1978). Methane release from soils of a Georgia salt marsh. Geochim. Cosmochim. Acta 42, 343-348.

Lelieveld, J., Crutzen, P. J., and Brühl, C. (1993). Climate effects of atmospheric methane. Chemosphere 26, 739-768.

Liu, L. L., and Greaver, T. L. (2009). A review of nitrogen enrichment effects on three biogenic GHGs: the $\mathrm{CO} 2$ sink may be largely offset by stimulated $\mathrm{N} 2 \mathrm{O}$ and $\mathrm{CH} 4$ emissions. Ecol. Lett. 12, 1103-1117.

Magenheimer, J., Moore, T., Chmura, G., and Daoust, R. (1996). Methane and carbon dioxide flux from a macrotidal salt marsh, Bay of Fundy, New Brunswick. Estuaries Coast 19, 139-145.

Magurran, A. E. (1988). Ecological Diversity and Its Measurement. Princeton: Princeton University.

McDonald, I. R., Bodrossy, L., Chen, Y., and Murrell, J. C. (2008). Molecular ecology techniques for the study of aerobic methanotrophs. Appl. Environ. Microbiol. 74, 1305-1315.

McDonald, I. R., Radajewski, S., and Murrell, J. C. (2005a). Stable isotope probing of nucleic acids in methanotrophs and methylotrophs: a review. Org. Geochem. 36, 779-787.

McDonald, I. R., Smith, K., and Lidstrom, M. E. (2005b). Methanotrophic populations in estuarine sediment from Newport Bay, California. FEMS Microbiol. Lett. 250, 287-293.

Moosvi, S. A., Mcdonald, I. R., Pearce, D. A., Kelly, D. P., and Wood, A. P. (2005). Molecular detection and isolation from Antarctica of methylotrophic bacteria able to grow with methylated sulfur compounds. Syst. Appl. Microbiol. 28, 541-554.

Moussard, H., Stralis-Pavese, N. Bodrossy, L., Neufeld, J. D., and Murrell, J. C. (2009). Identification of active methylotrophic bacteria inhabiting surface sediment of a marine estuary. Environ. Microbiol. Rep. 1, 424-433.

Nercessian, O., Noyes, E., Kalyuzhnaya, M. G., Lidstrom, M. E., and Chistoserdova, L. (2005). Bacterial populations active in metabolism of $\mathrm{C}-1$ compounds in the sediment of Lake Washington, a freshwater lake. Appl. Environ. Microbiol. 71, 6885-6899.

Neufeld, J. D., Chen, Y., Dumont, M. G., and Murrell, J. C. (2008). Marine methylotrophs revealed by stableisotope probing, multiple displacement amplification and metagenomics. Environ. Microbiol. 10 1526-1535.

Oremland, R. S., and Polcin, S. (1982). Methanogenesis and sulfate reduction: competitive and noncompetitive substrates in estuarine sediments. Appl. Environ. Microbiol. 44, 1270-1276.

Qiu, Q., Conrad, R., and Lu, Y. (2009). Cross-feeding of methane carbon among bacteria on rice roots revealed by DNA-stable isotope probing. Environ. Microbiol. Rep. 1, 355-361.

Redmond, M. C., Valentine, D. L., and Sessions, A. L. (2010). Identification of novel methane-, ethane-, and propane-oxidizing bacteria at marine hydrocarbon seeps by stable isotope probing. Appl. Environ. Microbiol. 76, 6412-6422.

Rigby, M., Prinn, R. G., Fraser, P. J., Simmonds, P. G., Langenfelds, R. L., Huang, J., Cunnold, D. M., Steele, L. P., Krummel, P. B., Weiss, R F., O’Doherty, S., Salameh, P. K., Wang, H. J., Harth, C. M., Mühle, J., and Porter, L. W. (2008). Renewed growth of atmospheric methane. Geophys. Res. Lett. 35, L22805.

Schloss, P. D., Westcott, S. L., Ryabin, T., Hall, J. R., Hartmann, M., Hollister, E. B., Lesniewski, R. A., Oakley, B. B., Parks, D. H., Robinson, C. J., Sahl, J. W., Stres, B., Thallinger, G. G., Van Horn, D. J., and Weber, C. F. (2009). Introducing mothur: open-source, platform-independent, communitysupported software for describing and comparing microbial communities. Appl. Environ. Microbiol. 75, 7537-7541.

Shimel, J. P., and Gulledge, J. (1998). Microbial community structure and global trace gases. Glob. Chang Biol. 4, 745-758.

Valentine, D. L. (2011). Emerging topics in marine methane biogeochemistry. Ann. Rev. Mar. Sci. 3, 147-171.

Vitousek, P. M., Hattenschwiler, S., Olander, L., and Allison, S. (2002). Nitrogen and nature. Ambio 31, 97-101.

Wilkinson, T. G., Topiwala, H. H., and Hamer, G. (1974). Interactions in a mixed bacterial population growing methane in continuous culture. Biotechnol. Bioeng. 16, 41-59.

Zhang, Y. H., Ding, W. X., Cai, Z. C., Valerie, P., and Han, F. X. 
(2010). Response of methane emission to invasion of Spartina alterniflora and exogenous $\mathrm{N}$ deposition in the coastal salt marsh. Atmos. Environ. 44, 4588-4594.

Conflict of Interest Statement: The authors declare that the research was conducted in the absence of any commercial or financial relationships that could be construed as a potential conflict of interest.

Received: 07 December 2011; paper pending published: 04 January 2012; accepted: 23 February 2012; published online: 19 March 2012.
Citation: Irvine IC, Vivanco L, Bentley PN and Martiny JBH (2012) The effect of nitrogen enrichment on $C_{1}$-cycling microorganisms and methane flux in salt marsh sediments. Front. Microbio. 3:90. doi: 10.3389/fmicb.2012.00090

This article was submitted to Frontiers in Terrestrial Microbiology, a specialty of Frontiers in Microbiology.
Copyright (c) 2012 Irvine, Vivanco, Bentley and Martiny. This is an openaccess article distributed under the terms of the Creative Commons Attribution Non Commercial License, which permits non-commercial use, distribution, and reproduction in other forums, provided the original authors and source are credited. 


\title{
Inhibition of methane oxidation by nitrogenous fertilizers in a paddy soil
}

\author{
M. Saiful Alam ${ }^{1,2}$ and Zhongjun Jia ${ }^{1 *}$ \\ State Key Laboratory of Soil and Sustainable Agriculture, Institute of Soil Science, Chinese, Academy of Sciences, Nanjing, Jiangsu Province, P.R. China \\ ${ }^{2}$ Graduate School of Chinese Academy of Sciences, Beijing, P.R. China
}

\author{
Edited by: \\ Paul Bodelier, Netherlands Institute \\ of Ecology (NIOO-KNAW), \\ Netherlands \\ Reviewed by: \\ Brajesh Singh, University of \\ Western Sydney, Australia \\ Anne Daebeler, Netherlands \\ Institute of Ecology (NIOO-KNAW), \\ Netherlands

\section{*Correspondence:} \\ Zhongjun Jia, State Key Laboratory \\ of Soil and Sustainable Agriculture, \\ Institute of Soil Science, Chinese \\ Academy of Sciences, East Beijing \\ Road, No. 71, Xuan-Wu District, \\ Nanjing, 210008, Jiangsu Province, \\ P.R. China. \\ e-mail: jia@issas.ac.cn
}

Nitrogenous fertilizers are generally thought to have an important role in regulating methane oxidation. In this study, the effect of ammonium on methane oxidation activity was investigated in a paddy soil using urea at concentrations of $0,50,100,200$, and $400 \mu \mathrm{g}$ $\mathrm{N}$ per gram dry weight soil (N/g.d.W.S) and ammonium sulfate at concentrations of 0,50 , and $200 \mu \mathrm{g} \mathrm{N} / \mathrm{g}$.d.w.s. The results of this study demonstrate that urea concentrations of $200 \mu \mathrm{g} \mathrm{N} / \mathrm{g}$. d.w.S. and above significantly inhibit methane oxidation activity, whereas no statistically significant difference was observed in methane oxidation activity among soil microcosms with urea concentrations of less than $200 \mu \mathrm{g} \mathrm{N} / \mathrm{g}$.d.w.s after incubation for 27 days. Similar results were obtained in a sense that methane oxidation activity was inhibited only when the ammonium sulfate concentration was $200 \mu \mathrm{g} \mathrm{N} / \mathrm{g}$.d.W.s in soil microcosms in this study. Phylogenetic analysis of pmoA genes showed that nitrogen fertilization resulted in apparent changes in the community composition of methane-oxidizing bacteria (MOB). Type I MOB displayed an increased abundance in soil microcosms amended with nitrogenous fertilizers, whereas type II MOB dominated the native soil. Furthermore, although no statistically significant relationship was observed between pmoA gene and amoA gene abundances, methane oxidation activity was significantly negatively correlated with nitrification activity in the presence of urea or ammonium sulfate. Our results indicate that the methane oxidation activity in paddy soils might be inhibited when the concentration of ammonium fertilizers is high and that the interactions between ammonia and methane oxidizers need to be further investigated.

\footnotetext{
Keywords: methane oxidation, nitrogenous fertilizers, particulate methane monooxygenase gene pmoa, nitrification activity, paddy soil
}

\section{INTRODUCTION}

Methane $\left(\mathrm{CH}_{4}\right)$, a potent greenhouse gas (GHG), is involved in a number of chemical and physical processes in the earth's atmosphere, including global warming (Crutzen, 1995). Despite a short residence time in the atmosphere (10 years), the ability of $\mathrm{CH}_{4}$ to absorb infrared radiation is $20-30$ times greater than that of $\mathrm{CO}_{2}$ (Rodhe, 1990). $\mathrm{CH}_{4}$ is more abundant in the Earth's atmosphere now than at any time in at least the past 650,000 years (IPCC, 2007). It has been estimated that $70 \%$ of the $\mathrm{CH}_{4}$ annually released into the atmosphere is due to human activities including agriculture, waste disposal, and biomass burning (Houghton et al., 2001). During most of the last 150 years, atmospheric $\mathrm{CH}_{4}$ has increased monotonically. However, even though the $\mathrm{CH}_{4}$ concentration in the atmosphere became erratic and did not increase overall from 1999 until 2007, it has begun to increase again (Rigby et al., 2008).

Paddy fields are an important source of atmospheric $\mathrm{CH}_{4}$, contributing approximately $40 \mathrm{Tg} \mathrm{year}^{-1}$ (Lelieveld et al., 1998; Wang et al., 2004). $\mathrm{CH}_{4}$, which is produced in the soil, enters the roots of the rice plants and is transported through the gas vascular system of the plants to the atmosphere, and oxygen is transported from the atmosphere into the roots. Thus, rice roots are partially oxic, which allows methane-oxidizing bacteria $(\mathrm{MOB})$ to be active in the rhizosphere (Conrad, 2004). MOB associated with the rhizosphere of rice plants oxidize $\mathrm{CH}_{4}$ aerobically and use it as a source of carbon and energy. Thus, MOB play an important role in the global $\mathrm{CH}_{4}$ budget by reducing $\mathrm{CH}_{4}$ emissions from rice ecosystems to the atmosphere (Groot et al., 2003).

When considering the world's continued population growth and economic prosperity, rice production must increase by $40 \%$ by 2030 to satisfy the growing demand without adversely affecting the resource base (Khush, 2005). The increasing demand for rice has led to the intensified application of nitrogenous fertilizers, which may affect $\mathrm{CH}_{4}$ oxidation because MOB are generally thought to be inhibited by ammonium-based fertilizers, as has been demonstrated for soils (Steudler et al., 1989; King and Schnell, 1994; Gulledge et al., 1997) and sediments (Bosse et al., 1993; Van der Nat et al., 1997). This outcome is at least partially due to the strong evolutionary links between the genetics of enzymes responsible for $\mathrm{CH}_{4}$ and ammonia oxidation, which allow MOB and ammonia-oxidizing bacteria $(\mathrm{AOB})$ and/or ammonia-oxidizing archaea $(\mathrm{AOA})$ to switch substrates (Dunfield and Knowles, 1995). This mechanism is believed to be responsible for the inhibition of $\mathrm{CH}_{4}$ uptake in soils exposed to high concentrations of available $\mathrm{N}$ (Hanson and Hanson, 1996).

In contrast, numerous studies have demonstrated that the activity and growth of $\mathrm{MOB}$ in the root zone of rice plants are 
stimulated upon fertilization (Bodelier et al., 2000a,b; Krüger et al., 2002; Krüger and Frenzel, 2003; Mohanty et al., 2006). This stimulating effect may be the result of a relief in $\mathrm{N}$-source limitation or a direct stimulation of $\mathrm{CH}_{4}$ oxidation by $\mathrm{NH}_{4}^{+}$$\mathrm{N}$ by an as yet unknown mechanism (Bodelier et al., 2000a), and a schematic overview of the general mechanisms by which $\mathrm{N}$-fertilization can influence $\mathrm{CH}_{4}$ production and oxidation in wetlands and uplands has been proposed by Bodelier (2011). It is noteworthy to mention that some studies have also demonstrated no effects of ammonium-based $\mathrm{N}$-fertilization on MOB (Dunfield et al., 1995; Delgado and Mosier, 1996; Dan et al., 2001). Even though the effects of nitrogenous fertilizers on $\mathrm{CH}_{4}$ oxidation have been the most investigated regulating factor of aerobic $\mathrm{CH}_{4}$ oxidation (reviewed in Bodelier and Laanbroek, 2004; Aronson and Helliker, 2010), it is obvious that the interactions between the nitrogen and methane cycle are complex and far from completely understood (Bodelier, 2011). Therefore, microcosm incubations were performed to investigate the effects of urea and ammonium sulfate on methane oxidation in a paddy field to better understand the interactions between the methanotrophic community and ammoniaoxidizing prokaryotes.

\section{MATERIALS AND METHODS \\ SOIL}

The soil used in this study was collected from a long-term field fertilization experiment at the Changshu Ecological Experimental Station of the Institute of Soil Science, Chinese Academy of Sciences. The paddy soil was developed from lake sediment and is classified as a Typic Haplanthrept based on U.S. soil taxonomy. A full description of this long-term fertilization experiment and its management regimes has been previously described (Wu et al., 2011). A rice-wheat rotation system was maintained in the field, and soil sampling was performed from triplicate plots that received chemical fertilizers (NPK) during the rice-growing season. Bulk soil (top $0-5 \mathrm{~cm}$ ) was collected and transported on ice to the laboratory immediately after sampling.

\section{MICROCOSM INCUBATION}

Five grams of fresh soil was placed into a $120 \mathrm{ml}$ crimp top serum vial, and treatments of $0,50,100,200$, and $400 \mu \mathrm{g}$ urea- $\mathrm{N} / g$ d.w.s or 0,50 , and $200 \mu \mathrm{g}\left(\mathrm{NH}_{4}\right)_{2} \mathrm{SO}_{4}-\mathrm{N} / g$ d.w.s were established in duplicate. For the soil microcosms amended with $\left(\mathrm{NH}_{4}\right)_{2} \mathrm{SO}_{4}, 388 \mu \mathrm{g} \mathrm{Na} \mathrm{CO}_{3}-\mathrm{C} / g$ d.w.s was also added as the carbon source for ammonia oxidizers. All soil microcosms contained slurries with a final volume of $50 \mathrm{ml}$ through the addition of sterile distilled water. The bottles were then sealed with rubber stoppers, and $\mathrm{CH}_{4}$ was injected into the headspaces to generate the targeted methane concentration of $\sim 5,000$ parts per million. The incubation of soil microcosms was performed at $28^{\circ} \mathrm{C}$ in the dark with shaking at $200 \mathrm{rpm}$ for 27 days. After consumption of $>95 \%$ of the $\mathrm{CH}_{4}$, the vials were flushed with air to remove any $\mathrm{CO}_{2}$ and to ensure that the slurries remained aerobic. The treatments were then renewed after $0,4,8,12,16,20$, and 24 days of incubation, providing the targeted concentrations of $\mathrm{CH}_{4}$ and nitrogenous fertilizers described above. $\mathrm{CH}_{4}$ concentrations were measured on a daily basis or every other day, and inorganic nitrogen $\left(\mathrm{NO}_{3}^{-}\right.$, $\mathrm{NO}_{2}^{-}$, and $\mathrm{NH}_{4}^{+}$) concentrations were determined at days 0,15 , and 27.

Gas samples were collected to determine the $\mathrm{CH}_{4}$ concentration in the headspace of the microcosms. Before gas samplings, the bottles were gently shaken by hand for $1 \mathrm{~min}$ to release the $\mathrm{CH}_{4}$ dissolved in the submerged water layer into the headspace. One milliliter of the gas sample in the headspace was analyzed using gas chromatography with a flame ionization detector, as described previously (Liu et al., 2011). Soil slurries were collected after 0,15 , and 27 days of incubation. Before sampling, the bottles were vigorously shaken by hand; $10 \mathrm{ml}$ of the slurries were transferred to centrifuge tubes and then centrifuged at $10,000 \mathrm{rpm}$ for $5 \mathrm{~min}$ to collect the soil pellets. The pellets were then stored at $-20^{\circ} \mathrm{C}$ for molecular analysis. The supernatants were collected and stored at $-20^{\circ} \mathrm{C}$ for inorganic nitrogen analysis. Inorganic nitrogen species $\left(\mathrm{NH}_{4}^{+}, \mathrm{NO}_{3}^{-}\right.$, and $\left.\mathrm{NO}_{2}^{-}\right)$were extracted with $2 \mathrm{M} \mathrm{KCl}$ and analyzed using a continuous flow analyzer (SA1000, Skalar, Netherlands).

\section{SOIL DNA EXTRACTION AND QUANTITATIVE POLYMERASE CHAIN REACTION}

DNA was extracted from approximately $0.5 \mathrm{~g}$ of soil pellet following the method of Griffiths et al. (2000) with slight modifications following a bead-beating step, which was performed in triplicate. The quality and quantity of the DNA was assessed using a NanoDrop spectrophotometer (NanoDrop Technologies, Wilmington, DE). Real-time quantitative PCR (qPCR) with three replicates for each sample was performed to determine the copy numbers of the amoA and $p m o A$ genes using the primer sets Arch-amoAF/Arch-amoAR for AOA (Francis et al., 2005), amoA-1F/amoA-2R-GG for AOB (Rotthauwe et al., 1997) and A189f/mb661r for MOB (Costello and Lidstrom, 1999) with a CFX96 Optical Real-Time Detection System (Bio-Rad Laboratories, Hercules, CA). The qPCR standard was generated using plasmid DNA from representative clones containing the bacterial or archaeal amoA gene or bacterial pmoA gene. A dilution series of a standard template across six orders of magnitude $\left(3.12 \times 10^{2}\right.$ to $3.12 \times 10^{8}$ for $\mathrm{AOB}, 1.56 \times 10^{2}$ to $1.56 \times 10^{8}$ for AOA and $1.82 \times 10^{2}$ to $1.82 \times 10^{8}$ for MOB) per assay was used to optimize the qPCR conditions. The blank was always run with water as the template instead of the soil DNA extract. The $20 \mu \mathrm{l}$ reaction mixture contained $10.0 \mu \mathrm{l}$ of SYBR Premix Ex Taq (TaKaRa Biotech, Dalian, China), $0.25 \mu \mathrm{M}$ of each primer, and $2 \mu \mathrm{l}$ of DNA template. The PCR conditions used for the archaeal and bacterial amoA genes were the same as previously described (Jia and Conrad, 2009). For the pmoA gene amplification, the PCR conditions were as follows: initial denaturation at $95^{\circ} \mathrm{C}$ for $30 \mathrm{~s} ; 40$ cycles consisting of denaturation at $95^{\circ} \mathrm{C}$ for $10 \mathrm{~s}$, primer annealing at $55^{\circ} \mathrm{C}$ for $30 \mathrm{~s}$ and elongation at $72^{\circ} \mathrm{C}$ for $30 \mathrm{~s}$. PCR amplification efficiencies of $101.9 \%$ with a $R^{2}$ value of $0.998,99.2 \%$ with a $R^{2}$ value of 0.990 and $101.4 \%$ with a $R^{2}$ value of 0.993 were obtained for the archaeal amoA gene, the bacterial amoA gene and the pmoA gene, respectively. The specific amplifications of $a m o A$ and $p m o A$ were also determined 
using a melting curve analysis, which always resulted in a single peak.

\section{POLYMERASE CHAIN REACTION-DENATURING GRADIENT GEL ELECTROPHORESIS (DGGE)}

For the DGGE analysis, PCR amplification of the archaeal and bacterial amoA gene was performed using the same primers as described above; however, the forward primer for the bacterial amoA was attached to a GC-clamp. The PCR reaction was performed in a $25 \mu \mathrm{l}$ volume containing $2.5 \mu \mathrm{l} 10 \times$ PCR buffer, $0.25 \mu \mathrm{M}$ of each primer, $200 \mu \mathrm{M}$ (each) deoxyribonucleoside triphosphate, $1.5 \mathrm{U}$ of Taq DNA polymerase, and $1 \mu \mathrm{l}$ of soil DNA. The PCR was performed in a Thermal Cycler Dice (Takara Bio, Shiga, Japan), as previously described for the AOA (Francis et al., 2005) and AOB (Nicolaisen and Ramsing, 2002). The PCR products were run in a $1.5 \%$ agarose gel to determine their specificity and were spectrophotometrically measured to determine their concentrations.

Approximately $150 \mathrm{ng}$ of PCR amplicons from each sample was subjected to DGGE analysis. For AOA, the PCR products were run in $6 \%$ acrylamide gels with a denaturing gradient of $20-50 \%$ ( $100 \%$ denaturant corresponds to $7 \mathrm{M}$ urea and $40 \%$ deionized formamide). For AOB, an $8 \%$ gel with a $45-75 \%$ denaturing gradient was used. The gels were run in $1 \times \mathrm{TAE}$ at $75 \mathrm{~V}$ for $17 \mathrm{~h}$ and stained with SYBR Green I dye. The stained gels were imaged (Gel Doc system, Bio-Rad Laboratories, Hercules, CA), digitized, and processed (Gelcompar II, Applied Maths, Inc., Austin, TX).

\section{SEQUENCING AND PHYLOGENETIC ANALYSIS}

The distinct DGGE bands for the amoA genes of AOB (10 bands) and AOA (5 bands) among all the treatments were excised and re-amplified using the previously described PCR conditions. These PCR products were cloned using the pEasy-T1 cloning kit (TransGen Biotech Co., Beijing). The clones that contained the correct insert were selected and sequenced using an ABI 3730 XL DNA analyzer (Beijing Genomics Institute, Beijing, China). For MOB, the PCR products from the five treatments [original soil sample (day 0$)$, 4th week Urea-0 (U-0), 4th week Urea-400 (U-400), 4th week AS-0 (AS-0), and 4th week AS-200 (AS-200)] were directly used for the cloning to construct a clone library. The cloning was performed following the same procedure as described above. At least 6-12 clones were randomly selected for each treatment. The sequences for the DGGE bands and the clones as well as their closest relatives obtained by BLAST analyses (http://blast.ncbi.nlm.nih.gov/Blast.cgi) were aligned using CLUSTAL X 1.83 (Thompson et al., 1997). Phylogenetic trees were constructed using the neighbor-joining method based on the Jukes-Cantor correction MEGA (Molecular Evolutionary Genetics Analysis) version 4 (Tamura et al., 2007).

\section{STATISTICS}

Spearman's correlation analyses were performed to assess the relationships among methane oxidation activity, nitrification activity and the abundance of the MOB (SPSS 11.5 package, SPSS, Chicago, IL). A One-Way ANOVA with Duncan's post hoc tests was performed to evaluate the differences within the datasets, with a $P$ value of 0.05 selected for significance.

\section{NUCLEOTIDE SEQUENCE ACCESSION NUMBERS}

The sequences obtained in this study have been deposited in GenBank with the accession numbers JQ990075-JQ990084, affiliated with the AOB; JQ990070-JQ990074, affiliated with the AOA and JQ990085-JQ990125, affiliated with the MOB.

\section{RESULTS}

\section{$\mathrm{CH}_{4}$ OXIDATION ACTIVITY}

The initial $\mathrm{CH}_{4}$ concentration in the headspace was approximately $2.5 \mu \mathrm{mol} \mathrm{g}^{-1}$ d.w.s., and methane oxidation was influenced by nitrogenous fertilizers during the microcosm incubations (Figure 1). After 27 days of incubation, there were no statistically significant differences in the $\mathrm{CH}_{4}$ concentrations among the soil microcosms amended with 0,50 , and $100 \mu \mathrm{g}$ urea $\mathrm{N} /$ g.d.w.s. $(1.14,1.20$, and $1.32 \mathrm{nmol} /$ g.d.w.s., respectively), but significantly higher $\mathrm{CH}_{4}$ concentrations were observed in the headspaces of the soil microcosms containing 200 and $400 \mu \mathrm{g}$ urea $\mathrm{N} /$ g.d.w.s $(31.7$ and $55.0 \mathrm{nmol} /$ g.d.w.s., respectively; Figure 1A). The methane concentrations were 1.57 and $1.45 \mathrm{nmol} / \mathrm{g} . d . w . s$. in the microcosms treated with ammonium sulfate at concentrations of 0 and $50 \mu \mathrm{g} \mathrm{N} / g . d . w . s$. , respectively (Figure 1B). A significantly higher $\mathrm{CH}_{4}$ concentration of $14.6 \mathrm{nmol} / \mathrm{g}$. d.w.s. was observed in the microcosms when treated with $200 \mu \mathrm{g}\left(\mathrm{NH}_{4}\right)_{2} \mathrm{SO}_{4}-\mathrm{N} / g$.d.w.s. It is interesting to note that the ammonium concentrations were remarkably higher in the soil microcosms where $\mathrm{CH}_{4}$ oxidation was apparently inhibited by U-400 and AS-200 (Figures 1C,D). For example, $61 \mu \mathrm{g} \mathrm{NH}_{4}^{+}-\mathrm{N}$ $\mathrm{g}^{-1}$ d.w.s. was observed in the soil microcosms treated with $400 \mu \mathrm{g}$ urea $\mathrm{N} / g . d . w . s$., which is compared to $1.5 \mu \mathrm{g} \mathrm{NH}_{4}^{+}-\mathrm{N} \mathrm{g}^{-1}$ d.w.s in the soil microcosms that received no nitrogenous fertilizers.

\section{NITRIFICATION ACTIVITY}

Regardless of the urea and $\left(\mathrm{NH}_{4}\right)_{2} \mathrm{SO}_{4}$ treatments, there was a strong nitrification activity in the presence of $\mathrm{CH}_{4}$. The production of nitrate and nitrite in the soil microcosms was positively related to the amounts of urea or $\left(\mathrm{NH}_{4}\right)_{2} \mathrm{SO}_{4}$ added (Figures 2A and $3 \mathrm{~A}$ ) while the native soil contained only $1.54 \mu \mathrm{g}$ (nitrate + nitrite) $\mathrm{N} \mathrm{g}^{-1}$ d.w.s. All the microcosms treated with urea and $\left(\mathrm{NH}_{4}\right)_{2} \mathrm{SO}_{4}$ displayed significant productions of soil nitrite and nitrate, demonstrating a strong nitrification activity over the course of the 27-day incubation. After 27 days of incubation, the soil nitrate and nitrite concentrations reached $294 \mu \mathrm{g}$ $\mathrm{N} /$ g.d.w.s. and $123 \mu \mathrm{g} \mathrm{N} /$ g.d.w.s. in the microcosms amended with $400 \mu \mathrm{g}$ urea-N/g.d.w.s. and $200 \mu \mathrm{g}\left(\mathrm{NH}_{4}\right)_{2} \mathrm{SO}_{4}-\mathrm{N} / g . d . w . s$. , respectively (Figures $\mathbf{2 A}$ and $\mathbf{3 A}$ ). As for the ammonium concentrations, $7.45 \mu \mathrm{g} \mathrm{N} / g . d . w . s$. was observed in the native soil, and the consumed ammonium was recovered in an almost stoichiometric amount to the nitrate and nitrite produced in the soil microcosm after 15 or 27 days of incubation. Similar findings were observed in the soil microcosms amended with ammonium sulfate.

\section{ABUNDANCE OF MOB, AOB, AND AOA COMMUNITIES}

The abundances of $\mathrm{MOB}, \mathrm{AOB}$, and $\mathrm{AOA}$ were determined using a qPCR targeting the $p m o A$ and amo $A$ genes (Figures $2 B-D$ and $3 \mathbf{B}-\mathbf{D})$. The $p m o A$ gene copy number varied significantly in the soil microcosms with different nitrogenous substrates. 


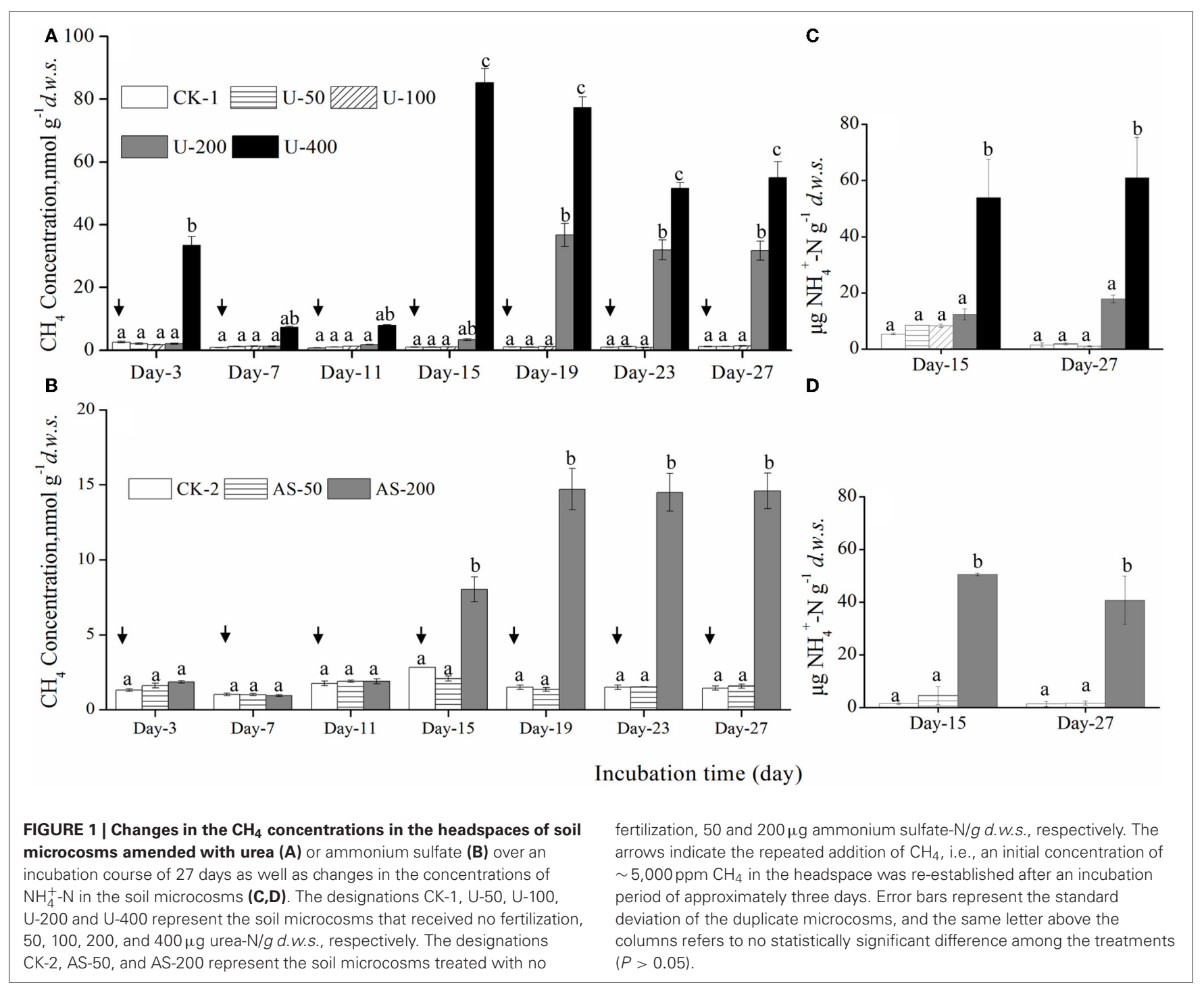

For the native soil, the copy number of the $p m o A$ genes was $1.37 \times 10^{7} \mathrm{~g}^{-1}$ d.w.s. After 27 days of incubation, the $p m o A$ gene copy numbers were $9.42 \times 10^{7}$ and $1.02 \times 10^{8}$ in the soil microcosms treated with 50 and $100 \mu \mathrm{g}$ urea N/g.d.w.s, respectively. In the microcosms containing 200 and $400 \mu$ g urea N/g.d.w.s., copy numbers of $1.56 \times 10^{7}$ and $4.27 \times 10^{6}$ were observed as well as $6.70 \times 10^{7} \mathrm{pmoA}$ genes within the control microcosms receiving no urea. Similarly, the $p m o A$ gene copy numbers decreased slightly in the soil microcosms containing 50 and $200 \mu \mathrm{g}\left(\mathrm{NH}_{4}\right)_{2} \mathrm{SO}_{4}$-N/g.d.w.s compared to the control microcosms receiving no $\left(\mathrm{NH}_{4}\right)_{2} \mathrm{SO}_{4}-\mathrm{N}$. After 27 days of incubation, the copy numbers of the $p m o A$ genes were $2.1 \times 10^{8}, 2.0 \times 10^{8}$ and $1.5 \times 10^{8}$ in the soil microcosms treated with 0,50 , and $200 \mu \mathrm{g}\left(\mathrm{NH}_{4}\right)_{2} \mathrm{SO}_{4}-\mathrm{N} / g . d . w . s .$, respectively.

The abundance of $\mathrm{AOB}$ and $\mathrm{AOA}$ amoA genes also varied within the soil microcosms amended with the different nitrogenous fertilizers. For the native soil, the bacterial and archaeal gene copy numbers were $1.34 \times 10^{8}$ and $1.12 \times 10^{8}$, respectively. After 27 days of incubation, the bacterial amo $A$ gene copy number increased with the application of 50, 100, and $200 \mu \mathrm{g}$ urea $\mathrm{N} / g . d . w . s$, as compared to the control treatment, while a decrease in the copy number was observed in microcosms treated with $400 \mu \mathrm{g}$ urea N/g.d.w.s. Similar results were observed for the copy numbers of the archaeal amoA genes, and a lower abundance of $1.87 \times 10^{7}$ was found in the soil microcosms that received the highest addition of $\mathrm{N}(400 \mu \mathrm{g}$ urea N/g.d.w.s.). As for the $\left(\mathrm{NH}_{4}\right)_{2} \mathrm{SO}_{4}$ treatment, the abundances of MOB, AOA and AOB appeared to remain constant over the course of the incubation (Figures 3B-D)

\section{RELATING METHANE AND AMMONIA OXIDATIONS WITH FUNCTIONAL GENE ABUNDANCES}

Regression analysis among the concentration of $\mathrm{CH}_{4}$ remained in the headspace, the amount of $\mathrm{NO}_{2}^{-}$and $\mathrm{NO}_{3}^{-}-\mathrm{N}$ and the copy number of $p m o A$ genes in the soil microcosms amended with urea and ammonium sulfate after 27 days of incubation were performed (Figure A1). Despite not being statistically significant $\left(R^{2}=0.484\right), \mathrm{CH}_{4}$ oxidation was positively correlated 

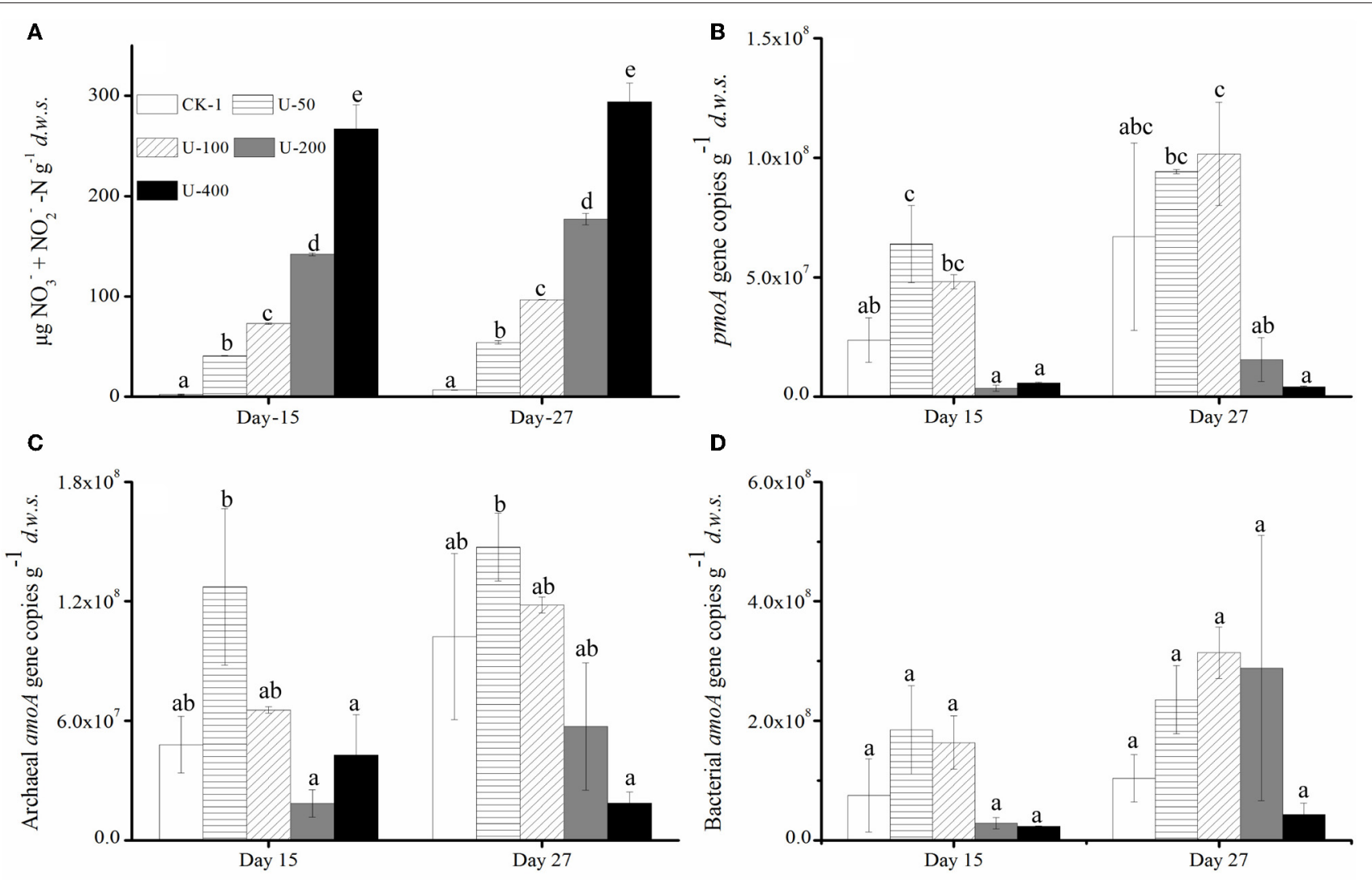

Incubation time (day)

FIGURE 2 | Changes in the concentrations of $\mathrm{NO}_{3}^{-}$and $\mathbf{N O}_{3}^{-}-\mathbf{N}(\mathbf{A})$ the abundances of the pmoA genes of the methane-oxidizing bacteria (B) and the amoA genes of the Archaea (C) and Bacteria (D) in the soil microcosms amended with urea. The designations are the same as in Figure 1. The error bars represent the standard deviation of the duplicate microcosms, and the same letter above the columns refers to no statistically significant difference among the treatments $(P>0.05)$. with pmoA gene copy number. For instance, soil microcosms containing 200 and $400 \mu \mathrm{g}$ urea N/g.d.w.s displayed a decreased pmoA gene copy number with lower $\mathrm{CH}_{4}$ oxidation rates after 27 days of incubation, as compared to the control treatment. Similar results were obtained for ammonium sulfate-amended treatment Interestingly, $\mathrm{CH}_{4}$ oxidation activity was significantly negatively correlated with the concentrations of $\mathrm{NO}_{2}^{-}$plus $\mathrm{NO}_{3}^{-}-\mathrm{N}$ in the presence of urea and/or ammonium sulfate $(\rho=-0.838)$, and the copy number of $p m o A$ genes was negatively correlated with the concentration of $\mathrm{NO}_{2}^{-}$plus $\mathrm{NO}_{3}^{-}-\mathrm{N}(\rho=-0.485)$. Moreover, the ratio of $\mathrm{AOA}$ to $\mathrm{AOB}$ was significantly positively correlated with $\mathrm{CH}_{4}$ oxidation activity $(\rho=0.57)$ but negatively correlated with the concentration of $\mathrm{NO}_{2}^{-}$plus $\mathrm{NO}_{3}^{-}-\mathrm{N}(\rho=-0.48)$.

\section{COMMUNITY COMPOSITIONS OF MOB, AOB, AND AOA}

Clone library of $p m o A$ genes was constructed, and phylogenetic analyses indicated contrasting changes of type I and II MOBs among the treatments (Figure 4). In total, 23 out of 41 sequences (up to 56\%) were classified as type I MOB, and the remaining 18 sequences were related to type II MOB. For the native soil sample, the ratio of type I to type II MOB was 0.75. After a 27-day incubation period, the ratios of type I to type II MOB were
$1.22,2.03,1.00$, and 2.45 for the U-0, U-400, AS-0, and AS-200 treatments, respectively. The type I MOB were affiliated with the Methylobacter, Methylomicrobium, Methylococcus and uncultured methanotrophic clones, whereas the type II clones were phylogenetically related to the Methylocystis and Methylosinus genera and uncultured clones.

The compositions of the AOB and AOA communities were revealed by DGGE fingerprinting analyses of the bacterial and archaeal amoA genes in duplicate microcosms for the urea and $\left(\mathrm{NH}_{4}\right)_{2} \mathrm{SO}_{4}$ treatments (Figures 5 and 6). Distinctly different DGGE fingerprints for the bacterial amoA genes were observed among the control treatment and the soil microcosms amended with different levels of nitrogenous fertilizers. Dominant AOB DGGE bands (1-10) were sequenced for phylogenetic analysis (Figure 7). Six DGGE bands (2-4 and 7-9) were affiliated with the Nitrosospira cluster 3 lineage, whereas bands 1 and 5 clustered with the taxonomically unclassified Nitrosospira sp. Nsp65 lineage. Additionally, DGGE bands 6 and 10 were related to Nitrosospira cluster 4. Comparisons of the DGGE patterns among the different treatments indicated that the relative intensities of DGGE bands 6 and 8 decreased upon the addition of higher levels of urea, whereas band 6 disappeared in the soil amended with 


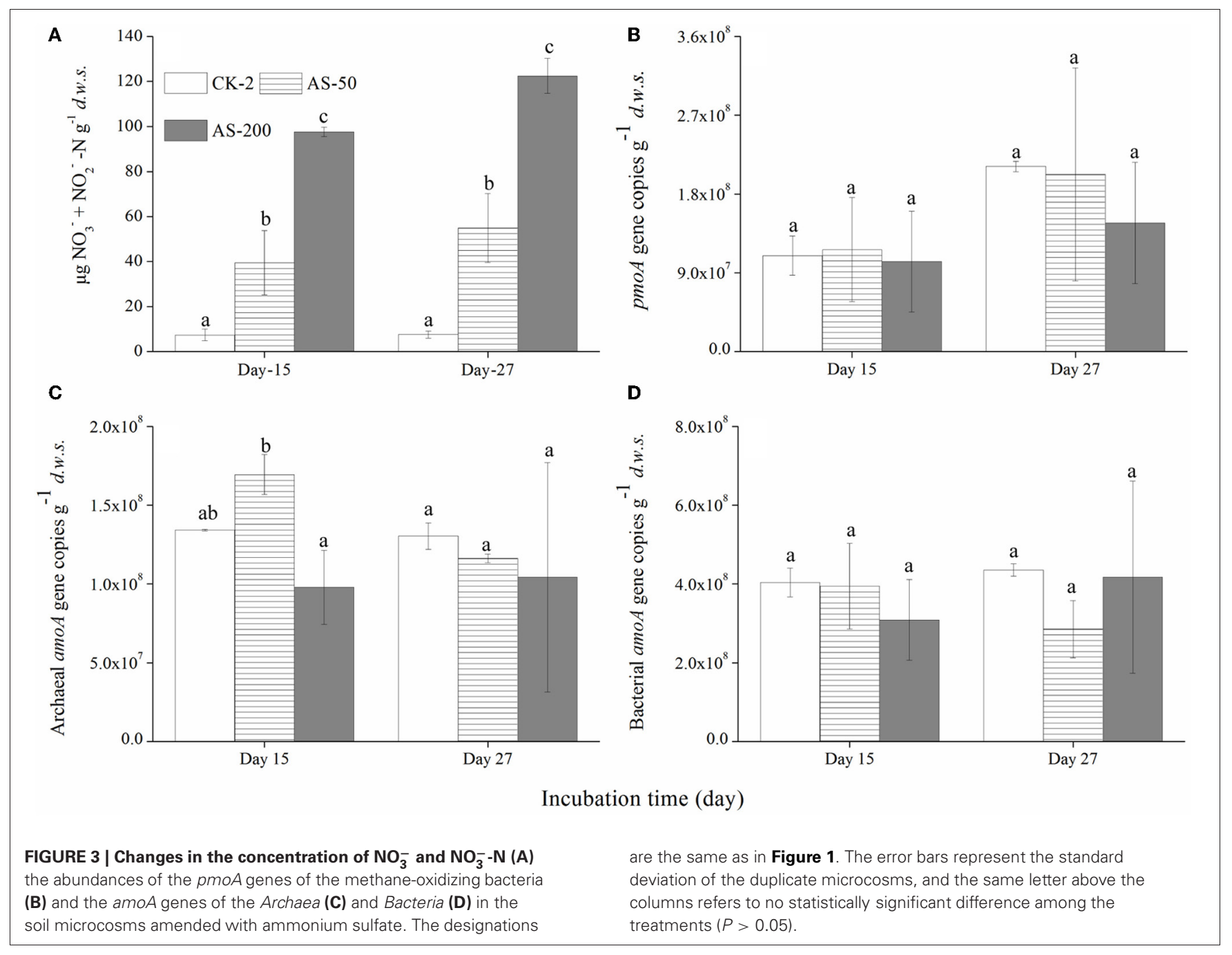

$200 \mu \mathrm{g}\left(\mathrm{NH}_{4}\right)_{2} \mathrm{SO}_{4} \mathrm{~N} /$ g.d.w.s. As for the AOA, 5 DGGE bands for the archaeal amoA gene were excised for sequencing (Figure 8). DGGE band 1 was either absent or the intensity of its band was lower in the soil microcosms treated with heavy fertilizations. Phylogenetic analyses indicated that all of the AOA sequences fall well within the soil group I.1b lineage.

\section{DISCUSSION}

\section{METHANE OXIDATION ACTIVITY}

The results of this study have revealed that $\mathrm{CH}_{4}$ oxidation activity in a paddy soil might be affected by nitrogenous fertilizations. $\mathrm{CH}_{4}$ oxidation was not significantly different among the microcosm treated with 0, 50 and $100 \mu$ g urea N/g.d.w.s. Similar results were observed for 0 and $50 \mu \mathrm{g}\left(\mathrm{NH}_{4}\right)_{2} \mathrm{SO}_{4}-\mathrm{N} / g . d . w . s$. , indicating that the ammonium fertilizer had no significant effect on $\mathrm{CH}_{4}$ oxidation. These observations are largely consistent with previous findings (Dunfield et al., 1995; Delgado and Mosier, 1996; Dan et al., 2001). However, 200 and $400 \mu \mathrm{g}$ urea N/g.d.w.s appeared to inhibit $\mathrm{CH}_{4}$ oxidation activity compared to other treatments. Interestingly, $200 \mu \mathrm{g}\left(\mathrm{NH}_{4}\right)_{2} \mathrm{SO}_{4}-\mathrm{N} /$ g.d.w.s. also inhibited $\mathrm{CH}_{4}$ oxidation. These findings are in agreement with those reported by (Steudler et al., 1989; King and Schnell, 1994; Bosse et al., 1993; Gulledge et al., 1997; Van der Nat et al., 1997). The main mechanism by which nitrogenous fertilizers inhibits $\mathrm{CH}_{4}$ oxidation is thought to be ammonia, which competes with $\mathrm{CH}_{4}$ for the methane monooxygenases in MOB. Even though the affinity of $\mathrm{MMO}$ for $\mathrm{CH}_{4}$ is 600-1300-fold higher than its affinity for ammonia, excessively high concentrations of ammonium are known to substantially inhibit $\mathrm{CH}_{4}$ oxidation (Be'dard and Knowles, 1989). The results of this study support this mechanism because the inhibition of $\mathrm{CH}_{4}$ oxidation appeared to be intensified with higher concentrations of ammonium.

In this study, ammonium-based fertilizers displayed either an inhibitory effect or no effect on $\mathrm{CH}_{4}$ oxidation, which was dependent on the concentration of the applied fertilizers. To the contrary, Bodelier and co-workers (2000a,b) have elegantly demonstrated a stimulation of $\mathrm{CH}_{4}$ oxidation by ammonium fertilization in paddy soils. This observation might result from the absence of inorganic nitrogen, which would lead to an inactive and most likely non-growing methanotrophic community. Thus, the addition of ammonium-based fertilizers would relieve the nitrogen-limiting conditions and stimulate $\mathrm{CH}_{4}$ oxidation 


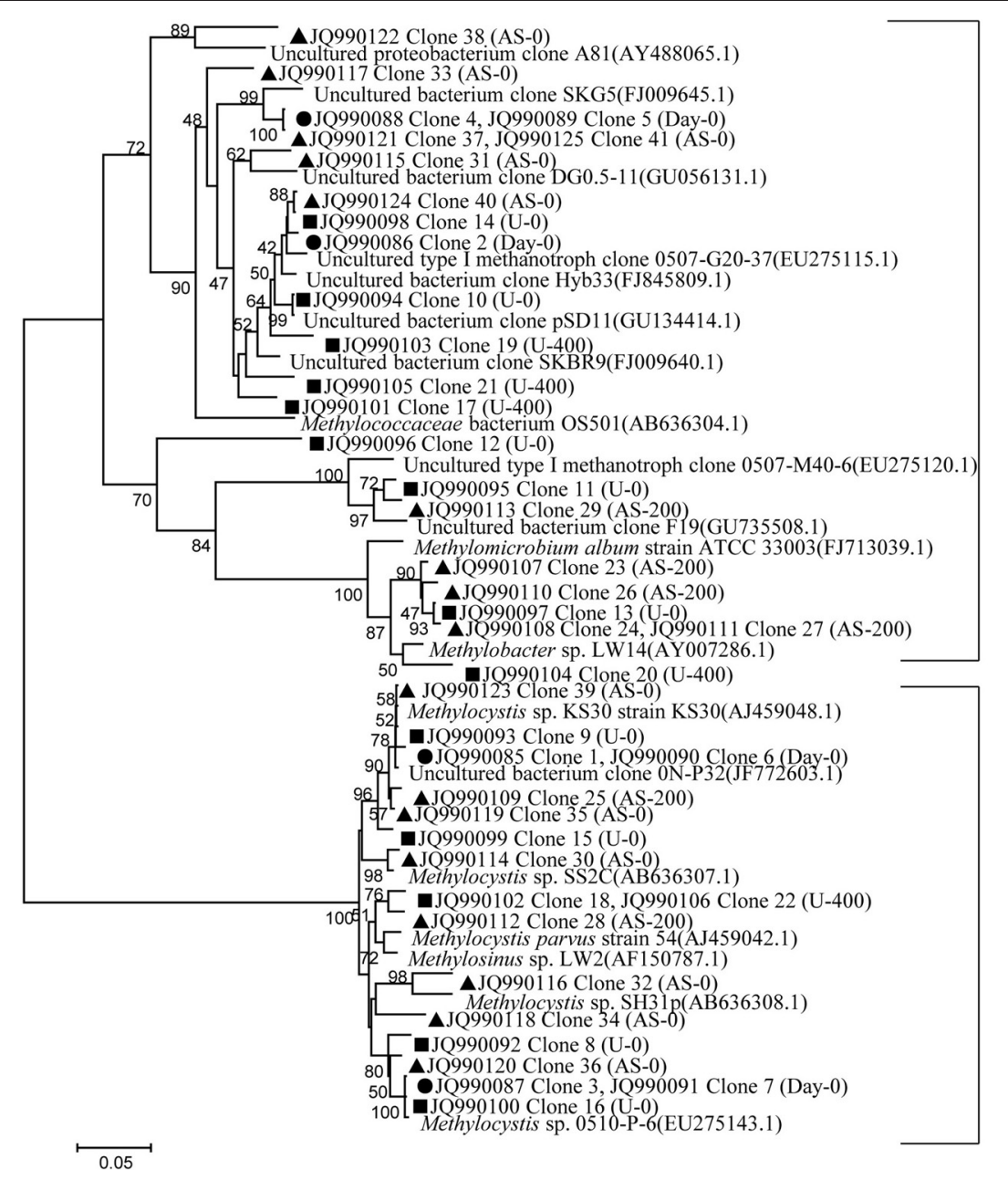

Type I

Type II

FIGURE 4 | Neighbor-joining tree showing the relationships of the pmoA genes retrieved from the clone library in this study to those in GenBank. The scale bar indicates 5 changes per 100 nucleotide positions. Bootstrap values (>40\%) are indicated at the branch points. $\bullet$ represents the native soil (day 0), and $\boldsymbol{\Delta}$ and $\mathbf{\square}$ represent the ammonium sulfate-and urea-amended soil microcosms, respectively. activity. It is likely that the soil used in this study was not constrained by the availability of $\mathrm{N}$ to support microbial growth. Therefore, the growth of methanotrophic communities was not restricted by the nitrogenous substrate, and no stimulation of $\mathrm{CH}_{4}$ oxidation activity was observed upon the addition of nitrogenous fertilizations. In addition to the soil's nitrogen status, our results also indicate a strong correlation between the concentration of the applied ammonium fertilizers and $\mathrm{CH}_{4}$ oxidation activity. Up to a certain concentration, ammonium-based fertilizers had no effect on $\mathrm{CH}_{4}$ oxidation; however, under higher concentrations, there was an inhibitory effect on the $\mathrm{CH}_{4}$ oxidation rate. $\mathrm{CH}_{4}$ oxidation in the paddy soils may have been inhibited when the concentration of urea/ $\left(\mathrm{NH}_{4}\right)_{2} \mathrm{SO}_{4}$ reached $200 \mu \mathrm{g} \mathrm{N} / g . d . w . s$ or above.

\section{NITRIFICATION ACTIVITY}

The nitrification activity responded positively to nitrogenous fertilizations. All the urea- and $\left(\mathrm{NH}_{4}\right)_{2} \mathrm{SO}_{4}$-treated microcosms displayed gradual increased productions of nitrate and nitrite over the incubation period upon the addition of nitrogenous fertilizers. Similar results have been reported by Avrahami et al. (2002) and Verhamme et al. (2011), that is, nitrification activity increased with increasing concentrations of ammonium in soil microcosms. Although a negative correlation between nitrification activity and $\mathrm{CH}_{4}$ oxidation activity was observed, it is interesting to note that the presence of $\mathrm{CH}_{4}$ appeared to have no adverse effect on nitrification activity in this study. We speculate that the stimulated nitrification activity might have led to a soil $\mathrm{pH}$ decline, as reported previously (Jia and Conrad, 2009). The acidification of the soil microcosms could have further inhibited $\mathrm{CH}_{4}$ oxidation activity by suppressing the growth of MOB in soil microcosms amended with higher concentrations of the nitrogenous fertilizers. In addition, the elevated concentrations of soil nitrate might have had an adverse effect on $\mathrm{CH}_{4}$ oxidation. Reay and Nedwell (2004) and Xu and Inubushi (2004) have shown a negative correlation between nitrate concentrations in soils and $\mathrm{CH}_{4}$ oxidation rates in coniferous and deciduous forest soils. However, the mechanism has yet to be determined. 

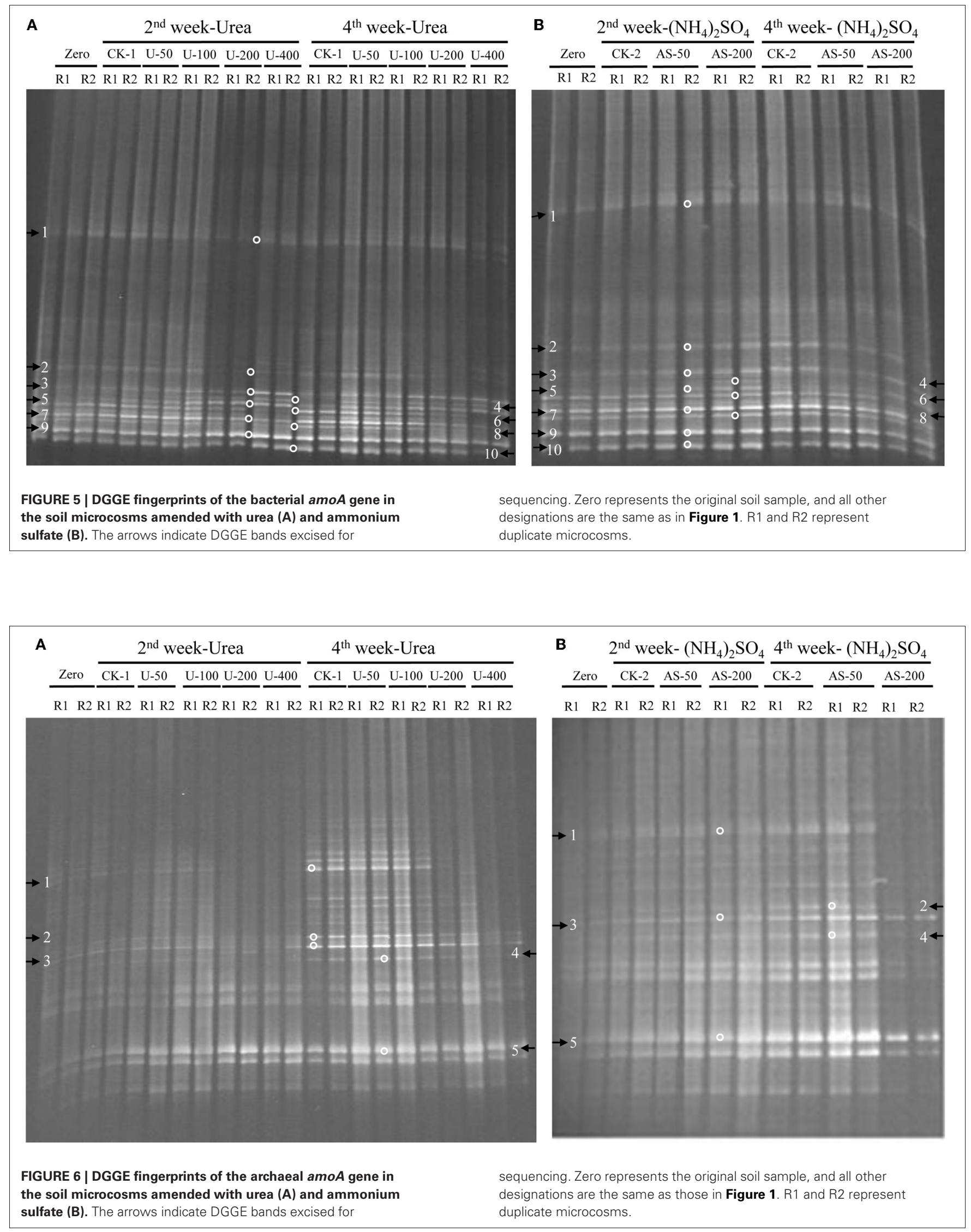


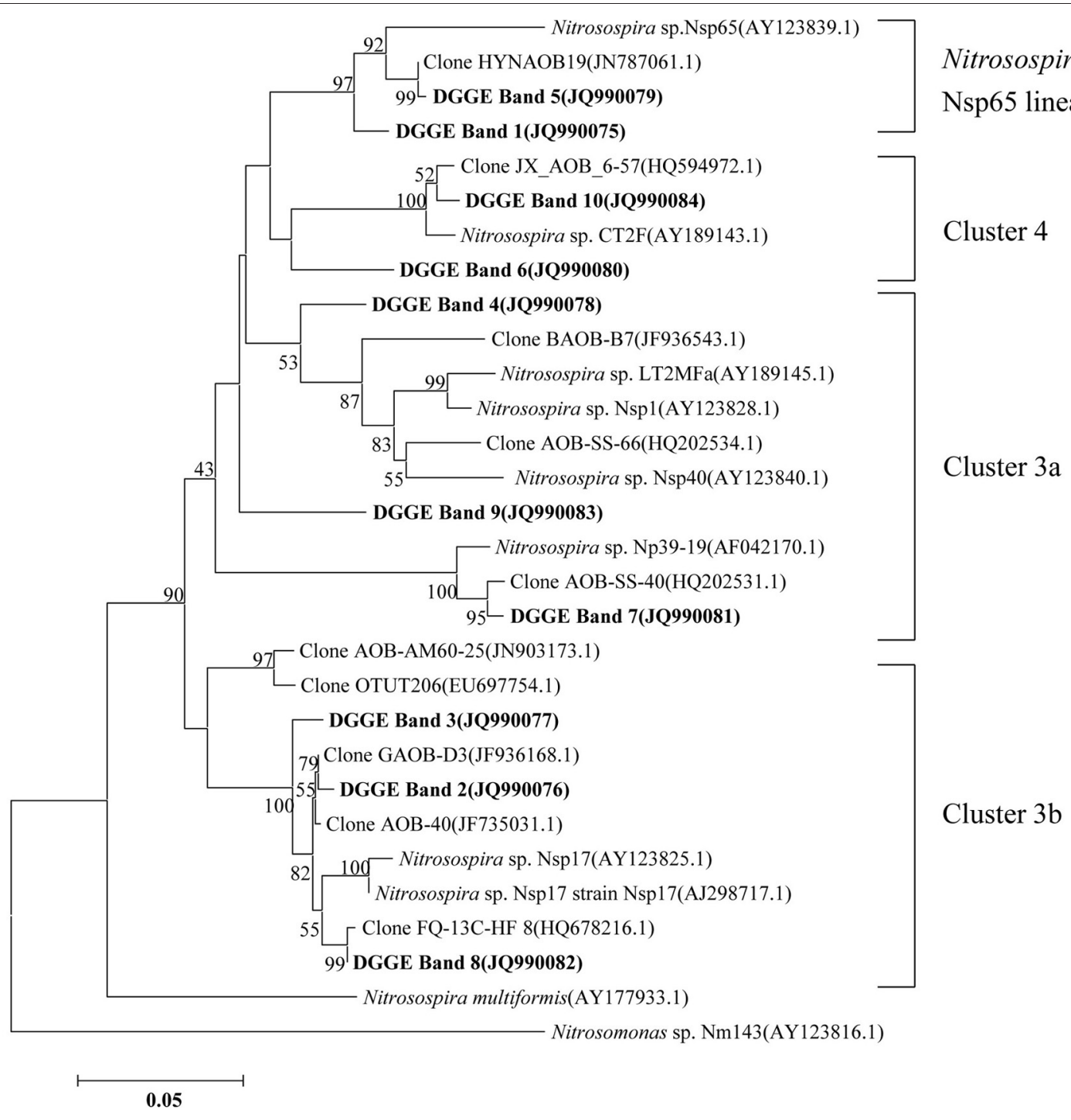

FIGURE 7 | Neighbor-joining tree showing the relationships of the bacterial amoA genes retrieved from the DGGE bands (bold) in this study to those in the GenBank. The scale bar indicates 5 changes per 100 nucleotide acid positions. Bootstrap values (>40\%) are indicated at branch points.

Several studies have suggested that cations associated with nitrate rather than nitrate itself are the main factors producing the inhibitory effect, but contrasting results have also been reported (Wang and Ineson, 2003). A comprehensive investigation of the microorganisms involved in nitrogen turnover, such as AOA and $\mathrm{AOB}$, would be helpful in better understanding the interactions between ammonia oxidation and $\mathrm{CH}_{4}$ consumption in paddy soil.

\section{ABUNDANCES OF MOB, AOB, AND AOA GENE COPY NUMBER}

Soil microcosms amended with 50 and $100 \mu \mathrm{g}$ urea N/g.d.w.s. displayed an increased abundance of pmoA gene copies while a low abundance was observed in microcosms treated with 200 and $400 \mu \mathrm{g}$ urea N/g.d.w.s. after 27 days of incubation, as compared to the control treatment. The $p m o A$ gene copy number was higher in 0 and $100 \mu \mathrm{g}$ ammonium sulfate N/g.d.w.s amended treatments compared to the $200 \mu \mathrm{g}$ ammonium sulfate $\mathrm{N} / g . d . w . s$ amended microcosms, where the $\mathrm{CH}_{4}$ oxidation rate was higher in the 0 and $50 \mu \mathrm{g}$ ammonium sulfate $\mathrm{N} / \mathrm{g} . d$.w.s than that of the $200 \mu \mathrm{g}$ ammonium sulfate $\mathrm{N} / \mathrm{g}$. d.w.s amended microcosm. This result suggests that this suppressed $\mathrm{CH}_{4}$ oxidation activity was most likely attributable to the low abundance of methanotrophic communities in the soil microcosms that received heavy fertilizations.

Despite the fact that an apparently low abundance was measured in soil microcosms treated with $400 \mu \mathrm{g}$ urea N/g.d.w.s. after a 27-day incubation, the bacterial amoA gene copy number was not significantly different among the microcosms treated with different levels of nitrogenous fertilizers. Similar results were obtained for the $\left(\mathrm{NH}_{4}\right)_{2} \mathrm{SO}_{4}$ treatments. As for the AOA, the archaeal amoA gene copy numbers remained largely unchanged irrespective of the urea and ammonium sulfate-N addition levels. 


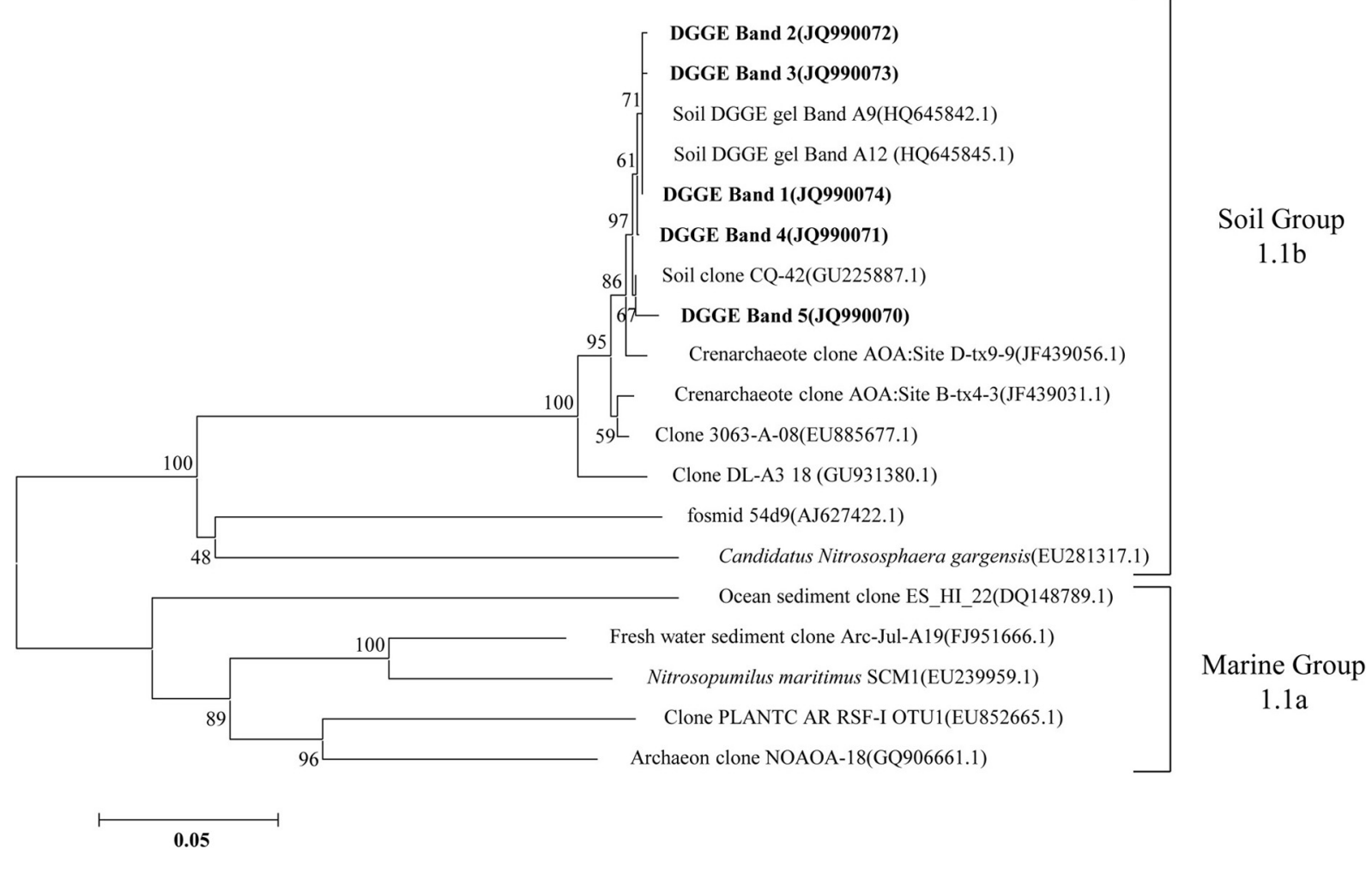

FIGURE 8 | Neighbor-joining tree showing the relationships of the archaeal amoA genes retrieved from the DGGE bands (bold) in this study to those in the GenBank. The scale bar indicates 5 changes per 100 nucleotide acid positions. Bootstrap values (>40\%) are indicated at branch points.

However, the treatment that received the highest $\mathrm{N}$ fertilizations of $400 \mu \mathrm{g}$ urea $\mathrm{N} /$ g.d.w.s. had relatively lower amoA gene copy numbers. This finding is in agreement with previous results using a German agricultural soil (Jia and Conrad, 2009), semi-arid and temperate grassland in China (Shen et al., 2011), and a grazed grassland soil treated with high doses of urine-N input in New Zealand (Di et al., 2010).

\section{COMMUNITY COMPOSITION OF MOB, AOB, AND AOA}

Distinct differences were found between the U-0 and U-400 treatments after four weeks of incubation, indicating that the MOB community was substantially altered upon the application of a higher amount of $\mathrm{N}$-fertilizer. The soil microcosm amended with ammonium sulfate also displayed relative changes of the MOB community compared with the control treatment. Our results indicate that the type I MOB related to the Methylobacter, Methylomicrobium, and Methylococcus genera were less abundant than the type II MOB in the native soils studied. However, a relative increase of the type $\mathrm{I}$ MOB was observed in the soil microcosms amended with nitrogenous fertilizers while the type II MOB appeared to be inhibited. This observation is consistent with findings from forest and rice field soils (Mohanty et al., 2006). This result could be an effect of a competition for $\mathrm{N}$ between the type I and type II MOB during the incubations. With respect to the effects of the nitrogenous fertilizers on $\mathrm{CH}_{4}$ consumption, it appears that no consistent patterns can be generalized (Mohanty et al., 2006). Currently, the established inhibition mechanisms of $\mathrm{CH}_{4}$ oxidation by ammonium application are that the type I MOB benefit significantly more from the presence of inorganic nitrogen than the type II MOB, possibly because of the ability of type II MOB to fix molecular nitrogen (Graham et al., 1993; Bodelier et al., 2000b; Bodelier and Laanbroek, 2004). The rapid response of the type I MOB to $\mathrm{N}$-addition may also be connected to nitrogen fixation, which is a capability that is widespread among MOB (Auman et al., 2001).

The effect of ammonium fertilizers on $\mathrm{CH}_{4}$ oxidation (stimulation or inhibition) obviously depends on the community's composition and, hence, on the biodiversity of the MOB present. Generally, it is assumed that $\mathrm{CH}_{4}$ consumption in a soil or sediment with a predominant type I MOB will not be affected by fertilizer application while $\mathrm{CH}_{4}$ uptake by a soil or sediment containing a predominant type II will be inhibited (Mohanty et al., 2006). Moreover, differentiation can also be expected within type I and II representatives. This scenario was clearly evident in the dominance of a specific type of MOB affiliated with Methylocella and Methylocystis in acid peat (Dedysh et al., 2001), a phylotype in association with Methylocystis and USC $\gamma$ in periodically water-saturated gleyic soils (Knief et al., 2006) and Methylomonas-like MOBs in lake sediments (Auman and Lidstrom, 2002; Eller et al., 2005). In this study, the native soil was clearly dominated by type II MOB, which could have very likely been inhibited by higher levels of ammonium fertilizer. 
The DGGE fingerprints of the bacterial amoA genes were altered by the addition of higher doses of nitrogenous fertilizers. A pairwise comparison of the DGGE patterns among the different treatments indicated that the relative intensities of DGGE bands 6 and 8 were significantly decreased within the soil microcosms containing higher levels of urea, whereas DGGE band 6 was absent in the soils that received $200 \mu \mathrm{g}\left(\mathrm{NH}_{4}\right)_{2} \mathrm{SO}_{4}$ $\mathrm{N} /$ g.d.w.s. Phylogenetic analyses indicated that DGGE band 6 was most closely affiliated with the Nitrosospira cluster 4 group while DGGE band 8 clustered with the Nistrosospira cluster $3 \mathrm{~b}$ group. We speculate that the AOB affiliated with DGGE bands 6 and 8 might not be the dominant ammonia oxidizers in the soils studied. It is very interesting to note that the dominant AOB DGGE bands were associated with Nistrosospira cluster 3 and the taxonomically unclassified Nitrosospira sp. Nsp65 lineage that could have been responsible for the stimulated nitrification activity observed in this study, which is consistent with the active ammonia oxidizers in an upland agricultural soil (Jia and Conrad, 2009). The interaction mechanisms between AOB and $\mathrm{MOB}$ remain unclear in a complex environment. For example, the contributions of $\mathrm{MOB}$ and $\mathrm{AOB}$ to ammonia oxidation and $\mathrm{CH}_{4}$ oxidation, respectively, and their possible interactions remain unresolved in complex environment (Bodelier, 2011). Furthermore, the discovery of AOA adds a new perspective to interactions between $\mathrm{CH}_{4}$ and ammonia oxidizers. AOA are very abundant and outnumber AOB in rice soils (Chen et al., 2008). However, it remains elusive as to whether $\mathrm{CH}_{4}$ oxidation could be affected by AOA in paddy soil and how AOA would compete with $\mathrm{MOB}$ for ammonium. Phylogenetic analyses demonstrated that archaeal ammonia oxidizers are dominated by AOA members within the soil Group I.1b. Although the DGGE fingerprints of the archaeal amoA genes displayed variations among the soil microcosms treated with different levels of nitrogenous fertilizers, such as DGGE band 1, this study provides no conclusive evidence

\section{REFERENCES}

Acton, S. D., and Baggs, E. M. (2011). Interactions between $\mathrm{N}$ application rate, $\mathrm{CH}_{4}$ oxidation and $\mathrm{N}_{2} \mathrm{O}$ production in soil. Biogeochemistry 103, 15-26.

Aronson, E. L., and Helliker, B. R. (2010). Methane flux in nonwetland soils in response to nitrogen addition: a meta-analysis. Ecology 91, 3242-3251.

Auman, A. J., and Lidstrom, M. E. (2002). Analysis of sMMOcontaining type I methanotrophs in Lake Washington sediment. Environ. Microbiol. 4, 517-524.

Auman, A. J., Speake, C. C., and Lidstrom, M. E. (2001). nifH sequences and nitrogen fixation in type I and type II methanotrophs. Appl. Environ. Microbiol. 67, 4009.

Avrahami, S., Conrad, R., and Braker, G. (2002). Effect of soil ammonium concentration on $\mathrm{N}_{2} \mathrm{O}$ release and on the community structure of ammonia oxidizers and denitrifiers.
Appl. Environ. Microbiol. 68, 5685-5692.

Be'dard, C., and Knowles, R. (1989). Physiology, biochemistry, and specific inhibitors of $\mathrm{CH}_{4}, \mathrm{NH}_{4}^{+}$, and $\mathrm{CO}$ oxidation by methanotrophs and nitrifiers. Microbiol. Rev. 53, 68-84.

Bodelier, P. L. E. (2011). Interactions between nitrogenous fertilizers and methane cycling in wetland and upland soils. Curr. Opin. Environ. Sustainability. 3, 379-388.

Bodelier, P. L. E., and Frenzel, P. (1999). Contribution of methanotrophic and nitrifying bacteria to $\mathrm{CH}_{4}$ and $\mathrm{NH}_{4}^{+}$oxidation in the rhizosphere of rice plants as determined by new methods of discrimination. Appl. Environ. Microbiol. 65, 1826-1833.

Bodelier, P. L. E., Hahn, A. P., Arth, I. R., and Frenzel, P. (2000a). Effects of ammonium based fertilisation on microbial processes involved in methane emission from soils

that $\mathrm{CH}_{4}$ oxidation is linked to the AOA. Methodological developments to differentiate $\mathrm{CH}_{4}$ oxidation from ammonia oxidation under in situ conditions will be crucial for answering this question (Bodelier and Frenzel, 1999). It has very recently been shown that $\mathrm{MOB}$ can switch from $\mathrm{CH}_{4}$ oxidation to ammonia oxidation upon fertilizer addition by using stable $\mathrm{C}$ and $\mathrm{N}$ isotope probing (Acton and Baggs, 2011).

\section{CONCLUSION}

Different levels of nitrogenous fertilizers can affect the $\mathrm{CH}_{4}$ oxidation activity as well as the abundance and composition of MOB. Inhibitory effects on $\mathrm{CH}_{4}$ oxidation were demonstrated in soil microcosms amended with $200 \mu \mathrm{g}$ urea N/g.d.w.s and above after 27 days of incubation. Similar results were obtained for ammonium sulfate-amended soil microcosms. The community structure of $\mathrm{MOB}$ changed in the soil microcosms amended with different levels of nitrogenous fertilizers. The native MOB in the background soil were dominated by type II; however, the addition of ammonium stimulated type I MOB. In addition, our study indicated strong nitrification in soil microcosms amended with nitrogenous fertilizers. Strong nitrification might lead to a $\mathrm{pH}$ decline, which may affect the niche differentiation of MOB. The interaction mechanisms among AOA, AOB, and MOB will require further investigation.

\section{ACKNOWLEDGMENTS}

This work was financially supported by the National Science Foundation of China (40971153 and 41090281), the Knowledge Innovation Programs of the Chinese Academy of Sciences (KSCX2-EW-G-16 and KZCX2-YW-BR-06). We thank two anonymous reviewers for constructive comments that improve the manuscript greatly. Mr. M. Saiful Alam received a doctoral fellowship from the Graduate University of Chinese Academy of Sciences and China Scholarship Council.

planted with rice. Biogeochemistry 51, 225-257.

Bodelier, P. L. E., Roslev, P., Henckel, T., and Frenzel, P. (2000b). Stimulation by ammonium-based fertilizers of methane oxidation in soil around rice roots. Nature 403, 421-424.

Bodelier, P. L. E., and Laanbroek, H. J. (2004). Nitrogen as a regulatory factor of methane oxidation in soils and sediments. FEMS Microbiol. Ecol. 47, 265-277.

Bosse, U., Frenzel, P., and Conrad, R. (1993). Inhibition of methane oxidation by ammonium in the surface layer of a littoral sediment. FEMS Microbiol. Ecol. 13, 123-134.

Chen, X. P., Zhu, Y. G., Xia, Y., Shen, J. P., and He, J. Z. (2008). Ammoniaoxidizing archaea: important players in paddy rhizosphere soil? Environ. Microbiol. 10, 1978-1987.

Conrad, R., (2004). "Methanogenic microbial communities associated with aquatic plants," in Plant Surface Microbiology, eds A. Varma, L.
Abbott, D. Werner, and R. Hampp (Berlin, Germany: Springer), 35-50.

Costello, A. M., and Lidstrom, M. E. (1999). Molecular characterization of functional and phylogenetic genes from natural populations of methanotrophs in lake sediments. Appl. Environ. Microbiol. 65, 5066-5074.

Crutzen, P. J. (1995). "The role of methane in atmospheric chemistry and climate," in Proceedings of the Eighth International Symposium on Ruminant Physiology, Ruminant Physiology: Digestion, Metabolism, Growth and Reproduction, eds W. Von Engelhardt, S. LeonhardMarek, G. Breves, and D. Giesecke (Stuttgart, Germany: Ferdinand Enke Verlag), 291-316.

Dan, J., Krüger, M., Frenzel, P., and Conrad, R. (2001). Effect of a late season urea fertilization on methane emission from a rice field in Italy. Agric. Ecosyst. Environ. 69, 69-80. 
Dedysh, S. N., Derakshani, M., and Liesack, W. (2001). Detection and enumeration of methanotrophs in acidic Sphagnum peat by $16 \mathrm{~S}$ rRNA fluorescence in situ hybridization, including the use of newly developed oligonucleotide probes for Methylocella palustris Appl. Environ. Microbiol. 67, 4850-4857.

Delgado, J. A., and Mosier, A. R. (1996). Mitigation alternatives to decrease nitrous oxides emissions and ureanitrogen loss and their effect on methane flux. J. Environ. Qual. 25, 1105-1111.

Di, H. J., Cameron, K. C., Shen, J. P., Winefield, C. S., O'Callaghan, M., Bowatte, S., and He, J. Z. (2010). Ammonia oxidizing bacteria and archaea grow under contrasting soil nitrogen conditions. FEMS Microbiol. Ecol. 72, 386-394.

Dunfield, P., and Knowles, R. (1995). Kinetics of inhibition of methane oxidation by nitrate, nitrite and ammonium in a humisol. Appl. Environ. Microbiol. 61, 3129-3135.

Dunfield, P. F., Topp, E., Archambault, C., and Knowles, R. (1995). Effect of nitrogen fertilizers and moisturecontent on $\mathrm{CH}_{4}$ and $\mathrm{N}_{2} \mathrm{O}$ fluxes in a humisol-measurements in the field and intact soil cores. Biogeochemistry 29, 199-222.

Eller, G., Deines, P., Grey, J., Richnow, H.-H., and Kruger, M. (2005). Methane cycling in lake sediments and its influence on chironomid larval $\delta^{13}$ C. FEMS Microbiol. Ecol. 54, 339-350.

Francis, C. A., Roberts, K. J., Beman, J. M., Santoro, A. E., and Oakley, B. B. (2005). Ubiquity and diversity of ammonia-oxidizing archaea in water columns and sediments of the ocean. Proc. Natl. Acad. Sci. U.S.A. 102, 14683-14688.

Graham, D. W., Chaudhary, J. A., Hanson, R. S., and Ranold, G. A. (1993). Factors affecting competition between type 1 and type 2 methanotrophs in two-organism, continuous-flow reactors. Microb. Ecol. 25, 1-17.

Griffiths, R. I., Whiteley, A. S., O'Donnell, A. G., and Bailey, M. J. (2000). Rapid method for coextraction of DNA and RNA from natural environments for analysis of ribosomal DNA- and rRNA-based microbial community composition. Appl. Environ. Microbiol. 66, 5488-5491.

Groot, T. T., VanBodegom, P. M., Harren, F. J. M., and Meijer, H. A. J. (2003). Quantification of methane oxidation in the rice rhizosphere using ${ }^{13} \mathrm{C}$-labelled methane. Biogeochemistry 64, 355-372.
Gulledge, J., Doyle, A. P., and Schimel, J. P. (1997). Different $\mathrm{NH}_{4}^{+}$inhibition patterns of soil $\mathrm{CH}_{4}$-oxidizer populations across sites. Soil Biol. Biochem. 29, 13-21.

Hanson, R. S., and Hanson, T. E. (1996). Methanotrophic bacteria. Microbiol. Rev. 60, 439-471.

Houghton, J. T., Ding, Y., Griggs, D. J., Noguer, M., Van der Linden, P. J., and Xiaosu, D. (eds.). (2001). Climate Change 2001: The Scientific Basis. Contribution of Working Group I to the Fourth Assessment Report of the Intergovernmental Panel on Climate Change. Cambridge: Cambridge University Press. IPCC, (2007). "Climate change 2007: the physical science basis," in Contribution of Working Group I to the Fourth Assessment Report of the Intergovernmental Panel on Climate Change, eds S. Solomon, D. Qin, M. Manning, Z. Chen, M. Marquis, K. B. Averyt, M. Tignor, and H. L. Miller (Cambridge, UK; New York, NY: Cambridge University Press), 996.

Jia, Z., and Conrad, R. (2009). Bacteria rather than Archaea dominate microbial ammonia oxidation in an agricultural soil. Environ. Microbiol. 11, 1658-1671.

Khush, G. S. (2005). What it will take to Feed 5.0 Billion Rice consumers in 2030. Plant Mol. Biol. 59, 1-6.

King, G. M., and Schnell, S. (1994). Effect of increasing atmospheric methane concentration on ammonium inhibition of soil methane consumption. Nature 370, 282-284.

Knief, C., Kolb, S., Bodelier, P. L. E., Lipski, A., and Dunfield, P. (2006). The active methanotrophic community in hydromorphic soils changes in response to changing methane concentration. Environ. Microbiol. 8, 321-333.

Krüger, M., Eller, G., Conrad, R., and Frenzel, P. (2002). Seasonal variation in pathways of $\mathrm{CH}_{4}$ oxidation in rice fields determined by stable carbon isotopes and specific inhibitors. Glob. Change Biol. 8, 265-280.

Krüger, M., and Frenzel, P. (2003). Effects of $\mathrm{N}$-fertilization on $\mathrm{CH}_{4}$ oxidation and production, and consequences for $\mathrm{CH}_{4}$ emissions from microcosms and rice fields. Glob. Change Biol. 9, 773-784.

Lelieveld, J., Crutzen, P. J., and Dentener, F. J. (1998). Changing concentrations, lifetime and climate forcing of atmospheric methane. Tellus 50B, 128-150.

Liu, D., Ding, W., Jia, Z., and Cai, Z. (2011). Relation between methanogenic archaea and methane production potential in selected natural wetland ecosystems across China. Biogeosciences 8, 329-338.

Mohanty, S. R., Bodelier, P. L. E., Floris, V., and Conrad, R. (2006). Differential effects of nitrogenous fertilizers on methane-consuming microbes in rice field and forest soils. Appl. Environ. Microbiol. 72, 1346-1354.

Nicolaisen, M. H., and Ramsing, N. B. (2002). Denaturing gradient gel electrophoresis (DGGE) approaches to study the diversity of ammoniaoxidizing bacteria. J. Microbiol. Methods 50, 189-203.

Reay, D. S., and Nedwell, D. B. (2004). Methane oxidation in temperate soils: effects of inorganic N. Soil Biol. Biochem. 36, 2059-2065.

Rigby, M., Prinn, R. G., Fraser, P. J., Simmonds, P. G., Langenfelds, R. L., Huang, J., Cunnold, D. M., Steele, L. P., Krummel, P. B., Weiss, R F., O'Doherty, S., Salameh, P. K., Wang, H. J., Harth, C. M., Muhle, J., and Porter, L. W. (2008). Renewed growth of atmospheric methane. Geophys. Res. Lett. 35, L22805.

Rodhe, H. (1990). A comparison of the contribution of various gases to the greenhouse effect. Science 248, 1217-1219.

Rotthauwe, J., Witzel, K., and Liesack, W. (1997). The ammonia monooxygenase structural gene amoA as a functional marker: molecular fine-scale analysis of natural ammonia-oxidizing populations. Appl. Environ. Microbiol. 63, 4704-4712.

Shen, X. Y., Zhang, L. M., Shen, J P., Li, L. H., Yuan, C. L., and He, J. Z. (2011). Nitrogen loading levels affect abundance and composition of soil ammonia oxidizing prokaryotes in semiarid temperate grassland. J. Soils Sediments 11, 1243-1252.

Steudler, P. A., Bowden, R. D., Mellilo, J. M., and Aber, J. D. (1989). Influence of nitrogen fertilization on methane uptake in temperate forest soil. Nature 341, 314-316.

Tamura, K., Dudley, J., Nei, M., and Kumar, S. (2007). MEGA4, molecular evolutionary genetics analysis (MEGA) software version 4.0. $\mathrm{Mol}$. Biol. Evol. 24, 1596-1599.

Thompson, J. D., Gibson, T. J., Plewniak, F., Jeanmougin, F., and Higgins, D. G. (1997). The CLUSTAL_X windows interface: flexible strategies for multiple sequence alignment aided by quality analysis tools. Nucleic Acids Res. 25, 4876-4882.

Van der Nat, F. J. W. A., DeBrouwer, J. F. C., Middelburg, J. J., and
Laanbroek, H. J. (1997). Spatial distribution and inhibition by ammonium of methane oxidation in intertidal freshwater marshes. Appl. Environ. Microbiol. 63, 4734-4740.

Verhamme, D. T., Prosser, J. I., and Nicol, G. W. (2011). Ammonia concentration determines differential growth of ammonia-oxidising archaea and bacteria in soil microcosms. ISME J. 5, 1067-1071.

Wang, J. S., Logan, J. A., McElroy, M. B., Duncan, B. N., Megretskaia, I. A., and Yantosca, R. M. (2004). A 3 $\mathrm{D}$ model analysis of the slowdown and interannual variability in the methane growth rate from 1988 to 1997 [Review]. Glob. Biogeochem. Cycles 18:B3011. doi:10.1029/2003 GB002180.

Wang, Z. P., and Ineson, P. (2003). Methane oxidation in a temperate coniferous forest soil: effects of inorganic N. Soil Biol. Biochem. 35, 427-433.

Wu, Y., Lu, L., Wang, B., Lin, X., Zhu, J., Cai, Z., Yan, X., and Jia, Z. (2011). Long-term field fertilization significantly alters the community structure of ammonia-oxidizing Bacteria rather than Archaea in a paddy soil. Soil Sci. Soc. Am. J. 75, 1431-1439.

Xu, X., and Inubushi, K. (2004). Effects of $\mathrm{N}$ sources and methane concentrations on methane uptake potential of a typical coniferous forest and its adjacent orchard soil. Biol. Fertil. Soils 40, 215-221.

Conflict of Interest Statement: The authors declare that the research was conducted in the absence of any commercial or financial relationships that could be construed as a potential conflict of interest.

Received: 15 November 2011; accepted: 18 June 2012; published online: 04 July 2012.

Citation: Alam MS and Jia Z (2012) Inhibition of methane oxidation by nitrogenous fertilizers in a paddy soil. Front. Microbio. 3:246. doi: 10.3389/ fmicb.2012.00246

This article was submitted to Frontiers in Terrestrial Microbiology, a specialty of Frontiers in Microbiology.

Copyright (c) 2012 Alam and Jia. This is an open-access article distributed under the terms of the Creative Commons Attribution License, which permits use, distribution and reproduction in other forums, provided the original authors and source are credited and subject to any copyright notices concerning any thirdparty graphics etc. 


\section{APPENDIX}
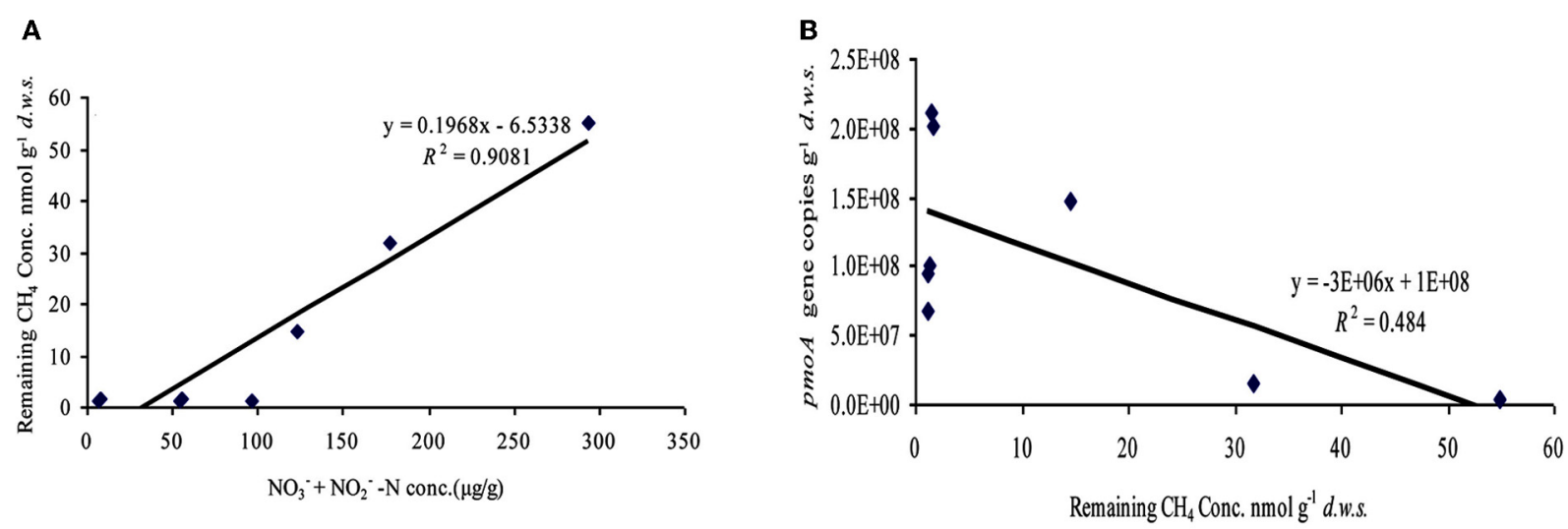

C

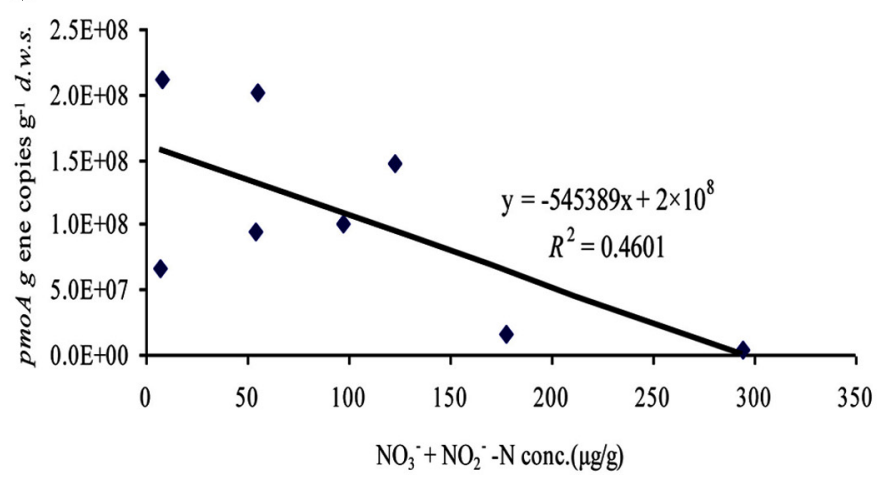

FIGURE A1 | Relationships among the concentration of $\mathrm{CH}_{4}$ remained in the headspace, the amount of $\mathrm{NO}_{2}^{-}$and $\mathrm{NO}_{3}^{-}-\mathrm{N}$ and the copy number of pmoA genes in the soil microcosms amended with urea and ammonium sulfate after $\mathbf{2 7}$ days of incubation. The black line is the linear regression line between two parameters. The $P$ values for panel (A) 0.001, (B) 0.055, and (C) 0.064 . 


\title{
Effects of nitrogen load on the function and diversity of methanotrophs in the littoral wetland of a boreal lake
}

\author{
Henri M. P. Siljanen ${ }^{1,2}{ }^{*}$, Anne Saari ${ }^{1}$, Levente Bodrossy ${ }^{3 \dagger}$ and Pertti J. Martikainen ${ }^{1}$ \\ ' Department of Environmental Science, University of Eastern Finland, Kuopio, Finland \\ ${ }^{2}$ Finnish Environment Institute, Kuopio, Finland \\ ${ }^{3}$ Department of Bioresources/Microbiology, Austrian Institute of Technology, Seibersdorf, Austria
}

\section{Edited by:}

Svetlana N. Dedysh, Russian

Academy of Sciences, Russia

\section{Reviewed by:}

Ingeborg Bussmann,

Alfred-Wegener-Institut, Germany

Yin Chen, University of Warwick, UK

\section{${ }^{*}$ Correspondence:}

Henri M. P. Siljanen, Department of

Environmental Science, University of

Eastern Finland, P. O. Box 1627,

Fl-70211 Kuopio, Finland.

e-mail: henri.siljanen@uef.fi

\section{${ }^{\dagger}$ Present address:}

Levente Bodrossy, National Research

Flagship, CSIRO Marine and

Atmospheric Research and Wealth

from Oceans, Hobart, TAS, Australia.
Methane is the second most abundant greenhouse gas in the atmosphere. A major part of the total methane emissions from lake ecosystems is emitted from littoral wetlands. Methane emissions are significantly reduced by methanotrophs, as they use methane as their sole energy and carbon source. Methanotrophic activity can be either activated or inhibited by nitrogen. However, the effects of nitrogen on methanotrophs in littoral wetlands are unknown. Here we report how nitrogen loading in situ affected the function and diversity of methanotrophs in a boreal littoral wetland. Methanotrophic community composition and functional diversity were analyzed with a particulate methane monooxygenase (pmoA) gene targeted microarray. Nitrogen load had no effects on methane oxidation potential and methane fluxes. Nitrogen load activated pmoA gene transcription of type I (Methylobacter, Methylomonas, and LW21-freshwater phylotypes) methanotrophs, but decreased the relative abundance of type II (Methylocystis, Methylosinus trichosporium, and Methylosinus phylotypes) methanotrophs. Hence, the overall activity of a methanotroph community in littoral wetlands is not affected by nitrogen leached from the catchment area.

Keywords: methane, littoral wetland, methanotrophs, nitrogen, pmoA gene, pmoA transcript, pmoA microarray

\section{INTRODUCTION}

Methane $\left(\mathrm{CH}_{4}\right)$ is the second most abundant greenhouse gas in the atmosphere after carbon dioxide. It is 25 times more efficient (with a time horizon of 100 years) as a greenhouse gas than carbon dioxide (Denman et al., 2007). It accounts for about $20 \%$ of the radiative forcing (warming effect) of the atmosphere (Denman et al., 2007). In oxic surface layers of wetlands, methanotrophs, which are aerobic methane oxidizing bacteria, can consume more than $90 \%$ of the $\mathrm{CH}_{4}$ produced in deeper anoxic layers (Oremland and Culbertson, 1992), implementing an important ecosystem service.

Taxonomically, methanotrophs belong to two phyla, Verrucomicrobia and Proteobacteria (Semrau et al., 2010). Verrucomicrobial methanotrophs have been shown to live only in extreme conditions in geothermal environments (Op den Camp et al., 2009), so they are not of particular interest to this study. Proteobacterial methanotrophs are divided into two classes, Gammaproteobacteria and Alphaproteobacteria (often referred to as type I and type II methanotrophs, respectively) on the basis of phylogeny, physiology, morphology, and biochemistry (Semrau et al., 2010). Type I methanotrophs are further divided into type Ia and type Ib subgroups based on their phylogeny (Bodrossy et al., 2003).

Methane mono-oxygenases (MMO) of methanotrophs are the key enzymes in the $\mathrm{CH}_{4}$ oxidation process, and the phylogeny of MMO genes corresponds well with 16S rRNA gene-based phylogeny. The gene fragments of the particulate form of MMO, $p m o A$, and soluble form of MMO, $m m o X$, can be used for the detection of a diversity of methanotrophs and their $\mathrm{CH}_{4}$ oxidation activity. Almost all methanotrophs possess the pmoA gene, and strains lacking it can be detected by $m m o X$-targeted approaches (Dedysh et al., 2005; Rahman et al., 2011; Vorobev et al., 2011). Most methanotrophs use only methane as their carbon and energy source, but some strains of Alphaproteobacteria methanotrophs have been shown to grow also with $\mathrm{C}_{2}$ substrates (Dedysh et al., 2005; Dunfield et al., 2010; Belova et al., 2011).

A littoral zone can contribute as much as $70 \%$ of the total $\mathrm{CH}_{4}$ emissions of lakes (Juutinen et al., 2003). Nitrogen (N) can either inhibit (Steudler et al., 1989) or stimulate (Bodelier et al., 2000) $\mathrm{CH}_{4}$ oxidation and subsequently cause higher or lower $\mathrm{CH}_{4}$ emissions. Both responses are possible in upland and wetland soils but the mechanisms behind the different effects are not fully understood (Bodelier and Laanbroek, 2004). Littoral wetlands, which are under the influence of the fluctuating water levels of lakes, are the target of $\mathrm{N}$ leached from the catchment. If $\mathrm{N}$ inhibits $\mathrm{CH}_{4}$ oxidation, the $\mathrm{CH}_{4}$ emissions from littoral wetlands can increase. However, the effects of nitrogen on the function and diversity of methanotrophs at the species level in littoral wetlands are unknown.

We studied the effects of experimental nitrogen loading in situ on the function and diversity of methanotrophs and fluxes of $\mathrm{CH}_{4}$ in a boreal littoral wetland during a growing season. The relative abundance of $p m o A$ genes and gene transcripts was examined with a pmoA targeting diagnostic microarray (Bodrossy et al., 2003).

\section{MATERIALS AND METHODS STUDY SITE}

The studied littoral wetland of the hypereutrophic Lake Kevätön is located in Eastern Finland $\left(63^{\circ} 6^{\prime} \mathrm{N}, 27^{\circ} 37^{\prime} \mathrm{E}\right)$. Since 
spatial variation contributes to the function and diversity of methanotrophs, six (three for $\mathrm{N}$ fertilization and three for control) study plots of $1.44 \mathrm{~m}^{2}$ were randomly established in the "intermediate" area of the wetland, i.e., in the area $7-10 \mathrm{~m}$ from the shoreline (Siljanen et al., 2011). This area has only minor spatial variation in hydrology and distribution of vegetation. The vegetation consists mainly of sedges and it did not vary among the study plots (variances were tested by the Kruskal Wallis rank sum test, $P>0.35$ ). The water level variation did not differ statistically significantly between the control and manipulated plots (Mixed model, $P>0.124 \ldots 0.421)$ although the N-treated plots had a slightly lower water table than the control plots (Figure A4 in Appendix).

\section{SOIL SAMPLING, NITROGEN LOAD, BIOGEOCHEMICAL ANALYSES, AND NUCLEIC ACID EXTRACTIONS FROM THE SOILS}

Soil samples were taken on June 7, July 7, and August 16, 2007 from triplicate nitrogen and control plots. Nitrogen treatment $\left(\mathrm{NH}_{4} \mathrm{NO}_{3}\right.$ dissolved in distilled $\mathrm{H}_{2} \mathrm{O}$, total dose $10 \mathrm{~g} \mathrm{~N} \mathrm{~m}^{-2}$, corresponds with $100 \mathrm{~kg} \mathrm{~N} \mathrm{ha}^{-1}$ ) was done four times during the 2007 growing season with 1 week intervals $\left(2.5 \mathrm{~g} \mathrm{~N} \mathrm{~m}^{-2}\right.$ each dose). Control plots received similar amounts of water (distilled $\mathrm{H}_{2} \mathrm{O}$ ) as the nitrogen treated plots. The first soil samples were taken 14 days before the first nitrogen dose. The second soil samples were taken 14 days after the start of the nitrogen loading, when 50\% $\left(5.0 \mathrm{~g} \mathrm{~N} \mathrm{~m}^{-2}\right)$ of the total nitrogen dose was applied (Figure A1 in Appendix). The last soil samples were collected 6 days after the nitrogen loading. Soil profiles were taken with a box corer (diameter $8 \mathrm{~cm} \times 8 \mathrm{~cm}$ ) from the plots and divided into 0-2, 210 , and $10-20 \mathrm{~cm}$ layers. Methane fluxes, $\mathrm{CH}_{4}$ oxidation potential, and soil chemical characteristics (nitrate and ammonium concentrations) were determined as described previously (Siljanen et al., 2011). From each soil layer, $15 \mathrm{ml}$ sub-samples were collected for molecular analyses of the methanotrophic community and were frozen immediately with dry ice at the study site. Soil was freeze-dried $\left(-50^{\circ} \mathrm{C}, 48 \mathrm{~h}\right)$. DNA extractions were performed as described previously (Siljanen et al., 2011). RNA extractions and clean-up were done according to a protocol described by Steenbergh et al. (2010) with minor modifications: contaminating DNA was removed according to the manufacturer's instructions with DNase I and cDNA synthesis with RevertAid MuLV-H reverse transcriptase, both provided by Fermentas.

\section{MOLECULAR ANALYSES OF METHANOTROPHS}

PCR products of $P m o A$ genes for microarray analysis were amplified with a semi-nested approach with reaction mixtures and cycling conditions, as described earlier (Siljanen et al., 2011). The primers used for the semi-nested approach were A189 (5'-GGNGACTGGGACTTCTGG-3'), A682T7 (5' -TAATACGACTCACTATAGGAASGCNGAGAAGAASGC$3^{\prime}$ ), and mb661-T7 (5' -TAATACGACTCACTATAGCCGGMGCAA CGTCYTTACC- $\left.3^{\prime}\right)$. The relative abundance of $p m o A$ genes and gene transcripts was examined with a $p m o A$ microarray as described previously (Bodrossy et al., 2003). The presence of Methylocella and Methylocella-like methanotrophs was determined with a PCR method (Rahman et al., 2011). For amplification, $2 \times$ Premix F (Epicentre), 1 unit of Taq polymerase (Invitrogen), and $50 \mathrm{ng}$ of template DNA or cDNA were used.
For amplification of $p m o A$ genes 25 pmol of each primer was used, and $40 \mathrm{pmol}$ of each primer was used for mmoX genes. Reactions were carried out in $50 \mu \mathrm{l}$ volume. The PCR cycling conditions for Methylocella primers were the following: denaturation $95^{\circ} \mathrm{C}, 15 \mathrm{~s}$, annealing $68^{\circ} \mathrm{C}, 1 \mathrm{~min}$, elongation $72^{\circ} \mathrm{C}, 1 \mathrm{~min}$ for 45 cycles. The primers used for Methylocella PCR were mmoXLF (5'-GAAGATTGGGGCGGCATCTG-3') and mmoXLR (5'-CCCAATCATCGCTGAAGGAGT-3'; Rahman et al., 2011). Cloned fragments of $m m o X$ genes of Methylocella palustris were used as a positive control for the assay. For analysis of the diversity of Methylocella methanotrophs, PCR products were ligated to a pDRIVE vector and cloned, as described previously (Siljanen et al., 2011). Clones were subjected to restriction fragment length polymorphism (RFLP). In RFLP analysis, DNA of clones was digested with SalI and BamHI restriction enzymes and restriction patterns were visualized with electrophoresis in a $2.5 \%(\mathrm{w} / \mathrm{v})$ agarose gel. Clones displaying identical restriction patterns were grouped into operational taxonomical units (OTUs). One to two clones per OTUs were sequenced. DNA sequencing was performed at the University of Eastern Finland Sequencing Laboratory with the MegaBACE 750 analysis system with a DYEnamic ${ }^{\text {TM}}$ ET Dye Terminator Cycle Sequencing Kit. The identity of clones was examined by BLASTn searches of the GenBank database (Altschul et al., 1990).

\section{STATISTICAL ANALYSIS}

The effects of the manipulation on $\mathrm{CH}_{4}$ fluxes, $\mathrm{CH}_{4}$ oxidation, and on the responses of community composition and functional diversity of methanotrophs at the species level were analyzed with a mixed-effect model (proportional to a repeated measure ANOVA; Laird and Ware, 1982). Amplification of pmoA genes for four cDNA replicates (10-20 cm layer, mainly clay with negligible $\mathrm{CH}_{4}$ oxidation potential) did not succeed even though re-extraction was performed. In these cases, duplicates instead of triplicates were used for the analysis. For evaluating the effect of nitrogen at the species level of methanotrophs, 1020 mixed-effect models were calculated, one model for both manipulated and control plots and for each of 85 microarray probes showing positive signals. Prior to the analysis, the microarray data were square-root transformed. The effects of nitrogen loading were evaluated with the difference between the models of the manipulated and control plots (see example of model results in Figure A3 in Appendix). The normality of residuals was tested for each variable group to fulfill the requirements of the analysis set-up. Mixed-effect model tests were done with the statistical program SPSS 17.0 (SPSS Inc., USA). The relation between the change in the methanotroph community (both community composition and functional diversity), $\mathrm{CH}_{4}$ oxidation and nitrogen load was studied with constrained correspondence analysis (CCA). CCA analyses were performed for those microarray probes showing change. The analysis included the probes Mb271, Mb C11-403, Mm531, MmES546, Ia 193, Ia 575, LW21-374, LW21-391, Ib453, Mcy233, Mcy413, Mcy264, Mcy459, Mcy255, McyM309, MsT214, Msi269, MsS314, Msi423, Msi294, and NMsiT-271. The probes targeting the RA14 group (probe RA14-591) and Methycapsa (probes B2all343, B2all341) were omitted from the analysis because of lack of hybridization to species-specific probes (RA14-594, B2-400). Constrained 


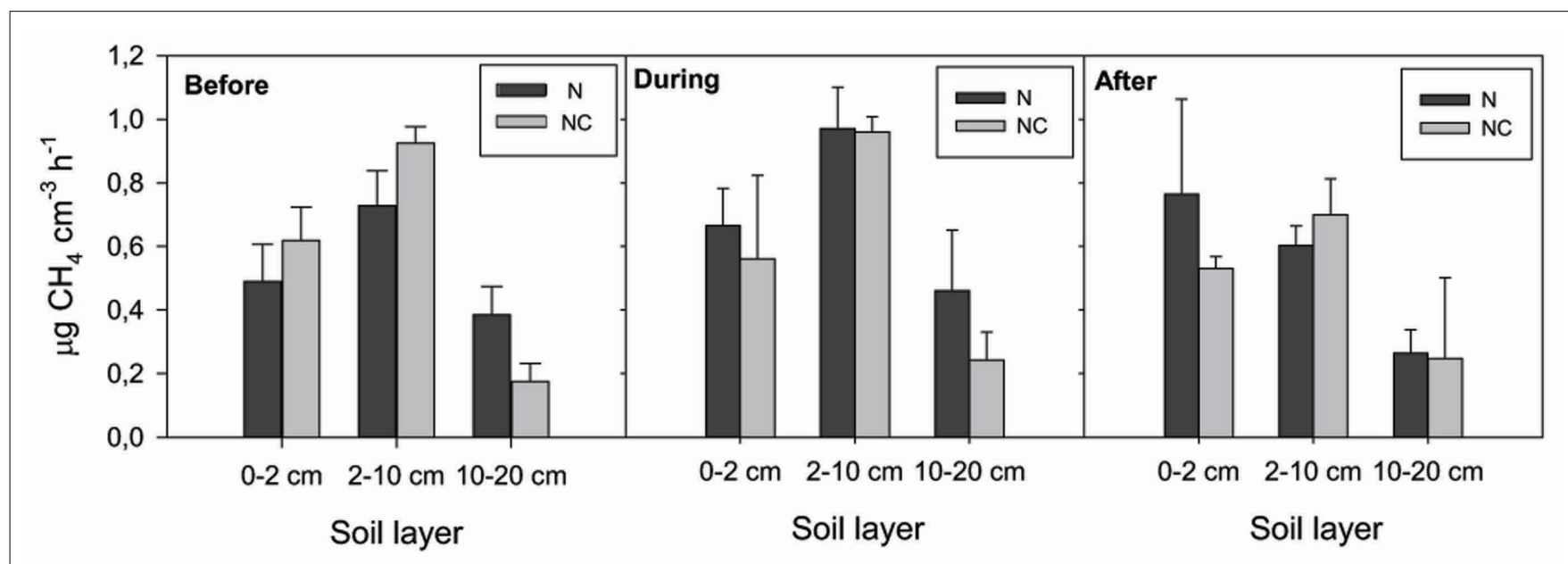

FIGURE 1 | Methane oxidation potential. N denotes nitrogen loading plots and NC control plots. Fixed effect of nitrogen load: $F_{0-2 \mathrm{~cm} \text { layer }}=0.105, P=0.762$; $F_{2-10 \mathrm{~cm} \text { layer }}=0.821, P=0.416 ; F_{10-20 \mathrm{~cm} \text { layer }}=2.035, P=0.227$.

correspondence analyses were conducted with the VEGAN (Oksanen et al., 2010) add-on package in the R 2.12.0 statistical program (R Development Core Team, 2010). The Pearson correlation coefficients between nitrate and ammonium concentrations, $\mathrm{CH}_{4}$ oxidation potential, and microarray data were also calculated with the R program.

\section{RESULTS \\ EFFECTS OF NITROGEN ON CH${ }_{4}$ OXIDATION AND $\mathrm{CH}_{4}$ FLUXES}

Nitrogen loading increased nitrate $\left(F_{\text {nitrate }}=12.792, P<0.005\right.$, maximum in loaded plots was $6 \mu \mathrm{g} \mathrm{NO}_{3}^{-}-\mathrm{N} \mathrm{cm}^{-3}$ ) concentration in the 0 - to $2-\mathrm{cm}$ soil layer (Figure A2 in Appendix). Ammonium concentration increased also slightly in this layer $\left(F_{\text {ammonium }}=4.366, P=0.059\right.$, the maximum in the loaded plots was $25 \mu \mathrm{g} \mathrm{NH}_{4}^{+}-\mathrm{N} \mathrm{cm}^{-3}$ ) as well as in the deeper layers $\left(2-10 \mathrm{~cm}\right.$ layer $F_{\text {ammonium }}=3.409, P=0.090 ; 10-20 \mathrm{~cm}$ layer $F_{\text {ammonium }}=3.825, P=0.076$; Figure $A 2$ in Appendix). Nitrogen load did not affect $\mathrm{CH}_{4}$ oxidation potential statistically significantly but $\mathrm{CH}_{4}$ oxidation increased during the experimental season in the 0 - to $2-\mathrm{cm}$ layer in both control and manipulated plots (Figure 1) as a result of changing environmental conditions (natural lowering in water table, Figure A4 in Appendix). Nitrogen loading had no significant effect also on the $\mathrm{CH}_{4}$ fluxes which decreased in both control and manipulated plots toward autumn as a result of the decrease in water level (Figure A4 in Appendix). The relative decrease in methane fluxes was higher in the $\mathrm{N}$-treated plots (Figure 2) also indicating that nitrogen load did not inhibit methane oxidation.

\section{EFFECTS OF NITROGEN ON THE METHANOTROPHIC COMMUNITY}

The methanotrophic community structure was close the same in the manipulated and control plots before nitrogen loading, only a few phylotypes showed some variation (14 days before fertilization started; Figure 3A). Nitrogen loading changed the community structure and functional diversity of methanotrophs as revealed by mixed-effect models (Figure 3A) and CCA analysis (Figures 3B-D). When the site had received $50 \%$ of the total

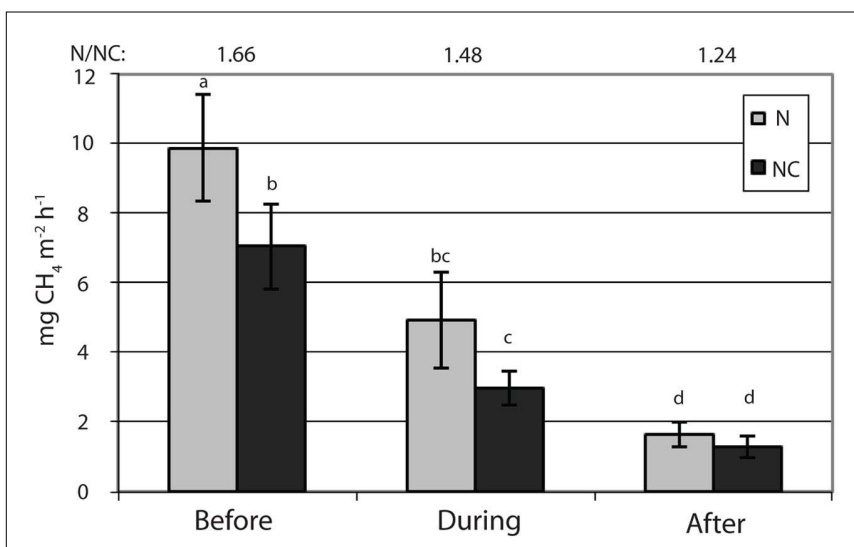

FIGURE 2 | Methane fluxes. $\mathrm{N}$ denotes nitrogen loading plots and NC control plots. Fixed effect of nitrogen load: $F=2.3, P=0.204$. Significant differences in fluxes are marked with letters $(P<0.05)$. The ratio of methane fluxes in the nitrogen loaded plots to those in the control plots are shown by numbers on top of the figure.

nitrogen load there was a decrease in the relative abundance of pmoA genes of type II (Methylocystis, Methylosinus trichosporium, and Methylosinus phylotypes, $P<0.05)$ methanotrophs in the 0 to $10-\mathrm{cm}$ soil layers (Figure 3A; Figure A3A in Appendix). There was also an increase in the relative abundance of $p m o A$ transcripts of type I (Methylobacter, Methylomonas, and LW21-freshwater phylotypes, $P<0.05$ ) methanotrophs in the 2 - to $10-\mathrm{cm}$ soil layer (Figure 3A; Figure A3B in Appendix). CCA multivariate ordination analysis revealed a correlation between the concentrations of ammonium and nitrate and microarray data measured during nitrogen loading in affected soil layers and gene pools, as samples during the experiment are clustered together with the ordinated arrows for ammonium and nitrate (Figures 3B-D). Manipulation had the strongest effect on the community in the 2 - to $10-\mathrm{cm}$ soil layer (Figures $3 \mathbf{C , D}$ ), and nitrate also had an effect on functional diversity after the experiment (Figure 3D). 


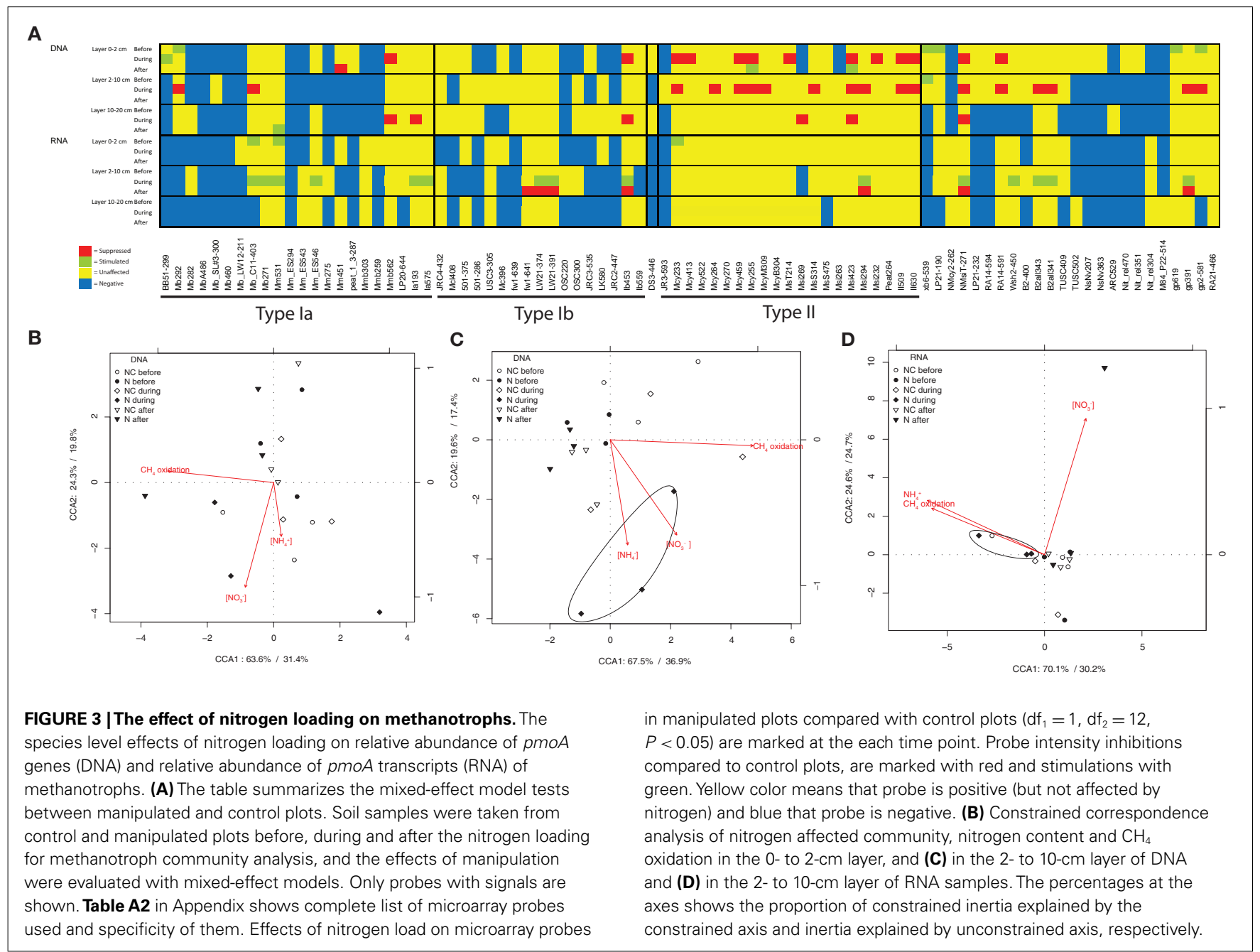

However, methanotrophic community also shows seasonal variation in the littoral wetland (Siljanen et al., 2012), and this variation was taken into account by comparing the nitrogen loading plots with non-treated control plots.

The effects of nitrogen loading on the methanotrophic community were also examined more deeply with correlation analysis for the relative abundance of $p m o A$ genes and gene transcripts (Table A1 in Appendix). The relative abundance of the $p m o A$ genes and gene transcripts of type I methanotrophs correlated positively with the content of ammonium and nitrate, while pmoA transcripts of type II methanotrophs correlated negatively with ammonium (Table A1 in Appendix). Across the experiment, type I and type II methanotrophs had opposite correlations with $\mathrm{CH}_{4}$ oxidation, suggesting differences in the reactions of the taxonomical groups to nitrogen (Table A1 in Appendix).

\section{DISCUSSION}

Methane fluxes declined similarly in the control and manipulated plots over the study period because of the decrease in water level toward autumn. Nitrogen load had no statistically significant effects on either $\mathrm{CH}_{4}$ oxidation potential or $\mathrm{CH}_{4}$ fluxes in the littoral wetland, suggesting that the overall activity

of methanotrophic communities there was not disturbed by nitrogen, although the methanotrophic community structure was affected. Similar observations on the tolerance of methane oxidation against nitrogen have been made previously in other soil types (Dunfield et al., 1995; Delgado and Mosier, 1996; Cai and Yan, 1999; Bykova et al., 2007).

As in our littoral wetland, nitrogen has been reported to inhibit type II methanotrophs in forest (Mohanty et al., 2006) and field soils (Cébron et al., 2007). The activity of type I methanotrophs was stimulated by nitrogen load in the present study as has been found in rice field soil (Bodelier et al., 2000; Mohanty et al., 2006; Noll et al., 2008; Shrestha et al., 2010) and in forest soil at high methane concentrations (Mohanty et al., 2006). Nitrogen leached from agricultural soils (Riley et al., 2001; Pare et al., 2006) to littoral wetlands evidently does not inhibit $\mathrm{CH}_{4}$ oxidation because methanotrophic communities there are dominated by type I methanotrophs (Siljanen et al., 2011).

In the littoral wetland, $p m o A$ gene transcription of type I methanotrophs was stimulated but not the relative abundance of these methanotrophs, indicating the existence of factors limiting the increase in their number. It can be that type I 
methanotrophs are nitrogen limited in the littoral wetland and subsequently stimulated by nitrogen load (see later) similarly to the rhizosphere of rice (Bodelier et al., 2000). Selective grazing by protists on type I methanotrophs (Murase and Frenzel, 2008) may be another reason for the lack of increase in their relative abundance.

It has been suggested that the inhibition of type II methanotrophs by nitrogen is due to competition between different types of methanotrophs (Cébron et al., 2007). In nitrogen-rich conditions, type I methanotrophs could outcompete type II methanotrophs. This can be associated to the better ability of type II methanotrophs to fix molecular nitrogen, which lowers their need for ammonium and nitrate (Murrell and Dalton, 1983). Thus, type I methanotrophs can increase their $\mathrm{CH}_{4}$ oxidation activity by nitrogen addition in nitrogen-limited environments. Biomass production of wetland plants in the littoral wetland studied is high (Larmola et al., 2003) causing high demand for nitrogen, and nitrogen can also be efficiently removed by denitrification in wetland. Competition for nitrogen there is thus high.

A similar inhibitory effect of nitrogen on type II methanotrophs, as in the littoral wetland here, has been detected among Methylocystis methanotrophs (Mohanty et al., 2006; Cébron et al., 2007). In the littoral wetland, Methylosinus and M. trichosporium methanotrophs were also inhibited (Figure 3A). However, nitrogen loading increased the relative abundance of $p m o A$ transcripts of one Methylosinus phylotype (Msi294). The results of the present study support the findings that nitrogen can reduce $\mathrm{CH}_{4}$ oxidation if type II methanotrophs dominate the methanotrophic community (Mohanty et al., 2006).

Since the microarray method depicts the relative abundance in methanotrophic communities, a change in the relative abundance of type II methanotrophs could be a result either of an increase in the relative abundance of type I methanotrophs over type II methanotrophs, or a decrease in the relative abundance of type II methanotrophs. However, microarray data indicated no distinctive co-increase of type I methanotrophs during the experiment when inhibition of type II methanotrophs took place (Figure A3A in Appendix), suggesting that type II methanotrophs have been inhibited by nitrogen load as such, not through competition between type I and type II methanotrophs. However, it is important to note that the methanotrophic community of the littoral wetland reacted rapidly to nitrogen load and acclimated to the prevailing conditions. The shift in the methanotroph community took place within 14 days after the start of the nitrogen loading, and the community recovered soon after the loading ended (Figure 3A). This reveals the ability of methanotrophic community in the littoral wetland to withstand environmental changes and perturbations.

\section{REFERENCES}

Altschul, S. F., Gish, W., Miller, W., Myers, E. W., and Lipman, D. J. (1990). Basic local alignment search tool. J. Mol. Biol. 215, 403-410.

Belova, S. E., Baani, M., Suzina, N. E., Bodelier, P. L. E., Liesack, W., and

The semi-nested PCR approach and microarray probe set-up targeted type I and type II methanotrophs as well as RA14 members of upland soil cluster $\alpha$ (USC $\alpha$ ) methanotrophs and Methylocapsa methanotrophs but excluded Crenothrix, Methylocella, and Verrucomicrobia methanotrophs. However, it was proven by analysis of A682 PCR products with the pmoA microarray (detects Crenothrix, Siljanen et al., 2011) that Crenothrix methanotrophs were not present in that part of the wetland studied here (data not shown). Thus, Crenothrix may play a role in littoral wetlands but only in the areas with a higher water table than that in the area used in this study (Siljanen et al., 2011). Methylocella specific primers mmoXLF/R (Rahman et al., 2011) showed only a few negligible and very faint products from DNA samples and none from RNA samples. Therefore, although Methylocella methanotrophs are found in the littoral wetland, they play only a limited role in the $\mathrm{CH}_{4}$ oxidation.

The studied littoral wetland has a moderately high diversity of methanotrophs: 47 OTUs with $93 \%$ similarity (Siljanen et al., 2011), compared with other environments: 26 OTUs in temperate forest soils, 93\% similarity (Degelmann et al., 2010), and about 35 OTUs, $90 \%$ similarity, in rice field soils (Lüke et al., 2010). Since the sub-communities of this diverse community in the littoral wetland react differently to nitrogen load, the overall effect of nitrogen loading was neutral, causing no change in $\mathrm{CH}_{4}$ oxidation potential or $\mathrm{CH}_{4}$ fluxes.

There are only a few studies where the effects of nitrogen on $\mathrm{CH}_{4}$ fluxes and the methanotrophic community composition in situ have been studied simultaneously. Previous studies have investigated the effects of nitrogen load on the functioning and diversity of methanotrophs using microcosms and incubation experiments (Bodelier et al., 2000; Mohanty et al., 2006; Cébron et al., 2007; Noll et al., 2008; Shrestha et al., 2010). Here we provide new insights into how the nitrogen load affects the methanotrophic community and its functioning in situ.

In conclusion, methane oxidation in boreal littoral wetland tolerates nitrogen load as a result of diverse methanotrophic community. Although some methanotrophs are suffered by nitrogen, there are methanotrophs responding positively to extra nitrogen.

\section{ACKNOWLEDGEMENTS}

We thank S. Hämäläinen, K. Martikainen, T. Rahkonen, N. Partanen, R. Laroma, N. Stralis-Pavese, and G. C. J. Abell for technical assistance, and V. Paganuzzi for comments on the language of the manuscript. The academy of Finland (ESF and EuroDIVERSITYMETHECO), the Maj and Tor Nessling Foundation, the Niemi Foundation, Maa-ja vesitekniikan tuki association, and the Kone Foundation are acknowledged for financial support. Research at AIT was supported by the ESF EuroDiversity program METHECO (No. FP018, local funding agencies: FWF, Austria, project number I40-B06).

sediments. FEMS Microbiol. Ecol. 47, 265-277.

tion as a survival strategy of peat inhabiting Methylocystis spp. Environ. Microbiol. Rep. 3, 36-46.

Bodelier, P. L. E., and Laanbroek, H. J. (2004). Nitrogen as a regulatory factor of methane oxidation in soils and
Bodelier, P. L. E., Roslev, P., Henckel, T., and Frenzel, P. (2000). Stimulation by ammonium-based fertilizers of methane oxidation in soil around rice roots. Nature 403, 421-424.
Bodrossy, L., Stralis-Pavese, N., Murrell, J. C., Radajewski, S., Weilharter, A., and Sessitsch, A. (2003). Development and validation of a diagnostic microbial microarray for methanotrophs. Environ. Microbiol. 5, 566-582. 
Bykova, S., Boeckx, P., Kravchenko, I., Galchenko, V., and Van Cleemput, O. (2007). Response of CH4 oxidation and methanotrophic diversity to $\mathrm{NH} 4+$ and $\mathrm{CH} 4$ mixing ratios. Biol. Fertil. Soils 43, 341-348.

Cai, Z. C., and Yan, X. Y. (1999). Kinetic model for methane oxidation by paddy soil as affected by temperature, moisture and $\mathrm{N}$ addition. Soil Biol. Biochem. 31, 715-725.

Cébron, A., Bodrossy, L., Stralis-Pavese, N., Singer, A. C., Thompson, I. P., Prosser, J. I., and Murrell, J. C. (2007). Nutrient amendments in soil DNA stable isotope probing experiments reduce the observed methanotroph diversity. Appl. Environ. Microbiol. 73, 798-807.

Dedysh, S. N., Knief, C., and Dunfield, P. F. (2005). Methylocella species are facultatively methanotrophic. Environ. Microbiol. 187, 4665-4670.

Degelmann, D. M., Borken, W., Drake, H. L., and Kolb, S. (2010). Different atmospheric methane-oxidizing communities in European beech and Norway spruce soils. Appl. Environ. Microbiol. 76, 3228-3235.

Delgado, J. A., and Mosier, A. R. (1996). Mitigation alternatives to decrease nitrous oxides emissions and ureanitrogen loss and their effect on methane flux. J. Environ. Qual. 25, 1105-1111.

Denman, K. L., Brasseur, G., Chidthaisong, A., Ciais, P., Cox, P. M., Dickinson, R. E., Hauglustaine, D., Heinze, C., Holland, E., Jacob, D., Lohmann, U., Ramachandran, S., da Silva Dias, P. L., Wofsy, S. C., and Zhang, X. (2007). "Couplings between changes in the climate system and biogeochemistry," in Climate Change 2007: The Physical Science Basis. Contribution of Working Group I to the Fourth Assessment Report of the Intergovernmental Panel on Climate Change, eds S. Solomon, D. Qin, M. Manning, Z. Chen, M. Marquis, K. B. Averyt, M. Tignor, and H. L. Miller (Cambridge: Cambridge University Press), 500-587.

Dunfield, P. F., Belova, S. E., Vorob'ev, A. V., Cornish, S. L., and Dedysh, S. N. (2010). Methylocapsa aurea sp. nov., a facultatively methanotrophic bacterium possessing a particulate methane monooxygenase. Int
J. Syst. Evol. Microbiol. 60, 2659-2664.

Dunfield, P. F., Topp, E., Archambault, C., and Knowles, R. (1995). Effect of nitrogen fertilizers and moisturecontent on $\mathrm{CH} 4$ and $\mathrm{N} 2 \mathrm{O}$ fluxes in a humisol-measurements in the field and intact soil cores. Biogeochemistry 29, 199-222.

Juutinen, S., Alm, J., Larmola, T., Huttunen, J. T., Morero, M., Martikainen, P. J., and Silvola, J. (2003). Major implication of the littoral zone for methane release from boreal lakes. Global Biogeochem. Cycles 17, 1117.

Laird, N. M., and Ware, J. H. (1982). Random-effects models for longitudinal data. Biometrics 38, 963-974.

Larmola, T., Alm, J., Juutinen, S., Martikainen, P. J., and Silvola, J. (2003). Ecosystem $\mathrm{CO} 2$ exchange and plant biomass in the littoral zone of a boreal eutrophic lake. Freshw. Biol. 48, 1295-1310.

Lüke, C., Krause, S., Cavigiolo, S., Greppi, D., Lupotto, E., and Frenzel, P. (2010). Biogeography of wetland rice methanotrophs. Environ. Microbiol. 12, 862-872.

Mohanty, S. R., Bodelier, P. L. E., Floris, V., and Conrad, R. (2006). Differential effects of nitrogenous fertilizers on methane consuming microbes in rice field and forest soils. Appl. Environ. Microbiol. 72, 1346-1354.

Murase, J., and Frenzel, P. (2008). Selective grazing of methanotrophs by protozoa in a rice field soil. FEMS Microbiol. Ecol. 65, 408-414.

Murrell, J. C., and Dalton, H. (1983). Nitrogen fixation in obligate methanotrophs. J. Gen. Microbiol. 129, 3481-3486.

Noll, M., Frenzel, P., and Conrad, R. (2008). Selective stimulation of type I methanotrophs in a rice paddy soil by urea fertilization revealed by RNA-based stable isotope probing. FEMS Microbiol. Ecol. 65, 125-132.

Oksanen, J., Blanchet, F. G., Kindt, R., Legendre, P., O’Hara, R. B., Simpson, G. L., Solymos, P., Stevens, M. H. H., and Wagner, H. (2010). vegan: Community Ecology Package. $R$ package version 1.17-4. Available at: http://CRAN.R-project.org/ package $=$ vegan

Op den Camp, H. J. M., Islam, T., Stott, M. B., Harhangi, H. R., Hynes,
A., Schouten, S., Jetten, M. S. M., Birkeland, N. K., Pol, A., and Dunfield, P. F. (2009). Environmental genomic and taxonomic perspectives on methanotrophic Verrucomicrobia. Environ. Microbiol. Rep. 1, 293-306.

Oremland, R. S., and Culbertson, C. W. (1992). Importance of methaneoxidizing bacteria in the methane budget as revealed by the use of specific inhibitor. Nature 356, 421-423.

Pare, K., Chantigny, M. H., Carey, K., Johnston, W. J., and Dionne, J. (2006). Nitrogen uptake and leaching under annual bluegrass ecotypes and bentgrass species: a lysimeter experiment. Crop Sci. 46 , 847-853.

R Development Core Team. (2010). $R$ : A language and environment for statistical Computing 2.12.0. Vienna: $\mathrm{R}$ Foundation for Statistical Computing. Available at: http://www.R-project.org

Rahman, M. T., Crombie, A., Chen, Y. Stralis-Pavese, N., Bodrossy, L., Meir, P., McNamara, N. P., and Murrell, J. C. (2011). Environmental distribution and abundance of the facultative methanotroph Methylocella. ISME J 5, 1061-1066.

Riley, W. J., Ortiz-Monasterio, I., and Matson, P. A. (2001). Nitrogen leaching and soil nitrate, nitrite, and ammonium levels under irrigated wheat in Northern Mexico. Nutr. Cycl. Agroecosys. 61, 223-236.

Semrau, J. D., DiSpirito, A. A., and Yoon, S. (2010). Methanotrophs and copper. FEMS Microbiol. Rev. 34, 496-531.

Shrestha, M., Shrestha, P. M., Frenzel, P., and Conrad, R. (2010). Effect of nitrogen fertilization on methane oxidation, abundance, community structure, and gene expression of methanotrophs in the rice rhizosphere. ISME J. 4, 1545-1556.

Siljanen, H. M. P., Saari, A., Bodrossy, L. and Martikainen, P. J. (2012). Seasonal variation in the function and diversity of methanotrophs in the littoral wetland of a boreal eutrophic lake. FEMS Microbiol. Ecol. (in press).

Siljanen, H. M. P., Saari, A., Krause, S. Lensu, A., Abell, G. C. J., Bodrossy, L., Bodelier, P. L. E., and Martikainen, P. J. (2011). Hydrology is reflected in the functioning and community composition of methanotrophs in the littoral wetland of a boreal lake. FEMS Microbiol. Ecol. 75, 430-445.

Steenbergh, A. K., Meima, M. M., Kamst, M., and Bodelier, P. L. E. (2010). Biphasic kinetics of a methanotrophic community is a combination of growth and increased activity per cell. FEMS Microbiol. Ecol. 71, 12-22.

Steudler, P. A., Bowden, R. D., Melillo, J. M., and Aber, J. D. (1989). Influence of nitrogen fertilization on methane uptake in temperate forest soils. Nature 341, 314-316.

Vorobev, A. V., Baani, M., Doronina, N. V., Brady, A. L., Liesack, W., Dunfield, P. F., and Dedysh, S. N. (2011). Methyloferula stalleta gen. nov., sp. nov., and acidophilic, obligately methanotrophic bacterium possessing only a soluble methane monooxygenase. Int. J. Syst. Evol. Microbiol. 61, 2456-2463

Conflict of Interest Statement: The authors declare that the research was conducted in the absence of any commercial or financial relationships that could be construed as a potential conflict of interest. Nucleotide sequence accession numbers: sequences from this study are under Accession numbers HE653916-HE653917 in the EMBLbank.

Received: 25 November 2011; accepted: 24 January 2012; published online: 20 February 2012.

Citation: Siljanen HMP, Saari A, Bodrossy $L$ and Martikainen PJ (2012) Effects of nitrogen load on the function and diversity of methanotrophs in the littoral wetland of a boreal lake. Front. Microbio. 3:39. doi: 10.3389/fmicb.2012.00039

This article was submitted to Frontiers in Terrestrial Microbiology, a specialty of Frontiers in Microbiology.

Copyright (C) 2012 Siljanen, Saari, Bodrossy and Martikainen. This is an open-access article distributed under the terms of the Creative Commons Attribution Non Commercial License, which permits non-commercial use, distribution, and reproduction in other forums, provided the original authors and source are credited. 


\section{APPENDIX}

Table A1 | Pearson correlation co-efficients across the experiment between methanotroph relative abundance of pmoA genes/pmoA transcripts, $\mathrm{CH}_{4}$ oxidation potential, and concentration of nitrate/ammonium $(n=18)$.

\begin{tabular}{|c|c|c|c|}
\hline & $\mathrm{CH}_{4}$ oxidation & {$\left[\mathrm{NO}_{3}^{-}\right]$} & {$\left[\mathrm{NH}_{4}^{+}\right]$} \\
\hline DNA: 0-2 cm layer & $\begin{array}{l}\text { Type I probes: } \\
\text { Mb_C11-403, } r=0.70, P<0.01\end{array}$ & $\begin{array}{l}\text { Type I probes: } \\
\text { BB51-299, Mb_SL\#3-300, DS3-446, } \\
r=0.77 \ldots 0.89, P<0.001\end{array}$ & \\
\hline DNA: 2-10 cm layer & $\begin{array}{l}\text { Type I probes: } \\
\text { fw1-641, P_LW21-391, LK580, } \\
\text { Ib453. } r=-0.54 \ldots-0.63, P<0.05 \\
\text { Type II probes: } \\
\text { Mcy_264, Msi_294, II509, } \\
r=-0.51 \ldots-0.57, P<0.05\end{array}$ & $\begin{array}{l}\text { Type I probe: } \\
\text { Mb_SL\#3-300, } r=0.71, P<0.01\end{array}$ & \\
\hline RNA: 0-2 cm layer & & $\begin{array}{l}\text { Type I probes: } \\
\text { Mm451, 501-375, fw1-641, } \\
r=0.63 \ldots 0.89, P<0.05\end{array}$ & $\begin{array}{l}\text { Type II probes: } \\
\text { Mcy413, Mcy522, Mcy459, Msi232, } \\
\text { Peat264, } r=-0.49 \ldots-0.53, P<0.05\end{array}$ \\
\hline RNA: 2-10 cm layer & $\begin{array}{l}\text { Type I probes: } \\
\text { Mb282, Mb_C11-403, Mm275, } \\
r=0.50 \ldots 0.52, P<0.05\end{array}$ & $\begin{array}{l}\text { Type I probe: } \\
\text { Mmb303, } r=0.57, P<0.05\end{array}$ & $\begin{array}{l}\text { Type I probes: } \\
\text { Mb282, b_C11-403, Mm275, } r=0.70 . . \\
0.78, P<0.01\end{array}$ \\
\hline
\end{tabular}

Only significant correlations are shown. 
Table A2 |The microarray probe set used in the study and probe specificity.

\begin{tabular}{|c|c|}
\hline Name & Intended specificity \\
\hline BB51-302 & Methylobacter \\
\hline Mb292 & Methylobacter \\
\hline Mb282 & Methylobacter \\
\hline Mb_URC278 & Methylobacter \\
\hline Mb267 & Methylobacter \\
\hline $511-436$ & Methylobacter \\
\hline $\mathrm{MbA486}$ & Methylobacter \\
\hline MbA557 & Methylobacter \\
\hline Mb_SL\#3-300 & Methylobacter \\
\hline Mb460 & Methylobacter \\
\hline Mb_LW12-211 & Methylobacter \\
\hline Mb_C11-403 & Methylobacter \\
\hline Mb271 & Methylobacter \\
\hline PS80-291 & Clone PS80 \\
\hline Est514 & Methylomicrobium-related clones \\
\hline Mm_pel467 & Methylomicrobium pelagicum \\
\hline Mb_SL-299 & Soda lake Methylobacter isolates and clones \\
\hline Mb_SL\#1-418 & Soda lake Methylobacter isolates and clones \\
\hline DS1_401 & Deep sea cluster \#1 \\
\hline Mm531 & Methylomonas \\
\hline Mm_ES294 & Methylomonas \\
\hline Mm_ES543 & Methylomonas \\
\hline Mm_ES546 & Methylomonas \\
\hline Mm_M430 & Methylomonas \\
\hline Mm_MV421 & Methylomonas \\
\hline $\mathrm{Mm} 275$ & Methylomonas \\
\hline Mm451 & Methylomonas \\
\hline peat_1_3-287 & Methylomonas-related peat clones \\
\hline Jpn284 & Clone Jpn 07061 \\
\hline Mmb303 & Methylomicrobium album \\
\hline Mmb259 & Methylomicrobium album + Landfill M. microbia \\
\hline Mmb562 & Mmb. album and Methylosarcina \\
\hline LP20-644 & Methylomicrobium-related clones \\
\hline la193 & Type I a (M. bacter-M. monas-M. microbium) \\
\hline la575 & $\begin{array}{l}\text { Type I a ( } M \text {. bacter-M. monas-M. microbium-M. } \\
\text { sarcina) }\end{array}$ \\
\hline JRC4-432 & Japanese rice cluster \#4 \\
\hline MclT272 & Methylocaldum tepidum \\
\hline MclG281 & Methylocaldum gracile \\
\hline McIE302 & Methylocaldum E10 \\
\hline MclS402 & Methylocaldum szegediense \\
\hline Mcl408 & Methylocaldum \\
\hline $501-375$ & $\begin{array}{l}\text { Methylococcus-related marine and freshwater sed- } \\
\text { iment clones }\end{array}$ \\
\hline $501-286$ & $\begin{array}{l}\text { Methylococcus-related marine and freshwater sed- } \\
\text { iment clones }\end{array}$ \\
\hline USC3-305 & Upland soil cluster \#3 \\
\hline Mc396 & Methylococcus \\
\hline fw1-639 & $\begin{array}{l}\text { fw1 group: } M . \text { coccus }-M \text {. caldum related marine } \\
\text { and freshwater sediment clones }\end{array}$ \\
\hline fw1-641 & $\begin{array}{l}\text { fw1 group: } M . \text { coccus }-M \text {. caldum related marine } \\
\text { and freshwater sediment clones }\end{array}$ \\
\hline
\end{tabular}

\begin{tabular}{|c|c|}
\hline Name & Intended specificity \\
\hline fw1-286 & $\begin{array}{l}\text { fw1 group: } M . \text { coccus-M. caldum related marine } \\
\text { and freshwater sediment clones }\end{array}$ \\
\hline LW21-374 & LW21 group \\
\hline LW21-391 & LW21 group \\
\hline OSC220 & Finnish organic soil clones and related \\
\hline OSC300 & Finnish organic soil clones and related \\
\hline JRC3-535 & Japanese Rice Cluster \#3 \\
\hline LK580 & fw1 group + Lake Konstanz sediment cluster \\
\hline JRC2-447 & Japanese Rice Cluster \#2 \\
\hline M90-574 & $\begin{array}{l}\text { M. coccus-M. caldum related marine and freshwa- } \\
\text { ter sediment clones }\end{array}$ \\
\hline M90-253 & $\begin{array}{l}\text { M. coccus-M. caldum related marine and freshwa- } \\
\text { ter sediment clones }\end{array}$ \\
\hline Mth413 & Methylothermus \\
\hline lb453 & $\begin{array}{l}\text { Type I b (M. thermus }-M \text {. coccus }-M \text {. caldum and } \\
\text { related) }\end{array}$ \\
\hline Ib559 & $\begin{array}{l}\text { Type I b (M. thermus-M. coccus-M. caldum and } \\
\text { related) }\end{array}$ \\
\hline DS3-446 & Deep sea cluster \#3 \\
\hline JR2-409 & JR cluster \#2 (California upland grassland soil) \\
\hline JR2-468 & JR cluster \#2 (California upland grassland soil) \\
\hline JR3-505 & JR cluster \#3 (California upland grassland soil) \\
\hline JR3-593 & JR cluster \#3 (California upland grassland soil) \\
\hline Nc_oce4 26 & Nitrosococcus oceani \\
\hline USCG-225 & Upland soil cluster Gamma \\
\hline USCG-225b & Upland soil cluster Gamma \\
\hline Mcy233 & Methylocystis \\
\hline Mcy413 & Methylocystis \\
\hline Мсу522 & Methylocystis A + peat clones \\
\hline Mcy264 & Methylocystis \\
\hline Mcy270 & Methylocystis \\
\hline Mcy459 & Methylocystis \\
\hline Mcy255 & M. cystis B (parvus/echinoides/strain M) \\
\hline МсуМзо9 & M. cystis strain $M$ and related \\
\hline МсуB304 & M. cystis B (parvus/echinoides/strain M) \\
\hline MsT214 & Methylosinus trichosporium OB3b and rel. \\
\hline Msi520 & M. trichosporium \\
\hline Msi269 & M. trichosporium \\
\hline MsS314 & Methylosinus sporium \\
\hline MsS475 & Methylosinus sporium \\
\hline Msi263 & $\begin{array}{l}\text { Methylosinus sporium + } 1 \text { Msi. trichosporium sub- } \\
\text { claster }\end{array}$ \\
\hline Msi423 & Methylosinus \\
\hline Msi294 & Methylosinus \\
\hline Msi232 & $\begin{array}{l}\text { M. sinus + most M. cystis-considered as additional } \\
\text { type II probe }\end{array}$ \\
\hline Peat264 & Peat clones \\
\hline 11509 & Type II \\
\hline 11630 & Type II \\
\hline xb6-539 & $\begin{array}{l}\text { Novel pmoA copy of type II and related environmen- } \\
\text { tal clones }\end{array}$ \\
\hline
\end{tabular}




\section{Table A2 | Continued}

\begin{tabular}{|c|c|}
\hline Name & Intended specificity \\
\hline LP21-190 & $\begin{array}{l}\text { Novel pmoA copy of type II and related environmen- } \\
\text { tal clones }\end{array}$ \\
\hline LP21-260 & $\begin{array}{l}\text { Novel pmoA copy of type II and related environmen- } \\
\text { tal clones }\end{array}$ \\
\hline NMcy1-247 & Novel pmoA copy of $M$. cystis \#1 $\left(^{*}\right)$ \\
\hline NMcy2-262 & Novel pmoA copy of $M$. cystis \#2 $\left({ }^{*}\right)$ \\
\hline NMsiT-271 & Novel pmoA copy of $M$. sinus trichpsporium $\left(^{*}\right)$ \\
\hline LP21-232 & $\begin{array}{l}\text { Novel pmoA copy of type II and related environmen- } \\
\text { tal clones }\end{array}$ \\
\hline RA14-594 & RA14 related clones \\
\hline RA14-591 & RA14 related clones \\
\hline Wsh1-566 & Watershed + flooded upland cluster 1 \\
\hline Wsh2-491 & Watershed + flooded upland cluster 2 \\
\hline Wsh2-450 & Watershed + flooded upland cluster 2 \\
\hline B2rel251 & Methylocapsa-related clones \\
\hline B2-400 & Methylocapsa \\
\hline B2all343 & Methylocapsa and related clones \\
\hline B2all341 & Methylocapsa and related clones \\
\hline pmoAMO3-400 & Clone pmoA-MO3 \\
\hline ESR-579 & ESR (Eastern Snake River) cluster \\
\hline TUSC409 & Tropical upland soil cluster \#2 \\
\hline TUSC502 & Tropical upland soil cluster \#2 \\
\hline mtrof173 & Universal \\
\hline mtrof362-I & Methanotrophs \\
\hline mtrof661 & Methanotrophs \\
\hline mtrof662-I & Methanotrophs \\
\hline mtrof656 & Methanotrophs \\
\hline NmNc53 3 & Nitrosomonas-Nitrosococcus \\
\hline Nsm_eut 381 & Nitrosomonas eutropha \\
\hline PS5-226 & Nitrosomonas-Nitrosococcus related clones \\
\hline PI6-306 & Nitrosomonas-Nitrosococcus related clones \\
\hline NsNv207 & Nitrosospira-Nitrosovibrio \\
\hline NsNv363 & Nitrosospira-Nitrosovibrio \\
\hline Nit_rel47 1 & AOB related clones/probably methanotrophs \\
\hline Nit_rel22 3 & AOB related clones/probably methanotrophs \\
\hline ARC529 & AOB related clones/probably methanotrophs \\
\hline Nit_rel47 0 & AOB related clones/probably methanotrophs \\
\hline Nit_rel35 1 & AOB related clones/probably methanotrophs \\
\hline Nit_rel30 4 & Crenothrix and related \\
\hline M84P105-451 & Environmental clones of uncertain identity \\
\hline WC306_54-385 & Environmental clones of uncertain identity \\
\hline M84P22-514 & Environmental clones of uncertain identity \\
\hline gp23-454 & Environmental clones of uncertain identity \\
\hline MR1-348 & Environmental clones of uncertain identity \\
\hline gp619 & Environmental clones of uncertain identity \\
\hline gp391 & Environmental clones of uncertain identity \\
\hline gp2-581 & Environmental clones of uncertain identity \\
\hline RA21-466 & $\begin{array}{l}\text { Clone RA21 - environmental clone of uncertain } \\
\text { identity }\end{array}$ \\
\hline
\end{tabular}

${ }^{*}$ Assignment based on limited information from cultivated methanotrophs. 


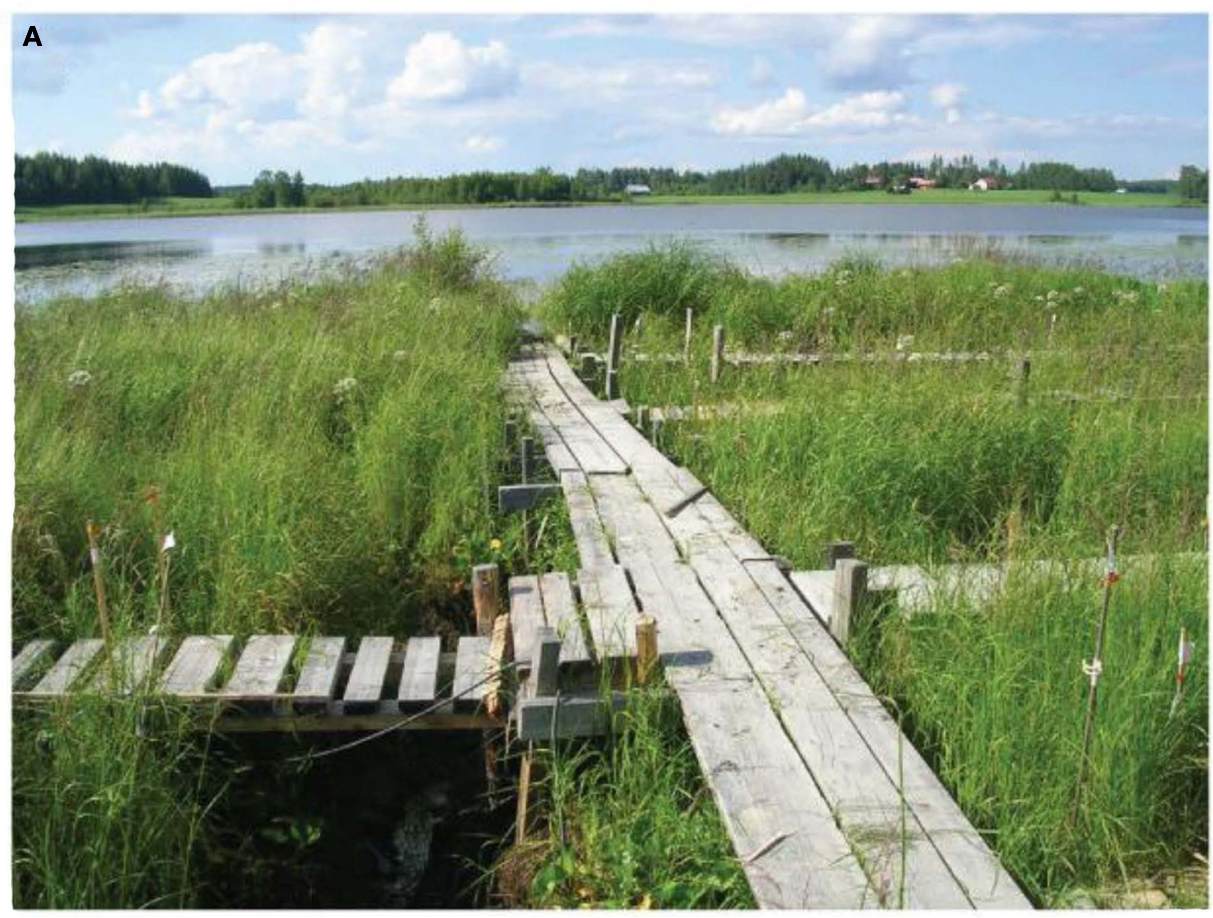

B

Nitrogen loading:

- $2.5 \mathrm{~g} \mathrm{~N} \mathrm{~m}^{-2}\left(\mathrm{NH}_{4} \mathrm{NO}_{3}\right)$ dose

loaded four times in growing season.

- Equal volume of $\mathrm{H}_{2} \mathrm{O}$ loaded

at the same time to control plots.

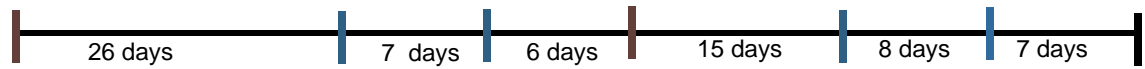

Soil sampling before manipulation: J un 7th
Soil sampling during manipulation: J ul 17th
Soil sampling

after manipulation:

Aug 16th

\section{Soil sampling from control and manipulated plots:}

FIGURE A1 | (A) The littoral wetland of Lake Kevätön in July 2007. For experiment, three control and three manipulated plots of $1.44 \mathrm{~m}^{2}$ were established to area having equal water level and vegetation. The chambers for measurements of in situ $\mathrm{CH}_{4}$ fluxes were inserted into study plots 2 weeks before the experiment. Soil sampling and in situ $\mathrm{CH}_{4}$ flux measurements were taken from boardwalks to omit disturbance of the soil. (B) Soil sampling and nitrogen loading scheme. Time points of soil samplings and nitrogen/water loading are colored with brown and blue respectively. Methane fluxes were measured three times before, during and after the nitrogen loading (with 1-2 week intervals). During the $\mathrm{N}$ loading period, fluxes were measured before addition of $\mathrm{NH}_{4} \mathrm{NO}_{3}$ solution or distilled water. 


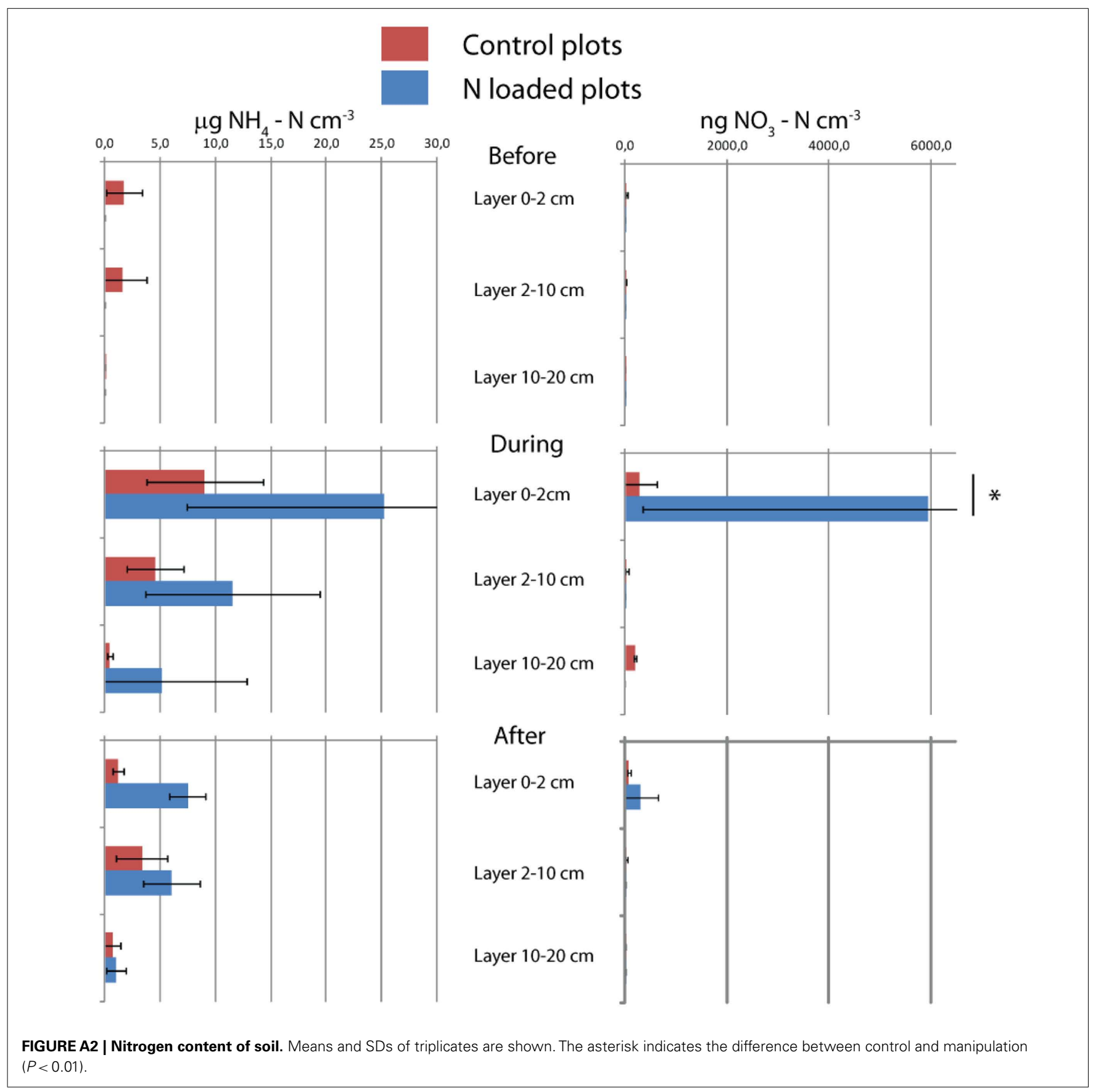




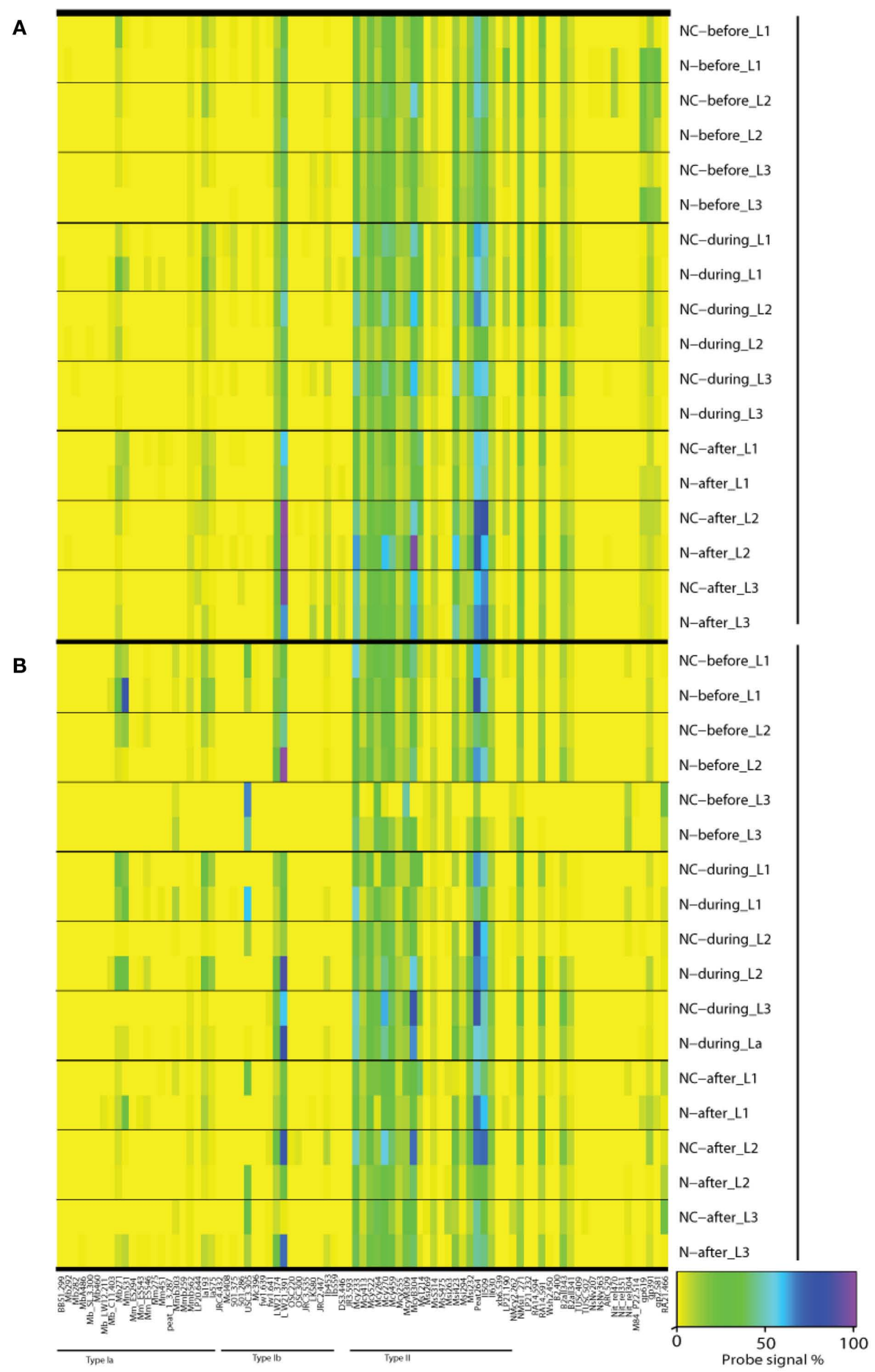

FIGURE A3 | Microarray results of community composition [(A), DNA] and functional diversity [(B), RNA] of methanotrophs before, during, and after nitrogen loading. Averages of triplicate plots are shown. A value of 100 (purple) indicates the maximum and a value of 0 (yellow) indicates the minimum signal intensity of a probe against reference hybridizations determined for each probe individually (Bodrossy et al., 2003). Only probes having positive hybridization are shown. $\mathrm{N}$ denotes nitrogen loading plots, NC control plots, L1 0-2 cm layer, L2 2-10 cm layer, and L3 10-20 cm layer. 


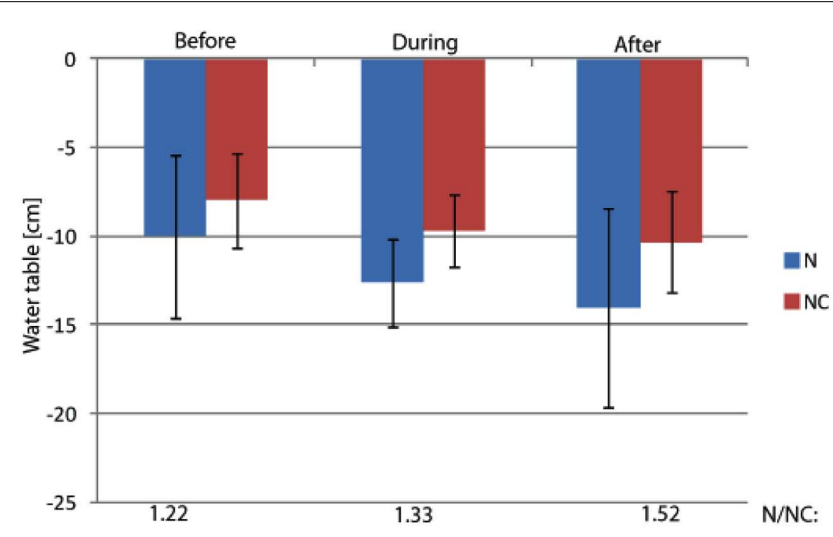

FIGURE A4 | The water table in the study plots. The water table was measured from perforated plastic tubes inserted in soil inside the study plots. The ratio of mean water level of nitrogen loaded and control plots is marked on bottom of the figure.

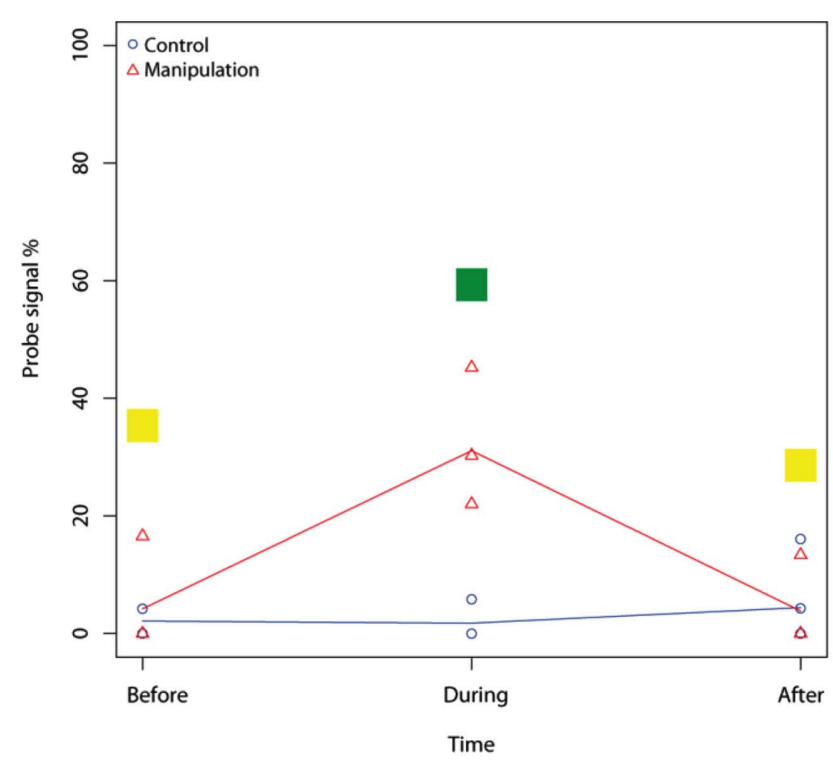

FIGURE A5 | Example of a mixed-effect model result for the microarray probe Mb271 (RNA samples, 2-10 cm). Mixed-effect model comparison evaluated the difference between two fitted models, the control and the manipulation model. In Figure 3A, the result of each comparison is shown in color, thus, no effect on studied microarray probe by nitrogen = yellow, stimulated effect = green, inhibited effect $=$ red, and for negative probes $=$ blue 


\title{
Water dispersal of methanotrophic bacteria maintains functional methane oxidation in Sphagnum mosses
}

\section{Anuliina Putkinen ${ }^{1}{ }^{*}$, Tuula Larmola ${ }^{2 \dagger}$, Tero Tuomivirta ${ }^{1}$, Henri M. P. Siljanen ${ }^{3}$, Levente Bodrossy ${ }^{4,5}$, Eeva-Stiina Tuittila ${ }^{2,6}$ and Hannu Fritze ${ }^{1}$}

\author{
1 Finnish Forest Research Institute, Southern Finland Regional Unit, Vantaa, Finland \\ ${ }^{2}$ Department of Forest Sciences, University of Helsinki, Helsinki, Finland \\ ${ }^{3}$ Department of Environmental Science, University of Eastern Finland, Kuopio, Finland \\ ${ }^{4}$ Department of Bioresources/Microbiology, Austrian Institute of Technology, Seibersdorf, Austria \\ ${ }^{5}$ CSIRO Marine and Atmospheric Research, Hobart, TAS, Australia \\ ${ }^{6}$ School of Forest Sciences, University of Eastern Finland, Joensuu, Finland
}

Edited by:

Svetlana N. Dedysh, Russian Academy of Sciences, Russia

\section{Reviewed by:}

Svetlana N. Dedysh, Russian Academy of Sciences, Russia Yin Chen, University of Warwick, UK

*Correspondence:

Anuliina Putkinen, Finnish Forest Research Institute, Southern Finland Regional Unit, P.O. Box 18

(Jokiniemenkuja 1), 01301 Vantaa,

Finland.

e-mail: anuliina.putkinen@metla.fi

\section{${ }^{t}$ Present address:}

Tuula Larmola, Mount Holyoke College, South Hadley, MA 01075, USA.
It is known that Sphagnum associated methanotrophy (SAM) changes in relation to the peatland water table (WT) level. After drought, rising WT is able to reactivate SAM. We aimed to reveal whether this reactivation is due to activation of indigenous methane $\left(\mathrm{CH}_{4}\right)$ oxidizing bacteria (MOB) already present in the mosses or to MOB present in water. This was tested through two approaches: in a transplantation experiment, Sphagna lacking SAM activity were transplanted into flark water next to Sphagna oxidizing $\mathrm{CH}_{4}$. Already after 3 days, most of the transplants showed $\mathrm{CH}_{4}$ oxidation activity. Microarray showed that the MOB community compositions of the transplants and the original active mosses had become more similar within 28 days thus indicating MOB movement through water between mosses. Methylocystis-related type II MOB dominated the community. In a following experiment, SAM inactive mosses were bathed overnight in non-sterile and sterile-filtered SAM active site flark water. Only mosses bathed with non-sterile flark water became SAM active, which was also shown by the pmoA copy number increase of over 60 times. Thus, it was evident that MOB present in the water can colonize Sphagnum mosses. This colonization could act as a resilience mechanism for peatland $\mathrm{CH}_{4}$ dynamics by allowing the re-emergence of $\mathrm{CH}_{4}$ oxidation activity in Sphagnum.

Keywords: plant-microbe interaction, peatland, pmoA, microarray, qPCR, ecosystem resilience

\section{INTRODUCTION}

Peatlands store over one third of global terrestrial carbon (Gorham, 1991). Although these ecosystems are carbon dioxide $\left(\mathrm{CO}_{2}\right)$ sinks they are also a major source of methane $\left(\mathrm{CH}_{4}\right)$, formed as the final product of anaerobic degradation of organic matter. Most carbon in these systems is derived from Sphagnum mosses (Clymo and Hayward, 1982), the dominant plant in bog-type northern peatlands. Mosses sequester atmospheric $\mathrm{CO}_{2}$ directly through photosynthesis. Methanotrophic bacteria (MOB) living inside the moss hyaline cells and on leaf surfaces (Raghoebarsing et al., 2005; Kip et al., 2010) also play an important role in carbon binding. These bacteria provide $\mathrm{CO}_{2}$ for the plant via $\mathrm{CH}_{4}$ oxidation, a mechanism that is especially important in submerged conditions where $\mathrm{CO}_{2}$ diffusion is slow (Kip et al., 2010). This phenomenon is of local and global importance as it has been detected in all 23 Sphagnum species of a peatland area (Larmola et al. (2010)) and in geographically distant peatlands (Kip et al., 2010) and may be partly responsible for the lower $\mathrm{CH}_{4}$ emissions of Sphagnum bogs in relation to other peatland types (Nykänen et al., 1998).

About 10-15 (Raghoebarsing et al., 2005) or 10-30\% (Larmola et al., 2010) of Sphagnum biomass carbon is from $\mathrm{CH}_{4}$ oxidation by MOB. Thus, it seems clear that mosses benefit from their partners and the relationship has been discussed to be symbiotic (Raghoebarsing et al., 2005). Still, there is evidence that the bacteria involved are only loosely connected to Sphagnum (Basiliko et al., 2004; Larmola et al., 2010). The study by Larmola et al. (2010) showed that peatland water table (WT) level is the main factor influencing MOB activity in mosses. Sphagnum associated methanotrophy (SAM) became de-/reactivated upon natural WT fluctuation. However, Larmola et al. (2010) did not provide evidence whether reactivated $\mathrm{CH}_{4}$ oxidation was caused by reactivation of the original MOB community, invasion of new $\mathrm{MOB}$ from the surrounding water or by both mechanisms. The ability of MOB to colonize Sphagnum from surrounding water would make ecosystem $\mathrm{CH}_{4}$ dynamics less vulnerable to extended periods of drought than a tight symbiosis between MOB and Sphagnum or relaying on the reactivation of original community. To test the importance of colonization we examined the question more thoroughly. First, we conducted a similar transplantation trial as in Larmola et al. (2010) where inactive mosses were planted next to active ones. Colonization process was followed by measurement of $\mathrm{CH}_{4}$ oxidation potentials and community analysis by a microarray that profiles diversity within the $\mathrm{pmoA}$ gene coding for particulate methane mono-oxygenase (pMMO), a key enzyme in $\mathrm{CH}_{4}$ oxidation (Bodrossy et al., 2003). By using this method covering 
a wider range of MOB diversity than Larmola et al. (2010) we aimed to reveal more detailed changes in community compositions. We hypothesized that colonization of MOB through the water phase is a substantial reason for methanotrophic reactivation. Since we presume that all mosses are colonized through the same pathway this should be reflected in MOB of the neighboring mosses influencing the microbial community of the transplanted moss. Second, we tested the hypothesis in the laboratory by treating inactive Sphagnum mosses with water from a wet depression (flark) harboring methanotrophic active Sphagnum mosses. As a control, parallel samples were treated with the same water after MOB removal through filtration. $\mathrm{CH}_{4}$ oxidation potentials were measured and MOB communities analyzed by $p m o A$-based quantitative PCR (qPCR) and denaturing gradient gel electrophoresis (DGGE) analysis followed by sequencing.

\section{EXPERIMENTAL PROCEDURES TRANSPLANTATION EXPERIMENT \\ Sphagnum transplantation}

The experiment was conducted at the Lakkasuo mire $\left(61^{\circ} 48^{\prime} \mathrm{N}\right.$, $24^{\circ} 19^{\prime} \mathrm{E} ; 150 \mathrm{~m}$. a.s.l), a boreal raised bog complex in southern Finland. On 7 July 2008, patches (8 cm in diameter) of inactive Sphagnum rubellum from site $\mathrm{O}$ were transplanted to six different flark sites (A-F) showing high Sphagnum associated methanotrophic (SAM; $\mathrm{CH}_{4}$ oxidation) activity (Figure 1). To control the effect of transplantation, $S$. rubellum was replanted in the original site and the native Sphagnum species (Table A1 in Appendix) gathered from each of six different flark sites were also returned to their original places. Thus, all samples were of transplanted Sphagnum. Moss samples were gathered at the beginning of the experiment ( 0 day), after 3 days, and 28 days. After gathering, mosses were rinsed with deionized water and dried overnight at $+4^{\circ} \mathrm{C}$. Only

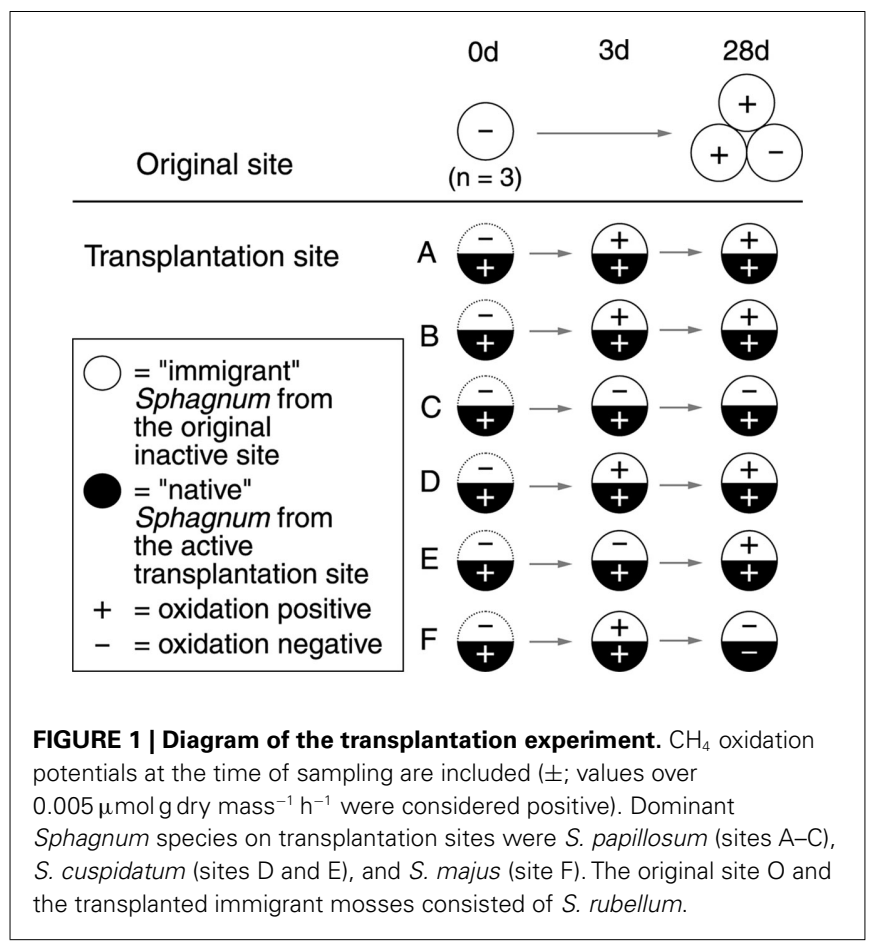

upper $10 \mathrm{~cm}$ of the moss plants were included in the following analysis. Ecological variables of the transplantation sites are listed in Table A1 in Appendix.

\section{Methane oxidation potential}

Methane oxidation potentials were measured as described in Larmola et al. (2010). Briefly, $30 \mathrm{~g}$ of moss was incubated in a $600 \mathrm{~mL}$ flask with an initial $\mathrm{CH}_{4}$ concentration of $10000 \mathrm{ppm}$ in the dark at $+15^{\circ} \mathrm{C}$ and the oxidation was monitored after 24 and 48 h by gas chromatography. Results are presented in micromole $\mathrm{CH}_{4}$ per gram dry weight per hour $\left(\mu \mathrm{mol} \mathrm{g} \mathrm{dw} \mathrm{g}^{-1} \mathrm{~h}^{-1}\right)$.

\section{Analysis of methanotrophic community composition by pmoA-microarray}

Community composition of MOB in Sphagnum samples was investigated using a microarray (Bodrossy et al., 2003) designed to detect diversity within the $p m o A$ gene. DNA was isolated as in Siljanen et al. (2011). A fragment of the pmoA gene was amplified using a semi-nested PCR approach with primer pairs A189f/T7A682r and A189f/T7-mb661r as in Siljanen et al. (2011) with the exception that after the first PCR-step, products not detectable on the gel were diluted 1:10 before being used as templates in the second PCR. Concentration of PCR products was quantified using a Qubit fluorometer (Invitrogen, Carlsbad, CA, USA). In vitro transcription and hybridization was performed as in Stralis-Pavese et al. (2004) and the applied probe set was similar to that applied by Abell et al. (2009). One of three parallel original inactive moss samples from the 0 day time point could be successfully analyzed (see Larmola et al. (2010) that SAM inactive Sphagnum mosses host MOB DNA). Probing pmoA diversity cannot detect Methylocella or the recently discovered Methyloferula (Vorobev et al., 2011) methanotrophs as the pMMO enzyme is not present in these bacteria. It should be noted that another newly discovered methanotroph group, Verrucomicrobia, is also not detectable by the probes we used.

\section{Statistical analysis of microarray data}

The quantitative nature of the microarray data was converted to a binary matrix (presence $=1$, absence $=0$ ) to reveal the community changes caused by different groups of MOB colonizing mosses after transplantation, and also to prevent false interpretation originating from non-quantitative nested PCR approach. The data were then analyzed using principal component analysis (PCA) carried out with CANOCO Version 4.52 (ter Braak and Smilauer, 2002). Sites A-F (Figure 1) were analyzed separately $(n=1)$ and as parallel samples $(n=6)$. Universal MOB probes (positive controls) and probes not hybridizing to any of the samples were excluded from the analyses (threshold for positive samples $\geq 3$ after normalization of the data to the scale of $0-100$ ).

\section{BATHING EXPERIMENT Flark water bathing}

Sphagnum mosses were gathered from Sallie's Fen in NH, USA $\left(43^{\circ} 12.5^{\prime} \mathrm{N}, 71^{\circ} 03.5^{\prime} \mathrm{W} 110 \mathrm{~m}\right.$. a.s.l.). Triplicate $(n=3)$ fresh samples of approximately $30 \mathrm{~mL}$ (volume based on the volume of water replaced by the mosses) of inactive $S$. magellanicum were subjected to the following treatments: (I) no treatment; (II) overnight (11 h) 
incubation in SAM active S. majus $200 \mathrm{~mL}$ flark; (III) overnight incubation in $200 \mathrm{~mL} 0.45 \mu \mathrm{m}$ filtered SAM active $S$. majus flark water; (IV) overnight incubation in $200 \mathrm{~mL}$ SAM active $S$. majus flark water followed by rinsing with deionized water. In the final treatment, S. majus gathered from the active (flark) site was included as a positive control $(n=3)$ in the analyses described below. SAM active flark water was collected directly from a wet depression next to $S$. majus vegetation and did not contain any macroscopic plant material. Each overnight incubation was conducted in the dark at $+20^{\circ} \mathrm{C}$. Following treatment, all mosses were dried overnight at $+4^{\circ} \mathrm{C}$. Only upper $10 \mathrm{~cm}$ of the moss plants were included in the following analysis.

\section{Methane oxidation potential and statistical analysis}

Methane oxidation potentials were measured as above in the transplantation experiment but on a Shimadzu 14A gas chromatograph equipped with a flame ionization detector (Shimadzu Corp., Kyoto, Japan). The results are presented in micromole $\mathrm{CH}_{4}$ per gram dry weight per hour. The difference between sample treatments was tested using Kruskal-Wallis non-parametric analysis of variance followed by Nemenyi test for pairwise comparisons $(p<0.05$; Zar, 1999).

\section{Analysis of community composition by DGGE and sequencing}

Diversity of MOB in Sphagnum samples from the bathing experiment was explored by $p m o A$-based PCR-DGGE analysis and sequencing as previously described (Tuomivirta et al., 2009; Larmola et al., 2010) using the primer pair A189f/GC-621 r designed to target methanotrophs abundant in boreal peatlands (Tuomivirta et al., 2009). DNA was isolated as above in the transplantation experiment. Determined $p m o A$ gene sequences were submitted to Genbank under accession numbers HQ651182 and HQ651183.

\section{Quantification of pmoA genes and statistical analysis}

Quantitative PCR was carried out as previously described (Tuomivirta et al., 2009) using the same primer pair as in the DGGE analysis (A189f/GC-621r). Results are expressed in $p m o A$ copy number per gram dry weight. To test the difference between sample treatments, values were $\ln$ transformed to normalize the data followed by ANOVA and Tukey's HSD test $(p<0.05)$.

\section{RESULTS AND DISCUSSION}

In the transplantation experiment SAM inactive Sphagnum rubellum mosses were planted on six different SAM active sites. Most of the originally inactive mosses showed detectable $\mathrm{CH}_{4}$ oxidation potentials $\left(>0.005 \mu \mathrm{mol} \mathrm{CH}_{4} \mathrm{~g}^{-1} \mathrm{~h}^{-1}\right.$ ) after 3 days and 28 days (Figure 1). Comparing transplantation sites individually indicated that initially different MOB communities became more similar with time (Figure A1 in Appendix). Averaging over the entire data set, the $p m o A$-microarray showed that the MOB community of the originally inactive mosses started to resemble that of the native mosses in the active site after 3 days (Figure 2). After 28 days, MOB communities from the majority of inactive Sphagnum mosses transplanted to active sites (immigrants in Figure 1) were more similar to those of native active mosses than to those in the inactive site at 0 day. Thus, this field experiment indicated that MOB could be transferred between mosses through the water

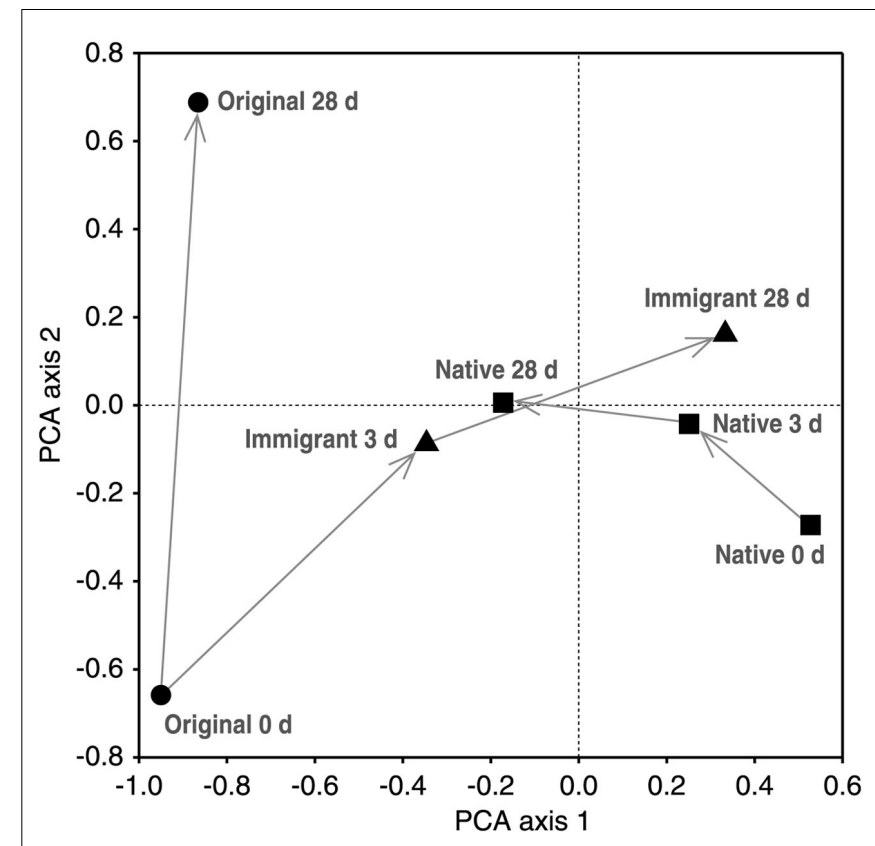

FIGURE 2 | Principal component analysis (PCA) of binary microarray data. Sample means from different sampling times in days (d) are showed [original 0 days $=$ original inactive moss $(n=1)$, original 28 days $=$ original moss transplanted back to the original site $(n=3)$, immigrant $=$ original moss transplanted to the active flark sites $(n=6)$, native $=$ native mosses of the active flark sites $(n=6)]$. The first and second PCA axes explain 25 and $11 \%$ of the compositional variation, respectively.

phase. In addition, the original inactive Sphagnum (site O) became active after transplantation in its original site and had a different MOB community than before transplantation, demonstrating possible new MOB movement through the water phase (Figures 2 and $\mathbf{3}$ and Figure A1 in Appendix). However, although SAM activity was induced in most of the samples together with invasion of new MOB this was not always the case and SAM activity could also be induced without major changes in community composition (Site E, Figure A1 in Appendix). Thus there are methanotrophs that move through water but we cannot state that for all community members. Some members of the methanotroph community seem to be permanently associated with the mosses regardless of whether conditions favor $\mathrm{CH}_{4}$ oxidation or not. In our transplantation experiment this factor hindered us from seeing the invading members of the community and partly explains why large changes in community composition were not always seen when $\mathrm{CH}_{4}$ oxidation was reactivated. As Methylocystis-related type II MOB were present in practically all samples in the transplantation experiment (Figure $\mathbf{3}$ and Figure A2 in Appendix), as shown by the probes Mcy413, Mcy522, Mcy270, Mcy459, Msi232, Peat264, II509, and II630, their movement between mosses could not be clearly detected. Still, probes targeting Methylocystis strain M (McyM309), Methylocystis subgroup B (McyB304), and the genus Methylosinus (Mst214, Mst314, MsS475, Msi294, NMsiT.271) gave more variable presence patterns among the type II methanotrophs, suggesting water-mediated movement. Compared to $\alpha$ proteobacterial type II MOB, the other main methanotrophic 


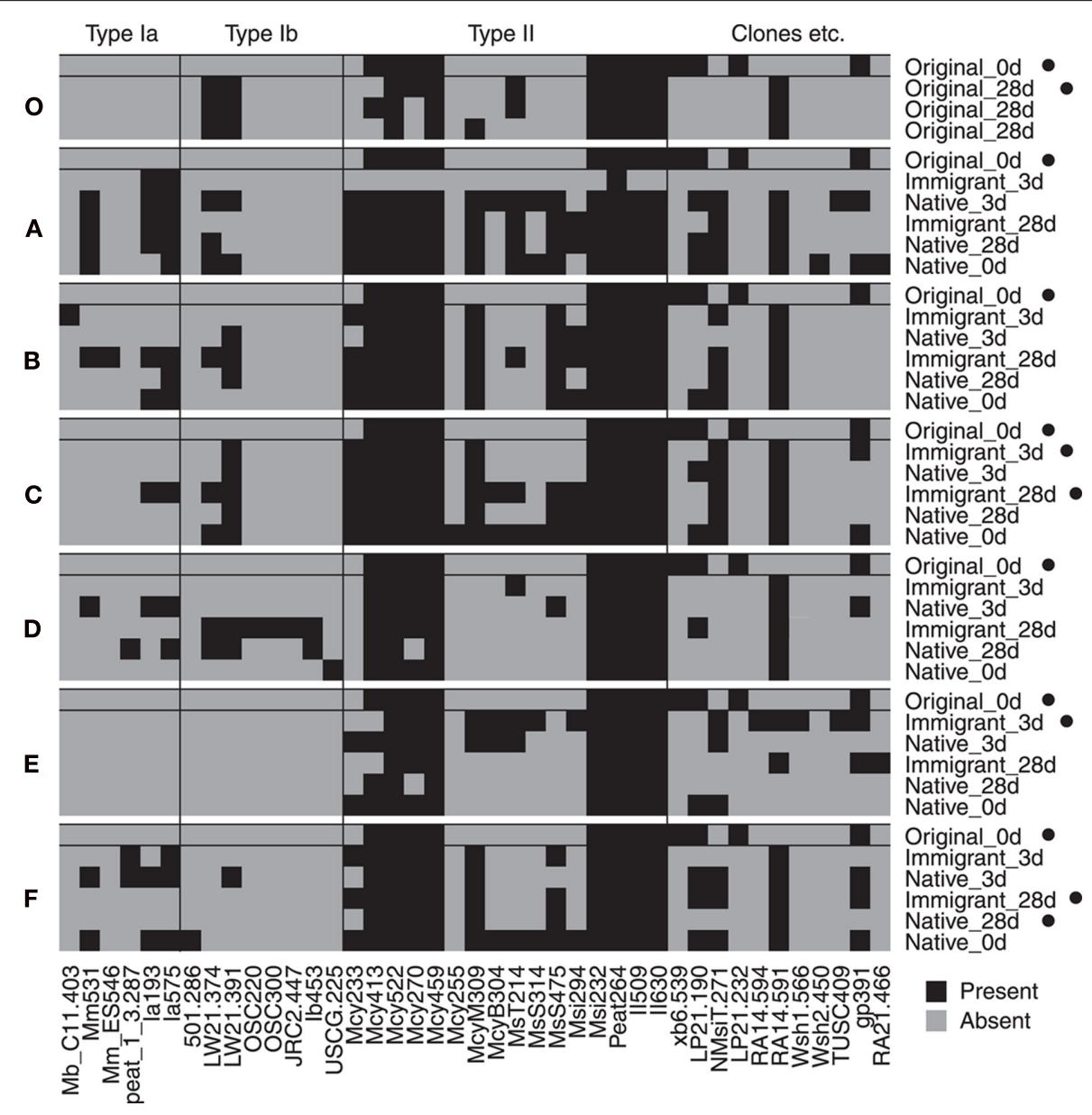

FIGURE 3 | Binary map of microarray results. Each site (A-F and O) is showed separately together with the original 0 day sample data for comparison. Microarray analysis was successful for only one of three parallel inactive original_0 day samples. Samples that were inactive in $\mathrm{CH}_{4}$ oxidation at the time of sampling are marked with a black dot (•). Only probes with a positive hybridization signal ( $\geq 3$ after normalization of the data to the scale of 0-100) on any of the samples are shown (universal $\mathrm{MOB}$ probes were not included). Binary results were converted from the semiquantitative data presented as a heatmap in the Figure A2 in Appendix. lineage, the $\gamma$-proteobacterial type I, was present more rarely and with more variability. Prior to transplantation, no type I methanotrophs were detected in inactive mosses. After 28 day, they were present in four of six "immigrant" samples transplanted to active sites. Type Ia subgroup was found only in mosses transplanted in the active flarks and the native mosses of these sites, suggesting that this group moved from the native mosses to the transplanted "immigrants." Type I MOB could not be clearly linked to the emergence of $\mathrm{CH}_{4}$ oxidation activity, although they were present in most of the active samples and absent from most of the inactive ones. Consequently, based on the transplantation experiment alone, we cannot exclusively state that invasion by nearby MOB is an imperative route in the reactivation of SAM activity.

To examine the hypothesis "the colonization of MOB through the water phase is a substantial reason for methanotrophic reactivation" further, a more simplified experiment was conducted in laboratory conditions. In this bathing experiment, SAM inactive S. magellanicum mosses exposed to unfiltered, SAM active flark water began $\mathrm{CH}_{4}$ oxidation within $11 \mathrm{~h}$, as indicated by $\mathrm{CH}_{4}$ oxidation potential measurements and community analyses including $p m o A$-based qPCR, DGGE fingerprinting and sequencing. Maximum $\mathrm{CH}_{4}$ oxidation potentials and $p m o A$ copy numbers were measured for mosses treated with unfiltered water (averages for rinsed mosses $0.33 \mu \mathrm{mol}$ $\mathrm{CH}_{4} \mathrm{~g}^{-1} \mathrm{~h}^{-1}, 1.9 \times 10^{7} \mathrm{pmoA}$ copies $\mathrm{g} \mathrm{dw}^{-1}$, and for unrinsed $0.29 \mu \mathrm{mol} \mathrm{CH}_{4} \mathrm{~g}^{-1} \mathrm{~h}^{-1}, 2.6 \times 10^{7} \mathrm{pmoA}$ copies $\left.\mathrm{g} \mathrm{dw}^{-1}\right)$ and positive control $S$. majus mosses (average $0.63 \mu \mathrm{mol} \mathrm{CH}_{4} \mathrm{~g}^{-1} \mathrm{~h}^{-1}$, $20 \times 10^{7}$ pmoA copies $\mathrm{g} \mathrm{dw}^{-1}$ ) from the active flark site (Figure 4). Respective values for mosses treated with filtered water (no $\mathrm{CH}_{4}$ oxidation detected, $0.03 \times 10^{7} \mathrm{pmoA}$ copies $\mathrm{g} \mathrm{dw}^{-1}$ ) and the negative control $\left(<0.005 \mu \mathrm{mol} \mathrm{CH}_{4} \mathrm{~g}^{-1} \mathrm{~h}^{-1}, 0.06 \times 10^{7} \mathrm{pmoA}\right.$ copies $\mathrm{g} \mathrm{dw}^{-1}$ ) were clearly lower. The pmoA copy number between filtered and non-filtered flark water treated $S$. magellanicum increased in average by a factor of 63. Also, DGGE revealed the transfer of two Methylocystis-related methanotrophs through unfiltered water (Figure 5). Filtered water did not induce $\mathrm{CH}_{4}$ oxidation activity. This experiment clearly demonstrated the watermediated dispersal of $\mathrm{MOB}$, but it also showed that compared to 
invasion by new MOB, reactivation of the original MOB was not a major mechanism in the reactivation of $\mathrm{CH}_{4}$ oxidation process in the studied mosses. In the DGGE gel the two Methylocystis bands are faintly present already in the unbathed negative control. Bathing of the mosses with sterile-filtered water caused these bands to fade away as shown also by the qPCR. On the contrary, treatment with unfiltered water caused emergence of high numbers of MOB and also high SAM activity. Thus the reactivation of the $\mathrm{CH}_{4}$ oxidation activity must have been brought up by MOB invading the moss through the water phase or the growth in MOB numbers should have been seen also in the moss bathed with filtered water. Moreover, known Methylocystis strains have doubling times of several hours when growing on $\mathrm{CH}_{4}$ in laboratory

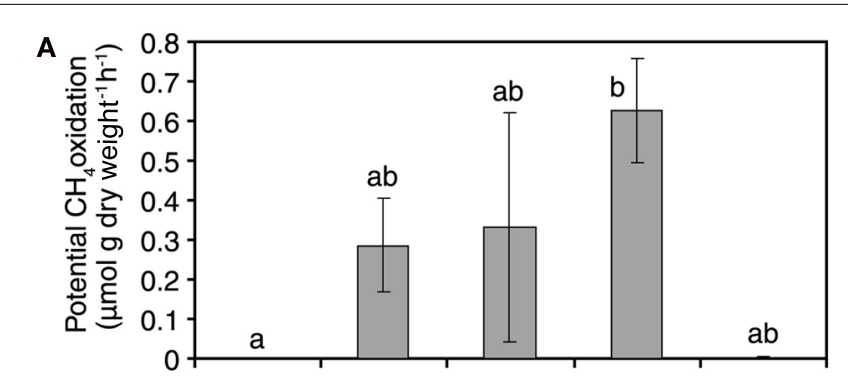

B

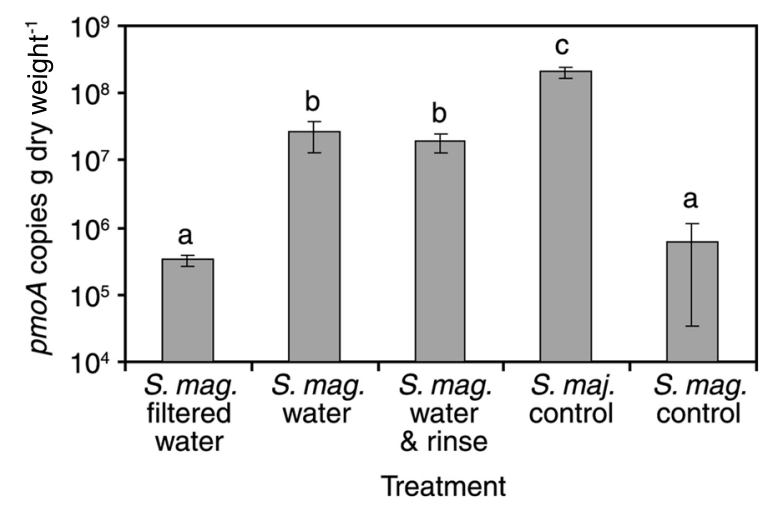

FIGURE 4 | $\mathrm{CH}_{4}$ oxidation potentials (A) and pmoA copy numbers (B) of differently treated moss samples (S. mag. = Sphagnum magellanicum, S. maj. = Sphagnum majus). Standard error bars are shown $(n=3)$. Same letter superscripts denote non-significant differences among treatments in the potential oxidation rates. Note the logarithmic scale on the $y$-axis (B). conditions (Wise et al., 1999; Dedysh et al., 2007; Baani and Liesack, 2008) suggesting that it would be highly unlikely for these MOB to increase their numbers over 60 times higher in $11 \mathrm{~h}$, as seen in the bathing experiment. Therefore we accept the posed hypothesis with a minor modification: MOB colonization through the water phase occurs and it obviously supports the reactivation of $\mathrm{CH}_{4}$ oxidation in Sphagnum mosses, but our experiments cannot rule out the possibility of reactivation of original community members. This could be investigated in a prolonged bathing experiment in combination with diurnal light rhythm, but was beyond the scope of this investigation.

Based on our results that $\mathrm{MOB}$ colonize the mosses from water, the relationship between MOB and Sphagnum seems to be a loose, mutually beneficial association rather than a tight symbiosis. This result is in line with a recent finding by Bragina et al. (in press) who showed by pyrosequencing that some bacteria are passed from the Sphagnum sporophyte to the gametophyte but no known methanotrophs were among them. Representatives of the genus Methylocystis, however, were detected in the gametophyte. Still, even though methanotrophs may not be obligately dependent on the mosses, they most likely prefer the plant cells over life in the water phase. This is supported by our results from the bathing experiment. Despite having slightly lowered the amount of $p m o A$ detected, mosses rinsed with sterile water had almost the same potential $\mathrm{CH}_{4}$ oxidation activity as unrinsed ones, indicating that loosely attached methanotrophs play only a minor role in the process. In addition, the rapid $(<11 \mathrm{~h})$ increase in $p m o A$ copy number suggests that methanotrophs present in the water phase quickly colonize Sphagnum. Compared to free-living bacteria, those associated with plants may gain an advantage from a stable $\mathrm{CH}_{4}$ gradient and supply of oxygen from photosynthesis, but it has yet to be demonstrated. In the bathing experiment methanotrophs moved to the mosses even in the dark when oxygen was not formed in photosynthesis, indicating that at the very least oxygen is not the only advantage bacteria gain from the mosses. In another study no $\mathrm{CH}_{4}$ oxidation activity was detected in peat water surrounding Sphagnum mosses (Kip et al., 2010), also indicating that, although present, $\mathrm{MOB}$ are not actively oxidizing $\mathrm{CH}_{4}$ in the water phase. Since the only MOB, Methylocystis, detected in the bathing experiment, is non-motile (Dedysh, 2009), it remains open how these MOB cells end up on the moss surface and inside the hyaline cells. On the other hand another peatland inhabiting type II MOB genus, Methylosinus (Dedysh et al., 2003; Chen et al.,

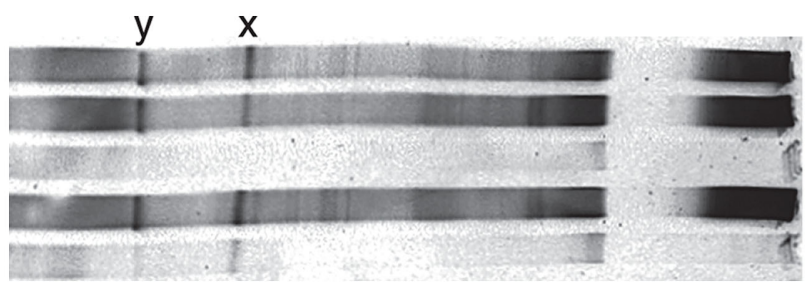

S. mag. water \& rinse

S. maj. positive control

S. mag. filtered water

S. mag. water

S. mag. negative control

FIGURE 5 | Denaturing gradient gel electrophoresis gel showing differently treated samples. Two Methylocystis bands are marked by $x$ and $y$ (S. mag. = Sphagnum magellanicum, $S$. maj. = Sphagnum majus). Closest database match to sequence $x$ (HO651182) was methanotrophic sequence from an acidic fen (FR726177) with 95\% similarity. Sequence y (HQ651183) was identical to a Methylocystis sequence previously found on Finnish peatlands (GQ468279, GQ279344, FJ930091) and Sphagnum mosses (GQ121280). 
2008), does contain motile species (Bowman et al., 1993) and has been isolated from Sphagnum mosses (Kip et al., 2011a).

Similar to previous studies (Tuomivirta et al., 2009; Larmola et al., 2010; Yrjälä et al., 2011) of Finnish peatlands, DGGE of our bathing experiment samples from Sallie's Fen, located in $\mathrm{NH}$, USA, detected only Methylocystis-like MOB. These were also the dominant methanotrophs in our transplantation experiment, run on the Finnish Lakkasuo raised bog complex, when the pmoAmicroarray was used. Dominance of type II MOB in our samples is in line with previous studies. Especially the high prevalence of Methylocystis in Sphagnum samples is not surprising as it is commonly found in northern peatlands (McDonald et al., 1996; Morris et al., 2002; Jaatinen et al., 2005; Dedysh et al., 2006; Chen et al., 2008). Although Kip et al. (2010) found, in contrast to our results, a high diversity of type I methanotrophs, Methylocystis was still the dominant species in their globally gathered Sphagnum samples (Kip et al., 2010) and also very abundant in mosses from a Dutch peat bog (Kip et al., 2011b).

We have demonstrated that water serves as an essential route for methanotroph dispersal and is thus an imperative part of Sphagnum-methanotroph association. This is likely to act as a backup mechanism for peatland $\mathrm{CH}_{4}$ dynamics. Drainage of peatlands can alter the methanotroph community composition (Jaatinen et al., 2005; Yrjälä et al., 2011) and reduce Sphagnum coverage (Yrjälä et al., 2011), consequently compromising this mutualistic association. A case study (Yrjälä et al., 2011) found that the particular Methylocystis sp., which was found now also in the mosses of Sallie's Fen (northeastern USA) of our bathing experiment and in the mosses of Lakkasuo (Larmola et al. (2010)), was lost when the WT dropped by $14 \mathrm{~cm}$, which is similar to the predicted drawdown for northern peatlands in the global warming scenario by $3^{\circ} \mathrm{C}$

\section{REFERENCES}

Abell, G. C. J., Stralis-Pavese, N., Sessitsch, A., and Bodrossy, L. (2009). Grazing affects methanotroph activity and diversity in an alpine meadow soil. Environ. Microbiol. Rep. 1, 457-465.

Baani, M., and Liesack, W. (2008). Two isozymes of particulate methane monooxygenase with different methane oxidation kinetics are found in Methylocystis sp. strain SC2. Proc. Natl. Acad. Sci. U.S.A. 105, 10203-10208.

Basiliko, N., Knowles, R., and Moore, T. R. (2004). Roles of moss species and habitat in methane consumption potential in a northern peatland. Wetlands 24, 178-185.

Bodrossy, L., Stralis-Pavese, N., Murrell, J. C., Radajewski, S., Weilharter, A., and Sessitsch, A. (2003). Development and validation of a diagnostic microbial microarray for methanotrophs. Environ. Microbiol. 5, 566-582.

Bowman, J. P., Sly, L. I., Nichols, P. D., and Hayward, A. C. (1993). Revised taxonomy of the methanotrophs: description of Methylobacter gen. nov., emendation of Methylococcus, validation of Methylosinus and Methylocystis species, and a proposal that the family Methylococcaceae includes only the group I methanotrophs. Int. J. Syst. Bacteriol. 43, 735-753.

Bragina, A., Berg, C., Cardinale, M., Shcherbakov, A., Chebotar, V., and Berg, G. (in press). Sphagnum mosses harbour highly specific bacterial diversity during their whole lifecycle. ISME J. doi:10.1038/ismej.2011.151

Chen, Y., Dumont, M. G., McNamara, N. P., Chamberlain, P. M. Bodrossy, L., Stralis-Pavese, N., and Murrell, J. C. (2008). Diversity of the active methanotrophic community in acidic peatlands as assessed by mRNA and SIP-PLFA analyses. Environ. Microbiol. 10, 446-459.

Clymo, R. S., and Hayward, P. M. (1982). "The ecology of Sphagnum," in Bryophyte Ecology, ed. A. J. E. Smith (London: Chapman and Hall), 229-289.

Dedysh, S. N. (2009). Exploring methanotroph diversity in acidic northern wetlands: molecular and

(Roulet et al., 1992). Restoration of drained peatlands aims to reactivate ecosystem function and restart methanogenesis (Tuittila et al., 2000). Any peatland restoration program should also aim to re-establish the conditions for the mutualistic association between methanotrophs and Sphagnum. Our study indicates that this could be done via transplantations of Sphagnum from donor sites with undisturbed $\mathrm{CH}_{4}$ dynamics. In natural environments Sphagnum associated methanotrophic communities may reduce the methane flux by as much as $80 \%$ (Kip et al., 2010). It is not yet known whether this phenomenon can reach that scale also in compromised ecosystems.

\section{CONCLUSION}

Here we showed, by two complementing experiments, that invasion of new MOB through water occurs and that it can be an important mechanism in the reactivation of $\mathrm{CH}_{4}$ oxidation in Sphagnum mosses. Based on this result, the relationship between Sphagnum and methanotrophs is a loose, mutually beneficial association, although some methanotrophs may have an even tighter connection to the mosses.

\section{ACKNOWLEDGMENTS}

We thank T. Ronkainen and L. Maanavilja for field and laboratory assistance, R. Varner, J. Bubier, A. Saari, and P. J. Martikainen for facilities, P. Crill, S. Whitlow, J. Digg, and N. Blake for access to Sallie's Fen, M. Hardman for checking the language, and S. Elomaa for the graphics. This work was mainly funded by Maj and Tor Nessling Foundation and the Academy of Finland (Project 121535). Additional funding was received from Maa- ja vesitekniikan tuki Foundation, Kone Foundation, and the Academy of Finland (Projects 118493 and 218101).

cultivation-based studies. Microbiol ogy 78, 655-669.

Dedysh, S. N, Belova, S. E, Bodelier, P. L. E., Smirnova, K. V., Khmelenina, V. N., Chidthaisong, A., Trotsenko, Y. A., Liesack, W., and Dunfield, P. F. (2007). Methylocystis heyeri sp. nov., a novel type II methanotrophic bacterium possessing 'signature' fatty acids of type I methanotrophs. Int J. Syst. Evol. Microbiol. 57, 472-479.

Dedysh, S. N., Dunfield, P. F., Derakshani, M., Stubner, S., Heyer, J., and Liesack, W. (2003). Differential detection of type II methanotrophic bacteria in acidic peatlands using newly developed 16S rRNAtargeted fluorescent oligonucleotide probes. FEMS Microbiol. Ecol. 43, 299-308.

Dedysh, S. N., Pankratov, T. A., Belova, S. E., Kulichevskaya, I. S., and Liesack, W. (2006). Phylogenetic analysis and in situ identification of bacteria community composition in an acidic Sphagnum peat bog. Appl. Environ. Microbiol. 72, 2110-2117.

Gorham, E. (1991). Northern peatlands: role in the carbon cycle and probable responses to climatic warming. Ecol. Appl. 1, 182-195.

Jaatinen, K., Tuittila, E. S., Laine, J., Yriälä, K., and Fritze, H. (2005). Methane-oxidizing bacteria in a Finnish raised mire complex: effects of site fertility and drainage. Microb. Ecol. 50, 429-439.

Kip, N., Ouyang, W., van Winden, J., Raghoebarsing, A., van Niftrik, L., Pol, A., Pan, Y., Bodrossy, L., van Donselaar, E. G., Reichart, G.-J., Jetten, M. S. M., Sinninghe Damsté, J. S., and Op den Camp, H. J. M. (2011a). Detection, isolation and characterization of acidophilic methanotrophs from Sphagnum mosses. Appl. Environ. Microbiol. 77, 5643-5654.

Kip, N., Dutilh, B. E., Pan, Y., Bodrossy, L., Neveling, K., Kwint, M. P., Jetten, M. S. M., and Op den Camp, H. J. M. (2011b). Ultra-deep pyrosequencing of pmoA amplicons confirms the prevalence of Methylomonas and Methylocystis in Sphagnum mosses from a Dutch peat bog. Environ. Microbiol. Rep. 3, 667-673. 
Kip, N., van Winden, J., Pan, Y., Bodrossy, L., Reichart, G.-J., Smolders, A. J. P., Jetten, M. S. M., Sinninghe Damsté, J. S., and Op den Camp, H. J. M. (2010). Global prevalence of methane oxidation by symbiotic bacteria in peat-moss ecosystems. Nat. Geosci. 3, 617-621.

Larmola, T., Tuittila, E.-S., Tiirola, M., Nykänen, H., Martikainen, P. J., Yrjälä, K., Tuomivirta, T., and Fritze, H. (2010). The role of Sphagnum mosses in the methane cycling of a boreal mire. Ecology 91, 2356-2365.

McDonald, I. R., Hall, G. H., Pickup, R. W., and Murrell, C. J. (1996). Methane oxidation potential and preliminary analysis of methanotrophs in blanket bog peat using molecular ecology techniques. FEMS Microbiol. Ecol. 21, 197-211.

Morris, S. A., Radajewski, S., Willison, T. W., and Murrell, J. C. (2002). Identification of the functionally active methanotroph population in a peat soil microcosm by stable-isotope probing. Appl. Environ. Microbiol. 68, 1446-1453.

Nykänen, H., Alm, J., Silvola, J., Tolonen, K., and Martikainen, P. (1998). Methane fluxes on boreal peatlands of different fertility and the effect of long-term experimental lowering of the water table on flux rates. Global Biogeochem. Cycles 12, 53-69.

Raghoebarsing, A. A., Smolders, A. J. P., Schmid, M. C., Rijpstra, W.
I. C., Wolters-Arts, M., Derksen, J., Jetten, M. S. M., Schouten, S., Sinninghe Damsté, J. S., Lamers, L. P. M., Roelofs, J. G. M., Op den Camp, H. J. M., and Strous, M. (2005). Methanotrophic symbionts provide carbon for photosynthesis in peat bogs. Nature 436, 1153-1156.

Roulet, N., Moore, T., Bubier, J., and Lafleur, P. (1992). Northern fens: methane flux and climatic change. Tellus B Chem. Phys. Meteorol. 44, 100-105.

Siljanen, H. M. P., Saari, A., Krause, S., Lensu, A., Abell, G. C., Bodrossy, L., Bodelier, P. L. E., and Martikainen, P. J. (2011). Hydrology is reflected in the functioning and community composition of methanotrophs in the littoral wetland of a boreal lake. FEMS Microbiol. Ecol. 75, 430-445.

Stralis-Pavese, N., Sessitsch, A., Weilharter, A., Reichenauer, T., Riesing, J., Csontos, J., Murrell, J. C., and Bodrossy, L. (2004). Optimization of diagnostic microarray for application in analysing landfill methanotroph communities under different plant covers. Environ. Microbiol. 6, 347-363.

ter Braak, C. J. F., and Smilauer, P. (2002). CANOCO Reference Manual and CanoDraw for Windows User's Guide: Software for Canonical Community Ordination. Version 4.5. Ithaca, NY: Microcomputer Power.
Tuittila, E.-S., Komulainen, V.-M. Vasander, H., Nykänen, H., Martikainen, P. J., and Laine, J. (2000). Methane dynamics of a restored cutaway peatland. Glob. Chang. Biol. 6 , 569-581.

Tuomivirta, T. T., Yrjälä, K., and Fritze, H. (2009). Quantitative PCR of pmoA using a novel reverse primer correlates with potential methane oxidation in finnish fen. Res. Microbiol. 160, 751-756.

Vorobev, A. V., Baani, M., Doronina, N. V., Brady, A. L., Liesack, W., Dunfield, P. F., and Dedysh, S. N. (2011). Methyloferula stellata gen. nov., sp. nov. an acidophilic, obligately methanotrophic bacterium possessing only a soluble methane monooxygenase. Int. J. Syst. Evol. Microbiol. 61, 2456-2463.

Wise, M. G., McArthur, J. V., and Shimkets, L. J. (1999). Methanotroph diversity in landfill soil: isolation of novel type I and type II methanotrophs whose presence was suggested by culture-independent 16S ribosomal DNA analysis. Appl. Environ. Microbiol. 65, 4887-4897.

Yrjälä, K., Tuomivirta, T., Juottonen, H., Putkinen, A., Lappi, K., Tuittila, E.-S., Penttilä, T., Minkkinen, K. Laine, J., Peltoniemi, K., and Fritze, H. (2011). $\mathrm{CH}_{4}$ production and oxidation processes in a boreal fen ecosystem after long-term water table drawdown. Glob. Chang. Biol. 17, 1311-1320.

Zar, J. H. (1999). Biostatistical Analysis. Upper Saddle River, NJ: Prentice Hall.

Conflict of Interest Statement: The authors declare that the research was conducted in the absence of any commercial or financial relationships that could be construed as a potential conflict of interest.

Received: 20 December 2011; accepted: 09 January 2012; published online: 23 January 2012.

Citation: Putkinen A, Larmola T, Tuomivirta T, Siljanen HMP, Bodrossy L, Tuittila E-S and Fritze $H$ (2012) Water dispersal of methanotrophic bacteria maintains functional methane oxidation in Sphagnum mosses. Front. Microbio. 3:15. doi: 10.3389/fmicb.2012.00015 This article was submitted to Frontiers in Terrestrial Microbiology, a specialty of Frontiers in Microbiology.

Copyright (c) 2012 Putkinen, Larmola, Tuomivirta, Siljanen, Bodrossy, Tuittila and Fritze. This is an open-access article distributed under the terms of the Creative Commons Attribution Non Commercial License, which permits noncommercial use, distribution, and reproduction in other forums, provided the original authors and source are credited. 


\section{APPENDIX}

Table A1 | Ecological variables of Lakkasuo sites in the beginning ( 0 day) and the end ( 28 days) of the transplantation experiment.

\begin{tabular}{|c|c|c|c|c|c|c|c|}
\hline \multirow[t]{2}{*}{ Site } & \multirow[t]{2}{*}{ Sphagnum species } & \multicolumn{2}{|c|}{$\mathrm{WT}^{\mathrm{a}}(\mathrm{cm})$} & \multicolumn{2}{|c|}{ Peat temperature $\left({ }^{\circ} \mathrm{C}\right)$} & \multicolumn{2}{|c|}{$\mathrm{CH}_{4}$ concentration in the pore water (ppm) } \\
\hline & & Start & End & Start & End & Start & End \\
\hline A & S. papillosum & -5 & -3 & 13.1 & 15.7 & 390 & 51.5 \\
\hline$B$ & S. papillosum & -4 & -8 & 13.8 & 15.7 & 3960 & 915 \\
\hline C & S. papillosum & -5 & -6 & 13 & 15.1 & 5710 & 689 \\
\hline$D$ & S. cuspidatum & -6 & -5 & 12.1 & 14.8 & 397 & 201 \\
\hline$E$ & S. cuspidatum & -7 & -7 & 13 & 15.7 & 205 & 4.22 \\
\hline $\mathrm{F}$ & S. majus & -5 & -5 & 13.3 & 15.4 & 3460 & 274 \\
\hline 0 & S. rubellum & -12 & -22 & 15.0 & 15.3 & 16800 & 8740 \\
\hline
\end{tabular}

aWT $=$ water table level as measured from the peat surface.

Sites $A-F=$ active sites where inactive original Sphagna were transplanted from site 0 . 

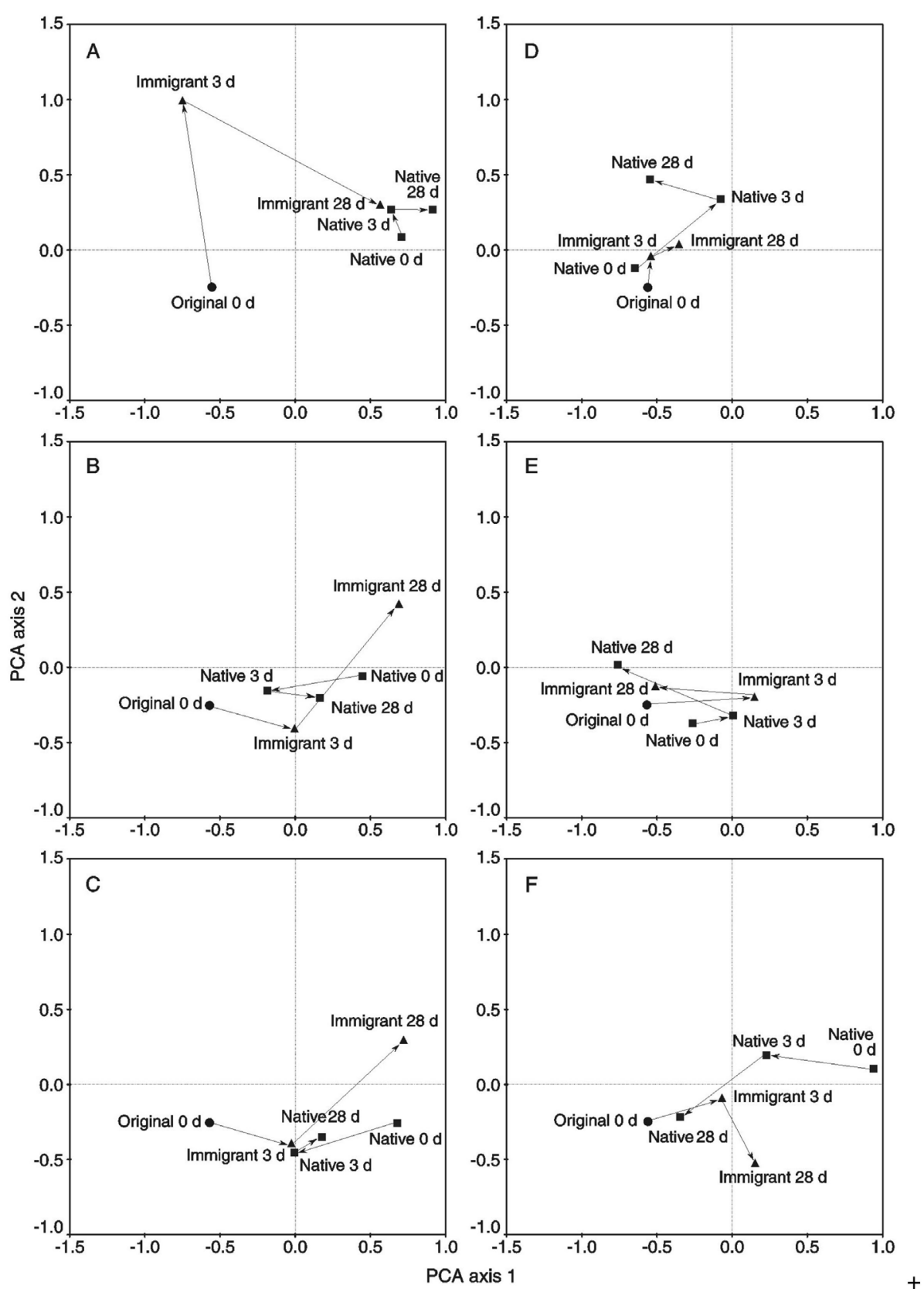

FIGURE A1 | The principal component analysis (PCA) results of the binary microarray data divided into transplantation sites

(A-F) (original 0 day = original inactive moss, original

28 days $=$ original moss transplanted back to the original site, immigrant $=$ original moss transplanted to the active flark site, native $=$ native moss of the active flark site). The first and second PCA axes explain 25 and $11 \%$ of the compositional variation, respectively. 


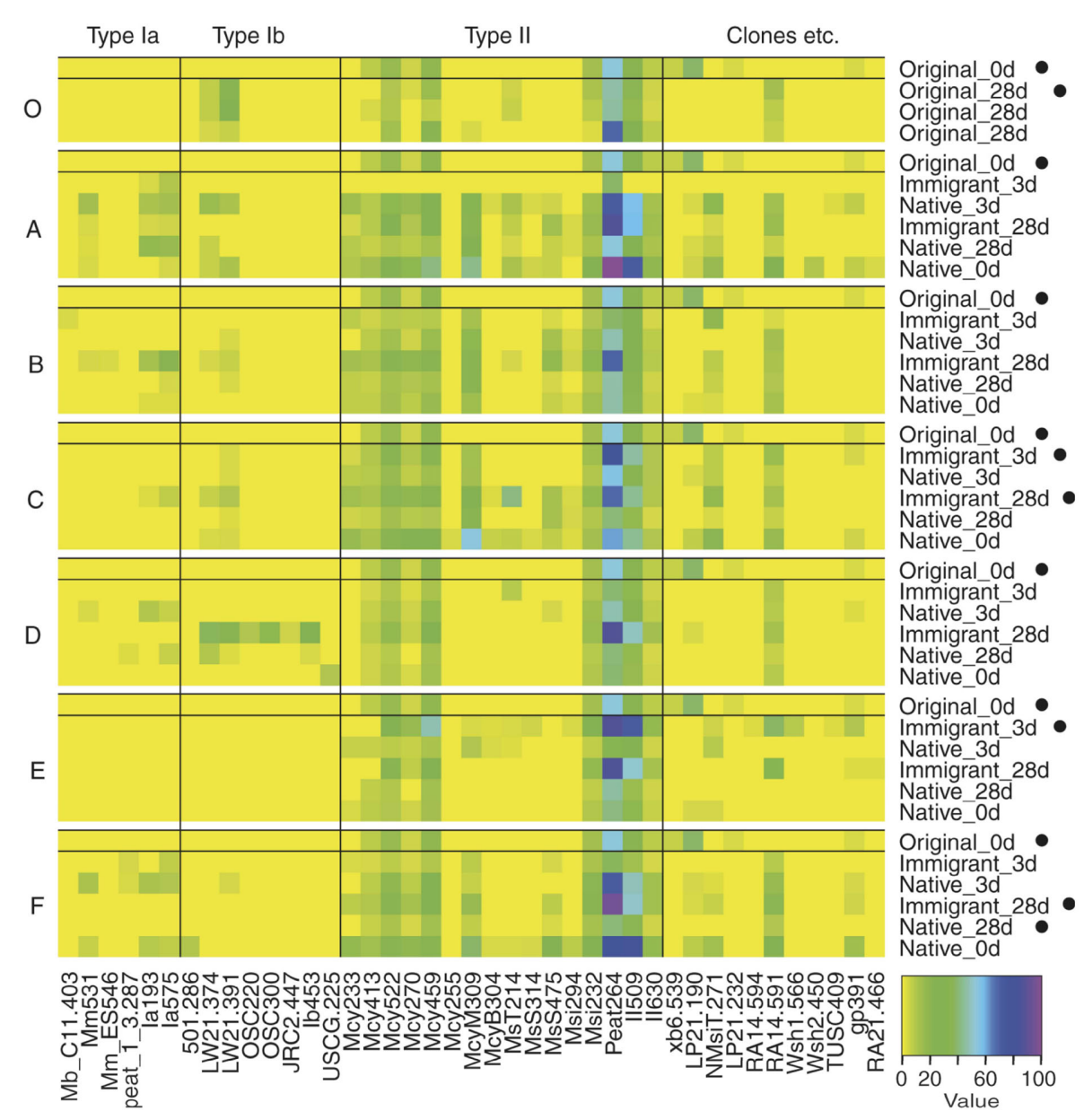

FIGURE A2 | Heatmap of semiquantitative microarray results. Each site $(\mathrm{A}-\mathrm{F}$ and $\mathrm{O})$ is showed separately together with the original $\mathrm{O}$ day sample data for comparison. Microarray analysis was successful for only one of three parallel inactive original_0 day samples. Samples that were inactive in $\mathrm{CH}_{4}$ oxidation at the time of sampling are marked with a black dot $(\bullet)$. A value of 100 (see color code bar) indicates maximum signal for an individual probe and zero represents no hybridization. Only probes with a positive hybridization signal on any of the samples are shown. 


\section{Anoxic iron cycling bacteria from an iron sulfide- and nitrate-rich freshwater environment}

\section{Suzanne C. M. Haaijer*, Gijs Crienen, Mike S. M. Jetten and Huub J. M. Op den Camp}

Department of Microbiology, Institute for Water and Wetland Research, Radboud University Nijmegen, Nijmegen, Netherlands

\section{Edited by:}

Paul Bodelier, Netherlands Institute of Ecology (NIOO-KNAW), Netherlands

\section{Reviewed by:}

Dimitry Y. Sorokin, Delft University of

Technology, Netherlands

Marzia Miletto, University of

California Berkeley, USA

*Correspondence:

Suzanne C. M. Haaijer, Department of Microbiology, Institute for Water and Wetland Research, Radboud University Nijmegen,

Heyendaalseweg 135, Nijmegen 6525 AJ, Netherlands.

e-mail: s.haaijer@science.ru.nl
In this study, both culture-dependent and culture-independent methods were used to determine whether the iron sulfide mineral- and nitrate-rich freshwater nature reserve Het Zwart Water accommodates anoxic microbial iron cycling. Molecular analyses (16S rRNA gene clone library and fluorescence in situ hybridization, FISH) showed that sulfuroxidizing denitrifiers dominated the microbial population. In addition, bacteria resembling the iron-oxidizing, nitrate-reducing Acidovorax strain BrG1 accounted for a major part of the microbial community in the groundwater of this ecosystem. Despite the apparent abundance of strain BrG1-like bacteria, iron-oxidizing nitrate reducers could not be isolated, likely due to the strictly autotrophic cultivation conditions adopted in our study. In contrast an iron-reducing Geobacter sp. was isolated from this environment while FISH and 16S rRNA gene clone library analyses did not reveal any Geobacter sp.-related sequences in the groundwater. Our findings indicate that iron-oxidizing nitrate reducers may be of importance to the redox cycling of iron in the groundwater of our study site and illustrate the necessity of employing both culture-dependent and independent methods in studies on microbial processes.

Keywords: freshwater anoxic iron bacteria, cultivation, nitrate, FISH, clone library

\section{INTRODUCTION}

Redox cycling of iron has profound effects on the chemistry of soils and sediments due to the sheer abundance of iron, and the interdependence with the cycling of virtually all other biochemically relevant elements (Stumm and Sulzberger, 1992; Davison, 1993; Nealson et al., 2002). Iron species are subject to both chemical and microbial transformations. Iron can be abiotically reduced in various manners. Photoreduction, and interactions with sulfhydryl groups, organic acids, and reducing ligands, all result in reduction of ferric oxides (Nealson and Saffarini, 1994; Castillo-Gonzalez and Bruns, 2005). In sulfur-rich, mainly marine, environments, hydrogen sulfide reduces ferric iron oxides which results in the formation of iron sulfide (FeS), pyrite $\left(\mathrm{FeS}_{2}\right)$, and elemental sulfur (Thamdrup et al., 1994; Carey and Taillefert, 2005). In nonsulfidogenic anoxic soils and sediments however, microbial iron reduction, coupled to organic carbon or hydrogen oxidation, is the dominant process (Sobolev and Roden, 2002). The importance of microbial iron reduction has been unequivocally demonstrated: in many environments it accounts for significant turnover of organic carbon, and has inhibitory effects on sulfate reduction and methanogenesis (Nealson and Saffarini, 1994; Thamdrup, 2000; Nealson et al., 2002). The first described iron-reducing bacterial species were fermenting bacteria that make use of the reduction as a means to dispose of electron equivalents (Lovley and Phillips, 1988). Nowadays, also a large variety of microorganisms, ranging from slightly psychrophilic to thermophilic, have been described that use energy generated through iron reduction for growth. Examples of such dissimilatory iron reducers are Geobacter sp., Rhodoferax ferrireducens, Geothrix fermentans, Ferribacterium limneticum, Geoglobus ahangari, and Shewanella sp. These microorganisms couple iron reduction to oxidation of a large variety of organic compounds, hydrogen, or elemental sulfur (Nealson and Saffarini, 1994; Cummings et al., 1999; Thamdrup, 2000; Tor et al., 2001; Kashefi et al., 2002; Nevin and Lovley, 2002; Finneran et al., 2003). Especially Geobacter species have received considerable attention because of their ability to convert pollutants such as uranium, aromatic hydrocarbons, and chlorinated solvents (Anderson et al., 1998; Lin et al., 2005; Nevin et al., 2005; Sung et al., 2006).

The microbial contribution to iron oxidation has long been subject of debate between microbiologists and geochemists (Ghiorse, 1984), especially because abiotic iron oxidation occurs rapidly in the presence of oxygen (Sobolev and Roden, 2002; Emerson and Weiss, 2004). Under anoxic conditions, nitrite is a chemical oxidant of ferrous iron (Moraghan and Buresh, 1977; Cooper et al., 2003; Coby and Picardal, 2005), although this may require millimolar amounts. In spite of these chemical reactions, it is presently accepted that microorganisms can contribute significantly to iron oxidation. Aerobic, acidophilic iron-oxidizing microorganisms play an important role in the generation of acid mine drainage (AMD; Baker and Banfield, 2003). Aerobic, neutrophilic, iron-oxidizing microorganisms, that have to compete with the rapid chemical oxidation, have been isolated from marine as well as freshwater environments, ranging from iron seeps, groundwater, and hydrothermal vents to root-plaque of wetland plants (Emerson and Revsbech, 1994; Emerson and Moyer, 1997; Emerson et al., 1999; Edwards et al., 2003, 2004). The ability to gain energy from anaerobic oxidation of iron is widespread among bacteria. Ferrous iron serves as an electron donor for phototrophic, purple, non-sulfur bacteria, and green sulfur bacteria under anoxic 
conditions (Ehrenreich and Widdel, 1994; Heising et al., 1999). Several bacterial species and an archeon, Ferroglobus placidus, have been described that couple ferrous iron oxidation to nitrate reduction (Hafenbradl et al., 1996; Benz et al., 1998; Straub et al., 2004; Senko et al., 2005; Kumaraswamy et al., 2006; Weber et al., 2006). It has been suggested that on a global scale nitrate-reducing, ironoxidizing bacteria are more important than the phototrophs, since they are not limited by the availability of light (Straub et al., 2001).

Straub et al. (1998) used ferrihydrite produced by ironoxidizing nitrate reducers to enrich iron-reducing bacteria. Indications for the coexistence of aerobic iron-oxidizing and anaerobic iron-reducing microorganisms in close proximity to each other were found by Weiss et al. (2003) and Roden et al. (2004). Furthermore, microbial anoxic iron cycling by a single organism (a Geobacter sp.) capable of both dissimilatory iron reduction and nitrate-dependent iron oxidation was proposed by Weber et al. (2005) and iron respiration with formate as electron donor as well as iron oxidation with nitrate as electron acceptor was demonstrated for the anaerobic ammonium-oxidizing bacterium Kuenenia stuttgartiensis (Strous et al., 2006).

Iron sulfide mineral- and nitrate-rich soils in freshwater ecosystems provide both a source of reduced iron and an electron acceptor that could promote growth of anaerobic, nonphototrophic iron-oxidizers. Oxidized iron species resultant from iron-oxidizing, nitrate-reducing activity could in turn serve as electron acceptors for microbial iron reducers. To determine whether the iron sulfide mineral- and nitrate-rich freshwater environment of the nature reserve Het Zwart Water (Venlo, The Netherlands) provides a suitable habitat for anoxic microbial iron cycling, groundwater from an iron sulfide/and nitrate-rich soil was examined using both culture-dependent and culture-independent methods.

\section{MATERIALS AND METHODS SAMPLING PROCEDURE}

In October 2004, a groundwater sample was collected in the freshwater nature reserve Het Zwart Water $\left(51^{\circ} 24^{\prime} \mathrm{N} ; 6^{\circ} 11^{\prime} \mathrm{E}\right.$, Venlo, The Netherlands) at $1.5 \mathrm{~m}$ depth, at a site situated $1.5 \mathrm{~m}$ from the edge of lake De Venkoelen. Previous measurements had shown increased concentrations of acid volatile sulfur (an indication for the presence of iron sulfide minerals) nitrate, soluble iron, and sulfate around the groundwater table of this system (Haaijer et al., 2006). The collected groundwater was enriched in iron(hydr)oxides (visible orange precipitates). The sample was transported to the lab in a glass serum bottle $(10 \mathrm{ml})$ closed with an aluminum crimp seal. Immediately upon arrival at the lab, high molecular weight DNA was extracted by standard procedures from $0.2 \mathrm{ml}$ of sample and $0.3 \mathrm{ml}$ of the sample was fixed for fluorescence in situ hybridization (FISH) by addition of $4 \%$ $\mathrm{w} / \mathrm{v}$ paraformaldehyde $(0.9 \mathrm{ml})$, incubating on ice $(2 \mathrm{~h})$, centrifuging (15 min, $13.000 \mathrm{rpm})$, and washing the resulting pellet with phosphate buffered saline (PBS) and finally adding $100 \% \mathrm{EtOH}$ and PBS (1:1) after which the sample was stored at $-20^{\circ} \mathrm{C}$ until analysis. Furthermore, mineral media enrichment cultures $(20 \mathrm{ml}$, for composition, see Haaijer et al., 2006) were established through 10 -fold dilution and supplemented with either ferrous iron chloride and nitrate (iron oxidizer culture medium) or ferric iron citrate and acetate (iron reducer culture medium), from anaerobic sterile stock solutions ( $5 \mathrm{mM}$ final concentrations). These enrichment cultures were incubated under a gas atmosphere of $\mathrm{N}_{2} / \mathrm{CO}_{2}$ (80/20\%), and incubated at $30^{\circ} \mathrm{C}$ and $150 \mathrm{rpm}$ for 1.5 months to determine whether the groundwater possessed anoxic ironoxidizing respectively iron-reducing capacity. All further liquid culturing was performed under the same conditions for at least 3 weeks with final concentrations of $8 \mathrm{mM}$ ferrous iron and $2 \mathrm{mM}$ nitrate in the iron oxidizer culture medium and $8 \mathrm{mM}$ ferric iron citrate and $1.5 \mathrm{mM}$ acetate in the iron reducer culture medium unless specified otherwise.

\section{ENRICHMENT AND ISOLATION OF ANAEROBIC IRON-OXIDIZING AND IRON-REDUCING BACTERIA}

The initial iron-oxidizing and reducing enrichment cultures were transferred by 10 -fold dilution and after 1.5 months of incubation used to inoculate iron oxidizer and iron reducer dilution series ( $10 \mathrm{ml}$ tubes, 10 -fold dilutions down to $10^{10}$ dilution). These dilution series were incubated for 1 month without agitation. The three highest dilutions $\left(10^{6}, 10^{7}\right.$, and $10^{8}$ for the iron reducer series, $10^{3}, 10^{4}$, and $10^{5}$ for the iron oxidizer series) exhibiting activity (changes in color: green to whitish-orange for the iron oxidizer, orange to white/green for the iron reducer series) were then used to inoculate new iron oxidizer and reducer cultures $(20 \mathrm{ml}$ volume, 20-fold dilution). Ferric and ferrous iron, nitrate, and nitrite concentrations were determined (see below) at least once a week. When a substrate was depleted, new additions were done from sterile stock solutions. The same procedure was applied to subsequent subcultures.

The 20-ml iron-oxidizing, nitrate-reducing culture obtained from the $10^{5}$ dilution was used to inoculate a larger volume enrichment culture (50-fold dilution, $50 \mathrm{ml}$ ) that was transferred once (50-fold dilution, $50 \mathrm{ml}$ ). To obtain template DNA for PCR (see below), $25 \mathrm{ml}$ of this last culture was centrifuged $(40 \times g, 1 \mathrm{~min})$ to pellet ferrous iron precipitates, the supernatant taken and centrifuged $(2600 \times g, 5 \mathrm{~min})$ to pellet the bacteria, and the resulting pellet was used to isolate high molecular weight DNA.

The 20-ml iron-reducing culture obtained from the $10^{8}$ dilution was used to inoculate a larger volume enrichment culture (50-fold dilution, $50 \mathrm{ml}$ ). This culture was then transferred once (50-fold dilution, $50 \mathrm{ml}$ ) and from the resulting culture a $500-\mathrm{ml}$ enrichment (100-fold dilution, incubation at room temperature, magnetic stirring: $150 \mathrm{rpm}$ ) was derived. Medium of this culture was replenished when ferric iron was depleted by allowing it to settle for at least $6 \mathrm{~h}$ and decanting after which fresh medium was added and the anaerobic gas atmosphere re-applied. The medium was replenished three times before DNA for PCR was extracted from $25 \mathrm{ml}$ culture material as described above. The 500 -ml culture was transferred six times (10-fold dilution). To exclude non-ironreducing contaminants, the iron-reducing culture was checked by plating $1 \mathrm{ml}$ portions on rich Luria Bertani (LB) medium supplemented with $20 \mathrm{mM}$ nitrate and solidified with agar $\left(15 \mathrm{gl}^{-1}\right)$. These plates were incubated at $30^{\circ} \mathrm{C}$ under a $\mathrm{N}_{2} / \mathrm{CO}_{2} 80 / 20 \%$ gas atmosphere. As long as growth was observed on these plates, iron-reducing dilution series were repeated $(3 \times)$. When no more contaminant, non-iron-reducing, growth was detected, concentrations of acetate, ferric iron, and ferrous iron were monitored in a 
50-ml iron-reducing culture over a 90-h period. After this, $0.3 \mathrm{ml}$ of the culture was fixed for FISH analyses as described before. To obtain single colonies of iron-reducing bacteria, liquid iron reducer mineral medium was solidified with agarose $\left(15 \mathrm{gl}^{-1}\right)$ and inoculated with $1 \mathrm{ml}$ aliquots from iron-reducing cultures and incubated at $30^{\circ} \mathrm{C}$ under a $\mathrm{N}_{2} / \mathrm{CO}_{2} 80 / 20 \%$ gas atmosphere for at least 1 month.

\section{ISOLATION OF THIOBACILLUS DENITRIFICANS STRAIN K6.2: A SULFUR-OXIDIZING DENITRIFIER}

An enrichment culture capable of iron sulfide oxidation at the expense of nitrate had been obtained previously from an iron sulfide-rich soil layer (Haaijer et al., 2006) and was used to isolate a sulfur-oxidizing denitrifier (Thiobacillus denitrificans strain K6.2). In short, a dilution series ( 10 consecutive $10 \mathrm{ml}$ volume 10 fold dilutions) in mineral medium (for composition: see Haaijer et al., 2006) amended with $5 \mathrm{mM}$ thiosulfate and $8 \mathrm{mM}$ nitrate per dilution was derived from the enrichment. After incubation at $30^{\circ} \mathrm{C}, 150 \mathrm{rpm}$ under a gas atmosphere of $\mathrm{N}_{2} / \mathrm{CO}_{2}(80 / 20 \%)$ for 2 weeks, the highest dilution $\left(10^{5}\right)$ exhibiting growth was identified by visual inspection (turbidity) and used to establish a 50-ml culture which was subsequently transferred twice (20fold dilution after 1 month of incubation). Aliquots of culture material were checked for the presence of heterotrophic contaminants as described above for the iron reducer cultures. Finally, half of the final pure subculture's volume was used to extract DNA for PCR and 16S rRNA gene sequence analysis as described below.

\section{CHEMICAL ANALYSIS}

Nitrate, nitrite, ferrous iron, and total iron analyses were performed as described previously (Haaijer et al., 2006, 2007). Acetate was measured through injections $(10 \mu \mathrm{l})$ of acidified $(5 \% \mathrm{v} / \mathrm{v}$ formic acid) samples on a Hewlett-Packard model 5890 gas chromatograph equipped with a flame ionization detector $\left(195^{\circ} \mathrm{C}\right)$ and a HP INNOwax column $(30 \mathrm{~m} \times 0.32 \mathrm{~m} \times 0.5 \mu \mathrm{m})$. Column temperature was increased from 35 to $110^{\circ} \mathrm{C}$. Isobutyric acid $(0.4 \mathrm{mM}$ final concentration) was added as an internal standard.

\section{S rRNA GENE SEOUENCE ANALYSIS}

Because most samples contained a high amount of iron species, isolated high molecular weight DNA was purified prior to PCR (QIAEX II gel extraction kit, Qiagen). Hot-start PCR reactions were performed in a Tgradient PCR apparatus (Whatman Biometra, Göttingen, Germany). Primer specifications were described previously (Haaijer et al., 2006). The general bacterial 16S rRNA gene PCR primers 616F and 630R yielded products of about $1500 \mathrm{bp}$. Direct sequencing was performed on the PCR product obtained for the pure culture of T. denitrificans strain K6.2 using sequencing primers M13F, M13R, 1390R, and 610IIF. PCR products of the iron-reducing and oxidizing enrichments were purified once again prior to cloning. The TOPO TA cloning kit was used according to the instructions supplied by the manufacturer (Invitrogen, Groningen, The Netherlands). Isolation of plasmid DNA was performed with the FlexiPrep kit (Amersham Pharmacia P-L Biochemicals Inc.). Clones were checked by restriction analysis of plasmid DNA
(EcoR1, Fermentas UAB, Vilnius, Lithuania). A clone library of the groundwater was constructed by partial sequencing (594840 bp fragments) of 67 clones with primer 610IIF. Preliminary screening of the iron-oxidizing and iron-reducing cultures was performed by partial sequencing (10 clones and 5 clones respectively) with primer 610IIF. One of the clones from the ironreducing culture was selected for full-sequencing with sequencing primers M13F, M13R, 1390R, and 610IIF. In addition, a persistent non-iron-reducing contaminant growing on rich medium plates inoculated with material from the iron-reducing culture was identified by using colony material suspended in MQ as a PCR template, followed by direct partial sequencing with primer 610IIF. 16S rRNA gene sequences were compared with their closest relatives by BLASTN searches ${ }^{1}$ or by pairwise alignment with selected relatives ${ }^{2}$. With the RDP classifier tool $^{3}$ (Wang et al., 2007), clones were assigned to the taxonomical hierarchy proposed in Bergey's Manual of Systematic Bacteriology, release $6.0^{4}$. Further phylogenetic and molecular evolutionary analyses were conducted using the software program MEGA version 5.0 (Tamura et al., 2011). The clone library data was organized by defining operational taxonomic units (OTU's) in which sequences exhibited $\geq 97 \%$ sequence identity. To evaluate the sampling effort in the clone library (Singleton et al., 2001), the coverage of the library $(C)$ was calculated according to the equation $C=\left[1-\left(n_{1} / N\right)\right] \times 100 \%$, where $n_{1}$ is the number of OTUs representing a single clone, and $N$ is the total number of clones analyzed.

\section{ACCESSION NUMBERS}

Sequences (16S rRNA gene) from the groundwater clone library are available in GenBank under accession numbers DQ997625DQ997691. Sequences from cultures are available under accession number EF014493 (representative clone oxo8 from the iron-oxidizing, nitrate-reducing culture), EF014495 (nearly fulllength sequence from the iron-reducing culture), EF014494 (contaminant in the iron-reducing culture), and EF079668 (nearly full-length sequence of $T$. denitrificans strain K6.2).

\section{FISH AND MICROSCOPIC INSPECTIONS}

Fluorescence in situ hybridization analyses were performed as described before (Haaijer et al., 2006). Vectashield (Vector Laboratories, Inc., Burlingame, CA, USA) mounting medium with DAPI (4,6-diamidino-2-phenylindole) was used to enhance the fluorescent signal and stain all DNA. Probes were selected based on the sequencing results from the clone library and cultures. A bacterial probe mix of Cy-5-labeled probes EUB338, EUB338 II, and EUB338 III (Daims et al., 1999) was used to hybridize all Bacteria. Probes Geo 1423, EPS 681 (targeting Geobacter sp. respectively Epsilonproteobacteria, Haaijer et al., 2008), Betthio 1001 (betaproteobacterial Thiobacilli, Haaijer et al., 2006), BrG1-829, and BrG2-830 (iron-oxidizing denitrifiers, Straub and BuchholzCleven, 1998) were used to specifically detect organisms of interest.

\footnotetext{
${ }^{1}$ http://www.ncbi.nih.nlm.edu/BLAST

${ }^{2} \mathrm{http}: / /$ pir.georgetown.edu/pirwww/search/pairwise.shtml

${ }^{3}$ http://rdp.cme.msu.edu/classifier/

${ }^{4} \mathrm{http}$ ://bergeysoutline.com
} 
The total cell number (DAPI) in the groundwater was determined by analysis of 50 images. To quantify specific probe signals, 10 images were analyzed for each probe. As a control, background fluorescence was determined by analysis of 10 images of DAPIstained groundwater without probes. Specific probe signals were only regarded as significant when they exceeded this number $(5 \pm 1.8 \%$ of the total DAPI count) in a statistically significant manner (Student's $t$-test).

\section{RESULTS \\ SAMPLE GEOCHEMISTRY}

The groundwater sample was collected in the freshwater nature reserve Het Zwart Water at $1.5 \mathrm{~m}$ depth, at a site situated $1.5 \mathrm{~m}$ from the edge of lake De Venkoelen. High acid volatile sulfur ( $60 \mathrm{nmol} \mathrm{g} \mathrm{DW} \mathrm{soil}^{-1}$; an indication for the presence of iron sulfide minerals) nitrate $\left(22 \mathrm{nmolg}\right.$ DW soil $\left.{ }^{-1}\right)$, soluble iron $(25 \mathrm{nmolg}$ DW soil $\left.{ }^{-1}\right)$, and sulfate $\left(90 \mathrm{nmolg}\right.$ DW soil $\left.{ }^{-1}\right)$ concentrations were observed around the groundwater table (van der Welle, unpublished results). The collected groundwater was enriched in iron(hydr)oxides visible as orange precipitates.

\section{CELL COUNT AND 165 rRNA CLONE LIBRARY}

The iron sulfide- and nitrate-rich freshwater wetland Het Zwart Water was assumed to provide a suitable environment for anoxic iron cycling bacteria. The groundwater collected from Het Zwart Water contained $8 \pm 3 \times 10^{7} \mathrm{ml}^{-1}$ bacteria based on the enumeration of DAPI-stained cells. The 16S rRNA gene sequence-based clone library derived from the bacteria present in the groundwater had a coverage of $66 \%$ and resulted in the identification of 30 separate OTU's. Table 1 provides an overview of these OTU's and provides information on the microbial processes that the first BLASTN hit with a cultured species is associated with for each OTU whenever such physiological information was available. If no published data was available for the microbial processes associated with the first BLASTN hit with a cultured species from GenBank, source information is listed in Table 1 instead. An exception was made for OTU 1 which encompasses $16 \mathrm{~S}$ rRNA gene sequences within the genus Thiobacillus. This genus harbors both species converting nitrate only to nitrite (e.g., Thiobacillus thioparus) and T. denitrificans a species capable of complete denitrification to dinitrogen. These species share a high 16S rRNA gene sequence similarity of about $98 \%$. Therefore, a comparison was made for OTU 1 sequences with the 16S rRNA gene sequence of the denitrifying, sulfur-oxidizing T. denitrificans strain K6.2 obtained within this study.

As described below, the culture-independent and culturedependent methods used in this study, yielded contrasting results for iron-oxidizing nitrate reducers, and iron reducers, respectively. In addition, sulfur-oxidizing denitrifiers were found the most abundant physiologically distinct group.

\section{IRON-OXIDIZING, NITRATE REDUCERS}

The clone library data from the groundwater (Table 1) contained multiple (OTU11, 9\% of total clones) sequences strongly resembling ( $\geq 97 \%$ sequence identity) the iron-oxidizing, nitratereducing Acidovorax strain BrG1 (Buchholz-Cleven et al., 1997; Straub et al., 2004). FISH analysis of the groundwater sample, with a combination of probe BrG1-829, and competitor probe BrG2-830, showed the in situ abundance of strain BrG1-like microorganisms ( $25 \pm 9 \%$ of the total DAPI count). The primary iron-oxidizing, nitrate-reducing enrichment culture derived from the groundwater exhibited activity (visible as a color change from green to whitish-orange due to the oxidation of ferrous iron). The dilution series derived from this primary enrichment demonstrated the presence of $10^{5} \mathrm{ml}^{-1}$ iron-oxidizing bacteria. Subsequent subcultures exhibited iron-oxidizing, nitrate-reducing activity. Stoichiometry of these cultures was in good agreement with the theoretical values of $10 \mathrm{~mol}$ ferrous oxidized at the expense of $2 \mathrm{~mol}$ of nitrate. In one of the subcultures for example $1.5 \mathrm{mM}$ of ferrous iron was oxidized at the expense of $0.4 \mathrm{mM}$ nitrate, accompanied by a minor formation of nitrite $(0.05 \mathrm{mM})$.

Despite the abundance of Acidovorax strain BrG1 ironoxidizing denitrifiers suggested by the clone library and FISH analyses data, these organisms were not detected in the final $50 \mathrm{ml}$ volume enrichment culture by $16 \mathrm{~S}$ rRNA analysis. Instead, a Klebsiella-like bacterium was detected. The consensus $16 \mathrm{~S}$ rRNA gene sequence obtained from the enrichment ( 10 clones, $830 \mathrm{bp}$ ), was identical to the sequence of representative clone oxo8 and exhibited $99 \%$ sequence similarity to the Klebsiella pneumoniae strain described by Ludwig et al., 1995, accession number X87276). The clone library of the original sample contained a clone (Table 1; OTU13) with $99 \%$ sequence identity to the 16S rRNA gene sequence obtained from the culture, indicating the presence of this organism in the groundwater. Upon further transfer of the iron-oxidizing, nitrate-reducing culture, the activity was lost and addition of acetate as an organic co-substrate did not restore activity (data not shown).

\section{IRON REDUCERS}

No 16S rRNA gene sequences of known iron-reducing species could be identified within the clone library data. FISH analysis of the groundwater using Geobacter-specific probe Geo1423 did not yield significant hybridization $(<5 \pm 1.8 \%$ of the total DAPI count cells hybridized). The iron-reducing dilution series of the initial enrichment culture however showed that this culture contained $10^{8} \mathrm{ml}^{-1}$ iron-reducing bacteria. Subcultures were readily obtained and very active: the medium of all subcultures needed to be replenished at least once a week. 16S rRNA gene sequence analysis demonstrated the presence of a Geobacter sp. in the final enrichment. The consensus sequence (five clones, $804 \mathrm{bp}$ ) and the nearly full-length $16 \mathrm{~S}$ rRNA gene sequence (1526 bp) generated exhibited $100 \%$ sequence identity. Both sequences exhibited $99 \%$ sequence identity to the Geobacter sp. previously described by Cummings et al., 2000, accession number Y19191). Plating on rich medium showed a persistent contamination with a Citrobacter freundii-like organism. The partial $16 \mathrm{~S}$ rRNA gene sequence of $684 \mathrm{bp}$ obtained from this organism exhibited $99 \%$ sequence identity to C. freundii strain DSM 30039 (accession number AJ233408, Sproer et al., 1999). The C. freundii-like organism did not possess any iron-reducing capacity as demonstrated by a lack of iron reduction after 2 months of incubation of $250 \mathrm{ml}$ iron reducer medium inoculated with this organism. Incubation of mineral media plates containing ferric citrate and acetate 
Table 1 | Overview clone library data from the groundwater of Het Zwart Water.

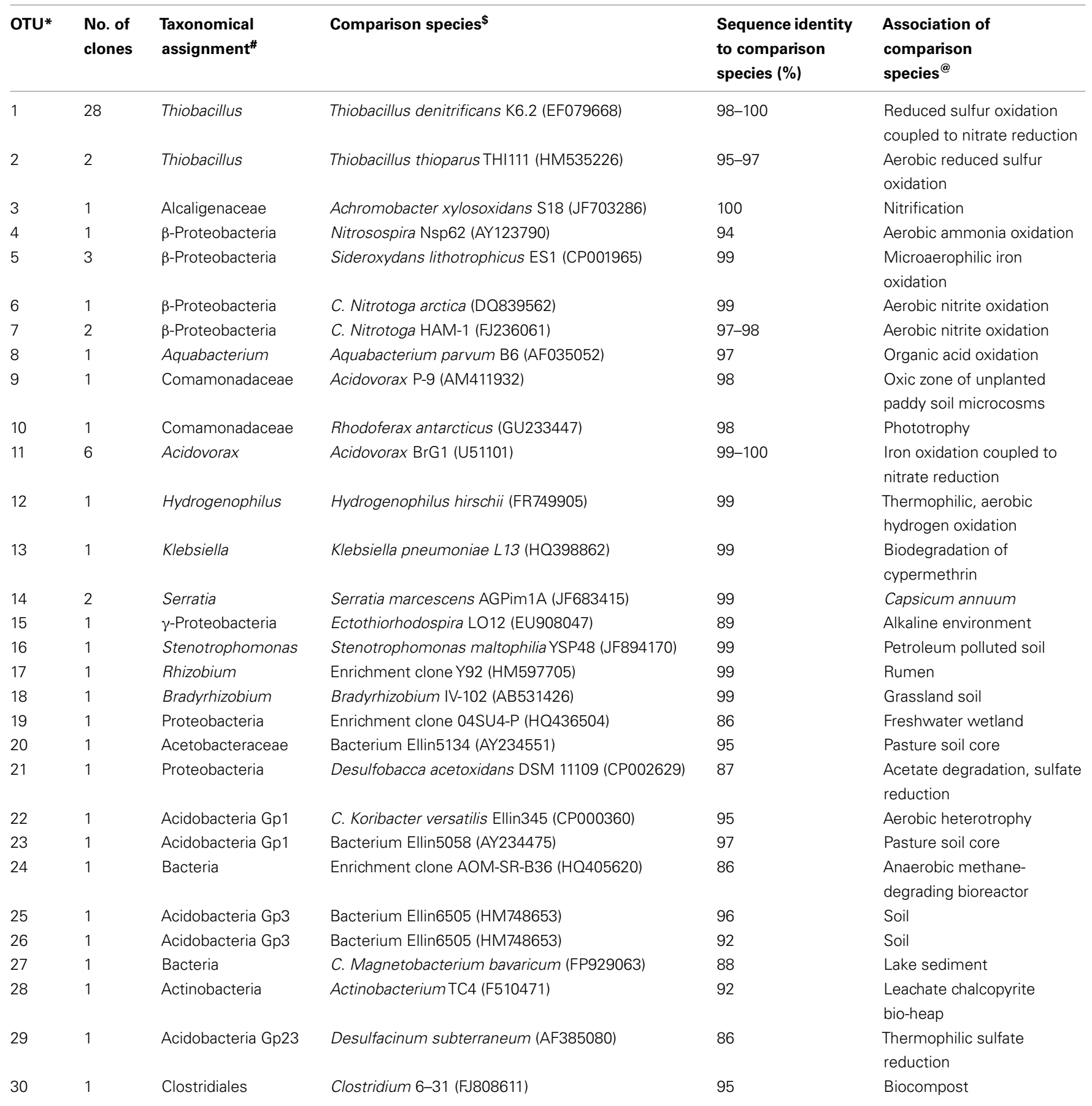

${ }^{*}$ An OTU consists of sequences exhibiting $\geq 97 \%$ sequence identity; ${ }^{*}$ based on the RDP classifier tool (http://rdp.cme.msu.edu/classifier/; Wang et al., 2007); $\$$ in case of OTU 1 the 16S rRNA gene sequence of the denitrifying Thiobacillus denitrificans strain K6.2 was used, for the others the first BLASTN hit of a cultured species was used; ${ }^{\circledR}$ if an association with a specific process was found this process is mentioned, otherwise the environment from which the sequence was retrieved is mentioned.

and inoculated with iron reducer enrichment material yielded growth of the contaminant bacterium only. The activity of the, through repetitive serial dilutions, obtained pure Geobacter sp. culture is shown in Figure 1. Over a period of $63 \mathrm{~h}, 1 \mathrm{mM}$ of acetate was consumed and $5 \mathrm{mM}$ ferric iron reduced. FISH analysis further confirmed the pure culture status because all DAPI-stained cells hybridized with the Geobacter-specific probe Geo1423. 


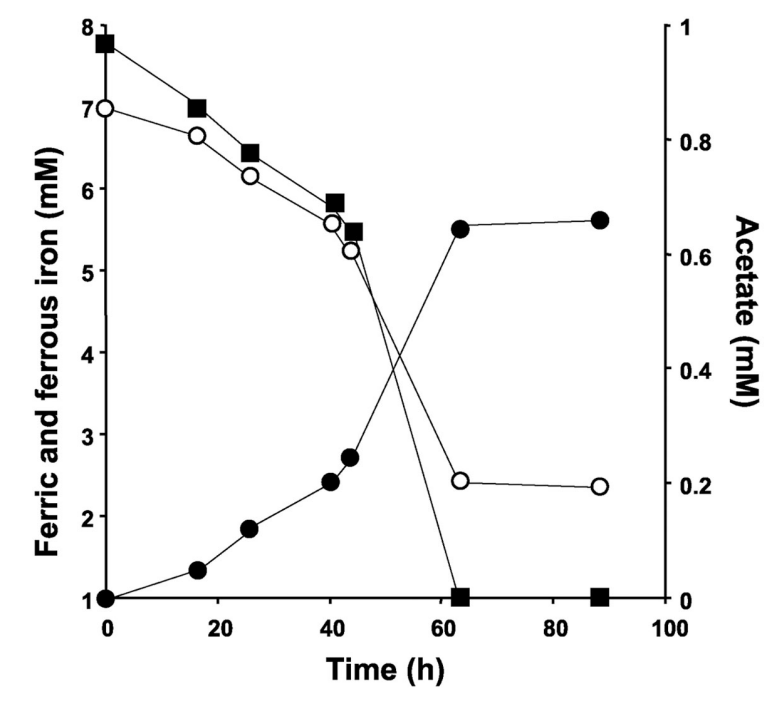

FIGURE 1 | Activity of the pure iron-reducing Geobacter sp. culture. The closed squares indicate acetate, the closed circles ferrous iron, and the open circles ferric iron.

\section{SULFUR-OXIDIZING NITRATE REDUCERS}

The clone library data (Table 1; OTU 1) revealed $42 \%$ of the clones exhibited a sequence identity higher than $98 \%$ to the $16 \mathrm{~S}$ rRNA gene sequence of $T$. denitrificans strain K6.2. FISH analysis of the groundwater material from Het Zwart Water with betaproteobacterial Thiobacilli-specific probe Betthio1001 corroborated the abundance of these microorganisms $(23 \pm 9 \%$ of the total DAPI count). Iron sulfide- and nitrate-rich environments like Het Zwart Water will be enriched in sulfide in addition to reduced iron as a possible electron donor for microbial growth. In addition to betaproteobacterial Thiobacilli, likely candidates for sulfide oxidation at the expense of nitrate are epsilonproteobacterial species like Sulfurimonas denitrificans (previously known as Thiomicrospira denitrificans; Schippers and Jørgensen, 2002; Takai et al., 2006) and members of the genus Sulfuricurvum (Kodama and Watanabe, 2004). Significant numbers of Epsilonproteobacteria were not detected (probe EPS 681) in the groundwater. In addition, the clone library did not contain epsilonproteobacterial sequences (Table 1).

\section{DISCUSSION}

IRON CYCLE BACTERIA IN THE GROUNDWATER OF HET ZWART WATER Although T. denitrificans possesses iron-oxidizing capacity in the presence of nitrate, specific reaction rates are much lower, weeks opposed to days, than those of the specific iron-oxidizing nitrate reducers previously described by Straub et al. (1996). Given the abundance of strain BrG1-like bacteria, it therefore seems most likely that the betaproteobacterial Thiobacilli detected in the groundwater are primarily involved in the oxidation of reduced sulfur compounds in Het Zwart Water as was demonstrated before (Haaijer et al., 2006, 2007).

Based on the abundance of Acidovorax strain BrG1-like bacteria, suggested by the clone library and FISH analyses data, these microorganisms are proposed as the mediators for anoxic iron oxidation in the groundwater from Het Zwart Water. In the iron sulfide- and nitrate-rich environment of Het Zwart Water these bacteria could be of particular importance. Edwards et al. (2004) demonstrated accelerated iron sulfide mineral dissolution in the presence of iron-oxidizing bacteria. This hypothesis is supported by earlier findings of the presence of this type of bacterium in an iron sulfide- and nitrate-fed enrichment culture (Haaijer et al., 2006). However, despite their abundance, strain BrG1-like bacteria were not detected in the final $50 \mathrm{ml}$ volume enrichment culture. Instead, a Klebsiella-like bacterium was detected. Iron-oxidizing, nitrate-reducing activity by Klebsiella sp. cells has been described by Senko et al. (2005) under non-growth conditions. It therefore seems likely the K. pneumoniae-like organism detected in the iron-oxidizing nitrate-reducing culture did not possess the capacity of generating sufficient energy for growth by coupled iron oxidation and nitrate reduction. This fact together with the absence of any obvious iron-reducing bacteria in the groundwater, as demonstrated with the molecular methods, shows that complete microbial iron cycling could not be convincingly demonstrated in the groundwater of Het Zwart Water. The isolation of the iron-reducing Geobacter sp., however, indicates that bacterial iron reduction at the least could be important in other compartments (e.g., the surrounding soil) of Het Zwart Water.

The iron-reducing Geobacter isolate converted $1 \mathrm{mM}$ of acetate at the expense of $5 \mathrm{mM}$ ferric iron and FISH analysis confirmed the pure culture status. This ratio does not agree well with the theoretical stoichiometry of $8 \mathrm{mM}$ ferric iron reduced at the expense of $1 \mathrm{mM}$ acetate (Lovley et al., 1987). The contribution of assimilation to the total amount of acetate consumed, however, can be high: $46 \%$ of total acetate metabolized was assimilated by Geobacter sulfurreducens grown in batch culture on fumarate and acetate (Galushko and Schink, 2000). This phenomenon may also explain the observed low amount of ferric iron reduced in the Geobacter sp. culture described presently.

\section{DIFFERENCES IN THE DETECTION OF IRON-OXIDIZING NITRATE REDUCERS AND IRON REDUCERS}

Molecular analyses (16S rRNA gene clone library and FISH) showed that the Acidovorax strain BrG1-like, iron-oxidizing nitrate reducers accounted for a major portion of the microbial community of the groundwater sample from Het Zwart Water. In contrast to the abundance demonstrated by the molecular data, the cultivation procedure did not lead to the enrichment or isolation of this type of bacterium. A probable cause is the completely autotrophic culturing conditions adopted in the ironoxidizing enrichments. Iron-oxidizing nitrate-reducing activity was first reported (Straub et al., 1996) for a solely lithotrophic enrichment culture. Isolated strains, however, seem dependent on the presence of organic co-substrates (Straub et al., 2004). In contrast to the results for iron-oxidizers, an iron-reducing Geobacter sp. culture was readily obtained. The molecular analyses, however, suggested the contribution of this bacterium was of little numerical relevance in the groundwater sample. Together, these results, conflicting as they are for the functional groups of interest in this study, illustrate the necessity to employ both 
culture-dependent and culture-independent methods in studies on microbial activity. To choose only one approach is to disregard the biases inherent to this approach, such as primer-induced biases in clone libraries (Forney et al., 2004), or selection of fast-growing microorganisms in culture media (Grosskopf et al., 1998). Inventory descriptive studies like ours, allow development

\section{REFERENCES}

Anderson, R. T., Rooney-Varga, J. N., Gaw, C. V., and Lovley, D. R. (1998). Anaerobic benzene oxidation in the $\mathrm{Fe}$ (III) reduction zone of petroleumcontaminated aquifers. Environ. Sci. Technol. 32, 1222-1229.

Baker, B. J., and Banfield, J. F. (2003). Microbial communities in acid mine drainage. FEMS Microbiol. Ecol. 44, 139-152.

Benz, M., Brune, A., and Schink, B. (1998). Anaerobic and aerobic oxidation of ferrous iron at neutral $\mathrm{pH}$ by chemoheterotrophic nitratereducing bacteria. Arch. Microbiol. 169, 159-165.

Buchholz-Cleven, B. E. E., Rattunde, B., and Straub, K. L. (1997). Screening for genetic diversity of isolates of anaerobic $\mathrm{Fe}$ (II)-oxidizing bacteria using DGGE and whole-cell hybridization. Syst. Appl. Microbiol. 20, 301-309.

Carey, E., and Taillefert, M. (2005). The role of soluble $\mathrm{Fe}(\mathrm{III})$ in the cycling of iron and sulfur in coastal marine sediments. Limnol. Oceanogr. 50, 1129-1141.

Castillo-Gonzalez, H. A., and Bruns, M. A. (2005). Dissimilatory iron reduction and odor indicator abatement by biofilm communities in swine manure microcosms. Appl. Environ. Microbiol. 71, 4972-4978.

Coby, A. J., and Picardal, F. W. (2005). Inhibition of $\mathrm{NO}_{3}{ }^{-}$and $\mathrm{NO}_{2}{ }^{-}$reduction by microbial $\mathrm{Fe}$ (III) reduction: evidence of a reaction between $\mathrm{NO}_{2}{ }^{-}$ and cell surface-bound $\mathrm{Fe}^{2+}$. Appl. Environ. Microbiol. 71, 5267-5274.

Cooper, D. C., Picardal, F. W., Schimmelmann, A., and Coby, A. J. (2003). Chemical and biological interactions during nitrate and goethite reduction by Shewanella putrefaciens 200. Appl. Environ. Microbiol. 69, 3517-3525.

Cummings, D. E., Caccavo, F., Spring, S., and Rosenzweig, R. F. (1999). Ferribacterium limneticum, gen. nov., sp. nov., an Fe(III)-reducing microorganism isolated from mining-impacted freshwater lake sediments. Arch. Microbiol. 171, 183-188.

Cummings, D. E., March, A. W., Bostick, B., Spring, S., Caccavo, F., Fendorf, S., and Rosenzweig, R. F. (2000). Evidence for microbial
$\mathrm{Fe}(\mathrm{III})$ reduction in anoxic, miningimpacted lake sediments (lake Coeur d'Alene, Idaho). Appl. Environ. Microbiol. 66, 154-162.

Daims, H., Bruhl, A., Amann, R. I., Schleifer, K. H., and Wagner, M. (1999). The domain-specific probe EUB338 is insufficient for the detection of all bacteria: development and evaluation of a more comprehensive probe set. Syst. Appl. Microbiol. 22, 434-444.

Davison, W. (1993). Iron and manganese in lakes. Earth Sci. Rev. 34, 119-163.

Edwards, K. J., Bach, W., McCollom, T. M., and Rogers, D. R. (2004). Neutrophilic iron-oxidizing bacteria in the ocean: their habitats, diversity, and role in mineral deposition, rock alteration, and biomass production in the deep-sea. Geomicrobiol. J. 21, 393-404.

Edwards, K. J., Rogers, D. R., Wirsen, C. O., and McCollom, T. M. (2003). Isolation and characterization of novel psychrophilic, neutrophilic, Fe-oxidizing, chemolithoautotrophic $\alpha$ - and $\gamma$-Proteobacteria from the deep sea. Appl. Environ. Microbiol. 69, 2906-2913.

Ehrenreich, A., and Widdel, F. (1994). Anaerobic oxidation of ferrous iron by purple bacteria, a new type of phototrophic metabolism. Appl. Environ. Microbiol. 60, 4517-4526.

Emerson, D., and Moyer, C. (1997). Isolation and characterization of novel iron-oxidizing bacteria that grow at circumneutral pH. Appl. Environ. Microbiol. 63, 4784-4792.

Emerson, D., and Revsbech, N. P. (1994). Investigation of an ironoxidizing microbial mat community located near Aarhus, Denmark: field studies. Appl. Environ. Microbiol. 60, 4023-4031.

Emerson, D., and Weiss, J. V. (2004). Bacterial iron oxidation in circumneutral freshwater habitats: findings from the field and the laboratory. Geomicrobiol. J. 21, 405-414.

Emerson, D., Weiss, J. V., and Megonigal, J. P. (1999). Iron-oxidizing bacteria are associated with ferric hydroxide precipitates (Fe-plaque) on the roots of wetland plants. Appl. Environ. Microbiol. 65, 2758-2761.

Finneran, K. T., Johnsen, C. V., and Lovley, D. R. (2003). Rhod-

of more direct approaches, necessary to understand ecosystem functioning.

\section{ACKNOWLEDGMENTS}

We thank Fons Smolders, Jack Van de Vossenberg, and Marcus Schmid for advice and discussion.

oferax ferrireducens sp. nov., a psychrotolerant, faculatively anaerobic bacterium that oxidizes acetate with the reduction of $\mathrm{Fe}(\mathrm{III})$. Int. J. Syst. Evol. Microbiol. 53, 669-673.

Forney, L. J., Zhou, X., and Brown, C. J. (2004). Molecular microbial ecology: land of the one-eyed king. Curr. Opin. Microbiol. 7, 1-11.

Galushko, A. S., and Schink, B. (2000) Oxidation of acetate through reactions of the citric acid cycle by Geobacter sulfurreducens in pure culture and in syntrophic coculture. Arch. Microbiol. 174, 314-321.

Ghiorse, W. C. (1984). Biology of iron-depositing and manganesedepositing bacteria. Annu. Rev. Microbiol. 38, 515-550.

Grosskopf, R., Janssen, P. H., and Liesack, W. (1998). Diversity and structure of the methanogenic community in anoxic rice paddy soil microcosms as examined by cultivation and direct $16 \mathrm{~S}$ rRNA gene sequence retrieval. Appl. Environ. Microbiol. 64, 960-969.

Haaijer, S. C. M., Harhangi, H. R., Meijerink, B. B., Strous, M., Pol, A., Smolders, A. J. P., Verwegen, K., Jetten, M. S. M., and Op den Camp, H. J. M. (2008). Bacteria associated with iron seeps in a sulfur-rich, neutral $\mathrm{pH}$ freshwater ecosystem. ISME J. 2, 1231-1242.

Haaijer, S. C. M., Lamers, L. P. M., Smolders, A. J. P., Jetten, M. S. M., and Op den Camp, H. J. M. (2007). Iron sulfide and pyrite as potential electron donors for microbial nitrate reduction in freshwater wetlands. Geomicrobiol. J. 24, 391-401.

Haaijer, S. C. M., van der Welle, M. E. W., Schmid, M. C., Lamers, L. P. M., Jetten, M. S. M., and Op den Camp, H. J. M. (2006). Evidence for the involvement of betaproteobacterial Thiobacilli in the nitrate-dependent oxidation of iron sulfide minerals. FEMS Microbiol. Ecol. 58, 439-448.

Hafenbradl, D., Keller, M., Dirmeier, R., Rachel, R., Rossnagel, P., Burggraf, S., Huber, H., and Stetter, K. O. (1996). Ferroglobus placidus gen nov, sp nov, a novel hyperthermophilic archaeum that oxidizes $\mathrm{Fe}_{2}{ }^{+}$at neutral $\mathrm{pH}$ under anoxic conditions. Arch. Microbiol. 166, 308-314.

Heising, S., Richter, L., Ludwig, W., and Schink, B. (1999). Chlorobium ferrooxidans sp. nov., a phototrophic green sulfur bacterium that oxidizes ferrous iron in coculture with a "Geospirillum" sp. strain. Arch. Microbiol. 172, 116-124.

Kashefi, K., Tor, J. M., Holmes, D. E., Van Praag, C. V., Reysenbach, A. L., and Lovley, D. R. (2002). Geoglobus ahangari gen. nov., sp. nov., a novel hyperthermophilic archeon capable of oxidizing organic acids and growing autotrophically on hydrogen with $\mathrm{Fe}(\mathrm{III})$ serving as the sole electron donor. Int. J. Syst. Evol. Microbiol. 52, 719-728.

Kodama, Y., and Watanabe, K. (2004). Sulfuricurvum kujiense gen. nov., sp nov., a facultatively anaerobic, chemolithoautotrophic, sulfuroxidizing bacterium isolated from an underground crude-oil storage cavity. Int. J. Syst. Evol. Microbiol. 54, 2297-2300.

Kumaraswamy, R., Sjollema, K., Kuenen, G., van Loosdrecht, M., and Muyzer, G. (2006). Nitratedependent [Fe(II)EDTA](2-) oxidation by Paracoccus ferrooxidans sp nov., isolated from a denitrifying bioreactor. Syst. Appl. Microbiol. 29, 276-286.

Lin, B., Braster, M., van Breukelen, B. M., van Verseveld, H. W., Westerhoff, H. V., and Röling, W. F. M. (2005). Geobacteraceae community composition is related to hydrochemistry and biodegradation in an iron-reducing aquifer polluted by a neighbouring landfill. Appl. Environ. Microbiol. 71, 5983-5991.

Lovley, D. R., and Phillips, E. J. P. (1988). Novel mode of microbial energy metabolism: organic carbon oxidation coupled to dissimilatory reduction of iron or manganese. Appl. Environ. Microbiol. 54, 1472-1480.

Lovley, D. R., Stolz, J. F., Nord, G. L., and Phillips, E. J. P. (1987). Anaerobic production of magnetite by a dissimilatory iron-reducing microorganism. Nature 330, 252-254.

Ludwig, W., Rosselo-Mora, R., Aznar, R., Klugbauer, S., Spring, S., Reetz, K., Beimfohr, C., Brockmann, E., Kirchhof, G., Dorn, S., Bachleitner, M., Klugbauer, N., Springer, N., Lane, D., Nietupsky, R., Weizenegger, M., and Schleifer, K.-H. (1995). Comparative sequence analysis of $23 \mathrm{~S}$ rRNA from 
Proteobacteria. Syst. Appl. Microbiol. $18,164-188$.

Moraghan, J. T., and Buresh, R. J. (1977). Chemical reduction of nitrite and nitrous-oxide by ferrous iron. Soil Sci. Soc. Am. J. 41, 47-50.

Nealson, K. H., Belz, A., and McKee, B. (2002). Breathing metals as a way of life: geobiology in action. Antonie Van Leeuwenhoek 81, 215-222.

Nealson, K. H., and Saffarini, D. (1994). Iron and manganese in anaerobic respiration: environmental significance, physiology, and regulation. Annu. Rev. Microbiol. 48, 311-343.

Nevin, K. P., Holmes, D. E., Woodard, T. L., Hinlein, E. S., Ostendorf, D. W., and Lovley, D. R. (2005). Geobacter bemidjiensis sp. nov. and Geobacter psychrophilus sp. nov., two novel $\mathrm{Fe}(\mathrm{III})$-reducing subsurface isolates. Int. J. Syst. Evol. Microbiol. 55, 1667-1674.

Nevin, K. P., and Lovley, D. R. (2002). Mechanisms for accessing insoluble $\mathrm{Fe}(\mathrm{III})$ oxide during dissimilatory $\mathrm{Fe}(\mathrm{III})$ reduction by Geothrix fermentans. Appl. Environ. Microbiol. 68, 2294-2299.

Roden, E. E., Sobolev, D., Glazer, B., and Luther, G. W. (III). (2004). Potential for microscale bacterial Fe redox cycling at the aerobicanaerobic interface. Geomicrobiol. J. 21,379-391.

Schippers, A., and Jørgensen, B. B. (2002). Biogeochemistry of pyrite and iron sulfide oxidation in marine sediments. Geochim. Cosmochim. Acta 66, 85-92.

Senko, J. M., Dewers, T. A., and Krumholz, L. R. (2005). Effect of oxidation rate and $\mathrm{Fe}(\mathrm{II})$ state on microbial nitrate-dependent $\mathrm{Fe}$ (III) mineral formation. Appl. Environ. Microbiol. 71, 7172-7177.

Singleton, D. R., Furlong, M. A., Rathbun, S. L., and Whitman, W. B. (2001). Quantitative comparisons of $16 \mathrm{~S}$ rRNA gene sequence libraries from environmental samples. Appl. Environ. Microbiol. 67. 4374-4376.

Sobolev, D., and Roden, E. E. (2002). Evidence for the rapid microscale bacterial redox cycling of iron in circumneutral environments.
Antonie Van Leeuwenhoek 81, 587-597.

Sproer, C., Mendrock, U., Swiderski, J., Lang, E., and Stackebrandt, E. (1999). The phylogenetic position of Serratia, Buttiauxella and some other genera of the family Enterobacteriaceae. Int. J. Syst. Bacteriol. 49, 1433-1438.

Straub, K. L., Benz, B., Schink, B., and Widdel, F. (1996). Anaerobic, nitrate dependent microbial oxidation of ferrous iron. Appl. Environ. Microbiol. 62, 1458-1460.

Straub, K. L., Benz, M., and Schink, B. (2001). Iron metabolism in anoxic environments at near neutral $\mathrm{pH}$. FEMS Microbiol. Ecol. 34, 181-186.

Straub, K. L., and Buchholz-Cleven, B. E. E. (1998). Enumeration and detection of anaerobic ferrous iron oxidizing, nitrate reducing bacteria from diverse European sediments. Appl. Environ. Microbiol. 64, 4846-4856.

Straub, K. L., Hanzlik, M., and Buchholz-Cleven, B. E. E. (1998). The use of biologically produced ferrihydrite for the isolation of novel iron-reducing bacteria. Syst. Appl. Microbiol. 21, 442-449.

Straub, K. L., Schönhuber, W. A., Buchholz-Cleven, B. E. E., and Schink, B. (2004). Diversity of ferrous iron-oxidizing, nitratereducing bacteria and their involvement in oxygen-independent iron cycling. Geomicrobiol. J. 21, 371-378.

Strous, M., Pelletier, E., Mangenot, S., Rattei, T., Lehner, E., Taylor, M. W., Horn, M., Daims, H., Bartol-Mavel, D., Wincker, P., Barbe, V., Fonknechten, N., Vallenet, D., Segurens, B., Schenowitz-Truong, C., Médigue, C., Collingro, A., Snel, B., Dutilh, B. E., Op den Camp, H. J. M., van der Drift, C., Cirpus, I., van de Pas-Schoonen, K. T., Harhangi, H. R., van Niftrik, L., Schmid, M., Keltjens, J., van de Vossenberg, J., Kartal, B., Meier, H., Frishman, D., Huynen, M. A., Mewes, H.-W., Weissenbach, J., Jetten, M. S. M., Wagner, M., and Le Paslier, D. (2006). Deciphering the evolution and metabolism of an anammox bacterium from a community genome. Nature 440 790-794.

Stumm, W., and Sulzberger, B. (1992) The cycling of iron in natural environments - considerations based on laboratory studies of heterogeneous redox processes. Geochim. Cosmochim. Acta 56, 3233-3257.

Sung, Y., Fletcher, K. E., Ritalahti, K. M., Apkarian, R. P., Ramos-Hernández, N., Sanford, R. A., Mesbah, N M., and Löffler, F. E. (2006). Geobacter lovleyi sp. nov. strain SZ, a novel metal-reducing and tetrachloroethene-dechlorinating bacterium. Appl. Environ. Microbiol. 72, 2775-2782.

Takai, K., Suzuki, M., Nakagawa, S. Miyazaki, M., Suzuki, Y., Inagaki, F., and Horikoshi, K. (2006). Sulfurimonas paralvinellae sp nov., a novel mesophilic, hydrogen- and sulfuroxidizing chemolithoautotroph within the Epsilonproteobacteria isolated from a deep-sea hydrothermal vent polychaete nest, reclassification of Thiomicrospira denitrificans as Sulfurimonas denitrificans comb. nov and emended description of the genus Sulfurimonas. Int. J. Syst. Evol. Microbiol. 56, 1725-1733.

Tamura, K., Peterson, D., Peterson, N., Stecher, G., Nei, M., and Kumar, S. (2011). MEGA5: molecular evolutionary genetics analysis using maximum likelihood, evolutionary distance, and maximum parsimony methods. Mol. Biol. Evol. 28 , 2731-2739.

Thamdrup, B. (2000). Bacterial manganese and iron reduction in aquatic sediments. Adv. Microb. Ecol. 16 41-84.

Thamdrup, B., Fossing, H., and Jørgensen, B. B. (1994). Manganese, iron, and sulfur cycling in a coastal marine sediment, Aarhus Bay, Denmark. Geochim. Cosmochim. Acta 58 5115-5129.

Tor, J. M., Kashefi, K., and Lovley, D. R. (2001). Acetate oxidation coupled to Fe(III) reduction in hyperthermophilic microorganisms. Appl. Environ. Microbiol. 67, 1363-1365.
Wang, Q., Garrity, G. M., Tiedje, J. M., and Cole, J. R. (2007). Naïve Bayesian classifier for rapid assignment of rRNA sequences into the new bacterial taxonomy. Appl. Environ. Microbiol. 73, 5261-5267.

Weber, K. A., Pollock, J., Cole, K. A., O'Connor, S. M., Achenbach, L. A., and Coates, J. D. (2006) Anaerobic nitrate-dependent iron(II) bio-oxidation by a novel lithoautotrophic betaproteobacterium, strain 2002. Appl. Environ. Microbiol. 72, 686-694.

Weber, K. A., Urrutia, M. M., Churchill, P. F., Kukkadapu, R. K., and Roden, E. E. (2005). Anaerobic redox cycling of iron by freshwater sediment microorganisms. Environ. Microbiol. 8, 100-113.

Weiss, J. V., Emerson, D., Backer, S. M., and Megonigal, J. P. (2003). Enumeration of $\mathrm{Fe}(\mathrm{II})$-oxidizing and $\mathrm{Fe}$ (III)-reducing bacteria in the root zone of wetland plants: implications for a rhizosphere iron cycle. Biogeochemistry 64, 77-96.

Conflict of Interest Statement: The authors declare that the research was conducted in the absence of any commercial or financial relationships that could be construed as a potential conflict of interest.

Received: 08 November 2011; accepted: 16 January 2012; published online: 03 February 2012.

Citation: Haaijer SCM, Crienen G, Jetten MSM and Op den Camp HJM (2012) Anoxic iron cycling bacteria from an iron sulfide- and nitrate-rich freshwater environment. Front. Microbio. 3:26. doi: 10.3389/fmicb.2012.00026

This article was submitted to Frontier in Terrestrial Microbiology, a specialty of Frontiers in Microbiology.

Copyright (C) 2012 Haaijer, Crienen, Jetten and Op den Camp. This is an openaccess article distributed under the terms of the Creative Commons Attribution Non Commercial License, which permits non-commercial use, distribution, and reproduction in other forums, provided the original authors and source are credited. 


\title{
Environmental controls on nitrogen and sulfur cycles in surficial aquatic sediments
}

\author{
Chuanhui Gu ${ }^{1}$, Anniet M. Laverman ${ }^{2 *}$ and Céline E. Pallud ${ }^{3}$ \\ ${ }^{1}$ Department of Geology, Appalachian State University, Boone, NC, USA \\ ${ }^{2}$ UMR 7619 Sisyphe, CNRS - Université Pierre et Marie Curie, 75005 Paris, France \\ ${ }^{3}$ Environmental Science, Policy and Management, University of California, Berkeley, CA, USA
}

Edited by:

Paul Bodelier, Netherlands Institute of

Ecology, Netherlands

\section{Reviewed by:}

Nick Bouskill, Lawrence Berkeley

National Laboratory, USA

Suzanne Caroline Marianne Haaijer,

Radboud University Nijmegen,

Netherlands

${ }^{*}$ Correspondence:

Anniet M. Laverman, UMR 7619

Sisyphe, Université Pierre et Marie Curie, 75005 Paris, France.

e-mail:Anniet.Laverman@upmc.fr
Enhanced anthropogenic inputs of nitrogen $(\mathrm{N})$ and sulfur $(\mathrm{S})$ have disturbed their biogeochemical cycling in aquatic and terrestrial ecosystems. The $\mathrm{N}$ and $\mathrm{S}$ cycles interact with one another through competition for labile forms of organic carbon between nitrate-reducing and sulfate-reducing bacteria. Furthermore, the $\mathrm{N}$ and $\mathrm{S}$ cycles could interact through nitrate $\left(\mathrm{NO}_{3}^{-}\right)$reduction coupled to $\mathrm{S}$ oxidation, consuming $\mathrm{NO}_{3}^{-}$, and producing sulfate $\left(\mathrm{SO}_{4}^{2-}\right)$. The research questions of this study were: (1) what are the environmental factors explaining variability in $\mathrm{N}$ and $\mathrm{S}$ biogeochemical reaction rates in a wide range of surficial aquatic sediments when $\mathrm{NO}_{3}^{-}$and $\mathrm{SO}_{4}^{2-}$ are present separately or simultaneously, (2) how the $\mathrm{N}$ and $\mathrm{S}$ cycles could interact through $\mathrm{S}$ oxidation coupled to $\mathrm{NO}_{3}^{-}$reduction, and (3) what is the extent of sulfate reduction inhibition by nitrate, and vice versa. The $\mathrm{N}$ and $\mathrm{S}$ biogeochemical reaction rates were measured on intact surface sediment slices using flow-through reactors. The two terminal electron acceptors $\mathrm{NO}_{3}^{-}$and $\mathrm{SO}_{4}^{2-}$ were added either separately or simultaneously and $\mathrm{NO}_{3}^{-}$and $\mathrm{SO}_{4}^{2-}$ reduction rates as well as $\mathrm{NO}_{3}^{-}$reduction linked to $\mathrm{S}$ oxidation were determined. We used redundancy analysis, to assess how environmental variables were related to these rates. Our analysis showed that overlying water $\mathrm{pH}$ and salinity were two dominant environmental factors that explain $58 \%$ of the variance in the $\mathrm{N}$ and $\mathrm{S}$ biogeochemical reaction rates when $\mathrm{NO}_{3}^{-}$and $\mathrm{SO}_{4}^{2-}$ were both present. When $\mathrm{NO}_{3}^{-}$and $\mathrm{SO}_{4}^{2-}$ were added separately, however, sediment $\mathrm{N}$ content in addition to $\mathrm{pH}$ and salinity accounted for $62 \%$ of total variance of the biogeochemical reaction rates. The $\mathrm{SO}_{4}^{2-}$ addition had little effect on $\mathrm{NO}_{3}^{-}$reduction; neither did the $\mathrm{NO}_{3}^{-}$addition inhibit $\mathrm{SO}_{4}^{2-}$ reduction. The presence of $\mathrm{NO}_{3}^{-}$led to $\mathrm{SO}_{4}^{2-}$ production most likely due to the oxidation of sulfur. Our observations suggest that metal-bound $\mathrm{S}$, instead of free sulfide produced by $\mathrm{SO}_{4}^{2-}$ reduction, was responsible for the $\mathrm{S}$ oxidation.

Keywords: aquatic sediments, denitrification, sulfate reduction, sulfide oxidation, salinity, salt marsh, estuarine sediments, wetland soils

\section{INTRODUCTION}

Human-induced disturbances to the nitrogen $(\mathrm{N})$ and sulfur $(\mathrm{S})$ biogeochemical cycles, resulting for instance from atmospheric deposition and agricultural activities, have altered the global storage and fluxes of those elements (Schlesinger, 1997; Galloway et al., 2008). More specifically, the $\mathrm{N}$ and $\mathrm{S}$ loadings to aquatic ecosystems have increased dramatically due to anthropogenic activities in recent decades (Schlesinger, 1997), which lead to intensified interactions between the $\mathrm{N}$ and $\mathrm{S}$ cycles. For example, increased $\mathrm{N}$ loading associated with coastal development may lead to overlapping zones of abundant $\mathrm{N}$ and $\mathrm{S}$ in tidal creeks and salt marsh estuaries (Howarth et al., 1996). Furthermore, S content in freshwater ecosystems used to be too low (Holmer and Storkholm, 2001) for interactions between the $\mathrm{N}$ and $\mathrm{S}$ cycles to play a significant role in the biogeochemical cycles of those elements in such systems. However, salt water intrusion due to frequent hurricanes and storm surge caused by climate change in coastal areas (Ericson et al., 2006) have resulted in an increase in S concentrations in freshwater systems. Furthermore, whereas atmospheric $\mathrm{S}$ deposition from fossil fuel burning has decreased in North America and Europe due to air pollution control measures (Mayewski et al., 1990; Fischer et al., 1998), it is still important in southern Asia (Duan et al., 2007). There is consequently a pressing need to understand how biogeochemical processes constitutive of the $\mathrm{N}$ and $\mathrm{S}$ cycles will interact with one another in these human-altered environments. The $\mathrm{N}$ and $\mathrm{S}$ cycles are driven by microbially mediated reactions affecting the redox states of both elements, and consequently their mobility and availability. Among them, denitrification converts nitrate $\left(\mathrm{NO}_{3}^{-}\right)$to dinitrogen gas $\left(\mathrm{N}_{2}\right)$, effectively removing $\mathrm{N}$ from the soluble and bioavailable pools (Knowles, 1982). Similarly, S cycling in anoxic aquatic sediments involves both reductive and oxidative processes (Holmer and Storkholm, 2001). Both $\mathrm{NO}_{3}^{-}$and sulfate $\left(\mathrm{SO}_{4}^{2-}\right)$ are commonly used as terminal electron acceptors (TEA) for microbial respiration in anoxic sediments, with $\mathrm{NO}_{3}^{-}$being energetically more favorable than $\mathrm{SO}_{4}^{2-}$ (Froelich et al., 1979). Whereas nitrate reduction is 
a widespread process carried out by members of the alpha, beta, gamma, and epsilon Proteobacteria, Gram-positive Bacteria, and Archaea (Zumft, 1997; Philippot, 2002), sulfate reduction is more specialized and restricted to members of the delta Proteobacteria and Archaea (Wagner et al., 1998; Muyzer and Stams, 2008). Whether as a competitive or inhibitory phenomenon, a decrease in sulfate reduction has been reported upon nitrate addition (Westermann and Ahring, 1987; Whitmire and Hamilton, 2005). Sulfide as the final product of sulfate reduction can be microbially oxidized coupled to nitrate, manganese, and iron reduction in anoxic environments or rapidly incorporated into minerals such as iron monosulfides $(\mathrm{FeS})$ and pyrite $\left(\mathrm{FeS}_{2}\right)$ (Thamdrup et al., 1994). An important interaction between the $\mathrm{N}$ and the $\mathrm{S}$ cycles is denitrification coupled with biotic sulfide oxidation (Brettar and Rheinheimer, 1991; Garciagil and Golterman, 1993; Burgin and Hamilton, 2007). The biogeochemical importance of $\mathrm{NO}_{3}^{-}$ use by $\mathrm{S}$-oxidizing bacteria has been widely recognized in marine sediments (Brettar and Rheinheimer, 1991) as well as freshwater sediments (Brunet and GarciaGil, 1996; Whitmire and Hamilton, 2005) and groundwater systems (Engesgaard and Kipp, 1992; Jorgensen et al., 2009). This process is used to mitigate toxic sulfide production in organic-rich sludge through $\mathrm{NO}_{3}^{-}$- mediated sulfide oxidation (Schwermer et al., 2010). Vice versa, elemental sulfur has also been applied to wastewater treatment to remove $\mathrm{NO}_{3}^{-}$by coupled sulfur oxidation and $\mathrm{NO}_{3}^{-}$reduction (Sierra-Alvarez et al., 2007).

Numerous studies have investigated the environmental (physical and biogeochemical) factors controlling the $\mathrm{N}$ and $\mathrm{S}$ cycling to better understand the processes involved, interpret the observed rates, and extrapolate them across temporal and spatial scales (Cornwell et al., 1999; Seitzinger et al., 2006; Wallenstein et al., 2006; Burgin and Hamilton, 2007). Most of those studies however, have examined the $\mathrm{N}$ and $\mathrm{S}$ cycling separately, either on individual sites or single ecosystem and the controls vary across systems. Therefore, the goal of the present study was to investigate the environmental factors controlling $\mathrm{N}$ and $\mathrm{S}$ biogeochemical reaction rates in a range of littoral sediments. For that purpose we compared fourteen surficial aquatic sediments from lakes, rivers, estuaries, salt marshes, and marine coastal sites that were characterized by a wide range of water salinity, $\mathrm{pH}, \mathrm{NO}_{3}^{-}$, and $\mathrm{SO}_{4}^{2-}$ concentration, as well as sediment porosity, organic carbon $\left(\mathrm{C}_{\mathrm{org}}\right), \mathrm{N}$, Arsenic (As), and iron (Fe) contents. We subsequently investigated possible interactions between the $\mathrm{N}$ and $\mathrm{S}$ cycles via comparison of $\mathrm{N}$ and $\mathrm{S}$ biogeochemical reaction rates measured when $\mathrm{NO}_{3}^{-}$and $\mathrm{SO}_{4}^{2-}$ were present separately or concomitantly. Understanding the effects of environmental parameters on the coupled $\mathrm{N}$ and $\mathrm{S}$ cycles will help us elucidate potential mechanisms that lead to this coupling and generalize our findings across ecosystems types.

\section{MATERIALS AND METHODS STUDY SITES}

We conducted a multi-site study, investigating surficial sediments from 14 aquatic systems ranging from freshwater to hypersaline in the USA and Europe. Identical analytical methods were used at all sites and a large number of water and sediment physical and chemical characteristics were measured as described below. The sites include temperate lakes, rivers, salt marshes, estuaries, and marine coastal waters in France, the Netherlands, and the USA (California; see Table 1). Sites were selected to encompass a range of salinities, as well as $\mathrm{NO}_{3}^{-}$and $\mathrm{SO}_{4}^{2-}$ concentrations in sediment overlying waters. We sampled two freshwater sites (Tresmes, Créteil), eight estuarine and salt marsh sites covering brackish (Elkhorn Slough, Elkhorn Slough Marsh, Waarde), brackish/saline conditions (Pescadero, Baylands) and saline conditions (Hourdel Port, Hourdel Salt Marsh, Rattekaai), two marine sites (Humboldt Bay and North CA Coast) and two hypersaline sites (Mono Lake Boat Launch and Mono Lake Black Point). Intact surficial sediment cores $(4.2 \mathrm{~cm}$ inside diameter) were collected from each site and samples corresponding to the top $1 \mathrm{~cm}$ of the sediments were used for the flow-through experiments and physico-chemical characterization (except North CA Coast and Humboldt Bay where the top $2 \mathrm{~cm}$ were used). All estuarine sediments were sampled by hand in intertidal mudflats. River and lake sediments were sampled by hand 1-2 $\mathrm{m}$ from the river bank in water depths no greater than $0.5 \mathrm{~m}$ to avoid surface perturbations and sediment resuspension. Marine sediments from the North California (CA) Coast and Humboldt Bay were sampled from a ship at water depths of 70 and $10 \mathrm{~m}$, respectively, using a bottom grab device that left the sediment surface intact. All sediment samples were transported and stored at $4^{\circ} \mathrm{C}$ under anoxic conditions for 1-3 days until the experiments started.

\section{WATER AND SEDIMENT CHARACTERIZATION}

$\mathrm{NO}_{3}^{-}$, nitrite $\left(\mathrm{NO}_{2}^{-}\right)$, and ammonium $\left(\mathrm{NH}_{4}^{+}\right)$concentrations in liquid samples were measured colorimetrically on a Nutrient Autoanalyzer 3 (Bran and Luebbe). $\mathrm{SO}_{4}^{2-}$ concentrations in liquid samples were measured by ion chromatography (IC, Dionex DX$120)$. Sediment porosity was calculated from the dry bulk density $\left(\rho_{\mathrm{d}}\right)$ and particle density $\left(\rho_{\mathrm{s}}\right)$ as $1-\left(\rho_{\mathrm{d}} / \rho_{\mathrm{s}}\right)$, with $\rho_{\mathrm{d}}$ determined from the weight loss of a known volume of wet sediment sample after drying ( 2 days at $105^{\circ} \mathrm{C}$ or freeze drying). $\mathrm{C}_{\text {org }}$, total $\mathrm{N}$ and total $\mathrm{S}$ contents were determined using a Carlo Erba $\mathrm{CN}$ analyzer. Mean grain size of bulk sediment was determined with a Malvern Instruments Mastersizer $\mathrm{S}$, after removal of organic matter (with $6 \% \mathrm{H}_{2} \mathrm{O}_{2}$ ) and carbonate (with $1 \mathrm{~N} \mathrm{HCl}$ ), followed by chemical (in $4.5 \% \mathrm{Na}_{4} \mathrm{P}_{2} \mathrm{O}_{7}+4.2 \% \mathrm{Na}_{2} \mathrm{CO}_{3}$ ) and ultrasonic dispersion. As and Fe were extracted from sediments after $0.2 \mathrm{~g}$ freeze dried samples were digested in $10 \mathrm{~mL} 2 \mathrm{M}$ trace metal grade $\mathrm{HCl}$ for $24 \mathrm{~h}$. Total As concentrations were determined by graphite furnace atomic absorption spectrometry (GFAAS) on a Unicam_989 QZ spectrometer. Total Fe concentrations were determined by a flame atomic absorption spectrometer and a solar S spectrometer.

\section{FLOW THROUGH REACTOR EXPERIMENTS}

Steady-state reaction rates [e.g., maximum potential nitrate and sulfate reduction rates, and nitrite and ammonium production rates] were measured on intact sediment slices using recently developed flow-through reactors (FTRs; Roychoudhury et al., 1998; Laverman et al., 2006; Pallud and Van Cappellen, 2006; Pallud et al., 2007). Undisturbed surface sediment slices were collected directly in Plexiglas ${ }^{\circledR}$ reactor cells $(4.2 \mathrm{~cm}$ inside diameter and 1 or $2 \mathrm{~cm}$ long) between June 2006 and July 2008. Input solutions were supplied to the reactors at a constant flow rate $\left(Q=2 \pm 0.15 \mathrm{~mL} \mathrm{~h}^{-1}\right)$ using peristaltic pumps, and the reactor 
Table 1 | Surface water and sediment characteristics of 14 study sites in USA (California) and Europe; the Netherlands (NL) and France (Fr).

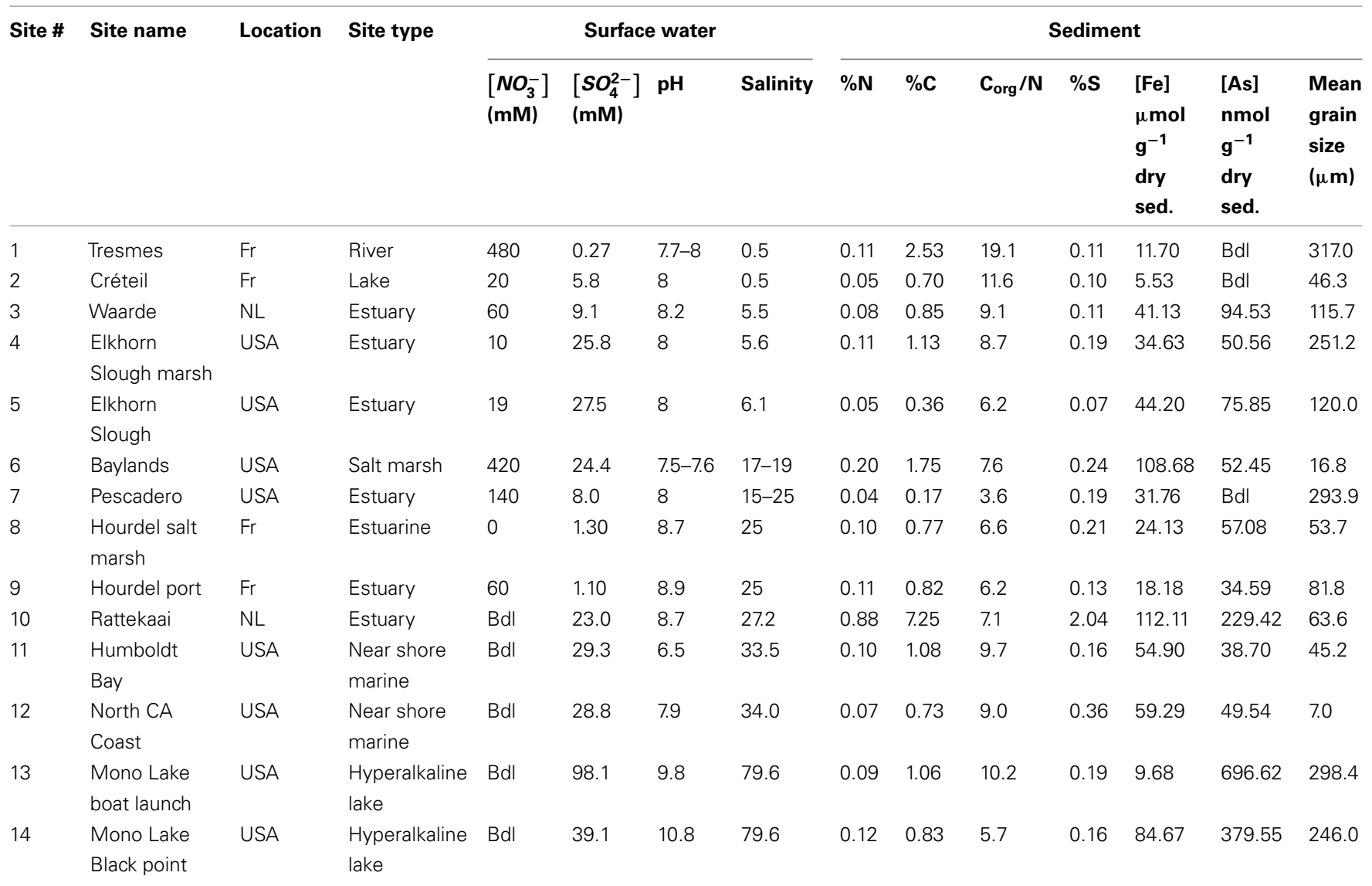

Bdl, below detection limit.

The detection limit for nitrate is $5 \mu \mathrm{M}$.

output samples were collected in tubes pre-filled with $2 \mathrm{~mL}$ of sulfide trap solution ( $1 \%$ zinc acetate) at 4 -h intervals using a fraction collector. Input solutions consisted of demineralized water containing $\mathrm{NO}_{3}^{-}$( $5 \mathrm{mM}$, supplied as $\mathrm{NaNO}_{3}$ ) or $\mathrm{SO}_{4}^{2-}(1.5 \mathrm{mM}$, supplied as $\mathrm{Na}_{2} \mathrm{SO}_{4}$ ) or both supplied simultaneously, $\mathrm{NaCl}$ at varying concentrations (see below), and for the Mono Lake sediments, also $\mathrm{Na}_{2} \mathrm{CO}_{3}(0.047 \mathrm{M})$ and $\mathrm{NaHCO}_{3}\left(0.28 \mathrm{M}\right.$; see below). $\mathrm{NO}_{3}^{-}$and $\mathrm{SO}_{4}^{2-}$ sulfate inflow concentrations have been chosen well above the half saturation constant $\left(K_{\mathrm{m}}\right)$ for $\mathrm{NO}_{3}^{-}(0.2-0.8 \mathrm{mM})$ and sulfate $(0.16-0.37 \mathrm{mM})$ that were measured in surface sediments using similar FTR systems (Laverman et al., 2006; Pallud et al., 2007 ) so maximum potential rates $\left(R_{\max }\right)$ would be measured. The input solutions were sterilized, then made anoxic by boiling and purging with $\mathrm{O}_{2}$-free $\mathrm{N}_{2}$. The salinity of the inflow solutions was adjusted with $\mathrm{NaCl}$ to match the salinity measured at the site (see Table 1). In order to mimic ambient hyperalkaline conditions in Mono Lake, the inflow $\mathrm{pH}$ for these reactors was adjusted using $\mathrm{Na}_{2} \mathrm{CO}_{3}(0.047 \mathrm{M})$ and $\mathrm{NaHCO}_{3}(0.28 \mathrm{M})$. For each site, two sets of duplicate reactors were treated as follows: one set was supplied with $\mathrm{NO}_{3}^{-}$for days $1-3(\mathrm{~N} 1)$, then with $\mathrm{SO}_{4}^{2-}$ for days 4-6(S2), and finally with $\mathrm{NO}_{3}^{-}$and $\mathrm{SO}_{4}^{2-}$ simultaneously for days 7-9 (N1S2); a second set of duplicates was supplied with $\mathrm{SO}_{4}^{2-}$ for days 1-3 (S1), then with $\mathrm{NO}_{3}^{-}$for days 4-6 (N2), and finally with $\mathrm{NO}_{3}^{-}$and $\mathrm{SO}_{4}^{2-}$

\section{Table 2 | Nomenclature of treatment groups.}

\begin{tabular}{llll} 
Treatments & Nitrate only (N) & Sulfate only (S) & Nitrate + sulfate (NS) \\
\hline Nitrate first & N1 & S2 & N1S2 \\
Sulfate first & N2 & S1 & N2S1
\end{tabular}

simultaneously for days 7-9 (N2S1). We will use the notation $\mathrm{N}$ to include both $\mathrm{NO}_{3}^{-}$only treatments ( $\mathrm{N} 1$ and N2), the notation $\mathrm{S}$ to include both $\mathrm{SO}_{4}^{2-}$ only treatments ( $\mathrm{S} 1$ and $\left.\mathrm{S} 2\right)$, and the notation $\mathrm{NS}$ to include both $\mathrm{NO}_{3}^{-}+\mathrm{SO}_{4}^{2-}$ treatments (N1S2 and N2S1). A summary of the notation system can be found in Table 2 . All FTR experiments were run at a constant temperature of $21 \pm 2^{\circ} \mathrm{C}$ under anoxic conditions.

\section{POTENTIAL REACTION RATE CALCULATIONS}

For each of the N1, N2, S1, S2, N1S2, N2S1 steps, potential steady-state reaction rates were calculated. Nitrate reduction rates (NRR), nitrite production rates (NiPR), ammonium production rate (APR), and sulfate production rates (SPR) were calculated for $\mathrm{N} 1$ and N2. Sulfate reduction rate (SRR), and APR were calculated for S1 and S2. Finally, NRR, NiPR, SRR, and APR were calculated for N1S2 and N2S1. Rates were determined by multiplying the 
flow rate $(Q)$ by the concentration difference between the input and output solutions normalized per volume of sediment for time intervals during which the outflow concentrations of the externally supplied electron acceptors $\left(\mathrm{NO}_{3}^{-}, \mathrm{SO}_{4}^{2-}\right.$ or both) remained constant (Laverman et al., 2006; Pallud et al., 2007), which typically happened after 10-24 h. Rates are expressed throughout in nanomolar analyte per cubic centimeter wet sediment per hour.

\section{STATISTICAL ANALYSIS}

MATLAB 9.0 was used to compute descriptive statistics and generate box plots of variables. Since the data were skewed, variables were log transformed before correlations and regressions were calculated. Variables having zero values were expressed as log $($ variable +1$)$. Log transforms improved the symmetry of the distributions. Differences in reaction rates across treatment types were tested with one way repeated measures ANOVA.

A principal component analysis (PCA) was conducted on the environmental variables and biogeochemical reaction rates, respectively. A multivariate analysis was conducted to analyze the relationships between explanatory variables (i.e., environmental variables) and response variables (i.e., biogeochemical reaction rates). The first step is to use detrended correspondence analyses (DCA) to obtain the gradient length of response variables. The linear model redundancy analysis (RDA) was suggested by the small gradient lengths ( $<1.5 \mathrm{SD}$ ). Stepwise RDA (Canoco Version 4.53; Wageningen, the Netherlands) was selected to study the effects of environmental variables on sediment biogeochemical reaction rates. RDA is a type of direct gradient analysis (Vandenwollenberg, 1977) that summarizes all the variance of response variables which is related to the explanatory variables and, at the same time, provides a synthetic and simple interpretation of the relationships between response and explanatory variables. Significant predictors were chosen using Canoco's forward selection procedure in the order of greatest additional contribution to the explained variance, but only if their addition did not cause any variation inflation factor to exceed 3.0. Statistical significance of variation components were tested with Monte Carlo Permutation tests (104 unrestricted permutations) on the trace statistic (Terbraak and Verdonschot, 1995). In the RDA triplot, the correlation between environmental variables and biogeochemical reaction rates is given by the cosine of the angle between the two vectors. Vectors pointing in roughly the same direction indicate a positive correlation, vectors crossing at right angles indicate a near zero correlation, while vectors pointing in opposite direction show a high negative correlation.

\section{RESULTS}

\section{WATER AND SEDIMENT CHARACTERISTICS}

Physical and chemical characteristics of the sediment and water column from the 14 study sites are summarized in Table 1. The overlying water $\mathrm{pH}$ and salinity values ranged from 6.5 to 10.8 and from 0.5 to 79.6 , respectively. The $\mathrm{C}_{\text {org }}: \mathrm{N}$ ratio ranged from 3.6 to 19.1 . The highest values (11.6 and 19.1) were observed in the freshwater sediments. The sediment $\mathrm{S}$ and Fe content ranged from 0.07 to $2.04 \%$ and from 5.53 to $112.11 \mu \mathrm{molg}^{-1}$ dry sediment, respectively, with the lowest values measured in the freshwater sediments. Sediment As content varied from below detection limit (bdl) to $696.62 \mathrm{nmol} \mathrm{g}^{-1}$ dry sediment and the lowest sediment As content were observed in the freshwater sediments.
The results of the PCA of the environmental variables revealed two main axes that explain most of the variation in all water and sediment characteristics (Figure 1). The first two principal components (PCs) explained 32 and $20 \%$ respectively of the total variance in the data. Correlations can be estimated by perpendicularly projecting the arrow tips of the other variables onto a particular variable arrow. The first component was mainly related to salinity, $\mathrm{SO}_{4}^{2-}$, and $\mathrm{NO}_{3}^{-}$concentration in the overlying water and sediment As content. The second PC was associated with sediment grain size and, to a lesser extent, with sediment total Fe content. Sediment total Fe content tended to increase with decreasing grain size. Coarse-grained sediments were generally poor in total Fe. In addition, sediment Fe content correlated positively with sediment $\mathrm{S}$ contents. The Fe and sulfur contents were negatively correlated to the $\mathrm{C}_{\text {org }}: \mathrm{N}$ ratio. The highest measured sediment $\mathrm{N}$ contents were associated with the highest measured Fe and/or $\mathrm{S}$ content. In general, sample sites were heterogeneously distributed around the origin of the coordinate system. On the basis of the distribution of sample PC scores on the PC1 and PC2 axes, several distinct sectors can be described: (1) the two hypersaline Mono lake sites (\#13 and 14) characterized by high $\mathrm{pH}$, salinity, $S_{4}^{2-}$ in overlying water and sediment As content; (2) the river sediment site at Tresmes $(\# 1)$ characterized by the highest $\mathrm{NO}_{3}^{-}$in overlying water and the highest $\mathrm{C}_{\mathrm{org}}: \mathrm{N}$ ratio; (3) the salt marsh estuarine site Rattekaai (\#10) characterized by high sediment $\mathrm{S}$ and Fe content; (4) the salt marsh site and two near coast marine sites (\#6, 11, and 12) characterized by fine texture and high sediment $\mathrm{Fe}$ content. The rest of the sample sites were within these extreme sectors.

\section{BIOGEOCHEMICAL REACTION RATES OF N AND S CYCLES}

The PCA of the reaction rates showed two main axes that explain most of the variation in all reaction rates (Figure 2). Note that all reaction rates reported in this study are maximum potential rates

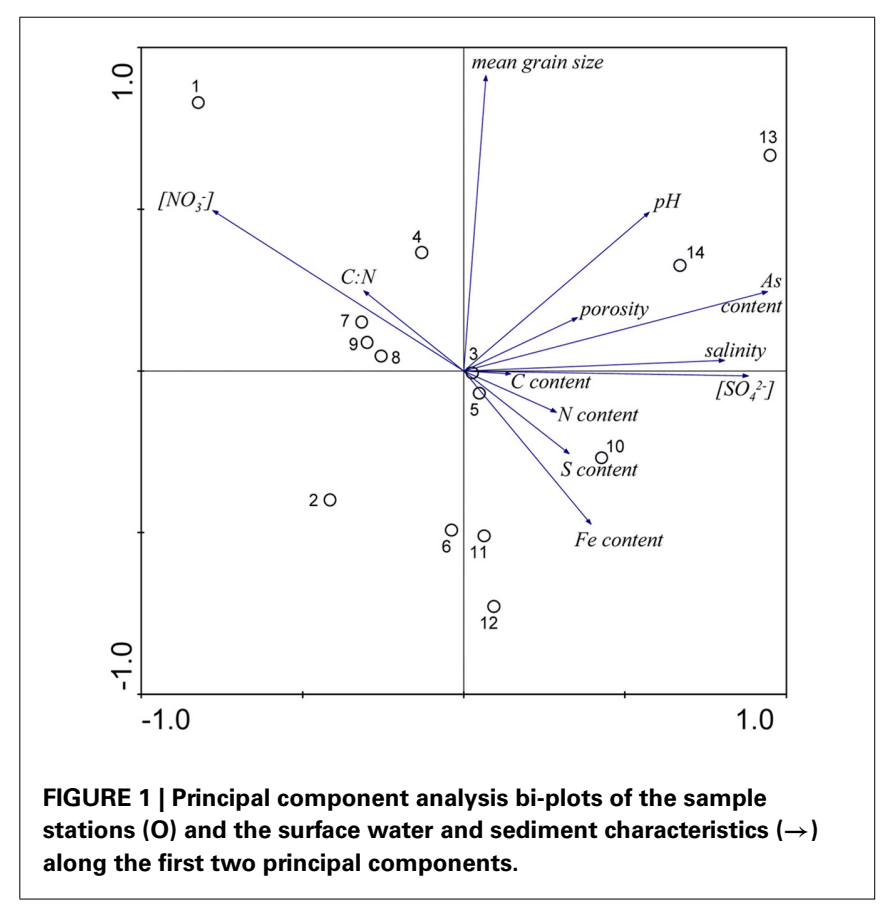




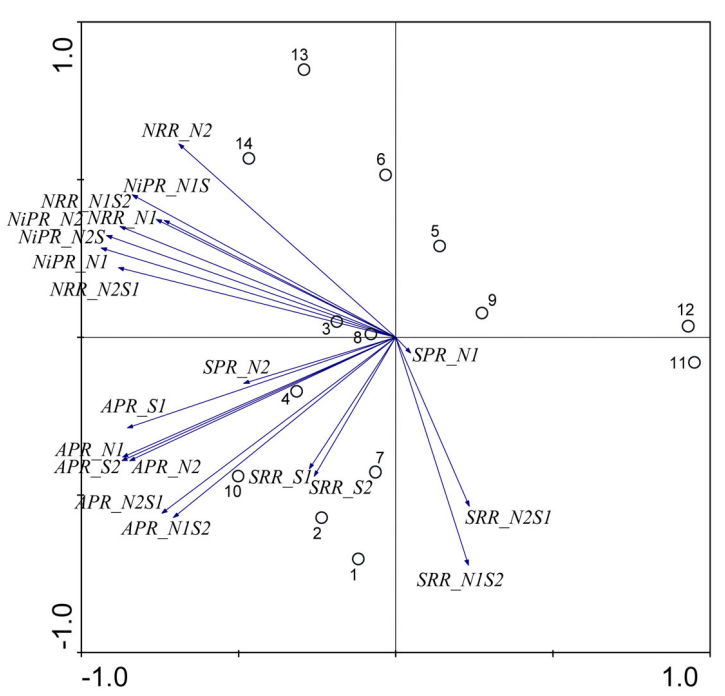

FIGURE 2 | Principal component analysis bi-plots of the sample stations $(0)$ and the potential reaction rates $(\rightarrow)$ along the first two principal components.

rather than field observed actual rates. The first two PCs explained 58 and $26 \%$ respectively of the total variance in the data. The first axis is related to NRR, NiPR, APR, and SPR. The second axis is defined mainly by SRR. NiRR increased with increasing NRR. Furthermore, NRR and APR for N treatments (i.e., N1 and N2) correlated strongly with those for NS treatments (i.e., N1S2 and N2S1). In contrast, there was no significant correlation between SRR for S treatment (i.e., S1 and S2) and SRR for NS treatments (i.e., N2S1 and N1S2). Several distinct sectors can be distinguished in all sediment sites based on the PC scores distribution: (1) the two hypersaline Mono Lake sites (\#13 and 14) characterized by high NRR and NiPR, and low SRR in the presence of $\mathrm{NO}_{3}^{-} ;(2)$ the river sediment site at Tresmes $(\# 1)$ and the freshwater lake site at Créteil (\#2) characterized by the highest SRR; (3) the estuarine site Rattekaai (\#10) characterized by the highest APR; (4) the two near coast marine sites (\#11 and 12) characterized by the lowest NRR and APR.

Nitrate reduction rates were highly variable within a given treatment [coefficient of variance (CV) ranged from 39 to $64 \%$, Figure 3]. There was no significant difference for the $\operatorname{NRR}(p=0.5$, repeated measures ANOVA) among the four treatment groups (i.e., N1, N2, N1S2, N2S1). The variances of NRR for N treatments were slightly larger than those for NS treatments.

Sulfate reduction rates varied greatly within a treatment (CV ranged from 46 to $94 \%$, Figure 4). The simultaneous application of $\mathrm{NO}_{3}^{-}$and $\mathrm{SO}_{4}^{2-}$ (NS) resulted in lower SRR than did a single application of $S_{4}^{2-}(\mathrm{S})$ ( $p=0.03$, repeated measures ANOVA). Note that the SRR here represented an apparent or net $\mathrm{SO}_{4}^{2-}$ removal after subtracting $\mathrm{SO}_{4}^{2-}$ produced by sulfide oxidation. By adding the SPR for the $\mathrm{N}$ treatments to the net SRR, we obtain estimates of the gross SRR (i.e., corrected SRR). Interestingly, there was no significant difference in the gross SRR between the $S$ and NS treatments ( $p=0.64$, repeated measures ANOVA). Additionally,

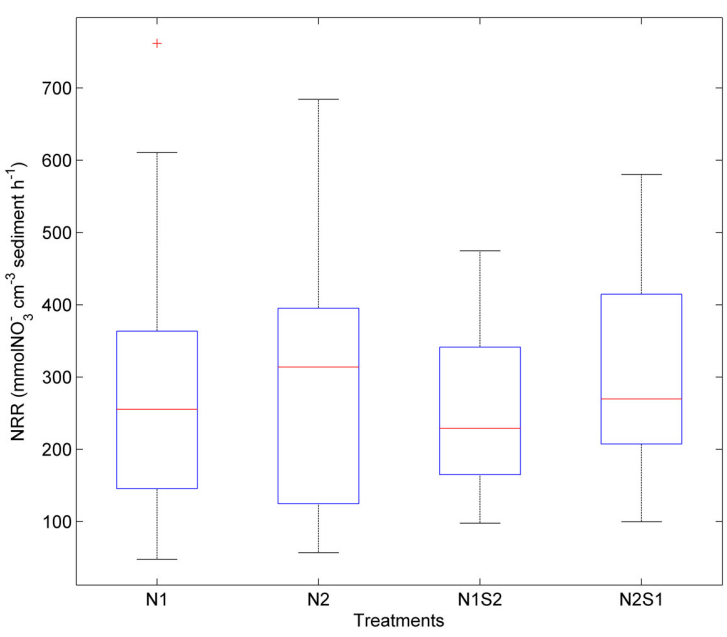

FIGURE 3 | Box plots of nitrate reduction rates (NRR) across all sites for the nitrate only treatments (N1 if nitrate first, N2 if sulfate first) and nitrate + sulfate treatments (N1S2 if nitrate first, N2S1 if sulfate first). Boxes encompass the upper and lower quartiles, while the line indicates the median. Asterisks are outliers.

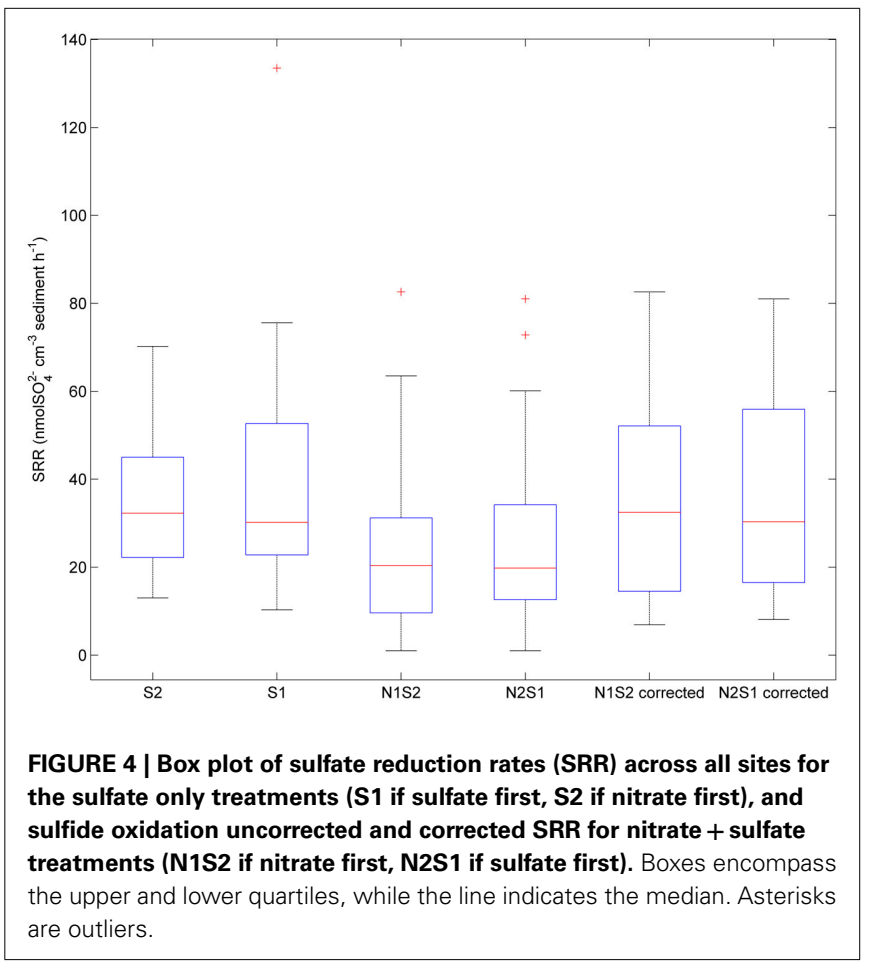

the average NRR was almost an order of magnitude higher than the average SRR.

The largest within-treatment variance was observed in APR (CV ranged from 77 to $149 \%$, Figure 5). APR did not vary greatly with treatments ( $p=0.3$, repeated measures ANOVA). However, the NS treatments had a greater variation of APR than the N or S treatment. The extremely high APR values indicated by the three outliers were all from the Rattekaai site. 


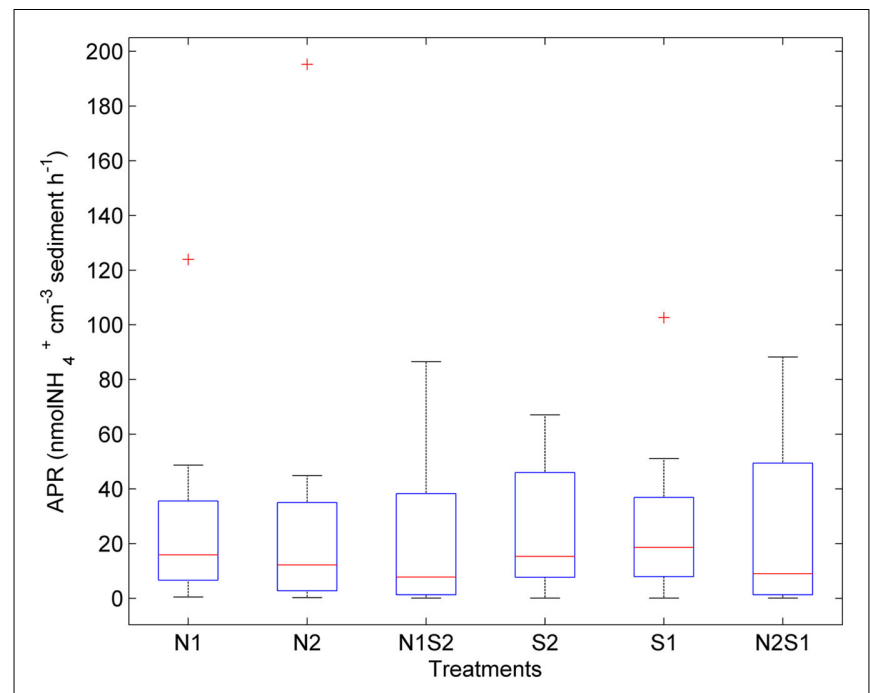

FIGURE 5 | Box plot of ammonium production rates (APR) across all for the nitrate only treatments (N1 of nitrate first, N2 if sulfate first), sulfate only treatments (S1 of sulfate first, $\mathbf{S 2}$ if nitrate first), and nitrate + sulfate treatments (N1S2 of nitrate first, N2S1 if sulfate first). Boxes encompass the upper and lower quartiles, while the line indicates the median. Asterisks are outliers.

\section{ENVIRONMENTAL CONTROLS ON BIOGEOCHEMICAL REACTION RATES}

Relationships between $\mathrm{N}$ and $\mathrm{S}$ biogeochemical reaction rates and the environmental variables measured were examined by RDA using the potential reaction rates measured on intact sediment slices as response variables for both separate and simultaneous addition of $\mathrm{NO}_{3}^{-}$and $\mathrm{SO}_{4}^{2-}$ (see Flow Through Reactor Experiments and Potential Reaction Rate Calculations) and the environmental variables listed in Table $\mathbf{1}$ as explanatory variables. The relative importance of various environmental factors is shown in Table 3. The single variable that explained the greatest percentage of variability in sediment biogeochemical reaction rates was the $\mathrm{pH}$ (lambda, the percentage of the variability explained by a single variable, is 0.24 ), followed by sediment As content, grain size, and $\mathrm{N}$ content that explained 21,17 , and $13 \%$ of the variability, respectively. After stepwise forward selection by RDA, three variables, namely $\mathrm{pH}$, salinity, and $\mathrm{N}$ content, that had a significant effect on the reaction rates in the sediments were retained ( $p<0.05$ tested by Monte Carlo permutation, Table 3). The $\mathrm{pH}$, salinity, and sediment $\mathrm{N}$ content describe the most variance (54\%) in the set of response variables that included all reaction rates. Exploratory RDA indicated that the $\mathrm{pH}$ of overlying water had the largest effect (lambda $\mathrm{A}$, the additional percentage of variability explained by a variable after the forward selection, is 0.24 , Table 3) for the $\mathrm{N}$ and $\mathrm{S}$ reaction rates. Salinity and sediment $\mathrm{N}$ content, as strong indicators of freshwater-marine ecosystem gradients, added an additional 18 and $12 \%$ to the total explained variance.

Redundancy analysis results are visualized in triplot ordination diagrams. Figure 6 shows the ordination diagram derived from running an RDA using the reaction rates measured when only one
Table 3 | Summary of 12 environmental variables by their effects on sediment biogeochemical reaction rates.

\begin{tabular}{lllll}
\hline Variable & Marginal effects & \multicolumn{3}{c}{ Conditional effects } \\
\cline { 3 - 5 } & Lambda 1 & Lambda A & $\boldsymbol{p}$ & $\boldsymbol{F}$ \\
\hline $\boldsymbol{p H}$ & 0.24 & 0.24 & $\mathbf{0 . 0 2}$ & 3.85 \\
$\mathrm{As}$ & 0.21 & 0.04 & 0.328 & 1.33 \\
$\mathrm{Grain}$ size & 0.17 & 0.06 & 0.158 & 1.57 \\
\% $N$ & 0.13 & 0.12 & $\mathbf{0 . 0 4}$ & 2.63 \\
{$\left[\mathrm{SO}_{4}^{2-}\right]$} & 0.12 & 0.09 & 0.09 & 2.12 \\
$\mathbf{S a l i n i t y}$ & 0.12 & 0.18 & $\mathbf{0 . 0 0 6}$ & 3.34 \\
$\% \mathrm{C}$ & 0.11 & 0.02 & 0.788 & 0.29 \\
$\% \mathrm{~S}$ & 0.09 & 0.03 & 0.35 & 1.23 \\
{$\left[\mathrm{NO}_{3}^{-}\right]$} & 0.07 & 0.04 & 0.304 & 1.23 \\
Fe & 0.06 & 0.04 & 0.4 & 1.04 \\
Porosity & 0.04 & 0.04 & 0.336 & 1.14 \\
$\mathrm{C}_{\text {org }}: \mathrm{N}$ & 0.04 & 0.06 & 0.172 & 1.72 \\
\hline
\end{tabular}

${ }^{1}$ Lambda 1 indicates the percentage of the variability in the sediment biogeochemical reaction rates explained by a single variable.

${ }^{2}$ Lambda $A$ indicates the percentage of the variability explained by a variable after the forward selection starting from the best variable (marginal effects).

Each subsequent variable is ranked on the basis of the fit that the variable gives in conjunction with the variables already selected (conditional effects). $p$ and $F$ values indicate the level of significance of each variable obtained by Monte Carlo permutations under the null model with 499 random permutations. The significant environmental variables were marked in italic bold.

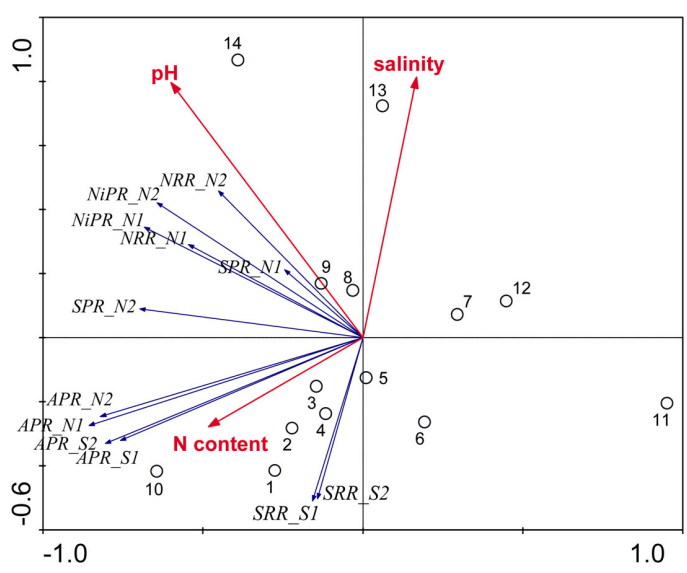

FIGURE 6 | Ordination triplots of first two axes (RDA1 and RDA2) generated from redundancy analysis using reaction rates (NRR, SRR, APR, NiPR, and SPR) measured when only one electron acceptor was added (treatments $\mathbf{N}$ and $\mathbf{S}$ ). Response variables (red vectors) include the combination of response variables (NRR and SRR). Explanatory variables (blue vectors) entered into the models were selected stepwise by Monte Carlo permutation test. Site numbers are located according to their ordination sample scores. Transform: response variable via log $10(x+1)$, and explanatory variables via square root. Vectors pointing in the same direction indicate a positive correlation, vectors crossing at right angles indicate a near zero correlation, while vectors pointing in opposite direction show a high negative correlation. 
electron acceptor was added (treatments $\mathrm{N}$ and $\mathrm{S}$ ). The first axis (horizontal) displayed a gradient of APR, and to a lesser extent, of SPR, NRR, and NiRR. The second axis (vertical) represented SRR, which were negatively correlated with salinity of the overlying water. In addition, the $\mathrm{pH}$ vector points in the same direction as the NRR and NiPR vectors indicating a significant positive correlation between $\mathrm{pH}$ and NRR and NiPR. pH explained 23\% of total variance, followed by salinity that contributed an additional 23\% and by sediment $\mathrm{N}$ content that explained an additional $15 \%$ of the total variance in reaction rates. The sites $1-5,8$, and 13 followed the salinity gradient strongly, while the sites $1-5,7$, and 12 were predominantly affected by the gradient of sediment $\mathrm{N}$ content. Finally, the variations associated with sites 5, 6, 8, 9, and 14 were mainly attributed to the variations in $\mathrm{pH}$.

An ordination diagram derived from running an RDA using the reaction rates measured for the NS treatments is shown in Figure 7. Again, $\mathrm{pH}$ and salinity are the two most dominant environmental variables that explained 30 and $17 \%$ of the total variance in reaction rates, respectively. The first RDA axis (horizontal) increased with decreasing $\mathrm{pH}$ and the second RDA axis (vertical) increased with salinity. The vectors of NRR and NiPR loaded negatively on the first axis, and pointed in a same direction as $\mathrm{pH}$, indicating a positive relationship with this explanatory variable. On the other hand, the vectors of SRR pointed roughly in a direction opposite to the salinity vectors, suggesting an inverse relationship between

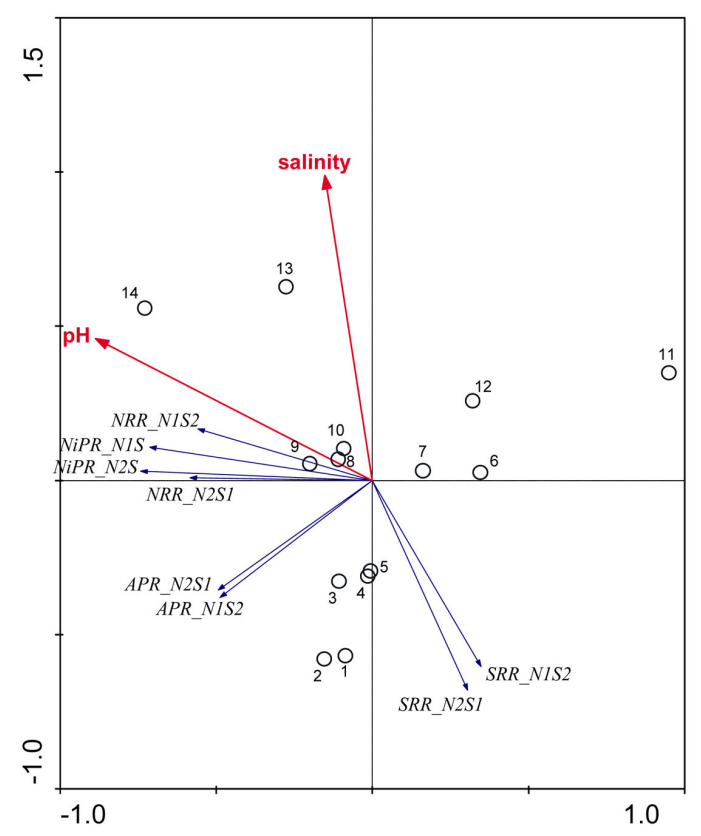

FIGURE 7 | Ordination triplots of first two axes (RDA1 and RDA2) generated from redundancy analysis using reaction rates (NRR, SRR, APR, and NiPR) measured when the two electron acceptors were added simultaneously (treatments NS). Response variables (red vectors) include the combination of response variables (NRR and SRR). Explanatory variables (blue vectors) entered into the models were selected stepwise by Monte Carlo permutation test. Site numbers are located according to their ordination sample scores. Transform: Response variable via log $10(x+1)$, and explanatory variables via square root. these variables. Contrary to the RCA results for reaction rates measured when only one TEA is present ( $\mathrm{N}$ and $\mathrm{S}$ treatments, Figure 6), sediment $\mathrm{N}$ content was not selected as a significant environmental factor on the reaction rates for the NS treatments.

To study the effect of environmental factors on the relative differences in NRR and SRR measured for separate (N or S) and simultaneous (NS) additions of $\mathrm{NO}_{3}^{-}$and $\mathrm{SO}_{4}^{2-}$, we derived a new set of response variables named Ratio_NRR and Ratio_SR, defined as the ratio of NRR and SRR measured in NS treatment compared to NRR and SRR measured for $\mathrm{N}$ and $\mathrm{S}$ treatment, respectively. These ratios indicate either an increase or a decrease in NRR or SRR when both TEAs are added compared to the supply of only one TEA. Stepwise RDA analysis (Figure 8) showed that the sediment As content (28\%), Fe content (17\%), and $\mathrm{C}_{\text {org }}: \mathrm{N}(14 \%)$ accounted for $59 \%$ of the total variance of the differences in NRR and SRR between separated or simultaneous addition of TEAs.

\section{DISCUSSION ENVIRONMENTAL CONTROLS ON POTENTIAL BIOGEOCHEMICAL REACTION RATES}

The PCA and RDA results revealed three dominant gradients in the variations in the sediment potential biogeochemical reaction rates. Gradient (1) is characterized by variations in the NRR, NiPR, and SPR, which were closely correlated with the overlying water $\mathrm{pH}$. Gradient (2) is characterized by variations in the APR, which were mainly controlled by the sediment $\mathrm{N}$ content. Gradient (3) is characterized by variations in the SRR, which were correlated with the overlying water salinity.

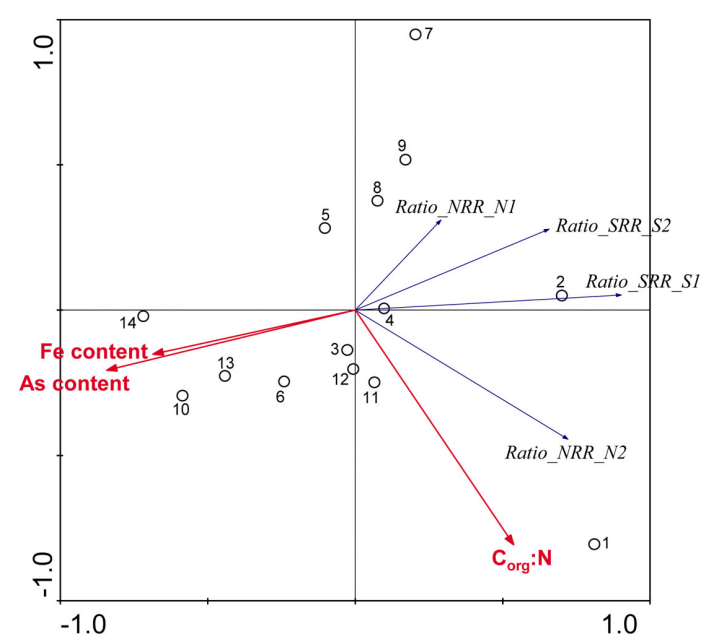

FIGURE 8 | Ordination triplots of first two axes (RDA1 and RDA2) generated from redundancy analysis using the ratio in NRR and SRR measured for separate ( $N$ or $S$ ) and simultaneous (NS) additions of nitrate and sulfate (RATIO_NRR and RATIO_SRR). Response variables (red vectors) include the combination of response variables. Explanatory variables (blue vectors) entered into the models were selected stepwise by Monte Carlo permutation test. All variables showed significant correlations with the canonical axes. Site numbers are located according to their ordination sample scores. Transform: response variable via log $10(x+1)$, and explanatory variables via square root. 
The RDA analysis suggested a significant positive relationship between in situ water $\mathrm{pH}$ and NRR and NiRR, which is in agreement with previous findings. Song et al. (2011) found a correlation between potential denitrification rates and the $\mathrm{pH}$ of the overlying water in constructed wetlands. In fact, several studies have shown that acidic conditions may reduce or even completely inhibit the nitrate reduction process in aquatic sediments (Knowles, 1982). In the present study, the in situ $\mathrm{pH}$ of overlying water is mostly slightly alkaline except for a slightly acidic $\mathrm{pH}$ of 6.5 at the near shore marine site, and for a hyperalkaline $\mathrm{pH}$ at the two Mono lake sites. Glass and Silverstein (1998) found that NRRs as well as the nitrate to nitrite ratios increased with above-neutral $\mathrm{pH}$ in activated sludge of a synthetic wastewater containing high nitrate concentration. Similar results were obtained in laboratory batch experiments by Zhang et al. (2009) showing increased nitrite accumulation with increasing $\mathrm{pH}$. Nitrite accumulation associated with nitrate reduction with increasing $\mathrm{pH}$ might be attributed to inhibition of nitrite reductase at high pH (Zhang et al., 2009).

Furthermore, our results suggest a positive correlation between APR and the sediment $\mathrm{N}$ pool. Sediment $\mathrm{N}$ can originate from various sources such as phytoplankton, benthic algae, and littoral deposition. As a result, littoral sediments are usually associated with high $\mathrm{N}$ content. In this study, the highest APR corresponded to the $\mathrm{N}$ rich sediment at the Rattekaai site, whereas the lowest APRs were found at two deep non-littoral marine sediments (\#11 and \#12). High N content sediments might lead to high APR through intensive anaerobic organic matter degradation and consequent nitrogen mineralization. Previous studies also observed increasing $\mathrm{NH}_{4}^{+}$production with decreasing $\mathrm{C}_{\mathrm{org}}: \mathrm{N}$ ratio (Blackburn and Henriksen, 1983). Under anoxic conditions, another $\mathrm{NH}_{4}^{+}$source is dissimilatory nitrate reduction to ammonium (DNRA). Our results, however, did not confirm that DNRA is significant. In fact, if DNRA was a major source of $\mathrm{NH}_{4}^{+}$, higher APR would be observed in the $\mathrm{N}$ only treatments than in the $\mathrm{S}$ only treatments. However, we did not find any significant difference in APR between these two treatments.

Finally, a freshwater to saline water gradient, represented by salinity in overlying water explained a large portion of variance of the sediment SRR. In situ salinity showed an inverse relationship with SRR. Under in situ conditions, SRR in most freshwater systems are usually very low and considerably lower than in most marine systems (Capone and Kiene, 1988) due to the limited $\mathrm{SO}_{4}^{2-}$ present in the overlying water. Despite these low in situ rates and activities, sulfate reducers have shown to be present and diverse in freshwater sediments (Kondo et al., 2007; Miletto et al., 2008), and with high potential activities (this study, Pallud and Van Cappellen, 2006; Kondo et al., 2007), most likely due to their metabolic diversity (Muyzer and Stams, 2008). In addition, in hypersaline anaerobic environments, the significant energetic requirements associated with halophilism may preclude the existence of microbial groups that obtain little energy from dissimilatory processes, including sulfate reduction (Oren, 2011). This could explain why the lowest SRR were observed in the two hypersaline sites.

We found both similarities and differences in the sets of environmental factors that explain the variance in the sediment $\mathrm{N}$ and $S$ potential reaction rates between separate and simultaneous addition of $\mathrm{NO}_{3}^{-}$and $\mathrm{SO}_{4}^{2-}$. Both treatments suggest that $\mathrm{pH}$ and salinity are the two most important predictors of variability of sediment $\mathrm{N}$ and $\mathrm{S}$ reaction rates. However, when $\mathrm{NO}_{3}^{-}$and $\mathrm{SO}_{4}^{2-}$ were added separately, the APR were also significantly affected by sediment $\mathrm{N}$ content, but not when $\mathrm{NO}_{3}^{-}$and $\mathrm{SO}_{4}^{2-}$ were added concomitantly. This indicates that other process(es) than anaerobic organic nitrogen mineralization might contribute to $\mathrm{NH}_{4}^{+}$ production when $\mathrm{N}$ and $\mathrm{S}$ were added together.

Distinct biogeochemical processes in response to separate and simultaneous addition of $\mathrm{NO}_{3}^{-}$and $\mathrm{SO}_{4}^{2-}$ can also be suggested by the comparison of NRR and SRR between separate addition and simultaneous addition of $\mathrm{NO}_{3}^{-}$and $\mathrm{SO}_{4}^{2-}$. Sediment As, $\mathrm{C}_{\mathrm{org}}$ : N ratio, and $\mathrm{Fe}$ content were the main factors that explained the variation of the NRR and SRR changes. The coupled sediment $S$, As, and Fe cycles, probably through the reactions listed in Table 4, explained the lower SRR in sediments when $\mathrm{NO}_{3}^{-}$and $\mathrm{SO}_{4}^{2-}$ were present. On the other hand, the quality of sediment organic matter, indicated by $\mathrm{C}_{\mathrm{org}}: \mathrm{N}$ ratio, might account for the majority of variance in the NRR changes.

\section{EFFECTS OF ALTERNATIVE TEAs ON POTENTIAL NITRATE AND SULFATE REDUCTION RATES}

The lack of correlation of SRR between S only and NS treatments suggested that distinct processes must be involved in $\mathrm{SO}_{4}^{2-}$ reduction. The observation that the presence of $\mathrm{NO}_{3}^{-}$results in lower overall SRR than when $\mathrm{SO}_{4}^{2-}$ is added alone suggests that $\mathrm{SO}_{4}^{2-}$ reduction was inhibited by the presence of $\mathrm{NO}_{3}^{-}$and/or that, $\mathrm{SO}_{4}^{2-}$ was produced by sulfide oxidation (reaction 1 in Table 4). The gross SRR in the NS treatments was calculated by adding the SPR measured in the $\mathrm{N}$ treatments to the net SRR measured for the NS treatments. The corrected SRR for the NS treatments were not significantly different than for the $\mathrm{S}$ treatments. This confirms that the lower SRR measured when $\mathrm{NO}_{3}^{-}$and $\mathrm{SO}_{4}^{2-}$ were added together are most likely due to the $\mathrm{SO}_{4}^{2-}$ produced from sulfide oxidation linked to $\mathrm{NO}_{3}^{-}$reduction. Therefore, not only do we observe active $\mathrm{SO}_{4}^{2-}$ reduction when $\mathrm{NO}_{3}^{-}$is present but we also conclude that overall there is negligible inhibition of $\mathrm{SO}_{4}^{2-}$ reduction by the presence of $\mathrm{NO}_{3}^{-}$. This contrasts with the current consensus that $\mathrm{SO}_{4}^{2-}$ reduction will be active only when $\mathrm{NO}_{3}^{-}$, a thermodynamically more favorable electron acceptor, is fully consumed (Froelich et al., 1979; Whitmire and Hamilton, 2005). However, it is supported by previous

Table 4 | Summary of stoichiometric reactions of sulfide oxidized by varying terminal electron acceptors.

\begin{tabular}{llc}
\hline TEA & Stoichiometric reactions & Number \\
\hline Nitrate & $5 \mathrm{HS}^{-}+8 \mathrm{NO}_{3}^{-}+3 \mathrm{H}^{+} \rightarrow 5 \mathrm{SO}_{4}^{2-}+4 \mathrm{~N}_{2}+4 \mathrm{H}_{2} \mathrm{O}$ & 1 \\
& $\mathrm{FeS}_{2}+14 \mathrm{NO}_{3}^{-}+4 \mathrm{H}^{+} \rightarrow 7 \mathrm{~N}_{2}+10 \mathrm{SO}_{4}^{2-}+$ & 2 \\
& $5 \mathrm{Fe}^{2+}+2 \mathrm{H}_{2} \mathrm{O}$ & \\
& $5 \mathrm{Fe}^{2+}+\mathrm{NO}_{3}^{-}+12 \mathrm{H}_{2} \mathrm{O} \rightarrow 5 \mathrm{Fe}(\mathrm{OH})_{3}+1 / 2 \mathrm{~N}_{2}+$ & 3 \\
& $9 \mathrm{H}^{+}$ & \\
Iron & $\mathrm{FeS}_{2}+8 \mathrm{H}_{2} \mathrm{O}+14 \mathrm{Fe}^{3+} \rightarrow 2 \mathrm{SO}_{4}^{2-}+15 \mathrm{Fe}^{2+}+$ & 4 \\
& $16 \mathrm{H}^{+}$ & \\
Arsenic & $4 \mathrm{HAsO}_{4}^{2-}+\mathrm{S}^{2-}+4 \mathrm{H}^{+} \rightarrow 4 \mathrm{H}_{2} \mathrm{AsO}_{3}^{-}+\mathrm{SO}_{4}^{2-}$ & 5 \\
Manganese & $\mathrm{FeS}_{2}+7.5 \mathrm{MnO}_{2}+11 \mathrm{H}^{+} \rightarrow \mathrm{Fe}(\mathrm{OH})_{3}+2 \mathrm{SO}_{4}^{2-}+$ & 6 \\
& $7.5 \mathrm{Mn}{ }^{2+}+4 \mathrm{H}_{2} \mathrm{O}$ & \\
& $\mathrm{FeS}+1.5 \mathrm{MnO}_{2}+3 \mathrm{H}^{+} \rightarrow \mathrm{Fe}(\mathrm{OH})_{3}+\mathrm{S}^{0}+1.5 \mathrm{Mn}^{2+}$ & 7
\end{tabular}


observations that $\mathrm{SO}_{4}^{2-}$ was actively reduced by microorganisms in the presence of $\mathrm{NO}_{3}^{-}$(Dalsgaard and Bak, 1994). It is very well likely, considering the metabolic versatility of both the $\mathrm{SO}_{4}^{2-}$ and $\mathrm{NO}_{3}^{-}$-reducers, that active sulfate reduction in the presence of nitrate is due to the use of different electron donors by the two bacterial groups. In addition, the sediment matrix could provide a spatial separation of the different microbial groups resulting in coexistence instead of a competition between the two processes within these sediments. Whether spatial separation or the use of different carbon pools allows the coexistence of sulfate and nitrate reduction in these sediments is subject to ongoing work.

On the other hand, the presence of $\mathrm{SO}_{4}^{2-}$, and subsequently of sulfide produced as a result of $\mathrm{SO}_{4}^{2-}$ reduction, did not significantly affect NRR. The strong correlation between NRR measured for $\mathrm{N}$ only and for NS treatments suggested that same processes must be involved in $\mathrm{NO}_{3}^{-}$reduction. Sulfide has been shown to inhibit nitrate reduction in estuarine and coastal sediments (Senga et al., 2006; Aelion and Warttinger, 2009). However, a positive effect of sulfide addition on NRR has been found in oxidized and low organic matter sediments (Canfield et al., 2010). Recent work in a marine environment off the Chilean northern coast suggests that $\mathrm{NO}_{3}^{-}$reduction is enhanced by sulfide addition in ocean waters (Canfield et al., 2010). In our study, however, the amount of sulfide produced as a result of $\mathrm{SO}_{4}^{2-}$ reduction was too low to enhance or inhibit $\mathrm{NO}_{3}^{-}$removal. We estimated the fraction of $\mathrm{NO}_{3}^{-}$removal due to sulfide oxidation to $\mathrm{SO}_{4}^{2-}$ by multiplying the ratio of the measured SPR to NRR by 1.6, which is the molar ratio of $\mathrm{NO}_{3}^{-}$ reduced to $\mathrm{SO}_{4}^{2-}$ produced as shown in Equation 1 (Table 4). In our survey, $\mathrm{NO}_{3}^{-}$mediated sulfide oxidation accounts for a small portion $(\sim 9 \%)$ of total $\mathrm{NO}_{3}^{-}$reduction on average, implying that this process did not affect overall $\mathrm{NO}_{3}^{-}$reduction significantly. Furthermore, the observation that $\mathrm{SO}_{4}^{2-}$ was produced in the absence of $\mathrm{SO}_{4}^{2-}$ addition suggests that sediment $\mathrm{S}$ content is the main source of sulfide in our systems, probably from sediment bound sulfide rather than produced by $\mathrm{SO}_{4}^{2-}$ reduction. However, the effect of $\mathrm{SO}_{4}^{2-}$ reduction as a sulfide source cannot be underestimated due to the fact that sediment sulfide is ultimately regenerated from $\mathrm{SO}_{4}^{2-}$ reduction.

In addition to $\mathrm{NO}_{3}^{-}$, oxidized metal(loid) species, such as $\mathrm{Fe}$, $\mathrm{Mn}$, and As, could be preferentially used over $\mathrm{SO}_{4}^{2-}$ by microorganisms as TEA for anaerobic respiration. For example, it has been shown that direct sulfide oxidation by $\mathrm{Fe}(\mathrm{III})$ might lead to $\mathrm{SO}_{4}^{2-}$ production (reaction 4, in Table 4; Holmer and Storkholm, 2001). In our study, SRR decreased in the NS treatments with increasing sediment As content suggesting that SRR might be inhibited by As, possibly by $\mathrm{As}(\mathrm{V})$ produced via $\mathrm{As}(\mathrm{III})$ oxidation coupled to $\mathrm{NO}_{3}$-reduction. Such an anoxic oxidation of As(III) linked to chemolithotrophic denitrification was shown to be feasible in continuous bioreactors (Sun et al., 2010). The oxidized As subsequently affect the sediment $\mathrm{S}$ cycle in two ways. First, $\mathrm{As}(\mathrm{V})$ and/or As(III) inhibit $\mathrm{SO}_{4}^{2-}$ reduction, presumably through a toxic effect (Dowdle et al., 1996). Second, $\mathrm{SO}_{4}^{2-}$ might be produced through As $(\mathrm{V})$-mediated sulfide oxidation (reaction 5 in Table 4). Recent studies (Hoeft et al., 2004; Oremland et al., 2005; Hollibaugh et al., 2006) found that sulfide oxidation coupled to As(V) reduction appears to proceed via a two electron transfer, resulting in the production of As(III) and of an intermediate $S$ compound such as thiosulfate that is subsequently disproportionated into sulfate. Oxidized Mn might also serve as electron acceptor to oxidize iron sulfide minerals (reactions 6 and 7 in Table 4). However, we did not measure sediment $\mathrm{Mn}$ content in our study and consequently cannot confirm the occurrence of Mn-mediated sulfide oxidation.

\section{ALTERNATIVE NITRATE REMOVAL PATHWAYS}

Our observation that in $70 \%$ of the studied sites $\mathrm{SO}_{4}^{2-}$ was produced when $\mathrm{NO}_{3}^{-}$was reduced suggested that $\mathrm{SO}_{4}^{2-}$ production was linked to $\mathrm{NO}_{3}^{-}$removal. The possibility of $\mathrm{NO}_{3}^{-}$reduction coupled to sulfide oxidation by sulfur-oxidizing bacteria is supported by research in both marine and freshwater ecosystems (Dannenberg et al., 1992; Fossing et al., 1995; Brunet and GarciaGil, 1996; Otte et al., 1999). On average, $9 \%$ of the NRR can be accounted for by sulfide oxidation to sulfate in our studied sediments (Laverman et al., 2012), which is much lower than the range of $25-40 \%$ reported for freshwater ecosystems (Burgin and Hamilton, 2008). Note that these could be minimum estimates because of the possibility that some of the $\mathrm{S}$ oxidation does not proceed completely to $\mathrm{SO}_{4}^{2-}$.

We were not able to ascertain the ultimate fate of the added $\mathrm{NO}_{3}^{-}$(i.e., denitrification or DNRA) in our sediments. Inhibition of denitrification by the presence of free sulfide might favor the reduction of $\mathrm{NO}_{3}^{-}$to $\mathrm{NH}^{4+}$ rather than to $\mathrm{N}_{2} \mathrm{O}$ and $\mathrm{N}_{2}$ (Brunet and GarciaGil, 1996), though accumulation of $\mathrm{N}_{2} \mathrm{O}$ has also been observed (Senga et al., 2006). An increase in NRR due to DNRA coupled with $S$ oxidation would likely be accompanied by an increase in APR (Payne et al., 2009). However our results did not show significant increase in APR when $\mathrm{NO}_{3}^{-}$and $\mathrm{SO}_{4}^{2-}$ were added together, ruling this hypothesis out. On the other hand, metalbound sulfides (e.g., FeS) could potentially enhance denitrification to $\mathrm{N}_{2}$ (Brunet and GarciaGil, 1996). We consequently speculate that denitrification instead of DNRA is the major pathway of $\mathrm{NO}_{3}^{-}$ reduction that couples with metal-bound sulfide oxidation in the present study.

Our RDA results revealed that nitrate-mediated oxidation of iron sulfide (FeS) or Fe disulfide $\left(\mathrm{FeS}_{2}\right)$, rather than free sulfide, might account for $\mathrm{SO}_{4}^{2-}$ production (reactions 2 and 3 in Table 4). This is supported by the positive correlation between change of SRRs (NS vs. S) and sediment Fe contents in our RDA analysis. $\mathrm{FeS}$ and $\mathrm{FeS}_{2}$ are compounds resulting from the chemical precipitation of reduced Fe and sulfur, and are commonly found in sediments, such as those investigated in this study. The sediment Fe content correlated positively with sediment $S$ contents in this study, which indicated that iron and sulfide could be present as iron sulfide minerals such as $\mathrm{FeS}$ and $\mathrm{FeS}_{2}$. The oxidation of iron disulfide coupled to $\mathrm{NO}_{3}^{-}$reduction produces $\mathrm{SO}_{4}^{2-}$ as end product (Brunet and GarciaGil, 1996). Under anoxic conditions FeS or $\mathrm{FeS}_{2}$ can be used as electron donors for denitrification by facultative anaerobic lithotrophs (Benz et al., 1998; Schwientek et al., 2008). Jorgensen et al. (2009) recently found that around 65$80 \%$ of the $\mathrm{NO}_{3}^{-}$reduction measured in a groundwater aquifer was coupled to the anoxic oxidation of pyrite by $\mathrm{NO}_{3}^{-}$, releasing $\mathrm{SO}_{4}^{2-}$. 


\section{CONCLUSION}

Our study shows that the effects of the presence of $\mathrm{NO}_{3}^{-}$and/or $\mathrm{SO}_{4}^{2-}$ on biogeochemical $\mathrm{N}$ and $\mathrm{S}$ cycles are complex, depending on various environmental factors. The environmental factors that explained the variability in the $\mathrm{N}$ and $\mathrm{S}$ biogeochemical reaction rates when $\mathrm{NO}_{3}^{-}$and $\mathrm{SO}_{4}^{2-}$ were present simultaneously were in situ water $\mathrm{pH}$ and salinity, whereas sediment $\mathrm{N}$ content, in situ water $\mathrm{pH}$ and salinity were the best explanatory variables when $\mathrm{NO}_{3}^{-}$and $\mathrm{SO}_{4}^{2-}$ were present separately. More specifically, potential NRR were positively correlated to in situ water $\mathrm{pH}$ and potential SRR were inversely correlated with salinity. Furthermore, the highest sediment As or Fe content was associated with the largest reduction in the potential SRR when $\mathrm{NO}_{3}^{-}$ or $\mathrm{SO}_{4}^{2-}$ were both present. Finally, our results indicate that the simultaneous presence of $\mathrm{NO}_{3}^{-}$and $\mathrm{SO}_{4}^{2-}$ led to sulfur oxidation coupled with $\mathrm{NO}_{3}^{-}$reduction and metal-bound S, instead of free sulfide produced by $\mathrm{SO}_{4}^{2-}$ reduction, was responsible for this $\mathrm{NO}_{3}^{-}$- mediated $\mathrm{S}$ oxidation.

Aquatic ecosystems are exposed to increasing $\mathrm{NO}_{3}^{-}$and $\mathrm{SO}_{4}^{2-}$ concentrations and intensified interactions between the $\mathrm{N}$ and $\mathrm{S}$ cycles. The sulfur induced nitrate reduction observed in this study implies that sediment $\mathrm{N}$ cycling is closely linked to the $\mathrm{S}$ cycling across a wide range of sediments. Increased $\mathrm{SO}_{4}^{2-}$ concentrations in freshwater ecosystems will lead to sulfide production in such

\section{REFERENCES}

Aelion, C. M., and Warttinger, U. (2009). Low sulfide concentrations affect nitrate transformations in freshwater and saline coastal retention pond sediments. Soil Biol. Biochem. 41, 735-741.

Benz, M., Brune, A., and Schink, B. (1998). Anaerobic and aerobic oxidation of ferrous iron at neutral $\mathrm{pH}$ by chemoheterotrophic nitratereducing bacteria. Arch. Microbiol. 169, 159-165.

Blackburn, T. H., and Henriksen, K. (1983). Nitrogen cycling in different types of sediments from danish waters. Limnol. Oceanogr. 28, 477-493.

Brettar, I., and Rheinheimer, G. (1991). Denitrification in the central balticevidence for $\mathrm{H} 2 \mathrm{~s}$-oxidation as motor of denitrification at the oxic-anoxic interface. Mar. Ecol. Prog. Ser. 77, 157-169.

Brunet, R. C., and GarciaGil, L. J. (1996). Sulfide-induced dissimilatory nitrate reduction to ammonia in anaerobic freshwater sediments. FEMS Microbiol. Ecol. 21, 131-138.

Burgin, A. J., and Hamilton, S. K. (2007). Have we overemphasized the role of denitrification in aquatic ecosystems? A review of nitrate removal pathways. Front. Ecol. Environ. 5, 89-96.
Burgin, A. J., and Hamilton, S. K. (2008). $\mathrm{NO}_{3}{ }^{-}$driven $\mathrm{SO}_{4}{ }^{2-}$ production in freshwater ecosystems: implications for $\mathrm{N}$ and S cycling. Ecosystems 11, 908-922. B., De Brabandere, L., Dalsgaard, T., Delong, E. F., Revsbech, N. P., and Ulloa, O. (2010). A cryptic sulfur cycle in oxygen-minimum-zone waters off the chilean coast. Science 330, 1375-1378.

Capone, D. G., and Kiene, R. P. (1988). Comparison of microbial dynamics in marine and fresh-water sediments - contrasts in anaerobic carbon catabolism. Limnol. Oceanogr. $33,725-749$.

Cornwell, J. C., Kemp, W. M., and Kana, T. M. (1999). Denitrification in coastal ecosystems: methods, environmental controls, and ecosystem level controls, a review. Aquatic Ecol. 33, 41-54.

Dalsgaard, T., and Bak, F. (1994). Nitrate reduction in a sulfate-reducing bacterium, desulfovibrio-desulfuricans, isolated from rice paddy soil - sulfide inhibition, kinetics, and regulation. Appl. Environ. Microbiol. 60, 291-297.

Dannenberg, S., Kroder, M., Dilling, W., and Cypionka, H. (1992). Oxidation of $\mathrm{H}-2$, organic-compounds and inorganic sulfur-compounds coupled to reduction of $\mathrm{O}-2$ or nitrate
Canfield, D. E., Stewart, F. J., Thamdrup,

ecosystems, where sulfide concentrations are usually low (Capone and Kiene, 1988). This sulfide can either be oxidized coupled to nitrate reduction as shown in this study, or serve as a sink for potentially toxic metals, such as As, $\mathrm{Cd}, \mathrm{Hg}$, and $\mathrm{Pb}$ (Moller et al., 2004). Increasing anthropogenic $\mathrm{NO}_{3}^{-}$input from acid deposition and agricultural runoff to ecosystems might affect the $\mathrm{S}$ cycle by stimulating anoxic iron sulfide oxidation in iron sulfide rich sediments. As observed in this study, the magnitude of the sulfide oxidation coupled to $\mathrm{NO}_{3}^{-}$reduction increases with increasing sediment As and $\mathrm{Fe}$ content, which means that saline sediments rich in metal (such as As and Fe) would be more strongly affected. Through the release of toxic metals by metal sulfide oxidation (Morse, 1994; Haaijer et al., 2007), this stimulation will have adverse effects on aquatic ecosystems. It is therefore crucial to better understand the coupling between the $\mathrm{N}$ and the $\mathrm{S}$ cycles given that $\mathrm{NO}_{3}^{-}$and $\mathrm{SO}_{4}^{2-}$ inputs to ecosystems are enhanced by anthropogenic activities, and are expected to increase in the future.

\section{ACKNOWLEDGMENTS}

C. Gu and C. Pallud are grateful to the Agricultural Experimental Station (AES) for funding the work done at UC Berkeley. The authors would also like to thank Jeffrey Abell for providing his data for the two near shore marine sites and Emmanuel Aubry for Fe and As analysis.

by sulfate-reducing bacteria. Arch. Microbiol. 158, 93-99.

Dowdle, P. R., Laverman, A. M., and Oremland, R. S. (1996). Bacterial dissimilatory reduction of $\operatorname{arsenic}(\mathrm{V})$ to $\operatorname{arsenic}(\mathrm{III})$ in anoxic sediments. Appl. Environ. Microbiol. 62, 1664-1669.

Duan, K., Thompson, L. G., Yao, T., Davis, M. E., and MosleyThompson, E. (2007). A 1000 year history of atmospheric sulfate concentrations in southern Asia as recorded by a Himalayan ice core. Geophys. Res. Lett. 34, L01810.

Engesgaard, P., and Kipp, K. L. (1992). A geochemical transport model for redox-controlled movement of mineral fronts in groundwater-flow systems - a case of nitrate removal by oxidation of pyrite. Water Resour. Res. 28, 2829-2843.

Ericson, J. P., Vorosmarty, C. J., Dingman, S. L., Ward, L. G., and Meybeck, M. (2006). Effective sea-level rise and deltas: causes of change and human dimension implications. Glob. Planet. Change 50, 63-82.

Fischer, H., Wagenbach, D., and Kipfstuhl, J. (1998). Sulfate and nitrate firn concentrations on the Greenland ice sheet -2 . Temporal anthropogenic deposition changes. J. Geophys. Res. 103, 21935-21942.

Fossing, H., Gallardo, V. A., Jørgensen, B. B., Hüttel, M., Nielsen, L. P.,
Schulz, H., Canfield, D. E., Forster, S., Glud, R. N., Gundersen, J. K., Küver, J., Ramsing, N. B., Teske, A., Thamdrup, B., and Ulloa, O. (1995). Concentration and transport of nitrate by the mat-forming sulfur bacterium Thioploca. Nature 374, 713-715.

Froelich, P. N., Klinkhammer, G. P., Bender, M. L., Luedtke, N. A., Heath, G. R., Cullen, D., Dauphin, P., Hammond, D., Hartman, B., and Maynard, V. (1979). Early oxidation of organic-matter in pelagic sediments of the eastern equatorial atlantic suboxic diagenesis. Geochim. Cosmochim. Acta 43, 1075-1090.

Galloway, J. N., Townsend, A. R., Erisman, J. W., Bekunda, M., Cai, Z., Freney, J. R., Martinelli, L. A., Seitzinger, S. P., and Sutton, M. A. (2008). Transformation of the nitrogen cycle: recent trends, questions, and potential solutions. Science 320 , 889-892.

Garciagil, L. J., and Golterman, H. L. (1993). Kinetics of FeS-mediated denitrification in sediments from the Camargue (Rhone delta, southern France). FEMS Microbiol. Ecol. 13, 85-91.

Glass, C., and Silverstein, J. (1998). Denitrification kinetics of high nitrate concentration water: $\mathrm{pH}$ effect on inhibition and nitrite accumulation. Water Res. 32, 831-839. 
Haaijer, S. C. M., Lamers, L. P. M., Smolders, A. J. P., Jetten, M. S. M., and den Camp, H. J. M. O. (2007). Iron sulfide and pyrite as potential electron donors for microbial nitrate reduction in freshwater wetlands. Geomicrobiol. J. 24, 391-401.

Hoeft, S. E., Kulp, T. R., Stolz, J. F., Hollibaugh, J. T., and Oremland, R. S. (2004). Dissimilatory arsenate reduction with sulfide as electron donor: experiments with mono lake water and isolation of strain MLMS-1, a chemoautotrophic arsenate respirer. Appl. Environ. Microbiol. 70, 2741-2747.

Hollibaugh, J. T., Budinoff, C., Hollibaugh, R. A., Ransom, B., and Bano, N. (2006). Sulfide oxidation coupled to arsenate reduction by a diverse microbial community in a Soda Lake. Appl. Environ. Microbiol. 72, 2043-2049.

Holmer, M., and Storkholm, P. (2001). Sulphate reduction and sulphur cycling in lake sediments: a review. Freshw. Biol. 46, 431-451.

Howarth, R. W., Billen, G., Swaney, D., Townsend, A., Jaworski, N., Lajtha, K., Downing, J. A., Elmgren, R., Caraco, N., Jordan, T., Berendse, F., Freney, J., Kudeyarov, V., Murdoch, P., and Zhu, Z. L. (1996). Regional nitrogen budgets and riverine N\&P fluxes for the drainages to the North Atlantic Ocean: natural and human influences. Biogeochemistry 35, 75-139.

Jorgensen, C. J., Jacobsen, O. S., Elberling, B., and Aamand, J. (2009). Microbial oxidation of pyrite coupled to nitrate reduction in anoxic groundwater sediment. Environ. Sci. Technol. 43, 4851-4857.

Knowles, R. (1982). Denitrification. Microbiol. Rev. 46, 43-70.

Kondo, R., Purdy, K. J., Silva, S. D. Q., and Nedwell, D. B. (2007). Spatial dynamics of sulphate-reducing bacterial compositions in sediment along a salinity gradient in a UK estuary. Microbes Environ. 22, 11-19.

Laverman, A. M., Pallud, C., Abell, J., and Van Cappellen, P. (2012). Comparative survey of potential nitrate and sulfate reduction rates in aquatic sediments. Geochim. Cosmochim. Acta 77, 474-488.

Laverman, A. M., Van Cappellen, P., van Rotterdam-Los, D., Pallud, C., and Abell, J. (2006). Potential rates and pathways of microbial nitrate reduction in coastal sediments. FEMS Microbiol. Ecol. 58, 179-192.
Mayewski, P. A., Lyons, W. B., Spencer, M. J., Twickler, M. S., Buck, C. F., and Whitlow, S. (1990). An ice-core record of atmospheric response to anthropogenic sulfate and nitrate. Nature 346, 554-556.

Miletto, M., Loy, A., Antheunisse, A. M., Loeb, R., Bodelier, P. L., and Laanbroek, H. J. (2008). Biogeography of sulfate-reducing prokaryotes in river floodplains. FEMS Microbiol. Ecol. 64, 395-406.

Moller, A., Grahn, A., and Welander, U. (2004). Precipitation of heavy metals from landfill leachates by microbially-produced sulphide. Environ. Technol. 25, 69-77.

Morse, J. W. (1994). Release of toxic metals via oxidation of authigenic pyrite in resuspended sediments. Environ. Geochem. Sulfide Oxidation 550, 289-297.

Muyzer, G., and Stams, A. J. M. (2008). The ecology and biotechnology of sulphate-reducing bacteria. Nat. Rev. Microbiol. 6, 441-454.

Oremland, R. S., Kulp, T. R., Blum, J. S., Hoeft, S. E., Baesman, S., Miller, L. G., and Stolz, J. F. (2005). A microbial arsenic cycle in a salt-saturated, extreme environment. Science 308, 1305-1308.

Oren, A. (2011). Thermodynamic limits to microbial life at high salt concentrations. Environ. Microbiol. 13, 1908-1923.

Otte, S., Kuenen, J. G., Nielsen, L. P., Paerl, H. W., Zopfi, J., Schulz, H. N., Teske, A., Strotmann, B., Gallardo, V. A., and Jorgensen, B. B. (1999). Nitrogen, carbon, and sulfur metabolism in natural Thioploca samples. Appl. Environ. Microbiol. 65, 3148-3157.

Pallud, C., Meile, C., Laverman, A. M., Abell, J., and Van Cappellen, P. (2007). The use of flow-through sediment reactors in biogeochemical kinetics: methodology and examples of applications. Mar. Chem. 106, 256-271.

Pallud, C., and Van Cappellen, P. (2006). Kinetics of microbial sulfate reduction in estuarine sediments. Geochim. Cosmochim. Acta 70, 1148-1162.

Payne, E. K., Burgin, A. J., and Hamilton, S. K. (2009). Sediment nitrate manipulation using porewater equilibrators reveals potential for $\mathrm{N}$ and $\mathrm{S}$ coupling in freshwaters. Aquat. Microb. Ecol. 54, 233-241.

Philippot, L. (2002). Denitrifying genes in bacterial and Archaeal genomes. Biochim. Biophys. Acto 1577, 355-376.

Roychoudhury, A., Viollier, E., and Van Cappellen, P. (1998). A plug flowthrough reactor for studying biogeochemical reactions in undisturbed aquatic sediments. Appl. Geochem. 13, 269-280.

Schlesinger, W. H. (1997). Biogeochemistry: An Analysis of Global Change. San Diego: Academic Press, 588.

Schwermer, C. U., Ferdelman, T. G., Stief, P., Gieseke, A., Rezakhani, N., van Rijn, J., de Beer, D., and Schramm, A. (2010). Effect of nitrate on sulfur transformations in sulfidogenic sludge of a marine aquaculture biofilter. FEMS Microbiol. Ecol. 72, 476-484.

Schwientek, M., Einsiedl, F., Stichler, W., Stögbauer, A., Strauss, H., and Maloszewski, P. (2008). Evidence for denitrification regulated by pyrite oxidation in a heterogeneous porous groundwater system. Chem. Geol. 255, 60-67.

Seitzinger, S., Harrison, J. A., Böhlke, J. K., Bouwman, A. F., Lowrance, R., Peterson, B., Tobias, C., and Van Drecht, G. (2006). Denitrification across landscapes and waterscapes: a synthesis. Ecol. Appl. 16, 2064-2090.

Senga, Y., Mochida, K., Fukumori, R. Okamoto, N., and Seike, Y. (2006) $\mathrm{N} 2 \mathrm{O}$ accumulation in estuarine and coastal sediments: The influence of $\mathrm{H} 2 \mathrm{~S}$ on dissimilatory nitrate reduction. Estuar. Coast. Shelf Sci. 67, 231-238.

Sierra-Alvarez, R., Beristain-Cardoso, R., Salazar, M., Gómez, J., RazoFlores, E., and Field, J. A. (2007). Chemolithotrophic denitrification with elemental sulfur for groundwater treatment. Water Res. 41, 1253-1262.

Song, K., Lee, S. H., and Kong, H. (2011). Denitrification rates and community structure of denitrifying bacteria in newly constructed wetland. Eur. J. Soil Biol. 47, 24-29.

Sun, W. J., Sierra-Alvarez, R., Hsu, I. Rowlette, P., and Field, J. A. (2010). Anoxic oxidation of arsenite linked to chemolithotrophic denitrification in continuous bioreactors. Biotechnol. Bioeng. 105, 909-917.

Terbraak, C. J. F., and Verdonschot, P. F. M. (1995). Canonical correspondence-analysis and related multivariate methods in aquatic ecology. Aquat. Sci. 57, 255-289.

Thamdrup, B., Fossing, H., and Jorgensen, B. B. (1994). Manganese, iron, and sulfur cycling in a coastal marine sediment, Aarhus bay, Denmark. Geochim. Cosmochim. Acta 58, 5115-5129.

Vandenwollenberg, A. L. (1977). Redundancy analysis an alternative for canonical correlation analysis. Psychometrika 42, 207-219.

Wagner, M., Roger, A. J., Flax, J. L., Brusseau, G. A., and Stahl, D. A. (1998). Phylogeny of dissimilatory sulfite reductases supports an early origin of sulfate respiration. J. Bacteriol. 180, 2975-2982.

Wallenstein, M. D., Myrold, D. D., Firestone, M., and Voytek, M. (2006). Environmental controls on denitrifying communities and denitrification rates: insights from molecular methods. Ecol. Appl. 16, 2143-2152.

Westermann, P., and Ahring, B. K. (1987). Dynamics of methane production, sulfate reduction, and denitrification in a permanently waterlogged alder swamp. Appl. Environ. Microbiol. 53, 2554-2559.

Whitmire, S. L., and Hamilton, S. K. (2005). Rapid removal of nitrate and sulfate in freshwater wetland sediments. J. Environ. Qual. 34, 2062-2071.

Zhang, Y. H., Zhong, F. H., and Xia, S. Q. (2009). Effect of initial ph on autohydrogenotrophic denitrification. Fresenius Environ. Bull. 18, 2352-2358.

Zumft, W. G. (1997). Cell biology and molecular basis of denitrification. Microbiol. Mol. Biol. Rev. 61, 533-616.

Conflict of Interest Statement: The authors declare that the research was conducted in the absence of any commercial or financial relationships that could be construed as a potential conflict of interest.

Received: 12 December 2011; accepted: 29 January 2012; published online: 27 February 2012.

Citation: Gu C, Laverman AM and Pallud CE (2012) Environmental controls on nitrogen and sulfur cycles in surficial aquatic sediments. Front. Microbio. 3:45. doi: 10.3389/fmicb.2012.00045

This article was submitted to Frontiers in Terrestrial Microbiology, a specialty of Frontiers in Microbiology.

Copyright (c) 2012 Gu, Laverman and Pallud. This is an open-access article distributed under the terms of the Creative Commons Attribution Non Commercial License, which permits noncommercial use, distribution, and reproduction in other forums, provided the original authors and source are credited. 